\title{
Christus in natura
}




\section{Studies of the Bible and Its Reception}

Edited by

Christine Helmer, Steven McKenzie, Thomas Römer, Jens Schröter,

Barry Dov Walfish and Eric Ziolkowski

\section{Volume 11}




\section{Christus in natura}

Quellen, Hermeneutik und Rezeption des Physiologus

Herausgegeben von

Zbyněk Kindschi Garský und Rainer Hirsch-Luipold 
Die Druckvorstufe dieser Publikation wurde vom Schweizerischen Nationalfonds zur Förderung der wissenschaftlichen Forschung unterstützt.

\section{FNSNF}

SWISS National SCIEnCE Foundation

ISBN 978-3-11-049470-9

e-ISBN (PDF) 978-3-11-049414-3

e-ISBN (EPUB) 978-3-11-049185-2

ISSN 2195-450X

\section{(cc) BY-NC-ND}

This work is licensed under the Creative Commons Attribution-NonCommercial-NoDerivs 4.0 License. For details go to http://creativecommons.org/licenses/by-nc-nd/4.0/.

\section{Library of Congress Control Number: 2019950606}

Bibliographic information published by the Deutsche Nationalbibliothek

The Deutsche Nationalbibliothek lists this publication in the Deutsche Nationalbibliografie; detailed bibliographic data are available on the Internet at http://dnb.dnb.de.

(c) 2019 Zbyněk Kindschi Garský and Rainer Hirsch-Luipold, published by Walter de Gruyter GmbH, Berlin/Boston. The book is published with open access at www.degruyter.com.

Logo: Martin Zech

Printing and binding: $\mathrm{CPI}$ books $\mathrm{GmbH}$, Leck

www.degruyter.com 


\section{Inhalt}

Abkürzungen — VII

Zbyněk Kindschi Garský, Rainer Hirsch-Luipold

Vorwort —IX

\section{Teil I: Einführung}

Zbyněk Kindschi Garský, Rainer Hirsch-Luipold

Einführung in den vorliegenden Tagungsband -3

Horst Schneider

Einführung in den Physiologus -5

\section{Teil II: Griechisch-römische Antike}

Herwig Görgemanns

Der Physiologus und die Tierkunde der Griechen -17

Beatrice Wyss

Die Weisheit der Tiere

Konzepte paganer Philosophen zur Frage der Rationalität und Spiritualität der Tiere -27

Marco Stroppa

The Physiologus and the Papyri from Egypt — 39

\section{Teil III: Alter Orient, Hebräische Bibel und Septuaginta}

Silvia Schroer

Tiere und ihre Symbolik im Alten Testament — 55

Thomas J. Kraus

Von Einhorn, Hirsch, Pelikan und anderem Getier

Septuaginta, Physiologus und darüber hinaus - 63

\section{Teil IV: Neues Testament und (früh-)christliche Rezeption}

Zbyněk Kindschi Garský

Der Physiologus und das Neue Testament

Die neutestamentlichen Wurzeln der frühchristlichen Naturdeutung — 83

Samuel Vollenweider

Der Erlöser im Tarnanzug

Eine Studie zur Christologie des Physiologus, zu seiner Datierung und zur Rezeptionsgeschichte von Psalm $24\left(23^{1 \times x}\right)-93$ 
Rainer Hirsch-Luipold

Unicornis captivatur

Das Deutungsverfahren des Physiologus und die Rezeption und theologische Deutung seiner Tiersymbolik in mittelalterlicher Dichtung und zeitgenössischer Musik — 133

Janet Spittler

The Physiologus and the Apocryphal Acts of the Apostles — 149

Katharina Heyden

Liber creaturae und sacra scriptura

Zur Bedeutung der Naturkunde für die Bibelexegese der lateinischen Kirchenväter

\section{Teil V: Der Berner Physiologus}

Florian Mittenhuber

Die Berner Physiologus-Handschriften

Drei Bücher, drei Geschichten — 177

Christoph Eggenberger

Der Physiologus Bernensis

Bild und Text -189

Burgerbibliothek Bern

Faksimile des Physiologus Bernensis - 195

Verzeichnis der Autorinnen und Autoren — 229

Bibliographie zum Physiologus (Auswahl) -231

Stellenregister (Auswahl) -237

Namen- und Sachregister (Auswahl) 249 


\section{Abkürzungen}

Die Abkürzungen folgen SBL Handbook of Style (Atlanta 2014) und IATG ${ }^{3}$ (Siegfried Schwertner, Internati-

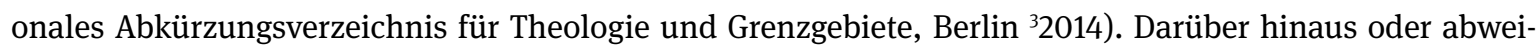
chend werden folgende Abkürzungen verwendet:

EC

Early Christianity

LXX.D

Septuaginta Deutsch

PCG

RhG Poetae Comici Graeci

SAPERE

Rhetores Graeci

Scripta Antiquitatis Posterioris ad Ethicam REligionemque pertinentia 



\section{Zbyněk Kindschi Garský, Rainer Hirsch-Luipold Vorwort}

Der vorliegende Sammelband geht auf das Berner Forschungsprojekt Das «Evangelium der Natur`: Der griechische Physiologus und die Wurzeln der frühchristlichen Naturdeutung (2014-2017) und das im Rahmen dieses Projektes veranstaltete internationale Kolloquium Christus in natura: Quellen, Hermeneutik und Rezeption des griechischen Physiologus zurück. Wir danken dem Schweizerischen Nationalfonds für die Förderung des Forschungsprojektes wie der Tagung und auch für die Übernahme der Kosten der Open-Access-Publikation. Den Herausgebern der Schriften zur Bibel und ihrer Rezeption danken wir für die Aufnahme des Bandes in die Reihe und dem Verlag De Gruyter, allen voran Albrecht Döhnert und Simone Hausmann für die wie immer ausgezeichnete Zusammenarbeit und für die Bereitschaft, den Band in einem übergrossen Format herauszubringen, um auf diese Weise die aussergewöhnliche Berner Physiologus-Handschrift im Faksimile abdrucken zu können. Stellvertretend für ein ganzes Team von Angehörigen des Instituts für Neues Testament an der Universität Bern, das an unterschiedlichen Stellen mitgeholfen hat, danken wir insbesondere David Staub und Barbara Hirsch für die Arbeit am Register und an der Erstellung des Druckmanuskripts. 

Teil I: Einführung 



\section{Zbyněk Kindschi Garský, Rainer Hirsch-Luipold Einführung in den vorliegenden Tagungsband}

Der vorliegende Band widmet sich einem Text, von dem kaum jemand je gehört zu haben meint: dem frühchristlichen Physiologus. Dabei handelt es sich bei der wenig nach der Abfassung des Neuen Testaments wohl in Ägypten entstandenen, ursprünglich in Griechisch abgefassten Schrift um einen der wirkmächtigsten Texte des frühen Christentums. Nur die Bibel selbst wurde häufiger übersetzt. ${ }^{1}$

Der Physiologus bietet unter Aufnahme biblischer wie paganer Motivik und Naturlehre eine christliche Gesamtdeutung der Natur. Über mittelalterliche Bestiarien findet die Symbolik des Physiologus Eingang in Kunst, Literatur und Heraldik. Auf den Physiologus gehen die mittelalterlichen Bestiarien und damit zu einem wesentlichen Teil die ikonographische Ausstattung unserer Kirchen zurück. Wer nach dem Hintergrund der manchmal wundersamen Tierdarstellungen fragt, die sich dort finden, nicht nur Schlangen und Löwen, sondern auch Elefanten, Pelikane mit ihren Jungen sowie Phoenix und Einhorn, der wird vielfach im Physiologus fündig. Die Tiere, so zeigt sich da, gehen zumeist auf markante Psalmworte zurück: „Wie der Hirsch schreit nach frischem Wasser...“ (Ps 42,1); „Ich wurde wie das Käuzchen in der Ruinenstätte“ (Ps 101,7); „Deine Jugend wird erneuert wie die des Adlers“ (Ps 102,5). Aber auch andere Bibelstellen bilden den Ausgangspunkt der Einzeldarstellungen. Selten entstammen sie dem Neuen Testament wie Mt 10,16 über Schlangen und Tauben, Mt 3,7 über die Nattern, öfter den alttestamentlichen Propheten, der Weisheitsliteratur und dem Pentateuch (Ameise: Spr 6,6; Ameisenlöwe: Hiob 4,11; Wildesel: Hiob 39,5; Panther: Hos 5,14; Rebhuhn: Jer 17,11; Hyäne: Dtn 14,8 oder gar „Dämonen, Sirenen und Igel“ in Jes 13,21). Bisweilen finden sich in der Schrift Tiere oder Wesen, die uns aus der biblischen Tradition nicht geläufig sind, wie eben der Pelikan, der Phoenix und die Sirene. Hier wird erst fündig, wer die Septuaginta, die griechische Übersetzung der Hebräischen Bibel zur Hand nimmt. ${ }^{2}$ Es ist diese Übersetzung der Bibel, die der Physiologus, wie die frühchristliche Tradition in ihrer Mehrheit, als autoritativ voraussetzt. Das Verständnis einer solchen christologisch grundgelegten Weltdeutung und Bildsprache, wie sie der Physiologus darbietet, bleibt heutigen Leserinnen und Lesern vielfach verschlossen und rätselhaft.

1 Vgl. zuletzt Schneider (2016), 740-741.

2 Seit einigen Jahren liegt eine Übersetzung der Septuaginta mit Kommentar vor, die bei der Stuttgarter Bibelgesellschaft erschienen ist (LXX.D 2009, 2011).
Die im vorliegenden Band versammelten Aufsätze gehen auf Vorträge bei einer in Bern im Jahr 2015 abgehaltenen interdisziplinären Tagung zurück, die im Zusammenhang des vom Schweizerischen Nationalfonds geförderten Projekts Das «Evangelium der Natur〉: Der griechische Physiologus und die Wurzeln der frühchristlichen Naturdeutung stand und die Spezialisten unterschiedlicher Fachgebiete aus der Schweiz und Deutschland sowie Finnland und den Vereinigten Staaten von Amerika zusammenführte. ${ }^{3}$ In den unterschiedlichen Beiträgen wird die Schrift mit ihren Quellen, ihren onto-theologischen Grundlagen, ihrer Hermeneutik und ihren Auslegungsmethoden sowie ihren Voraussetzungen in biblischer Bildsprache, hellenistischer Naturkunde und Philosophie und nicht zuletzt ihrer Rezeption breit interdisziplinär ausgeleuchtet, um auf dieser Basis eine vertiefte Verständnisgrundlage für diese in manchem fremdartige Schrift zu gewinnen und ihrer eigentümlichen Hermeneutik zwischen Bibelauslegung und Naturdeutung nachzuspüren.

Zunächst führt Horst Schneider in Gattung, Methode, Aufbau, Entstehung und Überlieferungslage des Physiologus ein. Teil II ist der griechischen naturkundlichen Betrachtung der Tiere und ihrem Einfluss auf den Physiologus gewidmet. Herwig Görgemanns beleuchtet die Quellen und Traditionen des Physiologus, insbesondere in griechischen Naturhandbüchern von Aristoteles bis Bolos von Mendes. Sie reichen von genauer naturwissenschaftlicher Analyse bis hin zu einer zunehmenden Mirabilienliteratur, die im Physiologus ebenfalls deutliche Spuren hinterlassen hat. Dies setzt Görgemanns zur symbolischen Deutung von Tieren bzw. Tiergöttern in Ägypten, zur hellenistischjüdischen Deutung biblischer Speisegebote und zur Aufnahme solcher Gedanken im frühchristlichen Barnabasbrief und dann im Physiologus in Beziehung. Beatrice Wyss widmet sich der Diskussion über die Rationalität der Tiere als Voraussetzung einer Übertragung von Strukturen aus dem Tierreich auf den Menschen. Ein Beitrag von Marco Stroppa zur frühesten Handschriftenüberlieferung schliesst diesen der griechischen Tradition gewidmeten Teil ab.

Teil III beleuchtet die biblischen Hintergründe der Tiersymbolik des Physiologus. Silvia Schroer richtet ihr

3 Internationales Kolloquium Christus in natura: Quellen, Hermeneutik und Rezeption des griechischen Physiologus, 20.-22. Oktober 2015, Universität Bern, vgl. die Webseite des Projektes: https://www. physiologus.unibe.ch. 
Augenmerk insbesondere auf die Bildsprache der Hebräischen Bibel und dahinter die altorientalische und altägyptische Tiersymbolik an den Beispielen Löwe, Esel und Taube, und hebt sie von der Diskussion derselben Tiere im Physiologus ab. Thomas Kraus gibt anschliessend einen Überblick und eine systematische Ordnung der Tiere in der für den Physiologus massgeblichen griechischen Übersetzung des Alten Testaments, der sogenannten Septuaginta, und geht exemplarisch auf einige besonders herausragende Tiere ein (Einhorn, Ameisenlöwe, Hirsch/Schlange, Pelikan).

Teil IV ist der frühchristlichen Rezeption sowie den unterschiedichen Hermeneutiken gewidmet. Zunächst führt Zbyněk Kindschi Garský in die Deutungsmethode des Physiologus ein und untersucht dabei die Funktion der Intertextualität und des Neuen Testamentes. Denn der Physiologus ist voll von biblischen Zitaten, Anspielungen und Echos, die in seiner Methode der Naturdeutung eine wichtige Rolle spielen. In seiner Analyse führt er vor, wie im Physiologus mit Hilfe der Bibel die gesamte Natur einer systematischen allegorischen Relektüre unterzogen wurde, wobei der Gedanke der Inkarnation des göttlichen Logos das theologische Fundament dieser christlichen Naturdeutung darstellt. Samuel Vollenweider schlägt ausgehend von einer detaillierten Untersuchung der christologischen Topoi (insb. des am Anfang der Schrift stehenden „Löwen“), die Christus als den verborgenen, engelsgleichen Erlöser präsentieren, eine Spätdatierung des Physiologus ins 4. Jh. vor. Insbesondere das (vor allem in „dissidenten“ Strömen frühchristlicher Literatur zu findende) „Mythologumenon vom die Sphären unerkannt durchschreitenden Erlöser" und die aufscheinenden origenistischen Traditionen der Engelsgleichheit Christi und der Verhüllung seiner Gottheit (verbunden mit dem Gedanken einer Täuschung des Teufels) lassen sich, so die These, nicht vor den dogmengeschichtlichen Diskussionen des 4. Jh.s erklären. Rainer Hirsch-Luipold beschreibt die Hermeneutik des Physiologus als Auflösung und Neukonstruktion der Bild- und Sinnelemente von Schriftworten. In einer komparatistischen Studie wird diese Hermeneutik zusätzlich profiliert durch die den Physiologus aufnehmende, aber ganz anders gelagerte heilsgeschichtliche Bildsprache des auf der lateinischen Tradition des Physiologus basierenden mittelalterlichen Hymnus Unicornis captivatur und dessen musikalischer Rezeption in einer Komposition des zeitgenössischen norwegischen Komponisten Ola Gjeilo. Zwei Beiträge zur frühchristlichen Rezeption des Physiologus schliessen sich an. Im griechischen Bereich finden sich Tierdeutungen an verschiedenen Stellen in den apokryphen Apostelakten, die Janet Spittler an einigen Beispielen vor dem Hintergrund des Physiologus diskutiert. Katharina
Heyden zeichnet zunächst die Rolle von Naturkunde und Naturdeutung in der Exegese einiger lateinischer Kirchenväter, insbesondere bei Augustinus, nach, um sich dann beispielhaft dem Kapitel über die „Schlangengeburt“ (Physiologus 10) zuzuwenden.

Einen ganz eigenen Schwerpunkt legt der V. Teil - fast unvermeidlich für ein Berner Projekt zum Thema - auf den sog. Berner Physiologus, die berühmteste illuminierte Handschrift aus dem 9. Jh., die in der Burgerbibliothek Bern aufbewahrt wird (Codex 318). Er ist in diesem Band in einer Art Faksimile vollständig und in originaler Grösse abgedruckt. Zwei Beiträge widmen sich dem Text und den Bildern des Berner Physiologus. Zuerst ordnet Florian Mittenhuber die Handschrift des Physiologus Bernensis kodikologisch ein und macht darauf aufmerksam, dass sich neben dem reich bebilderten Codex 318 noch zwei weitere karolingische Handschriften in Bern befinden (Codices 233 und 611). Nach einer kurzen Einführung in die lateinischen Versionen des Physiologus (Y, C und B) unterzieht er alle drei Physiologi Bernenses einer Vergleichsanalyse (mit einer tabellarischen Übersicht im Anhang) und widmet sich detailliert ihren inhaltlichen und kompositorischen Aspekten. Christoph Eggenberger wendet schliesslich den Blick ganz dem Bildprogramm des Berner Physiologus zu. 


\section{Horst Schneider}

\section{Einführung in den Physiologus}

Abstract: The Physiologus is a small book originally written in Greek in the $2^{\text {nd }}$ or $3^{\text {rd }}$ century CE. It focuses on animals, plants, stones and hybrid beings. The book is transmitted in 4 redactions and was, from the beginning, subject to constant revision and alteration. New texts were added, others were transformed. These texts had a great influence on medieval bestiaries and encyclopedias of nature. A typical chapter of this text begins with a statement of the "Physiologus", who is obviously a synonym for an anonymous nature expert. His description of the physis of an animal, a plant, stone or hybrid, often related to a certain passage of the bible in the first part of the chapter, is followed in the second part by a symbolic Christian interpretation. The stories and descriptions recorded by the Physiologus are taken from many different sources, e.g. from ancient everyday life, books on nature (e.g. Pliny's Natural history, Aelian's Historia animalium) and oral traditions. Although some of the stories may seem strange to us, they should be taken seriously, because they are intended to show how, according to Paul, the divine spirit can be found in nature (Romans 1:20).

\section{Einleitung}

Die kleine, nicht sehr umfangreiche Schrift des Physiologus, die wahrscheinlich im 2. oder 3. Jh. n. Chr. in Alexandria entstand und auf Griechisch verfasst wurde, war von Anfang an sehr beliebt und wurde bereits in frühester Zeit immer wieder abgeschrieben. ${ }^{1}$ Alleine im Bereich des Griechischen kennen wir vier verschiedene Redaktionen aus der Entstehungszeit bis zum byzantinischen Mittelalter. Schon die erste Redaktion läßt sich in weitere verschiedene Rezensionen aufgliedern. Der Text wurde also nie kanonisch, sondern blieb immer offen für Zusätze, Veränderungen und Modifikationen, er ist also ein sogenannter „Gebrauchstext“. ${ }^{2}$

1 Zur Kontroverse um die Datierung des Physiologus siehe exemplarisch die Beiträge von Janet Spittler (2. Jh. - vor Origenes) sowie Samuel Vollenweider (nach Origenes).

2 Hinzu treten zwei Appendizes in Sbordones Ausgabe (Sbordone 1936a), der als erster und einziger bisher die Aufgabe bewältigt hat,

Anmerkung: Der folgende Beitrag geht auf mehrere Vorträge zurück (Bochum 2004 und 2014; München 2012; Konstanz 2013; Bern 2015; Paris 2017); schließlich auf meinen Artikel über den Physiologus im Reallexikon für Antike und Christentum (Schneider 2016).
Tab. 1: Übersicht der vier Redaktionen nach Sbordone.

\begin{tabular}{llll}
\hline $\begin{array}{l}\text { Redactio } \\
\text { prima } \\
\text { alexandrina }\end{array}$ & $\begin{array}{l}\text { Redactio } \\
\text { secunda } \\
\text { byzantina }\end{array}$ & $\begin{array}{l}\text { Redactio } \\
\text { tertia } \\
\text { ps.-basiliana }\end{array}$ & $\begin{array}{l}\text { Redactio } \\
\text { quarta } \\
\text { poetica }\end{array}$ \\
\hline saec. 2./3. & $\begin{array}{l}\text { saec. } 5 . / 6 . \\
\text { vel saec. } \\
11 . / 12 .^{3}\end{array}$ & $\begin{array}{l}\text { saec. } 10 . / 11 . \\
\text { vel } 12 .\end{array}$ & saec. 13. \\
& 27 cap. & 30 cap. & 49 cap. \\
\hline
\end{tabular}

Wer sich zum ersten Mal inhaltlich mit dem Physiologus beschäftigt, wird sich allerdings alsbald wundern. Denn er sieht sich mit einer Reihe von merkwürdigen Geschichten konfrontiert: Das Wiesel empfängt durch den Mund und gebiert durch die Ohren, ein Einhorn läßt sich nur von einer reinen Jungfrau fangen, der Diamant kann nur durch Bocksblut erweicht werden, der Vogel Phönix verbrennt zu Asche und wird wiedergeboren, der Salamander ist feuerfest. ${ }^{4}$ Wer an ernsthafter Literatur interessiert ist, wird eine solche Lektüre nach dem ersten Eindruck schnell zur Seite legen, oder, wenn er auch noch feststellen muß, dass solche Geschichten in der Antike christlich ausgelegt wurden, nur den Kopf schütteln und über die vermeintliche Primitivität dieser christlichen Märchen lächeln.

Aus diesem ersten - gleichwohl fiktiven - Leseeindruck ergeben sich eine Reihe von Fragestellungen: Wie sind diese uns oft merkwürdig anmutenden Geschichten $\mathrm{zu}$ bewerten? Warum werden sie erzählt und noch dazu

eine kritische Edition aller (vier) Redaktionen zu schaffen (auf der Basis von 77 Handschriften). Der Text galt aufgrund der komplizierten Handschriftenlage eigentlich als unedierbar. Eine wichtige Ergänzung zu Sbordones Ausgabe ist die Edition von Dieter Offermanns (1966), der eine weitere, bedeutende griechische PhysiologusHandschrift G (= Codex 397, Pierpont Morgan Library, New York, 10./11. Jh.) zusammen mit der ebenfalls sehr alten Handschrift M (rezensiert von Perry 1968; Maas 1937, 379-380) heranziehen konnte, die Sbordone noch nicht kannte. Eine weitere synoptische Ausgabe nur der ersten Redaktion legte Dimitris Kaimakis (1974; rezensiert von Riedinger 1977) als Ergänzung zur Edition Offermanns', der die verschiedenen Überlieferungsstränge der ersten Redaktion, wie sie von Sbordone unterschieden wurden, in ihren wesentlichen Gundzügen darstellen wollte. Allerdings ist diese Ausgabe nicht immer zuverlässig. Caroline Macé arbeitet jetzt an einer neuen Textedition und berücksichtigt dabei auch die frühen Übersetzungen.

3 Zur Spätdatierung der 2. und 3. Redaktion vgl. Perry (1941, 11141115).

4 Siehe Kapitel 21: Wiesel; Kapitel 22: Einhorn; Kapitel 32, 32 ${ }^{\text {bis }}$, 42: Diamant; Kapitel 7: Phönix; Kapitel 31: Salamander. 
mit einer christlichen bzw. allegorischen Auslegung verknüpft? Wie muß man sich das sozio-kulturelle Umfeld, in dem dieser Text entstanden ist, vorstellen? Welches Publikum hatte der Verfasser im Blick? In welchem Zusammenhang stehen diese Geschichten zum Alten und Neuen Testament? Man könnte auch alle diese Fragen bündeln und einfach sagen: Wie sollen wir dieses literarische Phänomen aus der Frühzeit des Christentums verstehen?

\section{Begrifflichkeit}

Klären wir zunächst den Begriff „Physiologus“. In den einzelnen Texten beruft sich der anonyme Verfasser stets auf die Autorität eines Physiologus, d.h. eines ebenfalls anonym bleibenden „Naturwissenschaftlers“ (ò $\varphi v \sigma ı \lambda$ „óyoc: der Naturkundige); ähnlich wie etwa auch Aristoteles in seiner Poetik ${ }^{5}$ Empedokles mit dem gebräuchlichen Termi-

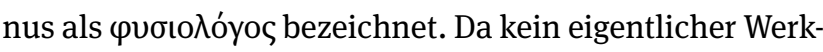
titel überliefert ist, hat sich eingebürgert, diesen Text nach dieser anonymen naturwissenschaftlichen Autorität Physiologus zu nennen. ${ }^{6}$

\section{Gattung}

Gattungstechnisch läßt sich der Physiologus am ehesten den antiken Naturkunden zurechnen, die seit hellenistischer Zeit entstehen. Zu nennen wären hier als literarische Vorbilder vor allem die naturkundlichen bzw. botanischen und zoologischen Werke von Aristoteles (Historia animalium/De partibus animalium) und Theophrast (De historia et causis plantarum), die Naturalis Historia des Plinius oder die Auszüge daraus des Solinus, die Schrift De natura animalium des Aelian oder Spezialwerke wie z. B. Juba II. von Mauretanien über Elefanten, Oppian über Fische und Jagd, Alexander von Myndos über Vögel, Dionysios über Vögel und Vogelfang, außerdem Lapidarien wie z. B. von Xenokrates von Ephesus oder Theophrast. Eine gewisse Nähe besteht außerdem zur antiken moralisierenden Tierfabel (Äsop, Phaedrus). ${ }^{7}$

5 Aristoteles, De arte poetica $1.1447 \mathrm{~b} 19$.

6 Schneider (2016, 724-725), s. auch H. Görgemanns im vorliegenden Band.

7 Schneider (2016, 725-726).

\section{Exegetische Methode}

Gegenstand der antiken Naturkunde sind üblicherweise Tiere, Pflanzen und Steine. Entsprechend antiker naturkundlicher Methodik beschreibt der Physiologus daher

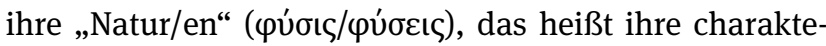
ristischen Eigenschaften. Dadurch erreicht er, dass der in ihnen verborgene Sinn entdeckt und erläutert werden kann, der für die Bibelerklärung und die christliche Lehre wichtig ist. Die allegorische Methode, die der Physiologus dabei benutzt, hat ihre antiken Vorläufer vor allem in der Homerallegorese sowie der Allegorese Philons von Alexandrien. ${ }^{8}$

Das exegetische Interesse, das den Verfasser des Physiologus leitet, hat Augustinus auf den Punkt gebracht:

\begin{abstract}
Die Unkenntnis der Dinge erzeugt aber dunkle, figürliche Redeweisen, wenn wir Eigenschaften von Lebewesen, Steinen, Pflanzen oder anderen Dingen nicht kennen, die meistens wegen irgendeines Vergleichspunktes in der Hl. Schrift angeführt werden. ... Denn sogar die Kenntnis des Karfunkelsteines, der im Finstern leuchtet, erhellt viele dunkle Stellen in den Büchern, wo auch immer er wegen eines Vergleichspunktes angeführt wird; die Unkenntnis von Beryll oder Diamant verschließt sehr oft die Tore des Verständnisses. ${ }^{9}$
\end{abstract}

In ähnlicher Weise entwickeln die Kirchenväter später auch die Vorstellung vom „Buch der Natur“ oder „Buch der Schöpfung“ („liber creaturae“, oft bei Augustinus ${ }^{10}$ belegt), das es zu lesen und zu deuten gilt. Die Natur bot sozusagen eine symbolische Sprache, die es zu entschlüsseln galt; sie beinhaltete „einen theologischen Text“"11, der mit staunenswerten göttlichen Wundern aufwarten konnte. $^{12}$

\section{Tiere, Mischwesen, Pflanzen, Steine}

Religionswissenschaftlich betrachtet sind die Beziehungen zwischen Göttlichem, Menschen, Tieren, Pflanzen und Steinen offen, so dass es mannigfache Beziehungen unter diesen geben kann bis hin zu Mischformen,

\footnotetext{
8 Siehe dazu den Beitrag von Zbyněk Kindschi Garský.

9 Augustinus, De doctrina christiana 2.16 (Pollmann 2002, 66-67).

$10 \mathrm{Vgl}$. z. B. De genesi ad litteram 5.1; Enarrationes in psalmos 45.7.

11 So Cox $(1983,436)$ : „Nature was a symbolic language, a theological text.“

$12 \mathrm{Zu}$ diesem Thema s. den Beitrag von Katharina Heyden in diesem
} Band. 
Metamorphosen oder Übergängen (Seelenwanderung). Deshalb nimmt der Physiologus neben Pflanzen, Steinen und Tieren auch sogenannte Misch- oder Fabelwesen in seine Sammlung auf. In all diesen Erscheinungsformen der kreatürlichen Welt, d.h. von zahmen, wilden oder gewöhnlichen und exotischen Tieren, Misch- oder Fabelwesen, Pflanzen und Steinen, können also verschiedene Formen des Göttlichen gefunden werden. ${ }^{13}$

Die Realität der Misch- und Fabelwesen wurde in der Antike zwar angezweifelt und kritisiert, doch wurde den Nachrichten über sie auch wegen mangelnder Überprüfbarkeit oder infolge der Berufung auf namhafte Autoritäten oft geglaubt, Gleiches galt für entsprechende - märchenhafte oder legendarische - naturkundliche Berichte. ${ }^{14}$

Was für Tiere, Pflanzen und Steine bzw. welche Mischoder Fabelwesen behandelt nun der Physiologus ${ }^{15}$ Der Physiologus behandelt bekannte symbolträchtige Tiere: Adler, Ameise, Biene, Löwe, Schlange; gewöhnliche Tiere des antiken Alltags: Biber, Eidechse, Eisvogel ${ }^{16}$, Esel, Fasan, Frosch (Land- und Wasserfrosch), Fuchs, Gemse, Hase, Hund ${ }^{17}$, Hirsch, Ibis, Ichneumon ${ }^{18}$, Igel, Käuzchen $^{19}$, Krähe, Kuckuck ${ }^{20}$, Rebhuhn ${ }^{21}$, Reiher, Salamander, Schlupfwespen, Schwalbe, Specht, Sperling ${ }^{22}$, Storch, Taube, Thunfisch ${ }^{23}$, Turteltaube, Wiedehopf, Wiesel, Wildschwein; außergewöhnliche (exotische) Tiere, Raubtiere und Aasfresser: $\mathrm{Affe}^{24}$, Bär ${ }^{25}$, Charadrius ${ }^{26}$, Prion/Pristis

13 Vgl. Speyer (2012, besonders 864-870).

14 Vgl. Speyer (2012, besonders 914-918).

15 Im Folgenden werden in der Regel nur dann erläuternde Hinweise in den Anmerkungen gegeben, wenn die Tiere, Mischwesen, Pflanzen und Steine nicht zu den bekannten Redaktionen I-III gehören, ihre Identifikation strittig ist bzw. zusätzliche Hinweise sinnvoll erscheinen.

16 Appendix Sbordone (1936a, 323).

17 Siehe Perry (1941, 1114-1115, Redaktion IV).

18 Eine Schleichkatzenart; siehe Mielsch (2005, 67-70).

19 So Treu (31998, 13-14, 134). Wörtlich: Nachtrabe. Die Zuweisung zum Käuzchen ist umstritten.

20 Der Kuckuck findet sich nur in der Handschrift G Kapitel 49 (Offermanns 1966, 158).

21 Oder Stein- bzw. Bläßhuhn, Wachtel; siehe Mielsch (2005, 112115).

22 Appendix Sbordone (1936a, 314).

23 Appendix Sbordone (1936a, 317).

24 Appendix Sbordone (1936a, 305-306, 318-319, 320-321).

25 Siehe Perry (1941, 1114-1115, Redaktion IV).

26 Vogel mit Heilkräften gegen Gelbsucht - wahrscheinlich fiktiv; siehe Kehl (1986); Mielsch (2005, 121-122). $\left(\right.$ Delphin/Sägefisch) ${ }^{27}$, Elefant, Enhydris ${ }^{28}$, Geier, Hyäne, Krokodil, Papagei, Pavian ${ }^{29}$, Pelikan, Pfau, Panther, Strauß, Wolf; sowie (teils symbolreiche) Misch- oder Fabelwesen: Basilisk ${ }^{30}$, Echidna, Einhorn, Gorgo, Greif, Phönix, Satyr $^{31}$, Sirenen ${ }^{32}$ und Hippo- oder Onokentauren ${ }^{33}$; nicht von antiken Quellen übernommen bzw. neu sind: Aspidochelone $^{34}$; Ameisenlöwe, Antholops ${ }^{35}$, Hydrippos ${ }^{36}$; Medeia-Tier ${ }^{37}$; Pristis/Prion ${ }^{38}$. An Steinen kommen vor: Achat, Magnet, Diamant, Feuerstein, Gebär- oder Geierstein $^{39}$, Indischer Stein ${ }^{40}$ sowie die Perle; an Pflanzen: Maulbeerfeige $^{41}$, der Baum Peridexion, Mandragora. ${ }^{42}$

\section{Reihenfolge der Kapitel}

Ein Aufbauschema oder Ordnungsprinzip der Kapitel ist nicht erkennbar, da diese einfach additiv aneindergereiht werden, wohl aber beginnt der Text in Redaktion I-III und den alten Übersetzungen mit dem König der Tiere: dem Löwen. Manche Kapitel folgen aufgrund ihrer gemeinsamen Nennung in einer Bibelstelle aufeinander. So wird der Igel in der Nachbarschaft mit Sirenen und Hippobzw. Onokentauren in der 1. Redaktion behandelt nach Jes $13,21-22^{\mathrm{LXX}}$; in der 3. ps.-basilianischen Redaktion in Nachbarschaft des Hasen nach Ps $103,18^{\text {LXX }} .^{43}$ Pelikan,

27 Vielleicht gemeint in Kapitel 39: Prion/Pristis wegen der Begleitung der Schiffe; siehe Diez $(1957,677)$.

28 Die Identifizierung mit dem Fischotter (so Seel ${ }^{3} 2005$, 38-39, 111) ist unsicher.

29 Mielsch (2005, 77).

30 Appendix Sbordone (1936a, 316).

31 Siehe Perry (1941, 1114-1115, Redaktion IV).

32 Vgl. Rahner (1964, 257).

33 Beide Formen sind überliefert.

34 Seeungetüm, vgl. Breitenbach und Witte-Orr (2004, 790).

35 Vielleicht die Antilope.

36 Wasserpferd; nicht gemeint ist das erst seit dem 9./10 Jh. aus dem nördlichen Europa bekannte Walross; vgl. Speyer (2012, 913); Schönberger (2001), rezensiert von Schneider (2002b, 1023-1024).

37 Benannt nach der kindstötenden Medea; Appendix Sbordone (1936a, 317-318).

38 Seetier namens „Säge“, siehe oben Delphin.

39 Im Geier-Kapitel vom Adlerstein übertragen; siehe Speyer (1976, 458); Schneider und Stemplinger (1950).

40 Auch Froschstein genannt; vielleicht der aus Plinius, Naturalis historia 37.190 bekannte Wasserstein.

41 Siehe Reichmann $(1969,687)$.

42 Gemeint ist Alraun; im Elefanten-Kapitel (2. Redaktion) als Aphrodisiakum (so schon Gen 39,14-15 belegt) von der Elefantenkuh benutzt; Parallele zur Sündenfallgeschichte; siehe Schneider (1950, 309); Opelt (1959, 1021).

43 Vgl. Witek (1996, 925-926). 
Käuzchen und Adler (Kapitel 4-6) folgen offenbar assoziativ nach dem Vorkommen in Ps $101,7^{\mathrm{LXX}}$ und $102,5^{\mathrm{LXX}}$ aufeinander in der 1. Redaktion. ${ }^{44}$

\section{Formale Struktur der einzelnen Kapitel}

Analysiert man die formale Struktur der einzelnen Kapitel des Physiologus, so kristallisiert sich ein typischer Aufbau heraus:

1. In einem ersten Teil haben wir zu Beginn oft ein Bibelzitat, in dem das betreffende Tier, Mischwesen, die Pflanze oder der Stein genannt wird. Sodann folgt eine naturkundliche Beschreibung der Eigenschaften bzw. der Natur, die sich auf die Autorität des Physiologus stützt.

2. In einem zweiten Teil werden diese Eigenschaften christlich bzw. allegorisch ausgelegt. Beschlossen wird das Kapitel im Regelfall durch einen formelhaften Rückgriff auf die Autorität des Physiologus (,Schön hat der Physiologus gesprochen ...“). ${ }^{45}$

\section{Der Aufbau eines Physiologus-Kapitels}

1. Teil

$$
1.1 \text { Beginn }
$$

\subsubsection{Bibelzitat}

1.1.2 Berufung auf die Autorität des Physiologus (z.B. „wie der Physiologus sagt“) und naturkundliche Beschreibung der Physis

2. Teil

2.1 Christliche Deutung der Physeis (allegorisch/typologisch) unter Berufung auf verschiedene Bibelstellen oder biblische Paradigmata

2.2 Formelhafter Abschluß mit erneutem Bezug auf die Autorität des Physiologus („Schön hat der Physiologus gesprochen ...“)

Ein Beispiel soll dies verdeutlichen, nämlich Kapitel 4:

$$
\text { VOM PELIKAN }{ }^{46}
$$

44 Siehe Alpers (1996, 597).

45 Diese Technik ist bereits seit den homerischen Reden bekannt. 46 Text: 1. Redaktion (Sbordone 1936a, 16-19). Die in diesem Beitrag abgedruckten Übersetzungen gehen auf ein Manuskript zurück, das ursprünglich von Ursula Treu stammt und der Redaktion Fontes Christiani übergeben wurde. Der Text der Übersetzung wurde von mir redigiert.
Bibelzitat

Schön sagt David: „Ich bin gleich dem Pelikan in der Wüste“ (Ps 101,7).

Naturkundliche Beschreibung mit Berufung auf den Physiologus Der Physiologus sagt vom Pelikan, dass er von Natur aus sehr kinderlieb ist. Wenn er die Jungen geboren hat und sie ein wenig herangewachsen sind, schlagen sie den Eltern ins Gesicht. Die Eltern züchtigen die Kinder dann und töten sie. Später bereuen die Eltern das und betrauern die Kinder drei Tage lang, die sie getötet haben. Am dritten Tage reißt sich ihre Mutter die Brust auf; das Blut tropft auf die Leichen der Jungen und sie weckt sie wieder auf.

\section{Christliche Hermeneia}

So sagte auch der Herr im Buch Jesaja: „Söhne habe ich aufgezogen und sie erhöht, und sie sind von mir abgefallen“ (Jes 1-2). Es hat der Schöpfer uns zu Herrn der gesamten Schöpfung geboren, und wir haben ihn geschlagen: Auf welche Weise haben wir ihn geschlagen? „Wir haben der Schöpfung mehr gedient als dem Schöpfer“ (Röm 1,25; Mk 1,5). Als unser Heiland an das Holz des Kreuzes hinaufgegangen war, hat er seine Seite geöffnet und Blut und Wasser zur Rettung und zum ewigen Leben vergossen. Das Blut durch den, der gesagt hat: „Er nahm den Kelch und dankte“ (Mt 26,27; Mk 1,4; Lk 3,3; Apg 13,24.19,9); das Wasser dient zur Taufe der Buße.

Fomelhafter Abschluß mit erneutem Bezug auf die Autorität des Physiologus

Schön hat der Physiologus über den Pelikan gesprochen.

Dieses Grundmuster wird vielfach variiert. So kann z. B. am Beginn das Bibelzitat fehlen oder häufig fehlt auch der Rückbezug auf die Autorität des Physiologus am Ende des Kapitels. Es gibt auch Kapitel, in denen der Physiologus gar nicht genannt wird. Allerdings reichen diese formalen Beobachtungen alleine nicht aus, um Rückschlüsse auf die Echtheit oder spätere Hinzufügung eines einzelnen Kapitels oder Textes zu ziehen.

\section{Die Varianten der Überlieferung: Zusätze, Scholien etc.}

Bei der Frage der Bewertung der überlieferten Textvarianten muß man sich vor allem klarmachen, dass schon der Text, den Sbordone in der ersten Redaktion bietet, keinen reinen Text einer ursprünglichen Physiologus-Fassung enthält, sondern vor allem die Hauptvarianten der wichtigsten Handschriftenfamilien, in die sich die erste Redaktion weiter untergliedern läßt. Diese enthalten aber eine Vielzahl von Zusätzen und Änderungen, insbesondere Glossen und Scholien. Dafür zwei Beispiele: 
1. Beispiel: Das Kapitel über den Salamander. ${ }^{47}$

\section{VOM SALAMANDER}

Es gibt ein Lebewesen, das Salamander heißt. Der Physiologus hat über ihn gesagt: wenn er in den Feuerofen kommt, verlöscht der ganze Ofen, und wenn er in die Fußbodenheizung (sc. Hypokausten) des Bades kommt, verlöscht die Fußbodenheizung. Wenn nun der Salamander das Feuer durch seine natürliche Anlage löscht, wie können dann bis heute noch Leute bezweifeln, dass die drei Jünglinge im Feuerofen keinen Schaden erlitten, sondern im Gegenteil den Ofen abkühlten? Denn es steht geschrieben: „Und selbst wenn du durchs Feuer gehst, wird die Flamme dich nicht verbrennen“ (Jes 43,2). So, oh Mensch, sei auch du in der Lage die ewige und unauslöschliche Flamme zu löschen.

Die Feuerfestigkeit des Salamanders, die in der Antike als pseudonaturwissenschaftliche Tatsache galt - sie wird z.B. von Aristoteles, Theophrast, Plinius und Aelian erwähnt ${ }^{48}$ - wird hier mit einem berühmten Rettungsparadigma aus dem Alten Testament erklärt: die drei Jünglinge im Feuerofen aus dem Buch Daniel. Eine ausführlichere Hermeneia und eine abschließende Bemerkung („Schön hat der Salamander gesprochen ...") fehlen allerdings in diesem Strang der Überlieferung.

In einigen Handschriften folgt jedoch noch ein weiterer Text, den Sbordone in zwei geringfügig voneinander abweichenden Fassungen in seinem Haupttext abgedruckt hat. Ich zitiere hier nur den ersten Text: ${ }^{49}$

\section{1.a. ÜBER DIE DREI HEILIGEN JÜNGLINGE}

Beim Propheten Daniel steht eine bewundernswerte Geschichte über die drei edlen Jünglinge geschrieben, die wegen einer Verleumdung in den Feuerofen geworfen worden waren und ein solches Loblied im Feuerofen sangen, dass man sie nur bewundern kann (vgl. Dan 3). Denn sie waren gerecht. Weshalb aber hätte sich dieses Wunder nicht wahrhaft ereignen können, da doch auch die heiligen Apostel Tote erweckt haben und größere Taten vollbracht haben als diese Gerechten? Und sie Berge ins Meer versetzt haben (vgl. 1 Kor 13,2)?

Zunächst fällt auf, dass dieser Exkurs inhaltlich nur noch auf die drei Jünglinge abhebt und den Salamander und seine Physis ganz außer acht läßt. Eine enge Verknüpfung mit der Geschichte des Salamanders fehlt. Zudem ist dieser Passus auch durch eine eigene Überschrift von dem vorhergehenden Text abgetrennt (in den Handschrif-

47 Text: Sbordone (1936a, 101-102).

48 Aristoteles, Historia animalium 5.19.552b15; Theophrast, De igne 60; Plinius, Naturalis historia 29.4.76, 10.67.188; Aelian, De natura animalium 2.31. Siehe den Apparat mit weiteren Belegen bei Sbordone (1936a, 101).

49 Text: Sbordone (1936a, 102-103). ten überliefert). Das legt den Schluß nahe, dass er nicht zur ursprünglichen Physiologus-Geschichte über den Salamander gehörte. Es handelt sich vielmehr um einen exegetischen Zusatz, der vielleicht sogar einmal als Scholion am Rand des Textes überliefert war und später in den Haupttext hineingelangte. Vielleicht empfand der Kopist den ihm vorliegenden Text als zu kurz oder als inhaltlich unbefriedigend und fügte deshalb diesen exegetischen Exkurs ein. Der Text ist offensichtlich als Veständnishilfe für die Anspielung des Physiologus auf die drei Jünglinge im Feuerofen gedacht. Der Physiologus setzt das Wissen um diese berühmte biblische Episode aber voraus, und er konnte das auch guten Gewissens tun. Denn dieses Exempel - wie auch andere alttestamentarische Rettungsparadigmen - war bei den frühen Christen bekannt: Wir kennen es z.B. auch aus der frühchristlichen Katakombenmalerei (Priscilla-Katakombe 3. Jh.). Sbordone hätte diesen Text also eigentlich als Scholion oder exegetischen Zusatz kennzeichnen sollen.

Ein ähnliches Phänomen können wir an einer anderen Stelle im Diamantkapitel beobachten, wo Sbordone eine Reihe von Bibelstellen mit in seinen Haupttext aufnimmt, zu denen er im Apparat lapidar bemerkt, dass er auch nicht wisse, warum diese Verse an dieser Stelle in diesen Handschriften überliefert seien, da sie mit dem voraufgegangenen Text nicht viel zu tun haben. ${ }^{50}$

2. Beispiel: Auch das Kapitel über den Diamanten läßt sich in der ersten Redaktion nach Sbordone genauer analysieren. Das Kapitel lautet

\section{Vom DiamantSTEIN}

Der Physiologus hat über den Diamanten gesagt, dass er im Land nach Sonnenaufgang hin gefunden wird. Er wird nicht tagsüber gefunden, sondern allein des Nachts. Adamas (sc. der Unbezwingliche) wird er genannt, weil er alles bezwingt, selbst aber von nichts bezwungen wird.

Auch unser Herr Jesus Christus richtet alle, ihn selbst aber kann keiner richten (vgl. 1 Kor 2,15). Denn er hat gesagt: „Wer von euch kann mich einer Sünde zeihen? (Joh 8,46)“ Im Osten wird er gefunden, denn wahrlich sagt der Pophet: „Aufgang (sc. Osten) ist sein Name“ (Sach 6,12).

Es fällt auf, dass hier lediglich die gebräuchliche Etymologie des Adamas (der nicht bezwungen werden kann) und die Auffindungslegende des Diamanten für die Darstellung der Physis und die sich anschließende Hermeneia benutzt werden. Außerdem fehlt die typische Abschlußformel, was aber durchaus häufiger vorkommt.

50 Apparat Sbordone (1936a, 106) zu Zeile 2-10: „,nescio quo pacto loca bibl. plane inutilia in A irrepserint“. 
Eine weitere Version, die von Sbordone in Kapitel $32^{\text {bis }}$ abgedruckt wurde, orientiert sich hingegen stark an Plinius $^{51}$ bzw. Xenokrates ${ }^{52}$ Beschreibung des Diamanten und erwähnt ganz besonders auch die Legende der Feuerfestigkeit, die Hammer-Amboß-Legende ${ }^{53}$ sowie die Bocksblutlegende. ${ }^{54}$

$$
32^{\text {bis }} \text {. }
$$

Es gibt einen Stein, der Diamant genannt wird, denn er wird weder vom Eisen geschnitten noch wird er auch Schnitzen weich. Er schmilzt auch nicht im Feuer, das alles verzehrt, sondern allein in Bocksblut, das, weil es heißer ist als alles andere, die unnach giebige Härte des Steines erweichen kann. ... Weswegen und warum ist diesem Ding ein so merkwürdiges Wesen gegeben? Deswegen, damit, wenn jemand der göttlichen Botschaft nach Christus Vertrauen schenkt, aber wider Willen nicht glauben kann, er doch das Geheimnis des Glaubens annehmen soll, wenn er nur auf den Diamanten blickt. ... So unbezwingbar durch Gewalt ist er: Was auch Könige und Tyrannen gegen ihn geplant haben, alle haben sie ihr Ziel verfehlt. Denn wie einen Diamantstein haben sie Christus angegriffen, aber sie wurden als ohnmäch tig entlarvt. ... Der aber, obwohl allen überlegen gefunden, wird wie der Diamant durch warmes Blut gebeugt. ... Durch warmes Blut wird also wie der Diamant auch Christus, der Unbesiegbare, besiegt, und sein eigenes Innere wird erweicht, und deshalb genießt er das Königreich im Himmel.

Der Verfasser dieser zweiten Version in Kapitel $32^{\text {bis }}$ verzichtet ganz auf die Nennung der Autorität des Physiologus. Er hat seine Quellen (vor allem Plinius, vielleicht Xenokrates) offenbar deshalb stärker ausgeschöpft, weil ihm die vorliegende Fassung des Physiologus-Textes zu kurz bzw. nicht ausreichend erschien. Hinzu kommt, dass die handschriftliche Basis, auf die sich diese Version stützen kann, ausgesprochen dünn ist. Denn sie ist nur in einer Handschrift der ersten Redaktion überliefert. ${ }^{55}$ Diese Version gehört daher sicher nicht zum ursprünglichen Bestand. Wann sie allerdings zum Physiologus-Text hinzukam, bleibt unsicher.

51 Plinius, Naturalis historia 37.15.55-61.

52 Plinius verweist u. a. auf das Gemmenlexikon des Xenokrates von Ephesus (1. Jh.n. Chr.), der für uns vor allem durch einen in späterer Zeit überlieferten Auszug über den Adamas faßbar ist, nämlich im Kommentar des Hieronymus zu dem biblischen Propheten Amos 7.7-9.

53 Hammer-Amboss-Legende bedeutet, dass der Diamant selbst durch beste Hämmer und Ambosse nicht zertrümmert werden kann. Siehe dazu Haas, Hödl und Schneider (2004, 139-142).

54 Die Bocksblutlegende besagt, dass der Diamant nur durch Bocksblut erweicht werden kann; vgl. Haas, Hödl und Schneider (2004, 146-156); Ohly (1976).

55 Sbordone (1936a, 106) zu den Codices: „in charta Allaciana 216 (CXLI) apud Bibl. Vallicellianam servatur“.
Die Hammer-Amboss-Legende wird auch noch genannt in Kapitel 42 - eine weitere Version, wieder ohne Nennung des Physiologus, wobei die magisch-apotropäische Kraft des Steines zusätzlich beschrieben wird:

\section{VOM [STARKEN] DiAMANTSTEIN}

Es gibt noch eine andere Eigenart des [starken] Diamanten. Dieser scheut nämlich weder Eisen, wenn man ihn damit schlägt, noch [scheut er] das Feuer, [wenn man versucht, ihn damit zu verbrennen], noch nimmt er den Dunst des Rauches an. Wenn er sich in einem Hause befindet, geht weder ein böser Geist dort hinein noch wird irgend etwas Böses gefunden. Der Mensch aber, der ihn besitzt, besiegt jeden Anschlag des Teufels. Der Diamant ist unser Herr Jesus Christus. Wenn du ihn also im Herzen festhältst, Mensch, wird dir kein Übel jemals widerfahren.

Gleiches gilt auch für ergänzende Kapitel, die mit der typischen Formel eingeleitet werden: „Es gibt auch noch eine weitere Physis ..." Solche Versionen liegen z. B. vor beim Wildesel (Kapitel 45) und auch wieder beim Diamanten (Kapitel 42). Auch diese Textfassungen wurden also erst später hinzugefügt.

Wichtig bleibt also festzuhalten, dass auch die von Sbordone ermittelte sogenannte erste Redaktion nicht eins zu eins identisch ist mit einer möglichen Ursprungsfassung.

\section{Entstehung und Interpretation des Textes}

Wie aber ist der Text selbst zu verstehen? Welches Interesse verfolgt der Verfasser mit diesen Texten und wie muß man sich Ihre Entstehung vorstellen?

Generell kann man sagen, dass der Physiologus die Informationen der ihm vorliegenden naturkundlichen Werke benutzt oder sich an bekannte naturkundliche Überlieferungen, Geschichten und Beobachtungen aus seiner Um-

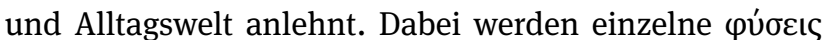
oder Geschichten unverändert aus der naturkundlichen Tradition übernommen, in Einzelheiten modifiziert, auf andere Arten übertragen, neu erfunden oder im Hinblick auf die Auslegung umgeformt. ${ }^{56}$ Die Tendenz sich von einer heidnischen Umwelt abzugrenzen und dem paganen Kult eine christliche Deutung der Welt und Natur entgegenzusetzen, wird in einigen Kapiteln besonders deutlich, so etwa im Kapitel über die Sonneneidechse.

\section{VON DER SONNENEIDECHSE}

56 Siehe hierzu Schneider (2016, 726-727 und 732-735). 
Es gibt eine Eidechse, die Sonneneidechse genannt wird, wie der Physiologus sagt. Wenn sie alt geworden ist, nimmt sie an beiden Augen Schaden und wird blind: Sie sieht das Licht der Sonne nicht mehr. Was macht nun die gute Natur in ihr? Sie sucht eine nach Osten gelegene Mauer und kriecht in eine Mauerspalte, und wenn die Sonne aufgeht, öffnen sich ihre Augen, und sie werden wieder gesund.

In dieser Weise suche auch du, o Mensch, wenn du das Gewand des alten Menschen trägst (vgl. Eph 4,22-24; Kol 3,9) und die Augen deines Herzens trübe werden, die aufgehende Sonne der Gerechtigkeit (Mal 3,20), unseren Herrn Jesus Christus, [dessen Name bei dem Propheten „Aufgang“ genannt wird] (vgl. Sach 6,12; Lk 1,78). Er wird die Augen deines Herzens öffnen.

Das Kapitel über die Sonneneidechse ist relativ kurz und nach dem bereits oben beschriebenen Schema aufgebaut. Es fehlen lediglich eine einleitende Bibelstelle und ein formelhafter Abschluß in diesem Zweig der Überlieferung. Zunächst wird im ersten Teil ihre Erblindung im Alter dargestellt. Diese heilt sie dadurch, dass sie sich in einer Mauerspalte in Richtung Osten verkriecht und den Sonnenaufgang betrachtet. Im zweiten Teil werden die wesentlichen Elemente dieser Geschichte wieder aufgenommen und allegorisch gedeutet. Der in das Gewand des alten Adam gehüllte Mensch, dessen Augen nicht mehr richtig sehen können, soll sich zur Sonne der Gerechtigkeit (sc. Christus) hinwenden, um sein Augenlicht zurückzubekommen.

Im ersten Teil knüpft die Geschichte über die Sonneneidechse an allseits bekannte Beobachtungen über die Mauereidechse an und ihr besonderes Verhältnis zur Sonne: Sie galt in der Antike als Sonnentier, das sich erst bei der Mittagshitze ins Kühle zurückzieht. Dieses Verhalten greifen Dichter wie Theokrit oder Vergil gerne auf, um die Mittagsstimmung zu beschreiben. In Theokrits Eidyllion 7.21-22 fragt Lykidas: „Wohin eilst du Simichidas denn jetzt in der Stunde des Mittags, wo sogar die Eidechsen in den Mauerritzen schlafen?“ Bekannte Eidechsenarten wie die Smaragdeidechse, Mauereidechse oder auch unsere heimische Zauneidechse waren in der Antike in Europa bzw. im Mittelmeerraum genauso verbreitet wie heute.

Der Text ist in seinem zweiten, allegorischen Teil mit wichtigen Bildern und Begriffen des christlichen Glaubens durchsetzt: das Gewand des alten Adam, die Blickrichtung nach Osten zur Sonne der Gerechtigkeit und der Sonnenaufgang als Symbol Christi bzw. seiner Auferstehung.

Dass hier aber ausgerechnet auf die Blindheit der Eidechse rekurriert wird, die sich ähnlich wie die Schlange verjüngen kann, wird erst vor dem Hintergrund der antiken medizinisch-magischen Praktiken verständlich, die man mit diesen Reptilien verband. Plinius kennt in seiner großen naturkundlichen Enzyklopädie gleich mehrere Rezepte, wie man mit Hilfe von Eidechsen verschiedene Mittel gegen Augenkrankheiten herstellen konnte. Z. B. sticht man einer Eidechse zunächst die Augen aus und läßt sie dann mit einem Eisen- oder Goldring zusammen in einem Glasbehälter. Sobald die Eidechse das Augenlicht wiedergewonnen hat, läßt man sie frei. Der Ring kann dann als apotropäisches Mittel gegen Augenentzündungen getragen werden. Oder man sperrt eine Eidechse zusammen mit neun Steinen, auf denen Eidechsen eingraviert sind, neun Tage lang in einem frischgebrannten Tongefäß ein. Dann nimmt man jeden Tag einen Stein weg. Am neunten Tag entläßt man die Eidechse wieder in die Freiheit. Die so gewonnenen Steine eignen sich nun zur Abwehr und Behandlung von Augenkrankheiten. Aelian berichtet sogar, dass er selbst einmal Augenzeuge bei einer solchen magischen Prozedur gewesen sei. ${ }^{57}$

Campbell Bonner hat in seinem Buch über magische Amulette insgesamt 16 solcher magischen Steine mit eingravierten Eidechsen beschrieben, die alle aus dem ägyptischen Raum stammen und in das 2. oder 3. Jh. datiert werden. ${ }^{58}$

Offenbar wurde die Geschichte über die Erblindung und Regeneration der Sonneneidechse im Physiologus als christliches Gegenstück zum paganen medizinischmagischen Volks- und Naturglauben konzipiert. Man wußte um diese Praktiken, akzeptierte sie sogar als pseudonaturkundliche Realität und versuchte eine christliche Deutung, um sie aus der heidnischen Sphäre in die christliche hinüberzuführen. Dieses Verfahren wendet der unbekannte Autor dieses Textes mehrfach an. ${ }^{59}$ Dabei beruft sich der Verfasser dieses Textes auf den Physiologus, das heißt einen anonymen Naturkundler oder Naturwissenschaftler, dessen Autorität unbestritten bzw. dessen Ansehen hoch ist. Spätere Kopisten oder Redaktoren empfanden diese anonyme Autorität des Physiologus allerdings als unbefriedigend. Deshalb wurde der Physiologus-Text immer wieder unterschiedlichen berühmten christlichen Autoritäten wie Chrysostomus, Basilius, Epiphanius, Ambrosius oder Hieronymus zugewiesen, um dem Text durch die Pseudoautorschaft eines bekannten Kirchenvaters einen höheren Stellenwert zu verleihen. ${ }^{60}$

Neben solchem pseudonaturkundlichem Wissen und manchmal auch märchenhaften oder legendenhaften Er-

57 Aelian, De natura animalium 5.47; Plinius, Naturalis historia 29.129-131.

58 Bei den Steinen handelte es sich meistens um Jaspis. Bonner (1950, 69-71). Diese Amulette, auch Ringe, sind jetzt bequem greifbar in The Campbell Bonner Magical Gems Database (Bélyácz, Endreffy und Nagy 2017): z. B. CBd-1183, 1233, 1255, 1708, 1792.

59 Z. B. in Kapitel 40: Ibis; vgl. Schneider (2002a, 151-164) und H. Görgemanns im vorliegenden Band. 60 Vgl. Perry (1941, 1076-1078). 
zählelementen, die durchaus auch aus der Bibel stammen können, steht aber auch echte Naturbeobachtung mit präzisen Beschreibungen. Wenn z. B. die Eigenschaft des Ibis als Wat- und Stelzvogel beschrieben wird, der nicht schwimmt bzw. sich nur im seichten Wasser aufhält.

Die breite Rezeption, die zahlreichen Handschriften, Versionen und Übersetzungen ${ }^{61}$ machen zudem deutlich, dass der Verfasser des Physiologus das christliche Wissen erfolgreich popularisierte. Seine christliche Naturkunde wurde so zu einer Art Volksbuch, das man gerne las und zitierte. Dabei dürfte der Text zunächst für den Unterricht und/oder die christliche Predigt/Seelsorge geschrieben worden sein, ${ }^{62}$ aus dem Bedürfnis heraus, einerseits in der Bibel und in der Alltagswelt vorkommende Tiere, Pflanzen, Steine und Mischwesen in den Zusammenhang der christlichen Botschaft zu stellen, und sie aus der Vor-

61 In der Spätantike wird der griechische Physiologus in alle wichtigen Sprachen des griechisch-römisch-orientalischen Kulturkreises übersetzt. Der ersten Redaktion entstammen die Vorlagen für alle lateinischen Übersetzungen sowie für die armenische, koptische, syrische, arabische und äthiopische Physiologus-Version. Die verschiedenen lateinischen Übersetzungsvarianten des Physiologus werden ihrerseits wieder im Mittelalter in die entsprechenden Nationalsprachen übersetzt, oft zu sogenannten Bestiarien umgearbeitet. Daneben wird der Physiologus ins Althochdeutsche, Italienische, Waldensische, Provenzalische, Spanische und Tosco-Venetianische übersetzt. Im slavischen Raum wird der Physiologus vor allem nach der 2. Redaktion ins Bulgarische, Russische, Serbische und Tschechische sowie ins Rumänische übersetzt, ins Georgische nach der 1. Redaktion, ebenso in skandinavische Sprachen. Ein eigenes Feld ist die kunsthistorische Nachwirkung; siehe ausführlicher Schneider (2016, 740-741) und die Beitrage zur Rezeption im vorliegenden Band von R. Hirsch-Luipold und K. Heyden.

62 Vgl. Schneider (2016, 731-732), leicht abgewandelt: „Die einzelnen Auslegungen der Geschichten klingen bisweilen wie kurze Predigten mit entsprechenden Ermahnungen (z.B. zu Enthaltsamkeit oder Fasten), auch Warnungen (z. B. vor sexueller Versuchung, Geiz oder Habgier) und lassen daher auch auf einen mündlichen Vortrag schließen. Dabei spricht der Physiologus weniger als Theologe, sondern mehr als Seelsorger/Lehrer, der den Dialog mit dem Gläubigen/Schüler sucht (häufige Ansprache an den Gläubigen in der 2. Person: ov̀ 21-mal). Der einzelne Gläubige wird oft nur allgemein als $\alpha \nu \theta \rho \omega \pi \varepsilon$ (,Mensch', 10-mal), aber auch als Glied der Gemein-

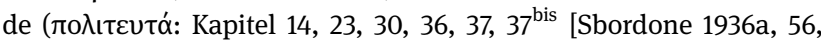
84, 99, 117, 118-119]; őv $\theta \omega$

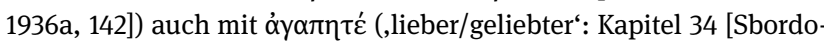

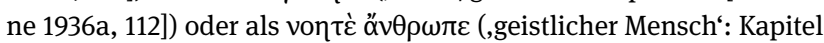
$30^{\text {bis }}$ [Sbordone 1936a, 101]) angesprochen, oder der Sprecher schließt

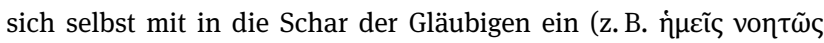
voń $\sigma \omega \mu \varepsilon$ : Kapitel 11 [Sbordone 1936a, 42]; oft Verwendung der 1. Person Plural in adhortativem Sinne). Die Sprache des Physiologus - biblisch (durch NT und LXX) geprägtes Koine-Griechisch - ist einfach und vermeidet komplizierte Satzkonstruktionen, was dem Predigtstil entspricht; sie weist in den späteren Redaktionen (bes. im Appendix) Einfluss der Volkssprache auf.“ stellungswelt einer feindlichen, heidnischen Gesellschaft herauszulösen und mit christlichen Assoziationen zu verknüpfen, andererseits die Neugier des christlichen Lesers oder Hörers durch teils wunderbare christlich inspirierte Geschichten zu fesseln, und zu zeigen, dass man auch mit christlichen Texten belehren und unterhalten kann. Dass die einfach strukturierten Geschichten über Tiere, Mischwesen, Pflanzen und Steine für das Vorstellungsvermögen der einfachen Gläubigen besonders gut nachvollziehbar sind und unmittelbar ansprechen, liegt auf der Hand. Außerdem dürfen wir nicht vergessen, dass die christliche Literatur in den ersten drei Jahrhunderten ja noch im Entstehen begriffen war. Das Wissen über das Christentum und seine verschiedenen Manifestationen und Glaubensinhalte mußte ja erst noch verbreitet werden. Wie die christliche Naturkunde des Physiologus offenbar als Gegenpol zu den paganen Tierbüchern und Naturkunden konzipiert wurde, so entsteht z. B. auch im 2. Jahrhundert in den apokryphen Apostelakten das christliche Pendant zum paganen Roman, der in dieser Zeit eine Blüte erlebt. ${ }^{63}$ Man darf auch nicht vergessen, dass der Außendruck für die christlichen Gemeinden in den ersten Jahrhunderten noch sehr groß war. Die Christen werden verfolgt, sie werden von gebildeten Heiden (wie z. B. Celsus) literarisch bekämpft, und sie müssen sich mit einem paganen Bildungsprogramm auseinandersetzen, das mit nicht-christlichen Inhalten operiert. Vor diesem Hintergrund wird deutlich, dass auch eine Schrift wie der Physiologus kein primär paradoxographisches Interesse verfolgt, das heißt er sammelt nicht Kuriositäten oder Naturwunder, um das Interesse eines sensationshungrigen Publikums zu befriedigen, wie wir das aus dem paganen paradoxographischen Schrifttum kennen. ${ }^{64}$ Vielmehr versucht er in erster Linie, das Geheimnis der christlichen Offenbarung auf einer naturkundlichen Basis zu vermitteln. Er lehrt ganz im paulinischen Sinne (Röm 1,20), Gott in der Schöpfung zu erkennen und bietet so eine frühchristliche Glaubens- und Naturlehre in nuce.

63 Vgl. z. B. zu Parallelen zwischen den Thekla-Akten und den zeitgenössischen Liebesromanen des 2. Jahrhunderts Schöllgen (2000). 64 Zuletzt vertreten von Schönberger (2001, 143), der von einem „Natur-Wunder-Buch mit heilsgeschichtlicher Deutung“ spricht. 


\section{Bibliographie}

\section{Textausgaben}

Kaimakis, Dimitris, Hg. 1974. Der Physiologus nach der ersten Redaktion. Meisenheim am Glan: A. Hain.

Offermanns, Dieter, Hg. 1966. Der Physiologus nach den Handschriften $G$ und M. BKP 22. Meisenheim am Glan: A. Hain.

Sbordone, Francesco, Hg. 1936a [1976, ${ }^{2}$ 1991]. Physiologus. Rom: Società Anonima Editrice ,Dante Alighieri‘ [Hildesheim: Olms] (zugrunde liegende Textausgabe).

\section{Übersetzungen}

Schönberger, Otto. (2001) 2014. Physiologus: Griechisch/Deutsch. Stuttgart: Reclam.

Seel, Otto. $(1960)^{3}$ 2005. Der Physiologus: Tiere und ihre Symbolik. (Zürich: Artemis \& Winkler) Düsseldorf: Patmos.

Treu, Ursula. (1981) ${ }^{3}$ 1998. Physiologus: Naturkunde in frühchristlicher Deutung, Hanau: Artia.

\section{Sekundärliteratur}

Alpers, Klaus. 1996. „Physiologus.“ TRE 36:596-602.

Bélyácz, Katalin, Kata Endreffy und Árpád M. Nagy, Hgg. (2010) 2017. The Campbell Bonner Magical Gems Database (CBd). Budapest: Museum of Fine Art. http://www2.szepmuveszeti. hu/talismans/.

Bonner, Campbell. 1950. Studies in Magical Amulets: Chiefly Graeco-Egyptian. Ann Arbor, MI: The University of Michigan Press.

Breitenbach, Alfred, und Johanna Witte-Orr. 2004. „Ketos (Meerdrache)." RAC 20:774-799.

Cox, Patricia. 1983. „The Physiologus: A Poiēsis of Nature“. Church History 52,4:433-443.

Diez, Erna. 1957. „Delphin.“ RAC 3:667-682.

Haas, Alois, Ludwig Hödl und Horst Schneider. 2004. Faszination Diamant: Zauber und Geschichte eines Wunders der Natur. Stuttgart: Springer.

Kehl, Alois. 1986. „Haradrius.“ RAC 13:585-593.

Maas, Paul. 1937. „B. E. Perry, Studies in the Text History of the Life and Fables of Aesop. Haverford, PA 1936. Physiologus ed. F. Sbordone. 1936. A. B. Drachmann, Die Überlieferung des Cyrillglossars. Kopenhagen 1936.“ Byzantinische Zeitschrift 37,2:376-381.

Mielsch, Harald. 2005. Griechische Tiergeschichten in der antiken Kunst. Mainz: Philipp von Zabern.

Ohly, Friedrich. 1976. Diamant und Bocksblut: Zur Traditions- und Auslegungsgeschichte eines Naturvorgangs von der Antike bis zur Moderne. Berlin: Erich Schmidt.

Opelt, Ilona. 1959. „Elefant.“ RAC 4:1001-1026.

Perry, Ben E. 1941, „Physiologus.“ PRE 20,1:1074-1129.

Perry, Ben E. 1968. „Der Physiologus nach den Handschriften G und M by Dieter Offermanns.“ Gnomon 40,4:416-418.

Pollmann, Karla. 2002. Augustinus: Die christliche Bildung (De doctrina Christiana). Stuttgart: Reclam.
Rahner, Hugo. 1964. Symbole der Kirche: Die Ekklesiologie der Väter. Salzburg: Otto Müller.

Reichmann, Viktor. 1969. „Feige II (Sykomore).“ RAC 7:683-689.

Riedinger, Rudolf. 1977. „D. Kaimakis, Der Physiologos nach der ersten Redaktion. Meisenheim am Glan [1974].“ Byzantinische Zeitschrift 70,1:109-112.

Schneider, Horst. 2002a. „Das Ibis-Kapitel im Physiologus.“ Vigiliae Christianae 56:151-164.

Schneider, Horst. 2002b. Rezension von „Physiologus, Griechisch/ Deutsch, übersetzt und herausgegeben von Otto Schönberger, Stuttgart 2001.“ Göttinger Forum für Altertumswissenschaft 5:1019-1034.

Schneider, Horst. 2016. „Physiologus.“ RAC 27:722-743.

Schneider, Käthe, und Eduard Stemplinger. 1950. „Adlerstein.“ $R A C$ 1:94.

Schneider, Käthe. [Stemplinger, Eduard]. 1950. „Alraun.“ $R A C$ 1:307-310.

Schöllgen, Georg. 2000. „Der Eros der Jungfräulichkeit: Zum Konzept der sexuellen Askese in den sogenannten Thekla-Akten.“ In Im Gedächtnis der Kirche neu erwachen: Studien zur Geschichte des Christentums in Mittel- und Osteuropa; Festgabe für Gabriel Adriányi zum 65. Geburtstag. Bonner Beiträge zur Kirchengeschichte 22, hrsg. v. Reimund Haas, Karl Josef Rivinius und Hermann-Josef Scheidgen, 597-606. Köln: Böhlau Verlag.

Speyer, Wolfgang. 1976. „Geier.“ RAC 9:430-468.

Speyer, Wolfgang. 2012. „Mischwesen.“ RAC 24:864-925. Witek, Franz. 1996. „Igel (Stacheltiere; Klippschliefer).“ $R A C$ 17:912-932. 

Teil II: Griechisch-römische Antike 



\section{Der Physiologus und die Tierkunde der Griechen}

\begin{abstract}
Introduction: Physiologus and its Relation to Ancient Zoology. 2. Brief introduction to Physiologus (chapter 5). 3. Aristotle's Zoology: a) Overview, b) Relation to philosophy, c) Presentation of De partibus animalium 1,5: Zoological research as an ideal image of bios theoretikós, contact with the religious. Conjecture: the of-

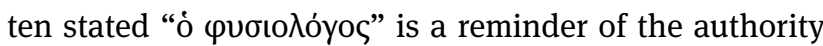
of Aristotle. 4. Hellenistic animal literature: a) the creation of reference works, b) the penetration of entertainment and mirabilia literature, c) the "occultism" of Bolos of Mendes. 5. Hellenistic philosophy: a) intelligence and character, legal relationship, b) the controversy Stoicism Academy (Philon, Plutarch). 6. Religious animal symbolism: a) Egyptians: Justification of the Egyptian animal cult by Hellenistic Egyptians of the Ptolemaic period. Presentation of Plutarch, De Iside et Osiride 74-76 (the symbolism mentioned here references the Greek mentality). Plutarch treats the subtleties of the symbolism with slight mockery, but on the philosophical level he accords animals very a prominent position as symbolic figures, because they are carriers of life and thus mirrors of the divine. b) Jews: Hellenized Jews try to justify the Old Testament prohibitions on certain foods ("impure animals") by symbolic interpretations. Letter of Aristeas 142-169; Philo, De specialibus legibus 4,100-118. c) Christians: Letter of Barnabas 10. Jewish dietary laws are not merely explained by symbolic interpretation, but also abolished.
\end{abstract}

\section{Einleitung: Der Physiologus und sein Bezug zur antiken Tierkunde}

Der Verfasser des Physiologus hat seine Aussagen über Eigenschaften der Tiere offensichtlich zum großen Teil aus der ausgedehnten Tierliteratur der griechisch-römischen Antike geschöpft. Diesem Hintergrund in der literarischen Tradition soll dieser Beitrag nachgehen. Die Forschung hat schon zu vielen Einzelheiten im Physiologus literarische Parallelen nachgewiesen. Eine klassische Quellenhypothese hat Max Wellmann (1930) entwickelt: Der Autor habe seine naturkundlichen Aussagen aus der (erschlossenen) Schrift eines Didymos von Alexandrien entnommen und dieser habe im wesentlichen die magisch-symbolische Naturkunde des Bolos von Mendes (um 200 v. Chr.) wiedergegeben. Die christlichen Deutungen müßte der Autor selbst hinzugefügt haben. Er weise auf seine Quelle immer wieder mit formelhaften Sätzen hin, am Anfang: „Der Phy- siológos hat gesagt“, am Ende: „Gut hat der Physiológos gesprochen. “1

Die zuletzt genannte Feststellung ist sicher richtig.

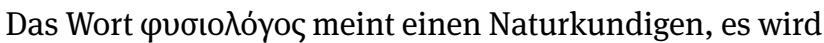
oft auf die vorsokratischen Philosophen angewendet. Es dürfte darin das Sinnelement einer alten, geachteten Autorität liegen, auf die man sich berufen kann. Es ist bezeichnend, daß es nicht kollektiv heißt: „die Naturkundigen sagen“ - dann würde man an gegenwärtige Fachleute denken -, sondern in einem emphatischen Singular „der Naturkundige“. Daß das Wort zum Titel der Schrift geworden ist, ist natürlich mißverständlich und sicher nicht im Sinne des Autors.

Nun sind gegen Wellmanns Hypothese aber viele Einwände erhoben worden und sie ist trotz des aufgewendeten Scharfsinns heute nicht mehr zu halten. ${ }^{2}$ Ein allgemeines Argument ist, daß manche Tiergeschichten offenbar aus der christlichen Deutung entwickelt sind, ${ }^{3}$ z. B. die Geschichte vom Einhorn (Kap. 22), das sich nur zähmen lasse, wenn es in den Schoß einer reinen Jungfrau springe. Dafür gibt es keine außerchristliche Parallelüberlieferung; es ist eine Erfindung, die die Jungfrauengeburt Christi verbildli-

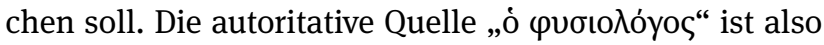
wohl eine Fiktion; man muß damit rechnen, daß der Autor den Stoff aus verschiedenen Quellen gesammelt, wenn nicht durch Verbindung griechischer Naturkunde mit biblischer Tradition selbst geschaffen hat.

Die Verfolgung einzelner Erzählmotive und ihrer Parallelen ergibt nur selten ein deutliches Bild von ihrer Herkunft. Darum scheint es fruchtbarer, die verschiedenen Bereiche der Tierliteratur in ihrer Eigenart und Entwicklung durchzugehen und von hier aus zu fragen, welche Spuren sie im Physiologus hinterlassen haben. Man kann im Großen vier Bereiche ansetzen:

- die Zoologie des Aristoteles,

- die Tierbücher des Hellenismus,

- die Mensch-Tier-Diskussion in der Philosophie,

- die religiöse Tiersymbolik in ägyptischem, jüdischem und christlichem Kontext.

Der Physiologus knüpft an die letztere an, und daß diese in Ägypten beheimatet ist, paßt zu der öfters gemachten

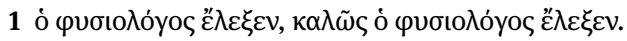

2 Ausführliche Diskussion bei Alpers (1984).

3 So schon Lauchert (1889, 4); dann Alpers (1984, 25-30, 35-41).
} 
Beobachtung, daß manche Einzelheiten in dieser Schrift auf eine Entstehung in Ägypten deuten.

\section{Kurze Vorstellung des Physiologus (Kapitel 5)}

$\mathrm{Zu}$ Beginn scheint es jedoch angebracht, an einem Beispiel deutlich $\mathrm{zu}$ machen, was die typischen Elemente des Physiologus sind, auf die sich die Beobachtungen beziehen sollten. Dafür sei Kap. 5 „Vom Nachtraben“ (Пєрі̀

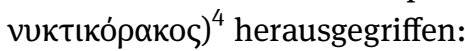

\begin{abstract}
Der Psalmist sagt: „Ich ward wie ein Nachtrabe an einer Ruinenstätte“ [Ps 102,7]. Der Physiologos sagte vom Nachtraben, daß dieser Vogel die Nacht mehr liebt als den Tag. So hat auch unser Herr Jesus Christus uns geliebt, die wir in Finsternis und Todesschatten saßen [Jes 9,2; Mt 4,16; Lk 1,79], uns, das Volk der Heiden - mehr als das Volk der Juden, welche die Sohnschaft und die Verheißung der Väter ererbt hatten. Darum sagte der Erlöser auch: „Fürchte dich nicht, du kleine Herde, denn es gefiel dem Vater, euch das Reich zu geben“ [Lk 12,32] und so fort. Indessen wirst du mir sagen, daß der Nachtrabe unrein ist gemäß dem Gesetz [Dtn 14,17]. Wieso wird ihm dann die Rolle des Erlösers gegeben? Gut sagt der Apostel: „Ihn, der keine Sünde kannte, hat er um unseretwillen zur Sünde gemacht“ [2 Kor 5,21]. Er hat sich selbst erniedrigt, um uns alle zu retten und damit wir erhöht würden. Gut hat also der Physiologos gesprochen über den Nachtraben. ${ }^{5}$
\end{abstract}

\footnotetext{
4 vขктıко́ $\alpha \xi$ wird in Ps 102,7 $\left(101,7^{\mathrm{LXX}}\right)$ und Dtn 14,16 von Luther mit „Käuzchen“ übersetzt; dem folgen neuere PhysiologusÜbersetzungen. Aber das Käuzchen heißt griechisch y $\lambda \alpha \tilde{u} \xi$ (oft auf Münzen von Athen abgebildet). Der „Nachtrabe“ wird mehrmals bei Aristoteles erwähnt; seine Angaben passen am besten auf die Waldohreule: Asio otus L., dazu Aubert und Wimmer $(1868,113)$; Thompson $\left.{ }^{2} 1936,207-209\right)$. Bei anderen Autoren kann mit dem „Nachtraben“ ein anderer Eulenvogel gemeint sein, so Strabo, Geographica 17.24: „,von der Größe eines Adlers“, wohl der Uhu.

5 Text nach Sbordone (1936a, 19-22): „Фпซìv ò $\Psi \alpha \lambda \mu \omega \delta$ ós.

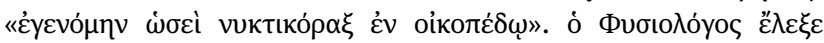

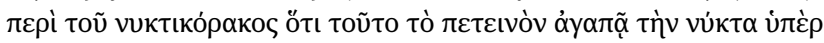

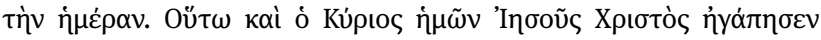

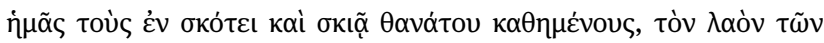

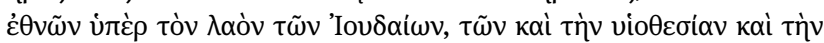

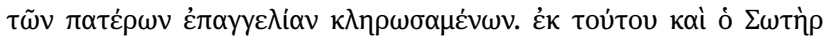

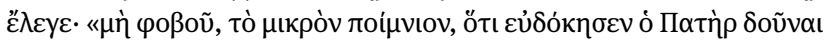

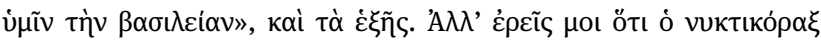

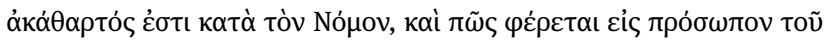

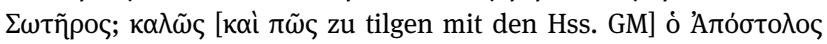

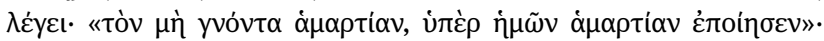

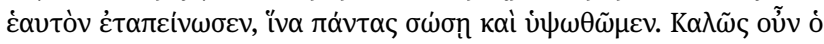

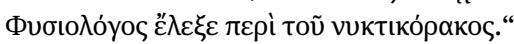

Der Autor geht von einer Psalmstelle aus, wo der Dichter sich mit einem „Nachtraben“ vergleicht, der an einer verödeten Stätte haust. Als zweites Element folgt eine naturkundliche Aussage des Physiológos: Dieses Tier liebe die Nacht mehr als den Tag. Eine entsprechende Aussage findet sich bei Aristoteles in der Historia animalium 9.34.619b18-23:

\begin{abstract}
Die Kauze und die Nachtraben und alle anderen Tiere, die bei Tag nicht zu sehen vermögen, beschaffen sich durch Jagd in der Nacht ihre Nahrung; allerdings tun sie das nicht die ganze Nacht lang, sondern bei Einbruch der Abenddämmerung und bei der Morgenröte. Sie jagen Mäuse, Eidechsen, Sphondylai [?] und andere Kleintiere dieser Art. ${ }^{6}$
\end{abstract}

Hier wird ein Unterschied in der Sichtweise erkennbar: bei Aristoteles eine sachliche Beschreibung des Verhaltens, das Jagen bei Nacht, verbunden mit einer kausalen Erklärung, dem schwachen Sehvermögen bei Tag; ${ }^{7}$ im Physiologus das subjektive „Lieben“, das mit den folgenden Schriftzitaten harmoniert.

Auf die zwei Vorgaben, die biblische und die naturkundliche, folgt die theologische Deutung, die beides in

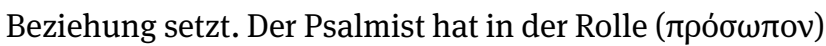
des Erlösers gesprochen (eine in der Psalmenexegese häufige Denkfigur), also liebt dieser die Nacht. Das scheint paradox; es ist so zu deuten, daß er die Menschen ,in Nacht und Todesschatten“, d.h. die Heiden, vor denen bevorzugt, die im Licht stehen, nämlich den Juden. Die Psalmstelle deutet also verschlüsselt auf die Ablösung der Juden als erwähltes Volk durch die Heiden. Dieser Vorgang wird mit einer weiteren Bibelstelle belegt, nach der ,das Reich (Gottes)“ vom Vater einer kleinen Herde gegeben wird. Diese exegetisch kühne Stellenkombination wird in großer Kürze, fast in einem Notizenstil, entworfen. ${ }^{8}$

Es folgt ein Einwand; man scheint fast einer theologischen Debatte beizuwohnen. Der Nachtrabe wird im Deuteronomium zu den unreinen Tieren gerechnet; wie kann

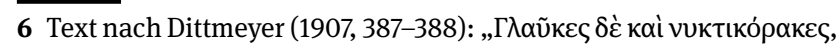

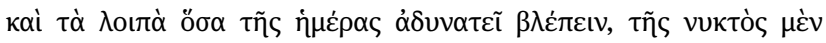

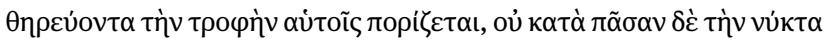

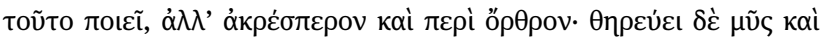

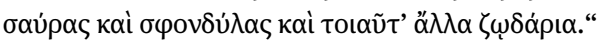

7 Nach neueren Erkenntnissen ist das Sehvermögen der Eulenvögel bei Tage durchaus nicht schwach; allerdings ist das Dämmerungssehen besonders hoch entwickelt. Brehm ('1879, 92); Grzimek (1970, 378). Eigentlich ist also die Formulierung des Physiologus treffender als die des Aristoteles.

8 So ist nicht leicht zu verstehen, warum mit der „kleinen Herde“ (Lk 12,32) die Heiden gemeint sein sollen. Diese sind zwar bei Lukas kurz vorher erwähnt $(12,30)$, aber als Gegenbeispiel, nicht als Empfänger der Verheißung. 
er dann Christus symbolisieren? Die Lösung wird mit zwei Paulus-Zitaten gegeben, die von der Dialektik der Menschwerdung sprechen: Der Erlöser hat sich erniedrigt, ist „,zur Sünde“ (also „unrein“) geworden, um uns von der Sünde $\mathrm{zu}$ retten. Auch das ist eine kühne Wendung, die eigentlich mit der ursprünglichen Deutung über Kreuz steht. Die unausgesprochene Pointe des Kapitels ist ja, daß ein unheimliches Nachttier ${ }^{9}$ zum Symbol des Erlösers wird; das wird zunächst damit erklärt, daß die Liebe zur Dunkelheit die Liebe zu den Heiden symbolisiert. Jetzt erhält die Dunkelheit einen anderen Sinn; sie ist „die Sünde“, zu welcher der Erlöser in paradoxer Weise geworden ist. Der Verfasser scheint zu experimentieren; er versucht mehrere Möglichkeiten, ein Paradoxon zu deuten; Naturkunde und Bibel bieten ihm dafür das Material.

\section{Zoologie des Aristoteles}

Von den ältesten tierkundlichen Schriften der Griechen, etwa denen Demokrits, ist wenig bekannt; sie wurden alle durch die überragenden Arbeiten des Aristoteles verdrängt. Aristoteles hat die Zoologie als wissenschaftliches Fach begründet; seine Schriften darüber machen mehr als ein Drittel des Umfangs seiner erhaltenen Werke aus. Er sammelte ein umfangreiches Faktenmaterial; dafür beutete er ältere Literatur aus und holte systematisch Informationen von Jägern, Tierzüchtern, Fischern und Tauchern ein. In den Jahren 348-342 hielt er sich in Assos (Kleinasien) und Mytilene (Lesbos) auf; dort scheint er intensive zoologische Beobachtungen gemacht zu haben, wie man aus Ortsangaben in seiner Historia animalium schliesst. ${ }^{10}$ Insgesamt werden in diesen Werken über 500 Tierarten behandelt. Er führte anatomische Studien mit Hilfe eigener Sektionen durch und fertigte einen anatomischen Atlas an. In der Auswertung dieses Materials entwickelte er Grundzüge einer Systematik, die in wesentlichen Zügen noch heute gilt; manche seiner Klassenbezeichnungen leben in lateinischer Form weiter, z. B. Ěvto $\mu \alpha$ - lateinisch „insecta“, deutsch „Kerbtiere“. Er untersuchte physiologische Funktionen z. T. in eigenen Monographien, so die Fortbewegung (De incessu animalium und De motu animalium) und die Fortpflanzung (De generatione animalium). Vergleichende Anatomie wird in De partibus animalium behandelt. Aristoteles legte großen Wert auf ein Verständ-

\footnotetext{
9 So heißt es z. B. in einem Epigramm des Nikarchos (Anthologia

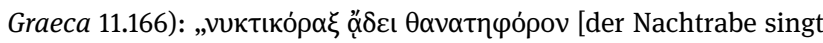
ein todbringendes Lied].“ 10 Leroi (2014).
}

nis von Kausalzusammenhängen. Gegen Legenden war er sehr kritisch; so bestritt er, daß das Wiesel seine Jungen aus dem Mund gebiert, ${ }^{11}$ daß die Hyäne jährlich ihr Geschlecht wechselt, ${ }^{12}$ daß der Elefant keine Gelenke in den Beinen hat und deshalb im Stehen, an einen Baum gelehnt, schlafen muß. ${ }^{13}$ Diese drei Legenden haben sich trotz seiner Autorität gehalten und tauchen mit Variationen auch im Physiologus auf (Kap. 21, 24 und 43). Im ganzen ist die Leistung des Aristoteles überwältigend; zwar sind ihm manche Fehler unterlaufen und viele seiner Versuche, allgemeine Regeln und Kausalzusammenhänge herzustellen, lassen sich nicht halten; aber dagegen steht eine Fülle von richtigen Beobachtungen und Einsichten.

Daß Aristoteles so viel Energie für die Zoologie aufgewendet hat, hängt mit seiner Vorstellung von Wissen und Wissenschaft zusammen. Platon hatte als eigentliches Objekt der Erkenntnis ein transzendentes Seiendes, die Ideen, erklärt; Aristoteles setzt an dessen Stelle die

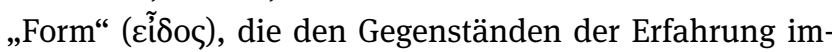
manent ist. Daraus folgt eine Hinwendung zur Empirie. Die Tierwelt erwies sich als besonders geeignetes Feld für die Anwendung seiner ontologischen Grundbegriffe:

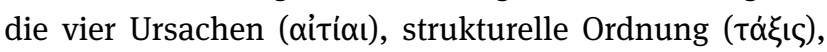

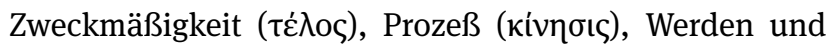

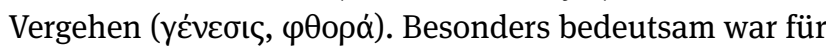
ihn, daß die artspezifische Struktur eines Lebewesens durch alle Prozesse erhalten bleibt und in der Fortpflanzung weitergegeben wird; hier ist die Dynamik des عĩos wirksam, und es wird sogar etwas Unsterbliches und Göttliches faßbar. ${ }^{14}$

Über das philosophische Interesse hinaus hat Aristoteles sich für zoologische Forschungsarbeit als solche begeistert. In einem berühmten und vielzitierten Kapitel ( $D e$ partibus animalium 1.5$)^{15}$ spricht er davon, daß man das Kleine, Geringfügige nicht verachten soll im Vergleich mit erhabenen Gegenständen wie der Sternenwelt. Der Astronom mag sich rühmen, mit göttlichen Sternwesen zu tun zu haben, aber die Gegenstände der Zoologie sind greifbarer, sie sind uns näher und unserer Natur verwandter

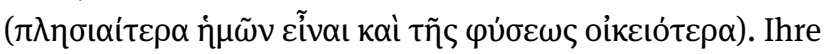
Objekte mögen für die sinnliche Wahrnehmung manch-

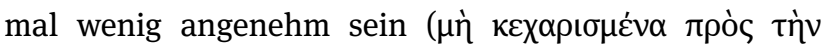
aı̈ $\sigma \theta \eta \sigma v)$ - da drängt sich der Gedanke an einen Aris-

\footnotetext{
11 De generatione animalium 3.6.756b13-757a2. 12 Historia animalium 6.32.579b16-30; De generatione animalium 3.6.757a2-13. Aus dem Wortlaut geht hervor, daß Aristoteles selbst die Genitalien einer Hyäne untersucht hat.

13 Historia animalium 2.1.498a9; De incessu animalium 9.709a9-10. 14 De anima 2.4.415a26-b7; De generatione animalium 2.1.731b24-35. 15 Den griechisch-deutschen Text s. Balss (1943, 8-13).
} 
toteles auf, der die Genitalien einer toten Hyäne inspiziert, umgeben von deren berüchtigtem Gestank -, aber ihre Betrachtung $(\theta \varepsilon \omega \rho i \alpha)$ bringt dem Forscher unermeßliche

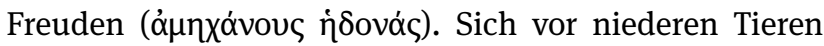
zu ekeln ist kindisch. Von Heraklit wird die Anekdote erzählt, er sei von Besuchern im Winter angetroffen worden, als er sich in dem schmutzigen Heizraum einer Bäckerei wärmte; da habe er gesagt: „Kommt nur herein, auch hier sind Götter!“ In jedem Tier steckt etwas Natürliches und Schönes, denn hier herrscht nicht blinder Zufall, sondern

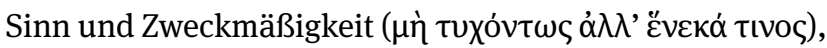
und das ist es, was Schönheit ausmacht. Auch der Mensch besteht aus abstoßenden Dingen, Blut, Knochen, Adern; seine Schönheit liegt in der Ganzheit der Gestalt.

Dieses Kapitel wirkt wie ein Hymnus auf die Tätigkeit des Zoologen; es erinnert an die Darstellung des ßíos $\theta \varepsilon \omega \rho \eta \tau$ menschlichen Lebens dargestellt wird. Und ebenso wie dort läßt Aristoteles ein religiöses Motiv anklingen: In der Mitte steht die Heraklit-Anekdote mit dem Spruch „Auch hier sind Götter.“ Im Studium der Tiere begegnet man dem Göttlichen. Man darf das wohl als ein persönliches Bekenntnis lesen.

Schließlich zwei Bemerkungen zum Physiologus. Dessen Autor hat wohl kaum Aristoteles selbst gelesen; direkte Berührungen (wie beim Nachtraben) sind selten. Aber Exzerpte daraus kann er gekannt haben (davon später), und der Ruf des großen Forschers mag zu ihm gedrungen sein. Könnte es nicht sein, daß hinter der Bezeichnung

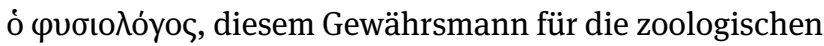
Tatsachen, die legendär gewordene Figur des Aristoteles steht? Dieser Gedanke ist gelegentlich geäußert, ${ }^{16}$ aber in neuerer Zeit nicht wieder aufgegriffen worden. Er würde aber den emphatischen Singular besser erklären als irgendeine obskure Quellenschrift. Ferner: Daß die Tierkunde für Aristoteles eine ins Religiöse gesteigerte Bedeutung hat, könnte eine Perspektive auf den Physiologus eröffnen. Freilich, eine echte Traditionslinie ist nicht zu verfolgen; in der griechischen Philosophie hat das keine Nachfolge gehabt. Allenfalls bei Plutarch könnte man ein Gegenstück sehen; aber da geht es um Tiersymbolik, nicht um Tierforschung. Immerhin ist der Gedanke gemeinsam, daß man im Blick auf die Tierwelt den Geheimnissen der Welt und des Göttlichen näherkommen könnte.

16 Ahrens (1885, 13); Lauchert (1889, 44); Goldstaub (1900, 346). Lauchert weist darauf hin, daß die von ihm benutzte Hand-

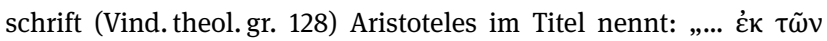

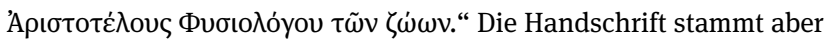
erst aus dem 14. Jh.

\section{Hellenistische Tierliteratur}

Die zoologischen Schriften des Aristoteles laden eigentlich zur Ergänzung, Nachprüfung, Korrektur ein. Aber in der hellenistischen Tierliteratur finden sich nur wenige Autoren, die in diesem Sinne weiterarbeiten; Theophrast und Straton von Lampsakos wären dafür zu nennen. Stattdessen bemühte man sich, sein Material leichter benutzbar zu machen; es entstanden Exzerpte in Katalogform. Eines wird mit dem Titel Zwïkó zitiert; es lief anscheinend unter dem Namen des Aristoteles selbst um. Ein anderes, Пврі $\zeta \omega \omega \nu$, wurde von Aristophanes von Byzanz verfaßt; davon ist ein Stück erhalten. ${ }^{17}$ Dieser Aristophanes, der zweite Leiter der Bibliothek von Alexandria, war eigentlich literarisch interessiert; er wollte offenbar das aristotelische Material als Bildungswissen in handlicher Form zugänglich machen. Natürlich kam auch neues Wissen dazu; später spielte im römischen Bereich der Brauch der Tierhetzen im Zirkus eine gewisse Rolle: Dafür wurden in großem Stil wilde Tiere vor allem in Afrika gefangen, und man lernte ihr Verhalten genauer kennen. Solches Material ist in die erhaltenen Tierbücher der Kaiserzeit eingegangen; die bedeutendsten sind die des Plinius (Naturalis historia,

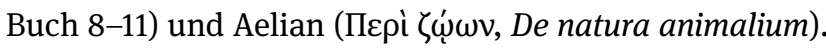
Solche Bücher hat der Verfasser des Physiologus sicher gekannt. Von ihnen kann er ein formales Element übernommen haben: die Katalogform. Geschlossene Kapitel werden gereiht, die oft stichwortartig mit dem Namen des Tieres anfangen. Bei Aristophanes gibt es besonders knappe, schnörkellose Aussagen fast nach Art eines Lexikons; die dem Physiológos zugeschriebenen Aussagen erinnern stilistisch daran.

Diese Tierbücher waren zunächst nur sachlich-informativ. Dann drang eine Tendenz ein, die man mit dem Begriff „Paradoxographie“ oder „Mirabilienliteratur“ bezeichnet. Da wurden Seltsamkeiten aller Art gesammelt; auch die Tierwelt hatte allerhand Bizarres und Anekdotisches zu bieten. Solche Tierbücher dienten weniger der Belehrung als der Unterhaltung. Verfasser solcher Bücher waren u.a. Antigonos von Karystos und Alexander von Myndos. Jetzt tauchten auch manche Legenden wieder auf, die Aristoteles bestritten hatte; davon war schon die Rede. Übrigens wurde ausgerechnet Aristophanes von Byzanz, der trockene Tier-Registrator, zum Opfer solcher erzählerischen Phantasie: Er soll sich in Alexandrien in eine Blumenverkäuferin verliebt haben, aber einen Riva-

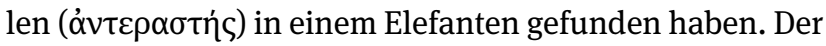
wurde öfters durch die Stadt geführt und jedesmal sei er

17 Herausgegeben von Lambros (1885). 
am Marktstand des Mädchens stehen geblieben, habe ihr mit dem Rüssel allerhand Leckereien gebracht und sei ihr dann unter das Hemd geschlüpft und habe ihre Brust gestreichelt. ${ }^{18}$ Diese Mirabilien-Literatur hat offensichtlich den Physiologus beeinflußt. Dessen Tiergeschichten haben oft ein Element des Erstaunlichen, Verblüffenden: z. B. die rührende Geschichte vom Pelikan, der die Jungen mit seinem Blut nährt (Kap. 4); von der Natter, deren Junges sich aus dem Bauch der Mutter herausfrißt und sie dadurch tötet (Kap. 10); vom Walfisch, der von Seefahrern für eine Insel gehalten wird, auf der sie landen können (Kap. 17).

Eine weitere Ausprägung der Tierkunde ist verbunden mit dem Namen des Bolos von Mendes (um 200 v. Chr.). Er interessierte sich für geheimnisvolle Wechselwirkungen, die er „Sympathie“ und „Antipathie“ nannte: Tiere, Pflanzen und Steine sind zu einem okkulten Wirkungszusammenhang verbunden; Krankheiten und ihre Behandlung spielen dabei eine große Rolle. Auch der Physiologus handelt manchmal von solchen Wirkungen; er flicht auch in die Reihe der Tiere einige Steine und Pflanzen ein (Diamant, Achat, Magnetstein, der sog. Gebärstein, der Peridexion-Baum, die Mandragora, die Sykomore). Die Lehre von okkulten Kräften klingt gelegentlich an. ${ }^{19}$

\section{Hellenistische Philosophie}

Das Verhältnis zwischen Mensch und Tier ist ein eigenes Thema. Seit archaischer Zeit wird in Tierfabeln menschliches Verhalten in Tieren gespiegelt; die attische Komödie spielt mit dem Gedanken (z.B. Aristophanes in den Vögeln), man denkt nach über die unterschiedliche natürliche Ausstattung von Mensch und Tier (etwa Protagoras in Platons gleichnamigem Dialog) und über eine mögliche Aufwärtsentwicklung des Menschen aus einem tierähn-

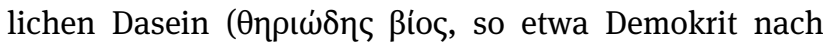
Diodor, Bibliotheca historica 1.8). Seit der Sophistenzeit gibt es verschiedene Meinungen über die Intelligenz der Tiere; man spricht von einem Wissen und Können, das sie nicht zu lernen brauchen, sondern das die Natur ihnen gibt (Xenophon, Kyropädie 2.3). Ein anderes Thema ist der Charakter: Manche Tiere sind tapfer, andere feige, sie können Dankbarkeit, Treue, Freundschaft zeigen. Bei Platon gibt es Reflexionen über eine naturhafte Vorstu-

18 Plutarch, De sollertia animalium 18; Plinius, Naturalis historia 8.13; Aelian, De natura animalium 1.38 .

19 Wellmann $(1930,19)$ führt fünf Stellen an; dies ist eine der Grundlagen seiner oben erwähnten Quellenhypothese. fe der Tugenden, die „tierhaft und sklavenhaft“ genannt werden kann (Politeia 430b8). Bei Aristoteles enthält die Historia animalium (Buch 8-9) eine große Materialsammlung zu Intelligenz und Charakter der Tiere; hier sind auch Studien des Theophrast in den Text eingeflossen.

Wenn man eine Wesensverwandtschaft zwischen Tier und Mensch annimmt, kann das praktische Folgen haben: Es wäre dann nicht erlaubt, sie zu töten, um sie zu essen. Der Vegetarismus war schon lange (wegen der Seelenwanderung) von Pythagoreern und Empedokles vertreten worden; jetzt wurde er auf einer ganz anderen Grundlage befürwortet. Wahrscheinlich geht auf Theophrast die Argumentation zurück, zwischen Mensch und Tier gebe es we-

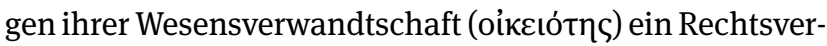
hältnis; die Tötung eines unschuldigen Tieres sei ein Unrecht, nur ein schädliches dürfe getötet werden. ${ }^{20}$

Die stoische Philosophie hat sich oft mit Tierpsychologie beschäftigt. In der Ethik wurde die Oikeiosis-Lehre mit der Berufung auf den Selbsterhaltungstrieb der Tiere und der Sorge für die Nachkommen illustriert. Jedoch

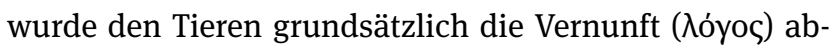
gesprochen; ihr intelligentes Verhalten sei nur eine QuasiVernunft. Chrysippos soll mehrmals die Symbiose der Steckmuschel ( $\pi i v v \alpha)$ mit einem Kleinkrebs, dem Muschel-

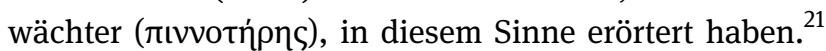
Poseidonios gab eine Analyse tierischen Verhaltens, die dem modernen Instinkt-Begriff sehr nahe kommt.

Dagegen entwickelte sich eine Opposition in der Akademie, vielleicht schon bei Karneades, wo auch den Tieren Logos zugesprochen wurde. Im 1. Jh. n. Chr. entwickelte sich zu diesem Thema eine Kontroverse, aus der zwei Texte erhalten sind: Philons von Alexandrien Dialog „Alexander oder über den Vernunftbesitz der Tiere“ (in armenischer Übersetzung erhalten) und Plutarchs Einleitung zu dem Dialog De sollertia animalium; aus späterer Zeit gehört dazu Porphyrios De abstinentia. Das philosophische Problem verband sich jetzt mit dem pythagoreischen Vegetarismus, und es wird sogar eine kosmische Dimension erkennbar: Die Stoiker dachten anthropozentrisch, die ganze Welt diene dem Interesse des Menschen; die Akademiker pluralistisch: Es gebe viele Wesen in der Welt, deren Interessen es verdienten, berücksichtigt zu werden.

Im Physiologus findet man wenige Spuren von solchen Mensch-Tier-Reflexionen. Natürlich ist von Intelligenzleistungen die Rede, der Fuchs kennt schlaue Tricks; es gibt moralisches Verhalten, die Elternliebe bei Pelikan und

20 Porphyrios, De abstinentia 2.22-24. Wie genau in dieser Paraphrase das Argument Theophrasts wiedergegeben ist, ist umstritten.

21 Hierüber wird in tierkundlichen Schriften oft gesprochen; ein Überblick etwa bei Gossen und Steier (1922, 1672-1673). 
Wiedehopf, die Monogamie bei der Turteltaube. Aber die Beziehung zum menschlichen Verhalten ist nur symbolisch, kein Zeichen von Verwandtschaft. Wenn der Biber, vom Jäger verfolgt, seine Geschlechtsteile opfert (Kap. 23), ist er ein Symbol für Keuschheit, aber nicht selber keusch.

Ein Gegenbeispiel findet man an ganz anderer Stelle in der frühchristlichen Literatur: Die Geschichte vom dankbaren Löwen. Sie ist in der Tierliteratur weit verbreitet: ${ }^{22}$ Ein entflohener Sklave namens Androklos trifft in der afrikanischen Wüste auf einen Löwen, der sich einen großen Dorn in den Fuß getreten hat und befreit ihn davon. Später wird dieser Androklos in Rom ad bestias verurteilt; in der Arena wird eben dieser Löwe auf ihn gehetzt; der erkennt ihn als seinen Wohltäter, wedelt mit dem Schwanz und leckt ihm Hände und Füße wie ein Hund. Diese rührende Geschichte ist in den apokryphen Paulus-Akten umgestaltet worden: Ein Löwe hatte sich in der Wüste von Paulus taufen lassen; später kommt es zu einer Begegnung in der Tierkampf-Arena und zu der dankbaren Wiedererkennung. Die Geschichte hat in christlichen Kreisen keinen großen Anklang gefunden; Hieronymus (De viris illustribus 7) lehnt den „getauften Löwen“ ausdrücklich ab, und der Text war verschollen, bis er aus einer koptischen Übersetzung und einem griechischen Papyrus rekonstruiert werden konnte. ${ }^{23}$

\section{Religiöse Tiersymbolik}

\section{1 Ägypter}

Religiöse Tiersymbolik, in Sprache und Bild, ist uralt und in vielen Kulturen verbreitet. Aber als bewußt angewendete Methode erscheint sie zuerst im Hellenismus im ägyptischen Bereich. Die Griechen waren früher vom ägyptischen Tierkult befremdet gewesen und hatten auch darüber gespottet; ${ }^{24}$ jetzt erscheinen explizite Erklärungen zum Symbolgehalt der verehrten Tiere, die zum Verständnis dieses Kultes beitragen können. Der ausführlichste erhaltene Text findet sich bei Plutarch, De Iside et Osiride $74-76,{ }^{25}$ der eine genauere Analyse verdient.

22 Gellius, Noctes Atticae 5.14 nach Apion; Plinius, Naturalis historia 8.56; Seneca, De beneficiis 2.19.1; Aelian, De natura animalium 7.48; Phaedrus, Fabulae 563 (Perry 1965, 526).

23 Schneemelcher ( $\left.{ }^{6} 1997,230,242\right)$; Stamatiou und Weckwerth (2010, 276-278).

24 Eine Liste von den Absurditäten der ägyptischen Tierverehrung gibt der Komiker Anaxandrides, frag. 40 (PCG 2).

25 Den griechisch-deutschen Text s. Görgemanns ( $\left.{ }^{2} 2009,258-267\right)$.
Eine Vorbereitung dazu gibt es schon in Kap. 10, das von der Hieroglyphen-Schrift handelt: Für „Himmel“ steht die Uräus-Schlange (áorí̧), weil sie nicht altert, ein Zeichen der Ewigkeit. Die Angehörigen des Kriegerstandes führen den Skarabäus (кóvӨ $\theta \rho \circ \varsigma)$ als Siegel, weil diese Käfer alle männlich sind. Das Verschlüsselte und Mysterienhafte dieser Bilder macht Plutarch dem griechischen Leser plausibel durch einen Vergleich mit den pythagoreischen $\sigma u ́ \mu \beta 0 \lambda \alpha$.

Nun zu Kap. 74-76. Der Tierkult hat zwei ernstzunehmende Gründe: Nützlichkeit und Symbolik. Für die Symbolik werden fünf Beispiele erläutert: Wiesel, Skarabäus, Uräus-Schlange, Krokodil, Ibis. Zu diesen Tieren einige Bemerkungen. Das Wiesel wird durch das Ohr begattet und gebiert aus dem Mund. (Plutarchs Bemerkung „das glauben und sagen viele noch immer“ zeigt, daß er von dem Widerspruch des Aristoteles wußte.) Das ist, wie Plutarch sagt, ein Gleichnis für „die Entstehung des Logos“ (

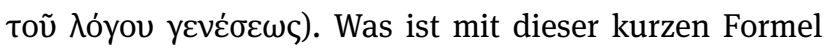
gemeint? Etwa, daß man mit dem Ohr eine Aussage aufnimmt und mit dem Mund wieder ausspricht? Das wäre die Weitergabe einer Information, aber nicht die „Entstehung“ des Logos. Vielmehr ist vielleicht in starker Verkürzung auf die stoische Theorie von der Entstehung der Erkenntnis angespielt. Sie geht von der Sinneswahrnehmung aus (dafür steht das Ohr), diese wird von der Ver-

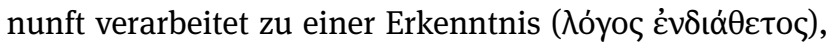
und diese wird sprachlich mit dem Mund geäußert ( $\lambda$ óyo $\pi \rho о \varphi о \rho ı к о ́ \varsigma)$. Die Symbolik würde also auf ein Lehrstück griechischer Philosophie hinauslaufen. Auch die Deutungen der anderen Tiere setzen griechisches Bildungsgut voraus. Die Bewegung des Skarabäus beim Rollen einer Kotkugel entspricht der doppelten Bewegung der Sonne: dem täglichen Umlauf von Ost nach West und dem jährlichen Umlauf von West nach Ost. Das ist ein elementares Lehrstück der griechischen Astronomie. Die UräusSchlange gilt als unsterblich; dieser Glaube findet sich auch sonst auf Schlangen bezogen (so im Physiologus 11); der Grund ist, daß die Häutung als Verjüngung verstanden wurde. Im Hellenismus ist die Schlange deshalb mit dem Zeitgott (Aion oder Chronos) verbunden; ihre göttlichen Eigenschaften werden ausführlich bei Philon von Byblos (FGH 790F4) dargestellt, der solche Deutungen den Phöniziern und Ägyptern zuschreibt. Das Motiv ist offenbar im hellenistischen Orient weit verbreitet. Das Krokodil, dieses gefährliche Raubtier, als göttlich zu erweisen, ist besonders schwierig; Plutarch führt vier Gründe an, darunter einen zahlensymbolischen: es legt 60 Eier, die Brutzeit ist 60 Tage, es lebt 60 Jahre. Die Zahl 60 als Grundlage des Sexagesimalsystems spielt in griechischen astronomi- 
schen Berechnungen eine wesentliche Rolle; das geht auf babylonische, nicht auf ägyptische Ursprünge zurück.

Diese Symbolismen sind also auf eine griechische, nicht auf eine ägyptische Vorstellungswelt abgestimmt. Plutarch führt sie aber ausdrücklich auf Ägypter zurück: „Man sollte sich nicht wundern, daß die Ägypter eine solche Liebe $\mathrm{zu}$ weit hergeholten Ähnlichkeiten [y $\lambda \dot{i} \sigma \chi \rho \alpha \iota$ ó zeichnung für symbolische Beziehungen, und y $\lambda$ ioxpos (mit der Grundbedeutung ,klebrig“) wird oft gebraucht, um mit leichtem Spott hartnäckige, gewaltsame, kleinliche Argumente und Fragen zu bezeichnen. ${ }^{26}$ Plutarch hat diese Deutungen also aus einer ägyptischen Quelle entnommen, der er kritisch, aber eher freundlich herablassend als ablehnend gegenübersteht. Wo diese Quelle zu suchen ist, läßt sich erraten: Deutungen der ägyptischen Religion in einem griechischen Denkhorizont gab es, seitdem dort mit den Ptolemäern die griechische Kultur dominierend geworden war; man war bestrebt, die einheimische Kultur nicht zu unterdrücken, sondern mit der griechischen auszugleichen. Ein frühes Beispiel ist Heka-

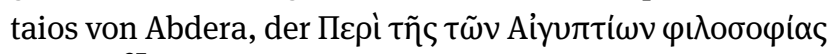
schrieb, ${ }^{27}$ auch gebürtige Ägypter wie Manethon von Sebennytos waren beteiligt. Dort war von Tieren wie Skarabäus, Schlange und Falke die Rede, in denen die Ägypter

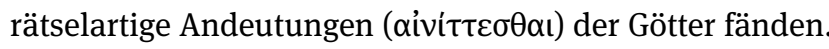
Auf solche Ägypter muß Plutarch sich beziehen; Max Wellmann hat vermutet, daß er eine Schrift des Ägypters Apion benutzt hat, die in der 1. Hälfte des 1.Jh. n. Chr. entstanden war. $^{28}$

Anknüpfend an diese „weit hergeholten Ähnlichkeiten“ entwickelt Plutarch dann ein tiefer greifendes Deutungsmuster. Symbolik, so sagt er, findet sich auch bei den Hellenen in Attributen der Götter, darunter auch Tiere; sogar Zahlen und geometrische Figuren haben (für die Pythagoreer) symbolisch-religiöse Bedeutung. Aber höher als die bildlichen Darstellungen bei den Griechen stehen lebendige Tiere als Symbolträger, weil sie beseelte Wesen sind. Schon in Kap. 74 (380F) hieß es, sie seien „undeutliche Bilder von der Wirksamkeit der Götter, so wie man in Regentropfen Bilder der Sonne sieht“; das wird jetzt $(76,382 \mathrm{~A})$ aufgegriffen: Sie sind „besonders klare,

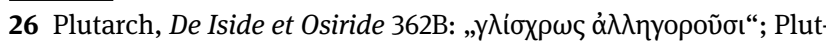
arch selbst hat eine bessere Erklärung. De recta ratione audiendi 43A:

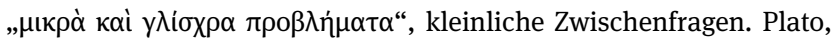
Politeia 488c, selbstironisch von einem gerade gebrauchten überraschenden Vergleich; Kratylos 414c, von verwegenen Etymologien, 435c von der Verlockung der Ähnlichkeit.

27 Diogenes Laertios Vitae philosophorum 1.10 (FGH 264F1).

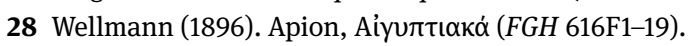

von der Natur geschaffene Spiegel“ des Göttlichen. Alles Beseelte, das die Fähigkeit der Selbstbewegung und des Erkennens besitzt, „hat einen Ausfluß und Anteil von der Schönheit des Denkenden in sich aufgenommen, ,von dem das Weltall gelenkt wird', wie Heraklit sagt." Hinter solchen Formulierungen steht die platonische Denkfigur von Vorbild und Abbild, Idee und Einzelding. Wesentliche

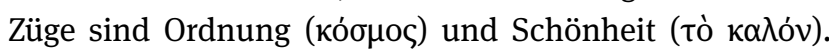
Man verehrt dann nicht die Tiere selbst (der ägyptische Tierkult als solcher ist also eine Verirrung), sondern durch sie das Göttliche. In diesen Stichworten klingt von ferne die Begeisterung des Aristoteles für die Zoologie an; auch Plutarch schwingt sich zu einem Hymnus auf Rang und Würde der lebendigen Tierwelt auf.

Gibt es von hier eine Verbindung zum Physiologus? Dieser hat keinen philosophischen Horizont, der mit Plutarch vergleichbar wäre; seine symbolischen Deutungen

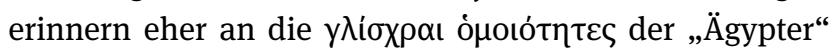
und sind oft ebenso künstlich konstruiert. Aber wenn man an die Wirkung des Büchleins denkt, läßt sich doch eine Beziehung denken. Ein Christ, der diese Fülle von Deutungen las, lernte eine Fülle von Sinnzusammenhängen kennen; die Tierwelt wurde zu einem Spiegel der christlichen Heilsgeschichte, so wie Plutarch darin die göttliche Weltordnung gespiegelt sah. Es ist vielleicht dieses Evidenzerlebnis, das hinter dem ungeahnten Erfolg des Buches im Mittelalter steht.

\subsection{Juden}

Ein zweiter Bereich, in dem Entwürfe einer religiösen Tiersymbolik entwickelt wurden, ist das hellenistische Judentum. Der Grund ist leicht zu verstehen: Die Speisegesetze des Pentateuch mit ihrer Unterscheidung der reinen und unreinen Tiere waren für die griechische Umwelt unverständlich. Die Tiersymbolik sollte helfen sie zu erklären. Unsere zwei Quellen dafür stammen aus Ägypten und es ist zu vermuten, daß die symbolischen Tierdeutungen der „Ägypter“ die Anregung dazu gaben.

Die erste Quelle ist eine Passage im Aristeasbrief (142169), welcher im 2. Jh. v. Chr. entstanden ist. Der Verfasser holt weit aus (143-145):

Allgemein gesprochen stehen alle Dinge, wenn man sie im Blick
auf die Natur versteht, in Analogie zueinander; sie werden von
einer einzigen Macht gelenkt, und in jedem Einzelfall hat es ei-
nen tiefen Sinn, daß wir von dem einen uns enthalten müssen,
das andere genießen dürfen. Beispielshalber will ich ein oder
zwei Fälle durchgehen und dir erklären. Denn du darfst nicht
in die unhaltbare Auffassung verfallen, daß Mose um der Mäu-
se oder Wiesel willen sich die Mühe gemacht hätte, diese Geset- 
ze zu erlassen; vielmehr sind diese feierlichen Vorschriften zum Zweck einer frommen Betrachtung und zur Besserung unseres Verhaltens im Sinne der Gerechtigkeit gegeben. ${ }^{29}$

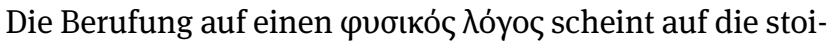
sche Lehre zu deuten, daß die ganze Natur vom göttlichen Logos durchdrungen und organisiert ist. Darauf beruht die „Ähnlichkeit“ aller Dinge (ö $\mu$ oı $\alpha$ ), das Analogieverhältnis, das symbolische Beziehungen möglich macht. (Es ist an

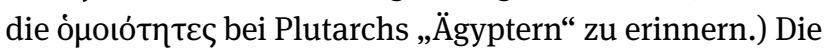
Tiersymbolik ist also mit stoischen Begriffen begründet, ähnlich wie Plutarch es mit platonischen tut.

Was die Speisegesetze betrifft, so wird ihr Sinn moralisch-erzieherisch gedeutet, sie sind ,um der Gerechtigkeit willen“ da. So sind von den Vögeln die zahmen, pflanzenfressenden rein, die Raubvögel unrein, weil sie das Prinzip von Unrecht und Gewalt verkörpern. Einhufige Tiere sind unrein, spalthufige rein: Die Spaltung symbolisiert die Unterscheidung von Gut und Böse (oder alternativ: Die Absonderung der Juden von den Heiden). Wiederkäuer sind rein, weil das Wiederkauen auf ein geduldiges Wiederholen deutet, wodurch etwas Gelerntes eingeprägt wird. Eine verblüffende Deutung bekommt das Wiesel, ein unreines Tier: Es empfängt im Ohr und gebiert aus dem Mund; das bedeutet den Spitzel, der Erlauschtes in boshafter Weise zur Anzeige bringt. Der Verfasser hat ein traditionelles Motiv mit einer offenbar in Alexandrien aktuellen politischen Spitze versehen.

Der zweite Text dieser Art ist von Philon von Alexandrien (Anfang des 1. Jh. n. Chr.): De specialibus legibus 4.100-118. Auch hier werden die Speisegesetze moralisch ausgelegt. Der Leitgedanke ist Bekämpfung der Leiden-

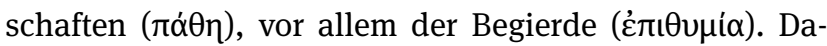
hinter steht die stoische Ethik. So sind besonders wohlschmeckende Fleischsorten verboten: Das Schwein und „schuppenlose Fische“, womit wohl die Muräne, der Luxusfisch der Römer, gemeint ist. Bezüglich der Raubtiere hat Philon einen komplizierten, fast paradoxen, Gedankengang. An sich wäre es gegenüber menschenfressenden Tieren eine gerechte Vergeltung, wenn man sie tötet und ißt (eine Erinnerung an die tierethischen Überlegungen Theophrasts). Aber das wäre eine Rachehandlung im Zorn

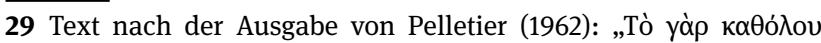

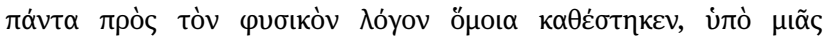

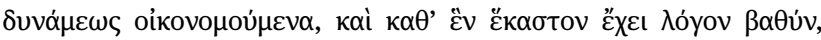

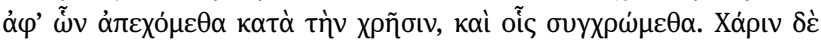

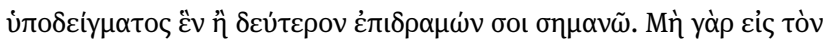

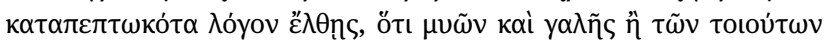

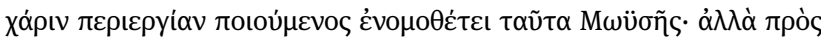

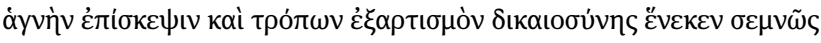

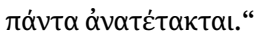

und zur Bekämpfung dieses ráӨo ist eben dies verboten! Das Verbot ist dann auf alle Raubtiere ausgedehnt. Über Spalthufer und Wiederkäuer sagt Philon Ähnliches wie der Aristeasbrief. Schließlich ein Beispiel für reine Symbolik: Wassertiere ohne Flossen sind unrein, denn sie lassen sich einfach treiben und symbolisieren damit ein hedonistisches Leben.

Die Verwandtschaft zwischen den zwei Texten zeigt, daß es im alexandrinischen Judentum eine Tradition von solchen Deutungen gegeben hat. ${ }^{30}$ Ein auffallender Zug ist ihnen gemeinsam: Viele Gedankengänge sind kühn, paradox, sie wirken gewollt geistreich, sogar spielerisch. Vielleicht ist es kein Zufall, daß manche Abschnitte des Physiologus einen ähnlichen Eindruck machen.

\subsection{Christen}

An die symbolische Auslegung der Speisegesetze auf jüdischer Seite knüpft offenbar der frühchristliche Barnabasbrief an. Sein Hauptthema ist die Absetzung des Christlichen vom Jüdischen, und in diesem Sinne werden in Kap. 10 die Speisegesetze behandelt. Die Juden halten sie fälschlich für praktische Vorschriften, aber Mose hat sie nur symbolisch gemeint. Während Aristeas und Philon die Gesetze durch die Symbolik nur erklären, will Barnabas sie ganz aufheben; die Juden hätten sie von Anfang an mißverstanden; in Wirklichkeit seien es rein moralische Mahnungen. ${ }^{31}$ Das Verbot, eine bestimmte Tierart zu essen, bedeute eine Mahnung, mit Menschen einer bestimmten Art nicht umzugehen, um ihnen nicht ähnlich zu werden.

Die in Kap. 10 behandelten Beispiele haben formale und inhaltliche Berührungen mit dem Physiologus, aber auch deutliche Abweichungen. ${ }^{32}$ Von Abhängigkeit im Sinne einer Quelle kann man nicht sprechen; eher hat man den Eindruck von Variationen über ein gemeinsames Thema. Es scheint, daß in christlichen Gemeinden ein Interesse für solche Deutungen verbreitet war und die beiden Schriften einzelne Motive daraus aufgegriffen haben.

30 Auch die Argumentation des Paulus (1 Kor 9,9-10) „Kümmert sich Gott etwa um die Ochsen?“ erinnert an diese symbolischen Deutungen.

31 Es wird oft betont, daß die Tiersymbolik der allegorischen oder typologischen Schriftdeutung nahesteht; Alpers (1984, 42-46) bevorzugt den letzteren Begriff, weil dabei der Literalsinn nicht aufgehoben werde. Bei Barnabas wird zwar nicht die Realität des Tieres, aber der Literalsinn der biblischen Gesetze aufgehoben.

32 Im Kommentar von Prostmeier (1999) sorgfältig berücksichtigt, vor allem 382-383 und 405. 
Drei Beispiele seien besprochen: die Hyäne, das Wiesel und das Motiv des „nicht schwimmenden Tieres“. Bei der Hyäne wird der Geschlechtswechsel in Barnabasbrief 10.7 und Physiologus 24 fast wörtlich gleich beschrieben. Im Barnabasbrief ist das ein Bild für den Ehebrecher

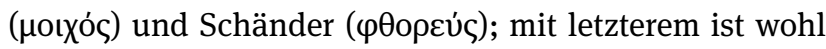
der Schänder einer Jungfrau gemeint. Der Physiologus dagegen bezieht den Geschlechtswechsel auf Bisexualität. Das ist einleuchtend, während die erstere Deutung nicht recht paßt. Es scheint, daß Barnabas die Kategorien der Sexualethik verwechselt oder jedenfalls unscharf bezeichnet.

Das Wiesel ist nach Barnabasbrief 10.8 „im Mund schwanger“; das entspricht der legendären Mundgeburt. Symbolisch ist das zu beziehen auf die, „die, wie wir hören, Gesetzlosigkeit ausüben im Mund aus Unreinheit“

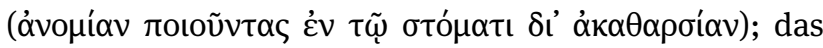
dürfte eine verdeckende Umschreibung für oralen $\mathrm{Ge}$ schlechtsverkehr einer Frau sein, in expliziter Sprache lateinisch fellatio, griechisch $\lambda \varepsilon \sigma \beta ı \alpha ́ \zeta \varepsilon ı v$. In der Gemeinde kennt man diese Art Unzucht gar nicht, deshalb der distanzierende Zusatz „wie wir hören“. Daß es sich um Frauen (Prostituierte?) handelt, geht daraus hervor, daß im folgen-

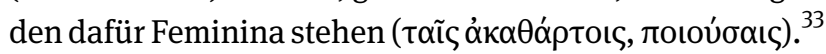
Der Verfasser stellt sich also vor, daß der Mundgeburt ein Mund-Coitus vorangegangen ist. Anders der Physiologus (Kap. 21): Das Wiesel zeugt im Mund (wie im Barnabasbrief), aber gebiert aus dem Ohr; das wird gedeutet auf einen Gläubigen, der in der Kirche das geistige Brot, den Glauben, aufgenommen hat, es aber später aus den Ohren wieder hinauswirft, also abtrünnig wird. Das wirkt sehr künstlich; Mund und Ohr kommen auch bei Plutarch vor (De Iside et Osiride 381A), aber in umgekehrter Funktion.

Eine Querverbindung zwischen dem Ibis-Kapitel des Physiologus (Kap. 40) und einigen Meerestieren des Barnabasbriefs (Kap. 10.5) entsteht durch das Motiv des NichtSchwimmens. Vom Ibis heißt es in Physiologus, „er kann

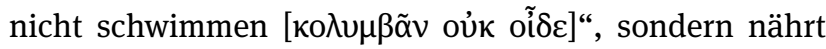
sich am Rand der Flüsse und Seen und kann nicht in die Tiefe ( $\tau \dot{\alpha} \beta \alpha \dot{\theta} \theta \eta)$ gelangen, wo die reinen Fische schwim-

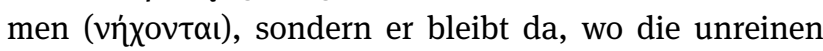

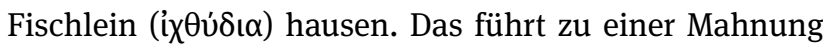
an die Christen, in die Tiefen der Gotteserkenntnis zu

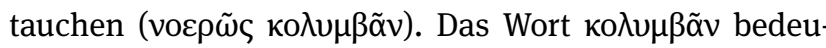
tet im engeren Sinn „tauchen“ (z. B. vom Schwammtaucher), wird aber im späteren Griechisch allgemeiner für

33 Die abweichende Deutung, es handele sich um frevlerische Reden (Prostmeier 1999, 400-401) paßt vor allem nicht zu dem Verbum

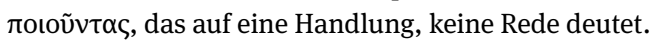

„schwimmen“ gebraucht. ${ }^{34}$ Im Barnabasbrief heißt es von drei Tieren, nämlich Muräne, Polyp und Tintenfisch, diese „Fischlein“ (ix $\theta \dot{\delta} \delta ı \alpha$ ) seien verflucht und schwömmen in

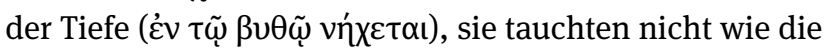
anderen, sondern wohnten auf der Erde unter der Meeres-

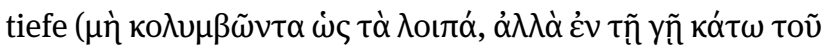

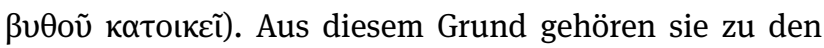
unreinen Tieren der Bibel. Hier gilt der Meeresboden als schmutzig und unrein; der Aufenthalt dort wird zwar als

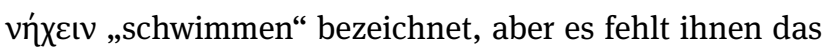

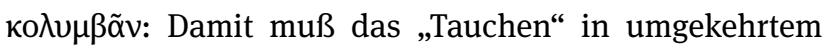
Sinn, ein Emporschwimmen von unten gemeint sein. Die zwei Abschnitte sind verbunden durch eine Verachtung der am Boden der Gewässer lebenden Tiere; einmal ist die Tiefsee, das andere Mal das Flachwasser gemeint; einmal geht es um die Tiere selbst, einmal um den Ibis, der von ihnen lebt. Auch sonst fallen Anklänge des Vokabulars auf: $\beta v \theta$ ó und $\beta \alpha \dot{\theta} \theta \eta$; das abschätzige Deminutivum ix $\theta v \dot{\delta} \iota \alpha$. Übereinstimmende Motive und Vokabeln werden also in verschiedener Weise kombiniert. Was die Wertungen betrifft, so enthält der Physiologus, ähnlich wie im Fall des Nachtraben, ein Element des Paradoxen: der Ibis, in Ägypten ein heiliger Vogel, wird abgewertet, der Nachtrabe aufgewertet.

Die Nähe des Barnabasbriefes zum Physiologus zeigt sich abgesehen von diesen Einzelfällen auch in allgemeinen Dingen:

1. Formal nähert sich die Besprechung der Tierarten dem Katalogcharakter mit jeweiligen Anfangs-Stichworten, während die zwei jüdischen Quellen eher versuchten, Sachgruppen zu bilden.

2. Es finden sich in Bezug auf Mose mehrere $\kappa \alpha \lambda \tilde{\omega} \varsigma$ Prädikationen (Barnabasbrief 10.11: , $\kappa \alpha \lambda \tilde{\omega} \varsigma$ ع $\varepsilon \tilde{\pi} \varepsilon v \beta \lambda \varepsilon^{-}$

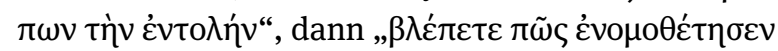

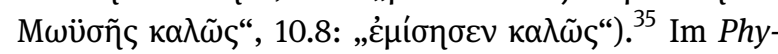
siologus wird diese Prädikation nicht nur auf die Bibel, sondern auch auf den Physiológos als Autorität bezogen, offenbar eine Erweiterung des Formelgebrauchs.

3. Die Speisegesetze werden auch im Physiologus mehrmals erwähnt, aber nur als Nebenthema.

4. Die Absetzung des Christentums vom Judentum kommt auch dort wiederholt zur Sprache, sie ist ein wesentliches theologisches Thema. Wir befinden uns anscheinend in einer Zeit, als dies noch ein aktuelles Thema in den christlichen Gemeinden war.

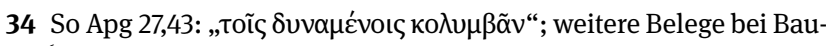
er $\left({ }^{6} 1988,899\right)$.

35 Hierzu Prostmeier (1999, 405); in Anm. 153 weist er auf Philon als Modell hin. 
Mit dem Barnabasbrief stehen wir gewissermaßen an der Schwelle zur Entstehung des Physiologus. Dessen Verfasser hat wesentliche Elemente einer Tiersymbolik vorgefunden; er hat sie aber in ein neues Konzept eingebaut. Das theologische Thema sind nicht mehr die alttestamentlichen Speisegesetze, sondern Kernfragen des Christentums: Christologie, Auferstehung und Wiedergeburt, das Leben der christlichen Gemeinde. Es werden nicht nur die Tiere der Speisegesetze besprochen, sondern allgemein biblische und auch einige nichtbiblische Tiere. Die Deutung nähert sich dem exegetischen Verfahren der Typologie an, alttestamentliche Sachverhalte als Vorausdeutung auf Christliches zu sehen. Schließlich wird „der Naturkundi-

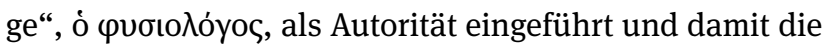
Rückbindung an die Tradition der antiken wissenschaftlichen Tierkunde ins Bewußtsein gebracht. Die Synthese dieser Elemente hat diese faszinierende Schrift hervorgebracht, die ihren Zauber erst nach anderthalb Jahrtausenden verlor.

\section{Bibliographie}

Ahrens, Karl. 1885. Zur Geschichte des sogenannten Physiologus. Ploen: S. W. Hirt's Buchdruckerei.

Alpers, Klaus. 1984. „Untersuchungen zum griechischen Physiologus und den Kyraniden. “In All Geschöpf ist Zung' und Mund: Beiträge aus dem Grenzbereich von Naturkunde und Theologie. Vestigia Bibliae: Jahrbuch des Deutschen Bibel-Archivs 6, hrsg. v. Heimo Reinitzer, 13-87. Hamburg: Friedrich Wittig.

Aubert, Hermann, und Friedrich Wimmer, Hgg. 1868. Aristoteles: Thierkunde. Bd. 1. Leipzig: Wilhelm Engelmann.

Balss, Heinrich, Hg. 1943 [2014]. Aristoteles: Biologische Schriften; griechisch und deutsch. München: Heimeran [Berlin: De Gruyter].

Bauer, Walter. ${ }^{6} 1988$. Griechisch-deutsches Wörterbuch zu den Schriften des Neuen Testaments und der frühchristlichen Literatur. Berlin: Walter de Gruyter.

Brehm, Alfred Edmund. ${ }^{2}$ 1879. Brehms Thierleben: Allgemeine Kunde des Thierreichs; Große Ausgabe. Bd. 5, Die Vögel. Leipzig: Verlag des Bibliographischen Instituts.

Ciccarese, Maria Pia. 2009. „Bibbia, bestie e Bestiari: l'interpretazione cristiana degli animali dalle origini al Medioevo.“ In Animali tra mito e simbolo. Biblioteca di testi e studi 503, hrsg. v. Sergio Botta, Alessandro Cerri, Maria Pia Ciccarese, Gilberto Mazzoleni und Adriano Santiemma, 75-124. Rom: Carocci.

Dierauer, Urs. 1977. Tier und Mensch im Denken der Antike: Studien zur Tierpsychologie, Anthropologie und Ethik. Studien zur Antiken Philosophie 6. Amsterdam: Grüner.

Dittmeyer, Leonard, Hg. 1907. Aristotelis De animalibus historia. Leipzig: Teubner.

Goldstaub, Max. (1899-1901) 1900. „Der Physiologus und seine Weiterbildung, besonders in der lateinischen und in der byzantinischen Literatur.“ Philologus: Zeitschrift für das klassische Alterthum; Supplementband 8,3:339-404.
Görgemanns, Herwig, et al. Hg. (2003) ${ }^{2} 2009$ [2014]. Plutarch. Drei religionsphilosophische Schriften. Düsseldorf: Artemis \& Winkler [Berlin: De Gruyter].

Gossen, Hans, und August Steier. 1922. „Krebs.“ PRE 11,2:16631690.

Griffiths, John G., Hg. 1970. Plutarch's De Iside et Osiride. Cardiff: University of Wales Press.

Grzimek, Bernhard. 1970. Grzimeks Tierleben. Bd. 8, Vögel II. Zürich: Kindler.

Kullmann, Wolfgang, Hg. 2007 [2009]. Aristoteles: Über die Teile der Lebewesen. Aristoteles Werke in deutscher Übersetzung 17,1, Zoologische Schriften II. Berlin: Akademie Verlag [De Gruyter].

Lambros, Spyridon P., Hg. 1885. Supplementum Aristotelicum. Bd. 1,1, Excerptorum Constantini de natura animalium libri duo: Aristophanis historiae animalium epitome. Berlin: G. Reimer.

Lauchert, Friedrich, Hg. 1889 [1974]. Geschichte des Physiologus. Strassburg: Karl J. Trübner [Genève: Slatkine].

Leroi, Armand Marie. 2014. The Lagoon. How Aristotle invented science. London: Viking.

Pelletier, André, Hg. 1962. Lettre d'Aristée à Philocrate. Sources Chrétiennes 89. Paris: Editions du Cerf.

Perry, Ben E. 1941. „Physiologus.“ PRE 20,1:1074-1129.

Perry, Ben E., Hg. 1965. Babrius and Phaedrus: Fables. Loeb Classical Library 436. Cambridge, MA: Harvard University Press.

Prostmeier, Ferdinand R., Hg. 1999. Der Barnabasbrief. Kommentar zu den Apostolischen Vätern 8. Göttingen: Vandenhoeck \& Ruprecht.

Sbordone, Francesco, Hg. 1936a. [1976, ${ }^{2}$ 1991]. Physiologus. Rom: Società Anonima Editrice ,Dante Alighieri“ [Hildesheim: Olms].

Sbordone, Francesco, 1936b. Ricerche sulle fonti e sulla composizione del Physiologus Greco, Neapel: Torella.

Schneemelcher, Wilhelm, Hg. ${ }^{6} 1997$. Neutestamentliche Apokryphen in deutscher Übersetzung. Bd. 2, Apostolisches, Apokalypsen und Verwandtes. Tübingen: Mohr Siebeck.

Sorabji, Richard. (1993) 1995. Animal Minds and Human Morals: The Origins of the Western Debate. Ithaca, NY: Cornell University Press.

Stamatiou, Aristides, und Andreas Weckwerth. 2010 „Löwe.“ RAC 23:257-286.

Thompson, D’Arcy Wentworth. (1895) ${ }^{2}$ 1936. A Glossary of Greek Birds. (Oxford: Clarendon Press) Oxford: Oxford University Press.

Wellmann, Max. 1896. „Aegyptisches.“ Hermes: Zeitschrift für classische Philologie 31,2:221-233.

Wellmann, Max. 1930. „Der Physiologos: Eine religionsgeschichtlich-naturwissenschaftliche Untersuchung." Philologus: Zeitschrift für das klassische Altertum. Supplementband 22,1:1116.

Wöhrle, Georg, Hg. 1999. Geschichte der Mathematik und der Naturwissenschaften in der Antike. Bd. 1, Biologie, Stuttgart: Franz Steiner. 


\section{Beatrice Wyss \\ Die Weisheit der Tiere}

\section{Konzepte paganer Philosophen zur Frage der Rationalität und Spiritualität der Tiere}

\begin{abstract}
Are animals rational beings? This question was tackled in philosophy and literature in antiquity. Examples of rational behaviour of animals are known by the Physiologus and pagan authors and philosophers. Fundamental thoughts about the relationship between humans, animals and $\operatorname{god}(\mathrm{s})$ are found in the Halkyone. This dialogue shows some structural similarities to the Physiologus.
\end{abstract}

\section{Einleitung}

Bücher über Tiere, um es so offen wie möglich zu formulieren, gibt es in der lateinischen und griechischen Literatur der ersten beiden Jahrhunderte einige. Besonders die Frage, ob Tiere Vernunft haben, ob sie rational sind, wurde unter Gebildeten diskutiert. An dieser Diskussion beteiligten sich nicht nur Philosophen unterschiedlicher Schulen, wie beispielsweise der Platoniker Plutarch von Chaironeia (40-125 n. Chr.) oder der Pyrrhoneer Sextus Empiricus (2. Jh.n. Chr.), sondern auch Enzyklopädisten wie der ältere Plinius von Como und Buntschriftsteller wie Claudius Aelianus von Palestrina. ${ }^{1}$ Auch der alexandrinische Jude und philosophisch gebildete Tora-Ausleger Philon (etwa 20 v. Chr. bis $45 \mathrm{n}$. Chr.) nahm an dieser Diskussion teil, und zwar in seiner auf Armenisch erhaltenen Schrift De animalibus. $^{2}$ Weil die pagane Kultur kein heiliges Buch kennt wie die jüdisch-christliche Tradition die Bibel, ${ }^{3}$ findet man eine genaue Entsprechung des Physiologus in der paganen Literatur nicht. Doch die erwähnten Autoren zeigen die weite und Weltanschauungen übergreifende Verbreitung der Rationalitätsdiskussion. Zwei Beispiele veranschaulichen, nach welchem Muster die Diskussion

\footnotetext{
1 Plinius der Ältere, gestorben 79 n. Chr. beim Vesuvausbruch, Naturalis historia Buch VIII Zoologie: Landtiere (König und Winkler 1976), und Buch IX Zoologie: Vögel. Weitere Einzelheiten aus dem Tierreich (König und Winkler 1986). Alle Übersetzungen von Plinius stammen aus diesen Ausgaben. Claudius Aelianus, Lebenszeit im 2. Jh. n. Chr., Historia animalium (Treu und Treu 1978). Alle Übersetzungen von Aelian stammen aus dieser Ausgabe.

2 Terian (1981), Wyss (2018).

3 Homer galt als „der Dichter“; Ilias und Odyssee sind für die kulturelle Prägung fundamental. Zwar wurden diese Werke auch philosophisch-theologisch interpretiert (z.B. Herakleitos), doch fanden sie m.W. im Kult keine Anwendung als liturgische Texte.
}

verläuft. Sie zeigen, dass der Physiologus (so nenne ich den unbekannten Autor des gleichnamigen Werkes) aus demselben Fundus an Informationen schöpft wie die paganen Autoren. Es geht mir nicht darum, erschöpfend alle Parallelen zwischen Physiologus und paganer Literatur aufzuzeigen, dazu verweise ich auf die Anmerkungen in der handlichen Reclam-Ausgabe von Otto Schönberger (2001).

Anschliessend geht es um den geistesgeschichtlichen Hintergrund der philosophischen Diskussion, ob es im Verhalten von Tieren Anzeichen angeborener Rationalität gibt. Weil Theologie ein Teil der Philosophie war, gehört zur Frage nach der Rationalität auch die Frage nach der Beziehung des Tieres zum Göttlichen. Deshalb stelle ich einige Beispiele aus der paganen Literatur vor, welche zeigen, dass man Tiere sehr wohl im Zusammenhang mit der göttlichen Sphäre gesehen hat, ein Aspekt, der in der Rationalitätsdiskussion in der Sekundärliteratur keine grosse Rolle spielt. ${ }^{4}$

Seneca verfasste zwar Naturales quastiones, doch diese eignen sich für die vorliegende Fragestellung nicht: Wir benötigen nicht so sehr Informationen über Tiere, sondern - und damit sind wir bereits bei den methodischen Vorbemerkungen - vermenschlichende Deutungen des Tierverhaltens. Die hier behandelten paganen Autoren begehen in den Augen heutiger Verhaltensforscher einen gravierenden Fehler: sie deuten Tierverhalten anthropologisch: Tiere haben in vergleichbaren Situationen dieselben Emotionen wie Menschen. Sie lieben ihre Jungen und fürchten ihre Feinde: die Autoren sprechen den Tieren denselben emotionalen Apparat zu, den sie auch den Menschen zusprechen. Dies mag aus Sicht heutiger Zoologen verfehlt sein, ist aber die Herangehensweise nicht nur der paganen, sondern auch der christlichen und jüdischen Autoren: nur weil man im Tier den Menschen sieht, kann man aus dem Tierverhalten Rückschlüsse auf das menschliche Verhalten ziehen. Hier möchte ich von „Verweischarakter des Tierverhaltens" sprechen, weil das Tierverhalten auf Rationalität verweist. Ich werde im letzten Teil erklären, was es damit auf sich hat.

4 Einschlägig: Sorabji (1993); Alexandridis, Wild und WinklerHoracek (2008). 
Eine zweite methodische Vorbemerkung betrifft die Art der Beziehung zwischen dem Physiologus und den übrigen Werken: Die Ähnlichkeiten, die wir im Folgenden sehen, sind inhaltlicher Art und beruhen nicht auf dem gleichen Wortlaut. Die Zusammenstellung dieser Ähnlichkeiten zeigt, dass der Physiologus teilweise dasselbe Material verwendet, wie pagane Autoren. Es bedeutet nicht, dass der Physiologus diese paganen Autoren als Quelle verwendet hat, weil der Wortlaut zu verschieden ist, sondern, dass es einen Fundus an Informationen zur Rationalität der Tiere gab, die verschiedene Autoren zu unterschiedlichen Zeiten an unterschiedlichen Orten genutzt haben. Diese Materialsammlungen, Handbücher, Listen etc. sind aber nicht erhalten. Spannender als der Wortlaut ist ohnehin die Deutung, welche ein und dieselbe Information in unterschiedlichen Bereichen erfährt.

\section{Panther und Igel}

Aus den Angaben, die der Physiologus im 16. Kapitel zum Panther gibt, greife ich diejenigen heraus, die für den Fortgang der Argumentation wichtig sind. Der Physiologus sagt vom Panther, er habe folgende Eigenschaften: Er sei das freundlichste aller Tiere, ruhig und sehr sanft. Er sei bunt und scheckig wie Josephs Rock. Wenn er gefressen habe, gehe er satt in seine Höhle und schlafe drei Tage. Am dritten Tag erwache er und rufe laut. Sein Ruf dufte und locke alle Tiere an. So habe auch Christus gerufen, als er am dritten Tag von den Toten auferstand.

Die Buntheit des Panthers kannte bereits Aristoteles (De generatione animalium 5.69), Plinius erwähnt die Flecken (Naturalis historia 8.62). In der Tat bezeichnet das Ad-

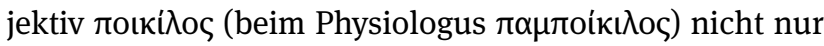
Buntheit im Sinne von ,verschiedenfarbig“, sondern auch „gescheckt“, „gesprenkelt“. ${ }^{5}$ Dass der Duft des Panthers alle Tiere anlocke, berichten seit Aristoteles zahlreiche Autoren: ${ }^{6}$ Plinius (Naturalis historia 8.62), Plutarch (De sollertia animalium 976D) ${ }^{7}$ und Aelian (Historia animalium 5.40); auffallend ist, dass der Physiologus den Ruf des Panthers als wohlriechend bezeichnet (eigentlich unmöglich - der Ruf ist ein Ton, kein Geruch), und nicht das Tier selbst.

5 LSJ s. v. „many-coloured, spotted, pied, dappled.“ (1996, 1430).

6 Aristoteles, Historia animalium 9.6.612a12-15.

7 Bouffartigue (2012). Der komplizierte Titel des Werks lautet auf Grie-

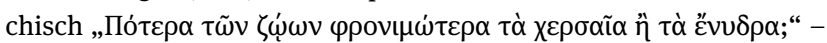
Ob von den Lebewesen die klügeren die Land- oder Wassertiere seien? Auf Lateinisch lautet der Titel De sollertia animalium - Von der Klugheit der Lebewesen. Die Übersetzungen aus Plutarch sind alle von der Autorin.
Ausgerechnet für ein Detail, das auf das erste Lesen hin wie eine christliche Konstruktion wirkt, findet sich eine Parallele in der paganen philosophischen Literatur: Es ist dies das dreitägige Fasten der Raubkatze, das der Physiologus christologisch auf Christi Aufenthalt in der Unterwelt und Auferstehung am dritten Tag deutet. ${ }^{8}$ Plutarch berichtet in De sollertia animalium Folgendes (974C):

Einem Tiger, der Diät hält, kann man ein Zicklein präsentieren, er frisst zwei Tage lang nichts. Am dritten Tag des Fastens aber fordert er etwas anderes und rüttelt an den Gitterstäben. Das Zicklein indes verschont er, weil er es für einen Gefährten und Verwandten hält.

Dieses Verhalten könnte man gut mit „friedlich und sehr sanft“ zusammenfassen (vgl. Physiologus 16: „ฑंซúxıv $\delta \dot{\varepsilon}$

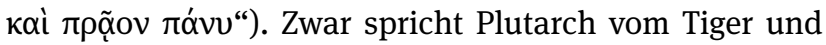
nicht vom Panther. Dass eine grosse Raubkatze zwei Tage fastet und erst am dritten Futter verlangt oder brüllt, ist wohl kein Zufall. Das beschriebene Verhalten kann auf Beobachtung von Raubkatzen beruhen: diese brauchen in der Tat nach einem Jagderfolg nicht gleich am nächsten Tag wieder Futter. Sowohl der Physiologus als auch Plutarch betonen, dass es der dritte Tag ist, an dem die Raubkatze „sich wieder meldet“. Die Angabe des dritten Tages stand wohl in einer Quelle, die entweder Plutarch oder der Physiologus der falschen Raubkatze zugeschrieben hat. Plutarch erwähnt das Verhalten übrigens als Beleg für die Rationalität des Tieres, weil es über angeborenes medizinisches Wissen verfüge: es hält Diät, in der Antike eine Stütze der Medizin (neben Diagnose und Therapie).

Noch eindrücklicher sind die Übereinstimmungen in Bezug auf den Igel. Der Physiologus beschreibt in Kapitel 14 ein spezielles Ernteverfahren des Igels:

Er klettert auf den Weinstock, gelangt zur Traube und wirft ihre Beeren zur Erde; dann wälzt er sich darin und wirft sich auf den Rücken, so dass sich die Beeren an seine Stacheln heften. Darauf bringt er sie seinen Jungen und lässt die Rebe ohne Traube zurück.

Ein ähnliches Ernteverfahren mit anderen Früchten und ohne Erwähnung der Jungen schildern Plinius ${ }^{9}$ und Aeli-

8 Weil der Physiologus von einem Panther spricht, Plutarch aber von einem Tiger, nimmt Schönberger Plutarch nicht unter die Similien auf. Die strukturellen Parallelen rechtfertigen m. E. aber eine Diskussion der Plutarch-Stelle.

9 Naturalis historia 8.133: „Auch die Igel sammeln Wintervorrat; sie wälzen sich auf abgefallenen Baumfrüchten, spiessen sie so auf ihre Stacheln, nehmen noch eine davon ins Maul, und tragen sie in hohle Bäume.“ 
an. ${ }^{10}$ Wie der Physiologus kennt auch Plutarch das Ernteverfahren mit Trauben zur Fütterung der Jungen. Er berichtet Folgendes (De sollertia animalium 971F-972A):

Raffinierter ist die Vorsorge [sc. des Igels] für die Jungen. Im Herbst huscht er unter die Weinstöcke und schüttelt mit den Pfoten die Trauben zu Boden; indem er sich darin wälzt, nimmt er sie mit seinen Stacheln auf: als wir Kinder waren und schauten, bot sich uns der Anblick einer kriechenden oder gehenden Traube, so voller Obst war er unterwegs. Dann verschwindet er in seinem Bau und lässt die Jungen sich von ihm bedienen und die Trauben nehmen.

Während der Igel in den Darstellungen der paganen Autoren als kluges Tier erscheint, das trickreich Futter für sich oder seine Jungen beschafft, kommt der Igel beim Physiologus nicht gut weg: er symbolisiert den Teufel, der Weinstock Christus. Woher kommt diese negative Wertung? Aus der paganen Literatur nicht. Zwar geht der Traubendiebstahl für einen Igel schlecht aus, den ein unbekannter $\mathrm{Au}$ tor in Verse fasst (Anthologia Palatina 6.45):

Hier diesen Igel, der spitz den Leib mit Stacheln bewehrt hat, / der an dem sonnigen Platz dörrende Trauben stibitzt / und über Beeren als Kugel sich rollte, ihn passte Komaulos / ab und hängte ihn gleich lebend für Bromios auf. ${ }^{11}$

Dieses Gedicht zeigt, wie bekannt das Ernteverfahren des Igels war, und gerade mit Trauben hat man ihn besonders in Verbindung gebracht. Freilich erklärt es nicht die negative Deutung des Igels beim Physiologus: Fast erhält man den Eindruck, dass der Physiologus den Igel nur deshalb erwähnt, weil er die anschauliche Geschichte von der Traubenernte erzählen will, die er kühn mit Joh 15,1-8 verknüpft. Den Weinstock deutet er gemäss Joh 15,1-8 als Christus und den Igel als bösen Geist (Kap. 14 tò rovnpòv $\pi v \varepsilon \tilde{v} \mu \alpha)$. Freilich lesen wir an der fraglichen Stelle bei Johannes nichts von einem bösen Geist.

10 Historia animalium 3.10: „Den Landigel hat die Natur nicht dumm und nicht ungelehrig gemacht, wenn es darum geht, sich einen Vorrat für seinen Bedarf anzulegen. Denn da er für das ganze Jahr Speise braucht, nicht jede Jahreszeit aber ihre Früchte bringt, so wälzt er sich, wie man erzählt, auf den Obstdarren und spiesst sich die Trockenfeigen, die dort liegen, in grosser Zahl auf seine Stacheln auf. Dann bringt er sie gemächlich heim und legt sich seinen sicheren Vorrat an." Hier kommt der Igel gut weg, andernorts spricht Aelian von der Bösartigkeit des Tieres (Historia animalium 4.17; 6.64). Zwar zeigt dies, dass der Igel nicht durchweg positiv konnotiert ist, doch erklärt es nicht, warum der Physiologus das Ernteverfahren als Schaden für den Weinstock deutet und den Igel als Verkörperung eines bösen Geistes.

11 Übersetzung von Beckby (1966). Ganz ähnlich ist Anthologia Palatina 6.169, ebenfalls von einem unbekannten Autor.
Noch nicht geklärt ist indes die Frage, warum der Igel negativ konnotiert ist und einen bösen Geist symbolisiert, eine Deutung, die nicht aus Joh 15,1-8 folgt. Hier hilft m. E. ein Blick auf das ägyptische Umfeld weiter, in dem der Physiologus wohl gelebt und gewirkt hat. Wie Florian Lippke in seinem Beitrag auf der Tagung zeigen konnte, ist der Igel in der ägyptischen Kultur dem Bereich der Wüste und der Unordnung zugewiesen. In dieser Sicht fügt sich die Nachricht, er symbolisiere einen bösen Geist, sehr gut ein: Böse Geister treiben ihr Unwesen gerne in der Wüste, da können sie sich gut in einem Tier wie dem Igel einkörpern, das ebenfalls als Wüstenbewohner gilt (vgl. Jes 13,21-22 ${ }^{\mathrm{LXX}}$ ).

\section{Hintergrund der Rationalitätsdiskussion}

Die Einzelbeispiele boten Hinweise auf die Existenz eines Fundus an Informationen zum Verhalten von Tieren. Wir wissen, dass Aristoteles und seine Nachfolger Informationen über Tiere gesammelt und klassifiziert haben. ${ }^{12}$ Es gab auch die sogenannte Mirabilienliteratur, die an Absonderlichkeiten aller Art interessiert war. ${ }^{13}$ Diese umfangreichen Sammlungen bilden den Grundstock an Informationen für alle Späteren. Nun gehen wir einen Schritt weiter, und fragen uns, wer weshalb ein Interesse an solchen Informationen hatte. Hier ist es wichtig, die Werke und den Hintergrund der verschiedenen Autoren zu unterscheiden. Plinius schreibt eine Enzyklopädie, eine Sammlung allen Wissens der Welt und geht deshalb auch auf Tiere ein; ${ }^{14}$ dabei interessiert ihn die Nutzbarkeit (als Nahrung, zur Zierde, Nutzen im Krieg oder zur Unterhaltung im Zirkus). Manchmal deutet er Tierverhalten als Zeichen von Rationalität (z. B. Naturalis historia 10.118). Aelian schreibt gehobene Unterhaltungsliteratur, er bietet Wissenshäppchen für den Small-Talk unter Gebildeten, Tierverhalten schildert er gerne in Kategorien menschlichen Verhaltens (z. B. Historia animalium 15.19; 17.5). So unterhaltsam und spannend diese Werke auch sind, sie helfen uns im $\mathrm{Zu}$ -

12 Einschlägige Schriften: Historia animalium, De generatione animalium, De incessu animalium, De motu animalium, De partibus animalium. Zu Aristoteles' Behandlung des Tieres s. Steiner (2008, 27-46, bes. 27-36).

13 Aristoteles, Mirabilia und De audibilibus (Flashar und Klein 1972, 7-36: Übersetzung, 39-154: Einleitung und Anmerkungen). Die Schrift stammt nicht von Aristoteles selbst, sondern entstand im 3. Jh.v. Chr. im Peripatos (Flashar und Klein 1972, 52); Brodersen (2002). Zum Thema Tiere in der Literatur siehe den Aufsatz von Herwig Görgemanns in diesem Band.

14 Naas (2002, zu Mirabilia bes. 293-325). 
sammenhang mit dem Physiologus nicht weiter, denn sie berichten Tierverhalten (manchmal menschlich gedeutet), doch verweist das Tierverhalten nicht auf etwas anderes als es selbst. Das Interesse der Autoren ruht auf dem Tier, dessen Verhalten er schildert. Nichts weiter will er darstellen, als dieses Verhalten. Einen anderen Hintergrund hat die Behandlung der Tiere bei Philosophen: Beobachtungen des Tierverhaltens verweisen über das Tier hinaus, auf Fragen der Stellung der Kreatur in der Welt und auf Fragen einer Stufenfolge des Lebens oder auf das Wesen der Rationalität. Zwar lesen wir auch in Werken von Philosophen zahlreiche Beispiele von Tierverhalten, dieses ist aber nicht Zweck an sich der Darstellung, sondern steht in einem argumentativen Zusammenhang, gehorcht der schulpolitischen Agenda des jeweiligen Autors und verweist immer über das Tierverhalten hinaus. Wir werden deshalb die Tierdiskussion unter Philosophen je nach Schulen betrachten.

\subsection{Stoiker und Peripatetiker: Die scala naturae}

Stoiker verweisen auf das kluge Verhalten von Tieren als Beispiel für die Pronoia Gottes (Cicero, De natura deorum 2.123-7). Freilich haben die Tiere gerade in der Stoa einen schlechten Stand: sie gelten zwar als beseelte Wesen mit

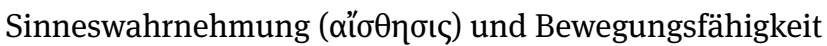
(òp $\mu \eta ́$ - wörtlich: Antrieb); weil ihnen aber der Verstand (入óyos) fehlt, fehlen ihnen die Fähigkeit sowohl zu artiku-

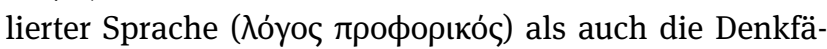

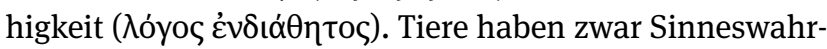
nehmungen, auf die sie reagieren; weil sie aber in Ermangelung des Verstandes keine vernünftigen Urteile treffen können, haben sie streng gesehen keine Affekte (Seneca, Dialogi 3.3.6: „muta animalia humanis affectibus carent, habent autem similes illis quosdam impulsus“). Denn im stoischen Denken entsteht ein Affekt erst durch willentliche Zustimmung zu einem Sinnenreiz. Erst wenn der $\lambda$ óyoৎ

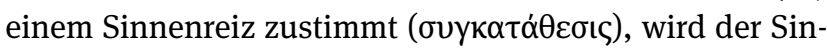
nenreiz zum Affekt (Seneca, Dialogi 4.3.1). Freilich gereicht dies den Tieren nicht zum Lob: Denn ihnen fehlt, ohne Entscheidungsvermögen, ohne begründetes Urteil, auch die Grundlage zu moralisch richtigem Verhalten. Tugend gilt als wahres und festes Urteil (Seneca, Epistulae 71.32: „quid erit haec uirtus? Iudicium uerum et immotum“), Tiere haben also keine Tugend, deshalb gilt Moral nicht für Tiere. Zusammengefasst hat das Tier bei den Stoikern zwar eine Seele, verfügt über Sinneswahrnehmung, nicht aber über Verstand; ohne Verstand keine artikulierte Sprache, keine vernünftigen Urteile, keine Denkfähigkeit. Doch haben Tie- re als beseelte und lebende Wesen im Verständnis der Stoiker Anteil am göttlichen Pneuma, das den ganzen Kosmos durchwaltet; Gott ist auch in ihnen, deshalb können sie als Instrumente göttlicher Pronoia dienen; doch ist der Anteil an Gott im Tier, salopp gesagt, geringer als im Menschen, und sehr viel geringer als in den perfekten beseelten lebenden Wesen, welche die Sterne und Daimones sind. Das Tier ist also im stoischen Weltverständnis dem Menschen untergeordnet, doch der Mensch ist auch nicht die Krone der Schöpfung: Daimones und Sterne sind die vollkommeneren Wesen. Dennoch betonen die Stoiker den Unterschied

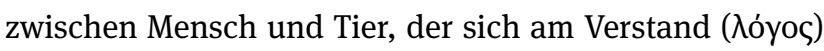
zeigt: Menschen haben ihn, Tiere nicht. ${ }^{15}$

Auch im Denken der Peripatetiker ist das Tier seit Aristoteles' grundlegender Schrift De anima ein Lebewesen, das gegenüber dem Menschen defizitär ist: es fehlt seiner Seele die Denkfähigkeit, der voũc. Anders als die Stoiker sprechen die Aristoteliker der Pflanze eine Seele zu, die dafür sorgt, dass die Pflanze wächst und Samen bildet, schliesslich aber abstirbt. (Laut den Stoikern ha-

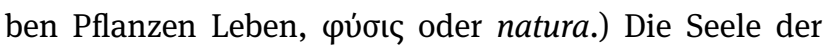
Pflanzen verfügt also über vegetative Fähigkeiten. Die Seele der Tiere verfügt darüber hinaus noch über Wahr-

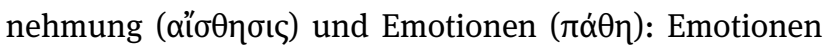
sind eine Seelenfunktion bei Aristoteles. Nur die Seele des Menschen hat Vernunft (voũ $)$, neben allen übrigen genannten Seelenfunktionen, die Pflanzen und Tiere haben. Aristoteles spricht zwar in den psychologischen und moralischen Schriften dem Tier die Denkfähigkeit kategorisch ab, doch in den Schriften, die sich mit dem Tierverhalten beschäftigen, lässt er bisweilen die Möglichkeit zu, dass Tiere eine Art von Denkfähigkeit haben oder er diskutiert die Frage, ob man bei Tieren metaphorisch von „Klugheit“ ( $\varphi \rho o ́ v \eta \sigma \iota \varsigma)$ sprechen soll - das ist ein hohes Diskussionsniveau, das später nicht mehr erreicht wird. ${ }^{16}$ Sowohl Stoiker als auch Peripatetiker diskutieren die Fähigkeiten der Tiere im Zusammenhang mit der Seelenlehre und teilen dabei den Tieren eine im Vergleich zum Menschen defizitäre Seele zu. Das Tierverhalten verweist also auf eine defizitäre, nicht rationale Seele.

15 Wildberger (2008, 47-70; 2006, zum Verhältnis Tier-Mensch-Gott: 203-243). Wildberger beschreibt die stoische Physik anschaulich und klar als eine Vermischung von Gott und Materie, wobei sich die unterschiedlichen Bestandteile der empirisch wahrnehmbaren Welt voneinander durch ein unterschiedliches Mischungsverhältnis von Gott und Materie unterscheiden. Siehe auch Newmyer (2008).

16 Steiner (2008, 34-36). Theiler (1983); zu den Pflanzen Aristoteles De anima 2.2.413a26-34; zum Tier De anima 2.2.413b1-414a3; zum Denkvermögen De anima 3.4.429a10-429b10. 


\subsection{Platoniker und Pyrrhoneer: Rationalität als Alleinstellungsmerkmal des Menschen?}

Wenn wir Plutarchs Werke lesen, fällt auf, dass das Thema Tier ihn beschäftigte: Einer heute nur unvollständig erhaltenen Schrift in ursprünglich zwei Büchern De esu carnium entnehmen wir, dass er eine Zeit lang als Anhänger des Pythagoreismus vegetarische Ernährung propagierte. Anschauliche Beispiele für rationales Verhalten von Tieren suchen wir in diesem Traktat vergebens.

Der Gryllus - An bruta animalia ratione uti (ob rohe Tiere Vernunft haben) ist ein rhetorisches Schaustück, eine Ethopoiie mit Gryllos, Odysseus' Gefährten, der von Circe in ein Schwein verwandelt wurde, als Hauptperson: Gryllos, den Odysseus wegen seiner Verwandlung bedauert (Gryllus 986C), kehrt den Spies um und erklärt Odysseus, dass das Leben als Schwein viel besser sei als das Leben als Mensch, und zwar nicht, weil er als Schwein alle niederen Instinkte frei ausleben darf, ${ }^{17}$ sondern weil er jetzt qua Schwein und Tier, gleichsam von selbst bzw. natürlich tugendhaft lebt. Diese These arbeitet er an Hand der Tugenden Tapferkeit (Gryllus 987C-988E) und Besonnenheit (Gryllus 988F-992C) argumentativ und mit Hilfe von Beispielen durch und das ist die Botschaft des Traktats:

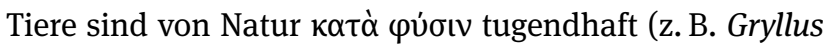
987B, 992A), der Mensch ist seiner Natur untreu geworden und deshalb ging er auch der Tugend verlustig (z. B. Gryllus 987F, 989C, 991A). Das Tierverhalten verweist hier auf die angeborene Fähigkeit zur Tugend der Tiere.

Im Hinblick auf den Physiologus und auf die Rationalitätsdiskussion am ergiebigsten ist aber ein weiteres Werk: De sollertia animalium (der vollständige Titel findet sich in Anm. 7) ist ein philosophisch-rhetorischer Dialog, der die Spezialfrage erörtert, ob Land- oder Wassertiere vernünftiger sind. Es geht also nicht um einen Beweis, dass Tiere vernünftig sind, im Gegenteil, dies wird vorausgesetzt, auch wenn sich im einleitenden Dialog einige Gegenargumente finden, die der Dialogteilnehmer Soklaros erfolglos vertritt. ${ }^{18}$ Es geht gleichsam um einen intellektuellen Wettbewerb unter Tiergruppen: welche sind klüger, die Landlebewesen oder die im Wasser lebenden? Plutarch unterscheidet offensichtlich nicht nach unseren heutigen

17 Dies lässt sich aus Gryllos’ Lob der Besonnenheit (988F-992C) herauslesen.

18 Soklaros spricht 960BC, 961F-962A, 963A, 963F-964C: Die Entgegnung des Autolykos, der für die Rationalität der Tiere argumentiert, sind jeweils deutlich länger: 960C-961F, 962A-963A, 963A-F, 964C-965B; dies zeigt die Tendenz des Dialogs. Zu den Dialogteilneh mern s. Bouffartigue (2012, XIV-XVII). zoologischen Gattungen (Säugetiere, Vögel, Reptilien, Amphibien, Fische. Weichtiere, Insekten u. a.m.), sondern er fasst Tiere nach Lebensraum zusammen. Zugleich will er ein Beispiel sprachlich gelungenen Philosophierens bieten (De sollertia animalium 960A). Dieses Werk enthält zahlreiche anschauliche Beispiele für rationales Verhalten von Tieren (s. oben, Panther und Ameise, weitere folgen unten). Ist er deswegen Tierrechtler, ein Vorläufer von Peter Singer in der Antike? Wohl kaum. Es geht ihm nicht um eine Neubewertung oder gar Umwertung des Verhältnisses Mensch-Tier, sondern um eine Ausdehnung der Kategorie Rationalität auf Tiere. ${ }^{19}$

Eine Kritik am prinzipiellen Anthropozentrismus der Philosophie finden wir beim Pyrrhoneer Sextus Empiricus, der mit der Absicht, sämtliche Philosophie als Sammlung haltloser Dogmata zu disqualifizieren, argumentativ den Nachweis erbringt, dass der Hund bessere kognitive Fähigkeiten besitze als der Mensch (Pyrrhonische Hypotyposen 1.62-78): Der Geruchssinn des Hundes übertreffe denjenigen des Menschen, ebenso seien Augen und Gehör besser (Pyrrhonische Hypotyposen 1.64). Der Hund verhalte sich gemäss stoischer Ethik, wenn er das Arteigene anstrebe, das Futter, und das Schädliche meide, die Peitsche (Pyrrhonische Hypotyposen 1.66). Von den Tugenden besitze er die Gerechtigkeit, weil er die Menschen, die ihn gut behandeln, schwanzwedelnd begrüsse, Fremde aber anbelle (Pyrrhonische Hypotyposen 1.67). Der Hund sei tapfer in der Verteidigung und klug, weil er seine Besitzer selbst nach langer Abwesenheit wiedererkenne. Der Hund verstehe etwas von Dialektik: wenn er bei der Verfolgung des Wildes an eine Wegkreuzung komme, schnüffle er an der ersten, wenn erfolglos, dann an der zweiten Abzweigung, wenn nochmals erfolglos renne er die dritte entlang, ohne nochmals geschnüffelt zu haben, weil er wisse, dass das Wild hier entlang gerannt sei (Pyrrhonische Hypotyposen 1.69). ${ }^{20}$ Der Hund verstehe etwas von Medizin: habe er sich einen Dorn in die Pfote getreten, versuche er diesen durch

19 Dies entnehme ich folgenden Äusserungen: Gryllus 992C: „Seit ich [sc. Gryllos] in diesen Körper [sc. Schweinekörper] eingetaucht bin, wundere ich mich über diejenigen Argumente, womit mich die Sophisten verleitet haben, alle für vernunftlos und ohne Denken zu hal-

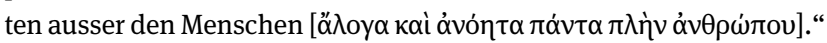
De sollertia animalium $985 \mathrm{C}$ (der Schlusssatz): „beide habt ihr wacker gerungen gemeinsam gegen die, welche die Lebewesen des Verstan-

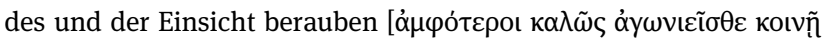

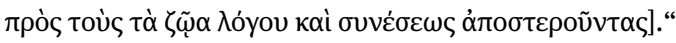

20 Pyrrhonische Hypotyposen 1.69: ,Jedenfalls behauptet Chrysipp, der Hund wende das fünfte mehrgliedrige unbewiesene Argument an, wenn er an einen Dreiweg komme und nach dem Spüren auf den zwei Wegen, die das Wild nicht entlang gelaufen sei, sofort den dritten entlang stürme, ohne hier überhaupt gespürt zu haben.“ Alle Überset- 
Wischen der Pfote am Boden zu entfernen (Pyrrhonische Hypotyposen 1.70-71). Zwar stellt Sextus den Vergleich zum Spott an, wie er selbst sagt, ${ }^{21}$ die Stossrichtung der Polemik ist aber deutlich: gegen die Stoiker geht es. Diese verbergen sich oft unter den Dogmatikern (Pyrrhonische Hypotyposen 1.62), doch nennt er im Abschnitt sowohl die Stoiker allgemein, ${ }^{22}$ als auch einen Stoiker namentlich, nämlich Chrysipp (Pyrrhonische Hypotyposen 1.69). Und zwar stützt Sextus sich für das Argument, dass Hunde etwas von Dialektik verstehen, auf Chrysipp; das ist sehr raffiniert und hinterhältig: er schlägt die Stoiker gleichsam mit ihrem Hauptvertreter.

Zweck der Argumentation ist der Nachweis, dass der Mensch sich nicht auf seine Sinne und auch nicht auf seinen Verstand stützen kann, um die Glaubwürdigkeit von Erscheinungen $\mathrm{zu}$ bewerten, weil erstens dieselbe Erscheinung von verschiedenen Lebewesen ganz unterschiedlich beurteilt wird und weil zweitens der Mensch nicht einfach davon ausgehen kann, seine, des Menschen Vorstellungen, seien ohnehin besser als die eines anderen Lebewesens. Als Abschluss dieses Gedankens bringt Sextus das humorvolle Plädoyer für den Hund als vernünftiges Wesen. Sinneswahrnehmung und Verstand waren im stoischen Denken die beiden Wahrheitskriterien; ${ }^{23}$ wenn Sextus ihnen die Zuverlässigkeit abspricht, hat er das stoische Wahrheitskriterium widerlegt. ${ }^{24}$

Bemerkenswert ist auch folgender Gedanke (Pyrrhonische Hypotyposen 1.74):

Wenn wir auch die Sprachen der sogenannten vernunftlosen Tiere nicht verstehen, so ist es doch nicht völlig unwahrscheinlich,

zungen des Sextus Empiricus sind von Hossenfelder (1985). Vgl. Plutarch, De sollertia animalium 969B.

21 Pyrrhonische Hypotyposen 1.62-63: „Zum Überfluss vergleichen wir jedoch auch noch die sogenannten vernunftlosen Lebewesen mit den Menschen hinsichtlich ihrer Vorstellungen. Denn wir verschmähen es nicht, nach den wirksamen Argumenten die aufgeblasenen und selbstgefälligen Dogmatiker noch zu verspotten. Bei uns pflegt man mit dem Menschen einfach die Masse der vernunftlosen Tiere zu vergleichen. [63] Da aber die spitzfindigen Dogmatiker das einen ungleichen Vergleich nennen, will ich zum grossen Überfluss den Spott noch weiter treiben und das Argument auf ein einziges Tier stützen, z. B. auf den Hund, wenn's recht ist, offenbar das ordinärste Tier. Wir werden nämlich auch so feststellen, dass die Tiere, von denen die Rede ist, uns hinsichtlich Glaubwürdigkeit der Erscheinungen nicht nachstehen."

22 Pyrrhonische Hypotyposen 1.65: „die uns am heftigsten befehdenden Dogmatiker, die Stoiker.“

23 Long und Sedley (1987, 241-253).

24 Sextus Empiricus, Adversus mathematicos 7, ist der Widerlegung der stoischen Wahrheitskriterien gewidmet. Zum Pyrrhonismus s. Hossenfelder (1985, 9-88, bes. 37); Long und Sedley (1987, 468-488); Barnes (1990). dass sie miteinander reden und wir es nur nicht verstehen. Denn wir verstehen ja auch nicht die Sprache der Barbaren, wenn wir sie hören, sondern halten sie für eine undifferenzierte Lautfolge.

So könne, schreibt Sextus auch der Hund in gewisser Weise sprechen, indem er vertraute Menschen mit anderen Lauten begrüsse als wenn er geschlagen werde.

Der Spott zielt freilich nicht nur auf die stoischen Wahrheitskriterien, sondern geht tiefer. Meines Wissens nur hier finden wir Überlegungen zum Verhältnis MenschTier, die zu einer starken Relativierung des Anthropozentrismus führen. Oder anders gesagt: Sextus sieht kein vernünftiges Argument, weswegen die Vorstellungen des Menschen bei der Bewertung der Erscheinungen der äusseren Welt höher gewichtet werden sollten als die der Tiere, wie er abschliessend festhält (Pyrrhonische Hypotyposen 1.76):

Wenn nun die Tiere den Menschen weder an Schärfe der Sinneswahrnehmung nachstehen noch hinsichtlich der innerlich denkenden Vernunft noch auch - um es zum Überfluss zu behaupten - hinsichtlich der sich sprachlich äussernden, dann sind sie in den Vorstellungen wohl kaum unglaubwürdiger als wir.

Diesen Gedanken bekräftigt er im Folgenden nochmals (Pyrrhonische Hypotyposen 1.78):

... dass wir unsere Vorstellungen nicht höher einschätzen kön-
nen als die der vernunftlosen Tiere. Wenn aber die vernunftlosen
Tiere für die Beurteilung der Vorstellungen nicht unglaubwür-
diger sind als wir und wenn entsprechend der Verschiedenheit
der Lebewesen unterschiedliche Vorstellungen entstehen, dann
werde ich zwar sagen können, wie mir jeder der zu grunde lie-
genden Gegenstände erscheint, wie er aber seiner Natur nach
ist, darüber werde ich mich wegen des oben Gesagten notwen-
dig zurückhalten.

Damit verlassen wir den Pyrrhoneer Sextus Empiricus und das Hinterfragen einer anthropozentrischen Weltsicht: nur er geht in der Kritik am Wahrheitsanspruch der Philosophie so weit, grundsätzliche Zweifel am Anthropozentrismus der Philosophie zu äussern.

Betrachten wir nochmals Plutarch: auch wenn er es nirgends offen ausspricht: er argumentiert implizit gegen die Position der Stoiker, wenn er für die Rationalität der Tiere plädiert. ${ }^{25}$ Doch was genau versteht er unter „Rationalität“? Eine Definition von „Rationalität“ suchen wir in Plutarchs Tier-Traktaten vergebens. Doch an Hand der Beispiele lässt sich beschreiben, was Plutarch darunter versteht: Rational heisst menschlich, die Rationalität der Tiere zeigt sich daran, dass sie in vergleichbaren Si-

25 Dies ist die Position von Newmyer (2014). 
tuationen handeln und reagieren wie Menschen. Diese anthropologische Verzerrung stört nicht etwa, sondern ist konstitutiv für das Verständnis und die Definition von Rationalität: die Tiere sind wie Menschen, sie sind vernünftig, sie planen, lernen, erinnern sich, sie verstehen etwas von Medizin, sie lieben ihre Kinder und ihre Gatten, sie sind treu, sozial, loyal, sie haben Tugenden wie Gerechtigkeit, Klugheit, Tapferkeit (Gryllus 987C-988E), Besonnenheit (Gryllus 988F-992C). ${ }^{26}$ Kurzum, wäre nicht explizit von Tieren die Rede, würde man glauben, es gehe hier um Menschen. Weil nun aber die Tiere sind wie Menschen und die Kriterien der Rationalität sämtlich erfüllen oder sogar übererfüllen, ist die Position der Stoiker, wonach Tiere nicht rational sind ( $\alpha{ }^{\prime} \lambda$ oy $\left.\alpha \zeta \tilde{\omega} \alpha\right)$ nicht haltbar. Man könnte natürlich auch sagen, wenn sogar Tiere die Kriterien der Rationalität erfüllen, sind vielleicht diese Kriterien nicht richtig gewählt. Diesen Schluss zieht Plutarch nicht. Ihm scheint es um die scharfe Trennung von

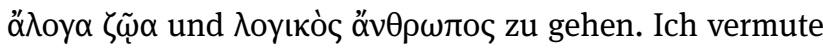
als Grund ein Unbehagen an der strikten Trennung von Lebewesen entlang einer Demarkationslinie, deren Existenz man zwar irgendwie als gegeben annimmt, die sich aber in Wirklichkeit nicht so trennscharf nachweisen lässt, es ist dies die Vernunft, der $\lambda$ óyoc, der voũc. ${ }^{27}$ Es ist diese Selbstsicherheit der Stoiker, die so genau wissen, dass sich das Tier, obwohl es Seele hat und ein Lebewesen ist und als solches Gottes teilhaftig ist (Gott ist in stoischer Sicht das aktive Prinzip in der Materie und in allen Lebewesen), dennoch ganz und gar vom Menschen verschieden ist, weil es eben keinen voũ und keinen $\lambda$ óyoc hat. Reicht dies aus, das Tier als defizitär zu betrachten? Im Hintergrund steht wohl durchaus die Frage, was den Menschen zum Menschen und das Tier zum Tier mache und ob diese Frage richtig gestellt ist. Vielleicht - und hier denke ich Plutarch etwas weiter - wenn Tiere auch über Rationalität verfügen, sind sie dem Menschen weit ähnlicher als es die Stoiker

26 Einige Beispiele aus De sollertia animalium sollen das veranschaulichen. Lernen und Planen: libysche Krähen werfen Steine in ein Gefäss mit Wasser, damit der Wasserspiegel steigt und sie trinken können (967A). Lernen und Erinnern: Elefanten lernen komplizierte Bewegungsabläufe auswendig und führen sie in der Manege vor (968BF). Sprechen: Papageien und Krähen lernen sprechen (972F-973A). Kunstfertigkeit im Nest- oder Netzbau: Spinne (966E), Biene (982F), Schwalbe (966D), Eisvogel (983B-E). Vorsorge für die Kinder (981F982E). Gattenliebe (972D-F). Tapferkeit des Ichneumons im Kampf gegen das Krokodil (966D - vgl. Physiologus 25-26). Treue des Hundes (969C).

27 Ob man nun von voũ oder hóyoৎ spricht, hängt mehr von der philosophischen Tradition ab, in der ein Autor steht, als dass es sich um sachliche Differenzen handelt. 入óyoc ist ein Schlagwort stoischen Denkens, voũ des aristotelischen. wahrhaben möchten. Tier und Mensch wären dann als Lebewesen, als beseelte und in gewisser Hinsicht rationale Wesen die Bewohner der sublunaren Welt, deren Kennzeichen Unvollkommenheit und Vergänglichkeit ist. ${ }^{28}$ Es gäbe dann auf der Welt, diesem Zusammenfluss von Erde und Wasser im Zentrum des Kosmos beseelte, mehr oder weniger rationale Lebewesen, die man Menschen oder Tiere nennt; auf dem Mond gibt es Daimones und Seelen, reinere weil körperlose Wesen, noch weiter oben die reinsten Wesen, die Gestirne. Mensch und Tier als Bewohner der sublunaren Welt wären in dieser Weltsicht zusammen genommen und deutlich getrennt von Daimones, Gestirnen und Göttern, den Bewohnern der supralunaren Welt der Ordnung und Ewigkeit. Dass sich Mensch und Tier ähnlicher sind, als es die Stoiker wahrhaben möchten, an diesem Punkt setzt die Argumentation Plutarchs ein. Denn es gibt zahlreiche Beobachtungen, welche es als wahrscheinlich erscheinen lassen, dass Tiere vielleicht doch über eine gewisse Form von Rationalität verfügen, wenn wir sie denn danach fragen könnten. Zwar spielt die subtile Frage nach der sprachlichen Form der postulierten Ähnlichkeit in Plutarchs rhetorischen Stücken keine Rolle: hat das Tier eine Form von Rationalität, die graduell oder quantitativ von derjenigen des Menschen verschieden ist, oder spricht man metaphorisch von „Tugend“, „Klugheit“ etc. - im letzten Fall käme dies einer Negation der Frage gleich: Tiere hätten eben doch keine Rationalität, wenn sie nur metaphorisch gesprochen klug sind, planen und sich erinnern. So tief in der Diskussion drin ist Plutarch nicht. Es scheint ihm zu genügen, eine Fülle von Beispielen auszubreiten, um durch die blosse Menge und Vielfalt an Informationen den stoischen Anspruch, Tiere seien

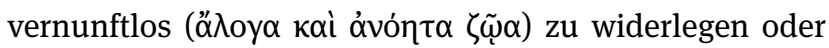
anders gesagt, die Kategorie Rationalität auf Tiere auszudehnen.

28 Die Erde als „durch und durch wandelbare und veränderliche - um es kurz zu sagen, die vergängliche und todgeweihte“ (Ps.Aristoteles, De mundo 392a31-33); zum Gegensatz Welt-Veränderung und Himmel-Ordnung s. Philon De Josepho 145; Dodds (1985, 17-43: Der Mensch und die materielle Welt, 44-66: Der Mensch und die dämonische Welt). Als Primärquelle: Aristoteles, Über die Welt (Strohm 1973), diese Schrift stammt freilich nicht von Aristoteles, sondern von einem unbekannten Autor; verfasst wurde sie vor der Mitte des 2. Jh. n. Chr. und wohl nach Poseidonios (Strohm 1973, 263: Mitte erstes Jh. v. Chr.). 


\subsection{Tiere und Gott}

Ein anderer Aspekt spielt bei Plutarch eine Rolle; es ist dies die Verbindung der Tiere mit dem Göttlichen. ${ }^{29}$ Vielversprechend schien das Ende vom Gryllus: Aber Tiere, so wendet Odysseus zum Schluss ein, haben keine Kenntnis

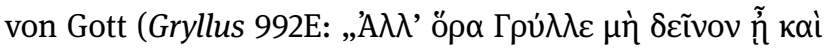

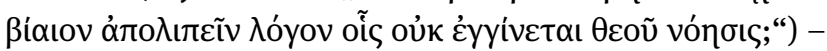
Gryllos antwortet: Dann bist Du, Odysseus, ein weiser Mann, nicht der Enkel des Sisyphos? Der Gedankengang ist: auch bei Menschen gibt es Atheisten, trotzdem halten sie sich für rational.

Ergiebiger ist De sollertia animalium; hier sagt der Redner deutlich, dass er nun auch über die Göttlichkeit und die mantischen Fähigkeiten der Tiere sprechen will und er erwähnt folgende Beispiele (ich paraphrasiere): ${ }^{30}$ Elefanten beteten mit erhobenem Rüssel zu den Göttern. Sie verehrten die aufgehende Sonne, ${ }^{31}$ reinigten sich im Meer (972CD). Ein heiliges Krokodil des Ptolemaios habe mantische Fähigkeiten besessen und den Tod des Königs vorhergesehen (976B). ${ }^{32}$ Fische dienten in Lykien der Mantik (976C). Der Gott (ó $\theta \varepsilon o ́ \varsigma)$ benutze die Tiere wie Werkzeuge für die Auguren (975A). Euripides nenne die Vögel „Herolde der Götter“ (975B): man könne unzählige Beispiele zitieren, wo Tiere die Gegenwart eines Gottes oder einer Göttin anzeigen. ${ }^{33}$ Plutarch erwähnt keines, dafür beispielsweise Ovid in den Metamorphosen Iuno im Pfauenwagen (2.531532) und Kybele auf dem Löwenwagen (14.538).

Die Beispiele, die Plutarch zur Spiritualität der Tiere gibt, sind etwas knapp; insbesondere wüssten wir gerne, wie man wusste, dass das heilige Krokodil den Tod des Königs voraussagte; nur im Beispiel der Elefanten gibt Plutarch eine Deutung des beobachteten Verhaltens: Dass Elefanten den Rüssel erheben und sich zur aufgehenden Sonne wenden, lässt sich wohl so beobachten; dass sie so die Götter verehren, ist Interpretation.

29 Plutarch ist m.W. der einzige Nicht-Ägypter, der die theriomorphen Götter- und Göttinnendarstellung der Ägypter verteidigt (s. De Iside 382AB).

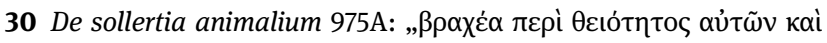

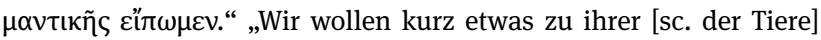
Göttlichkeit und Mantik sagen.“

31 Aelian berichtet, dass Elefanten den Mond verehren (Historia animalium 4.10).

32 Aelian erwähnt eine prophetische Schlange (Historia animalium 11.16).

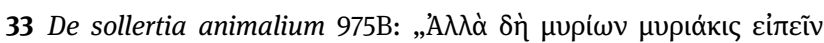

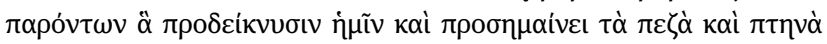
$\pi \alpha \rho \grave{\alpha} \tau \tilde{\omega} v \theta \varepsilon \tilde{\omega} v$.“ „Aber es gibt doch ungezählte Beispiele zu nennen, wo uns die Landtiere und die Vögel etwas von Seiten der Götter aufzeigten und darauf verwiesen.“
Auch wenn ich hier nur wenige und vage Beispiele geben kann, so zeigt Plutarch doch deutlich, dass er die Tiere auch mit dem Bereich des Göttlichen verband: wenn Tiere rational sind, verfügen sie über einen Bezug zum Göttlichen, weil im platonischen Denken Gott gedacht wird und nicht geglaubt: $:^{34}$ auch das Göttliche ist nicht die exklusiveZone des Menschen. Hier muss man der Objektivität halber erwähnen, dass sich das Verhältnis von Gott-MenschTier im Denken der Stoiker ganz anders gestaltet: der körperlich verstandene Gott, der aus leichtem, sehr beweglichem Pneuma besteht, durchwaltet den gesamten Kosmos, also auch Menschen und Tiere, ja sogar die unbeseelte Natur. ${ }^{35}$ Gott ist also in allem drin, nur je nach Lebewesen unterschiedlich viel. Im Denken der Stoiker stellt sich daher die Frage nicht, wie man Gott erkennen kann, weil man von ihm getrennt ist, sondern wie man erkennt, dass man von ihm erfüllt ist. Oder wie es Seneca unnachahmlich prägnant formuliert: Epistulae 41.1: „prope est a te deus, tecum est, intus est.“

Zum Schluss möchte ich ein kurzes, wenig beachtetes Werk vorstellen, das sich, wie ich glaube, strukturell mit dem Physiologus vergleichen lässt und zugleich die Verortung der Rationalitätsdiskussion der Tiere im platonischen Gedankengut zeigt: Es ist der Dialog Halkyone.

\section{Halkyone - Der Eisvogel}

Das kurze Stück findet sich unter den unechten Werken Lukians. Weil es ein Spurium ist, wird es in der Forschung wenig beachtet. Dabei ist der Text hoch interessant. Den Dialog in Gang setzt der klagende Ruf eines Vogels. Chairephon fragt Sokrates, was für ein Vogel es sei. Sokrates erzählt ihm darauf den Mythos von Keyx und Halkyone, er der Sohn des Morgensterns, sie die Tochter des Windgottes Aiolos, wunderschön und jung beide und sehr verliebt. Als Keyx jung stirbt, irrt Halkyone in Trauer umher, bis die Götter sie aus Mitleid in einen Vogel verwandeln,

34 Gott denken: z. B. Alkinoos, Didaskalikos 10; Kelsos, Alethes logos 7.45; Maximos von Tyros, Orationes 11.7-8, dazu Wyss (2017, 745-747). 35 Deshalb kann Dion von Prusa behaupten, dass Tiere auch ohne Verstand Gott erkennen (Orationes 12.35): „Ohne Vernunft und Verstand, erkennen sie doch Gott und ehren ihn und sind bereit, nach seiner Satzung zu leben. Noch viel auffälliger ist das bei den Pflanzen. Sie haben von nichts irgendeine Vorstellung, sind ohne Seele, ohne Stimme, werden von einfachen Naturkräften gelenkt - und doch bringen auch sie die Frucht, die jeder Art eigentümlich ist, aus freien Stücken und bereitwillig hervor. So völlig durchsichtig und unmissverständlich ist die Willenskundgebung dieses Gottes hier und seine Macht.“ Die Übersetzung stammt von Klauck (2000). 
in den Eisvogel (§ 1). Obwohl der Vogel klein ist, haben ihn die Götter für die grosse Liebe und Treue zum Gatten reich belohnt: während seiner Nistzeit im Winter ruhen die Stürme, es sind dies die halkyonischen Tage (§ 2). So nannte man die Tage um die Wintersonnenwende, die im Mittelmeer oft windstill waren, so dass mitten im Winter Schiffe das Meer befahren konnten; während der übrigen Winterzeit ruhte die Schifffahrt. Der klagende melodiöse Ruf des Vogels erklärt Sokrates mit dem Mythos: Halkyone, die Ehefrau, beklagte den vorzeitigen Tod des Gatten und die Klage hat die Metamorphose überdauert, auch der Eisvogel klagt. Sokrates distanziert sich freilich davon, indem er sagt, der klagende Vogel habe Anlass zu

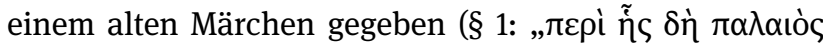

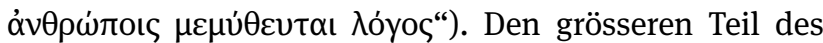
Dialogs nimmt die Frage ein, ob es möglich sei, dass eine Frau in einen Vogel verwandelt wird (§§ 3-8). Sokrates bringt nun, durchaus anachronistisch, Argumente aus der aporetischen Akademie, um die Frage - und das ist auf den ersten Blick erstaunlich, zu bejahen. Die Frage nach der faktischen Möglichkeit einer Verwandlung eines Menschen in einen Vogel dient dem Autoren als Anlass, die Allmacht Gottes oder der Natur zu belegen, in der Wortwahl schwankt der Autor. ${ }^{36}$ Die Weltsicht, insbesondere die Sicht auf den Menschen, ist dabei zutiefst skeptisch so wie auch wir das Wort noch brauchen: der Mensch ist ein Mangelwesen, er lebt nur kurz, er bleibt unvollkommen, kommt nicht zur Reife, ist schwach, unfähig, beschränkt, das Erkenntnisvermögen ist schwach: ein Urteil, dass diese Verwandlung nicht möglich ist (was jeder rational denkende Mensch erwartet), steht dem Menschen nicht zu (das ist die غ̇лoхи́, ${ }^{37}$ die Zurückhaltung im Urteilen der Pyrrhoneer). Doch bei diesem negativen Schluss belässt es der Autor nicht. Er zieht aus der Schwäche und Beschränktheit des Menschen den Schluss, dass es eine andere, vollkommene, starke, kluge, fähige, mächtige Macht geben muss, der alles möglich ist, auch scheinbar unmögliches. Diese Macht nennt er einmal Gott, einmal Natur. Sokrates schliesst, dass er die Geschichte der melodischen Dulderin Halkyone seinen beiden Ehefrauen erzählen werde, als Vorbild für fromme und treue Gattenliebe, und auch seinen Kindern.

Heute wohl am besten bekannt ist der Mythos in der literarischen Gestalt, die ihm Ovid in den Metamorphosen gibt (11.410-748). Plutarch widmet dem Eisvogel ein längeres Lob (De sollertia animalium 982F-983F): Musikalisch, treu, kinderlieb und handwerklich begabt sei der Vogel. Der Eisvogel war ein literarisch vielfältig beachtetes Tier, das zeigen Ovids Metamorphosen, Plutarchs Lob des Eisvogels in De sollertia animalium und die Existenz dieses kurzen Dialoges. ${ }^{38}$

Betrachten wir den Dialog genauer: Verwandelt wird eine Göttertochter, die Verwandlung veranlassen die Götter, Grund ist die grosse Trauer um den früh verstorbenen Mann. Strukturell kommt der Halkyone-Mythos im gleichnamigen Dialog der Handhabung von Naturphänomenen beim Physiologus nahe: Die Klage der Frau wurde zum klagenden Ruf des Vogels. Es ist dieser Ruf, also ein hörbares Phänomen aus der Natur, das die Geschichte in Gang setzt: der Mythos dient dazu, dieses Phänomen zu erklären. Beim Physiologus verweist oft ein sichtbares Phänomen der Natur auf die Bibel. Die Tatsache, dass der Vogel im Winter nistet, dient als Aition für die milden Wintertage, man erklärt ein Naturphänomen symbolisch mit einem anderen Naturphänomen, das mit dem ersten nach naturwissenschaftlichen Gesichtspunkten nichts zu tun hat: man erklärt die Natur aus der Natur.

\section{Philosophische Rationalitätsdiskussion und Physiologus}

Versuchen wir zum Schluss, die Fäden zusammenzuziehen und mit dem Physiologus zu verknüpfen. Tiere waren ein Thema in der paganen Literatur der ersten beiden Jahrhunderte n. Chr. und das in ganz unterschiedlichen literarischen Gattungen. ${ }^{39}$ Wie Philons De animalibus zeigt, hat sich im 1. Jh. n. Chr. in Alexandria auch ein Jude mit diesem Thema beschäftigt. Mit Philon sind wir in Alexandria in Ägypten. In Ägypten verortet man oft die Herkunft des Physiologus. Neben den griechischen und lateinischen Autoren gibt es in der Tat auch ägyptische, die sich mit Tieren beschäftigt haben: Aelian erwähnt den ägyptischen Gelehrten Manetho (3. Jh. v. Chr., Historia animalium 10.16) und den Philologen Apion (1. Jh.n.Chr., Historia animalium 10.29), mehrere Tiergeschichten spielen in Ägypten, besonders in Buch 10 der Historia animalium. Wir wissen, dass der Tierkult in Ägypten in ptolemäischer Zeit eine Hochblüte erlebte und auch in der frühen Kaiserzeit noch

38 Plinius, Naturalis historia 10.89-91, erwähnt den kunstvollen Nestbau und die halkyonischen Tage, ohne Hinweis auf den Mythos. 39 Siehe H. Görgemanns in diesem Band.
36 Götter § 3, Daimones §§ 3-4, Unsterbliche § 8, Physis § 7.

37 Sextus Empiricus, Pyrrhonische Hypotyposen 1.8, 1.29 und passim. Hossenfelder (1985, 51-59); Long und Sedley (1987, 468-488). 
intensiv praktiziert wurde. ${ }^{40}$ Ägypten ist also, auch wenn hier die Beleglage wegen des Verlustes an Texten besonders dünn ist, die dritte Grösse, die wir im Zusammenhang mit dem Physiologus in Rechnung zu halten haben. (Die Werke von Manetho und Apion sind nur noch in Fragmenten erhalten.) In Ägypten wurden Tiere kultisch verehrt, Tiere spielten eine Rolle in der Literatur von Ägyptern und über Ägypten.

Besonderes Augenmerk richtete ich auf die Diskussion unter Philosophen, und dies deswegen, weil das Nachdenken über Gott und das Göttliche Teil der Philosophie war. Es schien daher sinnvoll, die Argumente der Philosophen auch im Hinblick auf das Verhältnis des Tieres zum Göttlichen genauer zu betrachten. Grundsätzlich hat die Diskussion unter Philosophen, ob Tiere Verstand haben, nichts zu tun mit dem Physiologus, weil der Physiologus nicht an der Frage interessiert war, ob Tiere rational sind. Im philosophischen Kontext stammt die Argumentation für die Rationalität der Tiere aus der Auseinandersetzung zwischen Akademie bzw. Platonismus und Pyrrhonismus einerseits und Stoa und Aristotelismus andererseits. Die Argumente der Platoniker und Pyrrhoneer, dass ö $\lambda$ oy $\alpha$ $\zeta \tilde{\omega} \alpha \lambda$ óyov haben, richtet sich besonders gegen das Rationalitätsverständnis der Stoiker. Eine grundsätzliche Kritik am Anthropozentrismus findet sich beim Pyrrhoneer Sextus Empiricus im Bestreben, die Erklärungskraft der Philosophie insgesamt zu bestreiten.

Plutarch bringt einige, freilich wenige und vage Beispiele für die Spiritualität der Tiere - auch hier in einem implizit antistoischen Kontext: wenn Tiere in einem Bezug $\mathrm{zu}$ Gott stehen, wenn sie also in antiker philosophischer Sicht, wo man Gott denkt und nicht glaubt, zur höchsten kognitiven Leistung fähig sind, verwischt sich die Grenze zum Menschen noch mehr. Doch auch Aelian kennt einige wenige Beispiele für einen Bezug von Tieren zum Göttlichen: Kann man dies bereits als Hinweis darauf sehen, dass in den nicht mehr vorhandenen Materialsammlungen sich auch eine Rubrik „Tiere und Göttlichkeit“ fand? Wichtig an der philosophischen Diskussion ist, dass es den Philosophen dabei nicht um das Tierverhalten an sich ging, sondern dass Tierverhalten in Bezug auf etwas diskutiert wurde. Zwar lassen sich die Informationen über das Tier immer auch als Beschreibung möglichen Tierverhaltens lesen, oder als gute Geschichte darüber, wie auch beim Physiologus: Die Informationen über das Tier, die meist den Anfang der kurzen Kapitel bilden, lassen

40 Fitzenreiter (2013, Kapitel 5: Gesellschaft - Tierkulte und die soziale Dimension von Religion in der Spätzeit und in der griechischrömischen Zeit, 157-185, bes. 173-176). sich oft als Beobachtung des Tierverhaltens lesen. Doch dabei bleibt es nicht. Das Verhalten der Tiere interessiert die Philosophen insofern es auf etwas anderes verweist: ${ }^{41}$ Es verweist entweder darauf, dass Tiere Seele haben (so im Denken der Stoiker oder Peripatetiker) oder es verweist auf angeborene Rationalität (so bei Plutarch und Pyrrhon). Dieser Punkt ist wichtig, denn auch der Physiologus berichtet Tierverhalten nicht einfach aus Freude am Tier, sondern er deutet es als Hinweis auf etwas anderes, nämlich die Bibel. Aus dem Tierverhalten lässt sich gemäss Physiologus nun nicht ein Hinweis auf angeborene Rationalität lesen, also etwas, das die Menschen auszeichnet, sondern ein Hinweis auf die Bibel, auf eine Schrift. Das tertium comparationis ist der Verweischarakter des Tierverhaltens.

Dies finden wir auch im wenig bekannten Dialog Halkyone. Er zeigt im komplexen mehrfachen Verweischarakter des Tierverhaltens strukturelle Ähnlichkeiten mit dem Physiologus. Es ist ein hörbares Phänomen der Natur (der klagende Ruf des Vogels), der den Dialog und die Deutung in Gang setzt. Beim Physiologus sind es oft beobachtbare Phänomene der Natur (z. B. die Schlange, welche ihre alte Haut abstreift: Kap. 11, oder der Ibis, der im seichten Wasser watet: Kap. 40), welche den Ausgangspunkt der Deutung bilden. In der Halkyone verweist die Klage des Vogels auf einen Mythos, so wie beim Physiologus das Tierverhalten auf Bibelverse verweist. Der Mythos der Verwandlung der Halkyone in den Eisvogel bildet wiederum die Grundlage für das Nachdenken über die Möglichkeit einer Metamorphose an sich und über die Allmacht Gottes. Der gesamte Erzählkomplex (der klagende Vogel, die halkyonischen Tage, die Metamorphose) verweist auf etwas Weiteres, nämlich auf die Frage nach der Macht des Göttlichen. Dies möchte ich unter „mehrfachem Verweischarakter des Tierverhaltens" verstehen. So verweisen beim Physiologus, um auf das eingangs gewählte Beispiel zurückzukommen, verschiedene Aspekte des Panthers (Kap. 16) auf verschiedene Bibelstellen: die Buntheit (die Flecken des Panthers) verweisen auf Josephs bunten Rock (Gen 37,3), aber auch auf die Weisheit Gottes, wie er aus Psalm 45,10 herausliest, oder auch Christus, wie er aus Galater 5,22 liest. Das dreitägige Fasten der Raubkatze deutet er auf Karfreitag und Ostern und ganz allgemein deutet er die Information, der Panther sei ein Feind der Schlange, die in der Bibel seit Gen 3 einen schlechten Ruf hat.

Schliesslich lässt sich aus der Halkyone vielleicht ein Rückschluss auf das Bildungsmilieu des Schreibers zie-

41 Plutarch benutzt Verben dieser Bedeutung (De sollertia animalium 975B), Text in Anm. 33. 
hen: Der kurze Dialog, der ein sokratischer Dialog sein will (die Dialogpersonen sind Sokrates und Chairephon), macht den Fehler, Argumente aus der aporetischen Akademie (seit Arkesilaos im 3. Jh. v. Chr.) dem Sokrates in den Mund zu legen. Der Dialog dürfte wohl von keinem Berufsphilosophen stammen, sondern wohl eher von einem fortgeschrittenen Philosophie- oder Rhetorik-Schüler. Das heisst aber auch, dass Tierverhalten nicht nur von ausgebildeten Philosophen wie Plutarch oder Rednern wie Aelian behandelt wurde, sondern bereits im Unterricht. Der Autor des Physiologus hatte Zugang zu einem reichen Vorrat an Material, sowohl in Bezug auf Tierverhalten, als auch was Bibelbücher und ihre Deutung angeht und den Verweischarakter des Tierverhaltens mag er bereits im Unterricht eingeübt haben.

Die weite Verbreitung von Tiergeschichten in unterschiedlichen Genera in der Kaiserzeit, ${ }^{42}$ der im philosophischen Diskurs bereits etablierte Verweischarakter des Tierverhaltens, der bereits in der Ausbildung gelehrt wurde, und Ägypten mit seinen Tierkulten bilden den passenden Hintergrund für ein Werk wie den Physiologus.

\section{Bibliographie}

Alexandridis, Annetta, Markus Wild und Lorenz Winkler-Horacek, Hgg. 2008. Mensch und Tier in der Antike: Grenzziehung und Grenzüberschreitung. Wiesbaden: Reichert Verlag.

Barnes, Jonathan. 1990. „Pyrrhonism, Belief and Causation: Observations on the Scepticism of Sextus Empiricus." ANRW 36.4:2608-2695.

Beckby, Hermann, Hg. 1966. Anthologia Graeca: Buch I-VI. München: Heimeran-Verlag.

Bouffartigue, Jean, Hg. 2012. Plutarque: Oeuvres morales; Traité 63: L'intelligence des animaux. Paris: Les belles lettres.

Brodersen, Kai, Hg. 2002. Phlegon von Tralleis: Das Buch der Wunder und Zeugnisse seiner Wirkungsgeschichte. Darmstadt: Wissenschaftliche Buchgesellschaft.

Dodds, Eric Robertson. 1985. Heiden und Christen in einem Zeitalter der Angst: Aspekte religiöser Erfahrung von Mark Aurel bis Konstantin. Frankfurt a. M.: Suhrkamp.

Fitzenreiter, Martin. 2013. Tierkulte im pharaonischen Ägypten. Ägyptologie und Kulturwissenschaft 5. München: Wilhelm Fink.

Flashar, Hellmut, und Ulrich Klein, Hgg. 1972 [2009]. Aristoteles: Opuscula II und III; Mirabilia und De audibilibus. Aristoteles Werke in deutscher Übersetzung 18.2-3. Berlin: AkademieVerlag [De Gruyter].

Hossenfelder, Malte, Hg. 1985. Sextus Empiricus: Grundriss der pyrrhonischen Skepsis. Frankfurt a. M.: Suhrkamp.

42 Auf eine Gattung bin ich nicht eingegangen: die Fabeln. Diese fanden in der Kaiserzeit mit Babrius einen Vertreter.
Klauck, Hans-Josef, und Balbina Bäbler, Hgg. 2000. Dion von Prusa: Olympische Rede. SAPERE 2. Darmstadt: Wissenschaftliche Buchgesellschaft.

König, Roderich, und Gerhard Winkler, Hgg. (1976) ${ }^{2} 2007$. C. Plinius Secundus d. Ältere: Naturkunde / Naturalis historia libri XXXVII; Lateinisch-deutsch; Buch VIII; Zoologie: Landtiere. (München: Heimeran-Verlag) Düsseldorf: Artemis \& Winkler.

König, Roderich, und Gerhard Winkler, Hgg. (1986) ${ }^{2}$ 2007. C. Plinius Secundus d. Ältere: Naturkunde / Naturalis historia libri XXXVII; Lateinisch-deutsch; Buch X; Zoologie: Vögel; Weitere Einzelheiten aus dem Tierreich. (München: Artemis) Düsseldorf: Artemis $\&$ Winkler.

Long, Anthony A., und David N. Sedley, Hgg. 1987. The Hellenistic Philosophers. Bd. 1, Translations of the Principal Sources With Philosophical Commentary. Cambridge: Cambridge University Press.

Naas, Valérie. 2002. Le projet encyclopédique de Pline l'ancien. Rom: Collection de l'école française de Rome.

Newmyer, Stephen T. 2008. „The Human Soul and the Animal Soul: Stoic Theory and Its Survival in Contractualist Ethics.“ In Mensch und Tier in der Antike: Grenzziehung und Grenzüberschreitung, hrsg. v. Annetta Alexandridis, Markus Wild und Lorenz Winkler-Horacek, 71-80. Wiesbaden: Reichert Verlag.

Newmyer, Stephen T. 2014. „Animals in Plutarch.“ In A Companion to Plutarch, hrsg. v. Mark Beck, 223-234. Malden, MA: WileyBlackwell.

Schönberger, Otto. (2001) 2014. Physiologus: Griechisch/Deutsch. Stuttgart: Reclam.

Sorabji, Richard. (1993) 1995. Animal Minds and Human Morals: The Origins of the Western Debate. Ithaca, NY: Cornell University Press.

Steiner, Gary. 2008. „Das Tier bei Aristoteles und den Stoikern: Evolution eines kosmischen Prinzips." In Mensch und Tier in der Antike: Grenzziehung und Grenzüberschreitung, hrsg. v. Annetta Alexandridis, Markus Wild und Lorenz Winkler-Horacek, 27-46. Wiesbaden: Reichert Verlag.

Strohm, Hans, Hg. 1973. Aristoteles: Über die Welt. Berlin: Akademie-Verlag.

Terian, Abraham, Hg. 1981. Philonis Alexandrini De animalibus: The Armenian Text with an Introduction, Translation, and Commentary. Chico, CA: Scholars Press.

Theiler, Willy, Hg. 1983. Aristoteles: Über die Seele. Berlin: Akademie-Verlag.

Treu, Ursula, und Kurt Treu, Hgg. 1978. Älian: Die tanzenden Pferde von Sybaris; Tiergeschichten. Leipzig: Reclam.

Wildberger, Jula. 2008. „Beast or God? - The Intermediate Status of Humans and the Physical Basis of the Stoic scala naturae." In Mensch und Tier in der Antike: Grenzziehung und Grenzüberschreitung, hrsg. v. Annetta Alexandridis, Markus Wild und Lorenz Winkler-Horacek, 47-70. Wiesbaden: Reichert Verlag.

Wildberger, Jula. 2006. Seneca und die Stoa: Der Platz des Menschen in der Welt. Berlin: De Gruyter.

Wyss, Beatrice. 2017. „Gott denken oder Gott glauben: Zur Rolle der míotıs in den Stromateis des Klemens.“ In Glaube: Das Verständnis des Glaubens im frühen Christentum und in seiner jüdischen und hellenistisch-römischen Umwelt. WUNT 373, hrsg. v. Jörg Frey, Benjamin Schliesser und Nadine Ueberschaer, 721-751. Tübingen: Mohr Siebeck.

Wyss, Beatrice. 2018. „Philon aus Alexandreia und der fünfte Tag der Schöpfung.“ EC 4.9:379-403. 



\section{Marco Stroppa \\ The Physiologus and the Papyri from Egypt}

Abstract: Among papyri from Egypt, three pieces stand out in connection with the Physiologus. First, a fragment from a vertical roll written in Greek in the $6^{\text {th }}$ century CE, which was published in 2011, and is now located in Florence (PSI XVI 1577). Second, a fragment of a paper notebook written in Coptic from the $10^{\text {th }}$ century CE, which was published in 1895 and is now located in Berlin (P.Berol. inv. 7999). Both are direct testimonies of the text. The third papyrus is the so-called 'Artemidorus Papyrus', which on one side, the verso, shows a series of drawings of animals with legends. These papyri show both directly and indirectly the distribution and influence of the Physiologus, which evidently spanned centuries and cultures.

\section{Introduction}

During archaeological digs, fragments of ancient books and documents have emerged from the Egyptian soil, together with a great number of testimonies from the past. A lot of these texts are written in Greek because for around 1,000 years, from the $3^{\text {rd }}$ century BCE to the $7^{\text {th }}$ century $\mathrm{CE}$, Greek was the language of culture and administration in Egypt. Therefore, there are tens of thousands of fragments, some very small, which belonged to literary texts and offer a vast range of information on the Greek language and literature. From the $3^{\text {rd }}$ century CE on, Coptic began to spread and so books and documents written in this language were produced too.

Some testimonies of literature on animals can also be found among the papyri from Egypt: treatises on zoology, above all by Aristotle, ${ }^{1}$ or papyri which contain quotes taken from Aristotle's works, in particular commentaries and lexica. Then there are also some isolated testimonies, such as a Latin-Greek glossary with names of animals and a text on the Egyptian gods and their theriomorphic forms, preserved among the Lund papyri (the first is P.Lund inv. $5=\mathrm{MP}^{3} 3004$ and the second is P.Lund III 10).

Among them, three pieces from Egypt are related to the Physiologus: a fragment from a vertical roll written in Greek (PSI XVI 1577), a fragment of a paper notebook written in Coptic (P.Berol. inv. 7999); ${ }^{2}$ and thirdly, a very

1 Cf. H. Görgemanns in this volume, pp. 19-20.

2 Edited by Erman (1895).

Note: The present contribution is partly based on my paper in Reinardus (Stroppa 2016). famous roll, the so-called 'Artemidorus Papyrus'. ${ }^{3}$ One of the two sides of it, the verso, shows a series of drawings of animals, each one accompanied by a legend; a sort of title, "Beasts that live in the Ocean, that fly and walk, and sea monsters", according to the text reconstructed in the editio princeps, ${ }^{4}$ seems to introduce them. It was probably produced before the Physiologus itself, but it is a bestiary in a broader sense and it is worthwhile to compare some of its drawings of animals to the descriptions of them in the Physiologus.

The exact place of provenance is known for just one of the three pieces, the Berlin paper: it was found at Tebtynis in the Fayum.

\section{PSI XVI 1577: the Florentine papyrus fragment}

A small fragment of a papyrus written in Greek (Fig. 1), housed in Florence in the collection of the "Girolamo Vitelli” Papyrological Institute under inventory number 295 , came to light a few years ago. ${ }^{5}$ The fragment was recently published as PSI XVI 1577. It is the oldest testimony of the Physiologus dating from around the $6^{\text {th }}$ century CE.

It is a fragment measuring $8 \times 12$ centimetres and is torn on all sides. The back is blank. Fourteen lines are partially conserved:

3 Editio princeps: Gallazzi, Kramer, and Settis (2008); the bibliography is very large, a selected one is available on the CEDOPAL website (http://web.philo.ulg.ac.be/cedopal/) in the $\mathrm{MP}^{3}$ database, number 168.020.

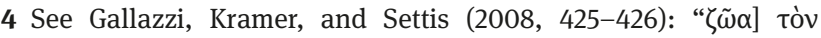

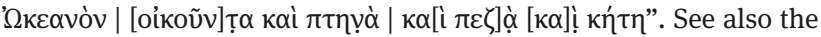

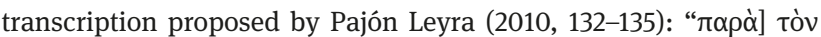

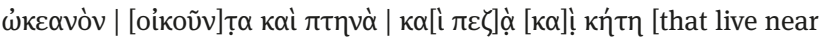
the Ocean, that fly, that walk and sea monsters]". Cf. the synoptic lists in Kraus, pp. 65-67 in this volume.

5 See Stroppa (2011, 173-92). 


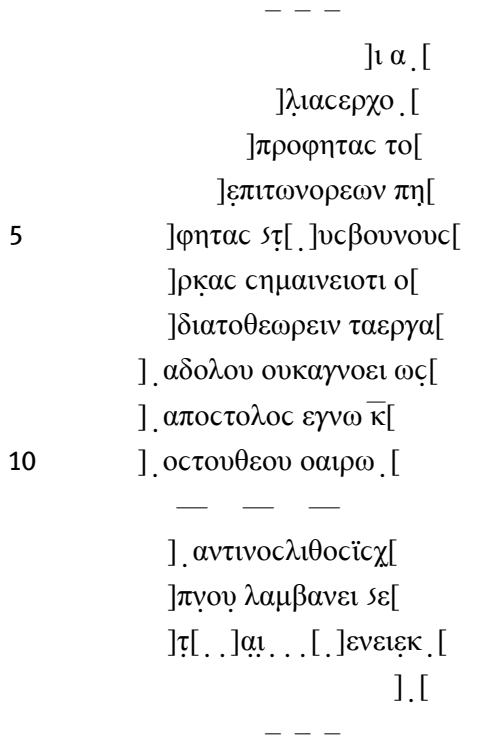

These letters belong to two different chapters: the first 10 lines to ch. 41 On the gazelle, the last 4 lines to ch. 42 On the powerful adamantine stone. The identity of the contents of the papyrus is certain, thanks to the comparison with the text of the Physiologus published by Francesco Sbordone. ${ }^{6}$

The papyrus text is similar to the redactio prima text, the oldest one, which is composed of five classes (although none of them is exactly represented in PSI XVI 1577). ${ }^{7}$ Furthermore, the papyrus text evidences the existence of other variants. It is useful also to compare it with the texts of ancient redactions of the Physiologus in Coptic, Amharic, Armenian, Arabic, Syriac, and the Latin versions too. Chapters 41 and 42 are both included in the following redactions: Latin (gazelle: ch. 21; powerful adamantine stone: ch. 24), Amharic (gazelle: ch. 42; powerful adamantine stone: ch. 43), Syriac (gazelle: ch. 18; powerful adamantine stone: ch. 66). These redactions are sometimes accurate translations of the Greek, but sometimes are full of new elements.

Relying on the mentioned texts it is possible to present a reconstruction of the original text of the papyrus: the length of a line is from 50 to 60 letters long. In particu-

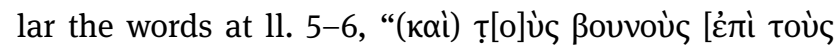

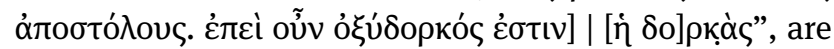
almost perfectly the same in all medieval manuscripts (cf. Sbordone's apparatus ad locum).

Relying on the letters in 1.11 - the beginning of ch. $42-$ it is also possible to suppose that 2-3 letters only are lost on the left and 35-40 on the right: each line should be $27 \mathrm{~cm}$ long and the artefact should have a width of $30 \mathrm{~cm}$.

Here is the complete text of ch. 41 and ch. 42 that is considered to have been written on PSI XVI 1577: I suppose that kai was always written with an abbreviation sign (s) as in 11.5 and 12 and that nomina sacra were regularly written

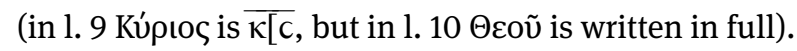

The first two lines and the last two lines are completely lost.

\subsection{Text}

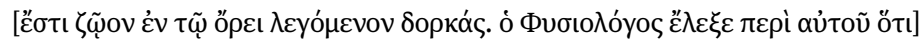

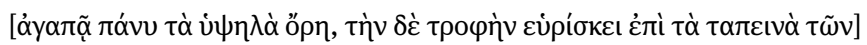

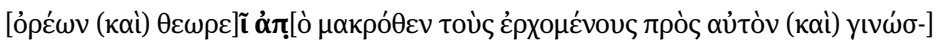

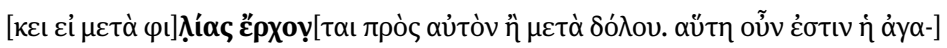

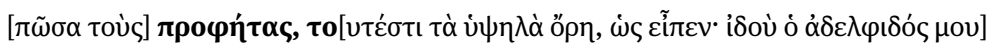

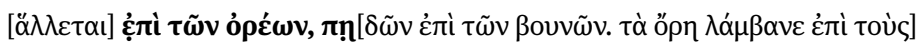

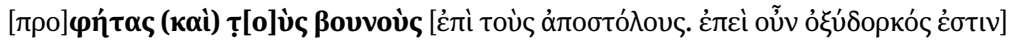

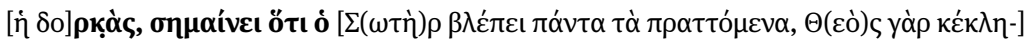

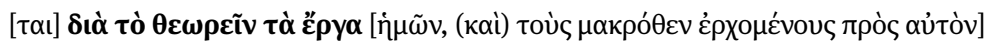

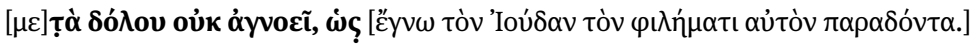

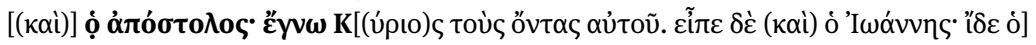

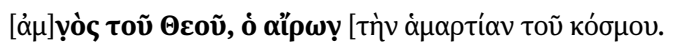
(vac.)

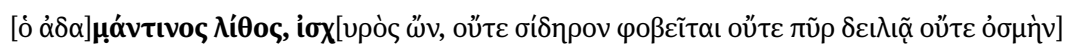

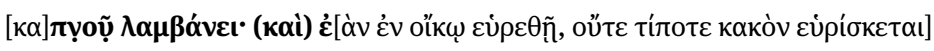

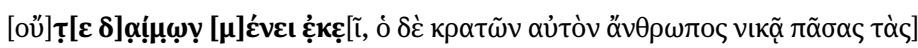

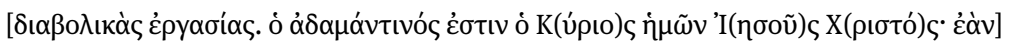

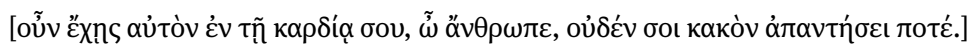

6 See Sbordone (1936a, 125-127).

7 Cf. H. Schneider in this volume, page 5. 


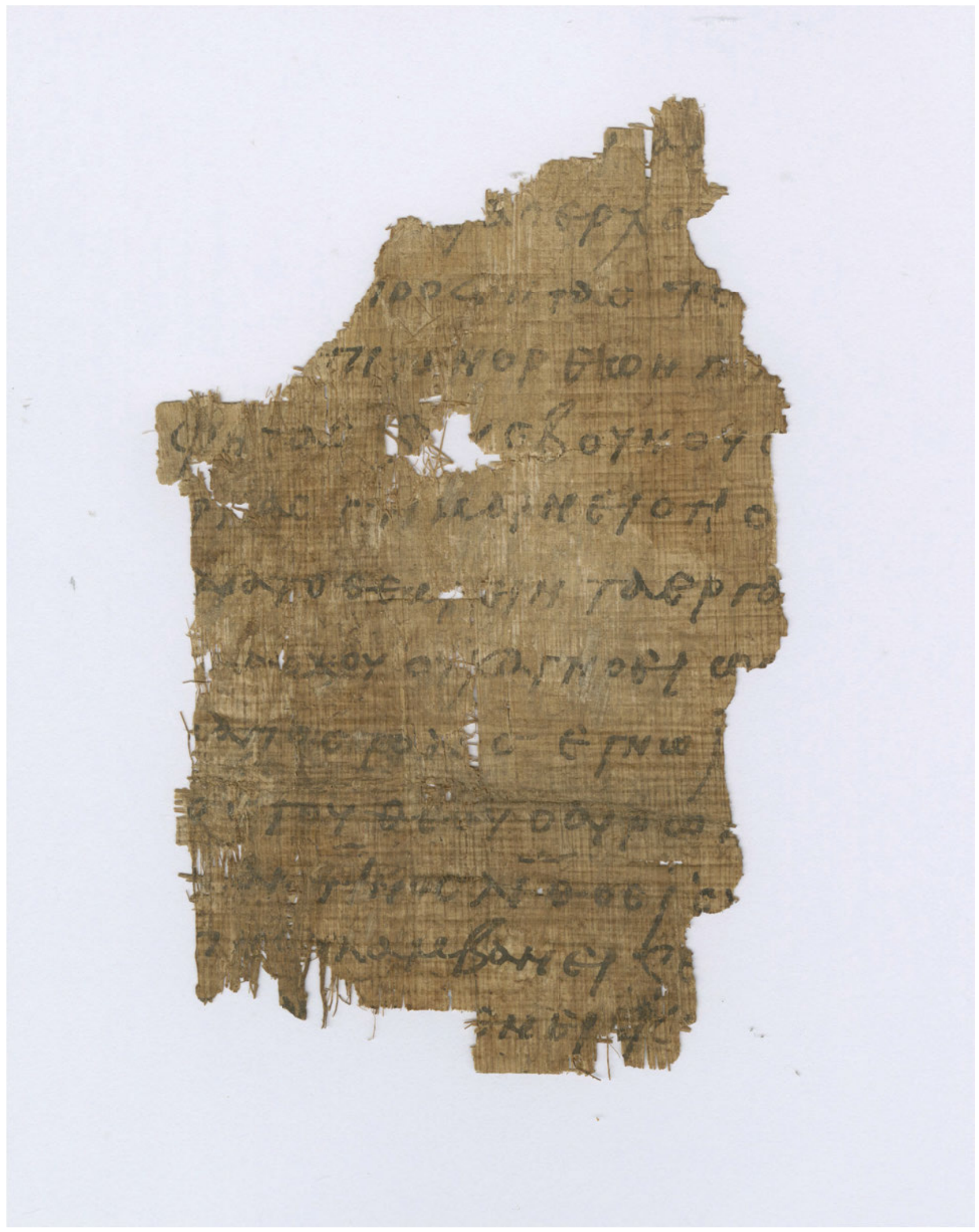

Fig. 1: PSI XVI 1577 (@ Istituto Papirologico “G. Vitelli”, Università degli Studi di Firenze). 


\subsection{Translation and commentary}

41. ON THE GAZELLE

There is on the mountains an animal called a gazelle. The physiologus told about it that it loves highest mountains very much, it finds nourishment in the valleys and it sees from afar who comes to it and it knows if he comes to it in a friendly manner, or with hostility. So it loves the prophets, namely the mountains, as it says: "my lover - here he comes springing across the mountains, leaping across the hills". Compare the mountains to the prophets and the hills to the apostles. Since therefore the gazelle has a sharp sight, it means that the Saviour sees every action (he is called God [ $\theta \varepsilon$ ó $]$ because he sees [ $\theta \varepsilon \omega \rho \varepsilon \tilde{]}]$ what we do) and he does not ignore who comes from afar to him with hostility, as he knew Judas would betray him with a kiss. The apostle assures: "The Lord knows those who are his". Also, John says: "Behold, the Lamb of God, who takes away the sin of the world”.

\section{ON THE POWERFUL ADAMANTINE STONE}

The adamantine stone, which is powerful, does not fear the iron, nor is afraid of fire, nor takes the smell of the smoke; and if it is found in a house, no evil ever is found, nor a bad spirit will be there. The man who owns it defeats all the diabolical works. The Adamantine is our Lord Jesus Christ; if therefore you have him in your heart, man, no evil will ever occur to you.

The text can be divided into six sections (A-F): for each one I will underline the news that the papyrus text gives.

Section A (1l. 1-2): the nature of the gazelle. In 1. 2,

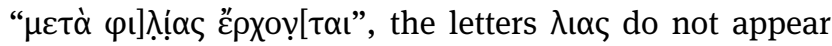
in any manuscript before the verb है $\rho \chi 0 \mu \alpha$. The string of words is present only in the papyrus and probably the reference to the friendship was put before the reference to the deceit, as it is in the whole of the manuscript tradition.

Section B (1l. 3-4): the quotation from the Song of

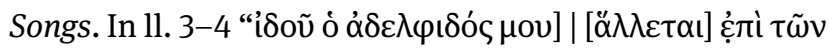

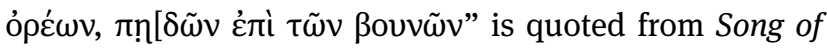
Songs 2:8-9. In all the manuscript tradition of the Physiologus the sentence is never written exactly as it is in the

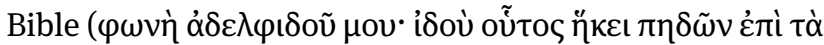

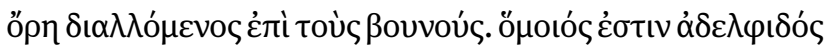

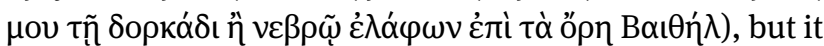
is probably a quotation known by heart. There is no place

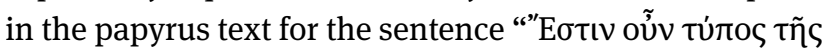

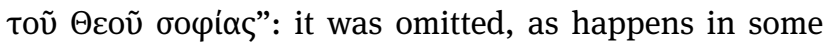
manuscripts. ${ }^{8}$

Section C (1l. 4-5): the comparisons of mountains with prophets and of hills with apostles. In 11.4-5 the sen-

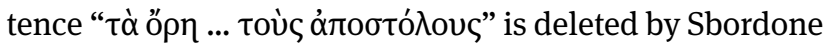
$(1936 a, 126)$ because it is lacking in some manuscripts, but it is undoubtedly present in the papyrus. The sign $s$ for $\kappa \alpha \mathrm{t}$ (see also 1.12) is very common in late antique documents and in Christian texts used for liturgy, for example P.Amst. I 21, 5 (Psalm 47) and PSI I 65, 9 (prayer).

Section D (ll. 6-8): the gazelle as symbol of the Saviour. In $1.6 \delta 0$ ] $\rho \kappa \alpha ́$ ' is the form of the animal's name: other

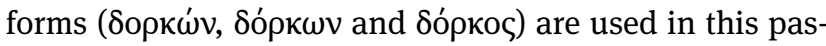

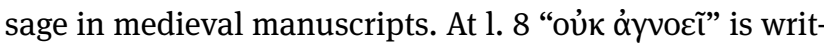
ten only in the papyrus; this expression is more refined

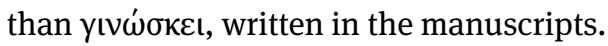

Section E (1l. 9-10): the quotations from David/Paul

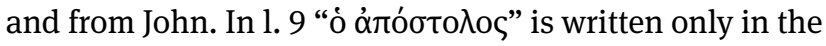
papyrus; in the manuscripts it is oddly written "ó $\Delta \alpha v^{\prime} \delta$ ".

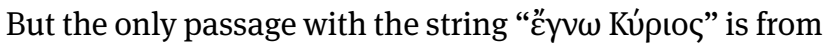

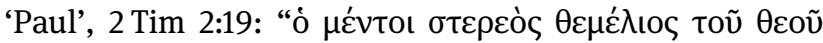

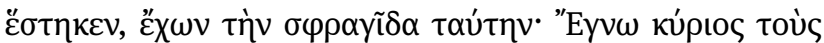

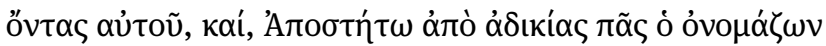

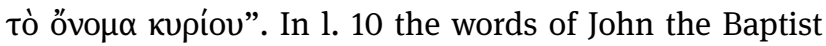

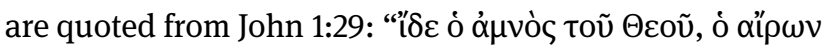

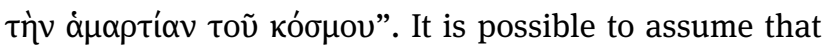

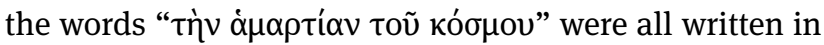
1. 10 and that the end of the line was blank. Three strokes appear under 1. 10. Their aim is to distinguish the end of ch. 41 from the beginning of ch. 42 .

Section F (1l. 11-13): the powerful adamantine stone.

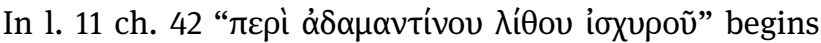

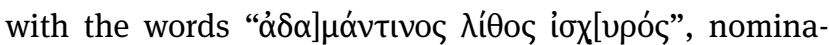

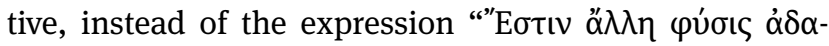

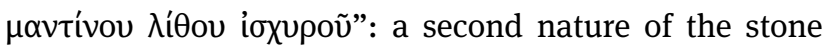
was not mentioned in the papyrus, but it is found in the

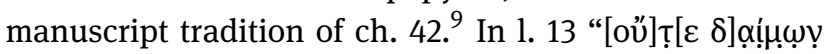

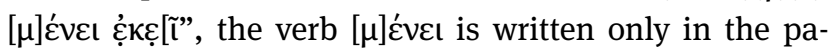

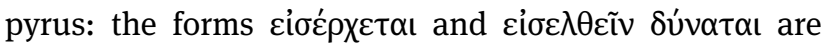
used in the manuscript tradition.

\subsection{The format of the artefact and its purpose}

In addition to the contents, what is also interesting about the Florentine fragment is its format. Even though it is not possible to determine if other chapters preceded or followed those preserved in the papyrus, or how long the text was - it may have occupied a roll or a sheet of varying lengths - it is nevertheless very likely that chapters 41 and 42 were copied in full. In the most important manuscripts, these chapters are set out consecutively and it is therefore most likely that other chapters also preceded or followed 
those directly attested. ${ }^{10}$ Therefore, the fragment of papyrus does not seem to come from an isolated sheet: we might expect a single chapter to perhaps be copied by itself. Two chapters, one after another, in the same order as they appear in the actual books of the following period, makes one think that there were also other chapters, even if not necessarily all of them.

The original format must therefore have been a rotulus, that is, a volumen written and used vertically. This custom seems to be taken from the administrative use to write letters, agreements and other documents transversa charta, from the Ptolemaic times on to the Roman times, and in particular in the $5^{\text {th }}$ and $6^{\text {th }}$ centuries CE. ${ }^{11}$ A new urge to copy Christian paraliterary texts on rotuli could maybe also be linked to the custom of the patriarchate of Alexandria, which sent a festal letter every year to each bishop and to each monastery to let them know the date of Easter and related feasts. Among the original documents only the $6^{\text {th }}$ century CE one is transvers a charta. ${ }^{12}$

Other fragments exist that can be attributed to written texts with similar characteristics to those of the PSI of the Physiologus, that is, written transversa charta, on rotuli probably used in gatherings, and dating from around the same period of the $6^{\text {th }} / 7^{\text {th }}$ centuries CE in Egypt. Some examples are PSI XV 1453, Basil of Seleucia, Oratio 22 and P.Col. VIII 192, Discourse 4 of the Asceticon by Abba Isaiah. ${ }^{13}$ The comparative analysis of all the rolls used vertically shows that they probably served a "public" use and the texts that contain homilies, acts of martyrs and prayers can quite rightly be deemed to have been used during catechesis. A work like the Physiologus (or extracts from it) could also fall into this category, as it definitely contains edifying teachings for a monk (and for a Christian in general) ${ }^{14}$ Probably the communal reading of such a text was not foreseen within the liturgical celebrations, rather in moments of spiritual formation, precisely such as catechesis. There are no doubts as to the centrality of the Scriptures in the liturgy and on the importance of catechesis in the monks' lives in the monasteries, as can be seen from numerous sources, such as the texts of Paul of Tamma, author of monastic exhortations in Coptic. ${ }^{15}$ Furthermore, in the Bohairic Life of Pachomius it says that catechesis was

10 See Stroppa (2012, 722-723) for a detailed description of the testimony given by the medieval codices.

11 See Fournet (2007, 353-367) for many examples in Dioscorus' archive.

12 See Stroppa (2013, 350-351) for the details.

13 See Stroppa (2013, 347-351) for a list of such papyri.

14 See Lazaris $(2016,119)$.

15 See Orlandi (1997). held three times per week, by the superior or the head of the monastery. ${ }^{16}$

\section{P.Berol. inv. 7999: the Coptic paper}

The Greek text of the Physiologus was translated into Coptic in the $5^{\text {th }}$ century CE and found wide circulation in the following centuries. At the present time, no complete manuscript of the Physiologus exists in Coptic, but there are fragments, clues and quotations that make us suppose that more than one translation was made in various dialects and at different times. ${ }^{17}$ That the Physiologus was translated into Coptic seems inevitable (one should be amazed if it were not the case) considering the origin, character and success of the work: ${ }^{18}$ the complete text of the Coptic Physiologus ${ }^{19}$ was most probably widespread in Egypt from beginning of the $6^{\text {th }}$ century, in particular in the monasteries, where the original Greek version nevertheless also circulated. ${ }^{20}$

The only direct testimony of the Coptic text of the Physiologus is as late as the $10^{\text {th }}$ century CE and turns out to be P.Berol. inv. 7999 (Fig. 2). It consists of three sheets (six pages) of a paper notebook. This is a brief and puzzling copy: page 2 is written on a separate sheet (and its back, that is page 6 , is blank); pages 3, 4 and 5 are written on the same bifolium of page 1, but upside down; page 5 is only partially written and 3 lines are deleted by strokes. Each complete page contains 20 lines of text. ${ }^{21}$ It contains the description of an animal (a bird?) called an alloe. Nevertheless, this animal is not to be found in any redaction of the Greek Physiologus; therefore, it is probably an original contribution by the Copts; furthermore, for the part on the alloe, this late testimony is accompanied by various testimonies in different dialects, which nevertheless display a partly different text. ${ }^{22}$ This chapter on the alloe is followed by one on the caladrius - the same as ch. 3

16 See Sheridan (1997, 211-215) on the Pachomian monasteries and catechesis.

17 See Kühner $(1985,144)$ and see also Suciu (forthcoming).

18 See Suciu (2014, 677-689).

19 See van Lantschoot (1950, 339-363) for the testimonies of a Coptic text of the Physiologus.

20 See Crum and Evelyn White $(1926,196)$ for the diffusion of Coptic in the monastery of Epiphanius at Thebes.

21 One whole page of P.Berol. inv. 7999 corresponds to around $1 / 4$ of the text published by Adolf Erman.

22 See van Lantschoot (1950, 346, note 6). 

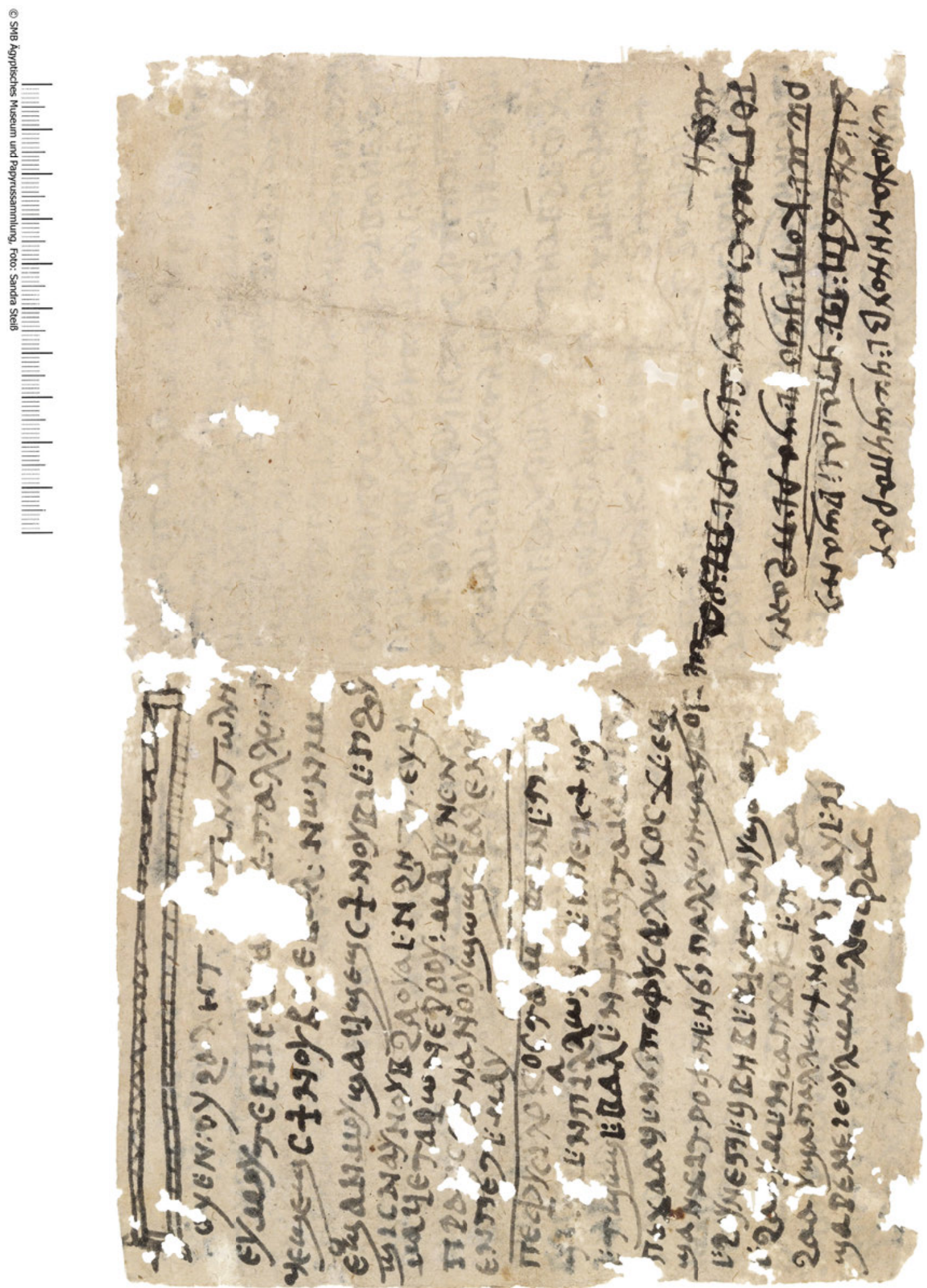

Fig. 2: P.Berol. inv. 7999, pages 1 and 5. Ägyptisches Museum und Papyrussammlung, Staatliche Museen zu Berlin, SPK. Photo: Sandra Steiss (৫ Ägyptisches Museum und Papyrussammlung, Staatliche Museen zu Berlin, SPK). 
in Greek - which is not complete; the writer did not finish copying the chapter, hence we deal with the only fragment that belongs to the Physiologus.

\section{The Artemidorus Papyrus}

Especially interesting in connection with the Physiologus Bernensis, the well known illuminated manuscript, because of its drawings is a third papyrus: the Artemidorus Papyrus. Evidently this third papyrus is not a fragment of the Physiologus, as the previous ones were. It is definitely not possible to establish a direct link between the Artemidorus Papyrus and the Physiologus: the author of the Physiologus (even if he lived in the $2^{\text {nd }}$ century $\left.\mathrm{CE}\right)^{23}$ surely and obviously did not have the Artemidorus Papyrus to hand (its verso was probably used in the $1^{\text {st }}$ century CE). ${ }^{24}$ However, it is possible to propose a comparison between the two catalogues in general, by setting out some data, though big differences between them remain: the Artemidorus Papyrus consists of drawings accompanied by legends and is a very precise object, unique; otherwise the Physiologus counts as a literary work and his text is known through around eighty medieval manuscripts (only for the Greek text), ${ }^{25}$ in addition to the Florentine papyrus from the $6^{\text {th }}$ century CE.

The possible point of contact can be sought generally in cultural expressions in Egypt, maybe in Alexandria in particular. It is to this milieu that in some way we can retrace the production of the Artemidorus Papyrus and then the production of the Physiologus. For this reason it is worthwhile to take a closer look at which animals appear both in the Physiologus and in the Artemidorus Papyrus, where a name is written alongside every drawing, ${ }^{26}$ enabling a direct comparison to be made. In actual fact there are five possible cases for comparison between an animal described in the Physiologus and the legends of the drawings on the verso of the Artemidorus Papyrus: the elephant, panther, pelican, beaver and sawfish.

For at least two of them, the elephant and the panther, we have some kind of traditional representation of

23 See Lazaris (2016, 17-30) for the dating.

24 About the "forgery discussion", cf. Elsner (2012) and the clear words by one of the more distinguished papyrologists, Jean-Luc Fournet (2018, 276); see P.Oxy. LXXXIII 5402 and 5403 for recently published drawings from Oxyrhynchus: they now demonstrate comparable technique and similar subject matter in papyri of undoubted authenticity.

25 Cf. H. Schneider in this volume, page 5, note 2.

26 See Montanari and Muratore (2009, 132-138) for the legends. their hostility towards the snake, common to this papyrus and the Physiologus. Therefore, some traditional motifs present in various literary sources and previous iconographies - and amongst these we can count the Artemidorus Papyrus - are taken up again and used in the Physiologus. $^{27}$

\subsection{Elephant}

The scene V16 (Fig. 3) in the papyrus is slightly damaged

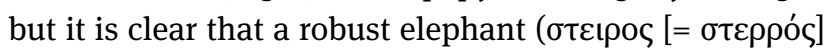

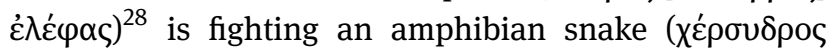
ö $\varphi$ เ), as the legend says, that is wrapped around the body of the pachyderm as it stands on its two back legs. This hostility is also mentioned in the Physiologus: in ch. 43

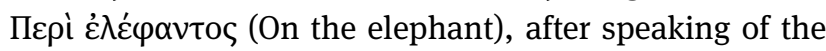
elephants' mating, it says that the serpent (ö $\varphi$ ı) is the elephant's enemy, and when the elephant finds it, it stamps on the serpent and kills it.

\subsection{Panther}

The panther ( $\pi \alpha \dot{v} \theta \eta \rho)$ appearing in the drawing V25 (Fig. 4) is also fighting against a snake ( $\delta \rho \alpha ́ k \omega v)$, as can clearly be read in the legend. In the Physiologus, ch. 16 Пврі

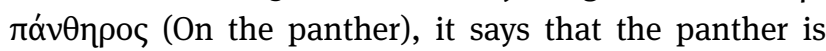
the friend of all animals, except the dragon; it is colourful, pretty and gentle, it gives forth a sweet perfume from the mouth and attracts the other wild beasts.

\subsection{Pelican}

In this example nothing except the name seems to link the animal drawn in the papyrus to the one in the Physiologus, but it is sure that the animal is the same: the pelican. The drawing V41 (Fig. 5) on the papyrus is a bird called

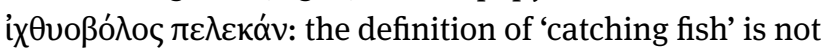
deemed useful in the view of the Physiologus, ch. 4 Пврі $\pi \varepsilon \lambda \varepsilon \kappa \alpha$ óvov (On the pelican), where it says that the pelican loves its children very much, but when they are grown, the children violently attack their parents who in turn kill them. After crying over the death of her children for three days, the mother strikes her side and her blood covers the dead children, bringing them back to life. There is no men-

27 See Stroppa (2016, 172-185) for further details. 28 See Gallazzi, Kramer, and Settis (2008, 374-375) for a possible "sterile" elephant. 
tion of the physical characteristics of the animal and the nature of the pelican described in the chapter is almost entirely a creation of the Physiologus. ${ }^{29}$

In further two examples, the beaver and the sawfish, the name is the same in the papyrus and in the Physiologus, but it is not clear what kind of animal it is.

\subsection{Beaver}

First of all it must be pointed out that the drawing V6 (Fig. 6) in the papyrus does not look like a beaver, as has been underlined by several parties. Nevertheless, there is

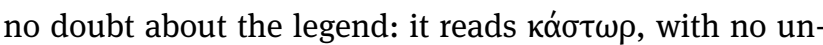

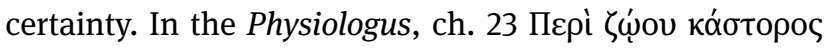
(On the beaver animal), the description of the animal's nature essentially concerns its behaviour towards hunters: hunters look for beavers for their testicles and, once they have been removed, the beaver lies on its back to show its privation to the hunters who are going away as the prey is no longer of any interest to them. In reality, the beaver is a problematic case in itself, because it is not an animal that lived in Egypt and therefore it appears particularly exotic and mysterious for those who lived in this country: practically no one had ever seen one in the flesh. ${ }^{30}$ Neither the author of the drawing in the papyrus nor even the author of the Physiologus had even seen a real beaver or had any idea of what one looked like. Therefore, the animal that we call a beaver does not appear to correspond either to the animal in the papyrus, or to the one in the Physiologus.

\subsection{Sawfish}

In this example it is again not absolutely clear what type of fish we are dealing with. Drawing V10 (Fig. 7) in the papyrus shows a fish with a saw's teeth on its tail; in this case, it could be a fish invented on the basis of the name. ${ }^{31}$ The caption on the papyrus is the oldest testimony of the term $\pi \rho i \omega v$, and the only other attestation of a fish of that

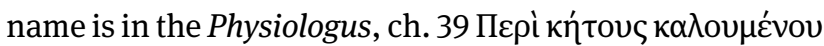
$\pi$ píovos (On the sea monster called saw). The only element

29 See Zambon $(1975,90)$.

30 See Bastianini $(2004,157-161)$ on testimonies of the term kóo $\tau \omega \rho$. 31 See Gallazzi, Kramer, and Settis (2008, 356-357). In this case, in my opinion it is impossible to try to identify it as a real animal. Indeed, Kinzelbach $(2009,35-36)$ proposes, perhaps taking it too far, that he sees a fish drawn on the papyrus as if observed from above and therefore conjectures that it is a type of ray fish (raja clavata). But in the papyrus there is no other fish seen from above and, nevertheless, in this case the side fins would be asymmetrical. describing the animal is the note that it has large fins that enable it to race against ships. In this case, we have an animal, the sawfish, which takes on the shape of a mythological animal, a process already begun in the earlier papyrus.

\subsection{Other animals}

These five animals - elephant, panther, pelican, beaver and sawfish - are the ones having an exact correspondence between the legend in the papyrus and title of the chapter of the Physiologus. Comparisons with other animals are nevertheless possible, for example, by taking the drawing as a starting point; however, in all these last examples the links are somehow very (perhaps too) complex. For example, the wild goat can be mentioned.

In the papyrus there is an olyoypos, that is, a wild goat (V38, Fig. 8), a кpı́óp $\omega v$, that is a wild ram (V4, Fig. 10),

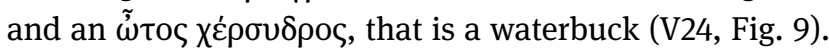
In the Physiologus in Greek, no animal appears with these names; nevertheless the animals in these three drawings

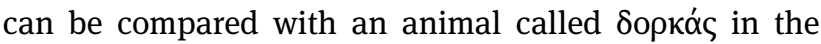

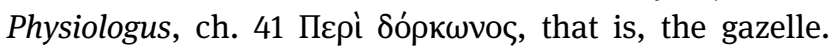
The Greek name סоркós is also translated as caprea (wild goat) in some Latin versions of the Physiologus. ${ }^{32}$ In this case, what appears to be a similar (the same?) animal has a different name in the papyrus and in the treatise (in the Greek language at least).

Furthermore, in the papyrus the drawing V22 depicts a $\mu v \dot{\rho} \mu \eta \xi$ fighting a snake: it is a sort of winged lion. In the Physiologus instead there appears a myrmecoleon in ch. 20

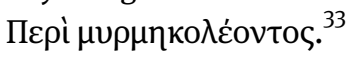

\section{Conclusion}

In recent studies Egypt is considered the place of origin of the Physiologus and this country is also the place where papyri were produced. ${ }^{34}$ They give evidence directly and indirectly for the spread and success of such a treatise which would have lasted across many centuries and cultures. ${ }^{35}$

32 For the variants of this word see Stroppa (2012, 723-724). 33 This animal has a very complicated story, hence I'll refer to the recent analysis by Moretti (2012, 581-596).

34 See Lazaris (2016, 31-36). 35 See Zucker ( $\left.{ }^{2} 2005,28-31\right)$. 


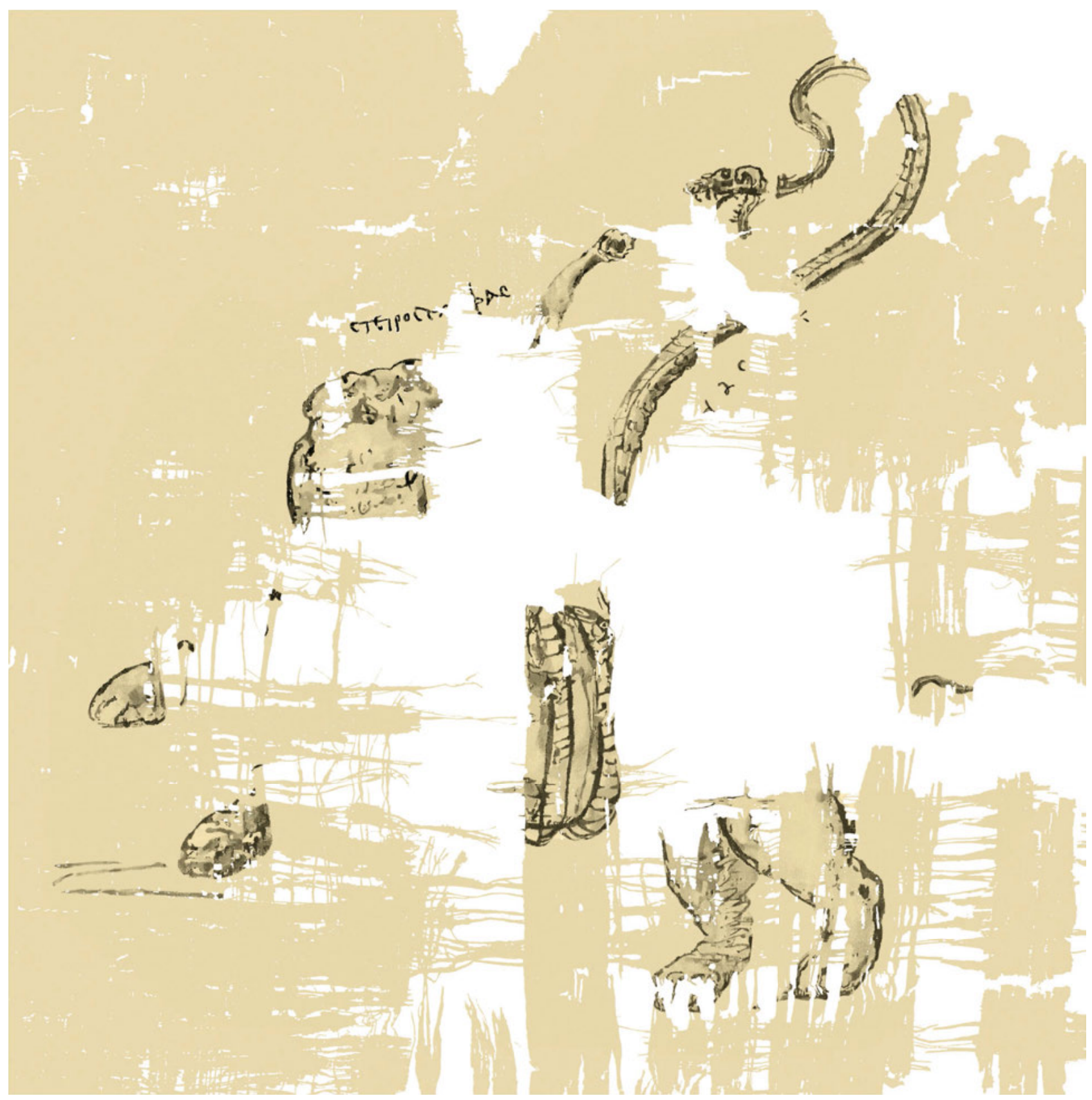

Fig. 3: P.Artemid. V16 (@ LED). 


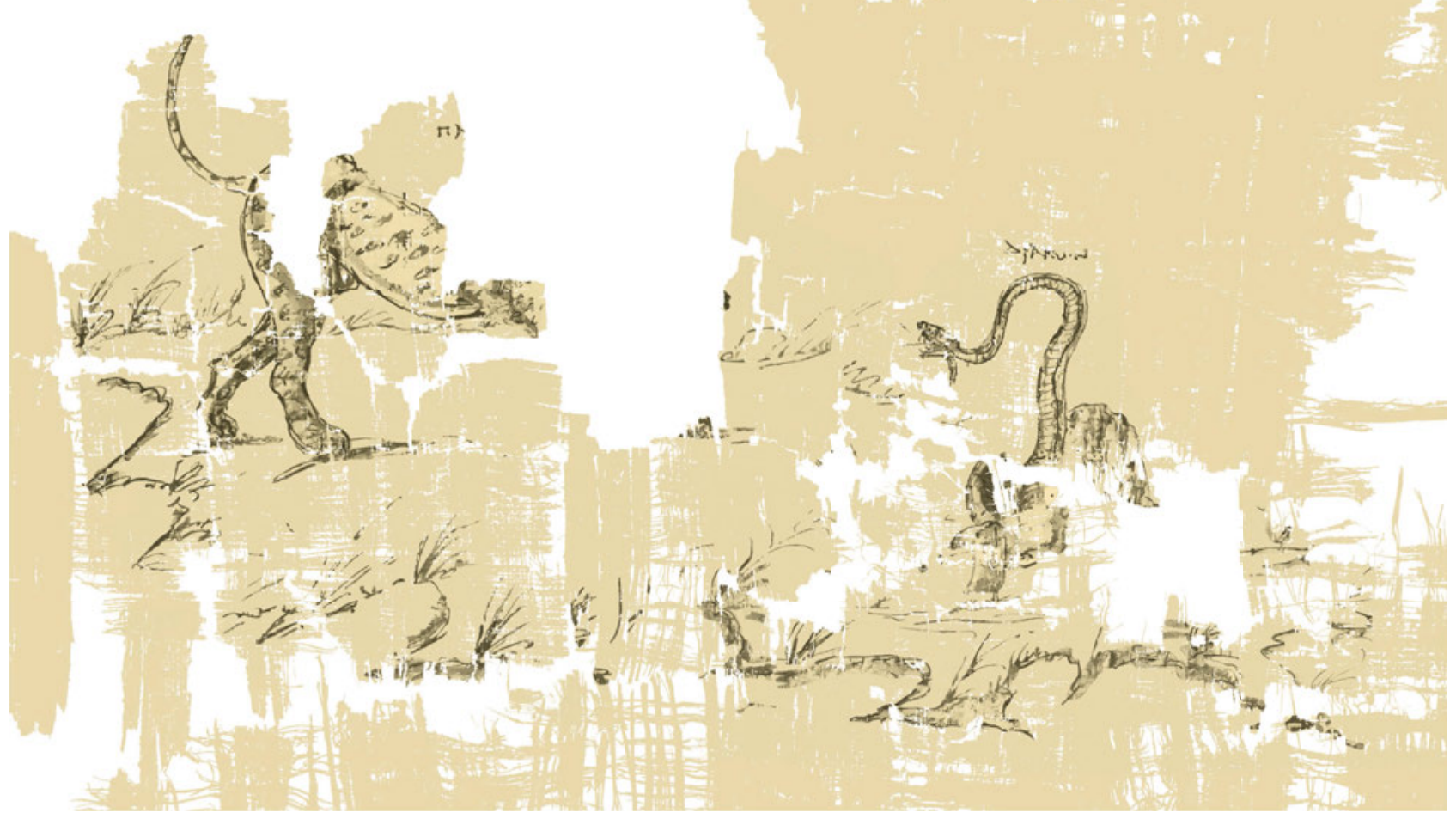

Fig. 4: P.Artemid. V25 (৫ LED).

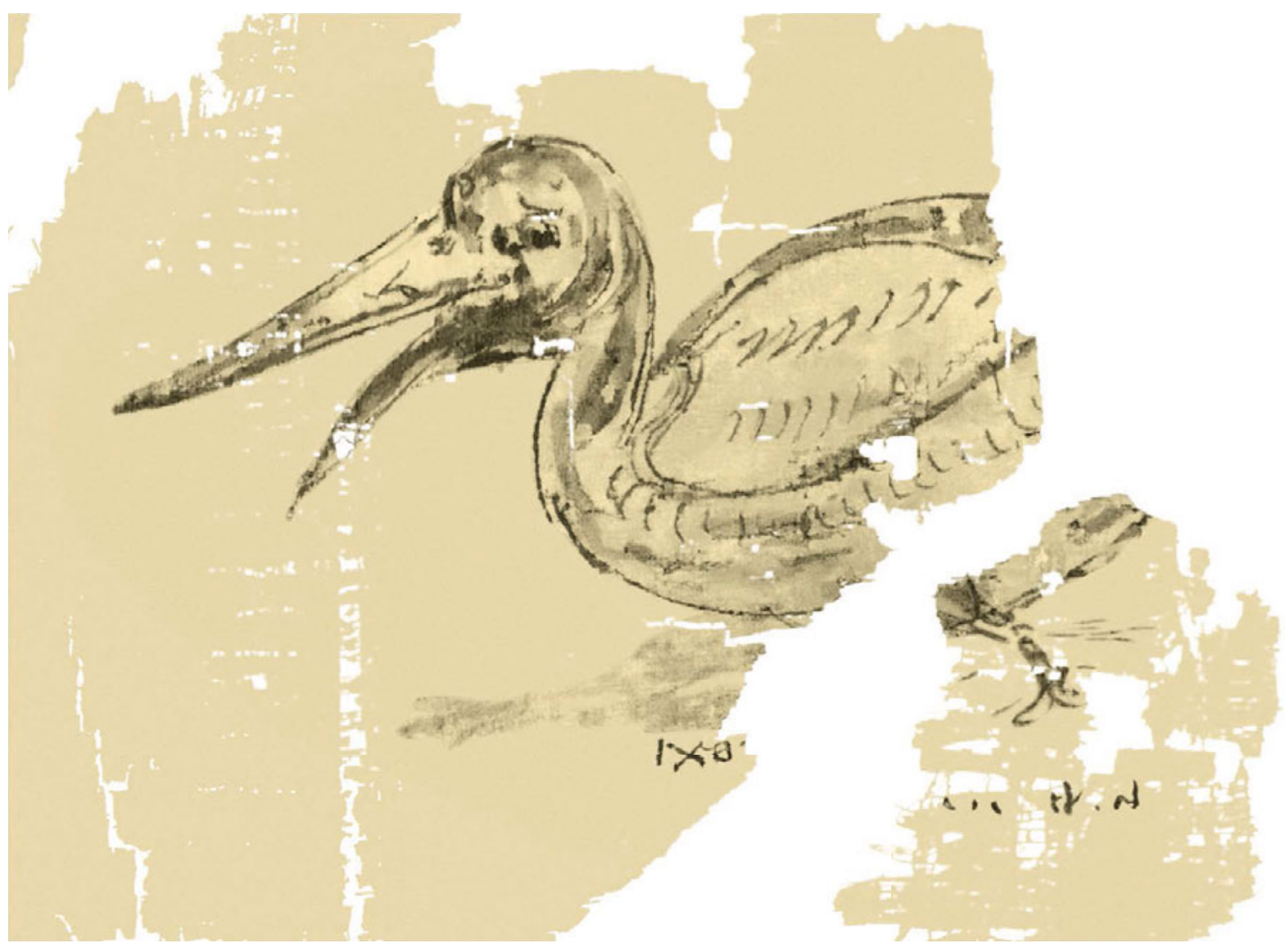

Fig. 5: P.Artemid. V41 (@ LED). 


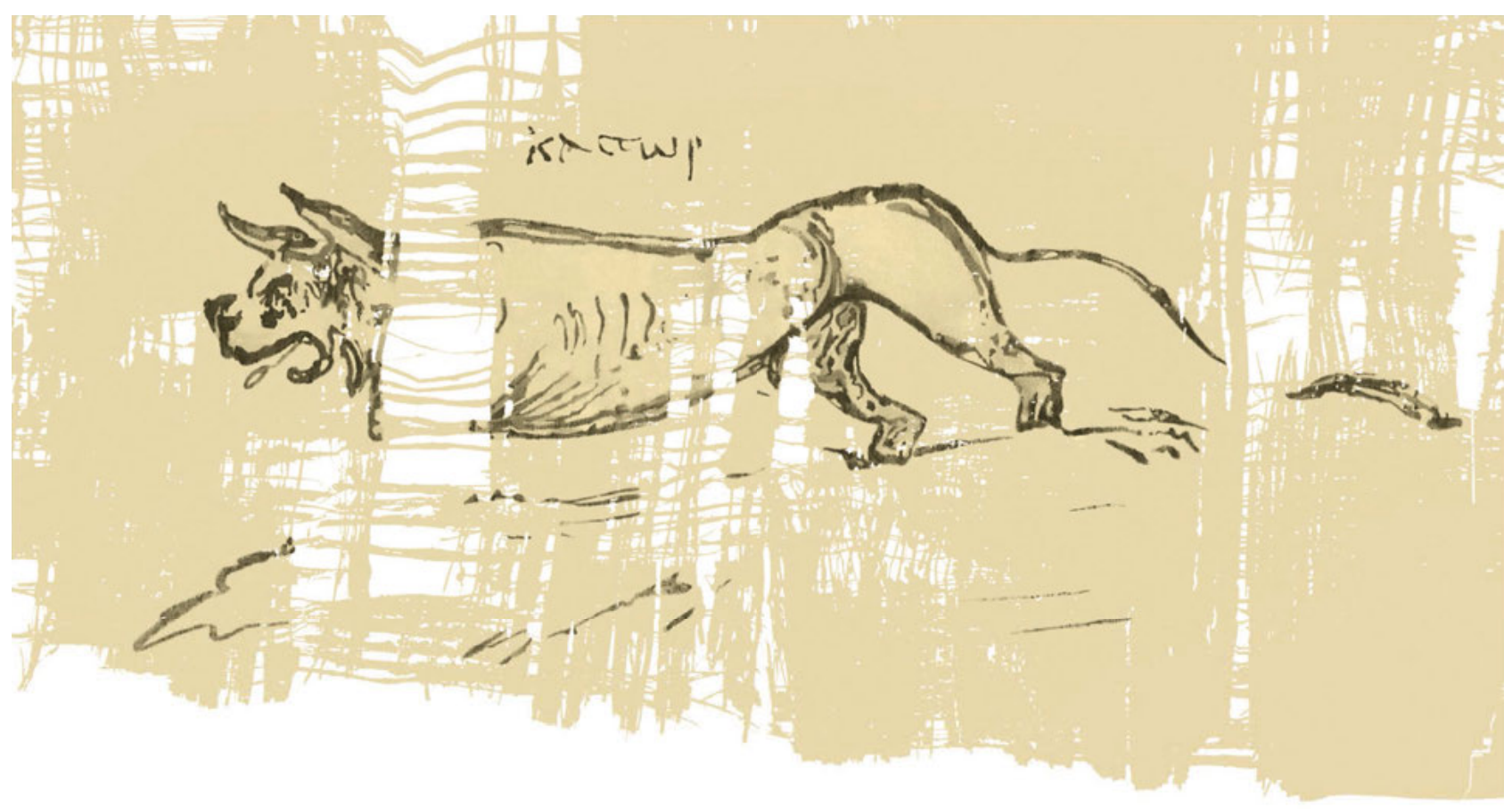

Fig. 6: P.Artemid. V6 (@ LED).

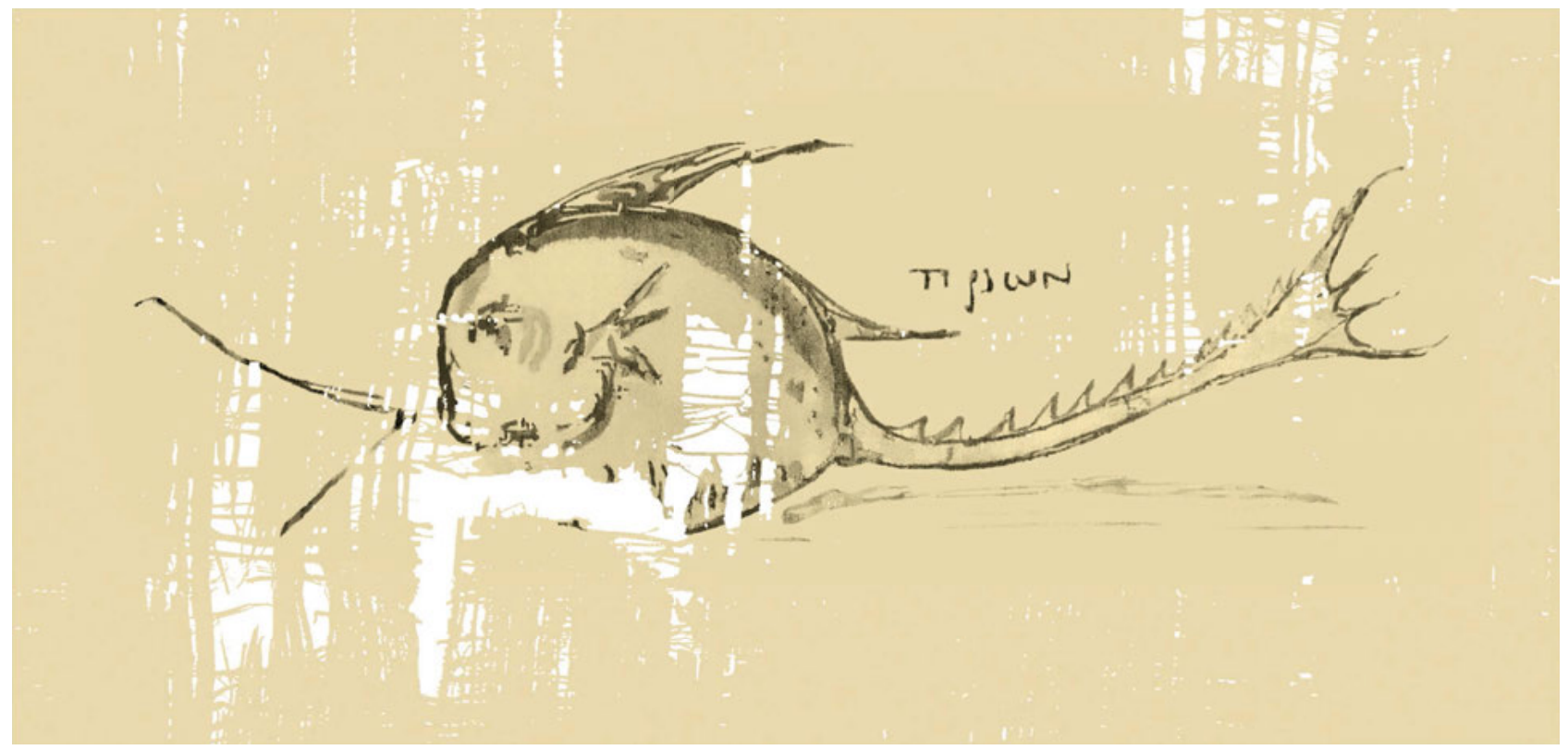

Fig. 7: P.Artemid. V10 (৫ LED). 


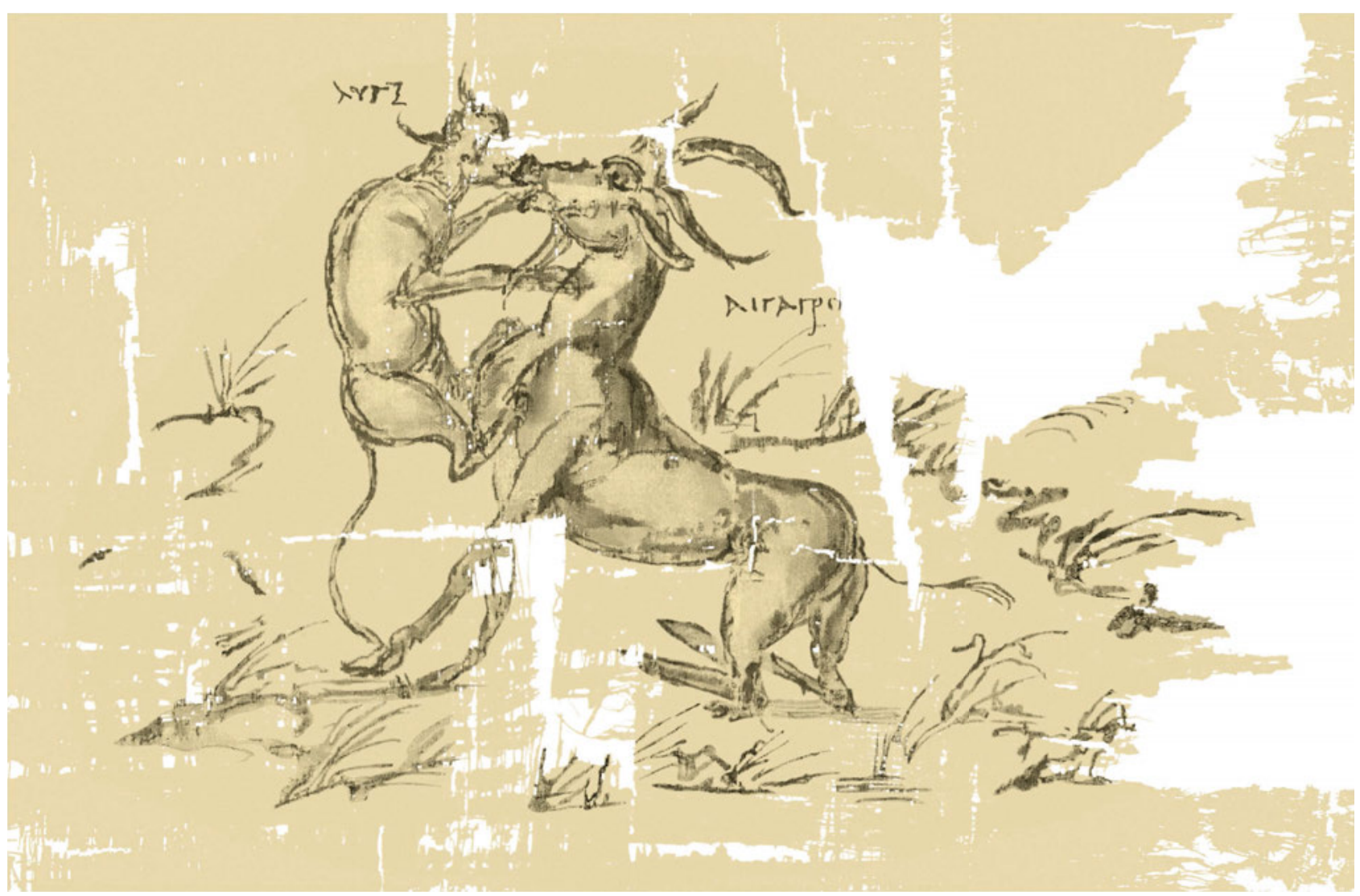

Fig. 8: P.Artemid. V38 (৫ LED).

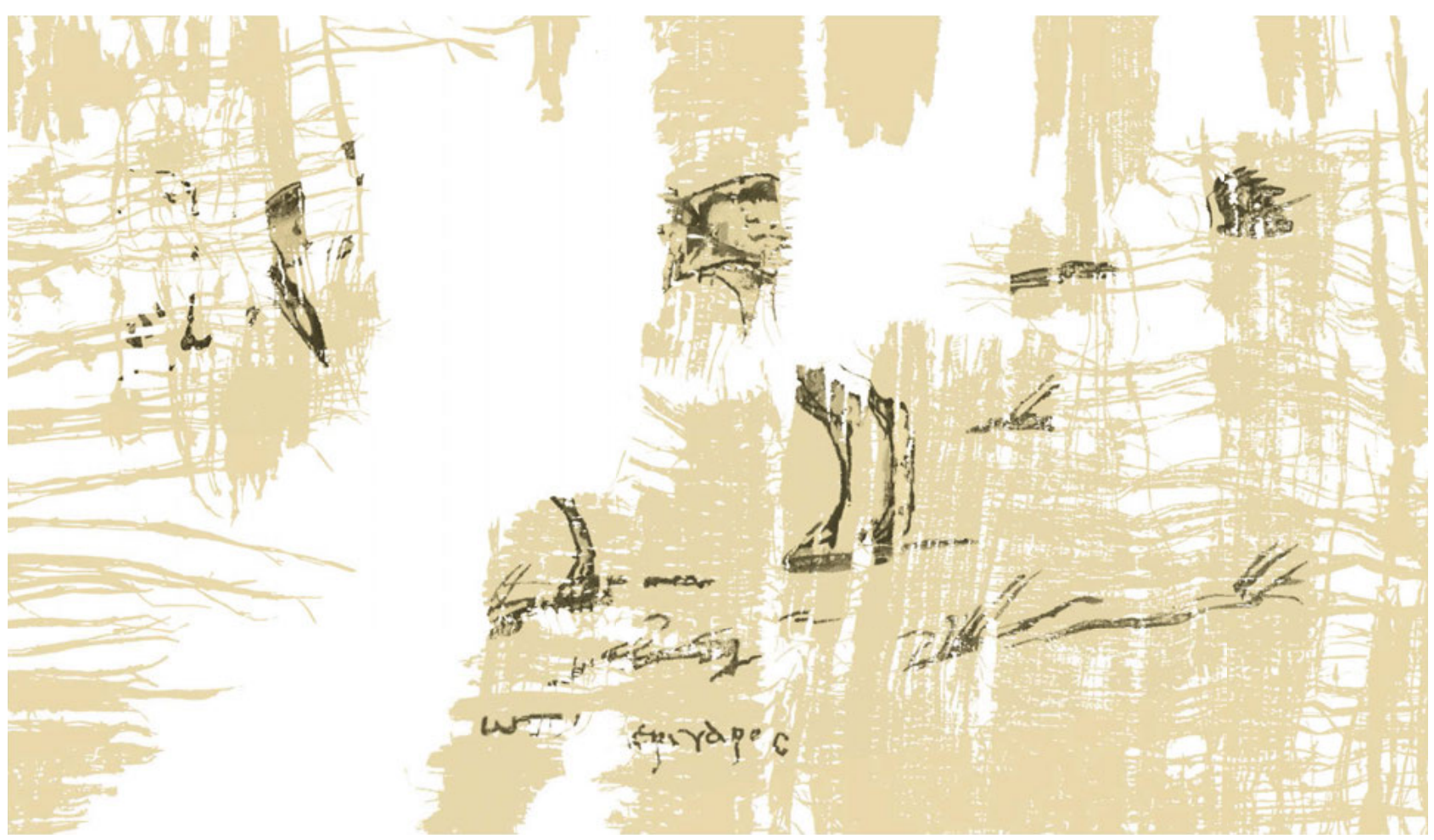

Fig. 9: P.Artemid. V24 (@ LED). 


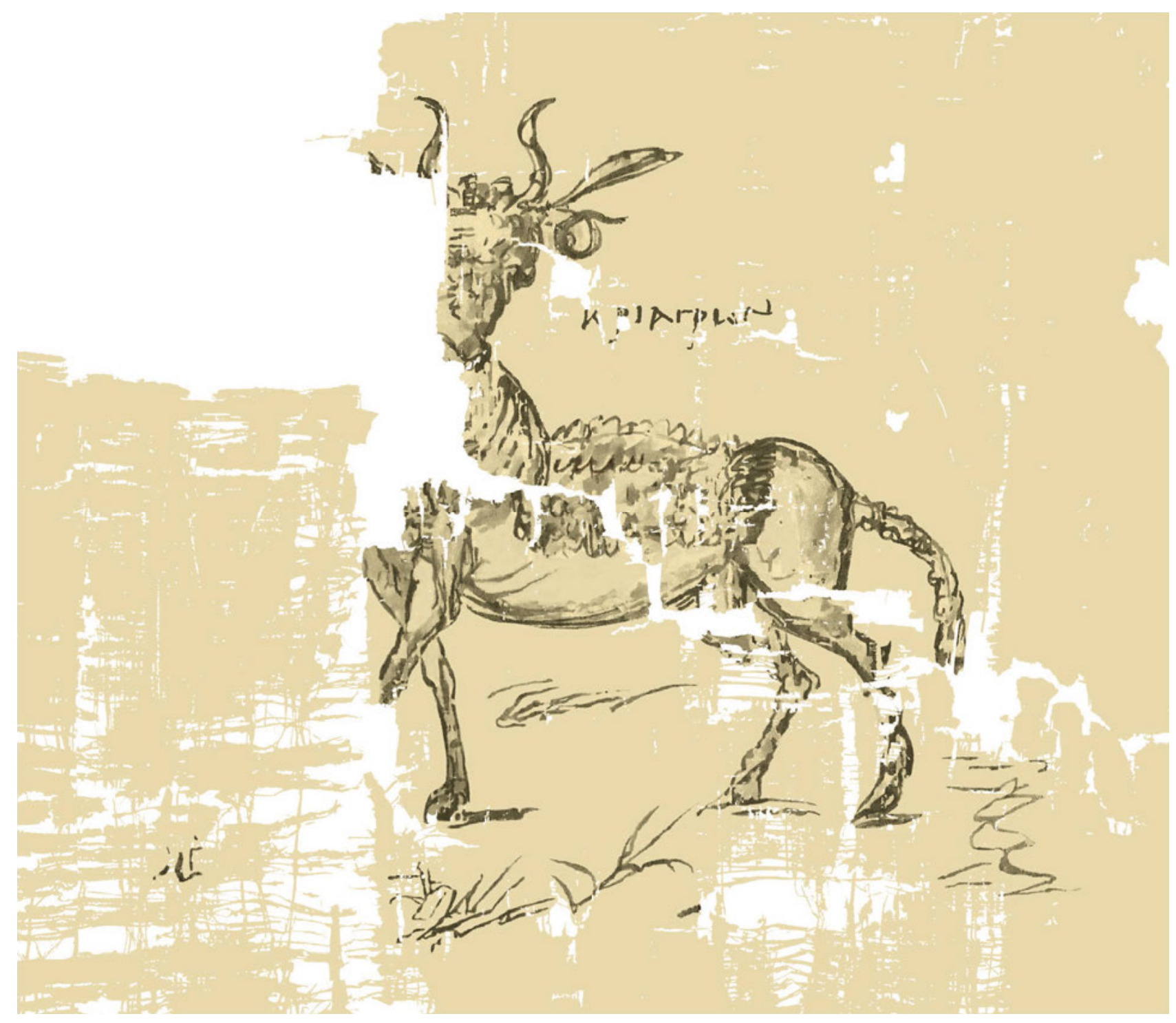

Fig. 10: P.Artemid. V4 (৫ LED). 


\section{Bibliography}

Bastianini, Guido. 2004 [2006]. "Il castoro del Nilo (Horap. II 65 and Hierocl., BKT IV col. III 10-19).” Aegyptus 84:157-161.

Crum, Walter Ewing, and Hugh G. Evelyn White, Eds. 1926. The Monastery of Epiphanius at Thebes. Part II. New York: The Metropolitan Museum of Art.

Elsner, Jaś. 2012. "New studies on the Artemidorus papyrus." Historia: Zeitschrift für Alte Geschichte 61,3:289-292.

Erman, Adolf. 1895. "Bruchstücke des koptischen Physiologus." Zeitschrift für ägyptische Sprache und Altertumskunde 33:5157.

Fournet, Jean-Luc. 2007. "Disposition et réalisation graphique des lettres et des pétitions protobyzantines: pour une paléographie 'signifiante' des papyrus documentaires." In Proceedings of the $24^{\text {th }}$ International Congress of Papyrology. Commentationes humanarum litterarum 122:1, ed. by Jaakko Frösén, Tiina Purola and Erja Salmenkivi, 353-367. Helsinki: Societas Scientiarum Fennica.

Fournet, Jean-Luc. 2018. "Le faux en écriture d'après la documentation papyrologique." In Imitations, copies et faux dans les domaines pharaonique et de l'Orient ancien, ed. by Hanane Gaber, Nicolas Grimal and Olivier Perdu, 274-303. Paris: AiblSoleb.

Gallazzi, Claudio, Bärbel Kramer and Salvatore Settis, Eds. 2008. Il papiro di Artemidoro (P.Artemid.). Milano: LED.

Kinzelbach, Ragnar. 2009. Tierbilder aus dem ersten Jahrhundert: Ein zoologischer Kommentar zum Artemidor-Papyrus. Berlin: De Gruyter.

Kühner, Ruth. 1985. "Physiologus." In Acts of the Second International Congress of Coptic Studies, ed. by Tito Orlandi and Frederik Wisse, 135-147. Rome: CIM.

van Lantschoot, Arnold. 1950. "A propos du Physiologus." In Coptic Studies in Honor of Walter Ewing Crum, 339-363. Boston: The Byzantine Institute.

Lazaris, Stavros. 2016. Le Physiologus grec. Vol. 1, La réécriture de l'histoire naturelle antique. Micrologus Library 77.1. Florence: SISMEL.

Montanari, Franco, and Davide Muratore. 2009. "Parole del papiro di Artemidoro." In Intorno al papiro di Artemidoro: I. Contesto culturale, lingua, stile e tradizione, ed. by Claudio Gallazzi, Bärbel Kramer, Salvatore Settis and Agostino Soldati, 132138. Milano: LED.

Moretti, Paola Francesca. 2012. “'Ut leo, sic formica vocor sermone Pelasgo': Some remarks about the ant-lion and its metamorphosis in the tradition of the Latin 'Physiologus'." In Meminisse iuvat: Studi in memoria di Violetta de Angelis, ed. by Filippo Bognini, 581-596. Pisa: ETS.

Orlandi, Tito. 1997. Opere: Paolo di Tamma. Rome: CIM.

Pajón-Leyra, Irene. 2010. "La didascalia general del animalario del verso del Papiro de Artemidoro: una nueva interpretación." Emerita 78:132-135.

Sbordone, Francesco, Ed. 1936a [1976, ${ }^{2}$ 1991]. Physiologus. Rome: Società Anonima Editrice ,Dante Alighieri‘ [Hildesheim: Olms].

Sheridan, Mark. 1997. "Il mondo spirituale e intellettuale del primo monachesimo egiziano." In L'Egitto cristiano: aspetti e problemi in età tardo-antica, ed. by Alberto Camplani, 177-216. Rome: Institutum patristicum Augustinianum.
Stroppa, Marco. 2011. "Un papiro inedito del Fisiologo (PSI inv. 295)." In I Papiri letterari cristiani. Studi e Testi di Papirologia N.S. 13, ed. by Guido Bastianini and Angelo Casanova, 173192. Florence: Istituto Papirologico "G. Vitelli".

Stroppa, Marco. 2012. "La gazzella e la pietra adamantina in un papiro del Fisiologo greco (PSI inv. 295)." In Actes du 26e Congrès international de papyrologie. Recherches et Rencontres 30, ed. by Paul Schubert, 721-727. Geneva: Droz.

Stroppa, Marco. 2013. "L'uso di rotuli per testi cristiani di carattere letterario." Archiv für Papyrusforschung 59:347-358.

Stroppa, Marco. 2016. "The Physiologus and the Greek Papyri. Animals in comparison." Reinardus 28:169-185.

Suciu, Alin. 2014. "Quotations from the Physiologus in a Homily of the Coptic Holy Week Lectionary." In $\Sigma Y N A \equiv I \Sigma$ KAOOЛIKH: Beiträge zu Gottesdienst und Geschichte der fünf altkirchlichen Patriarchate für Heinzgerd Brakmann zum 70. Geburtstag, ed. by Diliana Atanassova and Tinaitin Chronz, 677-689, Vienna: Lit Verlag.

Suciu, Alin. Forthcoming. "The Coptic Physiologus: Evidence of an Early Translation." In The Physiologus between East and West: Transmission and dissemination of an early Christian text on nature, 15-17 June 2017. Paris: Université Paris-Sorbonne.

Zambon, Francesco. 1975. Il Fisiologo. Milano: Adelphi.

Zucker, Arnaud. (2004) 22005. Physiologos: Le bestiaire des bestiaires. Grenoble: Jérôme Millon.

\section{Credits}

Fig. 1: Image courtesy of Istituto Papirologico “G. Vitelli”, Università degli Studi di Firenze.

Fig. 2: Image courtesy of Ägyptisches Museum und Papyrussammlung, Staatliche Museen zu Berlin, SPK.

Fig. 3-10: Images courtesy of LED - Edizioni Universitarie di Lettere Economia Diritto. 
Teil III: Alter Orient, Hebräische Bibel und Septuaginta 



\section{Silvia Schroer \\ Tiere und ihre Symbolik im Alten Testament}

\begin{abstract}
In ancient Israel, animals played an important role in the everyday life and in religious concepts. Relying on examples, this chapter aims to show how certain animals were associated with typical imagery within biblical tradition. Animal images, symbols or metaphors are often derived not from texts, but from more ancient - namely iconographic - traditions shared by Ancient Near Eastern cultures. Evidence for these pictorial traditions exists from the earliest ages onward, in some specific cases as early as the sixth millennium BCE. In contrast to the Physiologus, the animal imagery of the biblical tradition is an imagery "avant la lettre".
\end{abstract}

\section{Einleitung}

Der Physiologus bezieht sich auf Tiere, die in der Bibel vorkommen und manchmal auf konkrete Bibelstellen. Eine ganze Reihe der von ihm vorgestellten Tiere kommt aber in der hebräischen Bibel zweifelsfrei nicht vor, wie Sittich, Igel und Walross, andere fanden Eingang in die Sammlung aufgrund von heute nicht mehr diskutablen Übersetzungen, z. B. der Pelikan, der auf Ps 102,7 und ein Tier namens תַָ zurückgeht, das nach heutigen Erkenntnissen eher eine Eulen- oder Dohlenart ${ }^{1}$ bezeichnen dürfte, sicher nicht den Pelikan. Es kommen auch Fabeltiere wie der Phönix hinzu, während andererseits wichtige Vertreter der biblischen Tierwelt im Physiologus gänzlich fehlen, u.a. Schaf, Ziege, Rind bzw. Stier, Hund oder Pferd. Der Zugriff auf bestimmte Tiere ist inhaltlich vor allem durch das Interesse an Askese wie Fortpflanzung und an vermeintlichen geistig-geistlichen Bedeutungen des Tierverhaltens geprägt. Bekanntermaßen führt das nicht nur gelegentlich, sondern meistens zu ziemlich absurden, ja abstrusen Beschreibungen, wie überhaupt die allegorische Auslegung von einzelnen biblischen Versen im Physiologus in einer Art und Weise mit dem biblischen Text verfährt, die man heute aus historisch-kritischer Sicht nur als gewalttätig empfinden kann.

Die Tierwelt spielt im Alten Testament eine immense Rolle, praktisch auf jeder Seite ist von Tieren die Rede. Im Neuen Testament stehen sie weniger im Fokus, sind aber als tägliche Begleiter der Menschen in einer auf Landwirtschaft basierenden Kultur immer noch sehr präsent, was sich vor allem in Bildworten oder Metaphern (Hirt und Her-

1 Riede (2002, 282). de, Böcke und Schafe, Kamel und Nadelöhr) niederschlägt. Wo im Neuen Testament auf Tiere Bezug genommen wird, ob in weisheitlich geprägten Gleichnissen oder in den Bildern der Offenbarung, kann aber kein grundsätzlicher Bruch mit der altisraelitisch-biblischen Sichtweise festgestellt werden, wir bewegen uns in denselben kulturellen und symbolischen Parametern. ${ }^{2}$

Tiere werden in den alttestamentlichen Texten als Teil des Alltags einer antiken Kultur, Israels, sichtbar, d.h. wir erfahren recht viel über reale Tiere, Wildtiere und Nutztiere aller Art, wir erfahren viel über ihre Verhaltensweisen und über die Beziehung Mensch-Tier. Mit vielen Tieren verbindet sich eine einschlägige Metaphorik oder Symbolik. Diese speist sich aus Traditionen, die Israel mit den umliegenden Kulturen teilte, von Ägypten bis nach Mesopotamien. Für das Verständnis der Tiersymbolik spielen die Bilder eine mindestens so große Rolle wie Texte, in manchen Fällen ist ohne Kenntnis der darstellenden Kunst die Symbolik eines Tieres kaum rekonstruierbar. Bestimmte Tiere begleiten im Alten Orient Götter und Göttinnen, wie z. B. der Stier den Wettergott oder die Taube die erotischen Göttinnen Syriens und Kanaans. Diese Beziehung kann sehr eng sein, sodass das Tier die Gottheit repräsentiert, sie kann auch lockerer sein, indem beispielsweise Wächterschlangen göttliche Wesen beschützen und umgeben, wie die Serafim den Gott Israels in der Vision von Jes $6 .^{3}$ Die Tiersymbolik speist sich zu einem Teil aus natürlichen Verhaltensweisen von Tieren, geht aber oft darüber hinaus. Sie ist insofern artifiziell und sie entsteht „avant la lettre". Dies soll an drei Beispielen verdeutlicht werden. ${ }^{4}$ Die ausgewählten Bilder der zumeist vorbiblischen Kunst werden in Umzeichnungen und ohne Rücksicht auf Maßstäbe abgebildet. ${ }^{5}$

2 Riede (2010).

3 Keel (1977b).

4 Die Literatur zum Tier im Alten Testament, zur Tiermetaphorik und zu den ikonographischen Hintergründen ist inzwischen sehr umfangreich und kann nicht vollständig dokumentiert werden. Ich verweise auf Collins (2002), auf die älteren Publikationen von Bernd Janowski und Peter Riede, Janowski (1993) und Janowski und Riede (1999), auf die zahlreichen Tierbeiträge von Peter Riede im elektronischen Lexikon Wibilex, auf den Überblick in Schroer $\left({ }^{2} 2013\right)$ und auf mehrere Publikationen von Keel (1977b, 1978, 1980, 1984, 1986, $\left.{ }^{5} 1996\right)$ und von Keel und Staubli (2001).

5 Die Abbildungen sind den drei publizierten Bänden der „Ikonographie Palästinas/Israels und der Alte Orient“ entnommen, Schroer und Keel (2005); Schroer (2008, 2011). Dort finden sich zu jedem ein- 


\section{Der Löwe - wild, gefährlich, majestätisch}

Für den Löwen ${ }^{6}$ kennt das Hebräische sieben verschiedene Bezeichnungen. In diesen Differenzierungen spiegelt sich seine Präsenz in der biblischen Zeit. Es gab Löwen und sie stellten eine Bedrohung dar, weniger für Menschen, solange sich diese in geschützten Siedlungen aufhielten, aber ständig für Herdentiere, weshalb man diese nicht allein weiden ließ und ein Hirte sich auf die Konfrontation mit einem Löwen einstellen und bewaffnet sein musste. Allein das Brüllen eines Löwen zu hören war furchterregend (Am 3,8), die Begegnung mit dem Tier der Inbegriff von Schrecken und Todesangst. In den Psalmen beschreiben die Beter und Beterinnen ihre Not gern als Umzingeltsein von Löwen (Pss 7,3; 57,5). Wo die Gefahr groß ist, braucht es große Retter. Der Kampf gegen den Löwen ist Sache von Heroen, von Simson (Ri 14,5-6) über David (1 Sam 17,36) bis zu Herakles, insbesondere aber Sache von Königen. Die assyrischen Herrscher praktizierten eine rituelle Löwenjagd, aber schon lange vor ihnen gehört das Erlegen von Löwen zur Legitimation eines vorderasiatischen Herrschers. Dahinter steht die Idee, dass der König von Amts wegen alle Feinde zu bezwingen hat, ob menschliche Gegner im Krieg oder Tiere, die die wilde, chaotische Welt verkörpern, auf der Jagd. Das ägyptische Königtum hat sich weniger im Kampf gegen den Löwen präsentiert, sondern stattdessen den Löwen seit dem Ende des 4. Jt. v. Chr. zum Inbild des Königs gemacht (Abb. 1). Die kanaanäische Kultur hat die Bewunderung für das Löwenimage der ägyptischen Herrscher übernommen. Skarabäen, die in Palästina/Israel zwischen dem 18.-16. Jh. v. Chr. im Umlauf waren, zeigen den Löwen, der ein Tier reißt, aber auch über Feinde hinwegschreitet (Abb. 2). Dieses Sujet findet sich in der einheimischen Kleinkunst noch in der frühen Eisenzeit (um 1000 v. Chr.). Im Neuen Reich werden die Pharaonen in der ägyptischen Kunst gern in Begleitung von Löwen dargestellt, nicht nur bei der Jagd und im Krieg, sondern auch thronend (Abb. 3). Löwen galten als unbezwingbar, wer sie auf seiner Seite hatte und sie als Wächter einsetzen konnte, genoss höchste Sicherheit. Wenn der Thron Salomos von Löwenbildern umgeben ist (1 Kön 10,18-20) oder das Drohen des Königs mit dem Knurren eines Löwen verglichen wird (Spr 20,12), erkennen wir Spuren dieser ägyptischen Löwentradition.

zelnen Objekt weitere Erläuterungen und ein vollständiger kritischer Apparat.

6 Vgl. zum Löwen die umfangreiche Monographie von Strawn (2005).
Allerdings verzichten die biblischen Verfassergruppen darauf, die Könige Israels allzu deutlich als Löwen zu porträtieren (vgl. aber 2 Sam 1,23), eher werden Stämme als Löwen charakterisiert, so Dan (Dtn 33,20-22) und Juda (Gen 49,9). Hingegen kann Israels Gott JHWH wie ein Löwe brüllen und zum reißenden Löwen für Israel werden (Am 1,2; Hos 5,14).

Der Löwe ist ein mächtiger, überlegener Gegner, seine majestätische Symbolik (Spr 30,30) ist ihm bis in die moderne Heraldik oder die Bildsprache der Werbung nie streitig gemacht worden. Es gibt darüber hinaus allerdings eine weitere interessante und noch ältere Löwensymbolik, die das furchterregende Tier nicht mit dem Königtum, sondern mit Göttinnen verbindet. Diese Symbolik ist im Hohenlied bewahrt, ${ }^{7}$ wenn der Mann von seiner Geliebten schwärmt:

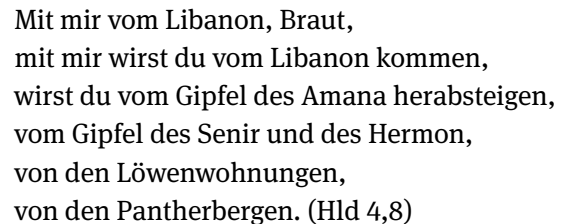

Göttinnen thronen oder stehen seit dem 6. Jt.v. Chr. in der vorderasiatischen Kunst gern auf Löwen oder Löwinnen, wodurch ihre wilde, unbezwingbare Seite betont wird. Die Geliebte wird in Hld 4,8 also wie eine Göttin beschrieben, die endlich aus den Bergen, einer unzugänglichen Wildnis mit Löwen und Panthern, heruntersteigt und sich in die Nähe der Menschen und vor allem des sie begehrenden Mannes begibt. Bekannt ist seit dem 3. Jt.v. Chr. der Typus der Göttin Ischtar, die ihren Fuß auf einen Löwen stellt (Abb. 4). In der ersten Hälfte des 2. Jt.v. Chr. wurde das kanaanäische Motiv einer nackten, frontal dargestellten Göttin auf dem Löwen, bezeichnet als Qedeschet („die Heilige“), in die ägyptische Stelenkunst übernommen (Abb. 5). Von den ägyptischen Göttinnen ist die Sachmet am engsten mit dem Löwen verbunden. Sie erscheint auffällig oft und über lange Zeiträume in der Amulettkunst Palästinas/Israels (Abb. 6). $\mathrm{Zu}$ allen diesen Löwengöttinnen lassen sich ikonographisch Bezüge in der Kunst Palästinas/Israels geltend machen, teilweise bis in die hellenistische Zeit.

7 Keel (1984, 39-45; 1986, 144-148). 


\section{Der Esel und der Wildesel}

$\mathrm{Zu}$ den wichtigsten Nutztieren gehörte in Ägypten wie in Vorderasien seit dem 3. Jt. v. Chr. der Esel, ${ }^{8}$ der neben Rindern und Kleinvieh die ökonomische Grundlage der sich entwickelnden Stadtkulturen bildete. Esel brauchte man vor allem zum Warentransport und für den Handel (Abb. 7), in Palästina/Israel und in Syrien benutzten Männer (Gen 22,3; 49,14-15) wie Frauen (1 Sam 25,42; 2 Kön 4,24) sie, anders als in Ägypten, auch zum Reiten (Abb. 8). Auch für dieses Tier kennt das Hebräische mehrere Bezeichnungen. Der Esel wird oft zusammen mit dem Rind erwähnt und wie diesem steht ihm ein freier Tag in der Woche, ein Sabbat, zu (Ex 20,17; Dtn 5,13.21). Das Image des Esels in der Bibel ist durchwegs sehr gut. ${ }^{9}$ Er gilt als friedliches Tier und seine bei uns sprichwörtliche Sturheit als unter Umständen klug, wie in der berühmten Geschichte von Bileams Eselin, die ja um einiges gescheiter ist als der Prophet, der auf ihr reitet (Num 22,22-33). Anders als das stolze Pferd, dessen kopflose Art, sich in eine lärmige Kriegsschlacht zu stürzen, man irritierend fand (Ijob 39,19-25), ist der Esel ein Inbild der geduldigen Bescheidenheit und Zuverlässigkeit. Sein Schicksal ist zwar Frondienst, woran das Ijobbuch etwas mitleidig erinnert $(39,7)$, aber er nimmt die großen Lasten und die Stockschläge klaglos hin. Den König der zukünftigen Heilszeit erwartet noch Sacharja (9,9-10) als Eselreiter, weshalb Jesus beim Einzug in Jerusalem auf einem Eselfüllen reitet und nicht auf einem Pferd (Mt 21,1-9 parr.), denn nur der Esel konnte seine messianische Friedfertigkeit überzeugend zum Ausdruck bringen. Wildesel und Onager, die es nota bene damals noch gab, sind hingegen im Alten Testament Sinnbilder der asozialen und menschenscheuen Existenz (Ijob 24,4; vgl. Dan 5,21). In der vorderasiatischen Kunst gehören sie zum Jagdwild der Könige, da sie die nicht bewohnbare und damit auch gefährliche Welt vertreten. Im Buch Ijob wird der Wildesel als nicht zähmbar beschrieben $(39,5-8)$.

\section{Die Taube}

Es gab in Palästina/Israel verschiedene Taubenarten, ${ }^{10}$ wahrscheinlich unter dem Oberbegriff יוֹנָה (griech. $\pi \varepsilon \rho$ -

8 Vgl. Schroer (2014).

9 Einzig seine Geilheit (Ez 23,20) wird in der prophetischen Metaphorik negativ gewertet.

10 Vgl. schon Keel (1984, 53-62; 1986, 71-75.187-189; 1992, 143-168).

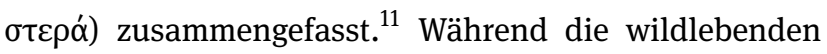
Felsentauben, die in Felswänden nisten (Jer 48,28; metaphorisch für die Unzugänglichkeit der Geliebten in Hld 2,14), und die Turteltauben, die als Zugvögel bekannt waren (Jer 8,7; Hld 2,12), eingefangen werden mussten, hielt man die domestizierten Felsentauben spätestens seit dem 6. Jh.v. Chr. in Taubenhäusern (Jes 60,8). Am häufigsten wird die Taube, sowohl im Alten als auch im Neuen Testament, als erschwingliches Opfertier im Tempel erwähnt (Lev 1,14-17; 14,22 u.ö.; Mt 21,12). Tauben konnten in den Tempelvorhöfen von Händlern erstanden werden. Sie waren das klassische Armeleuteopfer (Lev 14,22; Mk 11,15 parr.), das im Bedarfsfall, z. B. beim Reinigungsopfer einer Wöchnerin, ein Schaf oder eine Ziege ersetzen konnte (Lev 12,8; Lk 2,24).

Das Gurren der Tauben empfand man als Klagegesang (Jes 38,14; 59,11; Nah 2,8). Sprichwörtlich war ihre Arglosigkeit (Hos 7,11; Mt 10,16), symbolisch weit bedeutsamer aber ihre Botinnenfunktion. Die Taube erscheint als Botenvogel, wenn sie in der Sintflutgeschichte (Gen 8,8-12) das Ende der Flut und von Gott ermöglichtes neues Leben ankündigt. Die christliche Friedenstaubensymbolik entwickelte sich aus diesem Traditionsstrang. In Ps 68,44 verkünden geschmückte Tauben als Freudenbotinnen den Sieg über feindliche Könige. ${ }^{12}$ Wie in Ägypten ließ man beim Herrschaftsantritt eines Gottes oder Königs Vögel, in Israel wohl meistens Tauben, als Siegesboten fliegen.

Verbunden mit der Botinnenfunktion ist für die biblische Taubensymbolik die Assoziation der Taube mit Liebesgöttinnen, Ischtar, Astarte, Aphrodite (Turan) und Venus, bedeutungsstiftend. Im ganzen Vorderen Orient nicht aber in Ägypten - ist die Taube seit dem 3. Jt. v. Chr. deren wichtigstes Begleittier. Der Grund für diese Zuordnung dürfte im Paarungsverhalten (Turteln) der Vögel liegen, das schon in der Antike als Küssen gedeutet wurde. Ein berühmtes Fresko aus Mari (Abb. 9) beweist, dass bereits im früheren 2. Jt. v. Chr. in Syrien an Tempeln wei$\mathrm{Be}^{13}$ Zuchtformen der Felsentaube gehalten wurden. Kleine Tempelmodelle aus Syrien und Palästina/Israel sind vom 3. bis ins 1. Jt. v. Chr. häufig mit Tauben geschmückt. Altsyrische Rollsiegel zeigen eine einzelne oder mehrere Tauben, die von der erotisch attraktiven Göttin zu ihrem Partner (Wettergott, Stadtfürst) hinüberfliegen (Abb. 10). Die Taube übermittelt so die Botschaft der sinnlichen Liebe der Göttin, seltener die der Liebe des männlichen Part-

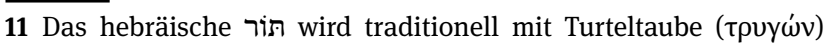
übersetzt, könnte aber an einigen Stellen auch ein Wildhuhn bezeichnen.

12 Keel (1977a).

13 Vgl. zur weißen Farbe die Assoziation mit Milch in Hld 5,12. 
ners zur Frau. Losgelöst von der dargestellten Göttin kann sie deren Präsenz repräsentieren bzw. andeuten. ${ }^{14}$ Auf diesem Hintergrund bedeutet die Metapher ,deine Augen sind Tauben“ in Hld 1,15; 4,1; 5,12, dass die Blicke des/der Geliebten Liebesbotschaften sind. Der Vergleich mit „Tauben, die in Milch gebadet über dem vollen (Becken) sitzen“ (Hld 5,12) betont die belebende Wirkung des Blicks, indem das in der darstellenden Kunst Palästinas/Israels seit dem 4. Jt.v. Chr. beliebte Motiv der Taube auf Gefäßrändern aufgegriffen wird. ${ }^{15}$

Die Botinnen- und Liebessymbolik der Taube hat sich im Bericht von der Taufe Jesu am Jordan (Mk 1,10-11 parr.), in allen Evangelien erhalten. ${ }^{16}$ Das Pneuma schwebt auf Jesus herab „wie eine Taube“, während gleichzeitig eine himmlische Stimme Gottes Liebeserklärung an Jesus von Nazareth erklingen lässt. Die Vermittlung des altorientalischen Symbols an die neutestamentliche Geistsymbolik könnte über die jüdische Weisheitstradition gelaufen sein, da schon Philon von Alexandrien (Quis rerum divinarum heres sit 127-128) ${ }^{17}$ die Felsen- und die Turteltaube einerseits mit der göttlichen, zurückgezogenen Weisheit und andererseits der geselligen, die Gemeinschaft suchenden Weisheit in Verbindung bringt, wie es der Physiologus (28 Von der Turteltaube) dann aufnimmt, doch ist in den Evangelien auch ein direkter Einfluss der hellenistischrömischen Göttinnensymbolik nicht auszuschließen. Die Stadtmünzen von Aschkelon zeigen immerhin bis ins 2./3. Jh.n. Chr. die Göttin Astarte mit Taube.

\section{Fazit}

Die biblische Tiersymbolik ist, fern von Allegorie, meistens ein Konglomerat, in welchem Natur und Kultur sich verbinden. Dabei können bei manchen Tieren verschiedene symbolische Traditionen zusammenfließen, auch wenn diese nicht homogen sind. Die Unreinheit eines

\footnotetext{
14 Die Verbindung von Göttin und Taube setzt sich in der griechischen, etruskischen und römischen Tradition fort.

15 Dieses Motiv der Kunst entspricht einer Verhaltensweise von Tauben, die tatsächlich gern an Wasserbecken oder Brunnen sitzen. Diese Beobachtung reiht sich neben die Kenntnis ihrer Nistplätze und die Beobachtung ihres Paarungsverhaltens.

16 Schroer (1986; 1996).

17 Eine Einsiedlerin ist die göttliche Weisheit, / weil sie wegen des einen Gottes, / dessen Besitz sie ist, / das Alleinsein liebt - symbolisch wird sie / Turteltaube ( $\tau \rho v y \omega ́ v)$ genannt, / mild, zahm und gesellschaftsliebend ist die andere, / die sich gern in den Städten der Menschen aufhält, / und der es in Gesellschaft von Sterblichen ge-

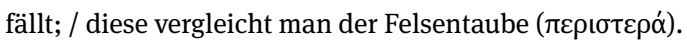

Tiers, z. B. des Gänsegeiers (נֶֶֶׁ Lev 11,13), der von seiner Natur her mit Verwesung und Tod in Berührung kam, war kein Hindernis, diesen Vogel mit positiven Regenerationsvorstellungen (Ps 103,5) und sogar mit dem Gottesbild (Ex 19,4; Dtn 32,11) zu verbinden. ${ }^{18}$ Das Schwein (חְזִ (חְיר) galt ebenfalls als unrein, aber es gibt den Männernamen Hezir (1 Chr 24,15; Neh 10,21), was zeigt, dass es durchaus positiv eingeordnet werden konnte. Überhaupt wirft die Vielzahl von Tiernamen, die als Personennamen im Umlauf waren, ${ }^{19}$ ein interessantes Licht auf die Beziehung zwischen Mensch und Tier. Verhaltensweisen, besondere Eigenschaften und das Aussehen eines Tieres können die Wahl eines solchen Namens für ein Kind bewirkt haben, aber auch die symbolischen Aspekte.

Dass der Löwe ein für Herden und Menschen gefährlicher Gegner war, verhalf ihm schon früh zu seiner majestätischen Symbolik. Diese wird in den biblischen Texten nicht neu erfunden, sondern von den Nachbarkulturen übernommen und adaptiert, wenn auch im Hinblick auf das konkrete Königtum Israels und Judas eher verhalten.

Der Physiologus (1 Vom Löwen) entnimmt der biblischen Löwensymbolik eklektisch Einzelheiten. Dass er den Löwen an die erste Stelle seiner Sammlung setzt, bildet die kulturübergreifende, unter anderem biblisch bezeugte königliche Löwenmetaphorik ab. Der Löwe erscheint in diesem Kapitel zudem als Emblemtier des Stammes Juda. Alle weiteren Ausführungen des Physiologus lösen sich von konkreten Bezügen zum Löwen und biblischen Texten.

Der Esel ist zwar auch in Ägypten und Mesopotamien verbreitet, seine Domestikation glückte etwa gleichzeitig in verschiedenen Regionen, aber mit Palästina/Israel ist er auf besondere Weise verbunden. Mit dem Pferd als Gegenbild wird die Eselssymbolik der biblischen Texte schärfer erkennbar. Der Esel ist in der gesamten biblischen Tradition ein antiimperialistisches Symbol. Wie beim Löwen ist das Verhalten des Tieres und seine Bedeutung in der geographischen Region natürlich ein wesentlicher innerer Kern der Eselssymbolik. Dazu gehört vermutlich auch eine religiöse Bedeutung, die wir noch nicht ganz durchschauen, die aber durch Eselbestattungen oder die Tatsache, dass der unreine Esel zu den Opfertieren gehörte (Ex 13,30; 34,20), angezeigt wird. Die Symbolik des viel seltener erwähnten Wildesels entspricht dem Image, das er im Vorderen Orient allgemein hatte, nämlich dem eines unzähmbaren Steppentiers.

18 Seit der Septuaginta wird das hebräische Wort für den Gänsegeier gern mit áztós und dem entsprechend Adler übersetzt, was aber unzutreffend ist, Schroer ('2013, 97); vgl. Mi 1,16. 19 Vgl. Keel und Staubli (2001, bes. 27-31). 
Tatsächlich beginnt der Abschnitt zum Wildesel im Physiologus mit einem Bezug zu Ijob 39,5-9, wo von der gottgewollten Freiheit, der Nicht-Domestizierung des Wildesels die Rede ist. Dann aber folgen sexuelle Phantasien und Spekulationen. Die Kastrierung der männlichen Wildeselfohlen durch ihren Vater wird mit den Eunuchen im Perserreich in Verbindung gebracht und dann der besseren Art von Enthaltsamkeit der Apostel gegenüber gestellt.

Bei der Taube sieht man die Verbindung von natürlichem Verhalten und kulturellen sowie künstlerischen Prägungen besonders gut. In Ägypten gibt es diese Taubensymbolik nicht, sie entstand in Syrien. Das Schnäbeln der Tiere war wohl ein Impuls, sie mit Verliebtheit und Liebe zu assoziieren. Aber auch die Möglichkeit, sie zu züchten, ihre Vorliebe für Wasserbecken und anderes spielte eine Rolle bei der Entwicklung der Metaphern, die wir aus dem Hohelied kennen.

Den Tauben widmet der Physiologus zwei Kapitel (28 Von der Turteltaube, 35 Von der Taube), die von den Evangelienberichten über die Taufe Jesu ausgehen, sich aber dann rasch Themen wie der Einsiedelei oder der Jungfräulichkeit zuwenden. Durchgehend gilt das Interesse des Physiologus nicht den realen Tieren und ihren Verhaltensweisen, d.h. nicht im mindesten einer echten Naturkunde, sein Interesse gilt auch nicht den biblischen Texten und Tiersymbolen, sondern er lässt sich von der biblischen Tradition oder anderen Traditionen allenfalls ein Stichwort geben, um seine eigenen Spekulationen daran anzuknüpfen.

\section{Bibliographie}

Collins, Billie Jean, Hg. 2002. A History of the Animal World in the Ancient Near East. Handbook of Oriental Studies, Section 1. The Near and Middle East, 64. Leiden: Brill.

Janowski, Bernd et al., Hgg. 1993. Gefährten und Feinde des Menschen: Das Tier in der Lebenswelt des alten Israel. NeukirchenVluyn: Neukirchener Verlag.

Keel, Othmar. 1977a. Vögel als Boten: Studien zu Ps 68,12-14, Gen 8,6-12, Koh 10,20 und dem Aussenden von Botenvögeln in Ägypten; Mit einem Beitrag von Urs Winter zu Ps 56,1 und zur lkonographie der Göttin mit der Taube. OBO 14. Freiburg, $\mathrm{CH}$ : Universitätsverlag Freiburg; Göttingen: Vandenhoeck \& Ruprecht.

Keel, Othmar. 1977b. Jahwe-Visionen und Siegelkunst: Eine neue Deutung der Majestätsschilderungen in Jes 6, Ez 1 und 10 und Sach 4. SBS 84/85. Stuttgart: Kohlhammer Verlag.

Keel, Othmar. 1978. Jahwes Entgegnung an ljob: Eine Deutung von ljob 38-41 vor dem Hintergrund der zeitgenössischen Bildkunst. FRLANT 121. Göttingen: Vandenhoeck \& Ruprecht.

Keel, Othmar. 1980. Das Böcklein in der Milch seiner Mutter und Verwandtes: Im Lichte eines altorientalischen Bildmotivs. ОВО
33. Freiburg, CH: Universitätsverlag Freiburg; Göttingen: Vandenhoeck \& Ruprecht.

Keel, Othmar. 1984. Deine Blicke sind Tauben: Zur Metaphorik des Hohen Liedes. SBS 114/115. Stuttgart: Kohlhammer Verlag.

Keel, Othmar. 1986. Das Hohelied. ZBK.AT 18. Zürich: Theologischer Verlag Zürich.

Keel, Othmar. 1972 [ $\left.{ }^{5} 1996\right]$. Die Welt der altorientalischen Bildsymbolik und das Alte Testament: Am Beispiel der Psalmen. Göttingen: Vandenhoeck \& Ruprecht.

Keel, Othmar. 1992. Das Recht der Bilder gesehen zu werden: Drei Fallstudien zur Methode der Interpretation altorientalischer Bilder. OBO 122. Freiburg, CH: Universitätsverlag Freiburg; Göttingen: Vandenhoeck \& Ruprecht.

Keel, Othmar, Thomas Staubli et al. 2001. Im Schatten Deiner Flügel: Tiere in der Bibel und im alten Orient. Katalog zur Ausstellung. Freiburg, $\mathrm{CH}$ : Universitätsverlag Freiburg.

Keel, Othmar et al. 1984. Orte und Landschaften der Bibel. Bd. 1, 100-181. Göttingen: Vandenhoeck \& Ruprecht.

Keel, Othmar, und Silvia Schroer. ${ }^{2} 2008$. Schöpfung: Biblische Theologien im Kontext altorientalischer Religionen. Göttingen: Vandenhoeck \& Ruprecht.

Riede, Peter, und Bernd Janowskis. 1999. Die Zukunft der Tiere: Theologische, ethische und naturwissenschaftliche Perspektiven. Stuttgart: Calwer.

Riede, Peter. 2002. Im Spiegel der Tiere: Studien zum Verhältnis von Mensch und Tier im alten Israel. OBO 187. Freiburg, CH: Universitätsverlag Freiburg; Göttingen: Vandenhoeck \& Ruprecht.

Riede, Peter. 2010. „Tier.“ In Das wissenschaftliche Bibellexikon im Internet (WiBiLex), hrsg. v. Michaela Bauks, Klaus Koenen und Stefan Alkier. Stuttgart: Deutsche Bibelgesellschaft. http://www.bibelwissenschaft.de/stichwort/35794/.

Schroer, Silvia. 1986. „Der Geist, die Weisheit und die Taube: Feministisch-kritische Exegese eines zweittestamentlichen Symbols auf dem Hintergrund seiner altorientalischen und hellenistisch-frühjüdischen Traditionsgeschichte." Freiburger Zeitschrift für Philosophie und Theologie 33:197-225. Reprint in Schroer, Silvia. 1996. Die Weisheit hat ihr Haus gebaut: Studien zur Gestalt der Sophia in den biblischen Schriften, 144-175. Mainz: Matthias-Grünewald-Verlag.

Schroer, Silvia, und Othmar Keel. 2005. Die Ikonographie Palästinas / Israels und der Alte Orient: Eine Religionsgeschichte in Bildern. Bd. 1, Vom ausgehenden Mesolithikum bis zur Frühbronzezeit. IPIAO 1. Freiburg, $\mathrm{CH}$ : Academic Press.

Schroer, Silvia. 2008. Die Ikonographie Palästinas / Israels und der Alte Orient: Eine Religionsgeschichte in Bildern. Bd. 2, Die Mittelbronzezeit. IPIAO 2. Freiburg, CH: Academic Press.

Schroer, Silvia. 2011. Die Ikonographie Palästinas / Israels und der Alte Orient: Eine Religionsgeschichte in Bildern. Bd. 3, Die Spätbronzezeit. IPIAO 3. Freiburg, CH: Academic Press.

Schroer, Silvia. ${ }^{2}$ 2013. Tiere in der Bibel. Freiburg i. Br.: Herder. Schroer, Silvia. 2014. „Tierschutz und Tierethik im Alten Testament: Am Beispiel des Esels.“ Amosinternational 8,3:13-19.

Schroer, Silvia. 2018. Die Ikonographie Palästinas / Israels und der Alte Orient: Eine Religionsgeschichte in Bildern. Bd. 4, Die Eisenzeit bis zum Beginn der achämenidischen Herrschaft. IPIAO 4. Basel: Schwabe.

Strawn, Brent. 2005. What is Stronger than a Lion? Leonine Image and Metaphor in the Hebrew Bible and the Ancient Near East. OBO 212. Freiburg, $\mathrm{CH}$ : Universitätsverlag Freiburg; Göttingen: Vandenhoeck \& Ruprecht. 


\section{Abbildungen}
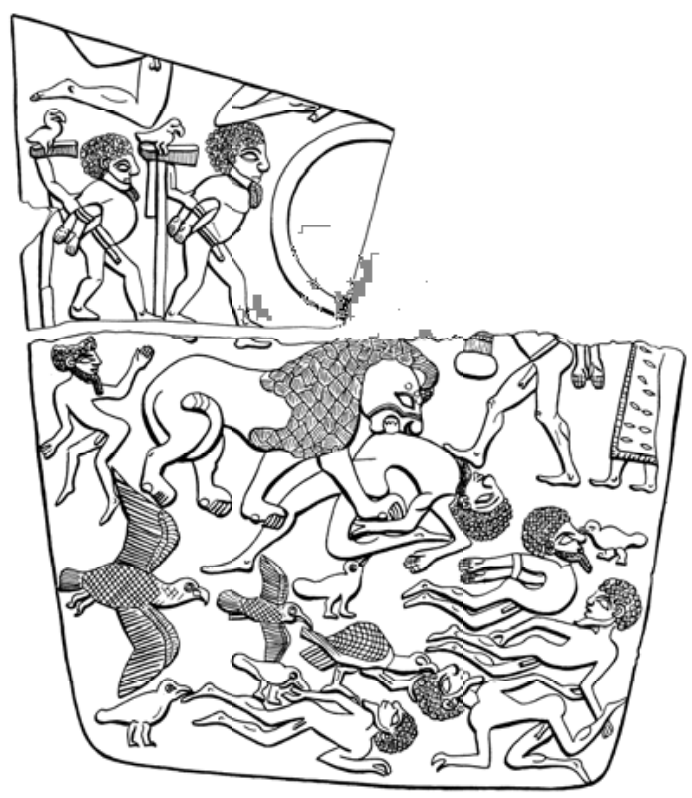

Abb. 1: Schieferpalette, wahrscheinlich aus Abydos in Ägypten, vor 3150 v. Chr. Ein Löwe mit gewaltiger Mähne überfällt auf einem Schlachtfeld einen wehrlos auf dem Rücken liegenden Mann (IPIAO 1 No 128).

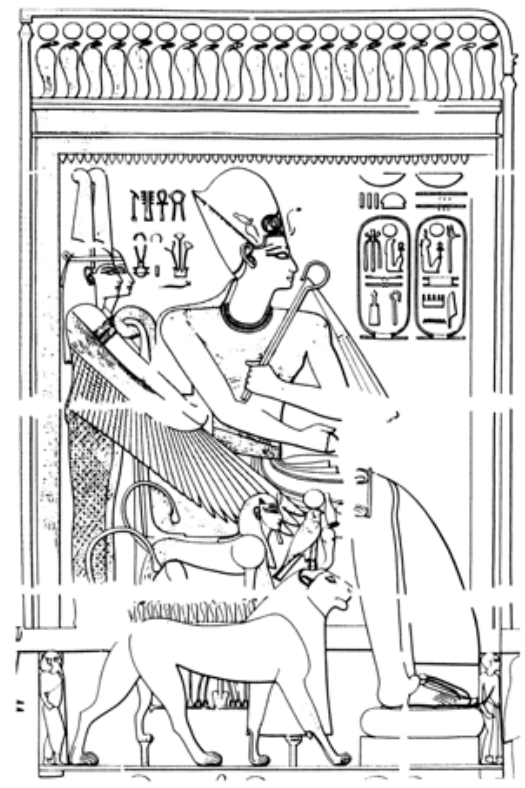

Abb. 3: Relief aus dem Totentempel Ramses' III. in Medinet Habu, 1183-1152 v. Chr. Der König ist in einer Kapelle thronend dargestellt. Hinter ihm steht in zweifacher Abbildung die Göttin Maat. Der Thronaufbau mit Sphingenlehnen wird von zwei vollplastischen Löwen flankiert. Auf ähnlichen Bildern handelt es sich manchmal aber auch um gezähmte lebende Tiere (IPIAO 3 No 560).

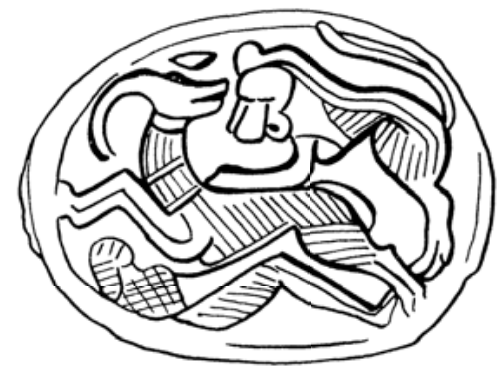

Abb. 2: Skarabäus aus Jericho, $1700-1550$ v. Chr. Ein Löwe fällt von hinten über einen fliehenden Capriden her, der den Kopf zum Angreifer wendet. Unter der Gruppe ist zudem ein auf dem Rücken liegender Mensch, der einen besiegten Feind darstellt, zu sehen (IPIAO 2 No 347).

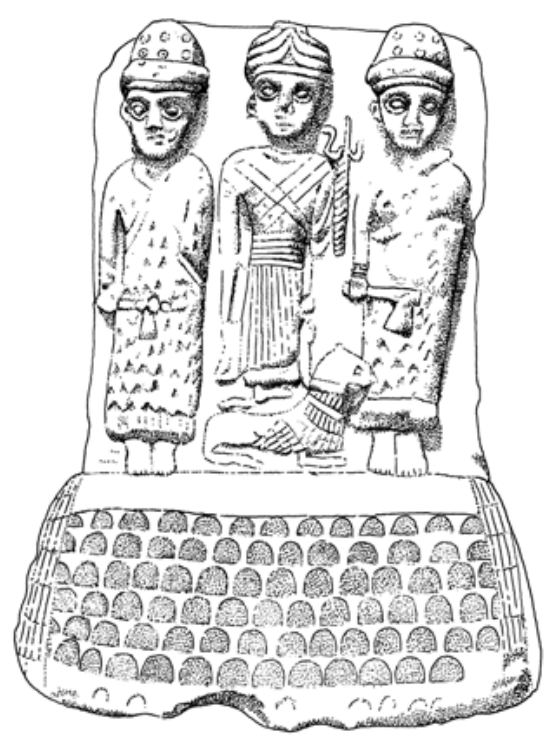

Abb. 4: Terrakottaplakette aus Mari, frühes 18. Jh. v. Chr. Die Göttin Ischtar steht zwischen zwei männlichen Begleitern auf einem kauernden Löwen. Ihre Waffen weisen sie als eine kriegerisch-kämpferische Göttin aus. Die ganze Gruppe steht auf einem durch Schuppenmuster angedeuteten Berg (IPIAO 2 No 449). 


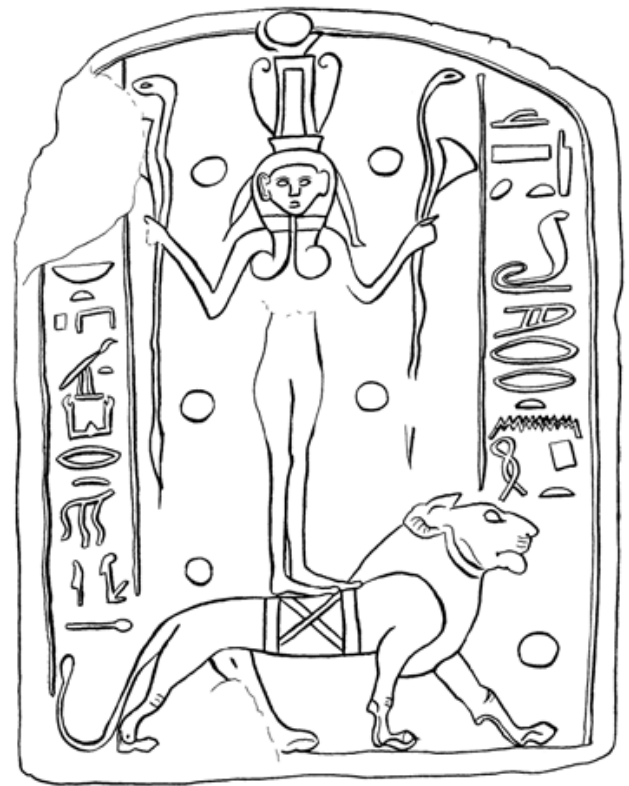

Abb. 5: Ägyptische Stele, 13. Jh. v. Chr. Eine kanaanäische Göttin steht frontal auf einem nach rechts schreitenden Löwen. Die erotische, nackte Göttin mit einer Lockenfrisur und einer Krone, die an das Sistrum der Hathor erinnert, hält in den Händen Schlangen und Blüten. In der Beischrift wird sie als Qedeschet, Geliebte des Ptah, bezeichnet (IPIAO 3 No 866).
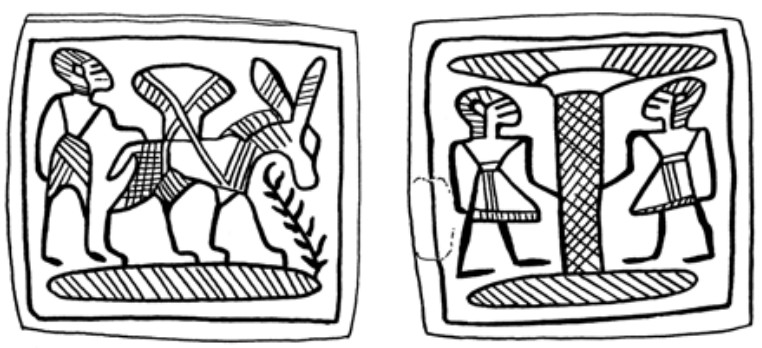

Abb. 7: Doppelseitig gravierte kleine Platte, wahrscheinlich aus der Gegend von Auaris im ägyptischen Delta, 1. Hälfte 16. Jh. v. Chr. Zu sehen ist auf einer Seite ein gezäumter Esel mit einer großen Last, begleitet von einem Eseltreiber. Auf der Rückseite stehen zwei Männer an einem stilisierten Baum, wahrscheinlich ein Hinweis auf einen Bündnisschluss oder Vertrag, der vielleicht mit Handel zu tun hatte. Der Esel spielte seit dem 3. Jt. v. Chr. eine bedeutende Rolle im Transport, im regionalen, aber auch im Fernhandel (IPIAO 2 No 267).

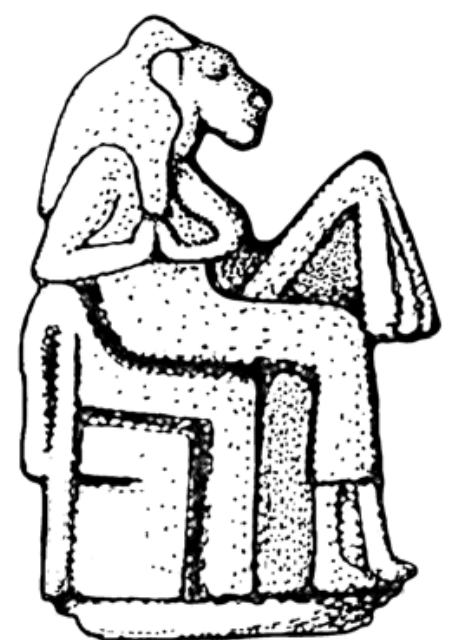

Abb. 6: Ägyptisches Amulettmodel, 13. Jh. v. Chr. Die ägyptische Partnerin des Gottes Ptah von Memphis war Sachmet, die als löwenköpfige Frau oder als Löwin dargestellt werden konnte. Hier thront sie, bekleidet, in einem eng anliegenden Kleid. Im Amulettwesen war die Göttin als Herrin über Seuchen und Krankheiten sehr beliebt (IPIAO 3 No 731).

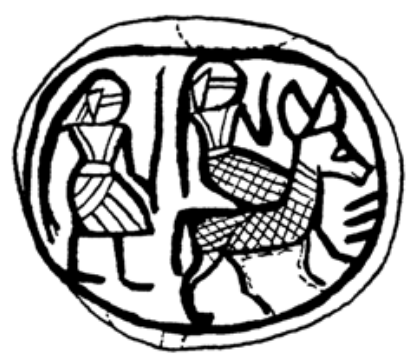

Abb. 8: Skarabäus aus dem Handel, 1700-1550 v. Chr. Zu sehen ist ein Eselreiter in Begleitung eines Mannes, der mit dem Stock den Esel antreibt. Das Reiten auf Eseln war ein Statussymbol, nur Angehörige der oberen Schichten konnten es sich leisten. In Ägypten betrachtete man das Eselreiten als typisch für die einheimische Bevölkerung im Sinai oder in Palästina/Israel (IPIAO 2 No 266). 


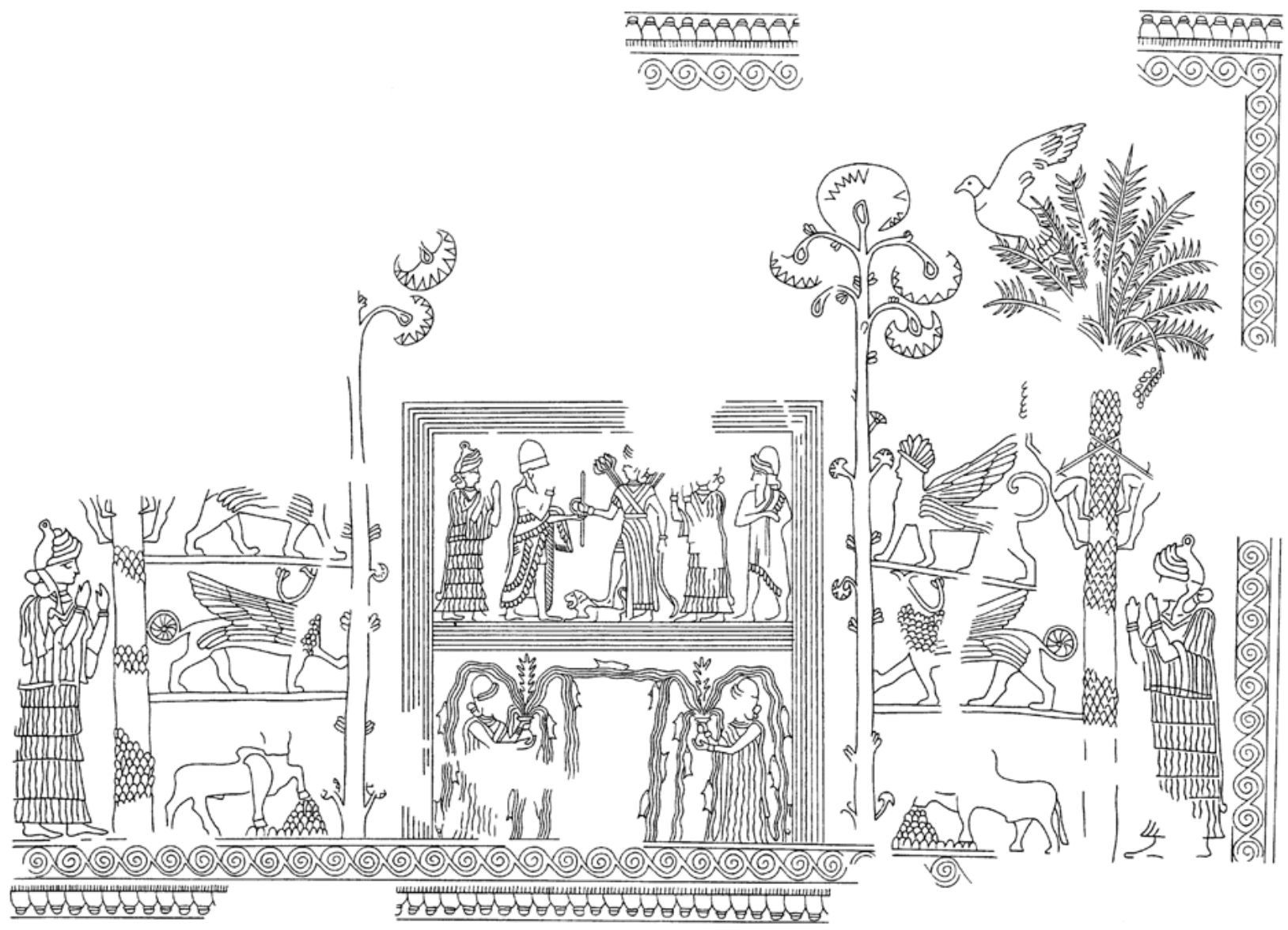

Abb. 9: Farbiges Fresko am Eingang des Thronsaals im Palast von Mari, um 1800 v. Chr. Auf dem einzigartigen Wandbild ist der Tempel der Ischtar inmitten eines Tempelgartens zu sehen. Dort begegnen sich der Herrscher von Mari und die Göttin, die den Fuß auf ihren Löwen stellt. Wächterwesen und fürbittende Göttinnen flankieren den Tempel, Quellgöttinnen im Untergeschoss sorgen für fließendes Wasser. Stilisierte Bäume und Dattelpalmen gehören zum Park. In den Ästen der Palmen sitzen weiße, übergroße Tauben, doch ist nur die Palme auf der rechten Seite mit der Taube erhalten (IPIAO 2 No 424).

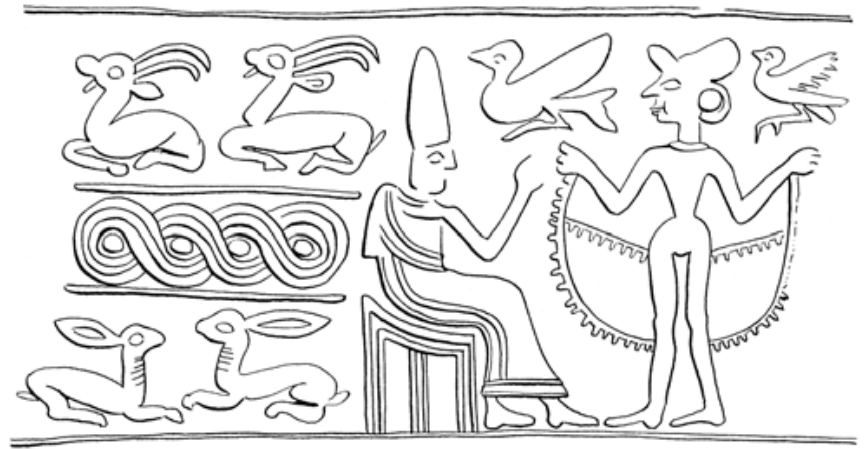

Abb. 10: Altsyrisches Rollsiegel, 18. Jh. v. Chr. Eine erotische Göttin entschleiert sich vor einem thronenden Stadtfürsten. Zwei Tauben fliegen von ihr zu ihm, um ihre Zuneigung deutlich zu machen. In den Nebenszenen finden sich Ziegen und Hasen, die die nackten Göttinnen oft begleiten (IPIAO 2 No 439). 


\title{
Von Einhorn, Hirsch, Pelikan und anderem Getier
}

\author{
Septuaginta, Physiologus und darüber hinaus
}

\begin{abstract}
The Physiologus describes many animals (or creatures), with which we are very familiar today as "beautiful" ( $\alpha \alpha \tilde{\omega} \varsigma)$, while others seem odd and still others rather mythical to us. In many cases its author quotes suitable verses from the Old and New Testament, arranges them accordingly and creates an independent interpretation without identifying these quotations as such and/or designating them as formulas. In doing so, the Physiologus relies on the Greek version of the Old Testament, the Septuagint, and quotes from it. This study provides an overview of the animals that can be found both in the Septuagint and the Physiologus. It focuses on selected example chapters of the Physiologus, describing the respective contexts and discussing their significance for the quotations. The study also seeks to determine why certain lexemes were used, while other available ones were not. Finally, this article offers suggestions about why certain mythically determined animals (or creatures) found their way into the Physiologus.
\end{abstract}

\section{Einleitung}

Castleton in der Grafschaft Derbyshire liegt malerisch im Peak District Nationalpark in Nordengland, ein Ort, der viele Ausflügler und Touristen anzieht. Hauptattraktionen sind die malerische Landschaft mit den atemberaubenden Anhöhen, die ansprechenden tea rooms und vor allem Peveril Castle, das auf normannische Ursprünge zurückgehen soll und dessen Ruinen nebst Burgfried majestätisch über der Ortschaft thronen. Wer die Stufen dorthin hinaufsteigt, kommt am ehemaligen Marktplatz an einem Denkmal vorbei, wie es sich in England vielerorts findet: Es wird an einer zentralen und gut einsehbaren Stelle der gefallenen Soldaten der beiden Weltkriege gedacht. Hier in Castleton handelt es sich dabei um ein Steinkreuz mit dezidierter Ornamentik und Ikonographie. Auf der Vorderseite des übermannsgroßen Kreuzes ist ein Engel zu sehen, der in aufrechter Haltung mit beiden Händen die Seitenenden des Griffs eines Schwerts hält, das mit der Spitze auf dem Boden steht. Darüber in der Kreuzung der Balken findet sich ein anmutiger, ruhender Hirsch in Seitenansicht inmitten eines detailliert ausgestalteten Lorbeerkranzes. ${ }^{1}$ Und auf der Unterseite des Querbalkens ist auf jeder Seite eine in sich eingedrehte Schlange abgebildet. Jeweils fünf weitere solche Schlangendarstellungen befinden sich unterhalb dieser beiden auf der linken und rechten Außenseite des Vertikalbalkens des Kreuzes. Selbstverständlich fallen für den Engel mit dem Schwert, ${ }^{2}$ den Hirsch $^{3}$ und die Schlangen ${ }^{4}$ sofort passende und gängige Bibelstellen ein. Wer sich aber mit dem Physiologus beschäftigt, der erinnert sich bei der Verbindung von Hirsch und Schlange auch an Kapitel 30 dieses erstaunlichen, wirkungsreichen und populären Texts, der wie kaum ein anderer schon sehr früh eine große Verbreitung fand und über das Mittelalter und die Renaissance hinaus zu einer Art allgemeinem Bildungsgut wurde. ${ }^{5}$ Seine Geschichten wirken bis heute nach und fanden vielfachen und vielfältigen Widerhall in Literatur und Kunst. ${ }^{6}$ Es verwundert nicht, dass der Physiologus in eine Vielzahl an Sprachen übersetzt wurde ${ }^{7}$ und

1 Eine knappe, aber unvollständige Beschreibung des Denkmals inklusive Foto findet sich auf den Internetseiten von geograph (http://www.geograph.org.uk/photo/3989500). Auf der dem Engel gegenüberliegenden Seite ist ,a mythical bird on a nest with four chicks“ dargestellt. Ansonsten sind noch keltische Elemente vorhanden (,Celtic knots on the east and west sides and swirls on the north and south sides“).

2 Vgl. Gen 3,24; Num 22,23; Jos 5,13-15. Auch wenn in Offb 12,7-9 nicht dezidiert von einem Schwert die Rede ist, wird in der christlichen Tradition und Ikonographie alsbald der Erzengel Michael als Kämpfer, Schützer und Retter mit einem Schwert vorgestellt, der wie ein Soldat und Heerführer in die Schlacht gegen den Satan und die Seinen zieht. Michael wird zusehends auch zum Seelenwäger beim Jüngsten Gericht, also quasi als Hüter des Paradiestors, eine Vorstellung, die seit dem Nikodemusevangelium 25 dann spezifische Ausprägungen findet. Generell zum Nikodemusevangelium vgl. Röder (2010).

3 In dieser Hinsicht einschlägig ist vor allem Psalm 42,2 $2^{\mathrm{MT}} / 41,2^{\mathrm{LXX}}$. Vgl. besonders die Studien von Schaper (2004).

4 Die Bedeutung der Schlange im Alten und Neuen Testament, im Judentum und frühen Christentum ist hinlänglich bekannt. Vgl. etwa Hendel (1999, 744-747); Charlesworth (2004, 499-515); Frey-Anthes (2008), besonders Abschnitt „3. Schlange im Alten Testament“. Von Belang sind auch die Beiträge derselben Autorin zu den Stichworten „Kobra/Natter“ und „Otter/Viper“ in WiBiLex.

5 Vgl. den Beitrag von S. Vollenweider.

6 Vgl. Treu (1981 ['1998], 122-128); Schönberger (2001, 151-158). Als Standard ist anzusehen Schneider (2016, 722-743).

7 Vgl. exemplarisch hierzu Hommel (1877); Dahlerup (1889, 199290); Peters (1898 [1976]); Graf (1906); Carmody (1939); MacCoull 
auch in mehreren Redaktionen bzw. Fassungen vorliegt, ${ }^{8}$ von denen sich manche inhaltlich und in Schwerpunktsetzungen offensichtlich weiterentwickelt und so von einer (hypothetisch) angenommenen ursprünglichen Textgestalt entfernt haben. ${ }^{9}$ So tradiert und rezipiert, stellt der Physiologus selbst eine interessante Quelle für die zahlreichen Bibelzitate aus dem Alten und Neuen Testament dar. ${ }^{10}$ Welche Form ist im Physiologus jeweils erhalten? Wie hat sich die Übertragung in eine andere Sprache auf den zitierten Bibeltext ausgewirkt? Dass die Untersuchung dieses singulären Aspekts bereits den Rahmen dieser Studie sprengen würde, ist bei einem kritischen Blick auf die Rezensionen und Übersetzungen schnell klar.

Was aber dennoch von Interesse erscheint und bislang keine Aufmerksamkeit erhalten hat, sind die Zitate aus dem Alten Testament, die jeweils mit einem im Physiologus - mehr oder minder - behandelten Tier zusammengebracht werden. Der ursprünglich auf Griechisch verfasste Physiologus zitiert die griechische Textform des Alten Testaments, also die Septuaginta. Anhaltspunkte für eine Bezugnahme auf den hebräischen Text gibt es im Physiologus nicht. Deshalb werden als griechische Textgrundlagen auch in Ermangelung kritischer Ausgaben für manche Bücher des Alten Testaments bzw. anstehender Neuausgaben aus dem Göttinger Septuaginta-Unternehmen - für die Septuaginta die Handedition von Rahlfs in der Neuedition von Hanhart ${ }^{11}$ und für den Physiologus die nach wie vor maßgebliche Ausgabe von Sbordone in Verbindung mit anderen und weiteren Arbeiten herangezogen. ${ }^{12}$

Allerdings kann sich die Aufgabe nicht allein darin erschöpfen, die griechischen alttestamentarischen Zitate im griechischen Physiologus zu lokalisieren und einfach

(1991); Stoykova (1994, 2009-2012); Armistead (2001); Gottheil (2003); Wentker (2004); Schneider (2016, 740-741).

8 Vgl. Kaimakos (1974); Henkel (1976); Treu (1982 [ [31998], 446-478); Schönberger (2001, 150); Schneider (2016, 737-743). Selbst einzelne Handschriften sind in diesem Zusammenhang aufschlussreich und interessant. Exemplarisch sei auf den Physiologus Bernensis verwiesen (Codex Bongarsianus 318 der Burgerbibliothek Bern). Hierzu die Ausgabe durch von Steiger und Homburger (1964/2012). Hierzu auch der Beitrag von Horst Schneider in diesem Band.

9 Für weitere Informationen vgl. v. a. Schneider (2016, 740-743), ferner Perry (1941, 1074-1129), Alpers (1996, 596-602). Zudem seien genannt die Studien von Henkel (1976) und Schröder (2005).

10 Vgl. Treu (1981 [31998], 118-121).

11 Vgl. Rahlfs und Hanhart (2006).

12 Vgl. Sbordone (1936a). Hierzu aber unbedingt Kaimakis (1976) sowie Alpers (1984); Offermann (1966). Als hilfreich erweisen sich die Anmerkungen (und die deutsche Übersetzung) von Treu (1981 [31998]) und die griechisch-deutsche Ausgabe mit Anmerkungen und Nachwort von Schönberger (2001). Zu Letzterer vgl. die Rezension von Schneider (2002, 1019-1034). quantitativ nach ihrer Herkunft aus bestimmten Büchern des Alten Testaments zu systematisieren. Darüber hinaus ist der Funktion der Zitate und der Art und Weise der Zitation, d.h. die Einpassung in den Kontext eines Abschnittes, nachzuspüren und somit die Intention des Autors und die Verzweckung der Septuaginta-Zitate zu bestimmen. Wo werden welche Tiere und entsprechende Zitate aus dem Alten Testament zusammengespannt? Welche inhaltliche Bedeutung spielen dabei die Zitate für den restlichen $\mathrm{Ab}$ schnitt? Wie lässt sich die Verbindung zwischen Zitation, Tier und zentraler Aussage des jeweiligen Abschnitts näher beschreiben ${ }^{13}$ Hat der Autor des Physiologus bei der Auswahl der Tiere und der Zitation aus dem Alten Testament bestimmte alttestamentarische Texte (und/oder Kontexte) ganz besonders im Sinn und bezieht sich auf diese? Die Gesamtbetrachtung aller Septuaginta-Zitate im Physiologus stellt ein Desiderat für eine analytischinterpretatorische Monographie dar.

Doch zeigt sich rasch, dass der Physiologus voller Geheimnisse steckt und gerade dann Schwierigkeiten birgt, wenn mit modernem Denken und Kategorisierungsversuchen an diesen faszinierenden Text herangegangen wird. Im Konkreten heißt das etwa, dass selbst die bloße Unterscheidung zwischen Tieren, Pflanzen und Steinen in den achtundvierzig dem eigentlichen Physiologus zugeschriebenen Kapiteln, wie sie oftmals einfach so erfolgt, nicht unproblematisch ist. Schließlich sind manche Wesen nicht der einen oder anderen der drei Kategorien zuzuordnen. Zudem beinhaltet der Physiologus zweiundvierzig Tier-, zwei Pflanzenarten und vier Arten von Steinen. Die „drei heiligen Jünglinge“ von Kapitel 31a jedoch mögen hier ebenso wenig passen wie die Sirenen und Kentauren von Kapitel 13, immerhin dort als halb Mensch und halb Tier ausgewiesen. Auch Mythisches hat offensichtlich Eingang gefunden, wobei zu hinterfragen ist, ob für die spätantike Leser- und Hörerschaft Sirenen und Kentauren (Kap. 13) oder der Ameisenlöwe (Kap. 20) nicht doch als Realität aufgefasst wurden. ${ }^{14}$ Das Einhorn (Kap. 22) jedenfalls galt als literarische Tatsächlichkeit. Selbst der oftmals konstatierte analoge Aufbau der Kapitel ist

13 Den Weg hierzu weist Treu (1981 [31998], 119-120), indem sie im Nachwort ihrer Übersetzung knapp anführt: „Nicht die Bücher werden am häufigsten zitiert, in denen Tiere überhaupt vorkommen, wie in den Mosebüchern, nein, der Physiologus bevorzugt durchaus die Psalmen und die Propheten, in denen die Tiere nicht reale zoologische Wesen sind, sondern sehr früh allegorisch gedeutet wurden.“ Das mag auf die konkreten Septuaginta-Zitate zutreffen, jedoch nicht auf Stellen, an denen die Septuaginta „öfter noch indirekt mit vielen Anspielungen“ (120) eingebunden ist.

14 Vgl. Schneider (2016, 724-725). 
letztlich zwar häufig gleich, jedoch gilt das nicht für alle Kapitel. Selbst die formelhaften Wendungen sind nicht verlässlich überall vorhanden bzw. dort, wo sie vorhanden sind, nicht überall gleich. ${ }^{15}$ Eindeutige und verbindliche Kategorisierungen der Kapitel werfen wiederum Probleme auf.

Trotzdem kann im Folgenden anhand ausgewählter Beispielkapitel, demnach exemplarischer Tiere, aufgezeigt werden, welche Rolle die Septuaginta überhaupt im Physiologus spielt. Denn eines wird bei der ersten Lektüre des Physiologus klar: Hier kennt jemand seine Quellen genau, ${ }^{16}$ geht aber dennoch äußerst flexibel mit diesen um, nimmt sich jemand selbstbewusst die Freiheit, in eine bestimmte interpretatorische Richtung zu gehen.

\section{Die Tiere im Physiologus - eine Zusammenschau mit Hilfe von Lev 11/Dtn 14}

Die Affinität des Autors des Physiologus mit biblischen Texten fällt rasch auf. So erscheint es arbeitshypothetisch gerechtfertigt, geeignete biblische Vergleichstexte $\mathrm{zu}$ suchen, in denen bestimmte Tiere auf engerem Raum vorkommen. Dabei werden meist Tiere nach bestimmten Kriterien kategorisiert und in fester Abfolge wiedergegeben. Es fallen in dieser Hinsicht in erster Linie auf:

(a) Schöpfungsbericht (Gen 1,1-2,4a) und Schöpfungserzählung bieten keine konkreten Tiere sondern nur Sammelbezeichnungen und Abstrakta wie Tiere im Wasser und in der Luft (Gen 1,20-22; 2,19) und „Vieh, Gewürm und Tiere des Feldes“ (Gen 1,24-25; 2,19), was für eine Verbindung zwischen den Tierarten in der Septuaginta und im Physiologus nicht wirklich weiterhilft.

(b) Die Unterscheidung zwischen Wasser-, Land- und Lufttieren jedoch schlägt sich auch anderweitig nieder. Lev 11 gibt klar vor, welche Tiere als rein und welche als unrein $\mathrm{zu}$ gelten haben, welche verzehrt werden dürfen und welche nicht und wie man generell diesbezüglich mit Reinheit und Unreinheit umzu-

15 So summarisch Schönberger (2001, 149). Dazu auch Schneider (2016, 731), der eher auf die einheitliche Struktur der Kapitel abhebt („Alle sind nach einem formalisierten Muster strukturiert“).

16 Mit Schönberger $(2001,143)$ ließe sich sogar behaupten: „Zudem besaß der Autor eine fundierte Kenntnis der Heiligen Schriften (AT, NT) und zitiert daraus höchst kunstvoll; oft erweckt er mit nur einem Wort die Erinnerung an eine oder gar mehrere in den Zusammenhang passende Bibelstellen.“ gehen habe. Analog ist damit auch Dtn 14 miteinzubeziehen. Generell wird dabei unterschieden zwischen

1) Tieren des Landes (Landtieren),

2) Tieren des Wassers (Fischen),

3) Flugtieren (Vögeln und Insekten) und

4) weiteren Landtieren und Tieren, die auf der Erde kriechen (Kriechtieren).

Diese Aufteilung erfolgt grundsätzlich nach „den Lebensräumen Erde, Wasser und Luft““. ${ }^{17}$ Dem lässt sich gut zuordnen, was der Physiologus als Tiere behandelt:

1) Tiere des Landes (in Klammern die jeweilige Kapitelnum$\operatorname{mer}^{18}$ )

\section{Löwe (1)

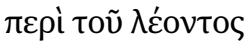

Wildesel (9) + (45)

пері ỏvóypou

Ameise (12)

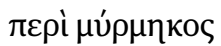

Igel (14)

$\pi \varepsilon \rho \grave{~ \varepsilon x \chi i ́ v o v ~}$

Fuchs (15)

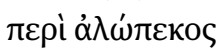

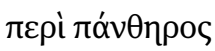

Ameisenlöwe (20)

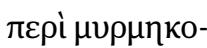

$\lambda$ ÉovTos

Wiesel (21)

$\pi \varepsilon \rho i$ y $\alpha \lambda \tilde{n} \varsigma$

Einhorn (22)

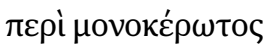

2) Tiere des Wassers:

Walfisch (17)

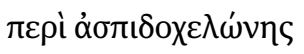

Biber (23)

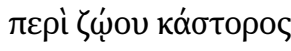

Fischotter (25)

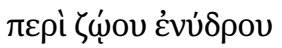

Panther (16)
Hyäne (24)

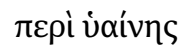

Ichneumon (26)

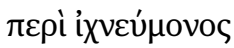

Landfrosch (29)

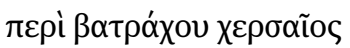

Hirsch (30)

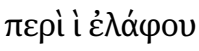

Antilope (36)

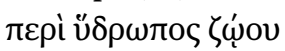

Gazelle (41)

$\pi \varepsilon \rho \grave{~ \delta o ́ p \kappa \omega v o \varsigma ~}$

Elefant (43)

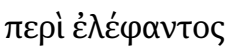

Affe (45)

$\pi \varepsilon \rho \grave{~ . . . ~} \pi \mathrm{\imath} \theta$ ńкоv
17 Vgl. Ego (2007). Weiterführend Janowski und Neumann-Gorsolke (1993, 214-218).

18 Nach Sbordone (1936a) und Schönberger (2001). 
3) Flugtiere:

\begin{tabular}{|c|c|}
\hline 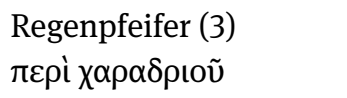 & 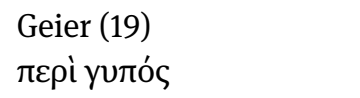 \\
\hline 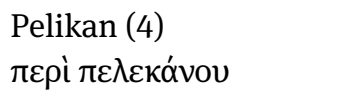 & 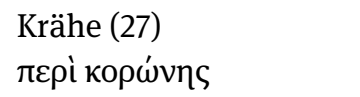 \\
\hline 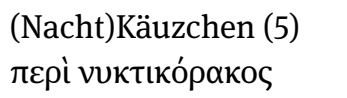 & $\begin{array}{l}\text { Turteltaube }(28+28 a) \\
\pi \varepsilon p i \text { } \rho \rho y o ́ v o \varsigma\end{array}$ \\
\hline $\begin{array}{l}\text { Adler (6) } \\
\pi \varepsilon \rho \grave{~ \alpha ̉ \varepsilon \tau o v ̃ ~}\end{array}$ & $\begin{array}{l}\text { Taube }(28 a+35+35 a+35 b) \\
\pi \varepsilon \rho i ̀ ~ . . . ~ \pi \varepsilon \rho ı \sigma \tau \varepsilon \rho \tilde{~} \varsigma\end{array}$ \\
\hline 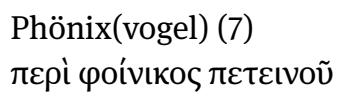 & $\begin{array}{l}\text { Schwalbe }(33+33 a+33 b) \\
\pi \varepsilon \rho i ̀ ~ \chi \varepsilon \lambda_{1} \delta \text { óvo }^{2}\end{array}$ \\
\hline 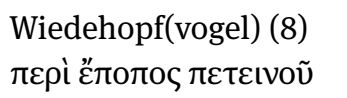 & 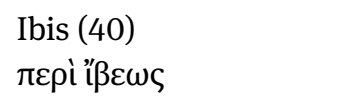 \\
\hline 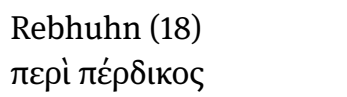 & $\begin{array}{l}\text { Reihervogel (47) } \\
\pi \varepsilon \rho \grave{~ \varepsilon ́ p o \delta เ o v ̃ ~ \pi \varepsilon \tau \varepsilon ı v o v ̃ ~}\end{array}$ \\
\hline
\end{tabular}

4) Weitere Landtiere und Tiere, die auf der Erde kriechen:

Sonnen-Eidechse (2)

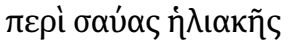

Schlange (11+30)

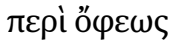

Natter (10)

$\pi \varepsilon p i ̀$ ćxíovns

Salamander (31)

$\pi \varepsilon \rho \grave{~} \sigma \alpha \lambda \alpha \mu \alpha \dot{v} v \delta \rho \alpha \varsigma$

Dabei ist von Interesse, welche dieser Tiere in der Septuaginta vorkommen, d.h. welche griechische Bezeichnung sich in der Septuaginta und im Physiologus findet. Diese sind im Folgenden mit einem Sternchen gekennzeichnet. Doch sei schon hier darauf hingewiesen, dass die Reihenfolge des Physiologus nicht mit jener in Lev $11^{19}$ und Dtn $14^{20}$ übereinstimmt:

\footnotetext{
19 Lev 11,1-38: 1) Vieh - Kamel - Hase - Kaninchen - Schwein // 2) Flossen und Schuppen // 3) Adler - Greif - Seeadler - Geier - Hühnergeier - Rabe - Strauß - Eule - Möwe - Falke - Langohreule - Kormoran - Ibis - Wasserhuhn - Pelikan - Schwan - Reiher - Regenpfeifer - Wiedehopf - Fledermaus // [Insekten] Bruchos-Heuschrecke - Attakes-Heuschrecke - Grille - Schlangenkämpfer // 4) Wiesel Maus - Landkrokodil - Feldmaus // Chamäleon - Gecko - Eidechse Maulwurf.

20 Dtn 14,3-20: 1) Jungstier - Lamm - Böcklein - Hirsch - Gazelle Antilope - Bockhirsch - Weißsteiß - Steinbock - Giraffe // Kamel Hase - Stachelschwein - Schwein // 2) Flossen und keine Schuppen // 3) Adler - Greif - Seeadler - Geier - Weihe - Rabe - Spatz - Eule Möwe - Falke - Reiher - Schwan - Ibis - Kormoran - Wiedehopf Nachtrabe/Käuzchen - Pelikan - Regenpfeifer - Wasserhuhn - Fledermaus.
}

1) Tiere des Landes:

\begin{tabular}{|c|c|}
\hline ^ Löwe (1) & ^ Hyäne (24) \\
\hline ^ Wildesel (9)+(45) & Ichneumon (26) \\
\hline ^ Igel (14) & Landfrosch (29) \\
\hline ^ Fuchs (15) & ${ }^{\star} \operatorname{Hirsch}(30)$ \\
\hline${ }^{\star}$ Panther (16) & Antilope (36) \\
\hline ^ Ameisenlöwe (20) & ${ }^{\star}$ Gazelle (41) \\
\hline ^ Wiesel (21) & ^Elefant (43) \\
\hline * Einhorn (22) & * Affe (45) \\
\hline
\end{tabular}

2) Tiere des Wassers:

\begin{tabular}{|c|c|}
\hline Walfisch (17) & Wasserfrosch (29) \\
\hline Biber (23) & Ungetüm „Säge“ (39) \\
\hline \multicolumn{2}{|l|}{ Fischotter (25) } \\
\hline \multicolumn{2}{|l|}{ 3) Flugtiere: } \\
\hline ^ Regenpfeifer (3) & ${ }^{\star}$ Geier (19) \\
\hline ^ Pelikan & * Krähe (27) \\
\hline * (Nacht)Käuzchen (5) & ^ Turteltaube (28) \\
\hline${ }^{\star}$ Adler (6) & * Taube $(28 a+35+35 a+35 b)$ \\
\hline Phönix(vogel) (7) & * Schwalbe $(33+33 a+33 b)$ \\
\hline${ }^{\star}$ Wiedehopf $(8)$ & ${ }^{\star}$ Ibis $(40)$ \\
\hline${ }^{\star}$ Rebhuhn (18) & ${ }^{\star}$ Reihervogel (47) \\
\hline
\end{tabular}

4) Tiere, die auf der Erde kriechen:
* Sonnen-Eidechse (2)
* Schlange (11+30)
Natter (10)
Salamander (31)

Natürlich handelt es sich hier um eine kritisier- und hinterfragbare Kategorisierung, die nur arbeitshypothetisch dazu dient, bestimmte Gruppierungen vorzunehmen und die Gruppen dann auch leichter ansprechen zu können. ${ }^{21}$ Dennoch fällt aber auf, dass gerade die Flugtiere (Vögel) allesamt in der Septuaginta vorkommen. Zudem weisen Septuaginta und Physiologus dieselben griechischen Lexeme für diese Tiere auf. Das mag umso mehr auf den ersten Blick erstaunen, da es sich mitunter durchaus um spezifische Vogelarten handelt. Weniger überraschend ist dagegen die Übereinstimmung beider Texte hinsichtlich so

\footnotetext{
21 Zoologisch betrachtet ist der Biber ein Tier, das sich außerhalb des Wassers (und auch in seinem Bau) aufhält, dennoch aber sich problemlos und natürlich im Wasser bewegt. Die Ameise gehört demnach auch weniger zu der schwammigen Kategorie der Landtiere als eher zu den Insekten. Diese beiden Tiere sollen genügen, um Obiges näher zu erläutern.
} 
mancher Landtiere, die letztlich gut bekannt und verbreitet waren. $\mathrm{Zu}$ bemerken ist darüber hinaus, für welche Tiere bzw. für welches Tierkapitel ein Septuaginta-Zitat Verwendung findet und sich so das Feld der hier für die Zwecke und Zielsetzungen der Studie anzuvisierenden Tiere weiter lichtet:

1) Tiere des Landes:

$\begin{array}{ll}\text { Löwe (1) } & \text { Ameisenlöwe (20) } \\ \text { Wildesel (9)+(45) } & \text { Wiesel (21) } \\ \text { Ameise (12) } & \text { Einhorn (22) } \\ \text { Fuchs (15) } & \text { Hyäne (24) } \\ \text { Panther (16) } & \end{array}$

2) Tiere des Wassers

3) Flugtiere

$\begin{array}{ll}\text { Regenpfeifer (3) } & \text { Geier (19) } \\ \text { Pelikan (4) } & \text { Krähe (27) } \\ \text { Käuzchen (5) } & \text { Turteltaube (28) } \\ \text { Adler (6) } & \text { Ibis (40) } \\ \text { Rebhuhn (18) } & \text { Reihervogel (47) }\end{array}$

4) Tiere, die auf der Erde kriechen:

Schlange (30)

Alle diese Abschnitte werden durch ein Septuaginta-Zitat eröffnet mit Ausnahme der Kapitel des Regenpfeifers (3) und des Ibis (40), die durch indirekte Verweise, d.h. kein wörtliches Zitat, sondern einer eher summarischen Bezugnahme auf das Alte Testament eingeleitet werden. Auf den Regenpfeifer wird mit Hilfe von Lev 11,19 bzw. Dtn 14,18 re-

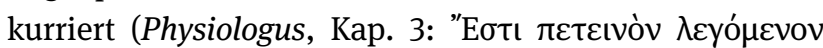

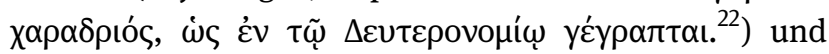
der Ibis gilt nach Lev 11,17 als unreines Tier (Physiolo-

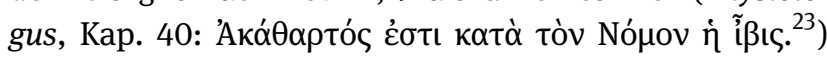
Dementsprechend sind bereits dadurch verschiedene Vorgehensweisen für die Verwendung der Septuaginta im Physiologus aufgezeigt, eben die wörtliche Zitation eines Bibelverses oder die summarische bzw. rein auf den Aussageinhalt konzentrierte Bezugnahme auf das Alte Testament. Zudem sind bereits durch diese Aufstellung Lev 11,138 und Dtn 14,3-21 und die entsprechenden Gebote bezüg-

22 Für textliche Varianten vgl. Sbordone (1936a, 11 Apparat). Allerdings werden diese für den vorliegenden Satz als unwesentlich erachtet, da sich dieser nicht wesentlich durch Akzeptanz einer Lesart verändern würde.

23 Für textliche Varianten vgl. Sbordone (1936a, 123 Apparat). lich Speisen und Reinheit/Unreinheit als Vergleichspunkte nahegelegt. ${ }^{24}$

\section{Einzelne Tiere in Septuaginta und Physiologus - Individuelles und Methodisches}

Im Physiologus werden Tiere trotz aller systematisch-strukturell ähnlichen bis gleichen Abläufe innerhalb etlicher Kapitel dennoch individuell behandelt, insbesondere wenn das Hauptaugenmerk auf die Verbindungslinien zwischen Septuaginta und Physiologus gelegt wird. Natürlich finden sich auch Tiere, die im Alten Testament und der griechischen Version nicht vorkommen, wie u.a. der zum Sprichwort gewordene Phönix ${ }^{25}$ oder das merkwürdige Ichneumon. Dennoch bleibt eine beachtliche Zahl an Tieren übrig, mit Hilfe derer eine Verhältnisbestimmung zwischen Septuaginta und Physiologus erfolgen kann. Und diese wird anders ausfallen als eine ebensolche hinsichtlich Neuem Testament und Physiologus. Denn grundsätzlich wird durch die herangezogenen neutestamentlichen Stellen und Zitate die Naturgeschichte auf den Erlöser und das Heilsgeschehen bezogen, werden wesentliche theologische Thematiken allegorisiert, ${ }^{26}$ zumal Naturgeschichtliches und Zoologisches ohnehin nicht im Vordergrund stehen und die Hauptintention des Autors darstellen. ${ }^{27}$

Im Folgenden liegt der Fokus auf vier Kapiteln - Einhorn [22], Ameisenlöwe [20], Hirsch und Schlange [3] und Pelikan [4] -, mit Hilfe derer die Unterschiedlichkeit sowie die Spezifika des Umgangs mit der Septuaginta durch den Autor des Physiologus illustriert wird. Die Auswahl beruht generell auf drei Kriterien: (a) Die Besonderheit der Rezeptions- und Wirkungsgeschichte (Einhorn, Hirsch und Schlange sowie Pelikan), (b) die Singularität der Darstellung (Ameisenlöwe) und (c) die verschiedene und gleichzeitig tendenziell analoge Funktion des SeptuagintaZitats für das gesamte Kapitel (alle vier ausgewählten Kapitel).

24 Auch die Relation der beiden Abschnitte Lev 11,1-38 und Dtn 14,321 zueinander wäre von Interesse, würde aber bei angemessener Behandlung den Umfang dieser Studie bei Weitem sprengen. 25 Über die Symbolik des Phönix vgl. Günter (2007, 73).

26 Vgl. Schneider (2016, 737). 27 Vgl. Schneider (2016, 726). 


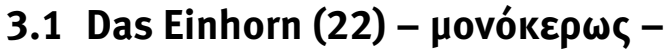 zwischen Mythos und Faktum?}

Gerade das Einhorn zog und zieht immer wieder großes Interesse auf sich. ${ }^{28}$ Für viele offensichtlich ein Fabelwesen, mystisch und mythisch, ein Wesen, das Anlass für mannigfaltige Spekulationen, Filme, Musiktitel und literarische Motive gab und gibt. The Last Unicorn trällerte die britisch-amerikanische Folkrock-Band America 1982 zum gleichnamigen Zeichentrickfilm. Bereits antike und spätantike Schriftsteller kennen das Tier bzw. die Tiere mit einem Horn (vgl. Aristoteles, Aelian, Oppian, Plinius der Ältere und Plutarch) und schreiben wie selbstverständlich über ein starkes, wildes und dem Esel oder auch Pferd ähnliches Tier, das vorne ein Horn trägt. ${ }^{29}$ Gerade dem Horn wird eine hohe Wirksamkeit zuerkannt, als Trinkgefäß etwa macht es verabreichtes Gift unwirksam. All das wird auf Ktesias von Knidos aus dem 5. bis 4. Jahrhundert vor unserer Zeitrechnung zurückgeführt, der das weiße, wilde Tier mit dem einen Horn geographisch an Indien festmacht. Ihm zufolge seien die Wildesel so groß wie Pferde, schnell und kräftig und können nicht lebend gefangen werden (FGrH 688 F 45q). Aelian weiß von einem spiralig gedrehten Horn (De natura animalium 3.41, 4.52). Interessanterweise fehlen in der griechisch-römischen Mythologie Hinweise auf das Einhorn, das auch ikonographisch keine Rolle spielt, dann aber in der mittelalterlichen Buchmalerei ein beliebtes Motiv wird. ${ }^{30}$

Wie dem auch sei, das Einhorn bzw. Tier mit einem Horn ist faktisch sowohl bei klassischen Autoren als auch

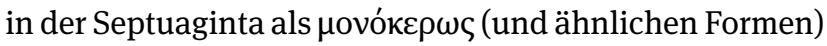
bezeichnet und belegt. Demnach gab es für den antiken Menschen ein Tier mit einem Horn, dem bestimmte Eigenschaften zugeschrieben wurden.

Der Abschnitt über das Einhorn (Kap. 22) ${ }^{31}$ ist im Physiologus wie folgt strukturiert: ${ }^{32}$

(1) Septuaginta-Stelle (Ps 91,11a ${ }^{\mathrm{LXX}}$ ):

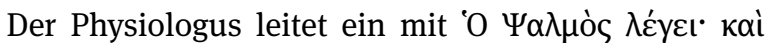

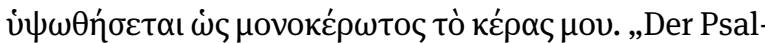

28 Gute Orientierung bietet v.a. Bloch (2006). Ferner Hünemörder (2006) und Hagenmaier (2003). Für eine rasche Orientierung vgl. Günter (2007, 32-34).

29 Vgl. Schönberger (2001, 138-139).

30 Vgl. Bloch (2006).

31 Das Kapitel fehlt in der redactio secunda byzantina. Vgl. Sbordone (1936a, LXXX-CV) und die Zusammenstellung von Schneider (2016, Abb. 1: Übersicht der ersten drei Redaktionen und Appendix [nach Sbordone]).

32 Zu den späteren Erweiterungen des Kapitels vgl. Treu (1981 [ ${ }^{3} 1998$ ], 42-44 und 137-138) sowie R. Hirsch-Luipold im vorliegenden Band, S. 139. mist sagt: ,Und erhöht werden wie das des Einhorns wird mein Horn.““

(2) Formelhafte Überleitung zum Physiologus:

Es folgt unmittelbar eine formelhafte Überleitung auf

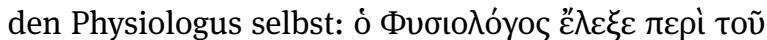

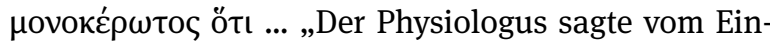
horn, dass ...“

(3) Explikation/Charakterisierung durch den Physiologus:

Das Einhorn wird beschrieben als klein, hitzig, stark, mit einem Horn mitten auf dem Kopf. Wichtig erscheint auch, zu wissen, wie das Einhorn zu bezwingen bzw. zu fangen sei. Bei Annäherung einer Jungfrau ( $\pi \alpha \rho \theta \varepsilon ́ v o \varsigma)$ wird das Einhorn zahm, denn es springt ihr auf dem Schoß und lässt sich zum König in den Palast bringen.

(4) Auslegung/Allegorese:

Das Einhorn wird nun im übertragenen Sinne als „Sinnbild unseres Erlösers“ gedeutet. Als Horn im Hause Davids (Lk 1,69) ist es uns allen zum Horn des Heils geworden, denn es wurde dort im Hause Davids, der als unser Vater bezeichnet wird, erweckt. Nach 1Petr 3,22 konnten seiner nicht mal Engel und Mächte habhaft werden. Aber er (der Erlöser) nahm dann Wohnung „im Leib der wahrhaft reinen Jungfrau Maria“

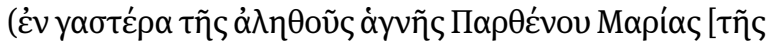

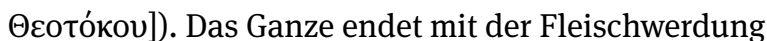

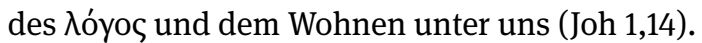

(5) Abschlussformel:

Fehlt hier (s.u.).

Im Physiologus wird Psalm 91,11a ${ }^{\mathrm{LXX}}$ wörtlich zitiert (vgl. die kritische Göttinger Ausgabe von Rahlfs [Gö] und die Handausgabe von Rahlfs und Hanhart [RaHan]:

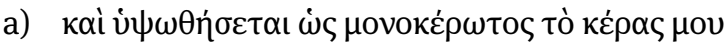

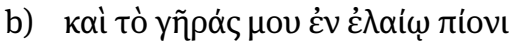

Der zweite Teil (V.11b) fehlt allerdings auch logischerweise, da durch diesen ein neues und weiteres Thema angerissen werden würde.

Hebräisch ראם (bzw. רים oder) wird an acht Stel-

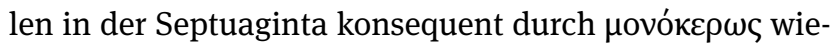
dergegeben (Num 23,22; 24,8; Dtn 33,17; Ijob 39,9; Ps 21,22 ${ }^{\mathrm{LXX}}$; $\left.28,6^{\mathrm{LXX}} ; 77,69^{\mathrm{LXX}} ; 91,11^{\mathrm{LXX}}\right)$. Die lateinische Überlieferung, speziell hier die Vulgata, jedoch unterscheidet an den acht Stellen, und zwar zwischen unicornis im Psalter und rinocerus außerhalb des Psalters. Die Vetus Latina allerdings hat nur unicornis. Das sind Beobachtungen, die weiter verfolgt werden sollten, selbst wenn zwischen „Nasenhorn“

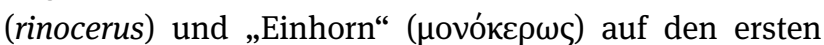
Blick kein großer Unterschied $\mathrm{zu}$ bestehen scheint und 
wir heute gedanklich das Rhinoceros mit einem Bild und natürlich auch zoologisch eindeutig festgelegt haben. ${ }^{33}$ Für die griechische Übersetzung des Alten Testaments wird hier ein Übersetzungsfehler von hebräisch ראם reklamiert, ${ }^{34}$ das ein Hörnertier bzw. ein Tier mit Horn oder Hörnern bezeichnet und oftmals als Stier, Ochse und anderes aufgefasst wird. Auch wird das Einhorn vom in Babylon und in Indien zweidimensional auf Siegeln und Reliefs naturalistisch dargestellten Auerochsen abgeleitet, von dem dann natürlich nur ein Horn zu sehen war. So sei die Annahme entstanden, es handele sich um ein Einhorn, dem alsbald fabelhafte und legendarische Eigenschaften zuerkannt wurden. Daneben werden auch das Rhinoceros (Nashorn) $)^{35}$ und die Oryxantilope ${ }^{36}$ als Schlüssel für das Verständnis und die Herkunft des Einhorns herangezogen.

Interessanterweise bietet Num 23,22 einen für diesen Zusammenhang wichtigen Vergleich, eben jenen zwischen der „Pracht wie die eines Einhorns“ (MT „wie Hörner eines Wildstiers“), ${ }^{37}$ was die Annahme nahelegt, das

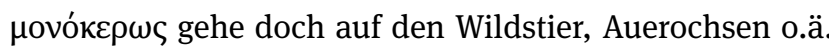
zurück. Und der habe ja doch nicht nur ein Horn. Zudem

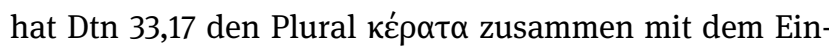
horn. Das ist erst einmal ein Widerspruch in sich. Allerdings kann hier philologisch diskutiert werden, ob nicht der Stichos inhaltlich den vorangehenden ausarbeitet. Dort ist vom „Erstgeborenen eines Stieres“ die Rede, dessen „Hörner“ vielleicht eben „wie Hörner eines Einhorns“ sind, also ein gedanklich ergänztes $\dot{\omega} \varsigma$ würde hier einen folgerichtigeren Bezug herstellen, der Plural wäre durch den vorausgehenden der Hörner des Stiers veranlasst und determiniert. Auf alle Fälle wird hier zwischen $\tau \alpha$ ũpo

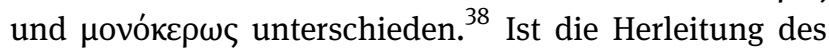
Einhorns also über Wildstier, Auerochs o.ä. hierdurch in Frage gestellt oder ist sie bereits nicht mehr präsent? Psalm 28,6 ${ }^{\mathrm{LXX}}$ hat das Einhorn im Plural, das als Sinnbild für die Stärke Israels gedeutet werden könne, später meist christologisch ausgelegt wird. ${ }^{39}$ Etwas Besonderes zeigt uns Psalm $78,69^{\mathrm{MT}}\left(=77,69^{\mathrm{LXX}}\right)$, wo im Hebräischen letztlich nicht eine Form von ראם (bzw. רים (b) רים oder), sondern „(Himmels)Höhen“, also כמו־רמים bzw. כמרמים רמם (vil.

33 Das Panzernashorn wird zoologisch-wissenschaftlich als rinocerus unicornis bezeichnet.

34 Meines Wissens seit Sander (1784, 101-115).

35 Hierzu Schönberger (2001, 117); Kepper und Witte (2011, 2:2119). Für Informationen über das Rhinoceros vgl. Hünemörder (2006).

36 Vgl. Reichholf $\left({ }^{2} 2008,213-226\right)$; idem (2008). Dabei weist Reichholf daraufhin, dass die Oryxantilope ebenjene Wesensmerkmale aufweise, die auch im Physiologus genannt werden.

37 Vgl. Schlund $(2011,489)$.

38 So Hertog $(2011,600)$.

39 Vgl. Brucker (2011b, 1578).
Ps $148,1^{\mathrm{MT}}$ ) steht, was Anlass dazu gab, über einen Übersetzungsfehler einerseits ${ }^{40}$ und über Alternativen bzw. Konjekturen andererseits nachzusinnen. ${ }^{41}$ Setzt der Übersetzer hier automatisch ראם voraus? Handelt es sich um einen Lesefehler und/oder eine andere Vokalisierung? ${ }^{42}$ Oder müssen wir mit einer anderen Vorlage rechnen?

Das alles bedarf auch heute noch weiterer philologischer Reflexion. Für diesen Kontext allerdings spielen Ableitung und genaues Wesen des Tiers mit dem einen Horn im Alten Testament nur eine untergeordnete Rolle, und es wäre zu überlegen, ob nicht sogar generell eine exakte Antwort auf die Frage nach der zoologischen Identifizierung und Herleitung des Tiers für die Auslegung der in Betracht kommenden Stellen nebensächlich sind. Dennoch zeigt dieser kleine Exkurs ein Mehrfaches: (a) In der Moderne sind gerade Identifizierung und Herleitung durchaus als wichtig erachtet worden. ${ }^{43}$ (b) Antike und spätantike Vorstellungen gehen mit dieser modern-analytischen Herangehensweise nicht zwangsläufig konform, mit anderen Worten ist nicht alles, was in der Moderne als nicht plausibel, widersprüchlich und/oder irreal aufgefasst wird, auch von Menschen in der (Spät)Antike so betrachtet worden. Die moderne Trennschärfe zwischen Historischem und Unhistorischem sowie Realem und Irrealen bestand in jenen Zeiten nicht oder war eine andere. ${ }^{44}$ (c) Es ist letztlich eine Tatsache, dass das Einhorn mit dem Lexem

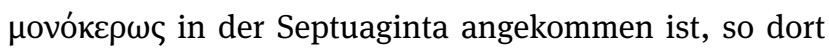
auch bewahrt wurde und eine sehr spezifische Rezeption und Wirkung erfahren hat, und das bis in die Moderne, bis in unsere heutigen Tage hinein. Das Einhorn kann also letztlich als in der Vorstellung der Menschen wie der Übersetzer, die offensichtlich an ihm keinen Anstoß nahmen, präsent und unproblematisch angenommen werden. Wesensmerkmale wie die Wildheit, Stärke und die Bedeutung des Horns (als Ausdruck von Macht und Stärke), wie sie Ktesias, Aristoteles, Aelian und andere konstatieren, sind

40 So seit Sander (1784, 101-115). Übernommen etwa von Kepper und Witte (2011, 2:2119); Brucker (2011b, 1578).

41 Hierzu etwa Kraus ( $\left.{ }^{5} 1978,2: 702\right)$; Seybold (1996, 307 und 312-313). 42 Vgl. Hossfeld und Zenger (2000, 419 und 442).

43 Vgl. aber auch die vorsichtige Einschätzung von Kraus ( ${ }^{5} 1978,329$, רמים in Bezug auf Ps 22,22 gemeint ist. Handelt es sich um das in altorientalischen Abbildungen häufiger nachweisbare Einhorn?“

44 Hier sei verwiesen auf den Bereich der Magie, abgebildet etwa in den magischen Papyri. Verurteilt und bekämpft durch die frühen christlichen Schriftsteller, gingen diese selbst aber offensichtlich auch von der Realität magischer Vollzüge und Kräfte aus. Auch ist heute oft vorschnell von magisch im Sinne von synkretistisch, häretisch und primitiv die Rede, was grundsätzlich für die Menschen in der (Spät)Antike als Kategorien so nicht gegolten haben mag. 
so auch im Alten Testament zu finden, in der Septuaginta

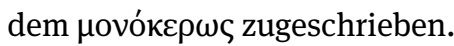

Der Autor des Physiologus bedient sich dieser Grundvoraussetzungen. Die Vorstellung, dass das Einhorn - dem von Anfang an von Jägern nachgestellt wurde wie Jesus Christus von Gegnern und feindlichen Mächten - nur von einer Jungfrau besiegt werden könne, so wie dies Aelian behauptet (De natura animalium 16.20), kann der Autor durchaus von dort oder ähnlichen Traditionen übernommen haben. Es ist dem Physiologus vorbehalten, diese Wesensmerkmale knapp aufzugreifen und für die eigene, kreative Interpretation einzubetten. Und genau das bleibt die genuine Leistung des anonymen Autors, die ebenjenes Tierwesen nachfolgend determinierte und die Tür für weitere fabelhafte Züge des Einhorns öffnete. Warum aber genau dieser Vers aus der Septuaginta hier ausgewählt wurde - oder war er dem Autor einfach präsent und die anderen nicht -, muss offen bleiben. Die Interpretation des einen Horns hin auf den Monotheismus spielt erst später eine Rolle, stellt dabei aber nie den Hauptstrang der Interpretation des Einhorns dar.

Summa summarum zitiert der Autor nur einen Teilvers von Ps $91,11^{\mathrm{LXX}}$, ohne auf diesen interpretatorisch näher einzugehen, bettet allseits Bekanntes aus unterschiedlichen Quellen und in knappen Zügen ein und legt das Ganze in Bezug auf den Erlöser aus. Der freie gestalterische Wille des Autors kommt gerade bei der Verknüpfung mit Hilfe des Jungfrau-Motivs zur Geltung, so dass eine Übertragung auf das Heilsgeschehen hin (vgl. u.a. Lk 1,69)

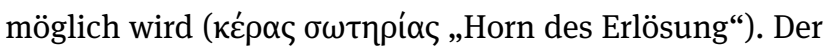
Hinweis auf die Jäger wird aber nicht explizit genannt und damit bleibt der Vergleich zwischen den Nachstellungen des Einhorns durch die Jäger und jener Jesu Christi

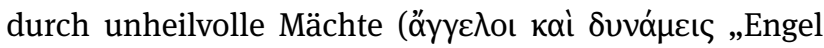
und Mächte“) unvollständig und eher schwach. Die kom-

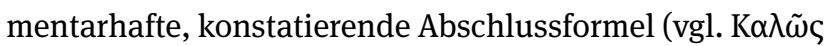

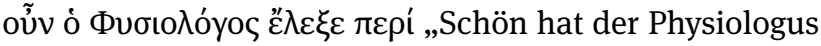
gesprochen ...") fehlt hier, findet sich aber in den Kapiteln 3-5, 7-9, 13, 15-20, 23-24, 27-29, 33-34, 38-39, 43, 45-47

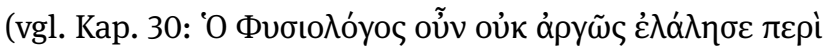
$\tau \tilde{\eta} \varsigma$ $\dot{\lambda} \alpha \dot{\alpha} \varphi \mathrm{v}$. „Der Physiologus hat treffend [nicht unnütz] vom Hirsch gesprochen.").

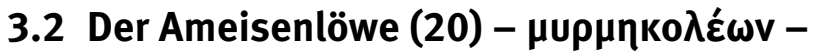 Unvereinbarkeit von Ja und Nein}

Der Ameisenlöwe stellt etwas ganz Besonderes, sogar Einzigartiges dar, bietet doch seine Beschreibung im Physiologus Absurditäten und Groteskes. Gleichzeitig verhilft ebendieses Tier noch mehr als das Einhorn, die Art und Weise des Umgangs mit Quellen im Allgemeinen und der Septuaginta im Speziellen durch den anonymen Autor des Physiologus zu illustrieren. Beide Tiere kommen in der Septuaginta als Realitäten vor, obgleich die Darstellung des Ameisenlöwen im Physiologus aus heutiger Sicht wirklich absurd und unvorstellbar wirkt, während die des Einhorns durchaus plausibel ist und auf (spät)antiken Quellen basiert (s.o.). Das mag auch ein Grund dafür sein, warum der als widernatürlich aufgefasste Ameisenlöwe in den Folgeredaktionen (redactio secunda byzantina und redactio tertia ps.-Basiliana) nicht vorkommt. ${ }^{45}$

(1) Septuaginta-Stelle (Ijob 4,11a):

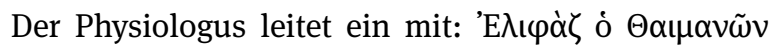

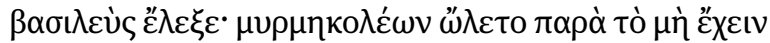
ßopáv. „Eliphas, der König von Theman, sagte: Der Ameisenlöwe ging zugrunde, weil er keine Speise hatte."

(2) Formelhafte Überleitung zum Physiologus:

Es folgt eine formelhafte Überleitung auf den Physio-

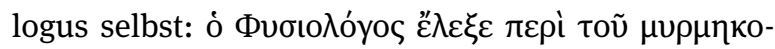
$\lambda \varepsilon ́ \omega v$ ö $\tau$.... „Der Physiologus sagte vom Ameisenlöwen, dass ..."

(3) Explikation/Charakterisierung durch den Physiologus:

Der Ameisenlöwe wird näher charakterisiert und beschrieben. Der vordere Körper sieht aus wie ein Löwe, der hintere wie eine Ameise. Das scheint für moderne Leser/innen schwer vorstellbar, muss es aber für den Autor des Physiologus nicht sein. Doch angesichts des noch Folgenden drückt es die schiere Unvereinbarkeit des einen mit dem anderen aus, die aber dennoch aktuelle Realität sein kann. Da das männliche Tier Fleisch fresse, das weibliche aber Hülsenfrüchte, kann das Junge weder Fleisch noch Hülsenfrüchte fressen, weshalb es dann verhungern müsse. Das wirkt - gelinde gesagt - absonderlich bis bizarr. Wie denn kam dann der Ameisenlöwe überhaupt in die Welt? Dieses bizarre Rätsel bleibt unaufgelöst, nur die Tatsächlichkeit des Bibelworts bleibt unumstritten. Der Ameisenlöwe könne keine Speise finden. Das ist damit offensichtlich hinreichend erklärt. ${ }^{46}$

45 Vgl. Sbordone (1936a, XXIX-CXC) und die Zusammenstellung von Schneider (2016, Abb. 1: Übersicht der ersten drei Redaktionen und Appendix [nach Sbordone]).

46 Gerade die Explikation verdeutlicht, dass es offensichtlich keine Rolle spielt, ob es sich wirklich um ein gänzlich absurdes Wesen handelt oder sich der Autor an die Larve der Ameisenjungfer erinnerte, die wirklich im vorderen Teil an eine Ameise erinnert und mit einem deutlich größeren, runden Körper ausgestattet ist. Im Vordergrund steht die Unvereinbarkeit von Pflanzen- und Fleischfresser, aufgrund 
(4) Auslegung/Allegorese:

Der Übergang zur Auslegung stellt einen Bruch dar. Wie leiten sich die zwei Seelen und die damit verbundene Unstetigkeit des Menschen (Jak 1,7-8) vom zuvor logisch Erläuterten ab? Auf zwei Wegen wandeln und/oder Doppelzüngigkeit beim Gebet sind verwerfliche Verhaltensweisen (Sir 2,12).

Das Ganze wird noch rhetorisch ausgefeilter, wenn der

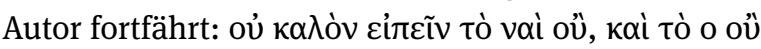

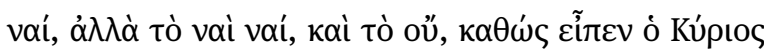

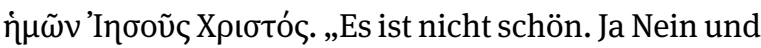
Nein Ja, sondern Ja Ja und Nein Nein, eben wie es Jesus Christus sagte." Das erinnert in Zügen deutlich an Mt 5,37 und 2 Kor 1,17-18 und kann getrost auch als enge Referenz zu diesen Stellen betrachtet werden.

(5) Abschlussformel:

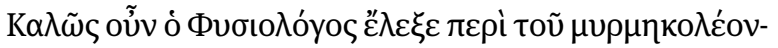

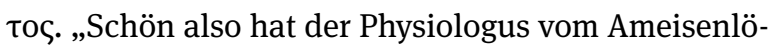
wen gesprochen.“

Wieder verwendet der Autor des Physiologus nur den ersten Vers (Ijob 4,11a), während der zweite über die Jungen

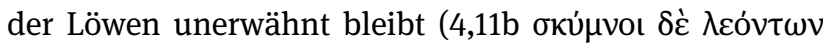

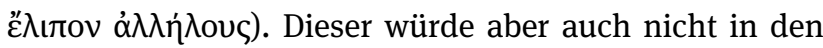
Kontext passen, thematisch die dichte und knappe Darlegung über den Ameisenlöwen und seine besondere bild-

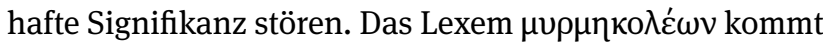
nur in Ijob 4,11a vor, ist ansonsten gänzlich unbekannt. Deshalb ist an eine äußerst bewusste Setzung und Beschreibung durch den Autor zu denken. Der Ameisenlöwe wird später auch durchaus, ausgehend vom Physiologus, rezipiert. ${ }^{47}$

Doch was steckt hinter diesem merkwürdigen Tier, von dem wir in der Septuaginta nur das eine erfahren, eben dass der Ameisenlöwe zugrunde geht, weil er nichts $\mathrm{zu}$ Fressen findet? Es ist eine Binsenweisheit, dass ein Lebewesen ohne Nahrung sterben werde. Das macht den Ameisenlöwen - welches Tier oder Fabelwesen das auch immer gewesen sein mag - eben zu nichts Besonderem. Der Wortstamm $\mu \nu \rho \mu$ - ist selbst in der Septuaginta nur mehr als Ameise ( $\mu$ úp$\mu \eta \xi)$ selbst erhalten in Sprüche 6,6 und 30,25 und Physiologus 12 (etymologisch erinnert noch

derer der Ameisenlöwe letztlich keine Nahrung finden konnte. Gerade die Ausführungen hinsichtlich Aussehen und Wesen des Ameisenlöwen erweist das hier beschriebene Tierwesen als unvereinbar mit der Larve der Ameisenjungfer. Über das Insekt vgl. Gepp und Hölzel (1989).

47 Hierzu Kepper und Witte (2011, 2076) unter Verweis auf Spekulationen bei den frühen christlichen Schriftstellern und auf Bertrand (1996, 222-224); Gerhardt (1965, 1-23). die offensichtliche Neuschöpfung $\mu v \rho \mu \eta \kappa \iota \alpha ́ \omega$ in Lev 22,22 hier an $\mu \nu \rho \mu$-), ein Stamm, der außerhalb der Septuaginta durchaus verbreitet ist für alles Mögliche, das mit Ameisen in Verbindung steht. Finden wir hier tatsächlich eine Neuschöpfung durch den Übersetzer dieser Stelle in der Septuaginta, die in der kreativen Beschreibung des Ameisenlöwen liegt, ganz gleich wie außergewöhnlich dieser auf uns heute wirken mag? In dieser Studie wird die letzte Alternative bevorzugt. ${ }^{48}$

Der Autor des Physiologus nimmt sich allerdings an dieser Stelle noch mehr Freiheiten heraus als etwa in Bezug auf das Einhorn, das immerhin an acht Stellen in der Septuaginta angeführt wird. Das eröffnet noch mehr an kreativen Möglichkeiten, dieses Tier mit seinen zwei Wesen, wie sie bereits der Name selbst vorgibt, für einen kreativ zu konstruierenden, heilsgeschichtlichen Kontext zu instrumentalisieren. ${ }^{49}$ Eine bestimmte Größe mag man sich für das Tier schon vorstellen, mehr aber können wir wohl kaum sagen. Auch der Niederschlag in der Ikonographie blieb hier aus, ${ }^{50}$ ganz im Gegenteil aber hinsichtlich

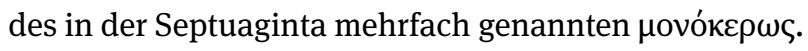

Summa summarum lässt sich festhalten: Wiederum wird der erste Teil eines Septuagintaverses zitiert, der nicht passende zweite Teil nicht. Das Wesen und Aussehen des Ameisenlöwen gestaltet der Autor offensichtlich selbst neu aus, indem die Herkunft (Vater als Fleisch-, Mutter als Pflanzenfresser) und das Dilemma (Verhungern) und dessen Begründung (zweifache, unvereinbare Natur) entsprechend seiner Intention angepasst werden, d.h. man könne nicht auf zwei Wegen wandeln bzw. Ja und Nein sagen. Da der Ameisenlöwe sonst nirgends belegt, über Wesen und Aussehen damit auch nichts bekannt ist, nutzt der Autor die gestalterische Freiheit für seine Zwecke. Dennoch verleiht das Zitat aus Hiob der Passage zwar Authorität, unterstreicht letztlich aber die Tatsächlichkeit und Rätselhaftigkeit des Ameisenlöwen. Das Motiv des Verhungerns mangels Nahrung wird Ausgangspunkt für Explikation und Auslegung auf den richtigen von Jesus

48 Vgl. Treu (1981 [31998], 137), die auf die Tatsächlichkeit des Ameisenlöwen als Lexem in Ijob 4,11a rekurriert, aber konstatiert: „[A]ber aus dem Kontext geht klar hervor, daß es sich um einen richtigen Löwen handelt. So steht es auch in sämtlichen Übersetzungen." Das trifft für den Hiob-Kontext zu und lässt die kreative Schöpfung der Beschreibung und Wesensart des $\mu \nu \rho \mu \eta \kappa о \lambda \varepsilon ́ \omega v$ noch kreativer und innovativer erscheinen.

49 Vgl. auch Schönberger (2001, 116), der die Darstellung des Ameisenlöwen im Physiologus als erfunden ansieht.

50 Dennoch sind die teils ausführlichen variae lectiones zu diesem Kapitel interessant, wenngleich der Ameisenlöwe und sein Wesen selbst durch diese nicht in Frage gestellt werden. Vgl. Sbordone (1936a, 73-76). 
Christus beschrittenen Weg hin (vgl. Mt 5,37; 2 Kor 1,1718). Eine Stichwortverbindung mit dem Löwen (Kap. 1)

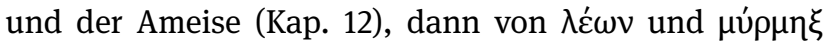
$\mathrm{zu} \mu \nu \rho \mu \eta \kappa \mathrm{\kappa} \lambda \dot{\varepsilon} \omega v$, erweist sich jedoch nicht als zwingend, weil die Inhalte der jeweiligen Kapitel miteinander nichts zu tun haben und auch Wesen und Art der drei Tiere nicht miteinander in klare Beziehung gesetzt werden können.

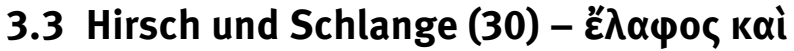 ö}

Das Kapitel ist eines der umfangreichsten im Physiologus und gleichzeitig eines der komplizierteren, nicht nur weil es grundsätzlich um zwei Tiere geht. ${ }^{51}$ Die Schlange selbst wird bereits zuvor in Kap. 11 behandelt, dort aber durchgehend als ö $\varphi$ ı bezeichnet, in Kap. 30 allerdings - mit Ausnahme des Titels - als $\delta \rho \alpha ́ \kappa \omega v$. Der aus der Septuaginta zitierte Vers Ps 41,2 erlebte durchaus eine rege Rezeptionsund Wirkungsgeschichte, wird auch ikonographisch umgesetzt, etwa in Bezug auf die Taufe.

(1) Septuaginta-Stelle (Ps 41,2):

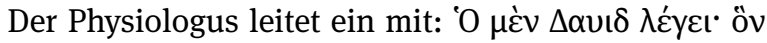

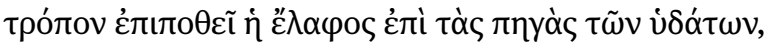

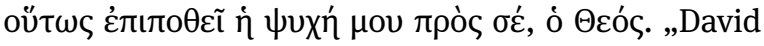
sagt: Wie der Hirsch nach dem Wasserquell verlangt, so verlangt meine Seele nach dir, o Gott.“

(2) Formelhafte Überleitung zum Physiologus:

Es folgt eine formelhafte Überleitung auf den Physio-

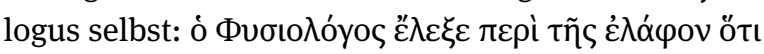

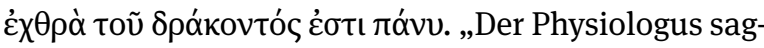
te vom Hirsch, er sei der Todfeind der Schlange.“

(3) Explikation/Charakterisierung durch den Physiologus:

Über den Hirschen braucht im Physiologus nichts Weiteres und Näheres ausgeführt werden. Sein Aussehen kann der Autor des Physiologus getrost voraussetzen, weshalb er sich sofort mit dem Verhalten von Hirsch und Schlange beschäftigen kann. Der Hirsch trinkt nicht nur zur Löschung seines Dursts, sondern er benutzt das Quellwasser dazu, die sich vor ihm versteckende Schlange aus der Erdspalte herauszutreiben und sie dann zu zertreten.

(4) Auslegung/Allegorese:

Die Allegorese dreht sich um diese inhaltliche Kom-

51 Der Hirsch erhält in den drei wesentlichen Redaktionen ein eigenes Kapitel. Vgl. Sbordone (1936a, XXIX-CXC) und die Zusammenstellung von Schneider (2016, Abb. 1: Übersicht der ersten drei Redaktionen und Appendix [nach Sbordone]). Eine Deutung bietet auch R. Hirsch-Luipold im vorliegenden Band auf S. 142. ponente. Das Quellwasser (als die Wasser der Himmel) ist wie das göttliche Wort bzw. die göttliche Weisheit: Das Septuaginta-Zitat birgt den signifikanten Vergleich aus der Natur (nach Wasser dürstender Hirsch) mit dem Verlangen des Menschen (nach Gott dürstende Seele). Die Schlange repräsentiert den Teufel, der - verfolgt allein durch die Anwesenheit des Herren (кúpıs) - sich in der Tiefe der Erde in einer großen Spalte versteckt hält und sich in Sicherheit wähnt. Blut und Wasser aus der Seite des Herrn nimmt die Schlange und damit die Macht des Teufels von uns. Etymologische Erklärungen in einigen Hand-

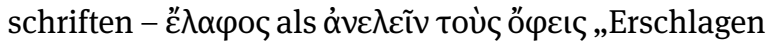
der Schlange“ und ö $\varphi$ ı durch ò $\varphi$ ńs „der Sprecher“, eben „der zu Eva Sprechende“ - sollen noch mehr zur Plausibilität des Geschehens beitragen.

Grundtenor der redundant wirkenden Schlussausführungen ist, dass die Evangelien wie das Quellwasser wirken, uns feien vor dem Bösen. Erfüllt von diesem Wasser werden wir das Schlechte ausspeien und so auch sinnbildlich die Schlange töten. AbschlieBend kommt dann noch Besonderes zur Sprache, nämlich etwas magisch-medizinisch Wirkendes: Die Haare des Hirschen im Haus und das Verbrennen von dessen Knochen bewahrt vor Schlangen. Denn so ist die Ehrfurcht vor Christus im Herzen und feit vor dem Schlimmen der Schlange, ihrem Gift.

(5) Abschlussformel:

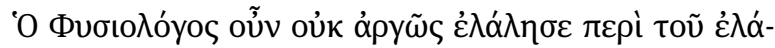
you. „Also hat der Physiologus sehr treffend vom Hirsch gesprochen." Ein Hinweis auf die Schlange bleibt demnach logischerweise aus. Die Formulierung des „sehr treffend(en)“ Redens findet sich nur hier (vgl. zu 3.1 Das Einhorn).

In diesem Kapitel wird ein vollständiger Vers aus der Septuaginta zitiert, der noch dazu beachtliches Interesse bei den frühen christlichen Schriftstellern erfuhr. Das entspricht weniger der sonstigen Zitationspraxis des Autors, der meist nur die Hälfte einer Bibelstelle anführt und in einen jeweils spezifischen Kontext setzt. ${ }^{52}$ Das Zitat entspricht wörtlich dem in der kritischen Göttinger PsalmenAusgabe von Rahlfs (Gö) Abgedruckten, Unterschiede zwischen Masoretischem Text und Septuaginta sind vorhanden, beeinflussen oder verändern jedoch das Verständnis des Verses nicht. ${ }^{53}$

52 So auch Treu (1981 [31998], 119).

53 Vgl. die Anmerkungen zu MT und LXX von Siffer-Wiederhold (2011, 1615). 
Der Hirsch wird insgesamt zwanzig Mal in der Septuaginta mit है $\lambda \alpha \varphi \circ$ bezeichnet und ist grundsätzlich positiv gezeichnet (vgl. Num 12,15.22; Hld 2,9.17; 8,14). An etlichen Stellen ist auch vom weiblichen Tier, der Hirschkuh bzw. Hinde, die Rede. Interessanterweise ist diskutabel, ob im Hebräischen die weibliche Form (אילה) oder der Hirsch (איל) in Ps 42,2 ${ }^{\mathrm{MT}}$ zu setzen sei. ${ }^{54}$ Vielleicht ist die feminine Form $\mathrm{zu}$ emendieren, ${ }^{55}$ was auf eine Angleichung an das feminine נפש von V.2b innerhalb des stark poetisch geprägten Kontexts zurückzuführen sein könnte. ${ }^{56}$ Andererseits kann die maskuline Form auch für das $\mathrm{Fe}$ mininum stehen. Das Lexem ö $\varphi$ ıs dagegen steht nur in der Überschrift in O, nicht in VL. ${ }^{57}$ In Kap. 11 wird ausschließlich ö $\varphi$ ıৎ verwendet. Dort finden sich auch keine variae lectiones, die das Lexem in Frage stellen würden. Im Fließtext von Kap. 30 jedoch steht ausschließlich $\delta \rho \alpha ́ \kappa \omega v$, das durchaus semantisch mit ő $\varphi$ ıৎ zusammenhängt. ${ }^{58} \mathrm{Die}$ Schlange und ihre Bosheit ist in Genesis ausschließlich mit dem Lexem ö $\varphi$ ıs abgedeckt, obgleich das Griechische eine Vielzahl an unterschiedlichen Lexemen geboten hätte. ${ }^{59}$ Die Septuaginta-Stelle wird nicht entsprechend ihres Kontexts in Psalm $41^{\mathrm{LXX}}$ im Physiologus gedeutet, sondern das Verlangen des Hirsches sinnbildlich als Verlangen nach Wahrheit und Evangelium gedeutet, das vor dem Bösen und Gefahren nicht nur schützt, sondern als aktive Waffen gegen Fehlverhalten und Abweichung gezeichnet wird. Evangelium und Wasser töten die Schlange, d.h. den Teufel, so wie Blut und Wasser aus der Seite Christi die Schlange und damit den Teufel von uns nahm.

Ps $41,2^{\mathrm{LXX}}$ stellt der Leserschaft einen klar formulierten Vergleich zwischen Hirsch und Davids Seele dar. Für das dann angeführte mutige und konzertierte Vorgehen des Hirschen gegen die Schlange ist eher an Plinius ( $\mathrm{Na}$ turalis historia 8.118), Aelian (De natura animalium 2.9), Oppian

(Kynegetika 2.236-238) u.a. als Quellen zu denken. Ihnen zufolge zwingt der Hirsch die Schlange mit seinem Atem aus der Erdhöhle. Demnach bleibt als Eigenleistung

\footnotetext{
54 Über Motiv und Hintergrund des nach dem Wasser verlangenden Hirsch bzw. der dürstenden Hinde vgl. Schaper (2004, 65-80). Ferner zur Stelle Kraus ( $\left.{ }^{3} 1978,474\right)$. In Bezug auf Struktur und Poesie der hebräischen Ps 42-43 einschlägig Alonso-Schökel (1976, 4-21); Schaper (2004, 18-24 und 47-64).

55 Vgl. Schaper $(2004,4)$.

56 Vgl. Seybold (1996, 175).

$57 \mathrm{O}=$ Codex Oxoniensis Baroccainus graecus $95, \mathrm{~V}=$ Codex Vaticanus graecus 695 und L = Codex Lipsiensis Universitatis 35, wobei die Nähe von V und L zu beachten ist. Hierzu Sbordone (1936a, 97, der

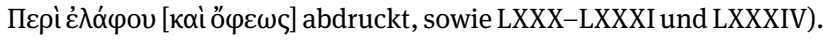
58 Hierzu Eynikel und Hauspie (2004, 126-135).

59 Vgl. Charlesworth $(2004,499-515)$.
}

des Physiologus - da ohne Parallele - das gezielte und geplante Vorgehen des Hirschen, der Quellwasser zu dem Zweck trinkt, um damit die Schlange, die das Wasser als Gefahr meidet, aus der Erdspalte hervorzutreiben und sie anschließend zu töten. Einige Kirchenväter verbinden z.B. auch in ihren Kommentierungen und Auslegungen von Ps $17,34^{\mathrm{LXX}}$ den Hirschen mit der Schlange und nutzen deren natürliche Feindschaft für ihre Aussageabsichten. ${ }^{60}$

Die fünf alternativen, sich an das eigentliche Kapitel anschließenden und auch redundant wirkenden Deutungen werden der ersten Redaktion zugeordnet, ${ }^{61}$ das erweiternde und vertiefende Motiv des Verschluckens der Schlange durch den Hirsch wirkt gerade später nach. ${ }^{62}$ Der Hirsch wird ein Sinnbild für Apotheken und findet sich auch am Wasser des Lebens (Taufe) dargestellt.

Summa summarum erscheint nicht zwingend, dass hier die Schlange als das Böse mit $\delta \rho \alpha ́ k \omega v$ wiedergegeben wird. Denn in Kapitel (9) war bereits schon von der Schlange die Rede, die konsequenterweise wie in Genesis als ő $\varphi$ ı bezeichnet ist. Ist das der Tatsache geschuldet, dass der Autor des Physiologus hier einfach ein Lexem für Schlange setzt? ${ }^{63}$ Verbindet der Autor gerade mit $\delta \rho \alpha ́ \kappa \omega \nu$ bestimmte Vorstellungen, die in diesem Kontext wichtig sein könnten? Ist dies der Verwendung von $\delta \rho \alpha ́ k \omega v$ in der LXX generell geschuldet?

Wie dem auch sei, der Hirsch wird zur Repräsentanz des Erlösers und dessen (erfolgreichen) Kampf gegen das Böse schlechthin, die Schlange, d.h. den Teufel. Dergleichen findet mannigfach Niederschlag in der Kommentarliteratur der frühen christlichen Schriftsteller. Blut und Wasser des Gekreuzigten spielen nicht nur hier eine wesentliche Rolle (vgl. den Abschnitt 3.4). Im ersten Teil des Kapitels sind neben der Aussage von Ps 41,2 ${ }^{\mathrm{LXX}}$ die Bilder außerhalb des Alten Testaments prägend (z. B. von Plinius, Aelian und Oppian). Die Verknüpfung mit dem Wasser als Werkzeug oder Waffe durch den Physiologus ermöglicht dann eine allegorische Deutung bzw. Übertragung des Verhaltens des Hirschen auf den Menschen. Demnach bildet die Zitation aus der Septuaginta, die in diesem Kapitel unter Anführung eines vollständigen Verses erfolgt, die Basis für die nachfolgende inhaltliche Ausgestaltung und Deutung.

\footnotetext{
60 Vgl. Brucker (2011a, 1543-1544).

61 Hierzu Schönberger $(2001,120)$.

62 Vgl. Treu (1981 [31998], 58-59, 139).

63 Immerhin bot das Griechische eine Vielzahl an Lexemen. Vgl. Charlesworth (2004, 499-515).
} 


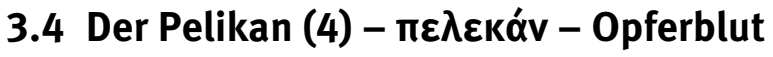 und Aufererweckung}

Zusammen mit den Kapiteln über Einhorn und Phönix wird meist auch der Pelikan als herausstechendes literarisches Wesenselement des Physiologus in Lexika und populären Kurzbeiträgen genannt. Der Pelikan fand rasch Eingang in die christliche Ikonographie, natürlich bedingt durch die Beschreibung seines außergewöhnlichen Verhaltens gegenüber den eigenen Kindern, das erbrachte Opfer und die Auferweckung der toten Pelikankinder mit Hilfe des Blutes der Eltern, das alles als eine exponiert dargestellte Parallele zu Jesu Christi Opfertod. Entsprechend ist es keine Überraschung, wenn sich - ausgehend von der Vorlage des Physiologus - der Pelikan als Symbol für Jesus Christus auf Kelchen, an Altären und Tabernakeln, in der Heraldik und auch in etlichen anderen Bereichen und an vielen anderen Orten findet. ${ }^{64}$ Und dabei spielt es - gerade für den vorliegenden Kontext - keine Rolle, ob die ikonographisch-symbolische Bedeutung die-

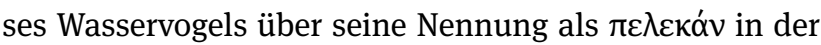
Septuaginta (Lev 11,18; Dtn 14,18; Ps 101,7 ${ }^{\mathrm{LXX}}$ ) und damit Rezeption durch den Autor des Physiologus in Kap. 4 auf einem „Missverständnis“65 beruht und damit ein anderer Vogel ursprünglich vorzustellen ist. ${ }^{66}$

(1) Septuaginta-Stelle (Ps 101,7a):

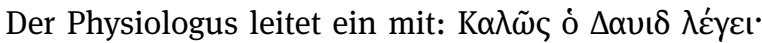

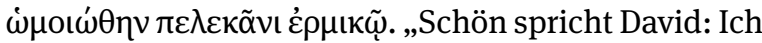
bin gleich geworden einem Pelikan in der Wüste.“

(2) Formelhafte Überleitung zum Physiologus:

Es folgt eine formelhafte Überleitung auf den Physio-

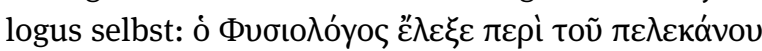

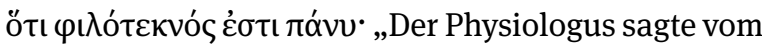
Pelikan, er liebe seine Kinder über die Maßen.“ Dies ist notwendig, um das Nachfolgende im rechten Licht erscheinen zu lassen und das weitere Verständnis des Handelns des Pelikans bereits hier zu determinieren.

(3) Explikation/Charakterisierung durch den Physiologus:

Die aufwachsenden Pelikankinder hacken auf ihre Eltern ein, die sich wehren und durch ihr Hacken die

64 Der Pelikan ist in allen drei wichtigen Redaktionen erhalten. Vgl. Sbordone (1936a, XXIX-CXC), die knappe Anmerkung von Treu (1981 [31998], 133-134) und die Zusammenstellung von Schneider (2016, Abb. 1: Übersicht der ersten drei Redaktionen und Appendix [nach Sbordone]).

65 Günter (2007, 71).

66 Das ist gängige Meinung. Vgl. u.a. Kraus $\left({ }^{5} 1978,864\right)$; Seybold (1996, 399); Brucker (2011c, 1786). Ferner deClaissé-Walford, Jacobson und LaNeel Tanner (2014, 749 und 752; dort aufgrund anderer Zählung als Ps 102,6).
Kinder töten. Die elterliche Liebe (vgl. die Überleitung zum Physiologus) allerdings verursacht Bedauern und Trauer. Am dritten Tag reißt sich die Mutter die Seiten auf. Das auf die toten Jungen tropfende Blut erweckt diese wieder zum Leben.

(4) Auslegung/Allegorese:

Es folgt eine allegorische Explikation mit Hilfe von Jes 1,2 über eigene Söhne, die jedoch abgefallen sind. Wir alle stammen von Gott, haben uns aber abgewandt, Gott so „geschlagen“. Der Erlöser $\Sigma \omega \tau$ ๆn $\rho$ aber stieg zum Kreuz empor, öffnete seine Seite und Blut und Wasser, beides vorher nicht erwähnt (vgl. Kapitel 30), wurden uns zur Erlösung und zum ewigen Leben. Mt 26,27 rundet hier summarisch ab: „Er nahm den Kelch und dankte." Hier wird dann noch die Bedeutung des Wasser nachgeschoben, das uns zur Taufe zur Buße werde. ${ }^{67}$

(5) Abschlussformel:

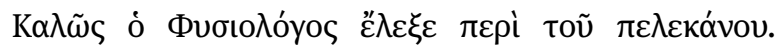
„Schön also hat der Physiologus über den Pelikan gesprochen.“

Aus Psalm 101,7 $7^{\mathrm{LXX}}$ wird wieder wörtlich zitiert (vgl. Gö), allerdings nur V.7a. Inhaltlich wird auf den Vers nicht eingegangen. Die merkwürdig-bizarre Vorstellung eines Pelikans in der Wüste bleibt im Fortgang des Abschnitts unberührt. Für den vorliegenden Kontext ändert sich an diesem Eindruck auch nichts, wenn eine nähere Bestim-

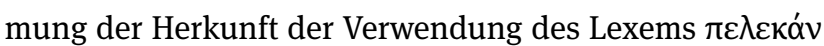
oder der eigentlich ursprüngliche Vogel in Ps $102,7 \mathrm{a}^{\mathrm{MT}}$ versucht wird. ${ }^{68}$ Das spielt keinerlei Rolle. ${ }^{69}$ Es scheint eher so, als würde die Nennung des Pelikans allein genügen, da die Darstellung des Verhaltens des Pelikans sowie die Auslegung nichts mehr mit dem Zitat aus der Septuaginta zu tun haben. ${ }^{70}$ Allerdings scheint gleichzeitig der Erweis des Tiers aus dem Alten Testament, also als autoritative

67 Grundsätzlich über die Adaption des Pelikan-Motivs im Christentum der ersten Jahrhunderte vgl. Nicklas und Spittler (2016, 323-337). 68 Hierzu Kraus ( ${ }^{5} 1978$, 864: Unreiner Wüstenvogel, also Eulenart oder Dohle); Seybold (1996, 399: Wüsteneule); Günter (2007, 71-72); Brucker (2011c, 1786: Eulenart); deClaissé-Walford, Jacobson und LaNeel Tanner (2014, 749 und 752: Owl).

69 Für das Verständnis von Ps $102,7^{\mathrm{MT}}$ in dieser Richtung Seybold (1996, 399): ,7f. verwendet den Vogelvergleich wohl in doppeltem Sinne: die klagenden Laute der Wüsten- oder Ruinen-Vögel ... und die Verlassenheit des einsamen, aufs Dach geflohenen Vogels ... kennzeichnen die Situation.“

70 Das scheint konform mit der Adaption und Rezeption des PelikanMotivs im Christentum der ersten Jahrhunderte zu gehen. Vgl. Nicklas und Spittler $(2016,337)$. 
Bezugsquelle als solche wichtig zu sein, wie das auch für die Zitate aus Jes und Mt zu konstatieren ist.

Unberührt bleibt auch die Herkunft der Vorstellung vom hackenden und die toten Jungen durch Blut wieder zum Leben erweckenden Muttervogel. Sicherlich mag dies vom Hautsack am Schnabel des Pelikans herrühren, aus dem die Jungen gefüttert werden, sozusagen das Futter ausgespien wird. ${ }^{71}$ Aelian weist auf die Füttergewohnheiten des Pelikans hin (De natura animalium 3.20), die aber in Bezug auf den Storch noch weiter spezifiziert werden: Aus Liebe zu ihren Kindern speien Störche die Nahrung des Vortags aus und füttern damit ihre Nachkommenschaft, wenn diese Futter benötigen (De natura animalium 3,23). Das tun, so mutmaßt Aelian, auch Reiher und Pelikane. Zentral für den vorliegenden Kontext ist das Motiv der Liebe (und liebenden Fürsorge).$^{72}$ Und genau wie der Pelikan im Physiologus aus Liebe seine Kinder wieder zum Leben erweckt, ${ }^{73}$ so handelt auch der Herr Jesus Christus für die Menschen. Es ist konsequent, den Autor des Physiologus als Ursprung der Pelikangeschichte anzunehmen, und das trotz der möglichen Parallele zu Aelian. Ganz konsequent und stringent erfolgt die Übertragung aber nicht. Denn letztlich ist in der Auslegung vom Fehlverhalten der „Söhne“ die Rede, die den Schöpfer „geschlagen haben“, vom Dienen der Schöpfung statt einem Dienen des Schöpfers. Das Bedauern sollte doch auf Seiten dieser Söhne, der Menschen, anzusetzen sein.

Summa summarum bleibt festzuhalten, dass zwar unklar bleibt, wie genau der Pelikan in Ps 101,7a $\mathrm{a}^{\mathrm{LXX}}$ hineinkam. Das spielt offensichtlich im Physiologus auch keine Rolle. Die Merkwürdigkeit des dortigen Vergleichs von David mit einem Wasservogel in der Wüste besteht bereits in der Septuaginta, selbst wenn sich dieser auf der Bildebene erklären lässt. Ist nicht ein Wasservogel wie der $\pi \varepsilon \lambda \varepsilon \kappa o ́ v ~ i n$ der Wüste grundsätzlich deplatziert? Den Autor des Physiologus scheint dies an dieser Stelle ebenso wenig zu stören wie schon den Septuaginta-Überetzer, wohl durch die an-

\footnotetext{
71 So Günter (2007, 71), der noch auf einen roten Punkt auf der Brust der Pelikane während der Brutzeit verweist. Auch Brucker (2011c, 1786) mit wertvollem Verweis auf קאר , קיא ,ausspeien“"

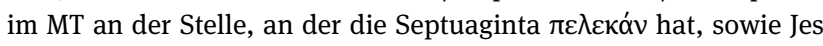
34,11 und Zef 2,17 als Nachweis für Tiere als Bewohner von Wüsten. 72 Hierzu Nicklas und Spittler (2016, 328-330). Ich danke Tobias Nicklas dafür, dass er mir das Manuskript noch vor Drucklegung zur Verfügung stellte.

73 Für die Übertragung des Verhaltens des Pelikans auf Jesus Christus im Physiologus zwar kein Thema, so ist doch die Frage zu stellen, ob die Pelikanmutter sich ihre Seiten aus Trauer und Entsetzen aufreißt und so Blut eher zufällig auf die toten Kinder herabtropft oder ob es sich um ein zielgerichtetes, bewusstes Handeln handelt, als dessen Ergebnis die Erweckung zum Leben steht.
}

gepeilte Unbeirrbarkeit und die Standfestigkeit eines auf Gott Vertrauenden, der selbst in hoffnungslos erscheinender Situation nicht verzweifelt und auf Gott setzen kann. Denn so ist wohl auch Vers 7b mit dem Käuzchen in den Trümmern eines Hauses zu verstehen, ein Vers, der im Abschnitt über den Pelikan natürlich fehlt, ${ }^{74}$ so wie wir das bereits auch aus anderen Abschnitten kennen. Denn durch die Nennung des Käuzchens - wörtlich des „Nach-

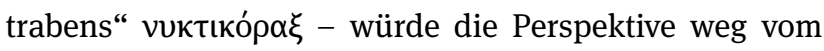
Pelikan hin auf ein anderes Tier erfolgen, dem ein mit Kapitel 5, also dem folgenden Abschnitt eine eigene Betrachtung gewidmet ist. Dort in Kapitel 5 zitiert der Autor des Physiologus dann konsequenterweise und wiederum wörtlich Psalm 101,7 $\mathrm{b}^{\mathrm{LXX}}$, wodurch die beiden Abschnitte 4 und 5 thematisch, motivisch und durch den Verweis auf die Septuaginta eng aneinander gebunden erscheinen. Insgesamt kommt der Pelikan in der Septuaginta auch nur dreimal vor, also außer im erwähnten Psalm noch in den beiden verlinkten Passagen zu den Speisevorschriften bzw. zu Reinheit und Unreinheit von Tieren in Lev und Dtn. Allerdings weisen Lev und Dtn die Reihenfolge Käuzchen-Pelikan (Lev 11,17-18; Dtn 14,17-18) auf, während die Abfolge im Physiologus umgekehrt erfolgt.

Interessant ist sicherlich, dass der Kreuzestod und die Erlösungstat Jesu Christi durch Blut und Wasser aus seiner Seite als aktive und bewusst-willentliche Handlungen dargestellt werden, weil Christus, wie verschiedentlich in der Tradition des Physiologus, mit dem Vater verschmolzen bzw. in eins geschaut wird. Dies ist so zentral, dass die Rollen anderer gänzlich ausgeblendet werden. Zwar findet sich auch außerhalb der Bibel der Pelikan durchaus beschrieben (z. B. Aelian, De natura animalium 3.20; 6.45), doch etwas über elterliche Liebe gibt es nur über den Storchenvogel (Aelian De natura animalium 3.23), obgleich dies auf den Reiher und Pelikan übertragbar erscheint. ${ }^{75}$ Die klare Parallele zum Pelikanabschnitt (4), Kyranides 3.39, jedoch, scheint vom Physiologus abhängig zu sein (eher als umgekehrt, wobei dies aber offen bleiben sollte). Der Autor des Physiologus ist also als Ursprung der Geschichte anzunehmen, selbst wenn die Vorstellung des Aufreißens der Brust durch die Beobachtung des Pelikans motiviert sein könnte, der sich beim Herausbringen des Futters für die Jungvögel mit seinem langen Schnabel an die Brust zu schlagen scheint oder wenn bereits im alten Ägypten der Pelikan als Symbol mit Tod und Leben nach dem Tod in der anderen Welt verbunden worden war. Das

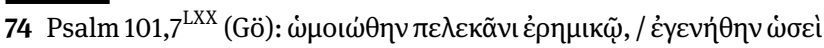

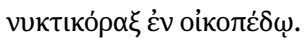
75 Vgl. Nicklas und Spittler (2016, 328-330).
} 
Drei-Tages-Motiv erinnert stark an Jona 2,1 (und ist nicht zu verwechseln mit dem Motiv „am dritten Tag“, was in 1 Kor 15,3-5 und Hos 6,2 zu finden ist). ${ }^{76}$ Insgesamt dient die Zitation aus der Septuaginta wiederum als Anker, ohne inhaltlich den Vergleich sowie das Bild vom Pelikan in der Wüste aufzugreifen und näher auszuwerten. Wichtiger ist die zusätzliche Bindung des Zitats an David, wodurch das Gesagte eine doppelte Authorität erhält, eben über die Verknüpfung von David-Septuaginta-Physiologus. Der Pelikan wird Symbol für Jesu Christi Opfertod, eine Selbstverständlichkeit, die Dante Alighieri in seiner Divina commedia voraussetzen kann. ${ }^{77}$

\section{Die Tiere in Lev 11,1-38/Dtn 14,3-21 und der Physiologus}

Was bereits anklang im Hinblick auf Pelikan (und Käuzchen) und vor allem hinsichtlich der arbeitshypothetischen Gruppierung der Tiere im Physiologus, soll hier Verdeutlichung erfahren. Etliche sehr spezifische Tiere sind mit den selben Lexemen sowohl in Lev 11 und/oder Dtn 14 als auch im Physiologus wiedergegeben (vgl. 2 Die Tiere im Physiologus - eine Zusammenschau mit Hilfe von Lev 11/Dtn 14). Die Überlappungen sind offensichtlich, auf engem Raum dicht gedrängt und - im Vergleich zu sonstigen Nachweisen von literarischen Beziehungen - gerade durch die Übereinstimmung an griechischen Lexemen eindrücklich. Gleichzeitig fällt aber auch sofort auf, dass der Physiologus gegenüber Lev 11 und Dtn 14 eine signifikant andere Aufeinanderfolge der Tiere bietet. Die Einteilung nach Lebensräumen der beiden einschlägigen Abschnitte des Pentateuch ist schlüssig durchgehalten. Für Lev 11,1-38 bedeutet das dann:

1) Tiere des Landes (Landtiere):

Vieh - Kamel - Hase - Kaninchen - Schwein.

2) Tiere des Wassers (Fische):

Tiere mit Flossen - Tiere mit Schuppen.

3) Flugtiere (Vögel und Insekten):

Adler - Greif - Seeadler - Geier - Hühnergeier - Rabe - Strauß - Eule - Möwe - Falke - Langohreule Kormoran - Ibis - Wasserhuhn - Pelikan - Schwan Reiher - Regenpfeifer - Wiedehopf - Fledermaus // Bruchos-Heuschrecke - Attakes-Heuschrecke - Grille - Schlangenkämpfer.

76 Vgl. Nicklas und Spittler (2016, 326 Anm. 10). 77 Vgl. Dante Alighieri, Divina commedia, paradiso, canto XXV (Dante Alighieri [31990, 423] und Amelung [31990, 552]).
4) Weitere Landtiere und Tiere, die auf der Erde kriechen (Kriechtiere):

Wiesel - Maus - Landkrokodil - Feldmaus // Chamäleon - Gecko - Eidechse - Maulwurf.

Ähnlich bis - in Teilen - analog wird in Dtn 14,3-20 unterschieden. Die Berührungspunkte zwischen den beiden Texten sind erkennbar, insbesondere was die Wasser- und Flugtiere angeht:

1) Tiere des Landes (Landtiere):

Jungstier - Lamm - Böcklein - Hirsch - Gazelle - Antilope - Bockhirsch - Weißsteiß - Steinbock - Giraffe Kamel - Hase - Stachelschwein - Schwein.

2) Tiere des Wassers (Fische): Tiere mit Flossen - Tiere mit Schuppen.

3) Flugtiere (Vögel und Insekten): Adler - Greif - Seeadler - Geier - Weihe - Rabe - Spatz - Eule - Möwe - Falke - Reiher - Schwan - Ibis- Kormoran - Wiedehopf - Nachtrabe/Käuzchen - Pelikan - Regenpfeifer - Wasserhuhn - Fledermaus.

4) Weitere Landtiere und Tiere, die auf der Erde kriechen (Kriechtiere):

Dagegen gehorcht die Reihenfolge der Tierkapitel des Physiologus weder den vier arbeitshypothetischen Kategorien (vgl. die Kapitelnummern in Klammer), noch überlappt die so hergestellte Reihung der Tiere mit den Abfolgen in Lev 11 und Dtn 14:

1) Tiere des Landes (Landtiere):

Löwe (1) - Wildesel (9) + (45) - Ameise (12) - Igel (14) Fuchs (15) - Panther (16) - Ameisenlöwe (20) - Wiesel (21) - Einhorn (22) - Hyäne (24) - Ichneumon (26) Landfrosch (29) - Hirsch (30) - Antilope (36) - Gazelle (41) - Elefant (43) - Affe (45).

2) Tiere des Wassers (Fische):

Walfisch (17) - Biber (23) - Fischotter (25) - Wasserfrosch (29) - Ungetüm „Säge“ (39).

3) Flugtiere (Vögel und Insekten): Regenpfeifer (3) - Pelikan (4) - (Nacht)Käuzchen (5) Adler (6) - Phönix(vogel) (7) - Wiedehopf(vogel) (8) Rebhuhn (18) - Geier (19) - Krähe (27) - Turteltaube $(28+28 a)$ - Taube $(28 a+35+35 a+35 b)-$ Schwalbe $(33+33 a+33 b)$ - Ibis (40) - Reihervogel (47).

4) Weitere Landtiere und Tiere, die auf der Erde kriechen (Kriechtiere):

Sonnen-Eidechse (2) - Natter (10) - Schlange (11+30) Salamander (31).

Ist dann nun eine Verbindungslinie zwischen Physiologus auf der einen und Lev 11 und Dtn 14 auf der anderen Seite 
zu ziehen? Die Tatsächlichkeit der Übereinstimmung zahlreicher Lexeme könnte auch daher rühren, dass diese von woanders her auf den Physiologus eingewirkt haben, wie durch außerbiblische Referenzen, Bezüge und Quellen mit Hilfe der vier ausgewählten Tierkapitel vor Augen geführt wurde. Gerade die durchaus beachtliche Anzahl an Tieren, die der Physiologus noch dazu mit denselben griechischen Lexemen aufweist, wie sie in der Septuagintafassung des Alten Testaments vorliegen, legt eine positive Antwort nahe. Dabei ist jedoch der Grad der Berührung, Übereinstimmung oder sogar Abhängigkeit des Physiologus von Lev 11 und Dtn 14 das entscheidendere Momentum:

(a) Die Tierabfolge im AT scheint für den Autor des Physiologus unbedeutend gewesen sein, so dass Kapitel mit anderen und weiteren Tieren sowie Pflanzen, Steinen und mythischen Wesen dazwischen gestreut wurden.

(b) Die Frage nach der Reinheit und Unreinheit, in Lev 11 und Dtn 14 auch und gerade nach Gebot und Verbot des Verzehrs, spielt im Physiologus keine Rolle.

(c) Ein solcher Gebrauch des Alten Testaments passt gut zu der für Einhorn, Ameisenlöwe, Hirsch und Schlange sowie Pelikan konstatierten Zitationsweise und Verwendung von Septuaginta-Versen, von denen meist vgl. aber Hirsch und Schlange (Kap. 30) mit Ps 41,2 LXX - nur die erste Hälfte angeführt und eingepasst wird. ${ }^{78}$

(d) Der Autor des Physiologus schöpft offensichtlich aus eigenem Wissen, aus vorliegenden oder erfragten Quellen und bekannten Traditionen, ohne dass damit gesagt ist, dass der Autor dann auch hätte benennen können, dass etwas beispielsweise von Plinius oder Aelian her entlehnt wurde. Ein analoges Vorgehen wäre auch für die Verwendung von Lev 11 und Dtn 14 denkbar, so dass hier möglicherweise aus der Erinnerung oder auf der Basis von Notizen gearbeitet wurde.

Die Aspekte (a) bis (d) scheinen in sich und für sich plausibel zu sein. Allerdings erhält die Plausibilität von (d) dann einen entscheidenden Makel, wenn die wortwörtliche, also genaue Zitation der Septuaginta-Stellen näher betrachtet wird, die in den in dieser Studie angeführten Kapiteln des Physiologus aufgeführt sind. Die SeptuagintaVerse sind absolut deckungsgleich mit dem, was in der modernen kritischen Göttinger Ausgabe von Rahlfs abgedruckt ist. Unterstellt man auf dieser Basis einen sehr hohen Grad an Exaktheit und postuliert gleichzeitig einen äußerst freien Umgang mit Lev 11 und Dtn 14, d.h. deren Auflistung von Tieren und ihre Reihenfolge, dann

78 So auch Treu (1981 [31998], 119). erscheint dies widersprüchlich, auch wenn man nicht umhin kommt, dem Autor des Physiologus ein hohes Maß an Kreativität und Flexibilität im Umgang mit seinen Quellen zu attestieren. Ergo bleiben auffällige Berührungspunkte zwischen Physiologus und Pentateuch in diesem Bereich zu nennen, die an eine zumindest assoziative oder aus der Erinnerung erfolgte Bezugnahme durch den Autor denken lassen.

Davon unberührt bleibt die Erkenntnis, dass die Septuaginta-Zitate inhaltlich graduell unterschiedlich bis gar nicht mit dem sie umgebenden Text verwoben sind. Deshalb dient die Rückbindung des Tieres zumindest auf der lexematischen Ebene an das griechische Alte Testament als Ausgangspunkt für die weitere Beschreibung von Aussehen und Wesen und der abschließenden Auslegung und Übertragung auf Jesus Christus bzw. das heilsgeschichtliche Geschehen. Somit dient die Septuaginta sowohl als anerkannte Autorität und als Teil einer gedanklichen Klammer zwischen Altem und Neuen Testament, innerhalb der eine konkrete Interpretation und ein Transfer erfolgt.

\section{Bibliographie}

Alonso-Schökel, Luis. 1976. „The Poetic Structure of Psalm 42.“ JSOT 1:4-21.

Alpers, Klaus. 1984. „Untersuchungen zum griechischen Physiologus und den Kyraniden. “ In All Geschöpf ist Zung' und Mund: Beiträge aus dem Grenzbereich von Naturkunde und Theologie. Vestigia Bibliae: Jahrbuch des Deutschen Bibel-Archivs 6, hrsg. v. Heimo Reinitzer, 13-87. Hamburg: Friedrich Wittig.

Alpers, Klaus. 1996. „Physiologus.“ TRE 36:596-602.

Amelung, Peter. ${ }^{3} 1990$. „Anmerkungen.“ In Dante Alighieri, Die göttliche Kömodie: Mit Illuminierungen aus dem Codex Urbinate Latino 365, 487-557. Darmstadt: Wissenschaftliche Buchgesellschaft.

Armistead, Mary Allyson, Hg. 2001. The Middle English Physiologus: A Critical Translation and Commentary. Blacksburg, VA: Virginia Polytechnic Institute and University.

Beer, Rüdiger Robert. 1972. Einhorn: Fabelwelt und Wirklichkeit, München: Georg D. W. Callwey.

Bertrand, D. 1996. „Le bestiaire de Job. Notes sur les versions greques et latines." In Le livre de Job chez le Pères, hrsg. v. Centre d'analye et de dokumentation Patristiques. CBiPA 5:215-271.

Bloch, René. 2006. „Einhorn.“ DNP. http://dx.doi.org/10.1163/ 1574-9347_dnp_e327420.

Bloch, René. 2010. „Einhorn.“ DNP 3:916.

Brucker, Ralph. 2011a. „Psalm 17[18].“In Septuaginta Deutsch. Bd. 2, Erläuterungen und Kommentare, hrsg. v. Martin Karrer und Wolfgang Kraus, 1537-1547. Stuttgart: Deutsche Bibelgesellschaft.

Brucker, Ralph. 2011b. „Psalm 28[29].“In Septuaginta Deutsch. Bd. 2, Erläuterungen und Kommentare, hrsg. v. Martin Karrer und Wolfgang Kraus, 1574-1580. Stuttgart: Deutsche Bibelgesellschaft. 
Brucker, Ralph. 2011c. „Psalm 101[102].“ In Septuaginta Deutsch. Bd. 2, Erläuterungen und Kommentare, hrsg. v. Martin Karrer und Wolfgang Kraus, 1785-1788. Stuttgart: Deutsche Bibelgesellschaft.

Carmody, Francis J., Hg. 1939. Physiologus Latinus: Éditions préliminaires versio $B$. Paris: Librairie E. Droz.

Charlesworth, James H. 2004. „Phenomenology, Symbology, and Lexicography, the Amazingly rich Vocabulary for 'Serpent' in Ancient Greek.“ RB 111:499-515.

Dahlerup, Verner. 1889. „Physiologus i to islandske Bearbejdelser.“ In Aarbøger for nordisk Oldkyndighed og Historie. 2. Reihe, Bd. 4, 199-290. Kopenhagen: Thiele.

Dante Alighieri. ${ }^{3} 1990$. Die göttliche Kömodie. Mit Illuminierungen aus dem Codex Urbinate Latino 365. Darmstadt: Wissenschaftliche Buchgesellschaft.

deClaissé-Walford, Nancy, Rolf A. Jacobson und Beth LaNeel Tanner. 2014. The Book of Psalms. Grand Rapids, MI: Eeardmans.

Ego, Beate. 2007. „Reinheit/Unreinheit/Reinigung.“ In Das wissenschaftliche Bibellexikon im Internet (WiBiLex), hrsg. v. Michaela Bauks, Klaus Koenen und Stefan Alkier. Stuttgart: Deutsche Bibelgesellschaft. https://www.bibelwissenschaft.de/stichwort/ 33086/.

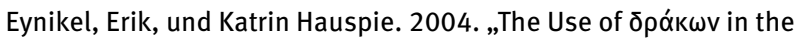
Septuagint." In Biblical Greek Language and Lexicography. Essays in Honor of Frederick W. Danker, hrsg. v. Bernhard E. Taylor et al., 126-135. Grand Rapids, MI: Eerdmans.

Frey-Anthes, Henrike. 2008. „Schlange.“ In Das wissenschaftliche Bibellexikon im Internet (WiBiLex), hrsg. Michaela Bauks, Klaus Koenen und Stefan Alkier. Stuttgart: Deutsche Bibelgesellschaft. http://www.bibelwissenschaft.de/stichwort/27148/.

Gepp, Johannes, und Herbert Hölzel. 1989. Ameisenlöwen und Ameisenjungfern - Myrmeleonidae. Neue Brehm-Bücherei 589. Magdeburg: Westarp.

Gerhardt, Mia I. 1965. „The Ant Lion: Nature Study and the Interpretation of a Biblical Text, from the Physiologus to Albert the Great." Vivarium: Journal for the Philosophy and Intellectual Life of the Middle Ages and Renaissance 3:1-23.

Gottheil, Richard. 2003. „The Greek Physiologus and Its Oriental Translations." The American Journal of Semitic Languages and Literatures 15:120-124.

Graf, Georg. 1906. „Der georgische Physiologus.“ Caucasica 2:93114.

Günter, Wolfgang. 2007. Taube, Löwe, Kreuz und Anker. Christliche Symbole und ihre Bedeutung. Wuppertal: R. Brockhaus.

Hagenmaier, Winfried. 2003. Das Einhorn. Eine Spurensuche durch die Jahrtausende. München: Eulen Verlag.

Henkel, Nikolaus. 1976. Studien zum Physiologus im Mittelalter. Hermaea: Neue Folge 38. Tübingen: Max Niemeyer.

Hertog, Cornelis den. 2011. „Deuteronomion: Deuteronomium/Das Fünfte Buch Mose.“ In Septuaginta Deutsch. Bd. 2, Erläuterungen und Kommentare, hrsg. v. Martin Karrer und Wolfgang Kraus, 576-601. Stuttgart: Deutsche Bibelgesellschaft.

Hommel, Fritz, Hg. 1877. Die äthiopische Übersetzung des Physiologus nach je einer Londoner, Pariser und Wiener Handschrift. Leipzig: J.C. Hinrichs.

Hossfeld, Frank-Lothar, und Erich Zenger. 2000. Psalmen 51-100. HThKAT. Freiburg: Herder.

Hünemörder, Christian. 2006. „Nashorn.“ DNP. http://dx.doi.org/ 10.1163/1574-9347_dnp_e817210.
Janowski, Bernd, und Ute Neumann-Gorsolke. 1993. „Reine und unreine Tiere." In Gefährten und Feinde des Menschen Das Tier in der Lebenswelt des alten Israel, hrsg. v. Bernd Janowski und Ute Neumann-Gorsolke, 214-218. Neukirchen-Vluyn: Neukirchener Verlag.

Kaimakis, Dimitris, Hg. 1974. Der Physiologus nach der ersten Redaktion. Meisenheim am Glan: A. Hain.

Kaimakis, Dimitris. 1976. Die Kyraniden. Beiträge zur klassischen Philologie 76. Meisenheim am Glan: A. Hain.

Kepper, Martina, und Markus Witte. 2011. „Job. Das Buch ljob/Hiob“. In Septuaginta Deutsch. Bd. 2, Erläuterungen und Kommentare, hrsg. v. Martin Karrer und Wolfgang Kraus, 2041-2126. Stuttgart: Deutsche Bibelgesellschaft.

Kraus, Hans-Joachim. ${ }^{3}$ 1978. Psalmen. 1. Teilband, Psalmen 1-59. BKAT 15,1. Neukirchen-Vluyn: Neukirchener Verlag.

Kraus, Hans-Joachim. ${ }^{5} 1978$. Psalmen. 2. Teilband, Psalmen 60150. BKAT 15,2. Neukirchen-Vluyn: Neukirchener Verlag.

MacCoull, Leslie S.B. 1991. „The Coptic Triadon and the Ethiopic Physiologus.“ Oriens Christianus 75:141-146.

Nicklas, Tobias, und Janet Spittler. 2016. „Christ and the Pelican: Function, Background and Impact of an Image." ETL 92:323337.

Offermanns, Dieter, Hg. 1966. Der Physiologus nach den Handschriften $G$ und M. BKP 22. Meisenheim am Glan: A. Hain.

Perry, Ben E. 1941, „Physiologus.“ PRE 20,1:1074-1129.

Peters, Emil, Hg. 1898 [1976]. Der griechische Physiologus und seine orientalischen Übersetzungen. Festschriften der Gesellschaft für deutsche Philologie 15. Berlin: S. Calvary [Hildesheim: Olms].

Rahlfs, Alfred, und Robert Hanhard, Hgg. 2006. Septuaginta. Id est Vetus Testamentum graece iuxta LXX interpretes. Duo volumina in uno, Editio altera quam recognovit et emendavit. Stuttgart: Deutsche Bibelgesellschaft.

Reichholf, Josef H. 2008. „Fabelhaftes Einhorn.“ Die Welt, 3. Januar 2008, http://www.welt.de/welt_print/article1512239/ Fabelhaftes-Einhorn.html.

Reichholf, Josef H. ${ }^{2}$ 2008. Warum die Menschen sesshaft wurden. Frankfurt a. M.: S. Fischer.

Röder, Jörg. 2010. „Evangelium nach Nikodemus.“ In Das wissenschaftliche Bibellexikon im Internet (WiBiLex), hrsg. v. Michaela Bauks, Klaus Koenen und Stefan Alkier. Stuttgart: Deutsche Bibelgesellschaft. http://www.bibelwissenschaft.de/stichwort/ 47929.

Ronald S. Hendel. 1999. „Serpent.“ In Dictionary of Deities and Demons in the Bible (DDD), hrsg. v. Karel van der Toorn, Bob Becking, und Pieter W. van der Horst, 744-747. Leiden: Brill.

Sander, Heinrich. 1784. Kleine Schriften. 1. Band, hrsg. v. Georg Friedrich Götz. Dessau: Buchhandlung der Gelehrten.

Sbordone, Francesco, Hg. 1936a [1976, ${ }^{2}$ 1991]. Physiologus. Rom: Società Anonima Editrice ,Dante Alighieri“ [Hildesheim: Olms].

Schaper, Joachim. 2004. „Wie der Hirsch lechzt nach dem frischen Wasser...": Studien zu Psalm 42/43 in Geschichte Theorie und Praxis. BThSt 63. Neukirchen-Vluyn: Neukirchener.

Schlund, Christine. 2011. „Arithmoi. Numeri/Das Vierte Buch Mose." In Septuaginta Deutsch. Bd. 2, Erläuterungen und Kommentare, hrsg. v. Martin Karrer und Wolfgang Kraus, 460-481. Stuttgart: Deutsche Bibelgesellschaft.

Schneider, Horst. 2002. Rezension von „Physiologus, Griechisch/ Deutsch, übersetzt und herausgegeben von Otto Schönberger, 
Stuttgart 2001." Göttinger Forum für Altertumswissenschaft 5:1019-1034.

Schneider, Horst. 2016. „Physiologus.“ RAC 27:722-743.

Schönberger, Otto. 2001. Physiologus: Griechisch/Deutsch, 151158. Stuttgart: Reclam.

Schröder, Christian, Hg. 2005. Der Millstätter Physiologus: Text, Übersetzung, Kommentar. Würzburger Beiträge zur deutschen Philologie 24, Würzburg: Königshausen \& Neumann.

Seiler, Stefan. 2011. „Psalm 77[78].“ In: Septuaginta Deutsch. Bd. 2, Erläuterungen und Kommentare, hrsg. v. Martin Karrer und Wolfgang Kraus, 1719-1728. Stuttgart: Deutsche Bibelgesellschaft.

Seybold, Klaus. 1996. Die Psalmen. HAT I,15. Tübingen: Mohr Siebeck.

Siffer-Wiederhold, Nathalie. 2011. „Psalm 41[42].“ In Septuaginta Deutsch. Bd. 2, Erläuterungen und Kommentare, hrsg. v. Martin Karrer und Wolfgang Kraus, 1615-1618. Stuttgart: Deutsche Bibelgesellschaft.

Steiger, Christoph von, und Otto Homburger, Hgg. 1964/2012. Physiologus Bernensis: Voll-Faksimile-Ausgabe des Codex Bongarsianus 318 der Burgerbibliothek Bern, Basel: Alkuin. / Bern, Burgerbibliothek, Cod. 318: Physiologus Bernensis, redigiert und ergänzt von Florian Mittenhuber, Juni 2012, http://www.e-codices.unifr.ch/de/list/one/bbb/0318.
Stoykova, Ana, Hg. 1994, 2009-2012. Comparative Study of the Medieval South Slavic Physiologus: Byzantine Recension. http: //physiologus.proab.info.

Treu, Ursula. (1981) ${ }^{3}$ 1998. Physiologus: Naturkunde in frühchristlicher Deutung, Hanau: Artia.

Treu, Ursula. 1982. „Vom Löwen bis zum Wildesel. Die dritte, sogenannte pseudobasilianische Redaktion des Physiologus.“ In Festschrift für Fairy von Lilienfeld. Zum 65. Geburtstag, hrsg. v. Adelheid Rexheuser und Karl-Heinz Ruffmann, 446-478, Erlangen: Institut für Gesellschaft und Wissenschaft an der Universität Erlangen-Nürnberg.

Wentker, Sibylle, Hg. 2004. Der arabische Physiologus: Edition, Übersetzung, Kommentar. Wien: Universitätsbibliothek der Universität Wien. 

Teil IV: Neues Testament und (früh-)christliche Rezeption 



\title{
Zbyněk Kindschi Garský \\ Der Physiologus und das Neue Testament
}

\author{
Die neutestamentlichen Wurzeln der frühchristlichen Naturdeutung
}

\begin{abstract}
This article examines the hermeneutic method of the Greek Physiologus, which Pitra (1855), in his critical edition, already described as allegory or allegoresis, and highlights the New Testament roots of this first Christian allegoresis of nature. Physiologus can be thus described because it is not an allegory in the classical sense, but in a genuinely Christian form. Such allegories are known primarily from the works of Clement of Alexandria and Origen, but their foundations were already laid by Paul and John in the New Testament. In Physiologus, Christ also serves as a hermeneutic key, but the Old Testament is replaced by nature, which is allegorically interpreted and rewritten: "So let the perfect Christian people also distinguish the words of the Old Testament from the Spirit, so that the letter does not kill you. Because Paul said: 'The law is spiritual”" (Physiologus 12).
\end{abstract}

\section{Zur Einführung: Paratextualität}

Die Minuskel GA $537^{1}$ ist eine relativ unbedeutende neutestamentliche Handschrift aus dem 12. Jh. n. Chr., ${ }^{2}$ in einem Punkt ist sie aber nicht ganz uninteressant: Sie fährt gleich nach dem Johannesevangelium (Joh 21,25) mit einem Fragment des griechischen Physiologus fort (fol. 145r). ${ }^{3}$ Es sind zwar nur 1,5 Seiten eines schlechten griechischen Textes (fol. 145r-145v), ${ }^{4}$ ihre paratextuelle Verbindung ${ }^{5}$ mit dem letzten Evangelium in einer neutestamentlichen Handschrift illustriert aber in vielerlei Hinsicht sehr schön das im Folgenden besprochene Thema. Denn der griechische Physiologus stellt neben der Bibel das meistübersetzte Buch der antiken christlichen Literatur und „eine der einflußreichsten und folgenreichsten Schriften des Altertums“ dar. ${ }^{6}$ Und im Laufe der Geschich-

1 University of Michigan Ms. 19.

2 Vgl. die Webseite des Instituts für Neutestamentliche Textforschung in Münster: http://ntvmr.uni-muenster.de/liste?docID=30537.

3 Siehe die digitalisierte Handschrift auf der Webseite des Center for the Study of the New Testament Manuscripts in Plano, TX: http://www. csntm.org/manuscript/View/GA_537 (GA_537_0145a.jpg).

4 Zur Beschreibung s. die Webseite des Institut de recherche et

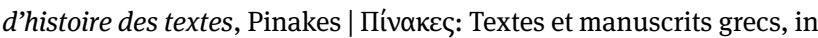
Paris: http://pinakes.irht.cnrs.fr/notices/cote/875/.

5 Zum Begriff s. Genette (1993, 11-13).

6 Alpers $(1984,46)$. te wurde er in der Tat fast zu einem fünften Evangelium, zum Evangelium der Natur, und zur Quelle der christlichen Naturtheologie. Diese konnte dann vor allem in der Spätantike und im Mittelalter die Lektüre des Physiologus im ,Buch der Schöpfung، (liber creaturae) fortsetzen: ${ }^{7}$

So steht das Büchlein des Physiologus am Beginn der geistlichen Tierinterpretation in Spätantike und Mittelalter. Ebenso ist der Physiologus einer der wichtigsten Wegbereiter, jedenfalls aber wohl der früheste Zeuge einer konsequenten „Vorstellung einer Natur sakramentalen Charakters, die geistliche Wahrheiten symbolisierte“, 8 zu einer consecratio mundi: ${ }^{9}$ „Daß es in den Jahrhunderten von Paulus bis zu den Kirchenvätern erreicht wurde, daß das Universum der geschaffenen Welt, soweit es im Wortschatz der Bibel in Erscheinung tritt, in das Licht seiner spirituellen Bedeutung gehoben wurde, ist die ungeheure Leistung einer schöpferischen, vom Geist der Bibel inspirierten, über Wesen und Wege des Heiles sinnenden Meditation“. ${ }^{10}$

Im Unterschied zur Bibel wurde diese Quelle der christlichen Naturtheologie in der neueren Geschichte allerdings praktisch vergessen. So wird auch das oben erwähnte Fragment des griechischen Physiologus in der Minuskel GA 537 von Scrivener in seinen Adversaria critica sacra (1893) lediglich als „foreign matter“ bezeichnet ${ }^{11}$ und bei Gregory (1900) heisst es: „enthält einiges aus Chrys[ostomus]“.12 Erst in den letzten Jahren wurde das Fragment wieder erkannt ${ }^{13}$ und auch das Forschungsinteresse am griechischen Physiologus (und den antiken Fabelwesen) scheint allgemein zu steigen, ${ }^{14}$ sodass man sich zusammen mit Umberto Eco fragen könnte, ob wir uns etwa nicht auch hier auf dem Weg zu einem Neuen Mittelalter befinden. ${ }^{15}$

Doch ungeachtet dessen, wie intensiv der Physiologus gelesen oder erforscht wird, bleibt er die Urquelle der

7 Vgl. den Beitrag von Katharina Heyden in diesem Band.

8 Crombie (1977, 5).

9 Ohly $(1966,20)$.

10 Alpers $(1984,46)$.

11 Scrivener (1893, xliv).

12 Gregory (1900, 200).

13 Vgl. Institut de recherche et d'histoire des textes, Pinakes | Пívaкє૬: Textes et manuscrits grecs, http://pinakes.irht.cnrs.fr/notices/cote/ $875 /$.

14 Vor kurzem wurde sogar das Bestiarium von Harry Potter (Rowling 2001) verfilmt: Fantastic Beasts and Where to Find Them, Warner Bros. Pictures 2016.

15 Vgl. Eco $\left({ }^{8} 2007,7-33\right)$. 
christlichen Naturdeutung. Denn die Wurzeln der christlichen Naturdeutung liegen in einer ,intertextuellen' Verbindung der Natur mit der heiligen Schrift und diese verdanken wir eben diesem kleinen Buch des ägyptischen Christentums - hier wird die Natur zum ersten Mal christologisch ausgelegt und die Bibel hiermit zum ,Paratext der Schöpfung. Auf den folgenden Seiten werden wir uns diese einzigartige Verbindung von Kosmos und Logos und die exegetische Methode des Physiologus etwas genauer anschauen.

\section{Die Methode des Physiologus}

\subsection{Allegorie/Allegorese}

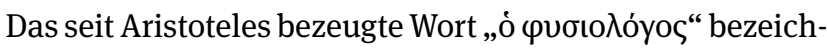
net in erster Linie eine Person - einen Naturkundigen, der die Natur und ihre Phänomene zu deuten versteht:

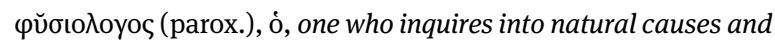
phenomena, esp. of the pre-Socratic philosophers, Arist.Metaph.

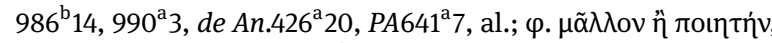
of Empedocles, Id.Po.1447 ${ }^{\mathrm{b}} 19$; ò $\varphi$., title of play by Sopater, Ath.3.101a; oi ỏ $\rho \chi \alpha \tilde{o l} \varphi$., title of work by Chrysippus, D.L.7.187; as

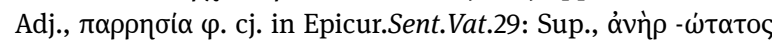

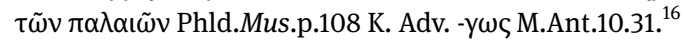

In unserem Fall muss man allerdings ergänzen: er versteht sie theologisch zu deuten - der Physiologus ist ein Theologe und ein Exeget der Natur. Die Interpretationsmethode, die er dabei anwendet und die hier genauer untersucht werden soll, wird in der Sekundärliteratur in der Regel als Allegorie bezeichnet. ${ }^{17}$ So spricht bereits Pitra (1855) in seiner kritischen Edition des griechischen Physiologus von „Physiologum allegoricæ interpretationes“18 und auch in der neueren Literatur hält man an dem Begriff der Allegorie oft fest. ${ }^{19}$ Eine Ausnahme scheint hier der Hamburger Altphilologe Klaus Alpers zu bilden. In seinem bedeutenden Artikel zum griechischen Physiologus aus dem Jahre 1984 bezeichnet er die Methode des Physiologus als „Typologie“ und will sie streng von der „Allegorie“ unterscheiden:

$\overline{16} \operatorname{LSJ}(1996)$.

17 Zur Begriffsgeschichte der „Allegorie“ siehe $E B R$ 1:780-815, insb. 793-806.

18 Pitra $(1855,338)$.

19 Dies betrifft sowohl die Literatur zum Physiologus (Seel 1960, Henkel 1976, Curley 1979, Treu 1981, Schönberger 2001) als auch die literaturwissenschaftliche Literatur (Kurz 1982, Eco 1993, oder Menke 2016) und die Lexika $\left(R G G^{4}, L T h K^{8}, E B R\right.$ 1:763-767 und 1:793-806).
Ihrer Herkunft und ihrem Wesen nach ist Typologie völlig verschieden von Allegorie; erst sekundär haben sich Berührungen und Überschneidungen dieser beiden Denkformen ergeben. Es ist daher erforderlich, die beiden Begriffe tunlichst scharf $\mathrm{zu}$ trennen. Allegorie hebt den Literalsinn auf, Typologie bewahrt ihn $[\ldots] .^{20}$

Doch alles, was Alpers hier und anderswo über die „Typologie“ schreibt, ${ }^{21}$ trifft m. E. genau auf den Begriff der „Allegorie“ zu. Zudem ist die „Typologie“ im Vergleich zur Allegorie ein relativ neuer Begriff ${ }^{22}$ und auch systematisch ist sie bestenfalls eine „Sonderform der Allegorese“. ${ }^{23}$ Aus diesem Grund werde ich in diesem Beitrag bei dem Begriff der Allegorie/Allegorese bleiben, diesen allerdings näher beschreiben und definieren.

Exkurs: Um besser zu verstehen, warum man heutzutage in der Exegese den Begriff der „Allegorie“ lieber meidet, ist es nötig, die Forschungsgeschichte zu kennen: Die allegorische Exegese, die im Westen mehr als 1500 Jahre die üblichste Methode der Bibelauslegung war, wurde mit dem Aufstieg der modernen Bibelwissenschaft im 18. und 19. Jh. als Interpretationsmethode aus dem Methodenkanon der (evangelischen) Exegese ausgeschlossen. ${ }^{24}$ Infolgedessen wurde später auch der Begriff der „Allegorie“ an sich problematisiert und zum Teil sogar tabuisiert. ${ }^{25}$ Seit den 70er Jahren des letzten Jahrhunderts sind in der Theologie zwar vereinzelte Stimmen zu hören, die nach einer Rehabilitierung der Allegorie als Interpretationsmethode rufen, ${ }^{26}$ die moderne Bibelwissenschaft ist aber auf die „Allegorie“ immer noch schlecht zu sprechen ${ }^{27}$ - als ob es das Phänomen in der Bibel nicht gebe bzw. nicht geben dürfte - und so gilt die „Allegorie“ vielen Exegeten heute immer noch „als eine - glücklich überwundene - Form von willkürlicher Exegese, bei der die Intention der Texte und ihrer Autoren grob mißachtet wird; eine Art Interpretation, bei der Assoziation und Phantasie freies Spiel haben und den Text nur als Spielball benützen“. ${ }^{28}$

\section{Alpers $(1984,42)$.}

21 Vgl. die Artikel von Alpers zum Physiologus in TRE und DNP.

22 Hier wirken immer noch die Arbeiten von Goppelt (1939) und Daniélou (1946) nach und zwar ungeachtet der Kritik von de Lubac (1947), der meines Erachtens überzeugend gezeigt hat, dass sich die moderne Unterscheidung von „Typologie“ und „Allegorie“ für die (früh-)christliche Exegese nicht aufrechterhalten lässt. Von der neueren Literatur vgl. z. B. Martens (2008).

23 Reiser (2007, 104). Dies illustriert sehr schön schon die blosse Tatsache, dass die in der exegetischen Literatur oft genannte Hagar-Sara„Typologie“ (Gal 4,21-5,1) im Neuen Testament selbst als Allegorie be-

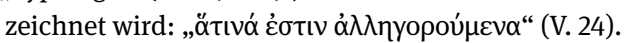

24 In der römisch-katholischen Kirche handelt es sich immer noch um eine legitime Methode der Schriftauslegung, vgl. KKK (2005), III.109-119.

25 Ausführlich dargestellt bei Reiser (2007) oder Kugel (1998, 2007). 26 Programmatisch z. B. Wilken in seinen Artikeln „In Defense of Allegory“ (1998) und „The Inevitability of Allegory“ (2005).

27 Auch hier gibt es natürlich Ausnahmen, vgl. z. B. Klauck (1986), Kugel (1998, 2007), Reiser (2007), oder Garský (2012).

28 Reiser (2007, 99). 
Für die Art der Allegorie/Allegorese, die der Autor des Physiologus verwendet, ${ }^{29}$ ist jedenfalls zutreffend, dass sie „eine universale christliche Denkform“ darstellt. ${ }^{30}$ Denn sie entspringt der poetischen Struktur und der Intertextualität der Heiligen Schrift :

Die (christliche) Allegorie ist eine symbolische Verfahrensweise, die in der poetischen Struktur und/oder der Intertextualität (der Heiligen Schrift ) verankert ist und dem Text eine zweite Bedeutung verleiht. ${ }^{31}$

Die Allegorie als eine Art der Doppelkodierung ${ }^{32}$ ist natürlich älter als das Christentum (und auch als die griechische Literatur), ${ }^{33}$ im Christentum wird sie aber von der Intertextualität der Schrift(en) katalysiert (und kontrolliert). Sie ergibt sich aus einem intertextuellen Zusammenspiel zwischen dem ,Alten' und ,Neuen Testament" bzw. aus der Tatsache, dass das ,Alte Testament' nach dem Tod (und der Auferstehung) des Jesus von Nazareth neu - christologisch - interpretiert werden muss, wobei hier eine zweite (geistige) ${ }^{34}$ Bedeutungsebene etabliert wird. Eben von dieser hermeneutischen Methode macht auch der Autor des griechischen Physiologus Gebrauch.

Dass er die geistige Schriftauslegung und das Zusammenspiel beider Testamente kennt, bezeugt er an mehreren Stellen, von denen ich hier nur zwei zitiere. Im 12. Kapitel „Von der Ameise“ heisst es: ${ }^{35}$

29 Zur christlichen Allegorie s. EBR 1:763-767 und 1:793-806. 30 So Alpers (1984, 42), allerdings über „Typologie“.

31 Garský (2012, 25). Diese Definition ist breiter als das im Jahr 1977 verwendete Kriterium von Hans-Josef Klauck (Klauck 1986, 354-361) und erweitert Paul Ricœurs Begriff der intentionalen Textur (hier der poetischen Struktur) um das Konzept der Intertextualität. Sie beruht nur auf der poetischen Struktur und der intentio intertextualitatis des Textes. Daraus resultiert eine abweichende Differenzierung von Allegorie, Allegorese und Allegorisierung: die Allegorie ist hier definiert, der Begriff Allegorese bleibt der Auslegung der Allegorie (der allegorischen Exegese) vorbehalten und mit Allegorisierung bezeichne ich eine nachträgliche ,Allegorisierung ' eines nichtallegorischen Textes. 32 Vgl. Eco (2003, 213-214) und Kurz (1982, 33).

33 Vgl. Selden (2016, 10): „The recent re-edition of The Princeton Encyclopedia of Poetry and Poetics (2012) would have provided an occasion for rethinking the history of allegory. Instead, however, the handbook continues to pander the received idea that ,allegorical literature began as far back as the sixth century BCE, when the poems of Homer began to be interpreted as if they concealed moral, scientific, philosophical, and even spiritual truths'. The earlier florescence of allegory in Egypt, however, pushes the date for the recourse to metaphora continua back by some 2500 years, not only to the Fourth Dynasty, but to the Predynastic period (5500-3100 BCE) itself, whose artistic achievements culminated in the Narmer Palette (c. 3100 BCE)“.

34 Vgl. Joh 2,21 und 12,26. Es ist die Funktion des Geistes, die Jünger in die ganze Wahrheit zu führen (Joh 16,13).

35 Deutsche Übersetzung nach Schönberger (2001).
So sollen auch die vollkommenen Asketen die Worte des Alten Testamentes vom Geist unterscheiden, damit dich nicht etwa der Buchstabe töte. Denn Paulus hat gesagt: „Das Gesetz ist geistlich“. ${ }^{36}$

In Kapitel 44 „Vom Achat und von der Perle“ kommt der Heilige Geist und der christologische Brennpunkt der beiden Testamente hinzu:

Die beiden Muschelschalen aber bedeuten das Alte und Neue Testament. In gleicher Weise bedeuten die Sonne, der Mond, die Sterne und der Tau den Heiligen Geist, der in die beiden Testamente Eingang fand; die Perle deutet auf unseren Erlöser Jesus Christus; er nämlich ist die kostbare Perle, die der Mensch gewinnen soll [...]. ${ }^{37}$

Die Perle (Christus) befindet sich also nicht einfach im Alten oder im Neuen Testament, sondern ,zwischen ihnen‘. Die christologische Deutung resultiert demnach aus der Intertextualität beider Testamente. Doch im Unterschied zu anderen frühchristlichen Schriften wird im Physiologus nicht die Schrift allegorisch gedeutet, sondern die Natur. Und wie Alpers richtig feststellt:

[I]m Physiologus [hat] der naturkundliche Bericht die Stelle des (historischen) Bibelberichtes eingenommen. Dadurch ist die Natur gewissermaßen in der Typologie an den Ort getreten, den sonst das Buch des AT einnahm. So wird also implicite die Natur zu einer Art Buch, in dem der Christ von Gott ,lesen' kann, denn omnis natura Deum loquitur. ${ }^{38}$ Wie sonst der eine Pol der Typologie im AT, der andere im NT liegt, verlegt der Physiologus den einen in die Natur, den anderen in die Bibel. Zwar benutzt er den Ausdruck ,Buch der Natur' noch nicht, aber er verwendet die Natur schon ganz im Sinne dieses Bildes, das wohl zuerst von Augustin geprägt worden ist [...]. ${ }^{39}$

Das ist ein fundamentaler Unterschied zum Beispiel zum Barnabasbrief, der in der Forschungsliteratur gerne als eine naheliegende Parallele zum Physiologus eingeführt wird. ${ }^{40} \mathrm{Im}$ Barnabasbrief werden Tiere im biblischen Text mit Hilfe von naturwissenschaftlichen Kenntnissen allego-

\footnotetext{
36 Physiologus 12, vgl. Röm 7,14 und 2 Kor 3,6.

37 Physiologus 44, vgl. Mt 13,46.

38 Hugo von St. Victor, Eruditio didascalica 6.5.

39 Alpers (1984, 46), vgl. auch den Beitrag von Katharina Heyden in diesem Band.

40 Aus der neueren Literatur vgl. z. B. Nicklas (2013, 228): „Die Wurzeln einer solchen Interpretation von Traditionen und Texten über Tiere lassen sich bis auf Philo von Alexandrien zurückverfolgen; einzelne Beispiele solcher allegorischer Interpretation von Tieren - dann auf Aspekte des christlichen Glaubens hin - finden sich bereits im Barnabasbrief, dem 1. Clemensbrief, Justins Dialog mit Trypho und anderen“. Zum Verhältnis des Barnabasbriefes zum Physiologus s. Prostmeier (1999, 382-383) und hier im Beitrag von Herwig Görgemanns das Kapitel 6.3.
} 
risch bzw. moralisch interpretiert, ${ }^{41}$ im Physiologus sind es dagegen Tiere in der Natur, die mit Hilfe der biblischen Texte interpretiert werden, wobei viele von ihnen in der Bibel nicht einmal vorkommen. ${ }^{42}$ Im Barnabasbrief ist die Natur das Paradigma der Deutung, beim Physiologus ist sie dagegen das Syntagma. ${ }^{43}$ Das gilt auch für die biblische Tiersymbolik: Ist im Neuen Testament ${ }^{44}$ Christus ein „Löwe“ (Offb 5,5), entdeckt Physiologus im Löwen den „Christus“.

Dieser Tatsache muss auch die Definition der Allegorie bzw. der Naturallegorie in Bezug auf den Physiologus Rechnung tragen:

Die christliche Naturallegorie ist eine symbolische Verfahrensweise, die in der poetischen Struktur und/oder der Intertextualität der Natur mit der Heiligen Schrift verankert ist und der Natur eine zweite Bedeutung verleiht.

Da diese Definition zuerst etwas befremdlich klingen mag, versuche ich hier die wichtigsten Aspekte dieser Deutungsweise etwas zu beleuchten:

1. Das Konzept des ,Buches der Natur ${ }^{45}$ ist für diese Deutungsweise absolut grundlegend, denn nur in diesem Fall kann man überhaupt von

2. der poetischen Struktur der Natur sprechen und

3. mit einem Modell der Intertextualität der Natur mit der Schrift arbeiten.

Was den Begriff der poetischen Struktur betrifft, verwende ich hier die Definition der poetischen Funktion des Prager

41 Vgl. z. B. Barnabasbrief 10, hier 10.1-3: , "Warum aber sagte Mose: ,Ihr sollt kein Schwein essen, noch Adler, noch Habicht, noch Raben, noch irgendeinen Fisch, der keine Schuppen hat'? Im (richtigen) Verständnis erhielt er (damit) drei Weisungen. ${ }^{2}$ Schließlich sagt er ja im Deuteronomium zu ihnen: ,Und ich werde meine Rechtsforderungen an dieses Volk aufstellen. 'Also geht das Gebot Gottes nicht dahin, nicht zu essen: vielmehr hat Mose geistlich gesprochen. ${ }^{3}$ Das Schwein hat er nun zu folgendem Zweck genannt: Du sollst dich nicht solchen anschließen, sagt er, die den Schweinen gleich sind, das heißt (solchen, die) solange sie im Überfluß leben, den Herrn vergessen, wenn sie aber Mangel haben, den Herrn (sehr wohl) kennen, wie das Schwein: Solange es frißt, kennt es den Herrn nicht, wenn es aber Hunger hat, schreit es, und, nachdem es (Nahrung) bekommen hat, ist es wieder still.“ Deutsche Übersetzung nach Lindemann und Paulsen (1992, 49-51).

42 Vgl. den Beitrag von Thomas Kraus in diesem Band auf S. 66.

$43 \mathrm{Zu}$ den Begriffen Paradigma und Syntagma s. u. bei Anm. 57.

44 Zum Alten Testament vgl. den Beitrag von Silvia Schroer in diesem Band.

45 Der Physiologus benutzt diesen Begriff zwar noch nicht, aber, wie oben schon gesagt wurde, ,er verwendet die Natur schon ganz im Sinne dieses Bildes“ (Alpers 1984, 46). Vgl. das Kapitel 3 auf S. 90 zu den onto-theologischen Grundlagen dieses Konzeptes.
Strukturalisten Roman Jakobson. ${ }^{46}$ In der Natur kommt die poetische Funktion z. B. dann zur Geltung, wenn wir sie wegen ihrer ,Schönheit' betrachten. Diese ,Schönheit‘ lässt sich wiederum mathematisch begründen ${ }^{47}$ und das „ästhetische Mass“ liesse sich mit Rückgriff auf die bekannte Formel des Harvarder Mathematikers George D. Birkhoff auch berechnen, ${ }^{48}$ zumal auch dieser ,Schönheit eine Symmetrie zugrunde liegt (s. Abb. 1). ${ }^{49}$

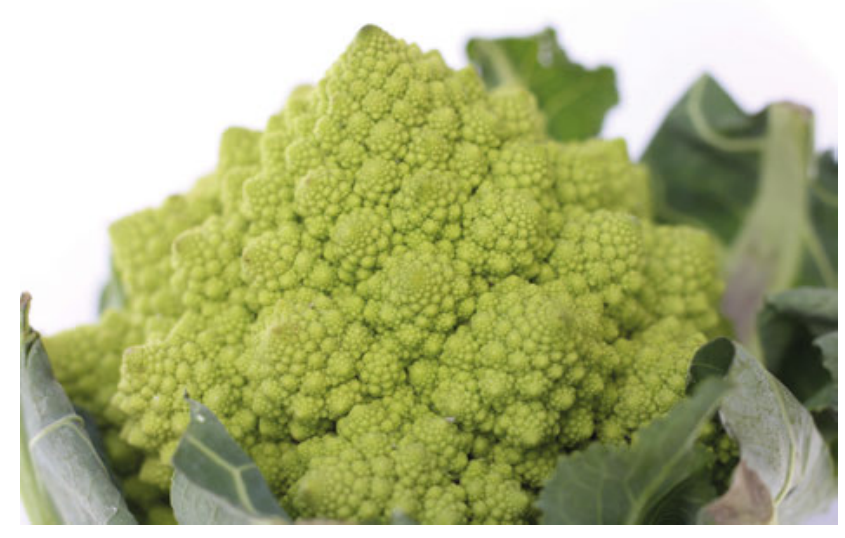

Abb. 1: Die Geometrie der Natur: Romanesco (৫ 2019 Bettina Kindschi).

Die Schönheit der Natur wurde natürlich schon immer wahrgenommen und auch theologisch interpretiert - die biblische Tradition stellt hier keine Ausnahme dar. ${ }^{50}$ Im Buch der Weisheit, das sehr wahrscheinlich auch in Ägypten verfasst wurde, allerdings schon irgendwann im 1. Jh. v. Chr., kann man beispielsweise folgende Zeilen lesen (Weish 13,1-5):

${ }^{1}$ Ohne Verstand waren von Natur aus alle Menschen, denen die
Gotteserkenntnis fehlte. / Aus den sichtbaren Gütern vermoch-
ten sie nicht den Seienden zu erkennen. / Beim Anblick der Wer-
ke erkannten sie den Meister nicht, ${ }^{2}$ sondern hielten das Feu-
er, den Wind, die flüchtige Luft, den Kreis der Gestirne, die ge-
waltige Flut / oder die Welt beherrschenden Himmelsleuchten

46 Vgl. Jakobson ( $\left.{ }^{4} 2005,92\right)$ : „Die Einstellung auf die BOTSCHAFT als solche, die Ausrichtung um ihrer selbst willen, stellt die POETISCHE Funktion der Sprache dar“.

47 Siehe z.B். Barnsley (1988).

48 Vgl. Birkhoff (1933, 4): „Within each class of aesthetic objects, to define the order $O$ and the complexity $C$ so that their ratio $M=O / C$ yields the aesthetic measure of any object of the class".

49 Sehr schön dargestellt im Video Nature by Numbers von Cristóbal Vila auf der Webseite https://www.etereaestudios.com/docs_html/ nbyn_htm/intro.htm.

50 Zu den bekanntesten Texten gehören z. B. Ps 19,2; Ijob 12,7-9; oder Röm 1,20a. 
für Götter. ${ }^{3}$ Wenn sie diese, entzückt über ihre Schönheit, schon für Götter hielten, / dann hätten sie auch erkennen sollen, wie viel besser ihr Gebieter ist, / denn der Urheber der Schönheit hat sie erschaffen. ${ }^{4}$ Und wenn sie über ihre Macht und Wirkkraft in Staunen gerieten, / dann hätten sie auch erkennen sollen, wie viel mächtiger jener ist, der sie geschaffen hat; ${ }^{5}$ denn aus der Größe und Schönheit der Geschöpfe / wird in Entsprechung ihr Schöpfer erschaut.

Der Physiologus steht also in einem Strom der Tradition von Exegeten, die ,aus der Schönheit der Geschöpfe in Entsprechung ihren Schöpfer erschauen können“ (Weish 13,5). Was ihn von den anderen Exegeten unterscheidet, ist die exegetische Methode, mit der er diese Allegorese der Natur systematisch betreibt, denn er setzt Weish 13,5 methodisch um. Diese exegetische Methode schauen wir uns nun genauer an.

\subsection{Intertextualität}

Ein typisches Kapitel des Physiologus ${ }^{51}$ beginnt meistens mit einem Schriftzitat (A.) aus dem Alten Testament. ${ }^{52}$ Es folgt eine Naturbeobachtung (B.), eingeleitet mit „ó

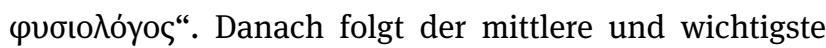
Teil mit der allegorischen Naturdeutung (C.), oft auch Hermeneia genannt. Diese ist meistens christologisch und es wird hier verständlicherweise eher das Neue Testament herangezogen. Das Ende des Kapitels (D.) fasst für den Leser ab und zu die Pointe zusammen. Das Kapitel wird

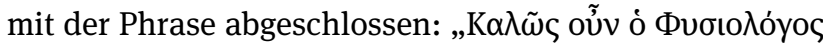

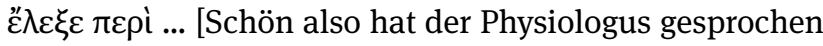
von ...]“.

Als ein Beispiel kann hier das relativ kurze 5. Kapitel

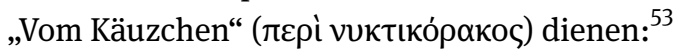

A. Der Psalmist sagt: „Ich wurde wie das Käuzchen in der Ruinenstätte“(Ps 101,7 ${ }^{\mathrm{LXX}}$ ).

B. Der Physiologus hat vom Käuzchen gesagt, dieser Vogel liebe die Nacht mehr als den Tag.

C1. So hat auch unser Herr Jesus Christus uns geliebt, die wir in Finsternis und Schatten des Todes saßen (Jes 9,1 / Mt 4,16), uns, das Heidenvolk, mehr als das Volk der Juden, die doch sogar die Sohnschaft und die Verheißung der Väter erlöst hatten (Röm 9,4). Deshalb sagte auch der Erlöser: „Fürchte dich nicht, du kleine Herde, denn es gefiel dem Vater, euch das Reich zu geben“ (Lk 12,32), und was folgt.

C2. Doch wirst du mir entgegnen, dass das Käuzchen unrein ist nach dem Gesetz (Lev 11,17), und wie kann man es dann als

51 Zum formalen Aufbau der Kapitel vgl. auch den Beitrag von Horst Schneider in diesem Band auf S. 8.

52 Siehe auch die Statistik unten bei Anm. 59.

53 Deutsche Übersetzung nach Schönberger (2001).
Sinnbild des Erlösers verstehen? Schön spricht der Apostel: „Er hat den, der keine Sünde kannte, für uns zur Sünde gemacht“ (2 Kor 5,21). Er hat sich selbst erniedrigt, um alle zu erlösen und uns zu erhöhen.

D. Schön also hat der Physiologus vom Käuzchen gesprochen.

Das 5. Kapitel beginnt mit einem Zitat aus dem Alten Testament (A.) und zwar aus dem Psalm 102,7b in der Version der Septuaginta (Ps 101,7 $7^{\mathrm{LXX}}$ ):

a. Ich bin gleich geworden einem Wüstenpelikan

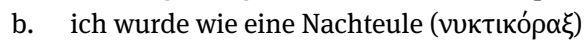
in den Trümmern eines Hauses

Danach folgt die Naturbeobachtung (B.) des Physiologus:

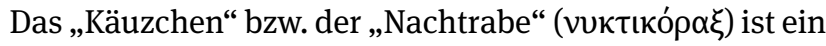
Nachtvogel $\rightarrow$ er liebt die Nacht mehr als den Tag. Aus der Verbindung „lieben“ und „Nacht“ schöpft dann die nachfolgende allegorische Deutung (C1.): „Christus“ wird mit dem „Käuzchen“ identifiziert und „wir“ bzw. das „Volk das in Finsternis sass“ mit der „Nacht“. Hier hilft dem Exegeten das Zitat aus Jesaja 9,1 (par. Mt 4,16):

Das Volk, das in der Finsternis ging, / sah ein helles Licht; über denen, die im Land des Todesschattens wohnten, / strahlte ein Licht auf.

Hiermit wäre das Fundament der allegorischen Deutung gelegt: das Käuzchen/Christus liebt die Nacht/uns. In unserem Kapitel werden aber noch zwei Zitate aus dem Neuen Testament herangezogen, die das eigentliche Paradigma der Deutung bilden, nämlich die „Liebe Christi“: Sie sind Israeliten; ihnen gehören die Sohnschaft, die Herrlich-
keit und die Bundesschlüsse; ihnen ist das Gesetz gegeben, der
Gottesdienst und die Verheißungen. (Röm 9,4)

Fürchte dich nicht, du kleine Herde! Denn euer Vater hat beschlossen, euch das Reich zu geben. (Lk 12,32)

Die „Liebe Christi“ zum „Heidenvolk“ (Nacht) ist grösser als zum „Volk der Juden“ (Tag). In einem zweiten Teil der Naturdeutung (C2.) wird der Einwand widerlegt, dass das Käuzchen unrein sei (vgl. Lev 11,17), und die Deutung mit Hilfe eines Zitates aus 2 Kor 5,21 weiter vertieft:

Er hat den, der keine Sünde kannte, für uns zur Sünde gemacht, damit wir in ihm Gerechtigkeit Gottes würden.

Das Käuzchen wurde also nicht nur zum Nachtvogel, sondern es wurde für uns zudem unrein gemacht. Danach schliesst das Kapitel mit dem typischen Gliederungselement (D.) „Schön also hat der Physiologus ... gesprochen“ ab. 
Diese Struktur variiert zwar etwas in den einzelnen Kapiteln, ${ }^{54}$ die zwei wichtigsten Elemente der Naturdeutung lassen sich aber fast immer finden:

1. die intertextuelle Verbindung der Naturbeobachtung

(A) mit einem Schriftzitat (B)

2. und die daraus resultierende Naturallegorese (C).

Schematisch kann man also schreiben $A \cap B \rightarrow C$ : Der Intertext, ${ }^{55}$ der hier interpretiert wird, ist in diesem Fall eine Schnittmenge ${ }^{56}$ aus verschiedenen Elementen und Strukturen der Schrift und des ,Buches der Natur. Was das Deutungsverfahren betrifft, gehören (in den meisten Fällen) die Elemente und Strukturen $A$ und $B$ zum Syntagma und die Elemente und Strukturen $C$ zum Paradigma der Deutung. ${ }^{57}$ In unserem Beispielkapitel bilden also das |Käuzchen| aus dem Psalm 101 ${ }^{\mathrm{LXX}}(A)$ und das |Käuzchen| aus der Natur $(B)$ das Syntagma der Deutung, zu dem auch die Elemente |lieben|, |Nacht| und |Tag| gehören. Das Paradigma der Deutung $(C)$ bildet dann die «Liebe Christi〉, zusammen mit den Elementen 〈Heidenvolk〉 und «Volk der Juden〉 und der Tatsache, dass «Christus〉 zur 〈Sünde〉 gemacht wurde. Hierzu gehören ferner alle Zitate, die zur Entfaltung des Paradigmas und zur Deutung gebraucht werden:

$$
\begin{aligned}
& \text { Jes 9,1 / Mt 4,16 } \rightarrow \mid \text { Nacht } \mid \equiv\langle\text { Heidenvolk〉} \\
& \text { Röm 9,4 } \rightarrow \mid \text { Tag } \mid \equiv\langle\text { Volk der Juden }\rangle \\
& \text { Lk 12,32 } \rightarrow\langle\text { Liebe Christi }\rangle \\
& 2 \text { Kor 5,21 } \rightarrow\langle\text { Christus }\rangle\langle\text { Sünde }\rangle
\end{aligned}
$$

Die Anspielung auf das Gesetz (Lev 11,17 $\rightarrow$ Käuzchen| $\equiv$ |unrein|) ist hingegen zum Syntagma zu rechnen, obwohl sie sich in dem Abschnitt mit der Deutung befindet (C2.).

Wir sehen hier also die für die Allegorie typische „punktuelle Übertragbarkeit““, ${ }^{58}$ die aus der primären Identifikation des Käuzchens mit Christus resultiert:

$$
\begin{aligned}
& \mid \text { Käuzchen } \mid \equiv\langle\text { Christus } \\
& \mid \text { Nacht } \mid \equiv\langle\text { Heidenvolk〉} \\
& \mid \text { Tag } \mid \equiv\langle\text { Volk der Juden }> \\
& \text { |unrein } \mid \equiv\langle\text { üunde }
\end{aligned}
$$

54 Eine Ausnahme bildet beispielsweise das Kapitel 45 „Vom Wildesel und vom Affen“, s. u. bei Anm. 62.

55 Plett $(1991,5)$.

56 Garský $(2012,125)$.

$57 \mathrm{Zu}$ den Begriffen und der folgenden Notation vgl. die Kapitel zur intertextuellen Poetik und strukturalen Analyse in Garský (2012, 3680.

58 Klauck (1998, 305).
Das zeigt, dass die Intertextualität bei der allegorischen Deutung des Physiologus eine zentrale Rolle spielt. Die Anhäufung von biblischen Zitaten und Anspielungen in allen Kapiteln des Physiologus ist in der Tat bemerkenswert. ${ }^{59}$ In dem kleinen Büchlein befinden sich mehr als 200 Zitate und Anspielungen aus verschiedenen biblischen Büchern. Im Alten Testament wird am meisten das Buch der Psalmen (Ps) und das Buch des Propheten Jesaja (Jes) verwendet, ${ }^{60}$ im Neuen Testament sind es die Evangelien nach Matthäus (Mt) und Johannes (Joh), ${ }^{61}$ wobei man berücksichtigen muss, dass das Matthäusevangelium an vielen Stellen mit den übrigen zwei Synoptikern (Mk, Lk) übereinstimmt.

Interessant ist auch die Verteilung der Zitate und Anspielungen auf den verschiedenen Ebenen der Deutung: Das Alte Testament wird vor allem auf der syntagmatischen Ebene der Deutung gebraucht (ca. 90\% aller Zitate und Anspielungen auf dieser Ebene), das Neue Testament hingegen auf der paradigmatischen Ebende der Deutung (ca. 71\% aller Zitate und Anspielungen auf dieser Ebene). Das macht natürlich Sinn, zumal viele Deutungen christologisch sind und das Neue Testament in der allegorischen Exegese allgemein als Deutungsschlüssel zum Alten Testament verwendet wird. In dieser Hinsicht ist auch nicht überraschend, dass die Schrift deutlich öfter auf der paradigmatischen Ebene der Deutung gebraucht wird (ca. 70\% von allen Zitaten und Anspielungen), denn sie ist beim Physiologus der Deutungsschlüssel zum ,Buch der Natur.

Es existieren natürlich auch hier Ausnahmen, die die Regel bestätigen, wie etwa das 45. Kapitel „Vom Wildesel und vom Affen“, wo wir kein einziges Schriftzitat und sehr wahrscheinlich auch keinen konkreten biblischen Prätext finden $(A)$. Hier kommt das oder in der Definition zur Geltung $^{62}$ - die poetische Struktur der Natur $(B)$ steht hier alleine und der biblische Prätext erklingt höchstens als Echo in

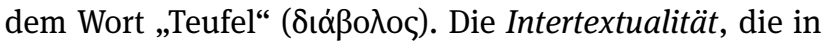
der exegetischen Methode des Physiologus eine Schlüsselrolle spielt, besteht aber nicht nur aus Zitaten. Es finden sich die unterschiedlichsten Formen der Intertextualität. Neben den mehr oder weniger wörtlichen Zitaten finden

59 Die komplette Statistik befindet sich in den Intertextual Studies zum Physiologus auf der Webseite http://www.intertextuality.net/ physiologus/.

$60 \mathrm{Zu}$ den weiteren Büchern gehören (nach Häufigkeit geordnet): Lev, Jer, Gen, Dtn, Hld, Ijob, Spr, Am, Sach, Sir, Bar, Ex, Num, Jos, Ri, Ez, Dan, Hos, Mal.

$61 \mathrm{Zu}$ den weiteren Büchern gehören (nach Häufigkeit geordnet): Lk, Röm, 1 Kor, Eph, 2 Kor, Gal, Mk, Kol, Jak, 1 Petr, Apg, Phil, 1 Joh, 1 Tim, Hebr, Offb.

62 Siehe oben auf S. 86. 
auch Anspielungen oder eben Echos Verwendung. ${ }^{63}$ Diese sind in ihrer Wirkung poetischer ${ }^{64}$ und auch der Autor des Physiologus macht von ihnen Gebrauch.

Im 43. Kapitel „Vom Elefanten“ beweist der Autor, dass er das intertextuelle Spiel mit der Natur und der Schrift sehr gut beherrscht. Im ersten (eigentlich zweigliedrigen) Teil mit der Naturbeobachtung (A) findet man kein einziges Schriftzitat. Trotzdem ist diese Erzählung aus dem ,Buch der Natur' voll von Intertextualität, denn sie wird auf der Folie des biblischen Buches Genesis (B) geschrieben und dieser Prätext wird auf eine sehr schöne Art und Weise in die Naturbeobachtung eingewoben: ${ }^{65}$

AB1. Es gibt ein Tier im Gebirge, Elefant geheissen (anders: Bergelefant). In diesem Tier wohnt keine Begierde nach Begattung [Gen 2,25]. Will es nun Nachwuchs zeugen, wandert es in den Osten, in die Nähe des Paradieses [Gen 2,8]. Dort aber wächst ein Baum, Mandragora genannt [vgl. Gen 30,14-16] Dorthin begeben sich nun das weibliche und das männliche Tier, und das weibliche Tier nimmt zuerst eine Frucht von dem Baum und reicht sie auch dem Mann und tändelt mit ihm, bis auch er davon isst [Gen 3,6]. Und wenn das Männchen davon gegessen hat, vereinigt es sich mit dem Weibchen und sogleich wird dieses trächtig [Gen 4,1]. Wenn nun die Zeit herankommt, dass sie gebären soll, geht sie an einen See und schreitet hinein, bis das Wasser an ihre Zitzen reicht, und nur so bringt sie ihr Kind auf dem Wasser zur Welt, und es kommt zu ihren Schenkeln heran und trinkt an den Zitzen seiner Mutter. Der Elefant aber bewacht sie während der Geburtswehen wegen der Schlange, denn die Schlange ist die Feindin des Elefanten [Gen 3,15],] und wenn der Elefant sie findet, zertritt und tötet er sie.

Die Enthaltsamkeit des Elefanten und seine Feindschaft mit der Schlange sind in der antiken naturgeschichtlichen Literatur zwar belegt (s. Abb. 2), ${ }^{66}$ die Story ist aber fraglos der Paradieserzählung entnommen und erzählt im Grunde die Geburtsstunde der Menschheit. Jeder, der die biblische Geschichte kennt, wird nicht sehr überrascht sein, dass jetzt die Erzählung über den 〈Fall〉 des Elefanten folgt:

AB2. Die Natur des Elefanten aber ist so beschaffen: Wenn er um fällt, kann er nicht mehr aufstehen; er besitzt nämlich keine Gelenke in den Knien wie die übrigen Tiere. Wie aber kommt er zu Fall? Wenn er schlafen will, lehnt er sich an einen Baum und schlummert. Die Jäger nun, die um diese Eigenheit des Elefanten wissen, schleichen hin und sägen den Baum etwas an. Nun kommt der Elefant, um sich anzulehnen, fällt mit dem Baum und fängt jämmerlich zu trom-

63 Vgl. Garský (2012, 32-36).

64 Garský $(2012,78)$.

65 Deutsche Übersetzung nach Schönberger (2001); die wichtigsten Anspielungen und Echos wurden von mir kursiv hervorgehoben. 66 Plinius, Naturalis Historia 8,12.32.

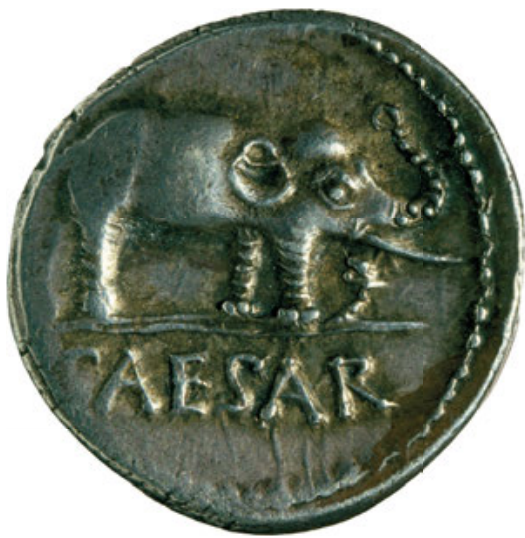

Abb. 2: Ein Elefant zertrampelt eine Schlange oder einen Drachen. Silberne Münze, geprägt im Namen des Gaius Julius Caesar, ca. 4948 v. Chr. (N 1966.34; Ex-Sammlung Kopp @ Stiftung BIBEL+ORIENT, Freiburg $\mathrm{CH})$.

peten an, und ein anderer Elefant hört ihn und kommt herbei, um ihm zu helfen, doch kann er ihn nicht aufrichten. Nun rufen aber beide, und es kommen zwölf weitere Elefanten, doch selbst diese sind nicht imstande, den Gefallenen aufzurichten. Da nun trompeten sie alle; als Letzter von allen aber kommt ein kleiner Elefant, schiebt seinen Rüssel unter den Elefanten und richtet ihn wieder auf. Die Eigenheit des kleinen Elefanten aber ist diese: Wenn man mit seinen Haaren oder Knochen irgendwo räuchert, findet dort weder ein böser Geist noch eine Schlange noch sonst etwas Schlimmes Eingang.

Das Buch der Natur erzählt hier also die Heilsgeschichte: vom 〈Gesetz〉 ( $\equiv$ dem grossen Elefanten), den 〈Propheten〉 ( $\equiv$ den zwölf weiteren Elefanten), bis hin zum 〈Christus〉 ( $\equiv$ dem kleinen Elefanten mit den magischen Kräften). Auch hier finden sich Analogien in der antiken Literatur. So lässt sich über die Jagd von Elefanten durch Ansägen der Bäume lesen ${ }^{67}$ und die in der antiken Literatur ebenso belegte $^{68}$ gegenseitige Hilfe der Elefanten, die sehr schön auch der Berner Physiologus illustriert, ${ }^{69}$ kann man tatsächlich in der Natur beobachten. ${ }^{70}$

Wie man sieht, resultiert die allegorische Bedeutung bereits aus dem intertextuellen Spiel des Autors mit der Natur und der Schrift. Der dritte Teil mit der Hermeneia formuliert diese nur aus und präzisiert einige Elemente:

C. Als Sinnbild nun von Adam und Eva werden der Elefant und sein Weibchen gedeutet. Solange sie im Paradies lebten vor dem Sündenfall, da wussten sie nichts von Begat-

67 Caesar, De bello Gallico 6.27.

68 Plinius, Naturalis Historia 8.24.

69 Siehe fol. 19v des Physiologus Bernensis am Ende dieses Bandes. 70 Vgl. z. B. das Video von Kruger Sightings: https://youtu.be/dGdNAnVweE. 
tung, ja hatten nicht einmal eine Vorstellung davon. Als aber die Frau vom Baume ass, das ist von der Mandragora im Geiste, und als sie davon auch ihrem Mann gab, da erkannte Adam das Weib, und sie gebar den Kain auf den bösen Wassern, wie David sagte [Ps 68, ${ }^{\mathrm{LXX}}$ ]: „, Rette mich, o mein Gott, denn das Wasser reicht mir schon an die Seele." Nun aber kam der grosse Elefant, nämlich das Gesetz, und er konnte den Gefallenen nicht aufrichten. Dann kamen die zwölf Elefanten, das ist die Schar der Propheten, und selbst diese vermochten ihn nicht aufzurichten. Als Letzter von allen aber kam der geistliche und heilige Elefant, unser Herr Jesus Christus und richtete den Menschen vom Boden auf. Er, der grösser als alle war, wahrer Christus nämlich und neuer Adam [1 Kor 15,45], wurde der Sklave aller. Er erniedrigte sich nämlich und nahm Knechtsgestalt an [Phil 2,6-8] (und wurde allen gleich), um alle zu erlösen [1 Tim 2,4].

Das Kapitel wird mit dem typischen Gliederungselement (D.) abgeschlossen:

\section{Schön hat der Physiologus vom Elefanten gesprochen.}

Nur der kleine Elefant (Christus) konnte den gefallenen Elefanten (die Menschheit) aufrichten, weil er sich eben erniedrigte (Phil 2,6-8).

\section{Das Neue Testament als Fundament der frühchristlichen Naturdeutung}

Im vorherigen Kapitel haben wir die exegetische Methode des Physiologus untersucht, die er zu seiner allegorischen Deutung der Natur verwendet. Es hat sich gezeigt, dass die Intertextualität ein zentrales Element dieser Methode darstellt: Der Autor verbindet auf der syntagmatischen Ebene die Schrift ( $A$ ) mit Hilfe von Zitaten, Anspielungen und Echos mit seiner Naturbeobachtung $(B)$. Aus dieser Verbindung resultiert ein Intertext $(A \cap B)$, der die Grundlage seiner Deutung, der Hermeneia ( $C$ ), bildet. Als Paradigma der Deutung dienen dem Physiologus die biblischen Texte, wobei hier von dem Autor als Deutungsschlüssel das Neue Testament eindeutig bevorzugt wird.

Dies ist zwar nicht überraschend, denn viele seiner Deutungen sind christologisch, ${ }^{71}$ dennoch stellt sich hier die Frage nach der onto-theologischen Grundlage dieser Deutung bzw. der primären Identifikation, wie Pelikan $\equiv$ Christus. Denn viele Tiere kommen in der Bibel gar nicht

71 Löwe, Pelikan, Käuzchen, Einhorn u. a.

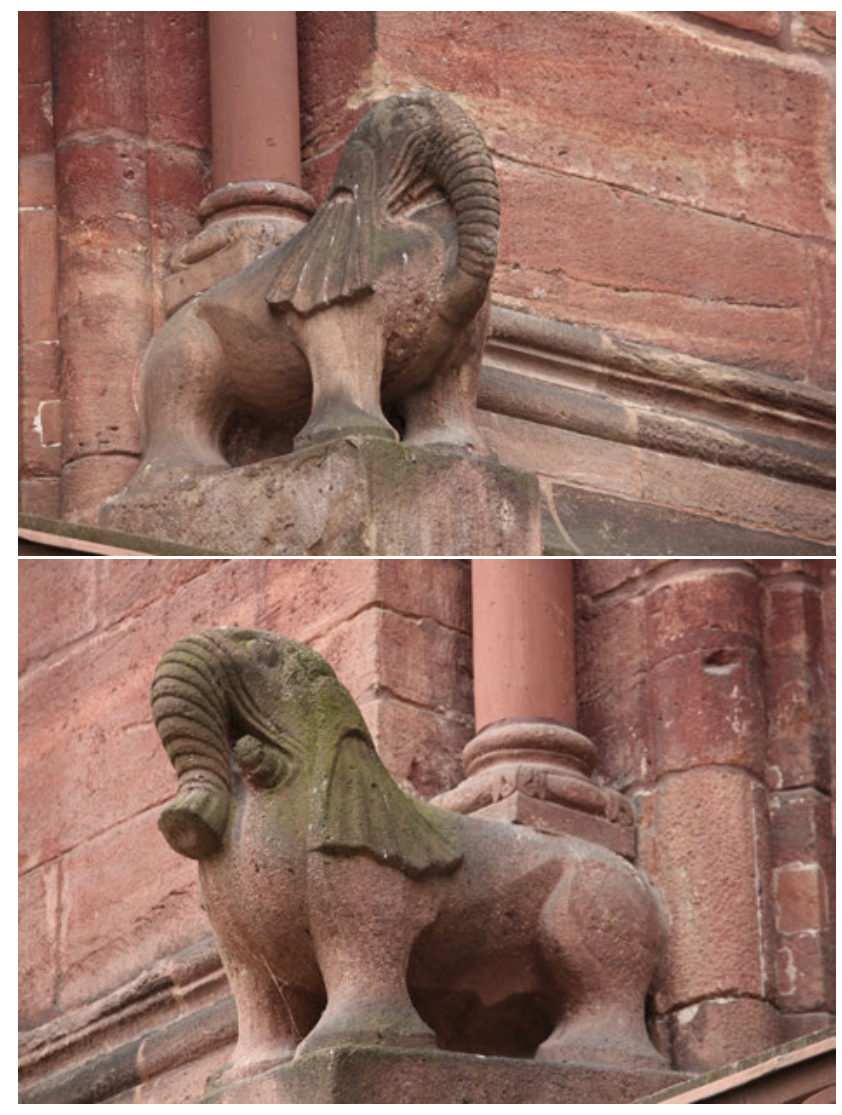

Abb. 3: Zwei Elefanten auf der Chorfassade des Basler Münsters (C) 2015 Bettina Kindschi).

vor, ${ }^{72}$ oder sie sind bereits negativ konnotiert (Käuzchen $\equiv$ unrein). Ausserdem kommen Deutungen von Tieren auf Menschen $^{73}$ oder sogar auf den Teufel vor. ${ }^{74}$

Im Physiologus wird also nicht nur einfach ,aus der Grösse und Schönheit der Geschöpfe ihr Schöpfer erschaut" (Weish 13,5), sondern die gesamte Natur (Tiere, Pflanzen, Steine u. a.) wird hier einer systematischen allegorischen Relektüre unterzogen. ${ }^{75}$

Die Antwort auf die Frage nach der Grundlage dieser allegorischen Naturdeutung lässt sich im Neuen Testament

\section{Phönix, Ichneumon u. a.}

73 Wiesel, Wiedehopf, Ameise, Adler u. a.

74 Affe, Wildesel, Fuchs u. a.

75 Diese allegorische Relektüre des Physiologus öffnet im christlichen Abendland den Weg zu einer universellen, symbolisch-allegorischen Weltbetrachtung (Eco ${ }^{7}$ 2007, 79), die im Mittelalter ihren Höhepunkt findet und noch bei Friedrich Schleiermacher nachklingt: „Auch die äußere Welt, mit ihren ewigsten Gesetzen wie mit ihren flüchtigsten Erscheinungen, strahlt in tausend zarten und erhabenen Allegorien, wie ein magischer Spiegel, das Höchste und Innerste unsers Wesens auf uns zurück. [...] Aber Wenige dringen ein in die heilige Allegorie, und verstehen den Sinn dieser Verknüpfung, zu welcher die Natur sie auffordert“ (Schleiermacher 1800, 5-6). 
und zwar konkret im Prolog des Johannesevangeliums finden (Joh 1,1-3.14):

${ }^{1}$ Im Anfang war das Wort, der Logos, und der Logos war bei Gott, und von Gottes Wesen war der Logos. ${ }^{2}$ Dieser war im Anfang bei Gott. ${ }^{3}$ Alles ist durch ihn geworden, und ohne ihn ist auch nicht eines geworden, das geworden ist.

${ }^{14}$ Und das Wort, der Logos, wurde Fleisch und wohnte unter uns, und wir schauten seine Herrlichkeit, eine Herrlichkeit, wie sie ein Einziggeborener vom Vater hat, voller Gnade und Wahrheit.

Das theologische Fundament der christlichen Naturdeutung ist die Inkarnation des göttlichen Logos ${ }^{76}$ Die Natur (Physis) ist durch Christus (Logos) Wirklichkeit geworden und so wohnt eine Art der Intertextualität zwischen der Physis und dem Logos dem ganzen Kosmos inne. Da es im Universum also nichts gibt, was nicht durch Christus geworden wäre, gibt es auch nichts, was sich mit ihm als ,Schlüssel' nicht öffnen liesse. Dank seiner Inkarnation hat der Mensch nun Zugang zu diesem Deutungsschlüssel des Universums. ${ }^{77}$

Deswegen können wir jetzt nicht nur die heiligen Schriften, ${ }^{78}$ sondern den ganzen Kosmos entschlüsseln und (christologisch) interpretieren. Die Geschöpfe mögen also von doppelter Art sein, „zu loben und zu tadeln“, wie es im 3. Kapitel des Physiologus „Vom Regenpfeifer“ heisst, und sie müssen nicht nur allegorisch und in Bezug auf Christus gedeutet werden, sondern können in Bezug auf den Menschen auch eine moralische oder anagogische Bedeutung haben. Denn nun kann der ganze Kosmos geistig interpretiert werden ${ }^{79}$ und dieser geistige Sinn ist vielfältig, wie es später im 13. Jahrhundert Augustin von Dänemark ausformuliert hat: ${ }^{80}$

\section{Littera gesta docet, quid credas allegoria, Moralis quid agas, quo tendas anagogia.}

Der Buchstabe lehrt das Geschehene; was du glauben sollst die Allegorie;

76 Vgl. Lobsien (2016, 389): „Die Inkarnation ist gleichsam die UrAllegorie; in den Worten des Prologs zum Johannes-Evangelium: ,Und das Wort ist Fleisch geworden und hat unter uns gewohnt, und wir haben seine Herrlichkeit gesehen“ (Joh 1,14)“.

77 Vgl. Boyarin (2010, 39): „Christian Logos theology, the notion of Christ as the incarnation of the Word, provided a solution to problems left unsolved by Platonism, precisely in that crucial area of epistemological theory, as well“.

78 Vgl. Lk 24,45 par.

79 Zur Entfaltung dieser christlichen Weltdeutung siehe Brinkmann (1980, 74-153).

80 Augustin de Dacia, Rotulus pugillaris 1.256.19. die moralische Deutung, was du tun sollst; wohin du streben sollst, die Anagogie. ${ }^{81}$

\section{Bibliographie}

Alpers, Klaus. 1984. „Untersuchungen zum griechischen Physiologus und den Kyraniden.“ In All Geschöpf ist Zung' und Mund: Beiträge aus dem Grenzbereich von Naturkunde und Theologie. Vestigia Bibliae: Jahrbuch des Deutschen Bibel-Archivs 6, hrsg. v. Heimo Reinitzer, 13-87. Hamburg: Friedrich Wittig.

Alpers, Klaus. 1996. „Physiologus.“ TRE 36:596-602.

Alpers, Klaus. 2006 „Physiologus.“ DNP. http://dx.doi.org/10. 1163/1574-9347_dnp_e924920.

Barnsley, Michael F. (1988) ${ }^{2}$ 1993. Fractals Everywhere. Cambridge, MA: Academic Press.

Birkhoff, George D. 1933. Aesthetic Measure, Cambridge, MA: Harvard University Press.

Boyarin, Daniel. 2010. „Origen as Theorist of allegory: Alexandrian contexts“. In Cambridge Companion to Allegory, hrsg. v. Rita Copeland und Peter T. Struck, 39-54. Cambridge: Cambridge University Press.

Brinkmann, Hennig. 1980. Mittelalterliche Hermeneutik. Tübingen: Max Niemeyer.

Crombie, Alistair C. 1977. Von Augustinus bis Galilei: Die Emanzipation der Naturwissenschaft. München: Deutscher Taschenbuch Verlag.

Curley, Michael J. (1979) ${ }^{2}$ 2009. Physiologus: A Medieval Book of Nature Lore. Chicago: University of Chicago Press.

Daniélou, Jean. 1946. „Traversée de la Mer Rouge et Baptême aux premiers siècles“. RSR 33:402-430.

Eco, Umberto. (1987) ${ }^{8}$ 2007. Über Gott und die Welt. München: Deutscher Taschenbuch Verlag.

Eco, Umberto. (1993) ${ }^{7}$ 2007. Kunst und Schönheit im Mittelalter, München: Deutscher Taschenbuch Verlag.

Eco, Umberto. (2003) 22006. Die Bücher und das Paradies: Über Literatur, München: Deutscher Taschenbuch Verlag.

Garský, Zbyněk. 2012. Das Wirken Jesu in Galiläa bei Johannes: Eine strukturale Analyse der Intertextualität des vierten Evangeliums mit den Synoptikern. WUNT 2.325. Tübingen: Mohr Siebeck.

Genette, Gérard. 1993. Palimpseste: Die Literatur auf zweiter Stufe. Frankfurt am Main: Suhrkamp.

Gregory, Caspar René. 1900. Textkritik des Neuen Testaments. Leipzig: J.C. Hinrichs.

Goppelt, Leonhard. 1939. Typos: Die typologische Deutung des Alten Testaments im Neuen. Beiträge zur Förderung christlicher Theologie 2.43. Gütersloh: Bertelsmann.

Haselstein, Ulla, Hg. 2016. Allegorie: DFG-Symposion 2014. Berlin: De Gruyter.

Henkel, Nikolaus. 1976. Studien zum Physiologus im Mittelalter. Hermaea: Neue Folge 38. Tübingen: Max Niemeyer.

Imorde, Joseph. 2003. „Physiologus.“ $R G G^{4}$ 6:1330.

Jakobson, Roman. (1979) ${ }^{4} 2005$. Poetik: Ausgewählte Aufsätze 1921-1971, hrsg. v. Elmar Holenstein und Tarcisius Schelbert. stw 262. Frankfurt am Main: Suhrkamp.

81 Deutsche Übersetzung nach Reiser (2007, 139). 
Klauck, Hans-Josef. (1978) ${ }^{2} 1986$. Allegorie und Allegorese in synoptischen Gleichnistexten. NTA.NF 13. Münster: Aschendorff.

Klauck, Hans-Josef. 1998. „Allegorie/Allegorese III“. RGG ${ }^{4}$ 1:305306.

Kugel, James L. 1998. Traditions of the Bible: A Guide to the Bible as it Was at the Start of the Common Era. Cambridge, MA: Harvard University Press.

Kugel, James L. 2007. How to Read the Bible: A Guide to Scripture, Then and Now. New York: Free Press.

Kurz, Gerhard. (1982) ${ }^{6}$ 2009. Metapher, Allegorie, Symbol. Göttingen: Vandenhoeck \& Ruprecht.

Lindemann, Andreas, und Henning Paulsen, Hgg. 1992. Die Apostolischen Väter: Griechisch-deutsche Parallelausgabe auf der Grundlage der Ausgaben von Franz Xaver Funk / Karl Bihlmeyer und Molly Whittaker; mit Übersetzungen von M. Dibelius und D. -A.Koch. Tübingen: Mohr Siebeck.

Lobsien Verena O. 2016. „Topopoetik der Herrschaft: Allegorische Ökonomien bei Spenser und Shakespeare“, In Allegorie: DFGSymposion 2014, hrsg. v. Ulla Haselstein, 382-413. Berlin: De Gruyter.

Lubac, Henri de. 1947. „«Typologie» et «Allegorisme»“. RSR 34:180-226.

Martens, Peter W. 2008. „Revisiting the Allegory/Typology Distinction: The Case of Origen“. JECS 16.3:283-317.

Menke, Bettine. 2016. „Allegorie. ,Ostentation der Faktur’ und ,Theorie'. Einleitung“. In Allegorie: DFG-Symposion 2014, hrsg. v. Ulla Haselstein, 113-135. Berlin: De Gruyter.

Nicklas, Tobias. 2013. „Staunen über Natur und christliche Lebenshaltung: Die Welten des Physiologus“. In Credible, Incredible: The Miraculous in the ancient Mediterranean. WUNT 321, hrsg. v. Tobias Nicklas und Janet E. Spittler, 227-250. Tübingen: Mohr Siebeck.

Ohly, Friedrich. [1966] 1977. „Synagoge und Ecclesia“. In Schriften zur mittelalterlichen Bedeutungsforschung, hrsg. v. Friedrich Ohly, 312-337. Darmstadt: Wissenschatliche Buchgesellschaft.
Pitra, Jean Baptiste, Hg. 1855. „Veterum gnosticorum in Physiologum allegoricae interpretationes." In Spicilegium Solesmense complectens sanctorum patrum scriptorumque ecclesiasticorum anecdota hactenus opera. Bd. 3, In quo praecipui veteres auctores de re symbolica proferuntur et illustrantur, hrsg. v. Jean Baptiste Pitra, 338-373; 391-394. Paris: Firmin Didot.

Plett, Heinrich F. 1991. „Intertextualities“. In Intertextuality. Research in Text Theory / Untersuchungen zur Texttheorie 15, hrsg. v. Heinrich F. Plett, 3-29. Berlin: De Gruyter.

Prostmeier, Ferdinand R., Hg. 1999. Der Barnabasbrief. Kommentar zu den Apostolischen Vätern 8. Göttingen: Vandenhoeck \& Ruprecht.

Reiser, Marius. 2007. Bibelkritik und Auslegung der Heiligen Schrift: Beiträge zur Geschichte der biblischen Exegese und Hermeneutik. WUNT 217. Tübingen: Mohr Siebeck.

Rowling, Joanne K. 2001. Fantastic Beasts and Where to Find Them. London: Bloomsbury.

Selden, Daniel. 2016. „The Crossing Out of Egypt: Introductory Essay“. In Allegorie: DFG-Symposion 2014, hrsg. v. Ulla Haselstein, 3-30. Berlin: De Gruyter.

Schleiermacher, Friedrich D. E. 1800. Monologen: Eine Neujahrsgabe. Berlin: Christian Sigismund Spener.

Schönberger, Otto. (2001) 2014. Physiologus: Griechisch/Deutsch. Stuttgart: Reclam.

Scrivener, Frederick H. A. 1893. Adversaria Critica Sacra. Cambridge: University Press.

Seel, Otto. (1960) ${ }^{3} 2005$. Der Physiologus: Tiere und ihre Symbolik. (Zürich: Artemis \& Winkler) Düsseldorf: Patmos.

Treu, Ursula. (1981) ${ }^{3} 1998$. Physiologus: Naturkunde in frühchristlicher Deutung. (Berlin: Union) Hanau: Artia.

Wilken, Robert L. 1998. „In Defense of Allegory“. Modern Theology 14.2:197-212.

Wilken, Robert L. 2005. „The Inevitability of Allegory“. Gregorianum 86:742-753. 


\title{
Samuel Vollenweider \\ Der Erlöser im Tarnanzug
}

\author{
Eine Studie zur Christologie des Physiologus, zu seiner Datierung und zur \\ Rezeptionsgeschichte von Psalm $24\left(23^{\text {LXX }}\right)$
}

\begin{abstract}
The article deals with the programmatic first chapter of the Physiologus, which concerns the lion. Its three allegories refer to Christ's incarnation, his death and his resurrection. In general, the author of the Physiologus only alludes to dogmatic conceptions and exegetical traditions of his age and expects his readers to fill any voids ('Leerstellen'). A detailed analysis of the complex religioushistorical background of the lion chapter supports some chronological conclusions (based on the assumption that the $1^{\text {st }}$ chapter has to be regarded as an integral part of the Physiologus' first version). Whereas the figure of the hidden descent of the Saviour can be traced back to 'heterodox' Christian traditions of the $2^{\text {nd }} / 3^{\text {rd }}$ centuries CE, the motive of his angelomorphic status and the intertextual reference to Ps $24\left(23^{\mathrm{LXX}}\right)$ are indebted to Origen and his theology. Moreover, the christological vocabulary namely the leitmotiv of Christ's "divine nature ( $\theta \varepsilon$ ótns) hidden in the flesh (/body)" - points most likely to the $4^{\text {th }}$ century CE. The lion chapter also shows traces of $4^{\text {th }}$ century debates about the status of Christ between death and resurrection (triduum mortis). If the first known version of the Physiologus originated in the first half of the $4^{\text {th }}$ century, his milieu might probably be found among Origenist monks in Egypt (who may also have transmitted Gnostic traditions and texts). Finally, the article adresses the hermeneutical profile of the Physiologus' allegorical method and his basic conception of the 'two books of God', nature and Scripture.
\end{abstract}

\section{Einleitung}

Im Abendland gilt der Physiologus als eines der viel gelesenen Bücher vor der Ära des Buchdrucks; er rangiert bald nach der Bibel und dem Alexanderroman. ${ }^{1}$ Eigenartigerweise ist der Traktat ein Stiefkind der Forschung geblie-

1 „Das seltsame Büchlein hat sich in der Weltliteratur dadurch eine ganz hervorragende Stellung verschafft, dass es einen mächtigen Einfluss auf die verschiedensten Gebiete der Literatur und auf die Kunst geübt und eine universelle Verbreitung bei den christlichen Völkern des Mittelalters erlangt hat, die vielleicht von keinem ihrer übrigen Volksbücher [...] erreicht und nur vom Buch der Bücher, der Bibel, übertroffen worden ist“, Goldstaub (1900, 341). Zur Wirkungs- ben. ${ }^{2}$ Umso erfreulicher ist es, dass er nun als Thema eines eigenen Bandes firmieren darf. Die Vernachlässigung der gelehrten Arbeit an unserer Schrift erstaunt noch mehr, wenn man ihrer weithin akzeptierten Datierung im zweiten Jahrhundert folgt. ${ }^{3}$ Man kann von einem nahezu etablierten Konsens sprechen, ${ }^{4}$ der auch vom vorliegenden Band dokumentiert wird. Zum Konsens zählt freilich auch, dass die für die frühe Datierung geltend gemachten Indizien nur sehr eingeschränkt belastbar sind. Zusätzlich er-

geschichte vgl. den von mehreren Autoren verfassten Artikel „Physiologus“ (LMA 6:2117-2122).

2 Eine Auflistung der einschlägigen Forschungsliteratur bringt es auf kaum mehr als drei Seiten; sieht man von Editionen und rezeptionsgeschichtlichen Studien ab, reduzieren sich die Titel auf recht wenige Einträge. In zwei neueren Handbüchern der antiken christlichen Literatur taucht der Physiologus fast gar nicht auf: Überhaupt keine Berücksichtigung findet er laut Index bei Moreschini und Norelli (2007); ganz knapp geschafft hat er es in die äthiopische Übersetzungsliteratur (!) in Drobner ( ${ }^{3} 2011,514$ [Fehlanzeige im Index]). Es handelt sich in der Tat um „eine sträflich vernachlässigte Quelle“, Klauck (2008, 100).

3 Die Frühdatierung geht v. a. zurück auf Lauchert (1889, 64-65), hier unter Berufung auf die Rezeption der noch frühen Gnosis des Simon Magus: „Es weist aber also Alles darauf hin, dass die Entstehung des Buches vor 140 fällt, und es hindert wenigstens nichts, dass es nicht noch im ersten Viertel des 2. Jahrhunderts entstanden sein könnte“; ergänzend tritt hinzu das Argument der Benutzung des Physiologus durch Justin (65; 68-69). Vgl. Peters (1898, 1): ,aus dem ersten Viertel des zweiten christlichen Jahrhunderts“.

4 Vgl. die Bilanzierung bei Schneider (2016, 729): „Die früheste Fassung des Ph. stammt wahrscheinlich aus dem 2. Jh. nC., vielleicht auch erst aus dem 3. Jh. nC.“; vgl. ders. in diesem Band S. 5. Noch resoluter urteilt Imorde (2003, 1330): ,wird heute einhellig zw. 150 und 200 n. Chr. datiert“. Ähnlich Riedinger (1973, 305): „die beiden letzten Jahrzehnte des 2. Jahrhunderts, die Jahre 180-200 n.Chr.“; Riedinger (1977, 111); Alpers (1996, 598): „in der zweiten Hälfte des 2. Jh.n. Chr. in Ägypten entstanden“; vgl. Alpers (1984, 14): „Als Entstehungszeit dürfte nunmehr mit Sicherheit das zweite Jahrhundert n. Chr. festgestellt sein“; Alpers (2000, 999); Seibt (1993, 2117): ,wohl im späten 2. Jh.“; Grant (1999, 52): ,partly from the second century“; Treu (1999, 276): „wohl vor 200“; Hoppe (2003, 1202-1203); Zucker (2005, 12): „plus probablement du IIe siècle“; Hagelberg (2007): „2. Jh. n. Chr.“; Henkel (2010, 213): „um 180/200“; Depietri (2010, 17); Lazaris (2016, 30): ,il s'agit d'une œuvre chrétienne primitive à laquelle il faut assigner une date très ancienne. On serait alors très proche du christianisme primitif de la première moitié du IIe siècle“; Ledegang (2018). Zu aktuellen Vertretern einer Spätdatierung (Scott 1998; Dorfbauer 2013) vgl. unten bei Anm. 224 und 225. 
schwert wird die chronologische Fixierung durch die für diesen Typ von Literatur charakteristische Vielfalt an Versionen, die es nicht einfach (und womöglich auch nicht sinnvoll) macht, eine „Urschrift“ zu identifizieren. ${ }^{5}$

In den folgenden Zeilen versuche ich eine Sondierung an den Allegorien des Löwen im ersten Kapitel vorzunehmen, mit einem Seitenblick auf einige damit verbundene Passagen. Die Spurensuche wird im Resultat dazu führen, die für uns noch erkennbare früheste Version des Physiologus nicht vor dem späten dritten Jahrhundert zu situieren; der Gesamtbefund weist eher in die erste Hälfte des vierten Jahrhunderts.

\section{Christus der Löwe (Physiologus 1)}

Wir beschäftigen uns mit dem Anfang des Physiologus; ${ }^{6}$ dem Beginn kommt ja antiker Gepflogenheit zufolge eine wichtige lektüreleitende Funktion zu. Das tiersymbolische Album wird mit dem Löwen, dem traditionellen König der Tiere, eröffnet. ${ }^{7}$ Der biblische Leittext für alle drei folgenden Gleichnisse ist der sogenannte Jakobssegen von Gen 49,9:

Ein Junglöwe ist Juda! Aus einem Spross, mein Sohn, wuchsest du hoch. Als er sich niederlegte, schlief er wie ein Löwe und wie ein Junglöwe: Wer wird ihn wecken?

Im überlieferten Physiologus-Text ${ }^{8}$ leitet der erste Teil des Orakels das gesamte Löwenkapitel ein, während sein zwei-

5 Grundlage für alle textkritischen Fragen: Sbordone (1936a). Nicht einschlägig für die uns hier interessierenden Passagen sind Papyrusfragmente; vgl. zu diesen den Beitrag von Marco Stroppa in diesem Band. Zum Charakter der Textüberlieferung vgl. Maas (1937, 376): „einerseits Erhaltung wertvoller antiker Reste, daneben aber Entstellung, Missdeutung, Umformung, Wucherung, vor allem eine bis in die Titel sich erstreckende Vielgestaltigkeit der nebeneinander laufenden Fassungen, die den von der klassischen Philologie herkommenden Herausgeber vor eine neuartige Aufgabe stellt."

6 Die Übersetzungen richten sich im Folgenden meist nach Schönberger (2001). Verglichen wurden auch die Übersetzungen von Seel (1960) und von Treu (1981).

7 Die Prominenz des Löwen in der Antike zeigt sich etwa daran, dass ein von verschiedenen Autoren stammender Artikel „Animal Symbolism“ gleich zu Beginn an seinem Beispiel die vielfältigen Facetten symbolischer Konstruktionen darstellt: EBR 2:1-27 (zum Physiologus selber: 15). Zur messianisch-christologischen Ikongraphie des Löwen vgl. Bloch (1971, 116-117).

8 Es ist zu beachten, "dass schon der Text, den Sbordone in der ersten Redaktion bietet, keinen reinen Text einer ursprünglichen Physiologus-Fassung enthält, sondern vor allem die Hauptvarianten der wichtigsten Handschriftenfamilien, in die sich die erste Redaktion weiter untergliedern lässt”(Schneider, in diesem Band S. 8); vgl. ter Teil die dritte Allegorie ausleitet, verbunden mit einem Lob (,wohlgesprochen hat also Jakob“), das in unserer Schrift sonst gern dem „Physiologos“ selber zugesprochen wird. Der biblische Prätext gibt mit der Abfolge von „spriessen“, „schlafen“ und „erwecken“ die Sequenz der drei Löwengleichnisse vor, die drei „Naturen“ des Löwen, die sich auf die drei Hauptstationen des Weges Christi, des „geistigen Löwen“, deuten lassen: Inkarnation, Kreuzestod und Auferstehung. Wir haben also ein umfassendes allegorisches Triptychon vor uns.

Auf das Schriftwort folgt die erste Erklärung des „Physiologos“ zu den drei Naturen des Löwen:

Seine erste Eigenheit [ $\varphi$ v́øı)] ist diese: Wenn er im Gebirge umhergeht, weht ihm die Witterung der Jäger zu, und er verwischt

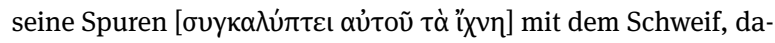
mit die Jäger nicht seiner Fährte folgen, sein Lager finden und ihn einfangen. ${ }^{9}$

Der Physiologus greift auf einen Wissensbestand zurück, der im Kern von Älians „Tiergeschichten“ dokumentiert wird: ${ }^{10}$

Der Löwe schreitet beim Gehen nicht geradeaus und lässt auch keinen Eindruck seiner Spuren, so wie er ist, sondern bewegt sich bald voran, bald wieder zurück, geht dann wieder vor- und wieder rückwärts und macht den Weg hin und her, so dass die

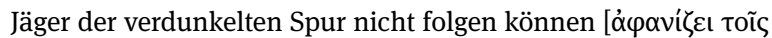

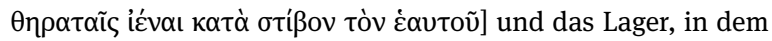
er ruht und mit seinen Jungen wohnt, nicht leicht auffinden können. Und dies ist eine den Löwen eigentümliche Gabe der Na-

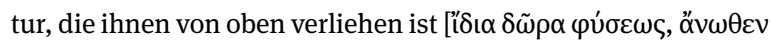

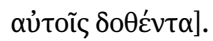

Schneider (2016, 278). Zu textkritischen Einzelheiten im Löwengleichnis selber, die den von Sbordone (1936a) konstituierten Text betreffen, vgl. Alpers (1984, 58 Anm. 15).

9 Die Ausgaben differieren hinsichtlich der Aspiration von AYTOY hier sowie gleich nachher in der Allegorese (aن்toṽ Sbordone; Schönberger; «ủtoṽ Offermanns; Kaimakis); die Hs. G hat an der ersten Stelle spiritus lenis (die zweite Stelle fällt hier aus). Am Sinn ändert sich nichts.

10 Älian, De natura animalium 9.30; übersetzt nach Brodersen 2018, 457. Vgl. Lauchert $(1889,6)$. Die „,von oben verliehenen Gaben der Natur" würden exzellent passen zur oberen Herkunft des Erlösers ( ${ }^{2} v \omega \theta \varepsilon v$, nur hier im Physiologus - vgl. bei Anm. 172), aber ob unsere Schrift Älians Tiergeschichten (um 200) kennt, ist mehr als unsicher (ganz zu schweigen von der chronologischen Frage). Die handschrift-

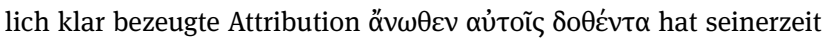
R. Hercher mutwillig getilgt; korrigiert von der neueren TeubnerAusgabe von García Valdés/Llera Fueyo/Rodríguez-Noriega Guillén (2009, 220; vgl. XIV: Hercher „multos textus locos iniuria commutavit, ut sermonem Aeliani ad id quod arbitrio suo exspectandum esset redigeret"). 
Unser Naturforscher reichert sein Portrait mit zwei zusätzlichen Elementen an: Mit dem Motiv des verwischenden Schwanzes spielt er wahrscheinlich eine AristotelesReminiszenz ein: Löwen flüchten bisweilen wie Hunde mit hängendem Schwanz. ${ }^{11}$ Und das versteckte Löwenlager wird mit einer Referenz auf Hld 4,8 versehen. ${ }^{12}$

Mit dem charakteristischen „so“ (oü $\tau \omega$ ) wendet sich der Blick von der Natur zur geistigen Welt, von der Bildhälfte zur Sachhälfte, nämlich zum Christus und seinem verborgenen Weg.

Exkurs: Vielleicht wirkt beim Verborgensein der „Spuren“ ein biblischer Prätext hinein (Ps 77,20): ${ }^{13}$ „Deine Fussspuren werden nicht erkannt werden.“

Es ist erstaunlich, mit welch steilem Mythologumenon der Verfasser des Physiologus seine Lehrschrift beginnt: ${ }^{14}$

So verbarg auch unser Erlöser, der geistige Löwe [, Sieger aus dem Stamm Juda, die Wurzel Davids (vgl. Offb 5,5)], gesandt vom unsichtbaren Vater, seine geistigen Spuren, nämlich die Gottheit

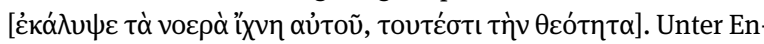
geln wurde er Engel, unter Erzengeln Erzengel, unter Thronen Thron, unter Mächten Macht, bis zu seiner Herabkunft; und er ging ein in den Schoss der heiligen Jungfrau Maria, um das verirrte Geschlecht der Menschen zu erlösen, „und das Wort ist Fleisch geworden und wohnte unter uns“ [Joh 1,14]. Daher erkannten sie ihn nicht, ihn, der von oben herab kam, und sprachen: „Wer ist dieser König der Ehren?“ [Ps 24,10a]. Dann antwortet der Heilige Geist: „Er ist der Herr der Mächte, er selbst ist der König der Ehren.“ [Ps 24,10b]

Die allegorische Deutung des Löwengleichnisses ist ausgesprochen dicht. ${ }^{15}$ Auf den ersten Blick wirkt die Passage

11 Aristoteles, Historia animalium 9.44.629b35-36. Vgl. Lauchert $(1889,6)$.

12 Hld 4,8 ${ }^{\mathrm{LXX}}$ („du wirst kommen ... von den Lagern der Löwen

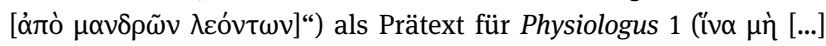

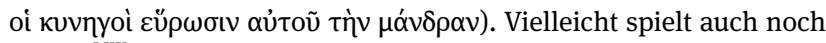

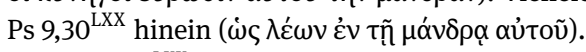

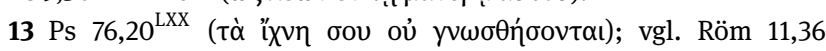

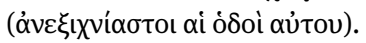

14 Die Übersetzung variiert diejenige von Schönberger 2001 und folgt dem Text von Sbordone 1936a, ausser bei der Partizipialkonstruktion, wo die Rede ist von dem, „,der von oben herab kam“; dazu s. unten bei Anm. 172.

15 Ich notiere eine interessante Rezeptionsspur des Physiologus, die dessen Allegorese noch einmal platonisch-ontologisch allegorisiert: Für Dionysios Areopagites symbolisiert die Gestalt des Löwen

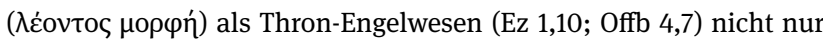
„Stärke und Unbezwinglichkeit“, sondern auch „die Tendenz zur möglichsten Angleichung an die Verborgenheit des unsagbaren Gottes-

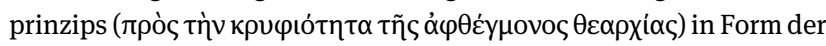
Verdeckung der Gedankenspuren und der geheimnisvoll unauffälli-

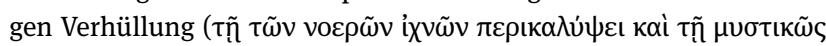

kohärent. Die Textbewegung folgt der Herabkunft des Erlösers; ${ }^{16}$ dieser bricht vom „unsichtbaren Vater“ auf und geht schliesslich in Mariens Schoss ein. Leitmotiv ist die

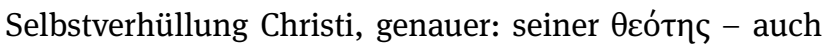
nachher in der Deutung der „zweiten Eigenheit“ des Löwen, seines Schlafens mit offenen Augen, wird auf Christi Gottheit fokussiert. Der Erlöser steigt die Himmelssphären hinab und kleidet sich jeweils als einer ihrer Bewohner, offenbar, um von diesen nicht erkannt zu werden. ${ }^{17}$ Die Abfolge der Engelklassen schert an diesem Punkt etwas aus, denn mindestens die Sequenz Engel-Erzengel ist ansteigend. ${ }^{18}$ Die Zielrichtung ist aber bleibend die Fleischwerdung; ${ }^{19}$ zitiert wird Joh 1,14. Man darf aufgrund des

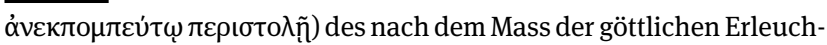
tung aufwärts gerichteten Wegs“, De caelesti hierarchia 15.8 (PTS 67, 57; deutsche Übersetzung: BGrL 22, 69; vgl. 94 Anm. 29). Prätext ist aber nicht nur Physiologus 1, sondern auch ein Chaldäisches Orakel (frag. 37: „eine geistige unvergängliche Form, auf deren unwelt-

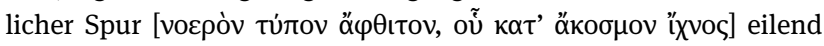
der Kosmos sichtbar wurde“), das auf neuplatonischer Seite vielfach rezipiert und über Proklos (vgl. In Timaeum 3.158.6-7 [Diehl

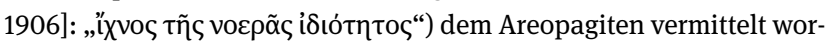
den ist. Eine weitere Rezeptionsspur findet sich wahrscheinlich im slawisch-orthodoxen Raum, nämlich in der „Leiter Jakobs“, worin Jakobs Traumvision (Gen 28) christologisch gedeutet wird (Climax Iacobi 4.46): Es ,wird der Erwartete kommen, <der>, dessen Pfad du bist, wird von niemandem erspürt werden“ (Übersetzung: Böttrich und Fahl [2015, 174-175; vgl. 66-67]).

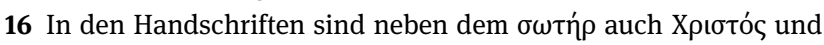

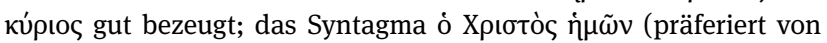
Sbordone) ist m. E. aber kaum ursprünglich: Es findet sich sehr selten in der altchristlichen Literatur (die drei Belege in Justins Dialog zählen nicht, da hier ja ein Christ mit einem Juden über den „Gesalbten“ diskutiert).

17 Da das Gleichnis selber von „Jägern“ spricht, legt es sich für die Leserschaft nahe, in der Allegorese die Rolle der Engelklassen negativ zu besetzen: Der Erlöser tarnt sich vor diesen. Diese Lektüre wird nicht nur durch die weiter unten zu besprechenden gnosisnahen Texte gestützt, sondern auch durch die Querbeziehung zur EinhornMiniatur in 22 (dazu unten bei Anm. 27).

18 Bei der Abfolge von Thronen und Mächten lässt sich nicht sagen, ob sie deszendent oder aszendent angeordnet ist, da die Vielfalt in den altchristlichen Angelologien notorisch ist. In der klassisch gewordenen neunfachen Hierarchie des Dionysios Areopagites (vgl. auch Anm. 15) aus dem frühen sechsten Jahrhundert rangieren die Throne über den (aufsteigend aufgelisteten) Fürstentümern (archai, principatus), Gewalten (exusiai, potestates), Mächten (dynameis, virtutes) und Herrschaften (kyriotētes, dominationes). Biblische Prätexte für die Kataloge sind vor allem Kol 1,16 (sive throni sive dominationes sive principatus sive potestates) und Eph 1,21 (supra omnem principatum et potestatem et virtutem et dominationem); vgl. 1Petr 3,22. Vgl. zur Hierarchisierung Michl (1962, 172). - In einem Strom der handschriftlichen Überlieferung fallen die Erzengel weg: Gruppen WO / AI $\Delta \Pi \varphi r$ (Kaimakis 1974, 6-7).

19 Entsprechend fügt ein Teil der Handschriften dem Gleichwerden

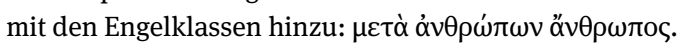


Kontextes der anderen beiden Löwengleichnisse wie im Blick auf weitere Passagen des Physiologus (3-4; 25; 44; 46; usw.) davon ausgehen, dass die Fleischwerdung selber das Erlösungsgeschehen von Kreuz und Auferstehung in sich beschliesst. ${ }^{20} \mathrm{Ob}$ der Physiologus das Löwenlager auf Mariens Schoss deutet, bleibt offen.

Bereits an dieser Stelle halten wir fest, dass die Engelgleichwerdung Christi, die in orthodoxer Perspektive zunehmend als häretisch beurteilt wurde, in der handschriftlichen Überlieferung teilweise ganz eliminiert oder wenigstens entschärft wird. ${ }^{21}$ Sie fehlt auch in den späteren Physiologus-Redaktionen aus (spätantik-)byzantinischer Zeit.

Schwieriger verhält es sich nun mit den auf das Johannes-Zitat folgenden Sätzen, die mit den Worten von Ps 24 $\left(23^{\mathrm{LXX}}\right)$ einen Dialog über den Erlöser wiedergeben. Auf Seiten der ,Bildhälfte' gibt es dazu keine Entsprechung. Bei den Fragenden, denen Ps 24,10a in den Mund gelegt wird, handelt es sich fast sicher um die Engelmächte, die gleich zuvor genannt wurden. Nicht eigens erwähnt wird der Aufruf zur Öffnung der Tore, die in Ps 24,7-10 Frage und Antwort begleitet. Bei welcher Gelegenheit erfolgt dieser biblische Dialog? Wir stellen diese Frage vorderhand zurück, da sie sich nicht beantworten lässt ohne Einbezug der theologischen Überlieferungsströme, die in unserem Textsegment rezipiert werden.

Im Blick auf die Deutung des Löwengleichnisses, genauer: seiner ersten Eigenheit, lassen sich drei traditionsgeschichtliche Komplexe unterscheiden: ${ }^{22}$ Erstens die Verborgenheit des Erlösers, zweitens seine Angleichung an

20 Die bei Schönberger gedruckte einleitende Anspielung auf Offb 5,5 (ihrerseits intertextuell bezogen auf Gen 49,9) verstärkt diese Implikation: Die Inkarnation wird als erfolgreiches Geschehen charakterisiert, das über die Passion (vgl. Offb 5,6: das geschlachtete Lamm) zum „Sieg“ führt. Die Allusion findet sich aber nur in drei von fünf Textfamilien (sowie in der äthiopischen und lateinischen Überlieferung); sie fehlt in den Hss. G und $\mathrm{M}$ und wird bei Sbordone als Zuwachs taxiert; für Urprünglichkeit plädiert Alpers (1984, 58 Anm. 15). 21 Die Engelgleichwerdung fällt aus in der Hs. p, während die Hs. B einen Ersatz bietet: Der angelische Status ist nun lediglich der Ausgangspunkt des Descensus ,von oberen und unteren Mächten und Gewalten“. Auch die äthiopische Übersetzung (bzw. vielleicht schon ihre griechische Vorlage) umgeht die Engelwerdung und schreibt dem noch nicht abgestiegenen Gottessohn Engelgestalt zu, möglicherweise angeregt von der „Gestalt Gottes“ in Phil 2,6: „Den Engeln gleich war er, bis er herabstieg und in den Schoss seiner Mutter Maria, der Jungfrau, einging, um das in der Irre gehende menschliche Geschlecht zu erlösen“ (Hommel 1877, 46; 1890, 13). Laut der lateinischen Überlieferung y verbirgt sich der Erlöser vor den ungläubigen Juden (eine Reminiszenz von Ascensio Isaiae 11,19, von 1 Kor 2,8 oder von Joh 8,59?); die Engelgleichwerdung bekommt damit einen anderen Status (Carmody 1941, 103).

22 Für alle drei Komplexe stellt viel Material zusammen Barbel ( $\left.{ }^{2} 1964\right)$; der Physiologus wird 297-299 behandelt (vgl. 305, 309), mit die Engelklassen, die auf die Menschwerdung zielt, und drittens die Wechselrede mit den Worten von Ps 24, die im Psalmenkontext zum Öffnen der Tore führt. Ein vierter Komplex ist theologiegeschichtlicher Art: die spezielle Figur der sich ,verhüllenden“ Gottheit Christi. Weiter unten werden diese vier Motiv-Verdichtungen im Einzelnen vorgestellt, um ihre spezifische Rezeption durch den Physiologus genauer bestimmen zu können. Die Abfolge impliziert auch eine historische bzw. chronologische Dimension: Wir bewegen uns von Stoffen, die sich gehäuft im zweiten und dritten Jahrhundert finden, zu solchen, die uns tief in das vierte Jahrhundert führen.

Wir wenden uns aber zunächst den beiden anderen Löwenallegorien zu. Die „zweite Natur“ des Löwen, nämlich sein Schlafen mit offenen Augen, wird folgendermassen gedeutet: ${ }^{23}$

So schläft auch der Leib meines Herrn am Kreuz, seine Gottheit

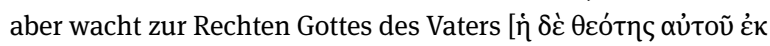

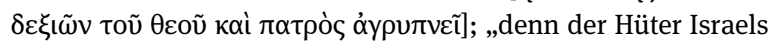
schlummert nicht noch schläft er“ [Ps 121,4].

Der für das erste Löwengleichnis einschlägige Prätext von Gen 49,9 steht mit dem Gegensatzpaar von "Schlafen“ und „Wachen“ auch hier im Hintergrund. ${ }^{24}$ Es wird zu fragen sein, ob sich die knappe Aussage des Physiologus vom „schlafenden“ und „wachenden“ Christus theologiegeschichtlich situieren lässt. Besonderer Aufmerksamkeit bedarf wieder die Rede von der $\theta \varepsilon o ́$ tn $\varsigma$ Christi, die die erste und die zweite Löwenallegorese miteinander verbindet.

Schliesslich bringt die dritte Löwenallegorie die Auferweckung Christi zur Sprache. Das von der Löwin tot zur Welt gebrachte Junge wird vom Vater am dritten Tag angehaucht und so zum Leben erweckt. ${ }^{25}$ Selbstverständlich bildet dieser Vorgang Ostern ab:

markanter Frühdatierung (,aus der ersten Hälfte des 2. Jahrhunderts“, 297).

23 Zum zoologischen Topos vgl. Plutarch, Quaestiones convivales 670BC; Horapollon, Hieroglyphica 1.19; Aelian, De natura animalium 5.39; Lauchert $(1889,5-6)$ und besonders die ausführliche textkritische, motiv- und wirkungsgeschichtliche Analyse von Alpers (1984, 49-56). Vgl. Stamatiou und Weckwerth (2010, 259, 275).

24 Zur Deutung des „Schlafens“ und „Erweckens“ von Gen 49,9 auf Tod und Auferweckung Christi vgl. unten Anm. 216 und 235.

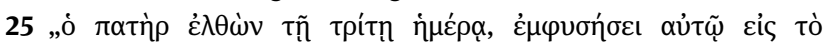

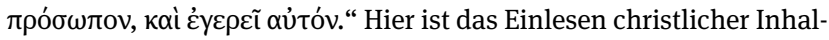
te in das Gleichnis selber mit Händen zu greifen (es gibt kaum naturkundliche Vorgaben; vgl. Lauchert [1889, 6]; Lazaris [2016, 107]; vgl. zu einem ähnlichen Befund anderwärts im Physiologus unten bei

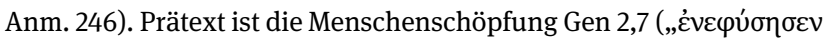

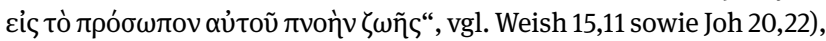

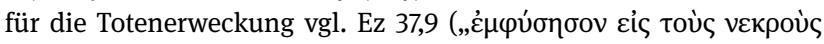
тov́тous“); 1 Kön 17,21. 
So hat auch unser Gott, der Allherrscher und Vater der Welt, am dritten Tage seinen vor aller Schöpfung erstgeborenen Sohn [Kol 1,15], unseren Herrn Jesus Christus, von den Toten erweckt, um das verirrte Geschlecht der Menschen zu erlösen.

Die Allegorese artikuliert Gottes Hoheitsstellung als Pantokrator und Allvater. Ebenso wird aber auch Christi Hoheitsposition unterstrichen - der am dritten Tag Erweckte ist zugleich der von Ewigkeit erstgeborene Sohn und Herr. Das dritte Löwenbild orientiert sich also wie die beiden anderen am Leitmotiv der Gottheit Christi. Auch die soteriologische Zielrichtung, die Menschenrettung, kennt die Leserschaft schon aus der ersten Allegorese. ${ }^{26}$

\section{Einhorn (Physiologus 22) und Ichneumon (Physiologus 26)}

Die erste Löwenallegorie hat, wie vielfach beobachtet worden ist, eine prägnante Entsprechung in der Deutung eines anderen Tiers: Das Einhorn, ${ }^{27}$ das von Jägern nicht gefangen werden kann, wohl aber von einer reinen Jungfrau, deutet der „Naturforscher“ unter Berufung auf Lk 1,69 auf den sich inkarnierenden Christus (22): ${ }^{28}$

26 Vier der fünf Handschriftengruppen (mit den beiden nicht papyrusförmigen ältesten Manuskripten) der „ersten Redaktion“ bezeugen den Finalsatz (vgl. dazu unten bei Anm. 190); er fehlt aber etwa in der äthiopischen und lateinischen Überlieferung. Lauchert und Sbordone halten ihn nicht für ursprünglich.

27 Beim Einhorn handelt es sich um ein schon traditionelles Symbol Christi (vgl. Justin, Dialog 91). Vgl. zur Motivgeschichte Brandenburg (1959, zum Physiologus: 851-852), mit der interessanten Beobachtung, dass die allegorische Deutung des Fangens, also die Gefährdung durch Engelmächte, kaum rezipiert worden ist (852-853); ferner Lauchert (1889, 22-24); Alpers (1984, 36-40); Greschat (2006) und den Beitrag von Hirsch-Luipold in diesem Band.

28 Nach Maria fügt der Hauptteil der handschriftlichen Überliefe-

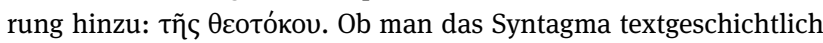
wirklich für sekundär erklären kann, scheint mir in Physiologus 22 alles andere als sicher zu sein. Sbordone (1936a, 82) beruft sich hier wie für Physiologus 1 (1936a, 4) auf Lauchert (1889, 230): „ein späterer Zusatz, da diese Bezeichnung für Maria erst auf dem Concil. Ephes. 431 festgesetzt wurde, worauf mich Herr Prof. Friedrich aufmerksam machte“. In Physiologus 1 ist die handschriftliche Bezeugung tatsächlich weit schwächer. Tilgt man $\theta \varepsilon$ cóóко in Physiologus 22 aber nicht, wird eine Datierung der ersten Physiologus-Version vor dem vierten Jahrhundert schwierig. In das fünfte muss man freilich nicht gehen; der Theotokos-Titel reicht in die Mitte des dritten Jahrhunderts zurück und wird im vierten durchaus gebräuchlich, neben den Alexandrinern auch gelegentlich bei den Kappadokiern (vgl. Gregor von $\mathrm{Na}$ zianz, Epistula 101.16 [SC 208, 42]).
Engel und Mächte vermochten ihn nicht zu überwinden [oủk

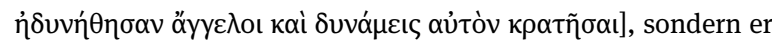
nahm Wohnung im Leib der wahrhaft reinen Jungfrau Maria, „und das Wort ist Fleisch geworden, und es wohnte unter uns“ [Joh 1,14].

Der Physiologus spielt mit den beiden Gruppen, den „Engeln“ und „Mächten“, vielleicht 1 Petr 3,22 ein. ${ }^{29}$ Allerdings geht es hier um die Unterwerfung der Mächte und Gewalten (vgl. Eph 1,21-22; ferner 1 Kor 15,24 und die Rezeptionsgeschichte von Ps 110,1), die sich (frühestens) mit der Erhöhung, also mit der Himmelfahrt Christi, zu realisieren beginnt. Inhaltlich viel näher liegt eine Aussage aus dem Johannesprolog - also dem zentralen Prätext sowohl hier in 22 wie in 1 -, wo es vom präexistenten Logos als dem „Licht“ heisst, dass „die Finsternis es nicht überwältigt“ habe (Joh 1,5) - so jedenfalls ist der Mehrheitsmeinung der griechischen Kirchenväter zufolge das

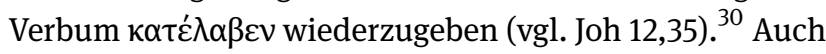
das Motiv des sich vor Gegnern und Volk verbergenden Jesus stammt ein Stück weit aus dem Vierten Evangelium

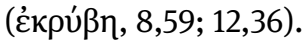

Exkurs: Zwischen Gleichnis und Allegorese besteht eine gewisse Spannung: Während in der Bildhälfte das Einhorn durch eine List der Jäger eingefangen wird, entgeht der Christus in der Sachhälfte just durch seine Inkarnation den angelischen Machenschaften. Dies könnte ein Hinweis darauf sein, dass die Deutung der Jäger als Engel auf eine Interferenz mit der ersten Löwenallegorie zurückgeht und vom Autor des Physiologus ad hoc vorgenommen worden ist.

Wir werfen einen Blick auf eine weitere Allegorie, auf den Ichneumon, eine Art von afrikanischem Mungo, der mit dem Drachen kämpft. Er wird vom Physiologus auf die Überwindung des Teufels gedeutet (26): ${ }^{31}$

So nahm auch unser Erlöser das Wesen des Erdengeschlechts an, bis er den Drachen tötete, [...] den Teufel. Denn wäre Christus körperlos gewesen, wie hätte er den Drachen vernichten können? Dann nämlich hätte ihm der Drache so entgegnet: „Du bist

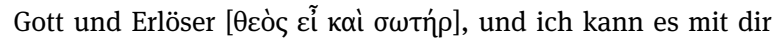

291 Petr 3,22: „der in den Himmel aufgefahren ist und jetzt zur Rechten Gottes sitzt, nachdem ihm die Engel, die Mächte und die Gewalten

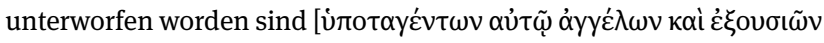

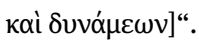

30 So exemplarisch Origenes, Commentarius in Iohannem 2.168-170

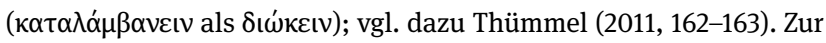
betreffenden Auslegungstradition vgl. Alpers (1984, 38-39), hier unter der Prämisse der Frühdatierung des Physiologus.

31 Zum Ichneumon als Bild für den Pharao von Ez 29,3 vgl. Gippert $(1997,174)$. Die erfolgreiche Taktik des Ichneumon im Kampf mit Reptilien ist in der antiken Naturkunde seit altägyptischer Zeit gut bekannt; vgl. Lauchert (1889, 25-26), z.B. Plinius, Naturalis historia 8.88-89 (dieses ägyptische Tier ist „hochberühmt“). 
nicht aufnehmen." Doch hat er, der grösser ist als alle, sich erniedrigt [vgl. Phil 2,7-8], um alle zu erretten [vgl. 1 Kor 9,22].

Weil der Teufel den fleischgewordenen Christus nicht erkennt, unterliegt er ihm schliesslich. Thematisch ist die Allegorese mit den bisher präsentierten verbunden durch die Figur der Verkörperung, die mittels einer Täuschung das Heil herbeiführt. ${ }^{32}$ Die Leserschaft kann von Physiologus 26 aus, von der körperlosen Seinsweise des Erlösers und seiner Verhüllung in der Leiblichkeit, eine Brücke zur Engelgleichwerdung in Physiologus 1 und in 22 schlagen, auch wenn hier das Täuschungsmanöver nicht explizit genannt wird. ${ }^{33}$ Eine Variante zur Allegorie vom Ichneumon bildet das gleich vorher platzierte Gleichnis vom „Otter“, der von Lehm umhüllt in den Rachen des Krokodils springt (25), gedeutet auf Christi Höllenfahrt. Beide Porträts verbindet nicht nur das Bildfeld - der mit Lehm getarnte raffinierte Kleinsäuger gegen das unaufmerksame Grossreptil -, sondern auch die Sachhälfte: Christi Verhüllung in einem irdischen Körper als Täuschungsmanöver, das zur Vernichtung des Teufels führt. ${ }^{34}$

In allen angesprochenen Allegoresen fällt auf, wie die theologischen und biblischen Zusammenhänge nur in Umrissen skizziert werden. Der Physiologus scheint mit der Kompetenz seiner Leserschaft zu rechnen, selbständig die theologischen und spirituellen Dimensionen der lediglich angedeuteten Themen und Figuren erschliessen zu kön-

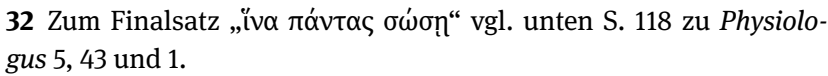

33 Die handschriftliche Überlieferung füllt die Leerstellen: In Physiologus 1 begründet die Handschrift p Christi Eingehen in Mariens Schoss mit den Worten: „um nicht erkannt zu werden durch

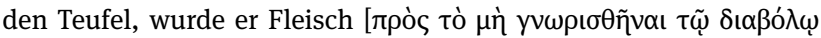

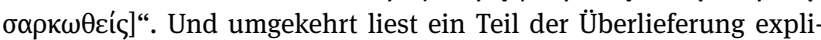
zit das „Verbergen der Gottheit“ in die Ichneumon-Deutung ein: „So nahm auch unser Erlöser das Fleisch des Erdengeschlechts an, und

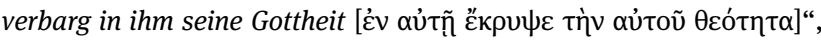
so die Hs. W (Kaimakis 1974, 76b) und die äthiopische Übersetzung: „so verbarg unser Heiland, nachdem er menschliches Fleisch angenommen, seine Gottheit“ (Hommel 1877, 72; 1890, 25). Zu vergleichbaren handschriftlichen Lektürevorgängen vgl. unten zum Einhorn, Anm. 183.

34 Wahrscheinlich handelt es sich bei dem „Otter“ (25, eigentlich $\dot{\eta}$ Évvסpıs [vgl. Treu 1981, 48; 138]) und dem Ichneumon um dasselbe Tier, die Pharaonenratte (vgl. Schönberger 2001, 118), das der Physiologus auf zwei Porträts verteilt. Von einer „Dublette“ sollte man aber nur schon deshalb nicht sprechen, weil die Sachhälften zwei verschiedene theologische Komplexe bilden: die Höllenfahrt, die von Haus aus nicht mit einem Inkognito operiert, und die Inkarnation als Überlistung des Teufels. Die assoziative Abfolge der beiden Porträts animiert zu einer kombinierenden Lektüre. nen. ${ }^{35}$ Die enorme handschriftliche Varianz zeigt, dass die Leser in der Tat den Physiologustext fortgeschrieben, ergänzt und durch Querbezüge komplementiert haben. Für die uns interessierenden Passagen wird in den Anmerkungen öfter verwiesen auf diese Rezeptionsgeschichte, die die Produktivität der Leser dokumentiert.

In den folgenden Abschnitten versuche ich, die religions-, traditions- und theologiegeschichtlichen Hintergründe der genannten vier Allegoresen des Physiologus herauszuarbeiten (Löwe I und II, Einhorn, Ichneumon).

\section{Der verborgene Erlöser}

Bereits Friedrich Lauchert hat, im Anschluss an Vorgänger, den Hintergrund der Aussage vom Verborgensein des herabsteigenden Erlösers vor den angelischen Mächten in der Gnosis geortet. ${ }^{36}$ Tatsächlich handelt es sich um eine beliebte Figur in den gnostischen Systemen. ${ }^{37}$ Laut der häresiologischen Überlieferung soll schon Simon Magus die folgende Lehre über den Erlöser vertreten haben: ${ }^{38}$

35 Zur Leseraktivität, die der Physiologus voraussetzt, etwa im Herstellen von Kohärenz zwischen den vom Verfasser teilweise nur angedeuteten Dimensionen von Tierbildern, Schriftbezügen und eigener Lebensführung, vgl. Nicklas (2013, 235-236, 249-250): „Jedes einzelne Kapitel kreiert ein Detail einer im Gesamt des Textes entstehenden ,Welt““ (250). Vgl. auch unten bei Anm. 192 sowie Lazaris (2016, 112$118 ; 144)$.

36 Vgl. Lauchert (1889, 48, 54-57, 64-65) mit Verweis auf Simon Magus u. a. Lauchert setzt sich insofern von seinen Gewährsleuten (etwa Pitra [1855, LXVII-LXIX]) ab, als er unterscheidet zwischen dem rezipierten Gut und dem Physiologus-Verfasser selber; dieser sei kein Häretiker. Später ist wieder ganz auf der „gnostischen“ Linie Riedinger (1973, 303): „Dem Physiologos blieben die Stücke gnostischen Flitters bis heute erhalten und haben seinem Ansehen nur selten geschadet"; Riedinger (1977, 111-112): „Der Physiologos stammt nun mit grösster Wahrscheinlichkeit aus hermetisch-gnostischen Kreisen Alexandreias, nach allem, was sich heute noch feststellen lässt, von Pantainos“. Ähnlich auch Lazaris $(2016,103)$ : „Le Physiologus est un texte gnostique ou, pour être plus précis, un écrit révélant d'une doctrine intermédiaire entre la gnose, l'hermétisme et la morale chrétienne“.

37 Vgl. Bousset (1973, 238-260) und vor allem die programmatische Skizze bei Bultmann (1967, 75-80): „Den Mächten dieser Welt erscheint der Gesandte als ein Fremder; sie kennen seine Herkunft nicht, denn er ist anderen Ursprungs als sie“ (75). Bultmann identifiziert den Mythos schon in neutestamentlichen Texten (namentlich im Johannesevangelium, in 1 Kor 2,9; 2 Kor 8,9; Phil 2,6-8).

38 Irenäus, Adversus haereses 1.23.3 (SC 264, 316/318 = FC 8, 292) par. Hippolyt, Refutatio omnium haeresium 6.19.6 (GCS 26, 147):

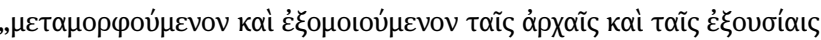

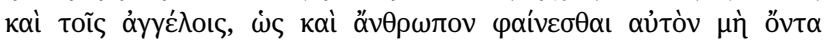

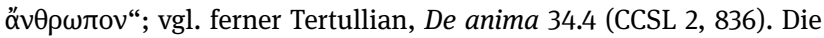
Lehrbildung geht bestimmt nicht auf den historischen Simon zurück, 
Er sei gekommen, um die Dinge in Ordnung zu bringen. Er habe sich verwandelt und sich den Kräften, Mächten und Engeln angeglichen und sei so herabgestiegen, dass er auch den Menschen als ein Mensch erschien, ohne ein Mensch zu sein.

Wie im Physiologus gleicht sich der Erlöser verschiedenen Engelklassen an (archai, exusiai, Engel), offenkundig, um sich vor ihnen zu verbergen. Der Abstieg kulminiert in der Menschwerdung, die hier doketistisch zugespitzt wird. ${ }^{39}$

Noch stärker ausgebaut wird die Figur in der Pistis Sophia, die in das späte dritte Jahrhundert gehört. Der Erlöser besucht jeweils in konformer Gestalt und Bekleidung die verschiedenen Sphären. ${ }^{40}$ In den unteren wird er jeweils zunächst nicht erkannt. Auch hier begegnen wir den im Physiologus genannten Engeln, Erzengeln und Gewalten (exusiai). Trägt er aber beim Aufstieg sein Lichtkleid, dann entsteht Aufregung unter den Mächten, die Tore öffnen sich und erstaunte Fragen werden laut: „Wie hat der Herr des Alls uns durchwandert, ohne dass wir es wussten?" ${ }^{41}$ In der Folge beten die Betroffenen den Verherrlichten an. Die retrospektive Erkenntnis ist ein Element, das im Physiologus auf der Textoberfläche so nicht begegnet.

vgl. Haar (2003, 92-93, 228-293). - Bei Epiphanios, Adversus haereses 21.2.4 (GCS.NF 10:1, 240), findet sich sogar eine Aussage in erster Person: „In jedem Himmel werde ich verwandelt hinsichtlich der Gestalt (der Bewohner) eines jeden Himmels, damit ich meinen angelischen Kräften verborgen bliebe [...]." Vgl. dazu Williams ('2009, 62 Anm. 11): „The direct quotes which Epiph gives in this Sect $<$ ion $>$ are his own dramatization of his sources".

39 Die doxographischen Überlieferungen von Simon, Menander, Sa tornil und Basilides überschneiden sich in vielem; zur Scheinkreuzigung und zum Gestaltenwandel bei letzterem vgl. Irenäus, Adversus haereses 1.30.4 und 6: „wie der Sohn allen unbekannt sei, so brauchten auch sie [die Gnostiker] von niemand erkannt zu werden, sondern, wie sie selbst alle kennen und durch alle hindurchgehen, so seien auch sie allen unsichtbar und unbekannt“; dazu Löhr (1996, 269270).

40 Pistis Sophia 7; 10-14 (deutsche Übersetzung: Schmidt [1925]; $\mathrm{GCS}^{3}{ }^{45}$ ). Nur am Rand verweise ich auf mandäische Texte, die die Verborgenheit des Erlösers bezeugen (Ginza, Rechter Teil, 5.138-139, 5.146 u. ö.). Mehr Material bei Bultmann (1967).

41 Pistis Sophia 1.11-13 (Schmidt 1925, 15-16 = NHS 9, 21-22).
Auch einzelne Texte aus Nag Hammadi dokumentieren das Muster des verborgenen Erlösers. ${ }^{42}$ Unter ihnen ragt besonders die „dreigestaltige Protennoia“ heraus: ${ }^{43}$

Unter den Engeln [angelos] zeigte ich mich in ihrer Gestalt, und unter den Kräften [dynamis], als ob ich eine von ihnen wäre; unter den Menschensöhnen aber, als ob ich ein Menschensohn wäre, obgleich ich (doch) der Vater eines jeden bin. Ich verbarg mich unter allen, bis ich mich in meinen eigenen Gliedern offenbart haben werde.

Der Unerkennbarkeitstopos, der über die Engelklassen hinaus auch die Menschenwelt umgreift, findet sich ebenso dort, wo nicht explizit von einem Abstieg durch die Sphären gesprochen wird. Die prägnanteste Formulierung stammt aus dem Philippus-Evangelium: ${ }^{44}$

Jesus hat unbemerkt alle (Gestalten) angenommen. Denn er zeig te sich nicht so, wie er war; sondern so, wie sie ihn würden sehen können, zeigte er sich. Diesen allen aber zeigte er sich: Er zeigte sich den Grossen als Grosser. Er zeigte sich den Kleinen als Klei-

42 Der zweite Logos des großen Seth (NHC 7,2) 56.22-26: „Als ich im Herabkommen war, sah mich niemand, denn ich veränderte meine Gestalten, indem ich das Aussehen (jeweils) wechselte. Und deswegen, als ich bei ihren Pforten war, nahm ich ihr Aussehen an: Denn leise zog ich an ihnen vorüber“ (56.21-29 - anders als beim Abstieg verhält es sich beim Aufstieg: „Die Welt seinen offenbaren Aufstieg in die Höhe [...] in unverhüllter Gestalt nicht ertragen“, 58.13-14); Zostrianos (NHC 8,1) 130 (Engel und Archonten erkennen ihn nicht); Noē$m a$ (NHC 6,4) 41-42 (die Unterweltsherrscher erkennen ihn nicht „wer ist das? was für einer ist das?!“). Für unsere Fragestellung nicht einschlägig ist eine Passage in der mehrfach überlieferten Schrift Sophia Jesu Christi (BG 3, 83 par. NHC 3,4, 94), die die Verborgenheit des höchsten Erlösergottes für Engelmächte (archē; exusia; hypotagē; physis) herausstreicht (par. auch Eugnostosbrief [NHC 3,3, 3; 5,1, 2]). Die Wiedergabe der NHC-Texte folgt der Übersetzung in Schenke, Bethge und Kaiser $\left({ }^{3} 2013\right)$.

43 Die dreigestaltige Protennoia (NHC 13,1) 47-49 in der EpiphanieRede (Zitat: 49,15-22). Vgl. auch 47.15-25: „(Bei meinem Abstieg) zeigte ich mich (den Mächten) in ihrer Gestalt; ja, ich trug ihrer aller Kleidung. Ich verbarg mich unter ihnen, und sie erkannten nicht den, der ihnen Kraft gibt; doch ich bin vorhanden in allen Mächten [archē] und Gewalten [dynamis], in den Engeln [angelos] und in jeder Bewegung, die es in der ganzen Hyle gibt. Ja, ich verbarg mich unter ihnen, bis ich mich meinen Brüdern offenbart haben werde. Und niemand von ihnen erkannte mich, obgleich ich es bin, der in ihnen wirkt.“

44 Philippus-Evangelium 26a (NHC 2,3) 57.28-58.3. Zur Interpretation vgl. Klauck (2008, 366-368). Es ist m. E. nicht zulässig, das gesamte Mythologumenon vom durch die Himmelswelten absteigenden Erlöser in diese Passage des Philippus-Evangeliums einzulesen; so aber Schenke (1997, 245): „Der Topos, der in unserem Paragraphen zur Sprache kommt, ist geläufig und wohlbekannt. Es handelt sich um den geheimen Abstieg und offenbar-triumphalen Wiederaufstieg des Erlösers durch die verschiedenen überirdischen und irdischen Seinssphären“. 
ner. Er zeigte sich den Engeln als Engel und den Menschen als Mensch. Deswegen blieb jedem verborgen, wer er wirklich war.

Der Text hält zwei entgegengesetzte Gewichte in der Schwebe: Einerseits verbirgt der Christus sein wahres Wesen vor allen. Andrerseits kommen seine Metamorphosen den Empfängern zugute; er passt sich ihrer (beschränkten) Seinsweise an, um sich zu offenbare ${ }^{45}$ - namentlich seinen Anhängern. Wir werden weiter unten sehen, dass Origenes diesen zweiten Aspekt der Polymorphie, die Akkommodation des Logos an das Fassungsvermögen von Menschen (und Engeln), erheblich verstärken wird.

Das uns interessierende Mythologumenon vom die Sphären unerkannt durchschreitenden Erlöser ist keineswegs auf die Gnosis im engeren Sinn beschränkt, sondern begegnet auch in anderen, später als mehr oder weniger heterodox taxierten Schriften. Besonders die Schilderung des herabsteigenden Christus in der Ascensio Isaiae, wohl aus dem zweiten Jahrhundert, deckt sich an einigen Punkten mit derjenigen des Physiologus. ${ }^{46}$ Der „Geliebte“ steigt unerkannt durch die sieben Himmel (samt Firmament und Totenreich), indem er den jeweiligen Engeln gleich wird. Gott sendet ihn mit folgenden Worten aus (10,9-12): ${ }^{47}$

Du sollst gleich werden dem Bilde aller, die in den fünf Himmeln sind, und der Gestalt der Engel im Firmament wirst du mit Sorg falt gleichen und auch den Engeln, die im Totenreich sind. Und keiner von den Engeln dieser Welt wird erkennen, dass du mit mir zusammen der Herr der sieben Himmel und ihrer Engel bist. Und sie werden nicht erkennen, dass du zu mir gehörst.

Er wird vom Gott dieser Welt und seinen Gefolgsleuten unwissentlich gekreuzigt $(9,12-15) .^{48}$ Erst bei seinem Wie-

45 Vgl. Philippus-Evangelium 67a (67.9-12): „Die Wahrheit kam nicht nackt in die Welt. Vielmehr ist sie gekommen in Symbolen und Bildern. Sie (sc. die Welt) kann sie nicht anders empfangen.“

46 Vgl. Peterson (1959, 237, 250-251). Peterson denkt an direkte literarische Abhängigkeit des Physiologus von der Ascensio Isaiae (vgl. dazu unten bei Anm. 61 und 90); die Übereinstimmungen sind aber nicht hinreichend genau. Lediglich eine Paraphrase bietet Hall (1999).

47 Übersetzung nach Müller ( $\left.{ }^{6} 1997,559\right)$. Zum descensus absconditus des Erlösers in Ascensio Isaiae 6-11 vgl. Norelli (1995, 509-515). Zur Verwandlung und zu möglichen paulinischen Rezeptionsspuren vgl. Nicklas (2015, 332-337). Knight (1996) identifiziert in der Ascensio Isaiae eine Spielart von angelomorpher Christologie, zu Kap. 10/11 vgl. 64-69; 124-130; 146-150; zur Berührung mit dem Physiologus 165: „The Physiologos agrees with the Ascension of Isaiah that the angelic appearance was an accommodation and in referring this disguise to salvific purposes“.

48 Zur Rezeption von 1 Kor 2,8 in Ascensio Isaiae s. Knight $(1996,68)$ : „Paul, however, has no ,hidden descent tradition““, ebenso 135; 79: „we find in the Ascension of Isaiah [...] an early form of ,exegesis““; 298-300. deraufstieg verzichtet er auf den Verwandlungsmodus; die Engel erkennen ihn und beten ihn an. ${ }^{49}$ Hinsichtlich der Engelbezeichnungen lassen sich aufgrund der Überlieferungslage der Ascensio Isaiae keine spezifischen Berührungspunkte mit dem Physiologus festmachen. ${ }^{50}$

Eine weitere aufschlussreiche Passage findet sich in der Epistula apostolorum, die uns wieder in das zweite Jahrhundert führt (13): ${ }^{51}$

Ich befand mich in den Himmeln, und die Erzengel und die Engel - ich ging vorüber an ihrer Gestalt, so als wäre ich einer mit ihnen in den Herrschaften und Gewalten. Ich durchschritt sie [...] Ich aber, ich bin geworden alles in jedem, dass ich die Heilsveranstaltung des Vaters des Ruhmes, desjenigen, der mich gesandt hat, vollende und zu ihm zurückkehre. ${ }^{52}$

Der Abstieg vollendet sich in der Menschwerdung; in der Gestalt des Erzengels Gabriels besucht der Christus Maria und geht in sie ein (14). Auch in diesem Text verbindet sich Christi Verborgenheit mit der Angleichung an verschiedene Engelklassen. Wichtig ist die Beobachtung, dass das Tarnungsmotiv nicht zu einem doketistischen Verständnis der Inkarnation Christi führt, es wird im Gegenteil die Materialität des Auferstehungsleibs betont (11-12).

Eine für unsere Fragestellung wichtige Bibelaussage darf an dieser Stelle nicht fehlen: Paulus deutet in seiner Weisheitsrede für die Vollkommenen (1 Kor 2,6-16) an, dass die Weltherrscher nur aufgrund ihres Unwissens den Christus gekreuzigt haben (V. 8-9):

Sie [sc. die verborgene Weisheit Gottes] hat keiner der Herrscher dieser Weltzeit je erkannt, denn hätten sie sie erkannt, hätten sie

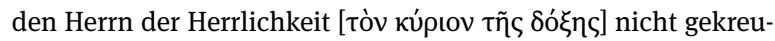
zigt.

In der Forschung hat unsere Passage vielfach Anlass gegeben, einen protognostischen Mythos hinter der paulini-

49 Ascensio Isaiae 11,23-33 (mehrfach heisst es: „Wie ist unser Herr uns verborgen geblieben, als er hinabstieg, und wir merkten nichts?").

50 Die äthiopische Version von Ascensio Isaiae 10,15 nennt „Fürsten und Mächte dieser Welt“ (vgl. 11,16: „Fürsten“); die lateinische Überlieferung hat „principes et virtutes et omnes angeli et omnia inicia“ (CCSA 7, 424; vgl. 10,11: „,neque angeli neque principes illius saeculi“), also archontes, dynameis, angeloi, archai (vgl. Peterson 1959, 237 Anm. 3). In Ascensio Isaiae 7,21.27; 8,8; 11,25 (und 7,15) sind „Thron(e)“ als Engelmächte zu verstehen (daneben spielen die Throne in der Ascensio Isaiae eine wichtige Rolle als ehrenvolle Sessel).

51 Übersetzung nach Müller (2012, 1070), zitiert ist die koptische Fassung.

52 In der Wendung „ich bin geworden alles in jedem“ (zur Übersetzung der koptischen Version vgl. Hornschuh [1965, 39-41]) liegt gewiss ein Reflex von 1 Kor 9,22b vor (nicht verzeichnet von der Biblia patristica 1:460). 
schen Formulierung zu vermuten. ${ }^{53}$ Man ist aber besser beraten, möglichst wenig textexternes Wissen zu postulieren, zumal das Objekt des Unwissens die verborgene Weisheit, nicht Christus als Herr der Herrlichkeit bildet. ${ }^{54}$ Der verborgene Abstieg durch die Himmelssphären ist keineswegs im Blick. Auch bei den Weltherrschern empfiehlt sich eine Deutung, die nicht speziell die Archonten gnostischer Systeme, sondern weiträumig himmlische wie irdische Machtträger in den Blick nimmt. So gesehen kommt die etwas kryptische Aussage nicht als Zeugin, sondern vielmehr als eine Impulsgeberin für den späteren Motivkomplex des sich vor den Mächten verbergenden Erlösers in Betracht. ${ }^{55}$

Exkurs: Schwierig zu beurteilen ist ein Passus in den Ignatiusbriefen, deren Echtheit heute ohnehin nicht mehr gesichert ist. Laut Eph 19,13 sind „dem Fürsten dieser Weltzeit“ die Jungfräulichkeit der Maria, die Geburt Jesu und sein Tod verborgen geblieben, „drei laut rufende Geheimnisse, die im Schweigen Gottes vollbracht wurden“. Sie wurden „den Äonen offenbar“ durch den Wunderstern, mit dem die alte Welt zu ihrem Ende kam. Der Stern von Mt 2,1-12 wird kosmischeschatologisch und soteriologisch gedeutet. Man muss sich aber davor hüten, das ganze von uns untersuchte Mythologumenon diesem knappen, nur andeutenden Text zu unterlegen. ${ }^{56}$

53 So etwa Lietzmann (1949, 12-13). Heutige Kommentatoren lehnen diese Hypothese dezidiert ab, vgl. Schrage (1991, 253-254); Lindemann $(2000,65)$. Meist wird die (Proto-)Gnosis-Hypothese für den grösseren Kontext, nämlich für 1 Kor 2,6-16, diskutiert, worin V. 8 eine Schlüsselposition zukommt; vgl. Kovacs (2015).

54 Vgl. Sellin (2009, 24): „Damit entfällt aber die ganze Theorie vom gnostischen Mythos, der hier angeblich im Hintergrund stehe: als habe sich der Urmensch-Erlöser verkleidet durch die Sphären der mythischen Archonten zu den Seinen geschlichen“.

55 Hanson (1980, 21-96: „A Quasi-Gnostic Pauline Midrash: I Corinthians 2.6-16“) findet in unserer Passage m. R. zwar keinen descensus absonditus (,there is no idea of a disguised descent behind I Corinthians 2.6-8. [...] Paul may have been thinking rather in terms of an ascension“, 38), dafür aber einen „Midrasch“ zu Ps 24. Aber weder 1 Kor 2 noch die Ascensio Isaiae (so Hanson 1980, 41-42) lassen irgendwelche Rezeptionsspuren von Ps 24 erkennen. Hanson beansprucht auch Physiologus 1 als (spät datierten!) Zeugen für „a Christian interpretation of Psalm 24 and the ascension or else with a disguised appearance of Christ on earth" (42).

56 Dies ist etwa der Fall bei Bultmann (1967, 77, 79); Hall (1999); zur Kritik vor allem an der gnostischen Deutung von Heinrich Schlier vgl. Schoedel (1990, 160-161). Zur Verbindung von Verborgenheit und Täuschung vgl. v. Heyden (2014, 347-359, besonders 352: „auch ein Grundmotiv des Doketismus“). Keine Hilfestellung für die religionsgeschichtliche Analyse bietet Stander (1989). Zum speziellen Verhältnis zwischen der Ignatius-Passage und Ascensio Isaiae 11 vgl. Norelli (1995, 562-569): traditionsgeschichtlicher, nicht literarischer Zusammenhang; bei Ignatius ist das Unwissen der Geistermächte nicht mit dem descensus verbunden. Auch für Lechner (1999, 253-255) liegt kein descensus incognitus vor, auch wenn die Passage vor einem va-
Wir ziehen eine erste Bilanz: Mit dem Mythologumenon des verborgenen Erlösers befinden wir uns in theologischen Milieus des zweiten und dritten Jahrhunderts. ${ }^{57}$ Der Befund als solcher würde zunächst durchaus für eine Frühdatierung des Physiologus sprechen. ${ }^{58}$ Die Figur begegnet mehrheitlich in ,dissidenten', teilweise gnostischen und später als häretisch oder mindestens als problematisch taxierten Texten. In den theologischen Bildungen der Mehrheitskirche findet sich $\mathrm{m}$. W. trotz der von 1 Kor 2,8 gelegten Spur das Mythologumenon nur selten. ${ }^{59}$ Dafür lassen sich zwei Gründe namhaft machen: Zum einen werden hier sowohl in Theologie wie in Frömmigkeit die Engel viel positiver gewertet als in Kreisen, die die vorfindliche Schöpfung als negativ oder mindestens als ambivalent beurteilen. Der herabsteigende Erlöser braucht sich vor ihnen nicht zu tarnen - er tut dies allenfalls lediglich gegenüber gefallenen, dämonisch gewordenen Mächten, also gleichsam gegenüber einer angelischen Teilmenge. Zum anderen hat Christus als der Logos eine prominente Vorgeschichte in der Epoche des Alten Bundes; er vermittelt sich etwa in den Theophanien und Angelophanien. Im Raum der biblischen Heilsgeschichte hat es wenig Platz für den unbekannten und akosmischen Erlöser. Die Unwissenheitstopik begegnet bei den Vätern in einer anderen Konfiguration, die überaus populär geworden ist: Es ist der betrogene Teufel, der im Verbund mit seinen Gesellen

lentinianischen Hintergrund gedeutet wird. Zur neueren Diskussion vgl. Lechner (2018, 52-54).

57 Zur Motivik des sich verbergenden Erlösers ist auch Oden Salomos 42.3-4 zu vergleichen: „weil ich mich verbergen werde vor jenen, die mich nicht festhielten; ich werde sein bei denen, die mich lieben“; Oracula Sibyllina 8.291-292 („dass keiner erkenne, wer und wessen er sei und woher“); 12.32: „dann wird kommen der Logos des Höchs-

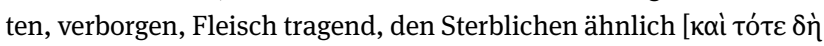

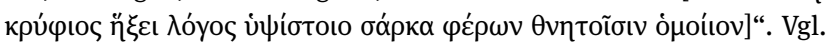

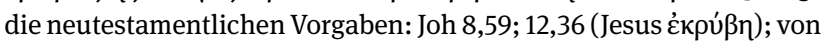

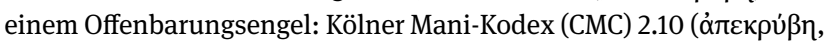
vgl. 119.10 vom Engel/Syzygos; 41.11 [?]; 38.2-3 in Manis Gebet: „dass ich vor meinen Feinden verborgen werde“). - Anders z.B. Clemens,

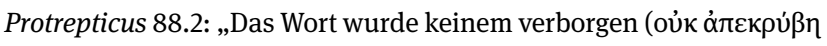

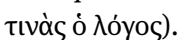

58 So z. B. Treu (1966, 104): es „trifft sich der Physiologus mit der apokryphen Literatur des 2. Jahrhunderts in einer bemerkenswerten ,ungeschützten` Sorglosigkeit der theologischen Aussagen, die in den Augen der Späteren häretisch [gnostisch usw.] erscheinen, während sie in Wirklichkeit nur eine frühe Phase kennzeichnen, in der die Fronten noch nicht verhärtet, die Begriffe noch nicht etikettiert waren“; Treu (1993, 200): „gnostic elements“, „some traces of Docetism“; so schon, noch früher datierend, Lauchert (1889, 64-65).

59 Einen Beleg dafür bietet die armenische Irenäus-Überlieferung, vgl. unten bei Anm. 92. Immerhin ist es etwa bei Clemens der Aufstieg der Seele, der an den Wächterengeln vorbei führt (Stromata 4.116.2, 4.117.2). 
Jesu Passion veranlasst und damit unwissentlich seine eigene Entmachtung herbeiführt. Dazu kommen noch zwei andere Assoziationsfelder: Zum einen ist zu nennen das temporäre Nichterkennen des Christus durch die Engel im Narrativ von seiner Himmelfahrt und/oder seiner Höllenfahrt, worin die „Torliturgie“ von Ps 24,7-10 inszeniert wird. Zum andern markiert der Inkarnationsmodus selber, das Sein im Fleisch bzw. in menschlicher Gestalt, eine Verborgenheit vor Menschen, zumal Gegnern, und vor widergöttlichen Mächten. Wir kommen auf alle drei Punkte zurück.

Exkurs: An dieser Stelle ist kurz einzugehen auf eine These, die Jean Daniélou 1974 prominent vertreten hat: Bei der „descente cachée“ handle es sich um ein altes Mythologumenon der "théologie du judéo-christianisme“ des ersten und zweiten Jahrhunderts n. Chr., das vom Physiologus in einer archaischen Form bezeugt werde. ${ }^{60}$ Daniélou schliesst sich der - steilen - Hypothese von Peterson an, der Physiologus sei literarisch abhängig von der Ascensio Isaiae, und zwar von einer älteren Version als der uns überlieferten. ${ }^{61}$ In dieser finde sich auch die Referenz auf Ps 24 samt dem heiligen Geist als den Engeln antwortender Sprecher. Die Ergebnisse unserer Untersuchung widersprechen dieser Hypothese diametral. Die relativ knappe Form, in der der Physiologus den vor den Engeln verborgenen Abstieg des Erlösers schildert, lässt sich besser verständlich machen als Skizze, die auf Seiten der Leserschaft bekanntes Gut voraussetzt; sie ist kein Zeichen von Archaizität. Auch die Kombination des Abstiegs mit der Wechselrede von Ps 24, auf die wir weiter unten eingehend zu sprechen kommen, weist nicht auf ursprüngliche Tradition, schon gar nicht auf eine verlorene Version der Ascensio Isaiae. ${ }^{62}$ Die beiden Komplexe werden überaus selten verbunden: neben dem Physiologus lediglich im armenisch überliefertenen Irenäus. ${ }^{63}$ Particula veri der These von Daniélou ist die Rückführung des descensus absconditus auf ein judenchristliches Milieu, in dem Angelophanien und speziell die Angelomorphie Christi eine grosse Bedeutung hatten. Der Befund in der Ascensio Isaiae zeigt, dass sich Traditionen dieser Art in eine

60 Daniélou (1974, 253-273): „nous avons sans doute ici la forme la plus archaïque“ der „descente cachée“ (265). Bündige Kritik an Daniélou bei Norelli (1995, 513-514).

$6 \mathbf{1}$ „Et cet ouvrage [sc. l'Ascension d'Isaïe] est sans doute celui dont tous les autres dépendent. Si nous avons commencé par le Physiologos, c'est parce que, selon la suggestion de Peterson, il reflète sans doute une version plus ancienne de l'Ascension d'Isaïe que celle que nous possédons“, Daniélou (1974, 266). Zu Peterson s. unten Anm. 90. 62 Auch der Verweis auf eine Predigt von Gregor von Nyssa ist abenteuerlich: hier werde nicht nur „le fond judéo-chrétien“ erkennbar, sondern auch die postulierte verlorene Version der Ascensio Isaiae (268). Zu Ps 24 stellt Norelli $(1995,513)$ richtig fest: „L'uso del Sal $23 \mathrm{mi}$ pare indiscutibilmente legato, alle origini, all'ascensione del Signore e non alla sua discesa.“ Wir deuten weiter unten Gregors auffällige Platzierung von Ps 24,7-8 beim Abstieg nicht als Relikt einer archaischen Form des descensus absconditus, sondern als Extrapolation der traditionellen Platzierung der Verse beim Aufstieg: Der Prediger verteilt aus exegetischen Gründen die doppelte Wechselrede auf Abstieg und Aufstieg (s. bei Anm. 108).

63 S. dazu unten bei Anm. 92.
Richtung entwickeln, die die Rezeption und Radikalisierung durch die Gnosis ermöglicht. ${ }^{64}$

\section{Gleichwerden mit Engeln}

Einen grossen Teil der für unsere Fragestellung wichtigen Texte haben wir bereits zusammengestellt: Der verborgene Erlöser passiert die vielfachen Himmel und nimmt die jeweilige Gestalt ihrer Bewohner an. In diesen Formen von subtiler himmlischer Leiblichkeit tarnt er sich erfolgreich. Zugrunde liegt der Motivkomplex der Polymorphie, die die verschiedenartigen Metamorphosen ermöglicht. ${ }^{65}$ Es kommt die überaus weite Topik der Engelwerdung und der Engelgleichheit hinzu, etwa der Frommen im Jenseits oder bei der Totenauferstehung. Die Angelomorphie wird gelegentlich nicht nur anthropologisch und eschatologisch artikuliert, sondern sogar christologisch: Es gibt im frühen Christentum auch entlegene Spuren einer Engelchristologie, oder vorsichtiger formuliert: einer angelomorphen Christologie. $^{66}$

Verbunden mit dem Nichterkennen von Seiten der Mächte zeigt die Angleichung an die Engel eine deutliche Zielrichtung: Sie kulminiert in der Menschwerdung. Auch und gerade in der menschlichen Gestalt verbirgt sich der Gottessohn. In einigen gnostischen Systemen wird das Inkognito doketistisch zugespitzt. Es gibt aber auch ganz andere Optionen, wie gerade die Epistula apostolorum mit ihrem dezidiert antidoketistischen Profil zeigt. Hier wie dort spielt die Rezeption von Phil 2,7 eine mehr oder weniger formative Rolle (,den Menschen ähnlich, in seiner Erscheinung wie ein Mensch“).

Abgesehen von den Texten, die wir durchmustert haben, verbindet sich die Figur der Angleichung Christi an die Engelmächte in der Alten Kirche prominent mit dem Namen des Origenes und seinen Anhängern.

Für Origenes selber ergibt sich die Angelomorphie Christi aufgrund des Prinzips, wonach der Logos alles Geschaffene durchdringt. Das Neue Testament bietet dafür nicht nur einige Basistexte (Joh 1,1-18; Kol 1,15-20; Eph 1,23 usw.), sondern auch eine apostolische Vorgabe,

64 Vgl. die Situierung der Ascensio Isaiae durch Knight (1996) oben Anm. 47, und zu archaischen Formen der Engelchristologie unten bei Anm. 66.

65 Vgl. zur Sortierung der Phänomene Klauck (2008, 303-374): „Christus in vielen Gestalten. Die Polymorphie des Erlösers in apokryphen Texten“; sodann Lalleman (1995); Markschies (2016, 391-393). 66 Vgl. Vollenweider (2002). 
nämlich das „Allen alles Werden“ des Paulus. Die wichtigste Ausführung findet sich im Johanneskommentar: ${ }^{67}$

Der Gott des Alls erschuf eine vernünftige Art [sc. von Geschöpfen], die erste an Würde, was meiner Meinung nach auf die sogenannten „Götter“ geht, als zweite Art seien jetzt „Throne“ genannt, als dritte, ohne Zweifel, „Mächte“. Auf diese Weise muss man vernunftgemäss bis zur letzten Stufe absteigen, wahrscheinlich also bis zum Menschen. Der Heiland ist auf noch viel göttlichere Weise denn Paulus „allen alles geworden“, damit er „alles“ „gewinne“ oder vollende; offenkundig ist er den Menschen Mensch und den Engeln Engel geworden [ó toívvv

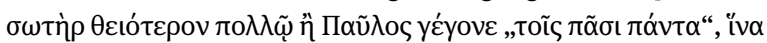

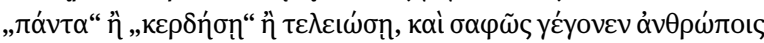

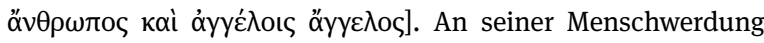
wird kein Gläubiger zweifeln. Dass er aber auch Engel wurde, davon werden wir überzeugt, wenn wir die Erscheinungen und Worte von Engeln beachten. Die Schrift lässt an einigen Stellen Engel sprechen, wenn er mit dem Amt eines Boten erscheint [...].

Der Kirchenlehrer kommt auch anderwärts auf die Engelgleichwerdung Christi zu sprechen. Dabei fällt auf, dass er sein Argument tentativ vorträgt, weil er ein biblisch nicht gesichertes und vor Missverständnissen zu schützendes Lehrstück präsentiert.

Besonders aufschlussreich ist eine Passage aus dem weitgehend nur lateinisch überlieferten - Römerbriefkommentar. Unter Bezug auf 1 Tim 3,16 (,den Engeln erschienen") wird die Engelgleichwerdung korreliert mit dem „ewigen Evangelium“ von Offb 14,6: ${ }^{68}$

Als er uns Menschen offenbar wurde, wurde er das nicht ohne Evangelium. Folgerichtig ergibt sich, dass er auch den Engelwesen nicht ohne Evangelium offenbar wurde [...] Muss man auch annehmen, dass er an den übrigen Himmelswesen etwas Ähnliches getan hat, dass er ihnen also in ihrer jeweiligen Gestalt offenbar wurde und den Frieden verkündete, weil er ja durch sein

67 Origenes, Commentarius in Iohannem 1.216-219 (GCS 10, 38-39 = SC 120, 164/166); zitiert in Anlehnung an Gögler (1959, 131). Zur christologischen Rezeptionsgeschichte von 1 Kor 9,22 vgl. Vollenweider (1989, 219-220); Mitchell (2017, besonders 209-212). Zum Topos bei Origenes vgl. speziell Barbel $\left({ }^{2} 1964,288-297\right)$ sowie die Belege in:

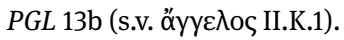

68 Origenes/Rufin, Commentarius in epistulam ad Romanos 1.6.2 (SC 532, 174 = FC 2,1; Heither [1990, 92]). Zur von Kol 1,20 angeregten Frage, ob Christi Tod über die Menschenwelt hinaus auch anderen $\mathrm{zu}-$ gutekomme, vgl. 5.7.5 (SC 539, 458); Homiliae in Leviticum 1.3 (SC 286, 76/78). Hier schliesst sich später die polemische Zuspitzung an, dass Christus in einer zukünftigen Weltzeit auch für die Dämonen sterben und sie so erlösen würde, vgl. Hieronymus, Epistula 124.12 (CSEL 56, 114); Justinian, Epistula ad Menam (ACO 3, 213) und die Anathematismen von 543 n. Chr. (Nr. 7: ACO 3, 213); vgl. unten bei Anm. 78. Die Topik gehört in die Diskussion darüber, ob Christus sich als Opfer nicht nur auf Erden, sondern auch im Himmel darbringt - zugunsten der (gefallenen) Engel bzw. Dämonen; dazu vgl. die Notiz in Crouzel und Simonetti (1980, 226-231).
Blut am Kreuz Frieden stiftete für alles, was nicht nur auf Erden, sondern auch im Himmel ist [vgl. Kol 1,20]? Auch das magst du für dich überdenken [etiam tu apud temet ipsum discutito]. ${ }^{69}$

Die notorische Frage, ob Origenes hier ein kühnes Theologumenon vorträgt, das dem theologischen Mainstream entgegensteht und das er deshalb lediglich als Option präsentiert, oder ob er zuhanden seiner Leserschaft Auslegungsalternativen skizziert im Wissen um die begrenzte Belastbarkeit exegetischer Schlussfolgerungen, können wir an dieser Stelle offen lassen. ${ }^{70}$

Die Motivik der Engelgleichwerdung Christi stammt wahrscheinlich aus dem Fundus ,dissidenter' bzw. ,apokrypher Traditionsbildungen, wie sie oben skizziert worden sind.

Exkurs: Im Johanneskommentar wird die Angelomorphie des Gottessohns, die in seiner das All umgreifenden Wesenheit gründet, noch ein weiteres Mal angedeutet (unter Berufung auf die Stufen im Tempel, die zum Allerheiligsten führen). Der „Einziggeborene Gottes“ schliesst in sich alle Stufen, die „wir“ aufzusteigen haben; beginnend von der untersten, seiner Menschennatur, „der Reihe nach, sodass wir aufsteigen durch ihn, der selber Engel und die übrigen Mächte ist“ ${ }^{71} \mathrm{Zu}$ verweisen ist schliesslich auf die explizite Korrelation der Engelgleichwerdung mit der Menschwerdung von Phil 2,7, der wir auch in den ,dissidenten“ Texten begegnet sind: ${ }^{72}$ „Daher meine ich: Wie er (sc. Christus) unter den Menschen ,der Erscheinung nach als

69 Anders als Barbel ( $\left.{ }^{2} 1964,288-289\right)$ braucht man nicht zu argwöhnen, der Übersetzer habe hier abgeschwächt. Die Methode, mehrere exegetische Alternativen vorzutragen, ist origeneisch; Rufin pflegt heikle Aussagen, wenn er sie nicht ganz tilgen will, etwa in den Mund von Gegnern oder Unverständigen zu verschieben. Ausserdem unterscheiden sich die Profile von Kommentarwerken und systematischen Traktaten wie De principiis. Vgl. zu Rufins Umgang mit „dogmatisch verdächtigen Stellen“ Hammond Bammel (1985, 48-53).

70 Für letzteres plädiert Vogt (1999, 107-108); für ersteres z. B. Kettler (1966, 1-12).

71 Origenes, Commentarius in Iohannem 19.38 (GCS 10, $305=$ SC

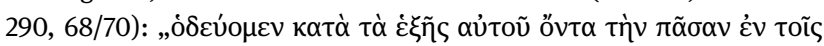

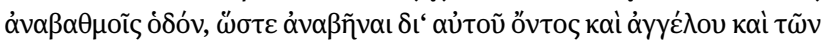

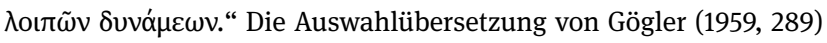
übergeht die „Engel und Mächte“!

72 Origenes, Homiliae in Genesim 8.8 (GCS 29, $83=\mathrm{SC}^{2} 7$, 228). Für Origenes bildet die Engelgleichwerdung Christi eine sachgemässe Extrapolation der traditionellen altkirchlichen Figur, wonach sich in den alttestamentlichen Angelophanien der präexistente Gottessohn manifestiert, vgl. Homiliae in Genesim 14.1; Commentarius in Iohannem 1.218 (oben Anm. 67); Commentarius in Matthaeum 28 (GCS 38, 53): „Aber nicht nur bei seiner Anwesenheit, sondern immer war der Christus in Person in Mose und in den Propheten gegenwärtig, noch mehr aber in den Engeln, die in den einzelnen Generationen dem Heil der Menschen dienten“ (Übersetzung nach Vogt [1983; 1990; 1993]). Crouzel und Simonetti verweisen für die Engelwerdung speziell auf den „,contexte qui l'explique, celui des théophanies: le Fils est l'agent de toutes les théophanies de l'Ancien Testament, apparaissant parfois sous forme d'homme ou d'ange, c'est-à-dire, nous semble-t-il, 
Mensch' erfunden wurde, so wurde er auch unter den Engeln der Erscheinung nach als Engel erfunden.“

Die Engelgleichwerdung Christi wird zu einem festen Baustein der origenistischen Systembildung. ${ }^{73}$ Besonders augenfällig sind diesbezüglich die Kontroversen, die sich noch im vierten und fünften wie schliesslich im sechsten Jahrhundert mit der Theologie des alexandrinischen Gelehrten verbinden. ${ }^{74}$ Unter den als häretisch inkriminierten Lehrstücken findet sich auch die Angleichung des Logos an die Engel. Im Edikt des Kaisers Justinian gegen Origenes aus dem Jahr 543 n. Chr. wird statuiert: ${ }^{75}$

Wenn einer sagt oder dafürhält, der Gott-Logos sei allen himm-

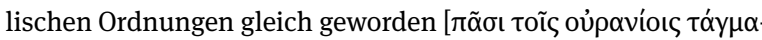
$\sigma \iota v \dot{\varepsilon} \xi o \mu o \iota \omega \theta \tilde{\eta} v \alpha \mathrm{l}]$, indem er für die Cherubim ein Cherub und für die Serafim ein Seraf wurde und schlechthin allen Mächten

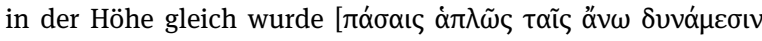
$\dot{\varepsilon} \xi o \mu o t \omega \theta \dot{\varepsilon} v \tau \alpha]$ - so sei er im Bann.

Die neun Anathematismen reflektieren origenistische Lehren des vierten Jahrhunderts, haben aber Anhalt an Originaltexten des Meisters. Dies gilt zumal für den Topos der Engelgleichwerdung Christi. In der zweiten Verurteilung des Origenes durch das Zweite ökumenische Konzil von Konstantinopel im Jahr 553 n. Chr. ist demgegenüber eine weiter entwickelte Form des Origenismus fassbar. ${ }^{76}$ So ist im uns interessierenden Lehrstück, das anathematisiert wird, das Subjekt der Inkarnation nicht eigentlich der Gott-Logos, sondern lediglich der mit diesem vollkommen geeinte Christus. Der Topos der Engelgleichwerdung selber bleibt sich aber gleich: ${ }^{77}$

dans son âme qui n'ayant pas péché a gardé l'indistinction primitive humano-angélique“ (1980, 231 Anm. 80; vgl. 57-58 Anm. 2). Die LogoTheophanien allein erklären die Figur der Engelgleichwerdung Christi aber nicht; ebenso wichtig sind die kosmische Christologie (auf der Linie von Kol/Eph) und die gnostisierenden Descensus-Traditionen. 73 Sie wird in der orthodox gewordenen Theologie üblicherweise abgelehnt, vgl. z. B. Didymos (?), De trinitate 2.7.8.9 (Seiler [1975] = PG

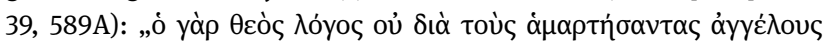

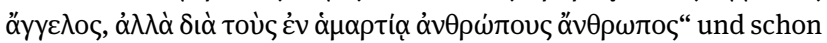
Tertullian, De carne Christi 14 (SC 216, 268/270).

74 Vgl. zur Vorgeschichte Prinzivalli (1999): von der impliziten Kontroverse in der zweiten Hälfte des dritten Jahrhunderts (200-204) zur offenen Kontroverse im vierten Jahrhundert (204-212); Vogt (1999, 241-263); Fürst (2011, 209-236).

75 Justinian, Epistula ad Menam Anathema 4 (ACO 3, 213 = DH 406); übersetzt nach Görgemanns und Karpp $\left(^{3} 1992\right)$.

76 Vgl. Guillaumont (1962, 96-99, 140-148, 158-159, 249-252); ferner Grillmeier (1990, 419-420, 425-430); Crouzel (1999).

77 Anathemata synodis Constantinopolitani 7 (ACO 4,1, 249); übersetzt nach Görgemanns und Karpp ( $\left.{ }^{3} 1992\right)$. In Z. 7 liegt in ACO (übernommen von Görgemanns/Karpp sowie vom TLG) wohl ein Druckfehler vor; statt $\mu \varepsilon \tau \alpha \mu о \rho \varphi \tilde{\omega} \sigma \theta \alpha$ ist zu lesen $\mu \varepsilon \tau \alpha \mu о \rho \varphi о \tilde{\sigma} \sigma \alpha$ เ.
Wenn einer sagt: Christus [...] sei zu allen gekommen, er habe sich in verschiedene Körper gekleidet und verschiedene Namen angenommen, er sei allen alles geworden [1 Kor 9,22], unter En-

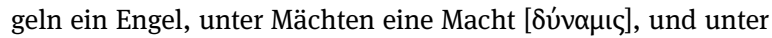
den anderen Ordnungen und Arten der Vernunftwesen habe er die zu einer jeden passende Gestalt angenommen; endlich habe er „ähnlich wie wir Fleisch und Blut erhalten“ [Hebr 2,14] und sei auch für die Menschen Mensch geworden [...] - so sei er im Bann.

In den heftigen origenistischen Debatten ist das aus 1 Kor 9,22 extrapolierte Prinzip, wonach Christus „allen alles geworden ist“, sogar dämonologisch pervertiert bzw. karikiert worden. Der alexandrinische Patriarch Theophilos stellt anfangs des fünften Jahrhunderts grimmig fest: ${ }^{78}$

Wenn nämlich Christus für die Menschen gelitten hat, indem er selber Mensch geworden ist [...], ist es folgerichtig, dass Origenes sagt: ,Auch für die Dämonen wird Christus leiden, selber Dämon geworden.

Die Engelgleichwerdung Christi verteilt sich bei Origenes selber und bei seinen Anhängern auf eine Mehrzahl von Stufen in den verschiedenen Himmelssphären, bis sie in seiner Inkarnation mündet. Die origenistische Tradition ist der Hauptkanal, über den die älteren ,dissidenten Überlieferungen von Christus, der sich den verschiedenen Engelklassen als Engel zeigt, Eingang in die Randbereiche des Mainstreams altkirchlicher Theologie finden. ${ }^{79}$ Dabei ist eine Akzentverschiebung zu beachten: Während die gnostisierenden Texte die Verborgenheit und das Nichterkanntwerden Christi herausstreichen, steht

78 Theophilos von Alexandria, Epistula paschalis (AD 401) (= Hieronymus, Epistula 96.10 [CSEL 55, 168]: „si enim Christus pro hominibus passus homo factus est, ut scripturarum testantur eloquia, consequens erit, ut dicat Origenes: ,et pro daemonibus passurus daemon futurus est“"'). Vgl. Epistula synodica (AD 400) (= Hieronymus, Epistula 92.4 [CSEL 55, 152]) und oben bei Anm. 68 zur Origenes unterstellten Kreuzigung Christi für die Dämonen. Vgl. Clark (1992, 12, 114). Beim Topos der Dämonwerdung Christi handelt es sich sicher wie bei manchen anderen häretischen Zuschreibungen ,um reine, gegen den einstigen alexandrinischen Theologen gerichtete bösartige Polemik“, Markschies (2016, 338); es kam Theophilos vor allem darauf an, „,möglichst skandalträchtige Sätze zu zitieren, die angeblich Origenes geschrieben hatte“ (339). Zur gezielten, massenmedial wirksamen rhetorischen Strategie des Patriarchen in seinen antiorigenistischen öffentlichen Briefen vgl. Banev (2015, 107-149, bes. 121-122).

79 Neben dem Physiologus ist auf einige weitere Belege hinzuweisen, die Barbel ('1964, 293-295, 297-299, 306-308 u. a.) zusammengestellt hat. Das (lateinische) Fragment aus dem Tractatus de fide unter dem Namen Melitons, das sich findet im Corpus Apologetarum Christianorum saeculi secundi (Otto 1857, 420; vgl. Barbel [21964, 293-294; 37 Anm. 1]), ist keinesfalls echt und gehört in eine spätere Zeit (so gut wie das unten bei Anm. 122 zitierte Meliton zugeschriebene frag. 6). $\mathrm{Zu}$ Gregor von Nyssa vgl. unten bei Anm. 108. 
seine Engelgleichwerdung bei Origenes im Zeichen der niveauangepassten Offenbarung. ${ }^{80}$ Der Kirchenlehrer kann sie deshalb mit dem verbreiteten Theologumenon, in den alttestamentlichen Theophanien und Angelophanien manifestiere sich der präexistente Logos, korrelieren. Die Inkarnation, in der sich Kenosis und Engelgleichwerdung vollenden, ist Ausdruck der göttlichen Akkommodation an die geschöpfliche Welt. ${ }^{81}$ Nur am Rand vermerken wir, dass die christliche Theologie beides, die Manifestation des Logos in Engeln und die Figur der göttlichen Akkommodation, besonders dem exegetischen Euvre des Alexandriners Philon verdankt. ${ }^{82}$

Blicken wir an dieser Stelle auf den Anfang des Physiologus zurück, so sind zwei Feststellungen zu treffen: Zum einen zeigt unsere Passage deutlich, dass sie mit ihrer Verborgenheitsmotivik Traditionen kennt, die vor allem von Texten abseits der Mehrheitskirche dokumentiert werden. Zum anderen zählt die Figur der Engelgleichwerdung Christi zu denjenigen Theologumena, die besonders im alexandrinischen Milieu begegnen, repräsentiert durch Origenes und vorbereitet durch Philon. Die namentlich genannten Engelklassen - Engel, Erzengel, Throne, Mächte (exusiai) - begegnen häufig, allerdings $\mathrm{m}$. W. nie in der genau gleichen Zusammenstellung. ${ }^{83}$ Wir formulieren schon an dieser Stelle die folgende Hypothese: Der Physiologus schöpft die Idee der Angelomorphogenese Christi aus den Kanälen, die sich im grosskirchlichen Raum vor allem aufgrund der Breitenwirkung von Origenes' Theologie gebildet haben.

80 Selbstverständlich kennen auch die Gnostiker diesen Aspekt (vgl. oben zum Philippus-Evangelium bei Anm. 45), aber er bleibt zweitrangig, da die Engelmächte ambivalent oder sogar negativ bewertet werden.

81 Zum Thema der göttlichen Akkommodation bei Origenes vgl. Gögler (1963, 307-319); Jacobsen (2009, 642): „The notion of accommodation implies that Logos takes a form and a shape which suits the capacity of those with whom he will communicate. The incarnation of Logos is the height of this divine process of accommodation“; Zambon/Wyrwa $(2018,989)$. Zum grösseren theologischen Kontext vgl. Be$\operatorname{nin}(1993,1-30)$.

82 Zur Akkommodation vgl. Philon, De opificio mundi 23; dazu Runia (2002, 146-147). Zur Angelomorphie des Logos vgl. De somniis 1.238; De migratione Abrahami 173-174; dazu Gieschen (1998, 107-112).

83 „Engeln“ und „Mächten“ o. ä. (exusiai, dynameis, usw.) sind wir oben in den meisten Texten begegnet. Die Throne sind selten; sie finden sich in der Ascensio Isaiae (vgl. Anm. 50) sowie bei Origenes (vgl. Anm. 67). Die Erzengel sind belegt in der Epistula apostolorum (s. Anm. 51) und in der Pistis Sophia (Engel, Erzengel, exusiai; s. bei Anm. 40).

\section{Eine Szene vor den Himmelstoren - Zur Rezeptionsgeschichte von Ps $24\left(23^{\text {LXX }}\right)$}

Der Physiologus bietet am Schluss seiner allegorischen Deutung der „ersten Eigenheit“ des Löwen einen kleinen biblischen Dialog, in dem die Engelmächte die Frage von Ps 24,10a stellen und vom heiligen Geist die Antwort von V. 10b erhalten. Unsere Schrift bewegt sich hier in einem stabilen Strom der christlichen Bibelrezeption.

Bei Ps 24,7-10 handelt es sich mit der zweifachen Abfolge von Aufforderung, Frage und Antwort um ,ein altes Ritual, mit dem die Ankunft Jahwes als eines siegreichen Königs inszeniert wurde““ ${ }^{84}$ In der christlichen Wirkungsgeschichte von Ps $24\left(23^{\mathrm{LXX}}\right)$ heftet sich die „Torliturgie“ bereits früh an die Himmelfahrt Christi; die Stadttore werden zu Himmelspforten und die Stadtwächter zu Engeln. ${ }^{85}$ Die Identität des Herolds, der den Wächtern antwortet, wird verschieden bestimmt; in der Regel sind es Engel, die den Auffahrenden begleiten. Für uns ist zunächst die Rezeption bei Justin, eine der ersten Spuren des Psalms im christlichen Bereich, ${ }^{86}$ von erheblichem Interesse: Wie im Physiologus handelt es sich um den Geist, der als Sprecher von V. $10 \mathrm{~b}$ agiert: ${ }^{87}$

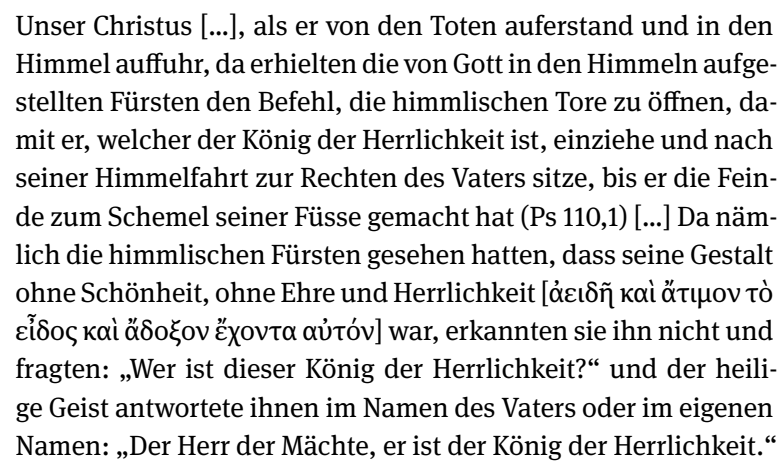

84 Müller (2008, 147; zur „Torliturgie“ vgl. 149-154). Die Szene „gehört ans Stadttor“ (150).

85 Zur Rezeptionsgeschichte von Ps 24 vgl. Kähler (1958, 43-73); Brucker (2014); ferner Aubineau (1972, 89-91); Geljon (2011). Einige Texte stellen zusammen Blaising und Hardin (2008, 187-191). Nicht zugänglich war mir die unpublizierte Diplomarbeit von Margoni-Kögler (1994).

86 Die erste Rezeption, die Ps 24 mit der Himmelfahrt Jesu verbindet, ist Apokalypse des Petrus 17 (Schneemelcher ${ }^{6} 1997$, 577-578, äthiopische Version); vgl. dazu Kähler (1958, 53-55). Demgegenüber zeigt 1 Kor 2,8 keine Einwirkung von Ps 24; dazu oben Anm. 55.

87 Justin, Dialog 36.3-6; übersetzt nach Haeuser (1917); vgl. dazu Kähler (1958, 55-56); Brucker (2014, 419-420). In Dialog 85.1-4 und Apologie 1.51.6-7 ist nicht vom Geist als Sprecher die Rede. 
Der Unwissenheitstopos, dem wir in den zuvor durchmusterten Texten beim Abstieg des Erlösers begegnet sind, hat hier einen anderen Stellenwert: Die Engel erkennen Christus nicht infolge seiner Niedrigkeitsgestalt. ${ }^{88}$ Das Nichtwissen wird durch die Wechselrede beendet. Die Passage ist deshalb so bemerkenswert, weil sich in ihr viele Elemente finden, die in der nachmaligen Rezeptionsgeschichte der Psalmverse zum Standard zählen: Auffahrt, Himmelstore und Engel, Niedrigkeits- bzw. Passionsgestalt Jesu. Anders verhält es sich beim Geist als Herold; diese Identifikation ist ausgesprochen selten bezeugt wir sind ihr aber im Physiologus begegnet. Nun ist nicht mit einer literarischen Beziehung zwischen diesem und Justin zu rechnen; das Euvre des Apologeten war in der christlichen Antike kaum bekannt. ${ }^{89}$ Offenbar handelt es sich um eine uns sonst wenig bekannte Sondertradition..$^{90}$ Da sich der Geist als Sprecher von Sätzen aus Ps 24 auch in einer Himmelfahrtspredigt im Corpus der ChrysostomosWerke findet - auch hier liegt keine Justin-Rezeption vor -, scheint sie sich vom zweiten bis ins fünfte Jahrhundert gehalten zu haben. ${ }^{91}$

Eine weitere aufschlussreiche Passage findet sich in der Epideixis des Irenäus: ${ }^{92}$

Eben dasselbe sagt auch David: „Erhebt, ihr Fürsten, eure Pforten; ja, erhöht euch, ihr uralten Pforten, dass der König der Herrlichkeit einziehe“ (Ps 24,7). Denn die uralten Pforten sind die Himmel. Weil aber das Wort in einer für die Geschöpfe unsichtbaren Weise herabgestiegen ist, so ist ihnen davon nichts kund geworden. Nun war das Wort Fleisch geworden, und sichtbar stieg es hinauf. Und als die Mächte ihn sahen, haben die unteren Engel denen, die auf der Feste waren, zugerufen: „Erhebt eure Pforten; ja, erhöht euch, ihr uralten Pforten, dass der König der Herrlichkeit einziehe“. Und da sie staunten und fragten: „Wer ist es

88 Hier wird offensichtlich die Gottesknechtsbeschreibung rezipiert:

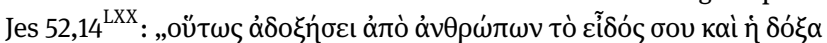

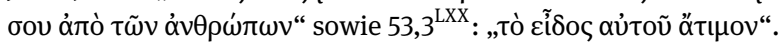

89 Justins echte Werke sind in einer einzigen Handschrift überliefert. 90 Schon gar nicht kann man eine Benutzung des Physiologus durch Justin postulieren, wie es etwa Lauchert $(1889,65,68)$ getan hat. Viel zu weit hergeholt ist die Vermutung von Peterson (1959, 251), der Physiologus und Justin bezögen den heiligen Geist als Sprecher aus einer nicht erhaltenen Version der Ascensio Isaiae (in der erhaltenen Schrift hat der Geist tatsächlich eine wichtige Funktion, aber nicht in Bezug auf Ps 24). Zu dieser Hypothese vgl. auch oben Anm. $61 \mathrm{zu}$ Daniélou.

91 Vgl. unten bei Anm. 114. Das exegetische Manöver, Worte und Laute in den Psalmen dem Geist zuzuschreiben, begegnet auch sonst; vgl. etwa Eusebios, Commentarius in Psalmos 23 (PG 23, 224A), wo „Jauchzen und Trompetenschall“ in Ps 47,6 vom heiligen Geist ausgehen; zugleich stammen sie aber (auch) von Engeln.

92 Irenäus, Demonstratio 84 (FC 8,1, 87 = TU 31,1, 44); Übersetzung aus dem Armenischen von Ter-Mekerttschian und Ter-Minassiantz (1907). denn?“, bezeugten diejenigen, die ihn gesehen hatten, nun zum zweiten Mal: „Der Herr, gewaltig und mächtig, er ist der König der Herrlichkeit“ (Ps 24,8-10).

Wie bei Justin gibt auch bei Irenäus der irdische Leib Jesu den Anlass für das erstaunte Fragen der angelischen Mächte. Nun wird ausdrücklich gesagt, dass diese den Logos schon bei seinem Abstieg nicht erkannt haben ein sonst bei den Kirchenvätern kaum je begegnender Topos. ${ }^{93}$ Die Kombination von drei Elementen - erstens der Verborgenheit beim Abstieg, zweitens der Fleischwerdung, und drittens dem Zitat von Ps 24 - verbindet diesen Text mit dem Physiologus. ${ }^{94} \mathrm{Zu}$ beachten ist in der Epideixis ausserdem die detaillierte Identifizierung der Auffordernden, Fragenden und Antwortenden. Die Frage stellt sich, ob Irenäus und der Physiologus auf eine gemeinsame frühe Auslegungstradition von Ps 24 zurückgreifen, die auch die Topik des vor den Engeln verborgenen absteigenden Erlösers mitführt. Nun liegt die Passage lediglich in armenischer Überlieferung vor, die auch wesentlich späteres Gut aufgenommen haben kann. Der armenische Irenäus bietet kein belastbares Argument für die Identifizierung einer alten gemeinsamen Überlieferung, ${ }^{95}$ die er mit dem Physiologus teilte, und kommt daher auch nicht als Indiz für die Frühdatierung des Physiologus in Frage. ${ }^{96}$

Für unsere Fragestellung einschlägig ist erneut das Euvre von Origenes, in dem sich die Rezeptionsspuren von Ps 24 kumulieren. Der Einzug Jesu in Jerusalem im Matthäusevangelium $(21,10)$ ist für den Kommentator Anlass, die Wechselrede im Himmel einzuspielen: ${ }^{97}$

$93 \mathrm{Zu}$ beachten ist dabei die zurückhaltende Formulierung: „für die Geschöpfe unsichtbar“.

94 Beachtenswert ist in der Epideixis auch der kleine Katalog der rebellischen Engelklassen, die nach Ps 110,1 unterworfen werden (85): Engel, Erzengel, Mächte und Throne. Dies entspricht genau der Liste im Physiologus! Derselbe Katalog findet sich auch bei Irenäus, Adversus haereses 3.8.3 (hier aber nicht gefallene Engel); vgl. 2.30.3.

95 Es ist nicht zu sichern, dass Irenäus selber die Ascensio Isaiae gekannt und benutzt hat (so Knight [1996, 160-161; 163; 165-166], im Anschluss an Daniélou [1958]). Die partielle Parallele zwischen der Ascensio Isaiae und Irenäus' Epideixis ist eher traditionsgeschichtlich zu erklären, möglicherweise auf einer erst relativ späten Überlieferungsstufe (von der Ascensio Isaiae gibt es allerdings m. W. keine armenische Version). Schon gar nicht auszumachen sind Anzeichen dafür, dass die Ascensio Isaiae oder 1 Kor 2,6-8 einen intertextuellen Bezug herstellen zu Ps 24; anders Hanson (1980).

96 Die für uns interessanten Elemente fehlen gerade in den übrigen Referenzen auf die „Torliturgie“, die sich in Irenäus' besser erhaltenem Werk finden, in Adversus haereses (3.16.8, 4.33.13).

97 Origenes, Commentarius in Matthaeum 16.19 (GCS 40,2, 539-540); übersetzt nach Vogt (1990, 197); hier auch zum „Fahrzeug“ (228-230) und zur Rezeption von Jes 63 (230-231). 
Er (Jesus) zog in das wahre Jerusalem ein. Die himmlischen Mächte aber, welche „die ganze Stadt“ genannt werden, waren

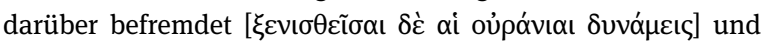
fragten: „Wer ist dieser?“ Das steht im Einklang mit dem, was im 23. Psalm über die Aufnahme des Heilands und das Befremdetsein der himmlischen Mächte vorausgesagt ist, die befremdet

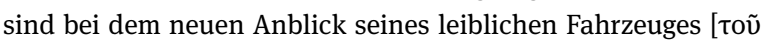

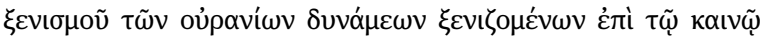

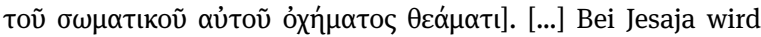
über den Aufstieg des Heilands nach dem Heilswirken ähnliches vorausgesagt; da steht nämlich: ,Wer ist dieser, der von Edom herkommt mit rotem Gewand aus Bosor, der schön ist in seinem Kleid?' (Jes 63,1). Den ganzen Inhalt dieser Stelle wirst auch du verstehen können, wenn du vergleichst, was die Mächte sagen, die über das Emporsteigen des heilschaffenden Leibes befremdet sind, und was ihnen geantwortet wird.

Auch in einer der kürzlich entdeckten Psalmenhomilien nimmt Origenes Bezug auf die Wechselrede von Ps 24 und reichert sie wieder an mit derjenigen von Jes $63,1-2:^{98}$

Angesichts des neuen Ereignisses sind die himmlischen Mächte verwirrt, weil sie Fleisch, das in den Himmel hinaufsteigt, schauen. ${ }^{99}$

Der Prätext ist Ps 15,9 ${ }^{\mathrm{LXX}}$ („mein Fleisch wird in Hoffnung wohnen"), den Origenes auf den auffahrenden Fleischkörper Jesu deutet. ${ }^{100}$ Der Dialog folgt zunächst Jes 63,1-3, mit zweimaligem Fragen der Engel und zweimaliger Antwort von Jesus selber. Die Engel sind perplex angesichts des irdischen Leibs Jesu mit den Wundmalen der Passion. ${ }^{101}$ Nach einem kurzen Rückbezug auf den Haupttext spielt der Ausleger die Wechselrede von Ps $23,7-10^{\mathrm{LXX}}$ ein, wiederum als zweifachen Dialog zwischen den Jesus vorange-

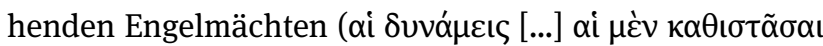

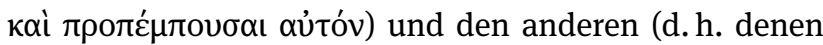

98 Origenes, Homilia 2 in Psalmum 15 (GCS.NF 19, 105-107). Ein Teil der Passage war schon vorher bekannt (abgedruckt in: PG 12, 1215), nämlich aus Rufins Übersetzung von: Pamphilos, Apologia 143 (SC 464, 228/230 = FC 80, 360/362). Vgl. zu den Homilien Mitchell (2016).

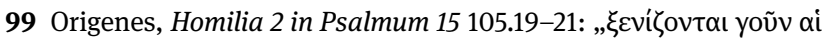

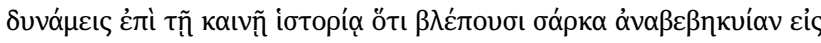

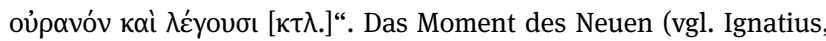
Epistula ad Ephesos 19.2: das Neue des Sterns) wird in der Rezeptionsgeschichte von Ps 24 gern betont, z. B. Hesychios, In pascha ho-

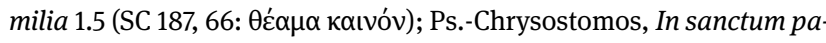
scha 6.61 (SC 27, 189): Die Himmelsmächte „sehen das neue Wunder-

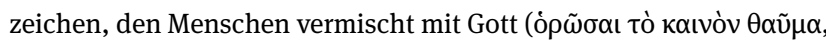

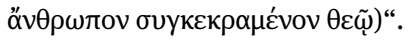

100 Vgl. zu Ps 16,10 im Kontext des Sterbens Jesu unten Anm. 202.

101 Origenes versteht in Jes 63,1 Edom als „rote Erde“ und leitet „Bosor“ ab von hebr. basar, „Fleisch“. an den Toren). ${ }^{102}$ Der Kommentator legt den erstgenannten bei der zweiten Aufforderung auch noch die Worte in den Mund: „Grösser ist er, eure Tore können den Christus nicht fassen."

Der Kirchenlehrer; bezieht sich auch sonst vielfach auf die „Torliturgie““, ${ }^{103}$ etwa im Johanneskommentar. ${ }^{104}$ Das Muster bleibt identisch: Wechselrede beim triumphalen Aufstieg Christi, Befremden der Himmelsmächte ob dem Passionsleib (Jes 63,1-3). Bei den auf die Fragen antwortenden Sprechern (Ps 24,8b.10b) handelt es sich jeweils um Engel, die den auffahrenden Jesus begleiten; gelegentlich bleiben sie aber auch unbestimmt.

Exkurs: Einen besonderen Akzent legt Origenes in seiner Abhandlung über das Passa, die wir einem Papyrusfund verdanken: ${ }^{105}$ Hier ermöglicht die Auffahrt Christi im Gefolge seiner Höllenfahrt den Aufstieg der Geister von 1 Petr 3,19. ${ }^{106}$ Die später markant hervortretende Korrelation von Ps 24 und triumphaler Höllenfahrt, etwa im Nikodemusevangelium, ${ }^{107}$ wird hier vorbereitet.

Zum Abschluss dieses Abschnitts über die antik-christliche Rezeption von Ps 24 werfen wir einen Blick auf eine

$102 \mathrm{Zu}$ den angelischen Begleitern Christi, die vorangehend zum Öffnen der Tore auffordern, vgl. auch: Commentarius in Iohannem 6.288

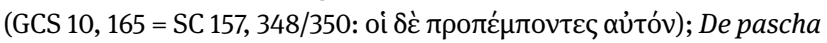
(unten Anm. 105). Jesus selber antwortet mit Jes 63,3b: Commentarius in Matthaeum 16.19. Eine klare Rollenverteilung kennt, wie Irenäus, Demonstratio 84 (dazu oben bei Anm. 92), auch Hippolyt, frag. 20 in Ps 23,7 (GCS 1.2, 47 = Theodoret, Eranistes Florilegium 2.16 [Ettlinger 1975, 157]): Die Jesus begleitenden und vorangehenden Engel kommunizieren mit anderen himmlischen Mächten; ähnlich differenziert Ambrosius, De fide 4.1.9-14 (CSEL 78, 161); De mysteriis 7.36 (FC 3, 230/232); Ps.-Chrysostomos, In sanctum pascha 6.61 (SC 27, 189). Vgl. weiterhin Buchinger (2005, 776 Anm. 2110) sowie unten zum lateinischen Physiologus (Anm. 179).

103 Von den ca. 20 Referenzen, die die Biblia patristica 3:158, für Ps 24,7-10; bei Origenes bietet, sind die meisten für uns redundant. Die Sprechenden sind jeweils Engel (z. B. Origenes, Excerpta in Psalmos [PG 17, 112] aus Katenen; Homiliae in Isaiam 3.2 [GCS 33, 256]). Die Engelfrage mit dem Zitat von Jes 63,2 ebenso bei Märtyrern: Homiliae in librum Iudicum 7.2 (GCS 30, 508; vgl. SC 157, 349 Anm. 4).

104 Origenes, Commentarius in Iohannem 6.288 (GCS 10, 165 = SC 157, 348/350). Origenes unterstreicht die triumphale Auffahrt des Aufer-

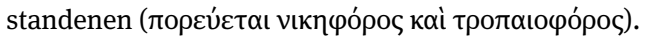

105 Origenes, De pascha 2.28-30; siehe Witte (1993, hier 146,9-17).

106 Vgl. Buchinger (2005, 778): „relativ ungewohnt war zur Zeit des Origenes wohl auch die Verbindung von Ps 23 [24] 7-10 mit der in Anlehnung an 1 Petr 3,19; 4,6 formulierten Hadespredigt Christi“. Dass der „Wiederaufstieg der gefallenen Geistwesen [...] wohl in zwei Etappen vor sich gehen“ soll (so Witte 1993, 204), kann ich nicht erkennen; die „zweimalige Aufforderung zum Öffnen der Himmelstorevon Ps LXX 23,8.10, die er anschliessend zitiert“, gibt das nicht her.

107 Nikodemusevangelium 21; ähnlich Quaestiones Bartholomaei 1115 (Markschies und Schröter 2012, 259; 714-715). Vgl. dazu Brucker (2014, 420-423) und unten bei Anm. 118. 
Predigt Gregors von Nyssa, die wahrscheinlich zum neuen Fest von Christi Himmelfahrt gehalten wurde. ${ }^{108}$ Sie dokumentiert deutlich Impulse, die von Origenes ausgehen. Hier findet sich die explizite Korrelation der Engelwerdung Christi (bei seinem Descensus) mit der angelischen Wechselrede (Ps 24,7-10). Die letztgenannte geschieht sowohl beim Abstieg wie beim Aufstieg; bei jenem erkennen die Engel Christus nicht aufgrund seiner Engelgestalt, bei diesem nicht infolge seiner Menschennatur.

Exkurs: Die Homilie besteht in einer Auslegung von Ps 23 und 24. Der „Prophet David“ erhebt sich in die Höhe, gesellt sich den himmlischen Mächten zu und schildert uns deren Worte. Die doppelte Torszenevon Ps 24 wird, m. W. nur hier bei Gregor, auf Descensus (V. 8-9) und Ascensio (V. 10-11) verteilt. ${ }^{109}$ Beim Abstieg fordern die dem Erlöser vorangehenden Engel diejenigen, die die Tore zur Erde und Menschenwelt verwalten, zur Öffnung auf. „Er, der das All umfängt, passt sich jeweils, wohin er gelangt, den Empfängern an - denn er ist nicht nur unter Menschen Mensch geworden, sondern folgerichtig gewiss auch unter Engeln (so) geworden, indem er sich zu ihrer Natur herabgelassen hat. Deshalb fragen die Torwächter den Herold: ,Wer ist dieser König der Herrlichkeit?““110 Der Absteigende wird identifiziert als Befreier der Menschen und Vernichter des Todes. ${ }^{111}$ Die zweite Runde von Aufforderung, Frage und Antwort erfolgt beim Aufstieg, nach dem „erfüllten Todesgeheimnis“ und dem Auferstehungssieg über die Feinde. Jetzt ist das Nichterkennen durch die Himmelswesen nicht dem Engelleib geschuldet wie beim

108 Gregor von Nyssa, In ascensionem Christi (GNO 9, 323-327). Vgl. die Skizze von Moutsoulas (2010, 86-87): „Gregory's homily on the Ascension [...] is the first witness to this feast as an autonomous feast celebrated fifty days after Easter“; Mateo-Seco (2010, 452). Der Sermon wird berücksichtigt auch bei Kähler (1958, 61-62); Barbel ( ${ }^{2} 1964$, 307-308); Brucker (2014, 423-424).

109 Zur Verdoppelung der Wechselrede notiert Euseb, es gebe auch solche, die die zweite Frage und Antwort nicht den nächst höheren oberen Mächten in den Mund legen, sondern nochmals denselben (Commentarius in Psalmos 23 [PG 23, 221D]). Interessant ist eine Auslegung, die die doppelte Toröffnung verteilt auf Höllenfahrt (dazu s. bei Anm. 107 und 118) und Himmelfahrt (Augustin, Sermo 377.1 [PL 39, 1672; englische Übersetzung ACCSOT 7, 190-191]).

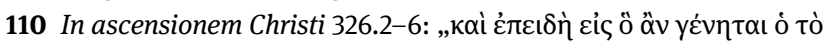

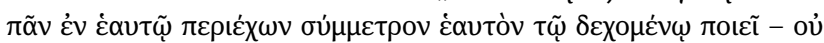

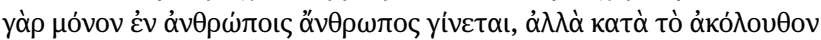

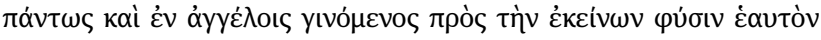
бчүкато́уยเ“. Man kann sich fragen, ob die origeneische Figur auch schon im Hintergrund des Predigtanfangs steht: Vom „Propheten David“ als „süssem Reisegefährten des menschlichen Lebens“ heisst es, „er wird allen alles“ (324.11-12): Origenes hat ja 1 Kor 9,22 auf Christi Engelgleichwerdung hin extrapoliert (vgl. oben bei Anm. 67). - Zur Alldurchdringung Gottes vgl. Oratio catechetica 25.1 (GNO 3,4, 63-64); 32.6 (79).

111 Ps 24,8 wird auch noch in Homilia 5 in Canticum canticorum 2.15 (GNO 6, 166) bezogen auf Engelmächte, die dem zur Inkarnation absteigenden (!) Herrn vorangehen.
Abstieg, sondern dem menschlichen Leib (schmutziges Kleid) bzw. Passionsleib (Blutröte: Jes 63,2). ${ }^{112}$

Wir notieren im folgenden Exkurs noch drei für unseren Vergleich mit dem Physiologus interessante Passagen; auf zwei von ihnen hat Joseph Barbel aufmerksam gemacht. Alle drei Texte gehören in das späte vierte Jahrhundert (Nr. 3) bzw. in das fünfte Jahrhundert (Nr. 1; 2) - Indizien, die wiederum eine Frühdatierung unseres „Naturforschers“ nicht begünstigen.

\section{Exkurs:}

1. In der Psalmenauslegung von Theodoret wird das Nichtwissen der Himmelsmächte thematisiert (unter Einspielen von Eph 3,10). Bei der Himmelfahrt Christi „,sehen sie nur die menschliche Natur, schauen aber nicht die in ihr verborgene Gottheit ( [...] $\theta \varepsilon o ́ \tau \eta \tau \alpha) “ “{ }^{113}$ Wir kommen auf diese Figur zurück.

2. In einer Himmelfahrtspredigt unter dem Namen von Johannes Chrysostomos ist es der heilige Geist, der sowohl zur Toröffnung auffordert wie den fragenden Engeln die beiden Antworten von Ps 24 erteilt (V. 8b „der Herr, stark und mächtig“; V. 10b „der Herr der Heerscharen“). ${ }^{114}$ Dem heiligen Geist als Herold sind wir bei Justin und eben beim Physiologus begegnet.

3. Gregor von Nazianz unterstreicht anlässlich des Osterfests den Stellenwert des Passionsleibs Christi in seiner Auffahrt durch die zu öffnenden Himmelstore. ${ }^{115}$ Genau hier liegt der Unterschied zum Descensus. Der Prediger ruft seine Zuhörer auf, mit in den Himmel zu steigen, sich unter die eskortierenden oder empfangenden Engel zu mischen; ,antworte denen, die perplex sind wegen dem Körper und wegen der Leidenszeichen, die er jetzt anders als bei seinem Abstieg

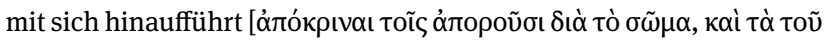

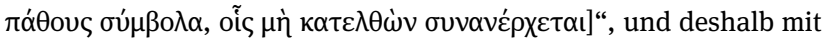
den Psalmworten fragen. Anders als beim Aufstieg kennen demnach die Engel Christus ganz selbstverständlich bei seinem Abstieg; dies ist anders als im Physiologus und in den ,dissidenten ' Überlieferungen, wo sich der Erlöser verbirgt vor den Engeln. Zu beachten ist sodann,

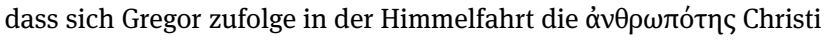
und seine $\theta \varepsilon$ ótn $\varsigma$ in besonderer Weise verbinden. Wir kommen unten auf diese Sprachregelung zurück.

$112 \mathrm{Zu}$ Jes 63,2 vgl. oben zu Origenes bei Anm. 98.

113 Theodoret, Commentarius in Psalmum 23.7-10 (PG 80, 1033A/B); vgl. Barbel $\left({ }^{2} 1964,308\right)$ und unten bei Anm. 154. Zur Rezeption von Eph 3,10 vgl. bes. Johannes Chrysostomos, De incomprehensibili dei natura 4.133-158 ( $\mathrm{SC}^{2} 28$, 240; hier mit der Unterscheidung der positiven himmlischen Mächte von den „Mächten dieser Welt“ [Eph 6,12]): Leitthema ist die Unerkennbarkeit Gottes schlechthin (also nicht nur der Gottheit Christi) für Engel (3.53-193) und Menschen. Zu Eph 3,10 bei Origenes s. Anm. 163.

114 Ps.-Chrysostomos, In ascensionem Domini 4 (PG 52, 802):

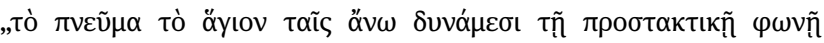

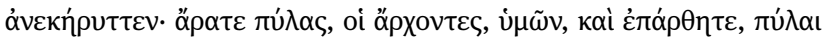

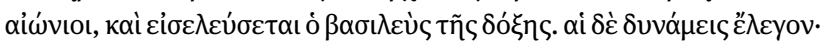

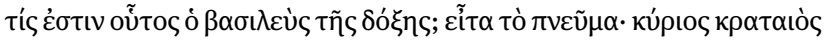

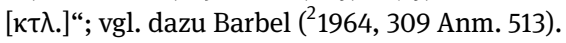

115 Gregor von Nazianz, Oratio 45.25 (PG 36, 657B/C). Zu Gregors Aussagen zur Gottheit Christi vgl. unten bei Anm. 151-153. 
Wir ziehen eine Zwischenbilanz. In der Alten Kirche bildet sich früh eine stabile Auslegungstradition von Ps 24,7-10 heraus, deren Sitz im Leben hauptsächlich das Osterfest bildet. Die „Torliturgie“ haftet an Christi Himmelfahrt. ${ }^{116}$ Die Engelmächte erkennen den Gottessohn nicht, weil er einen niedrigen menschlichen (und gemarterten) Leib trägt; dieser verhüllt seine Identität. ${ }^{117}$ Wiederum ist es das Werk des Origenes, in dem sich die Überlieferungen verdichten. Im Ganzen fällt auf, dass die Torszene kaum je beim Abstieg durch die Himmelssphären begegnet. Die m. W. einzige Ausnahme, eine Himmelfahrtshomilie Gregors von Nyssa, bestätigt die Regel: Der Prediger ergänzt die - konventionelle - Toröffnung bei der Ascensio um eine entsprechende beim Descensus, angeregt von der doppelten Wechselrede in Ps 24,7-10, also aus exegetischen Gründen. Was sich aber spätestens im 3./4. Jahrhundert n. Chr. als Variante etabliert, ist die Platzierung der Torszene unmittelbar nach Christi Tod in seiner triumphalen Höllenfahrt - einer Himmelfahrt mit umgekehrtem Vorzeichen. $^{118}$

\section{Die im Fleisch verhüllte Gottheit}

Das Leitmotiv für die erste Löwenallegorie im Physiologus ist das „Verhüllen der Gottheit“ Christi (દ่kó $\lambda v \psi \varepsilon[. .$. тทे $\theta \varepsilon o ́ \tau \eta \tau \alpha)$. Diese verbirgt sich in Engelleibern und dann namentlich im „Fleisch“. Mit dem programmatischen Einsatz dieser spezifischen Begrifflichkeit artikuliert unsere Schrift einen altkirchlichen Typ von Christologie, der der göttlichen Natur Christi, seiner $\theta \varepsilon o ́$ đn menschliche oder sarkische Natur gegenüberstellt, seine

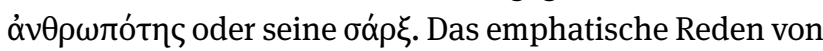
Christi $\theta \varepsilon o ́ \tau n \varsigma$, das sich nicht nur zweimal im Löwenka-

116 Eine Nebenlinie ist die psychologische Interpretation: Der „König der Herrlichkeit“ zieht durch das Tor der Seele ein, z. B. Gregor von Nyssa, Homilia 11 in Canticum canticorum (GNO 6, 333).

117 Vgl. bes. die oben Anm. 98 angeführte Passage aus Origenes' Psalmenhomilie. Es ist der sarkische Auferstehungskörper, der die Ascensio vom Descensus unterscheidet - wie es Hieronymus ausdrückt: der Herr „maior regreditur ad caelos, quam ad terras venerat“ (Sermo paschale 2 [CCSL 78, 548]). Später spricht Asterios, Homilia in Psalmum 15.16 (Richard 1956, 115; deutsche Übersetzung BGrL 56, 288-289), vom „herrlichen Leib“ als „leuchtendem Lehm“ ( $\pi \eta \lambda$ ò $\lambda \lambda \dot{\alpha} \mu \pi \omega v$ [aus Ijob 10,9?]).

118 Formuliert in Umkehrung des bekannten Diktums von Kroll (1932, 59): „der Ascensus durch die versperrten Sphären ist ein Descensus mit umgekehrtem Vorzeichen.“ Zu Ps 24 vgl. 46-47; 105; 348 und oben Anm. 107 zum Nikodemusevangelium. Der Physiologus kennt zwar die Höllenfahrt (Physiologus 25), verbindet sie aber nicht mit Ps 24. pitel, sondern auch im übrigen Textbestand findet (vgl. 3; 19), schliesst m. E. eine Frühdatierung des Physiologus im zweiten Jahrhundert von vornherein aus. ${ }^{119}$ Zwar gibt es schon überaus frühe Zeugnisse für die Göttlichkeit Christi, die in das erste Jahrhundert und in das Neue Testament zurückführen (vgl. Joh 1,1.18; 20,28; Hebr 1,8-9; Tit 2,13; 2Petr 1,1; 2Clem 1,1). In unserer Studie geht es aber um ein spezifisch theologisches Vokabular, in dem sich die Überzeugung vom Gottsein Christi als Gottessohn und Logos herauskristallisiert, nämlich um die christologische Prädi-

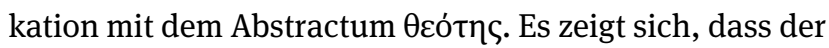
Physiologus theologische Entwicklungen des späten dritten und vor allem des vierten Jahrhunderts voraussetzt. Die Grundlagen dafür entstehen erst mit der Theologie des Origenes; in den trinitarischen Debatten des vierten Jahrhunderts verdichtet sich das Reden vom „Verborgen-

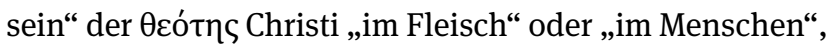
das auch für den Physiologus charakteristisch ist. Eine besondere Zuspitzung erfährt diese Figur dort, wo sie sich verbindet mit dem Motiv des getäuschten Teufels, der sich an der im Menschen verborgenen Gottheit vergreift. Allerdings wird im Physiologus, wenigstens auf der Textoberfläche, keine Verbindung vorgenommen zwischen der Verhüllung der Gottheit vor den Engeln $(1 ; 22)$ und derjenigen vor dem Teufel (26).

Im Folgenden mustern wir die Semantik der „Gottheit“ Christi und speziell ihrer „Verhüllung“ anhand einiger exemplarischer Texte durch. Dabei ist zu beachten, dass es sich beim Verständnis der Inkarnation als Verhüllung (bzw., komplementär dazu, als Manifestation) Gottes um ein schon sehr frühes christliches Theologumenon handelt, ${ }^{120}$ das während des vierten Jahrhunderts im Kontext

119 Der Terminus $\theta \varepsilon$ ćtns ist in der für uns noch erkennbaren Erstversion des Physiologus, der sogenannten ersten Redaktion, an allen einschlägigen Stellen textkritisch stabil; er findet sich alternativlos schon in den entsprechenden fünf Handschriftengruppen. Für Christi Acótns vgl. neben Physiologus 1 (Löwe) auch 3 (vom Regenpfeifer - der vom Himmel her kommende Christus wendet seine Gottheit ab von den Juden); 19 (vom Geier - der Herrenleib hat in sich den

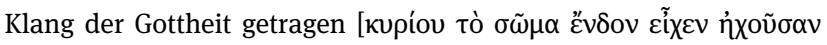

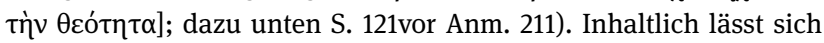
den genannten Belegen zur Seite stellen 26 (vom Ichneumon: Christus als $\theta$ cós, wo handschriftlich auch $\theta \varepsilon$ cótns eingelesen wird; s. oben Anm. 33). Eine wesentlich spätere Schicht bildet 44b (von den Per-

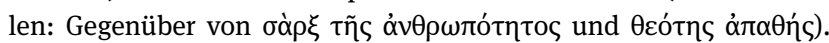
Schliesslich ist von den späteren Redaktionen aufzulisten 6 (Sbordone 1936a, 183; vom Geier, 2. Redaktion) und 11 (Sbordone 1936a, 277;

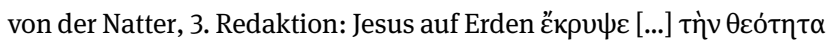

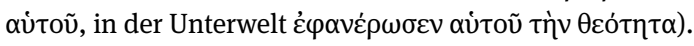

120 Vgl. Barnabasbrief 5.10-11 (der Herr kam ins Fleisch, weil die Menschen seine unverhüllte Herrlichkeit nicht hätten schauen können; vgl. 5.6). Viele Parallelen dazu führt auf Windisch (1920, 330- 
der Auseinandersetzungen um den Status der Gottheit Christi aufdatiert wird. Die Spuren führen zurück bis zu Aussagen wie Joh 1,14, Phil 2,6-8 und vielleicht 1 Tim 3,16, die dann ihrerseits als überaus produktive Impulsgeber gewirkt haben. Am Ursprung des gesamten Komplexes, mit dem wir es in dieser Studie zu tun haben, steht das religionsgeschichtliche Modell der verborgenen Epiphanie: Göttliche Wesen verbergen oder offenbaren sich in menschlicher Gestalt. Für die theologiegeschichtliche Verortung des Physiologus ist aber nicht diese für die Antike schlechthin charakteristische Figur als solche ausschlaggebend, sondern deren ganz spezifisches Format.

1. Unser Augenmerk gilt also zunächst der Terminologie. Soweit ich sehe, wird in der christlichen Literatur vor (und neben) Origenes $\theta \varepsilon o ́ t \eta$ s kaum spezifisch auf Christus bezogen. Der christologisch verwendete Terminus - und um diesen handelt es sich hier, nicht um die generische Referenz auf Gott (wie z. B. Kol 2,9; Hermas 40.4-6 usw.) begegnet gehäuft erst beim alexandrinischen Theologen,

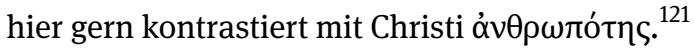

Exkurs: Diesem für die frühere Zeit negativen Befund stehen allerdings einige Texte entgegen, bei denen zu prüfen ist, ob sie nicht doch schon in das zweite oder frühe dritte Jahrhundert gehören.

a. Am gewichtigsten sind die Reste des Euvre, das Meliton von Sardes zugeschrieben wird. Ein Fragment spricht von Christi „verborgener Gottheit im Fleisch“ (frag. 6,22-23): ${ }^{122}$ Taten und Zeichen

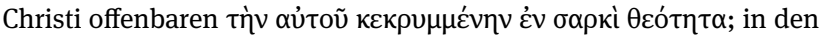
dreissig Jahren vor seiner Taufe „verbarg er aber die Zeichen seiner

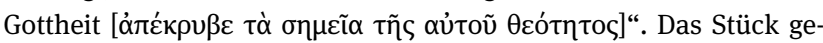
hört aber mit grösster Wahrscheinlichkeit in eine deutlich spätere Zeit, wohl in das vierte oder sogar in das fünfte Jahrhundert. ${ }^{123}$ Auch andere Werkzuschreibungen an Meliton unterliegen schweren Be-

331). An eine „alexandrinische Tradition“ denkt Prostmeier (1999, 248), im Anschluss an J. P. Martín.

121 Es handelt sich bei Origenes um Dutzende von Belegen für das christologische Lemma $\theta$ cótnS; vgl. die Auswahl in: PGL 637-638; z. B. Origenes, Commentarius in Iohannem 1.107 (GCS 10, 22-23). Weitgehend derselbe Befund liegt vor beim christologischen Lemma $\theta \varepsilon$ cótns (wiederum abgesehen von der generischen Verwendung [wie Röm 1,20]): Vor Origenes taucht es nur vereinzelt auf, zweimal bei Clemens (Paedagogus 1.23.2; Stromata 6.94.5); vgl. PGL 620b.

122 Meliton, frag. 6 (Hall 1979, 70 = Goodspeed 1914, 310), überliefert bei Anastasios Sinaites, Hodegos 13,7 (CCSG 8, 237-238). Hiernach

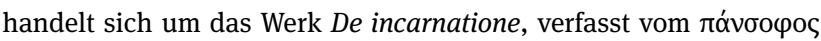

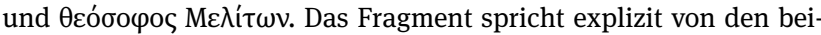

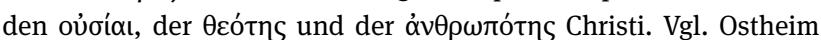
(2008, 45-46).

123 Vgl. Hall (1975; 1979, xxx-xxxi); Uhrig (2004, 103-110); ferner Grillmeier (1989, 211): „In Wirklichkeit jedoch entstammt der Text der Zeit der diphysitischen Kontroverse“. denken. ${ }^{124}$ Immerhin gibt es Aussagen in Melitons Passa-Homilie, an die die „Fortschreibung“ seiner Theologie in den spuria andocken konnte. Der Prediger spricht nämlich davon, dass Christus „auferstanden ist von den Toten als Gott, der Natur nach Gott und Mensch

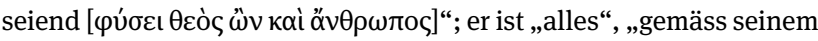
Begrabensein Mensch, gemäss seinem Auferstehen Gott““ ${ }^{125}$ Offenkundig ist (der echte) Meliton Repräsentant einer monarchianischen, nicht eigentlich trinitarischen Theologie. ${ }^{126}$ Für unsere Fragestellung ist ausschlaggebend, dass das entscheidende technische Stichwort, Christi $\theta \varepsilon$ ótns, bei ihm noch nicht auftaucht.

Auch abgesehen von den melitonischen spuria sind einige Belege für die christologische $\theta \varepsilon o ́$ tn $\varsigma$ in der vororigeneischen Literatur zu verzeichnen, die den skizzierten Gesamtbefund aber nicht substantiell tangieren. ${ }^{127}$

b. Valentin, frag. $3:^{128}$ Der Lehrer stellt Jesus Christus als vollendeten Enkratiten dar, der „seine Gottheit verwirklichte [ $\theta \varepsilon \tau^{\tau} \eta \tau \alpha$

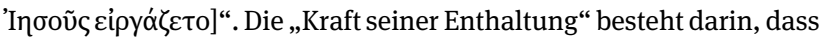
er isst, ohne auszuscheiden. Die Formulierung und die Vorstellung selber sind so eigenartig, dass sie eher zeigen, wie sich die Theologie in ein neues Terrain vortastet, als dass sie schon verfestigte christologische Begriffsbildungen bezeugen. Ein Stück weit lässt sich mit Valentins Ausdruck das Argument des Christengegners Celsus vergleichen: ${ }^{129}$ Wenn Jesus „aber so gross war, hätte er zum Erweis

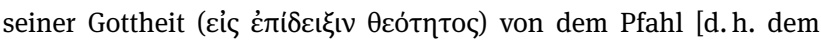
Kreuz] mindestens sogleich entschwinden müssen“.

c. Martyrium Andreae prius in den Andreasakten: ${ }^{130}$ In seinem kurzen Gebet an Christus unmittelbar vor seinem Märtyrertod wünsch sich Andreas, dass durch seinen als glücklicher Wechsel verstandenen Tod ,viele durch mich zum Glauben an dich kommen, und dass

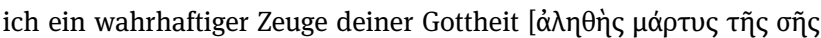

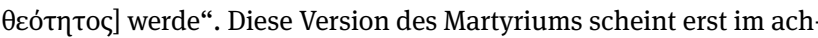
ten Jahrhundert entstanden zu sein, ${ }^{131}$ während der Grundbestand von Acta Andreae bis in das frühe dritte Jahrhundert zurückreicht.

124 Vgl. zu frag. 14 (Hall 1979, 81: „Einfachheit seiner Göttlichkeit“),

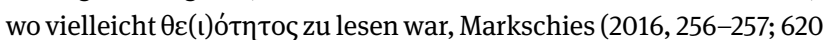
Anm. 46).

125 Meliton, Passa-Homilie 8-9 (Hall 1979, 6 = SC 123, 64).

126 Von einer „Pneuma-Sarx-Christologie“ spricht Grillmeier (1990, 211 Anm. 205). Zur möglichen Abhängigkeit Melitons von Noët von Smyrna, einem monarchianischen Theologen, vgl. Hübner (1999).

127 In eine deutlich spätere Zeit gehören ausserdem Ps.-Clemens,

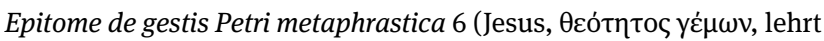
und wirkt Wunder); Ps.-Ignatius, Epistula ad Antiochenos (recensio longa) 5.1 (ein Teufelssohn ist, wer Gott verkündigt unter Tilgung $\tau \tilde{\tau} \varsigma$

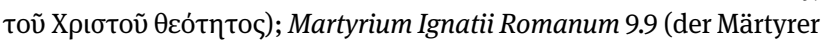
als „Teilhaber an den Leiden Christi und als wahrer und treuer Zeuge seiner Gottheit").

128 Valentin, frag. 3 (= Clemens, Stromata 3.59.3). Vgl. dazu Markschies (1992, 94-98; mit der Diskussion von Übersetzungsoptionen); Markschies (2016, 387, 735 Anm. 64).

129 Celsus, frag. 2,68 (Bader 1940) (= Origenes, Contra Celsum 2.68); vgl. Lona (2005, 164-165).

130 Acta Andreae (A): Martyrium Andreae prius 16 (CCSA 6, $701=$ AAAp 2.1, 57). „The martyrdom of Andrew is a sublime trip, the passing away from material to spiritual reality“, Bovon $(2003,207)$.

131 Vgl. MacDonald (1990, 23, 184-185). Das Martyrium prius wird deshalb auch gar nicht abgedruckt in Schneemelcher ( ${ }^{6} 1997,93-137$; teilweise anders noch Hennecke ${ }^{1} 1904,459-473$, aber gerade nicht für 
d. In einer apokryphen Johannesapokalypse zeigt Jesus Christus nach seiner Himmelfahrt dem Johannes auf dem Tabor „seine reine

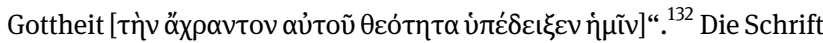
mag altes Gut enthalten, stammt in ihrer vorliegenden Form aber frühestens aus dem fünften Jahrhundert.

e. In der Apokalypse des Sedrach, die möglicherweise einen jüdischen Grundbestand enthält, wird die Bussfrage erörtert (12-16), mit klar erkennbarem christlichem Profil (14/15). Gott lässt Sedrach wissen, dass die getauften Bussunwilligen „tun, was meine Gottheit hasst (پ̊ $\mu$ Sedrach beruft sich in der Folge auf Gottes Erbarmen, „deine Gottheit

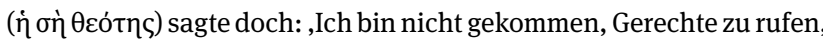
sondern Sünder zur Buße““. ${ }^{133}$ Obschon sich der Dialog zwischen Sedrach und Gott selber abspielt, stellen die Referenz auf das Herren wort (Mk 2,17 parr.) und vielleicht auch die Possessivpronomina eine Beziehung zu Jesu eigener Gottheit her. Die in nur einer Handschrift überlieferte Apokalypse trägt in ihrer vorfindlichen byzantinischen Gestalt für unsere Fragestellung nichts aus.

f. Thomasakten: In einem doxologischen Christusgebet des Thomas heisst es: ${ }^{134}$ „Preis sei deiner Stärke, die um unsertwillen schwach wurde; Preis sei deiner Gottheit, die um unsertwillen in einem Menschenbilde erschien; Preis sei deiner Menschheit, die um

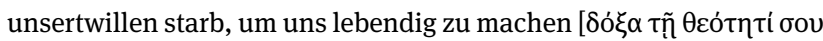

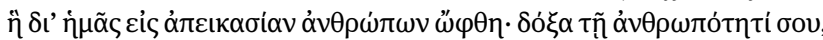

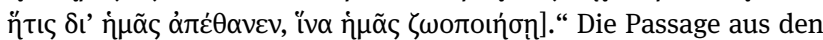
Akten, die aus der ersten Hälfte des dritten Jahrhunderts stammen, bedürfte einer genaueren Prüfung, unter Einbezug der Übersetzungen, da es sich m. W. um den einzigen (und eher verdächtigen) Beleg in der frühchristlichen Literatur vor oder neben Origenes handelt, wo Christi Gottheit und Menschheit einander prägnant gegenübergestellt werden. ${ }^{135}$

g. Schliesslich stellen die Hippolyt zugeschriebenen Texte vor besondere Herausforderungen. Das Lemma $\theta \varepsilon o ́$ tns findet sich in mindestens acht „Nestern“, darunter prominent in der Schrift Contra Beronem et Heliconem haereticos. ${ }^{136}$ Eine grobe Durchmusterung legt

die Sterbeszene, 473). Zur Datierung der Acta Andreae vgl. Bremmer (2000, 20): „close to 200“; Klauck (2005, 127): „die Jahre 200-210“.

132 Apocalypsis apocrypha Iohannis 1 (Tischendorf 1866, 70; knappe Charakterisierung bei Schneemelcher $\left.{ }^{6} 1997,626\right)$. Eine Spätdatierung legt sich auch wegen 13 nahe: Die Engel retten in der Endzeit Kreuze und Bilder (!); die Engel beten dann das Kreuz an.

133 Apocalypsis Sedrach 14,8; 15,2 (PVTG 4, 45; englische Übersetzung OTP 1, 613).

134 Acta Thomae 80 (AAAp 2,2, 196), Übersetzung Han J.W. Drijvers (Schneemelcher $\left.{ }^{6} 1997,335\right)$. Zur Datierung von Acta Thomae vgl. Bremmer (2001, 74-78): „220s or 230s“ (77).

$135 \mathrm{Zu}$ diesem Gebetstext vgl. Klauck (2005, 173-174) und Rouwhorst (2014, 208-209).

136 Zu Ps.-Hippolyt, Contra Beronem et Heliconem haereticos vgl. die Ausgabe: Diekamp ( $\left.{ }^{2} 1981,321-326\right)$; das Florilegium selber stammt aus dem späten siebten Jahrhundert (Diekamp ${ }^{2}$ 1981, LXXIX-LXXX). Zur Charakteristik des Werkfragments vgl. Möhler (1840, 594-595): „der ganze Aufsatz trägt die Lehre von der Doppelheit der Naturen und den entsprechenden Operationen in der Einen Person des Erlösers, in so abgerundeten Formeln vor, wie sie nur immer gegen die Monergeten diese bestimmte Fassung annehmen konnte“; trotzdem hält der Verfasser die Schrift nicht „für unterschoben“! Zu anderen Hippolyt-spuria vgl. unten bei Anm. 159 und 208. den Schluss nahe, dass diese Literatur ausnahmslos nicht vor dem fünften Jahrhundert entstanden ist, möglicherweise noch erheblich später.

h. Interessant ist schliesslich der Befund in der lateinischen christlichen Literatur. Der Neologismus deitas, den auch der lateinische Physiologus verwendet, findet sich erst im vierten Jahrhundert. Divinitas wird hingegen schon um die Wende zum dritten Jahrhundert auf Christus appliziert. Offenbar empfindet man $\theta$ cótnৎ/deitas („Gottheit“) als enger und präziser als divinitas („Göttlichkeit“; es kann auch für $\theta \varepsilon$ เótnऽ u.a. stehen), ${ }^{137}$ wie eine Bemerkung von $\mathrm{Au}$ gustin zu erkennen gibt (De civitate Dei 7.1: „hanc divinitatem vel, ut sic dixerim, deitatem, nam et hoc verbo uti iam nostros non piget,

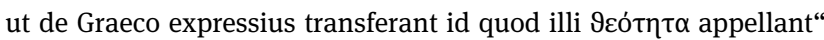
[CCSL 47, 185]). Für Tertullian ist die divinitas Christi das Gegenstück zu den heidnischen Ansprüchen auf divinitas. ${ }^{138}$ Bei Novatian hat Christi divinitas, im Kontrast zu seiner schwachen menschlichen Natur, eine geradezu programmatische Position. ${ }^{139}$ Auf nizänischen Bahnen bewegt sich Marius Victorinus, wo nun auch divinitas und deitas zusammengeführt werden. ${ }^{140}$ Schliesslich ist auf den eigenartigen Tatbestand aufmerksam zu machen, dass die Vulgata in Offb 5,12

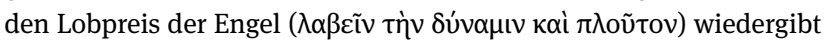
mit ,accipere virtutem et divinitatem“. ${ }^{141}$

2. Im Gegenzug zu den vereinzelten Belegen für die Ver-

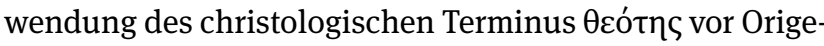
nes ist auf zahlreiche Schriften ab dem vierten und fünften Jahrhundert hinzuweisen, die wie der Physiologus vom „Verborgensein“ oder „Verhülltsein der Gottheit“ im Inkarnierten sprechen. Die Hülle besteht entweder im „Fleisch“ oder in der menschlichen Natur Christi bzw. in seiner „Knechtsgestalt“ (Phil 2,7). Die Gegenüberstellung von „Gottheit“ und „Fleisch“ wird offenbar weithin als ganz unproblematisch empfunden, ungeachtet der christologischen Auseinandersetzungen rund um Apollinaris. Sie

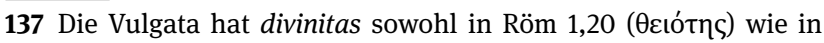

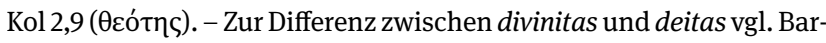
dy (1959, 575-576).

138 Vgl. Tertullian, Apologeticum 5.2 und 21.30-31 (CCSL 1, 94-95; 127-128: ,ista divinitas Christi“); im Apologeticum häuft sich der generische Gebrauch von divinitas. Vgl. zur Übersetzung Georges (2011, 123 Anm. 57; 353: „Aus der Erkenntnis, dass Christi divinitas wahr ist, folgt eine Absage an die falsche divinitas“). Vgl. ferner Scorpiace 9.1 (CCSL 2, 1084: „alia in Christo et divinitas“); Adversus Praxean 30.5 (CCSL 2, 1204).

139 Novatian, De trinitate 11.4 (Christi Wundertaten erweisen potestates divinitatis); vgl. 11.1; 12.5 (,überwältigt von der Wahrheit der divinitas Christi“) u. ö. (CCSL 4, 28-29; 31).

140 Vgl. Marius Victorinus, Commentarius in epistulam ad Philippenses 2.6 (CSEL 83,2, 188: „potentia et [...] deitas vel virtus“) mit Adversus Arium 1.24 (CSEL 83,1, 95: von der „,zweifachen Zeugung“ führt die eine ,in divinitatem et in filietatem, occulta, divina“).

141 Neben divinitatem hat die Vetus Latina auch divitias - entweder eine Rückanpassung an das Griechische oder aber eine ursprünglichere Version, die dann wegen der Ähnlichkeit der Wörter zur Entstehung des für die himmlische Liturgie passenderen divinitatem geführt hat. 
wird portiert von zentralen Aussagen der Bibel wie Joh 1,14, 1 Tim 3,16 („Gott [so eine Lesart] offenbart im Fleisch“ komplementär zur Verhüllung im Fleisch) und Röm 8,3 (Sendung in der „Ähnlichkeitsgestalt des Fleisches“). Die Affirmation des göttlichen Status von Jesus Christus steht natürlich im Zusammenhang mit der Entwicklung des trinitarischen Dogmas im vierten Jahrhundert.

\section{Exkurs:}

a. Vorbereitet wird die Figur von Origenes selber: ${ }^{142}$ „Das Wort Gottes wirkt, was es für die Menschen plant, nicht durch die nackte

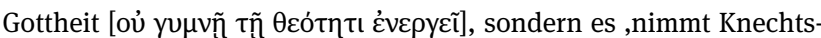
gestalt an' (Phil 2,7), so dass sein Weg der Verwirklichung des Heils-

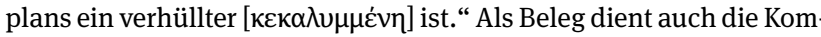
bination von Abstieg und Dunkelheit in Ps 18,10 (,er neigte den Himmel und stieg herab, und Dunkelheit war unter seinen Füssen“). Der Kirchenlehrer extrapoliert die Selbstverhüllung des Gottessohns im Fleisch sogar in das Feld der Bibelhermeneutik: „Das Wort Gottes gelangte aus Maria mit Fleisch bekleidet in diese Welt [...] - der Anblick des Fleisches an ihm stand nämlich allen offen, wenigen nur und Auserwählten ward die Kenntnis der Gottheit geschenkt (divinitatis agnitio). [...] Wie er dort durch den Schleier des Fleisches, so wird er hier durch den des Buchstabens verhüllt, so, dass zwar der Buchstabe angeschaut wird, gleichsam wie Fleisch, der innen verborgene geistige Sinn aber wie die Gottheit erkannt wird" (Homilia in Leviticum 1.1 [GCS $29,280=$ SC 286, 66])..$^{143}$

b. Die ,Verhüllung der Gottheit im Fleisch' begegnet in ganz verschiedenen theologischen Strömungen des vierten und fünften Jahrhunderts. Euseb beruft sich dabei besonders auf den „verborgenen Gott“ von Jes 45,15. ${ }^{144}$ In Alexandria lässt sich die Figur sowohl bei Arianern ${ }^{145}$ wie bei Orthodoxen ${ }^{146}$ nachweisen. In der Folge wird namentlich Apollinaris die Meinung zugeschrieben, das menschli-

142 Origenes, frag. 18 in Commentarius in Iohannem (GCS 10, 498; Übersetzung: Gögler 1959, 187-188); bei den Katenen-Bruchstücken ist die Echtheit allerdings kaum verlässlich zu sichern. Ps 18,10 ist auch Prätext für: Origenes, Excerpta in Psalmum 17 (PG 17, 112B), wo das „Neigen“ auf die „Erniedrigung aus der Höhe“, das „Absteigen“

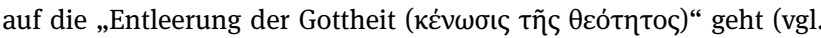
Phil 2,7-8). Überaus interessant ist die Fortsetzung im Anschluss an Ps 18,11 (,er wurde auf Cherubim erhoben“): Bei Jesu Auffahrt, nun mit Körper, sprechen die Himmelsmächte die Worte von Ps 24,7.9.

143 Vgl. ähnlich Origenes, Commentariorum series in Matthaeum 27 (GCS 38, 45: „Christus celatus venit in corpore, ut [...] deus intellegatur").

144 Euseb stellt der LXX-Fassung von Jes 45,15 („du bist Gott, und wir wussten es nicht“) die späteren jüdischen Übersetzungen gegenüber, die dem hebräischen Text (,du bist ein Gott, der sich verbirgt“)

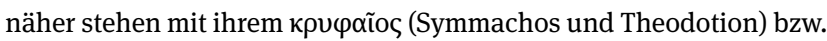

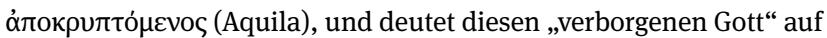
Christus (Demonstratio evangelica 5.4.4-9 [GCS 23, 224-225]; Commentarius in Isaiam 2.28 [GCS 9, 294-295]).

145 Vgl. Grillmeier (1990, 375: „Arius bekennt sich nur zum Fleische Christi allein als der Hülle der Gottheit“) mit Verweis auf Ps.-Athanasios, De incarnatione contra Apollinarium 2.3 (PG 26, $1136 \mathrm{C} / 1137 \mathrm{~A})$.

146 Vgl. Athanasios, Oratio contra Arianos 2.8.1 (Metzler und Sav-

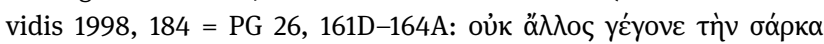

che Fleisch verhülle den Logos nur noch wie ein Umhang, während die Antiochener die Verhüllung in der (ganzen) menschlichen Natur Christi verorten. ${ }^{147}$

c. Für unsere Fragestellung ist das Euvre Gregors von Nyssa sehr wichtig. Die Inkarnation, entfaltet im Gegenüber von Gottheit und Fleisch, hat, wie vielfach in der altkirchlichen Theologie, den Doppelaspekt von Manifestation und Verhüllung. Die letztgenannte findet Gregor in Hld 1,16b ${ }^{\mathrm{LXX}}$ (vom Bräutigam: „du bist schattig“); der Gottessohn als Bräutigam ,verhüllt den reinen Strahl mit der Knechtsgestalt“, „umschattet die Strahlen der Gottheit mit dem Umwurf des Körpers“; gerade so kommt die Mittlung und damit die Vergöttlichung der „Braut“ zustande. ${ }^{148}$ Ganz der Täuschung hingegen dient die Verhüllung dort, wo der Teufel mittels des Fleisches geködert wird. Die Figur findet sich in einer zentralen Passage der grossen katechetischen Rede (19-26): ${ }^{149}$ „Deshalb verhüllte sich die Gottheit

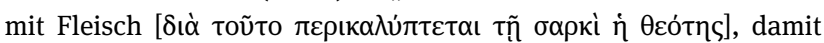
(der Feind) beim Anblick des vertrauten und verwandten (Fleisches) nicht durch die Nähe der höchsten Gewalt erschreckt würde.“ Hier konvergiert das Gerechte, nämlich die erfolgreiche Bezwingung des Bösen, mit dem Guten, nämlich mit dem Sich-zugänglich-Machen der göttlichen Macht durch Umhüllung mit einem Körper (23,4); die Vereinigung der $\theta \varepsilon o ́$ tn

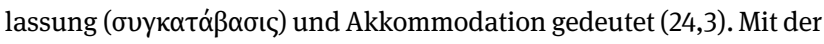
Täuschung assoziiert sich das Bildfeld des Fischens und der Krokodiljagd (Leviatan, vgl. Ijob 40,25-32): Im Köder des Fleisches ist der Angelhaken der Gottheit verborgen. ${ }^{150}$

d. Für Gregor von Nazianz „erstrahlte“ Christus auf dem Verklärungsberg in seiner Gottesgestalt, „er manifestierte seine Gottheit und entblösste den im Fleisch Verborgenen“. ${ }^{151}$ Einer Epiphanias-

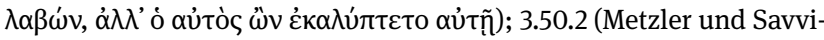
dis 2000, 361 = PG 26, 429A); 3.67.6 (Metzler und Savvidis 2000, $381=$ PG 26, 465C); Fragment bei Theodoret, Eranistes Florilegium 1.39 (Ettlinger 1975, 102 = PG 26, 1240A mit der Deutung des „Umhangs“ von Gen 49,11 auf den Körper als „Hülle der Gottheit“); ferner Grillmeier (1990, 478).

147 Vgl. Theodoret, De incarnatione 18 (PG 75, 1448C) und unten zu den Antiochenern Anm. 154.

148 Gregor von Nyssa, Homilia 4 in Canticum canticorum (GNO 6,

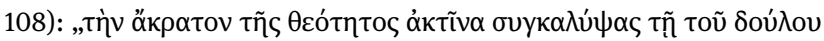
$\mu о \rho \varphi \tilde{n ̃} “$ Zum Verständnis von Hld 1,16b und zur Inkarnation als „,Selbstverdunkelung“ des Logos zugunsten der Menschen“ vgl. Dünzl (1994, 258 Anm. 14 und 15; 1993, 88, 316-317).

149 Gregor von Nyssa, Oratio catechetica 23.3 (GNO 3,4, 60); deutsche Übersetzung Barbel (BGrL 1, 65); vgl. 24.4 (62): „das Göttliche verhüll-

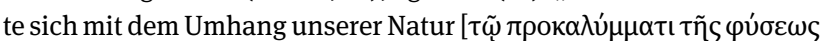

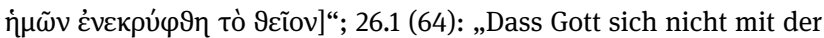
nackten Gottheit, sondern ohne Wissen des Feindes bedeckt mit der

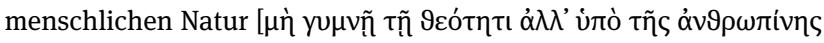

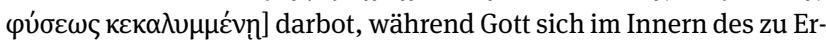
fassenden befand, das ist doch eine Art Täuschung“. Zur - für moderne Menschen befremdlichen - Lösegeldtheorie bei Gregor vgl. Kees (1995, 110-114); zum „trompeur trompé“ Winling (2000, 82-83); Fürst (2011, 282-287) zur „Nutzlüge“.

150 Oratio catechetica 24,4 (62); vgl. unten Anm. 166 zu In Christi resurrectionem 1.

151 Gregor von Nazianz, Oratio 32.18 (SC 318, 122): „iva Tñ $\mu о \rho \varphi \tilde{n}$

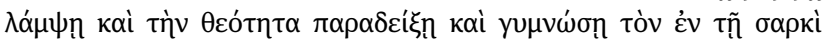
критто́ $\mu \varepsilon v v^{\prime \prime}$. 
predigt zufolge eröffnet Jesus Christus den Weg zum transzendenten Gott, „damit der Unzugängliche zugänglich werde“: Der Gottessohn „verkehrt mit uns mittels des Fleisches wie durch einen Vorhang, da die Werden und Vergehen unterworfene Natur seine reine Gottheit nicht ertragen könnte““ ${ }^{152}$ Wieder fällt auf, dass eine so zentrale Figur wie die christologische Vereinigung von Gottheit und Menschheit gern korreliert wird mit der Täuschung des Teufels. Während dieser „uns mit der Hoffnung auf Gottsein täuschte, wird er selber

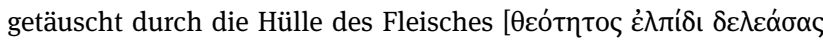

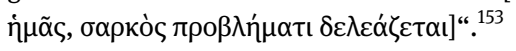

e. Im fünften Jahrhundert zeigt etwa Theodoret, wie standardisiert das theologische Vokabular geworden ist, auch bei den Antiochenern: Der Herr „zog die menschliche Gestalt an und verbarg die unsichtbare mittels der sichtbaren Natur; er bewahrte seine sichtbare Natur sündlos $\left(\right.$ Hebr 4,15) und die verborgene rein““. ${ }^{154}$ Die Frage der Angemessenheit von Metaphern wie Vorhang, Hülle u. ä. für den Leib bzw. das Fleisch Christi wird bei Theodoret ausgiebig diskutiert, u. a. mit Berufung auf die neutestamentliche Identifizierung von Tem-

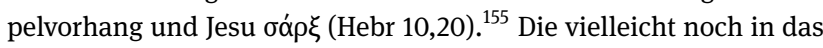

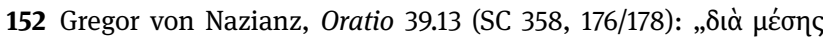

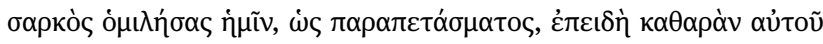

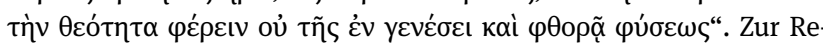
de vgl. Daley (2006, 127), zu unserer Passage (233 Anm. 501): „This sentence, another of Gregory's memorable characterizations of the Christian Mystery, is often quoted in the florilegia of the fifth-century councils and later Patristic works on the person of Christ“; Beeley (2008, 113, 126, 139). Vgl. zu Gregors Deutung der Himmelfahrt oben bei Anm. 115.

153 Vgl. Oratio 40.10 (SC 358, 216): кó $\lambda \nu \mu \mu \alpha$. Nach Oratio 24.9 bekommt es der Teufel unwissentlich mit der Gottheit zu tun, wie er die

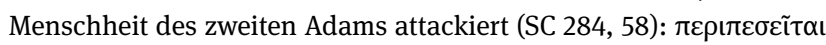

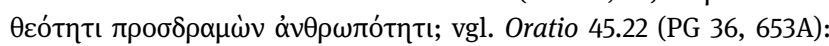
Gott selber als Lösegeld.

154 Theodoret, Curatio graecarum affectionum 6.77 (SC 57, 282).

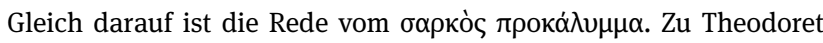
vgl. auch oben Anm. 113. Bergjan (2015, 249-254) verfolgt, wie die göttliche Selbstverhüllung in der antiochenischen Theologie ausdifferenziert wird: Theodoret greift auf die Versuchungsgeschichte zurück, um die apollinaristische Vorstellung, das menschliche Fleisch verhülle den Logos nur wie ein Umhang, abzuwehren; Gott verbirgt sich in dem Menschen Jesus, der damit ganz Mensch ist und bleibt

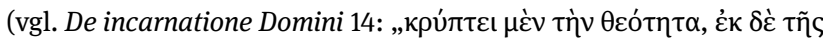

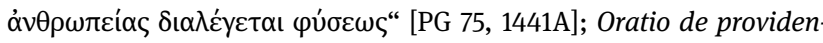

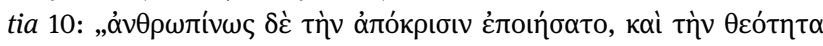

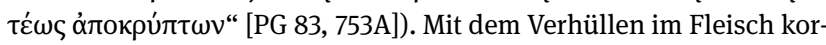
reliert die Einwohnung im Tempel. „Theodorets Christologie ist stark durchzogen von dem Gedanken des im Menschgewordenen verborgenen Gottes“, Bergjan (2015, 253); Bergjan (2018, 1631): „Gott bedient

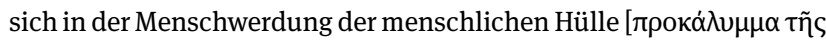

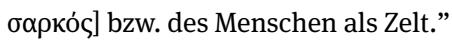

155 Theodoret, Eranistes Dialog 1 (Ettlinger 1975, 76-77): das tò

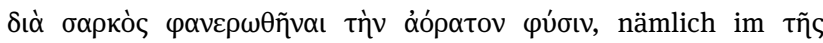

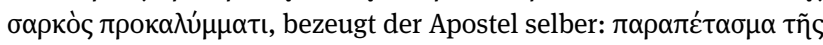

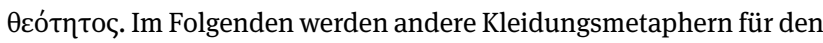
Körper diskutiert. Interessant ist der Einwand des Gesprächspartners, dass es sich beim Bild $\pi \alpha \rho \alpha \pi \varepsilon ́ \tau \alpha \sigma \mu \alpha$ für Jesu Körper um eine „Neuerung“ handle; der „Orthodoxe“ entkräftet ihn sogleich mit Verweis auf Hebr 10,20. späte vierte Jahrhundert zurückreichenden Textcorpora von Makarios/Symeon bieten ebenso die uns schon bekannten Figuren: den „Logos, der Fleisch anzieht und seine eigene Gottheit verbirgt, um Gleiches durch Gleiches zu retten“, „die Gottheit, die sich in der Menschheit verbirgt und den Menschenkörper wie eine Hülle oder einen Umhang benützt“, hier gezielt verbunden mit der Verfluchung der Mächte und Gewalten samt der Zurschaustellung Satans. ${ }^{156}$

Die technisch gewordene Begrifflichkeit begegnet später in zahlreichen Texten, sogar in Konzilsakten, gerade auch in spätbyzantinischer Zeit. ${ }^{157}$ Die Figur gehört offenkundig zum Grundstock orthodox gewordener Theologie.

f. Einen besonderen Hinweis verdienen drei Textgruppen: Die Topik der deitas in carne abscondita findet sich, wie nicht anders zu erwarten, auch in den Johannes Chrysostomos zugeschriebenen homiletischen und exegetischen Werken, wohl aus dem fünften Jahrhundert. ${ }^{158}$ Ähnlich verhält es sich im Fall der Schriften unter Hippolyts Namen, namentlich De theophania. ${ }^{159}$ Schliesslich bietet die pseudoathanasianische Schrift Quaestiones aliae in einer ausgedehnten Passage das gesamte Inventar der Motive, vom urgeschichtlichen Sün-

156 Makarios, Homilia 15.44 (PTS 4, 153); Sermo 4.30.3 (GCS I, 71). 157 So z. B. Gelasius, Historia ecclesiastica 2.19.26 (GCS 28, 83); Basileios von Seleukia, Oratio 28.1 (PG 85, 317C); 23.1 (PG 85, 273A); Collectio Sabbaitica 8 = Akakios, Epistulae (ACO 3, 18:31-36); Catena in Epistolam ad Philippenses $\Gamma$ (Cramer 1844b, 252-253); Prokop, Commentarius in Isaiam (PG 87, 2276); Anastasios Sinaites, Hexaemeron 4.5.5

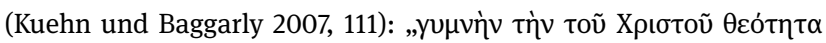

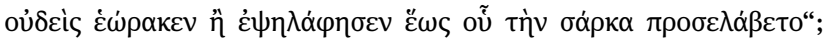
12.5.1 (480): „Fleisch seiner Menschheit, worin er seine [...] Gottheit verbarg“; Ps.-Anastasios, Adversus Iudaeos disputationes 2 (PG 89, 1228C); Adversus Iudaeos dialogus alius (PG 89, 1276C). In das 15. Jh. n. Chr. gehört ein Brief von Joasaph, Metropolit von Ephesus, der das Heilsgeschehen in den klassischen Figuren summiert: In der Urzeit besiegt der Teufel mit List die Menschheit Adams, mit Christus besiegt die im Fleisch verborgene Gottheit mittels Köder den Teufel: Epistula Joasaphi ad Nilum 501-548 (TLG).

158 Ps.-Chrysostomos, Oratio de nativitate 1 (Uthemann, Regtuit und Tevel 1994, 31): ,der Arzt ist vom Himmel her zu uns gelangt, verbarg seine Gottheit in einem fleischlich und sterblichen Gefäss, nahm un-

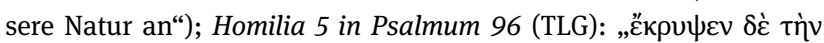

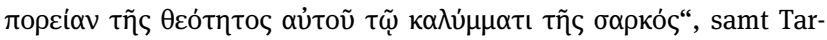
nungsmotiv mit intertextuellem Bezug auf Eph 3,10 und 1 Kor 2,9 sowie mit Deutung der „Finsternis“ von Ps 96,2 ${ }^{\mathrm{LXX}}$ auf das Sich verbergen; De Pharisaeo (PG 59, 591): Jesus ist beim Pharisäer von Lk 11,37 $\mathrm{zu}$ Besuch und verbirgt seine strahlende Gottheit mit seiner Menschheit, seine königliche Würde mit dem fleischlichen Lederpanzer; In assumptionem Domini (TLG): „verbarg die Gottheit in menschlichem Umhang"; In annuntiationem et contra Arianos (PG 62, 765): der gute Hirte verhüllt mit dem Schaffell seine eigene Gottheit und ruft die verirrten Schafe zu sich; In centurionem (PG 61, 771) vom Hauptmann:

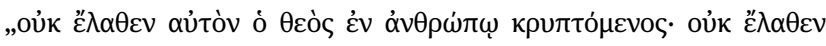

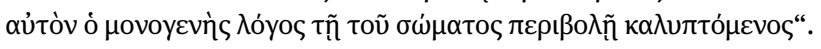
159 Ps.-Hippolyt, De theophania 4 (GCS 1,2, 259): Der Herr begegnet

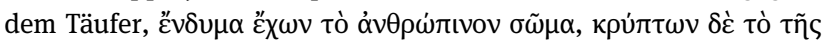

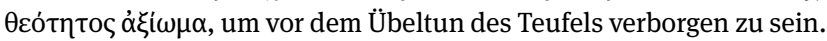
$\mathrm{Zu}$ anderen pseudo-hippolyteischen Schriften vgl. oben bei Anm. 136 und zur „verhüllten Gottheit“ unten bei Anm. 208. 
denfall über die Verhüllung der Gottheit in Christus bis zur Köderung des Drachen. ${ }^{160}$

Es fällt auf, wie oft sich die Semantik der verhüllten Gottheit Christi mit dem Topos vom betrogenen Teufel verbindet. Wir hatten oben darauf aufmerksam gemacht, dass das Mythologumenon der Tarnung Christi, das die ,dissidenten' Überlieferungen im Abstieg Christi durch die Himmelssphären wahrnehmen, von mehrheitskirchlichen Theologen vor allem mit dem Erlösungswerk des Inkarnierten assoziiert wird: Das Mysterium von Fleischwerdung und Opfertod musste vor den widergöttlichen Mächten verborgen werden (vgl. Ignatius, Epistula ad Ephesos 19,1; 1 Kor 2,8 [?]).

Auch an diesem Punkt ist das Werk von Origenes überaus aufschlussreich. Das Täuschungsverfahren entnimmt er der paulinischen Andeutung in 1 Kor 2,7-8, dass die Weltherrscher unwissend den „Herrn der Herrlichkeit“ gekreuzigt haben: ${ }^{161}$

Da sie [sc. die angelischen ,Fürsten dieser Welt‘] nicht wussten, wer sich in ihm verbarg, bereiteten sie ihm alsbald Nachstellungen (Ps 2,2) [...]. Der Apostel hat ihre Nachstellungen erkannt und durchschaut, was sie gegen den Sohn Gottes ins Werk setzten, als sie ,den Herrn der Herrlichkeit kreuzigten` (1 Kor 2,8).

Auch wenn es im erhaltenen Werk des alexandrinischen Theologen m. W. nicht explizit formuliert wird, wäre es folgerichtig, dass sich Christi Verborgenheit vor den widergöttlichen Geistwesen auch schon auf seinen Descensus durch die Himmelswelten erstreckte. ${ }^{162}$ Bei den „Herrschern dieser Welt" handelt es sich nämlich um Geistermächte und Dämonen - ohne irdische Machtträger auszuschliessen -, namentlich um den Teufel. ${ }^{163}$ Mit der Tötung des Gottessohns führen sie ihre eigene Vernichtung herbei,

160 Ps.-Athanasios, Quaestiones aliae 20 (PG 28, 792D-793C). 161 Origenes, De principiis 3.3.2; Übersetzung nach Görgemanns und Karpp ( ${ }^{3} 1992$, 590-591); mit Zitat von 1 Kor 2,6-8.

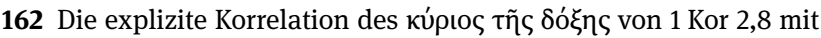

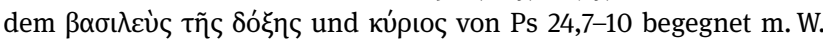
im erhaltenen Werk von Origenes nicht. $\mathrm{Zu} 1$ Kor 2,7-8 s. oben bei Anm. 53.

163 Vgl. zur Rezeption von 1 Kor 2,8: Origenes, Fragmenta in Lamentationes 107 (GCS ${ }^{2}$ 6, 273), wo auch Ps 2,2 (die „Könige der Erde“ verschwören sich gegen den Herrn und Gesalbten) und Eph 3,10 (archai und exusiai in den Himmeln) eingespielt werden; Commentariorum series in Matthaeum 125 (GCS 38, 260-261): durch römische Soldaten wirken „unsichtbare Könige“; wieder mit Ps 2,2; Commentarius in Matthaeum 12.30 (mit Ps 2,2); Selecta in Psalmos (PG 12, 1101; vgl. 1312: betrogener Teufel). Die erstaunliche Aussage von Eph 3,10 wird bei Origenes sonst nicht aufgenommen (anders bei Theodoret [s. Anm. 113]). - Zur Genese Satans als gefallener Engel bei Origenes vgl. Vollenweider (2012, 219-221). die mit Auferstehung und Auffahrt ihren Anfang nimmt (wofür sich Origenes speziell auf Kol 2,15 bezieht). ${ }^{164}$

Exkurs: Die neutestamentlichen Erzählungen, die trotzdem die klare Kenntnis Jesu als des Gottessohns bei widergöttlichen Geistern voraussetzen, werden exegetisch gewunden entschärft. Wenn die Dämonen Jesus erkennen - wie es zumal bei Mk im Zeichen des „Messiasgeheimnisses“ dramatisch inszeniert wird -, handelt es sich um niedriger gestellte Geistwesen, deren entsprechend geringere Bosheit auch weniger Verblendung mit sich bringt. ${ }^{165}$

In der späteren theologischen Literatur werden diese Linien nicht nur weiter ausgezogen, sondern sie verbinden sich mit der Figur der verhüllten Gottheit Christi. Neben den bereits besprochenen Texten verweise ich exemplarisch auf eine Osterpredigt Gregors von Nyssa: Der Teufel fällt einem Lockvogel zum Opfer; er lässt sich täuschen durch das „Fleisch“, die menschliche Gestalt Jesu. So schluckt der „Drache“ den Köder am Angelhaken der Gott-

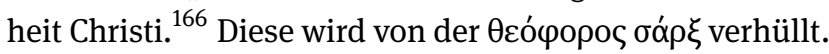

Im Physiologus selber setzt die Allegorese des Ichneumon (26) die Figur des überlisteten Teufels, der sich an der verhüllten Gottheit Christi verschluckt, voraus. ${ }^{167}$ Auch an diesem Punkt gibt die in unserer Schrift als ganz selbstverständlich präsentierte theologische Figur einen chronologischen Fingerzeig: Erst Origenes scheint die Idee der Inkarnation als einer Täuschung des Teufels in die christliche Theologie eingeführt zu haben. ${ }^{168}$

164 Origenes, Commentarius in Matthaeum 12.18 und 40; Commentariorum series in Matthaeum 76 und 92; Homiliae in Genesim 9.3; u.ö. Zum „Lösegeld“ (Mt 20,28 par.) der Seele Jesu, durch das sich der Teufel täuschen liess, s. Commentarius in Matthaeum 16.8 (GCS 40, 498). 165 So Origenes, Homiliae in Lucam 6.4-6 (SC 87, 144/146): Die Jungfrauengeburt blieb dem Teufel verborgen (mit Zitat von Ignatius, Epistula ad Ephesos 19!), weil Josef Maria ehelichte; „absconditum igitur fuit a principibus huius saeculi mysterium salvatoris“ (5). Aber niedrigere Dämonen wissen den Evangelien zufolge dann doch mehr (6). Zum Thema der Nichterkennbarkeit Gottes für Engel schlechthin vgl. oben bei Anm. 113.

166 Gregor von Nyssa, In Christi resurrectionem 1 (GNO 9, 280-283, bes. 281:8-10), mit Anspielung auf Ijob 40,24.26. Zur Täuschung des Teufels vgl. oben Anm. 150. Zur Osterhomilie (auch bekannt als: De tridui spatio) vgl. Maspero (2010), unten Anm. 203 und besonders Drobner (1982, hier zur Überlistung des Teufels 87-90).

167 Vgl. oben bei Anm. 31.

168 Vgl. Fürst (2011, 282-283): „führte Origenes die Idee einer ,Täuschung des Teufels“ in die christliche Theologie ein“ (mit Hinweis auf den Physiologus); vgl. Schwager (2015, 83-84). 


\section{Der verborgene und offenbare Gottessohn im Physiologus}

Wir sind damit zum Anfang des Physiologus zurückgekehrt. Es ist offenbar das Leitmotiv der „verhüllten Gottheit“, das den Verfasser auf die ältere Tradition des descensus absconditus zurückgreifen lässt: Der Löwe, der seine Spuren vor den Jägern verbirgt, wird in der Allegorese ja auf den Erlöser gedeutet, der sich gegenüber den Engelmächten so tarnt, dass er ihre jeweilige Gestalt annimmt. Diese Figur ist uns vornehmlich in ,dissidenten' Überlieferungen begegnet, weniger in solchen, die zum kirchlichen Mainstream gehören. $\mathrm{Zu}$ einer doketistischen Zuspitzung, wie sie einige gnostisierende Texte vertreten, kommt es im Physiologus aber nicht, im Gegenteil: Christi Herabkunft mündet in Jungfrauengeburt und Inkarnation, wie das Zitat von Joh 1,14 verdeutlicht.

Hinsichtlich der Frage nach dem Verhältnis von „Heterodoxie“ und „Orthodoxie“ im griechischen Physiologus zeichnet sich damit ein geradezu paradox anmutender Befund ab. Die im Lauf der Zeit als heterodox taxierte Figur des descensus absconditus zielt in unserer Schrift auf einen ausgesprochen „orthodoxen“ Skopus, nämlich auf das Theologumenon der in der Inkarnation verhüllten Gottheit Christi. Dieses zählt seit dem vierten Jahrhundert zum festen Inventar der griechischen Dogmatik, quer durch alle theologischen Milieus hindurch.

Nun fällt in der ersten Löwenallegorese auf, dass die Fleischwerdung und vor allem die anschliessende Wechselrede keinen Haftpunkt mehr im Gleichnis selber haben. In der Wechselrede heisst es, dass „sie“ ihn nicht erkannten „als den von oben Herabgestiegenen“. Gemeint sind die Engelmächte, von denen gleich zuvor die Rede war.

Die Frage stellt sich, bei welcher Gelegenheit der mit den Worten von Ps 24,10 geführte biblische Dialog erfolgt. Es bieten sich drei Optionen an: Erstens beim Abstieg des Erlösers, zweitens bei seiner Inkarnation oder drittens bei seiner Himmelfahrt.

Exkurs: Im Folgenden werden wir die genannten Möglichkeiten im Einzelnen prüfen. Dabei ist allerdings die Frage wachzuhalten, ob trennscharf entworfene Interpretationsoptionen, wie sie nun aufgefächert werden, bei einer Textsorte wie dem Physiologus überhaupt greifen können. Für den Sinn exegetischer Differenzierung spricht die Beobachtung, dass unsere Schrift nicht nur als ein konfuses Amalgam überaus heterogener Überlieferungen anzusprechen ist, sondern als ein Text mit einem durchaus reflektierten theologischen Profil, das ge- rade in den jeweiligen Allegoresen der zoologischen Porträts greifbar ist. $^{169}$

1. Die auf den ersten Blick naheliegendste Interpretation situiert die Wechselrede beim Abstieg des Erlösers. Tatsächlich lässt unsere Passage eine deutliche Leserlenkung erkennen: Die Bewegung geht von oben nach unten, von der Sendung durch den ,unsichtbaren Vater“ bis zur Inkarnation. Entlang dieser Fluchtlinie begleiten auch Frage und Antwort den Abstieg Christi, beziehen sich also zurück auf die vor der Inkarnationsaussage zu lesende Engelgleichwerdungsaussage. ${ }^{170}$ Der Vorteil dieser Lesart besteht darin, dass sie mit einer einzigen Bewegung, eben dem Abstieg, auskommt. Sprachlich wird dies unterstützt durch den Hinweis darauf, dass die Fragenden denjenigen „nicht erkannten, der von oben herab kam

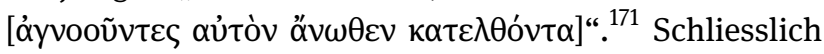
spricht auch das Arrangement der drei Löwengleichnisse mit ihrer Abfolge von Inkarnation, Kreuzestod und Auferweckung dafür, dass wir uns mit dem Zitat von Ps 24 noch an der ersten Station befinden.

Exkurs: $\mathrm{Zu}$ beachten ist allerdings eine alternative Lesart, die von F. Sbordone, dem Herausgeber der kritischen Edition, bevorzugt wird: ${ }^{172}$ „Daher erkannten sie ihn nicht, sie, die von oben herab kamen, und sagten [...].“ Diese Entscheidung ist nicht leicht nachvollziehbar, zumal die älteste Ganz-Handschrift für den gesamten Abschnitt ausfällt und die zweitälteste an dieser Stelle nicht klar lesbar ist. ${ }^{173}$ Innere Kriterien sprechen entschieden für die Beziehung des Partizips „herabkommend“ auf den Erlöser, nicht auf die Engel:

169 Richtig Alpers (1984, 39, 41): Der Verfasser des Physiologus ist kein unselbständiger stupider Kompilator, als den man ihn oft abgewertet hat, sondern ein kreativer Autor. Vgl. Dorofeeva (2017: 666668) sowie zur Leserdimension oben bei Anm. 35 sowie unten bei Anm. 192 und 249.

170 So wird meist stillschweigend gelesen; explizit etwa Brucker (2014, 424 Anm. 63).

171 Offenbar versteht neben der syrischen (Land 1875, 33*) auch die äthiopische Übersetzung den Satz so: „Aber die, welche ohne dies zu wissen, auf seine Herabkunft achthatten, sprachen: ,Wer ist dieser König der Ehren?““ (Hommel 1877, 46); vgl. Hommel (1890, 13): „Aber die, welche ohne ihn [näher] zu kennen auf seine Herabkunft achteten, sprachen: ,Wer ist dieser König der Herrlichkeit?““ Das Nichtwissen bezieht sich dabei wohl auf die Engelgleichheit Christi, die der Äthiopier vor dessen Herabkunft platziert (vgl. oben Anm. 21), also auf die Herkunft Christi. In der Folge entfällt die Antwort des Geistes.

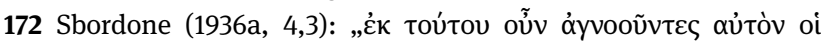

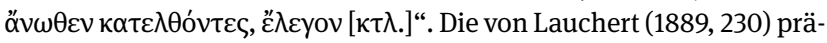
ferierte Version der Hs. W ist aufgrund der griechischen Syntax sicher

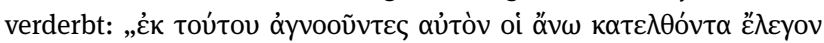
$[\kappa \tau \lambda$.$] “. Eine Mischform bietet die lateinische Überlieferung (y, b): Sie$ bezieht das „Herunterkommen“ auf Christus, das „(von) oben“ auf die Engel, s. unten Anm. 174 und 179.

173 Zur ältesten Ganz-Handschrift G (die Sbordone noch nicht kannte) vgl. die Ausgabe von Offermanns (1966, 16; warum G unseren gan- 
Diese sind im vorfindlichen Kontext nicht als Herunterkommende im Blick, so gewiss sie in anderen Zusammenhängen als professionelle Absteiger (und Aufsteiger) gezeichnet werden (vgl. die Leiter Jakobs, Gen 28,12). Die Übersetzungen bleiben meist, soweit ich sehe, beim näher liegenden Bezug auf den Erlöser, ebenso wie die älteren Ausgaben. ${ }^{174}$

Die Lokalisierung der biblischen Wechselrede im Abstieg hat aber einen entscheidenden Nachteil, nämlich einen Mangel an inhaltlicher Konsistenz: Durch die Proklamation des „Herrn der Mächte“ und „Königs der Ehren“ verliert die vorgängige Tarnung ihren Sinn. Wir kommen gleich auf dieses Argument zurück.

Exkurs: Eine relativ einfache Lesart ergäbe sich dann, wenn die Engelwerdung des Erlösers gar nicht um der Tarnung willen erfolgt, sondern einfach das Prinzip der Verhüllung der „Gottheit Christi“ in einem Leib realisiert. Hier wären es angelische Leiber, gefolgt vom irdischen Körper bei der Inkarnation. Die Wechselrede von Ps 24 würde dann schon gut zum Abstieg passen. Diese Lesart ist aber aus zwei Gründen schwierig: Erstens insinuiert die Bildhälfte der Löwenallegorie mit ihren Jägern selber schon eine negative Kodierung der Engel auf Seiten der Sachhälfte, und zweitens spricht die Einhorn-Miniatur (22) explizit von der Gefährdung des herabsteigenden Erlösers durch Engel und Mächte. ${ }^{175}$

2. Eine weitere denkbare Lesart ist die Situierung von Frage und Antwort an der Station der Menschwerdung selber - die ja gleich zuvor genannt wird -, also auf der Erde. Die Engel würden angesichts des Fleischgewordenen dieselbe Frage stellen, die den Evangelien zufolge auch die Menschen aufwerfen: „Wer ist dieser?“ (Mk 4,41 u.ö.). Die-

zen Abschnitt nicht wiedergibt, ist nicht klar). In der nur wenig jünge-

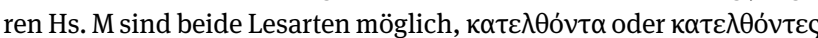
(,M syllaba finalis compendio vix legibili scripta“, Offermanns 1966,

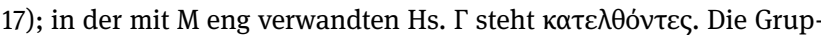
pen $\Sigma$ as und $\mathrm{AI} \Delta \Pi \varphi \mathrm{r}$ haben die verbreitete, oben auch vorausgesetzte

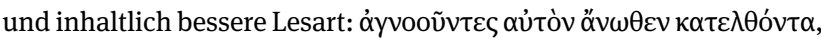
die Hs. O liest ähnlich wie $\Gamma$ (aber nur o̊v $\omega$ ). Vgl. Kaimakis (1974, 8-9); er hält den Text der Hs. $\mathrm{O}$ offenbar für verderbt.

174 So die Übersetzungen von Peters (1898); Seel (1960); Treu (1981); Schönberger (2001); ebenso schon die zweisprachige Ausgabe aus

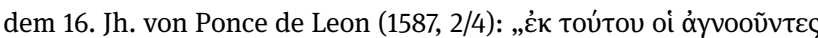

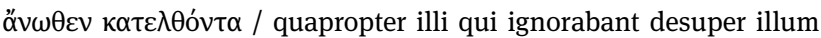

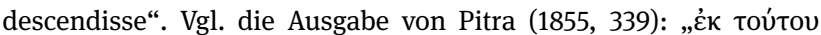

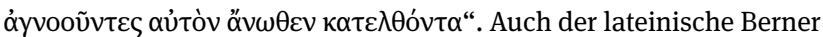
Physiologus liest dementsprechend (Steiger 1964, 52): „Et hoc ignorantes eum omnes descendentem dicebant [...]“. Zur lateinischen Version Y vgl. unten Anm. 179. Demgegenüber übersetzt Grant (1999, 52) nach Sbordone: „Therefore in ignorance of him, those who descended from above said“. Auch auf die Engel bezogen wird das „oben“ in der englischen Übersetzung (Curley 1979, 4): „those who are on high not knowing him as he descended“; sie folgt nämlich der lateinischen Version (xxxiii).

175 Vgl. oben Anm. 17. se Hypothese ist aber ganz unwahrscheinlich (und wird m. W. auch von niemandem vertreten): ${ }^{176}$ Die „Torliturgie“ von Ps 24,7-10 setzt ein Passieren voraus, es geht also um einen Transit, der im Physiologus wie in all den anderen oben durchmusterten christlichen Traditionen vertikal geschieht.

Exkurs: Um einen solchen Transit würde es sich bei der Höllenfahrt handeln, gleich im Anschluss an Christi Erdenleben. Sie ist zwar dem Physiologus bekannt (25) und sie verbindet sich gern mit Ps 24. ${ }^{177}$ Aber unser Text bietet nicht den geringsten Hinweis auf diese Assoziation.

3. Eine dritte Hypothese versteht die Nennung von Inkarnation und Einwohnung, in denen sich der Descensus vollendet, als abschliessende Aussage. Das Zitat von Joh 1,14 markiert eine Zäsur, die die Wende einleitet. Frage und Antwort von Ps 24 beziehen sich, so gesehen, dann nicht mehr auf den Absteigenden zurück, sondern vielmehr auf den wieder Aufsteigenden. ${ }^{178}$ Diese Deutung, die das Achtergewicht auf das Johanneszitat legt, rechnet also mit Breviloquenz.

Exkurs: In der Tat zeigt die handschriftliche Überlieferung, dass das Frage- und Antwortspiel gelegentlich explizit bei der Himmelfahrt Jesu lokalisiert wird. ${ }^{179}$ Der Hauptgrund für diese Versionen besteht in

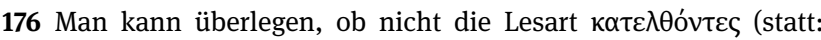

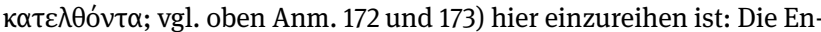
gel kommen von oben herab und erkennen den inkarnierten Christus nicht.

177 S. dazu Anm. 107, 109 und 118.

178 So deuten Lauchert $(1889,57)$ : „die Auslegung von Ps. 23 [...], wonach die Engel im Himmel Christum bei seiner Himmelfahrt nicht kennen und desshalb fragen“, sowie - vielleicht lediglich aufgrund einer summarischen Lektüre - Barbel $\left({ }^{2} 1964,305\right)$ : „Der Apologet Justinus deutet den Ps. 23 mit seinem Frage- und Antwortspiel, wie der Physiologus, auf den Himmelsaufstieg des Herrn“. Hanson $(1980,42)$ bemerkt zu Recht zum Zitat von Ps 24,10 in Physiologus 1: „This is set in the context of a descent, but in fact the words of the psalm would fit an ascension much better.“

179 Die Leerstelle wird ausgefüllt etwa von der Handschrift p (Ambrosianus graecus C 255 inf.; vgl. Sbordone 1936a z. St.). Sie tilgt

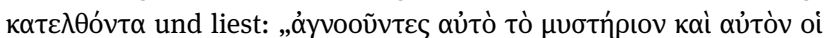

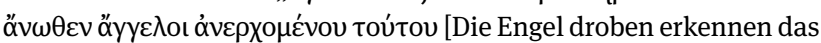
Geheimnis und ihn selber nicht, jetzt, wo dieser auffährt].“ Auch die lateinische Übersetzung des Typs y platziert den kleinen Dialog explizit beim Aufstieg (Hss. $\mathrm{Y}^{2}, \mathrm{Y}^{3}$ ): ,Et hoc, ignorantes eum descendentem atque ascendentem, hi qui sursum sunt“; vgl. Carmody $(1941,103)$. Sie macht auch detailliertere Angaben zu den Sprechenden (analog zu den oben Anm. 102 genannten Texten): „hi qui sursum sunt, dicunt: ,Quis est iste rex glorie?‘ et angeli deducentes eum responderunt ,Dominus [etc.]“. Ähnlich die lateinische Version b: „Et hoc ignorantes, eum ascendentem ad patrem, hi qui sursum erant angeli dicebant ad eos qui cum domino ascendebant: ,Quis est iste rex gloriae?' responderunt illi: ,Dominus [etc.]“; vgl. Carmody (1939, 11; in der Hs. Z entfallen die „mit dem Herrn Aufsteigenden“). 
der Gravitation der Wirkungsgeschichte von Ps 24,7-10 (dazu gleich unten).

Der Nachteil dieser Lesart liegt auf der Hand; sie trägt eine textexterne Information, die Himmelfahrt, ein - ein Vorgehen, worauf man im Auslegungsgeschäft nicht ohne Not zurückgreifen sollte. Im Gegenzug sprechen für diese Lektüre aber drei entscheidende Gründe:

Der erste Vorteil ist textinterner Natur. Wann macht die Wechselrede von Frage und Antwort Sinn? Beim Abstieg ist das nicht der Fall: Die Angleichung an die verschiedenen Engelwesen zielt ja gerade auf Tarnung, auf das Inkognito. Die Verhüllung muss sich dieser Logik zufolge auch noch auf die irdische Existenz erstrecken, die zur Kreuzigung und damit zur Heilswende führt. Erst dann wäre der Moment gekommen für die Proklamation des heiligen Geistes, die das wahre Wesen des Erlösers offenbart: Er ist der „Herr der Mächte“ und „König der Ehren“. So gesehen ist der Umschlag vom Verborgensein zum Offenbarwerden am besten nach der vollbrachten Menschwerdung (samt Tod und Auferstehung) zu situieren. Die Identifikation des Erlösers bereits bei seinem Abstieg, noch vor der Inkarnation, konterkariert demgegenüber die Tarnung. Diese Überlegung wird gestützt durch die Traditionsgeschichte: Gerade die gnosisnahen Texte, die wir oben durchmustert haben, verbinden das Erkennen des Gesandten erst mit dessen Wiederaufstieg. ${ }^{180}$

Exkurs: Wie notiert hat die Wechselrede im Löwengleichnis keine Entsprechung. Projiziert man Frage und Antwort versuchsweise in das Naturbild zurück, würde den Jägern die Spur zum Löwen gewiesen. Die Engelmächte könnten den Erlöser finden, etwa als Inkarnierten auf der Erde, und ihn überwältigen - $\mu$ 门̀ yévoıto! Wir folgen dem Gedankenexperiment aber nicht weiter, da die bewährten Regeln heutiger Gleichnistheorien den Rückimport von der Sachhälfte zur Bildhälfte verbieten. An dieses Regelwerk hält man sich mit Vorteil auch in der Interpretation von schulgerechten Allegorien.

Der zweite Vorteil legt sich im Blick auf die Wirkungsgeschichte von Ps 24 nahe: Die „Torliturgie“ haftet hauptsächlich an der Himmelfahrt Jesu. Man darf annehmen, dass auch unsere Physiologus-Passage der enormen Gravitationswirkung dieser überaus stabilen exegetischen und homiletischen Tradition gehorcht.

Exkurs: Die Formulierung, dass sie „ihn, der von oben herab kam, nicht erkannten“, ist auch unter dieser Voraussetzung verständlich: Er steigt ja auf, weil er dorthin zurückkehrt, von wo er herabgekom men ist. Ein Stück weit erinnert diese Figur an die Selbstpräsentation Jesu im Johannesevangelium $(3,31 ; 8,23)$ - „niemand ist in den

180 Vgl. oben zur Pistis Sophia (bei Anm. 41) und zur Ascensio Isaiae (bei Anm. 49).
Himmel hinaufgestiegen ausser dem, der aus dem Himmel herabgestiegen ist“ (3,13; vgl. Eph 4,10). Gerade im Blick auf die altkirchliche Rezeptionsgeschichte von Ps 24 lässt sich die vom Physiologus vorgenommene Herkunftsortung des wieder Aufsteigenden gut deuten: Die Engel sind verwirrt und erkennen den auffahrenden Jesus in seiner menschlichen Gestalt nicht - ihn, der doch von oben herabgekommen ist. Vor allem nimmt diese Lesart das begründende ćk

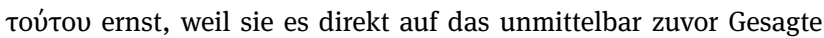
bezieht, auf die Inkarnationsaussage von Joh 1,14: Die Verhüllung seiner $\theta$ cótᄁৎ in fleischlicher Gestalt ist der Grund dafür, dass ihn die Engel jetzt beim Aufstieg nicht identifizieren können, so wie sie ihn damals beim Abstieg infolge seiner angelischen Form auch nicht erkannt hatten. ${ }^{181}$

Ein drittes Argument zugunsten der dritten Hypothese bietet der Physiologus selber, also der Makrokontext, in einer späteren Passage, nämlich im Gleichnis des Einhorns (22): ${ }^{182}$ Leserinnen und Leser erinnern sich sowohl beim Bild selber („,äger“ versuchen, das Tier zu fangen) als auch bei der Allegorese (,Engel und Mächte vermochten ihn nicht zu überwinden“) an das Gleichnis vom Löwen im programmatischen Eingangskapitel. Das erneute Zitat von Joh 1,14 verstärkt den Wiedererkennungseffekt. Lesen wir Physiologus 22 von 1 her, so ergibt sich der Schluss, dass die Mächte den Herabsteigenden deshalb nicht überwältigen konnten, weil sie ihn gar nicht erkannt haben. ${ }^{183}$ In die genau gleiche Richtung weist die Allegorese des Ichneumon (26): Weil Christus als Gott und Erlöser im Körper verborgen ist, überwindet er den Teufel.

Exkurs: Die handschriftliche Überlieferung verstärkt in 22 die kontex-

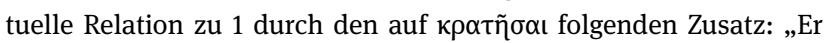
wurde allen alles, bis er in Mariens Schoss einging [ $\mu \varepsilon \tau \dot{\alpha} \pi \alpha \dot{\alpha} v \tau \omega \nu$

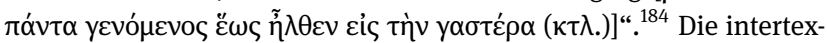
tuelle Beziehung zu 1 Kor 9,22, der wir auch bei Origenes begegnet sind, ist offensichtlich. ${ }^{185}$ Die genannte Version hat auch Eingang

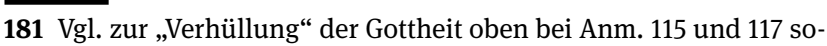
wie Abschnitt 7.

182 Vgl. oben bei Anm. 27.

183 Es erstaunt auch nicht, dass in einer Handschrift (I) explizit davon die Rede ist, dass „die angelischen Mächte sich der Gottheit nicht

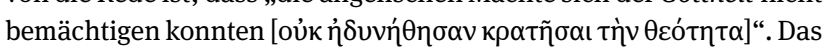
Nichterkennen wird explizit eingetragen in der lateinischen Version b (als „scharfsinnigstes“!), zusammen mit der Angleichung der Engelklassen an die Reihe von Physiologus 1 und samt der Höllenfahrt (!): ,acerrimum vero quod dicit eum, id est quod neque principatus, neque potestates, non throni neque dominationes intelligere potuerunt, nec infernus tenere valuit“. Ein Teil der Hss. fügt nach poterunt noch den betrogenen Teufel hinzu: ,nec ipse subtilissimo diabolus investigare potuit“; s. Carmody (1939, 31-32). Zu vergleichbaren Einträgen, die Querbezüge schaffen und die Textkohärenz steigern, vgl. oben Anm. 33 zu Löwe und Ichneumon.

184 So neben anderen, auch wieder leicht differierenden Varianten (vgl. Kaimakis 1974, 69a) die Hs. П: Karnejev $(1894,63)$.

185 Vgl. oben bei Anm. 67; auch Anm. 52 zur Epistula Apostolorum. 
in die armenische Überlieferung gefunden. ${ }^{186}$ Die syrische Version des Physiologus Leidensis liest 1 Kor 9,22 sogar in die erste Löwenallegorie ein, als Auftakt zur Engelgleichwerdung Christi (also wie bei Origenes!). ${ }^{187}$

Wir halten an dieser Stelle fest, dass Physiologus 43, worin Christus als der „geistliche Elefant“ porträtiert wird, ebenfalls auf 1 Kor 9,22 zurückgreift, hier in Verbindung mit Phil 2,7 und Mk 10,44: ${ }^{188}$ „Er, der grösser als alle war, wurde der Sklave aller (Mk 10,44). Er erniedrigte sich nämlich und nahm Knechtsgestalt an (Phil 2,7) [und wurde allen gleich], ${ }^{189}$ um alle zu erlösen.“ Für den Finalsatz „iv $v \alpha$

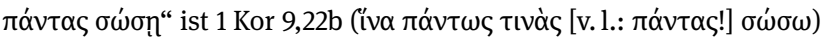
der wichtigste Prätext; die christologische Pointierung (vgl. oben bei Anm. 67) wird befördert durch 1 Tim 2,4 (von Gott als Retter: „ôs

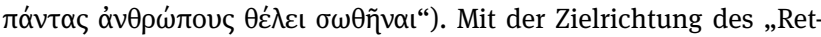

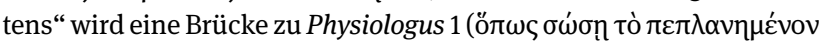

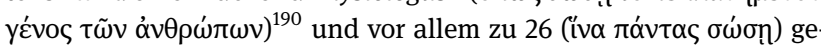
schlagen: Die Deutung von Ichneumon (26) und Käuzchen (5) arbeitet mit den Prätexten Phil 2,7-8 und 1 Kor 9,22. ${ }^{191}$

Wir kehren zurück zur Interpretation der Wechselrede in Physiologus 1. Die Wahl zwischen der oben genannten ersten und der dritten Option fällt nicht leicht. Ich entscheide mich für die letztere, da ich die fehlende Situierung von Frage und Antwort bei Christi Himmelfahrt nicht stark gewichte und hier mit Breviloquenz rechne. Einlesen darf man auch den Ruf zur Öffnung der Himmelstore, auch wenn er nicht eigens genannt wird: Er ist intertextuell mit der Wechselrede von Ps 24,7-10 gegeben und begleitet konstant deren gesamte Rezeptionsgeschichte, zumal in der exegetischen und homiletischen Überlieferung. Natürlich spielen bei der exegetischen Entscheidung auch Annahmen über die erste Version des Physiologus eine Rolle. Je mehr man einer Spätdatierung zuneigt und mit einer stabilen Auslegungstradition von Ps 24 rechnet, desto mehr schlagen die Argumente für die dritte Deutung zu Buch.

Exkurs: Auch der Kontext, die Sequenz der drei Löwengleichnisse mit ihrer Abfolge von Inkarnation, Tod und Auferweckung, legt der Wahl der dritten Option kein ernsthaftes Hindernis in den Weg: Der Physiologus hält sich nicht an eine Abfolge der Heilereignisse; einzelne Aussagen können also gut auf etwas vorausblicken, was wenig später zum Hauptthema wird. So orientiert sich der Finalsatz in der ersten Allegorie („um das verirrte Menschengeschlecht zu retten“) am Erlösungsziel. Die sessio ad dexteram in der zweiten Allegorie antizipiert ihrerseits die Himmelfahrt. Überdies hält sich die Kompositionstech-

186 Vgl. Muradyan $(2005,56,157-158)$.

187 Vgl. Land (1875, 32 [lat.]; 33* [syr.]).

188 Die Hs. s fügt nach „grösser als alle“ hinzu: „wahrer Christus nämlich und neuer Adam“ (vgl. 1 Kor 15,45).

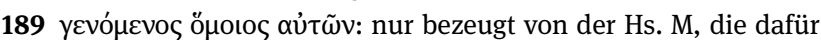
auf den schliessenden Finalsatz verzichtet. Das „Gleichwerden“ stellt eine Beziehung her zur Angleichung des Erlösers an Engel und Menschen.

190 Dazu vgl. oben bei Anm. 26.

191 Dazu vgl. oben S. 98. nik unserer ganzen Schrift bekanntlich an fast gar keine erkennbaren Regeln.

Wie auch immer: Der Verfasser des Physiologus setzt bei seiner Leserschaft erhebliche Schriftkompetenz und Vertrautsein mit theologischen Standardtraditionen voraus zumal homiletischen und exegetischen -, die er deshalb nicht bis in die Details zu entfalten braucht. Die brevitas gilt auch hinsichtlich vieler anderer theologischer Figuren, mit Hilfe derer die Tierbilder dechiffriert werden: Der „Naturforscher“ entwirft meist nur Skizzen der von den Tieren symbolisierten geistigen Wirklichkeit. ${ }^{192}$ Er rechnet mit der Fähigkeit seiner Adressaten, die lediglich umrissenen biblischen und theologischen Zusammenhänge vervollständigen und Beziehungen zwischen den Tiersymbolen samt ihren Deutungen herstellen zu können. ${ }^{193}$ Dies ist ein Zeichen dafür, dass sich unsere Schrift an Bildungsträger richtet. ${ }^{194}$

\section{Vom triduum mortis - die zweite Löwenallegorie}

Wir kommen zurück zum zweiten Löwengleichnis. Der Löwe, der mit offenen Augen schläft, wird gedeutet auf Christus unmittelbar nach seinem Sterben. Es liegt eine räumliche Unterscheidung vor: Der Leichnam „schläft“ am Kreuz, die Gottheit „wacht“ zur Rechten Gottvaters, also im Himmel.

Im Folgenden wird die These vertreten, dass die Allegorese im Kontext eines christologischen Diskurses des vierten Jahrhunderts zu situieren ist, der sich um den Status des Gottmenschen zwischen Tod und Auferstehung, nämlich im triduum mortis, dreht. Zum christologischen Prüfstein wird das Sterben Jesu in diesem Diskurs aus drei Gründen: Erstens intensiviert sich in ihm die Polarität von Christi göttlicher und menschlicher Natur, zweitens provoziert es die Frage nach dem zugrunde liegenden anthropologischen Modell, und drittens ruft das spannungsvolle Nebeneinander der letzten Worte Jesu hinsichtlich seines nachtodlichen Geschicks nach Auslegung: Gottes-

192 Vgl. ähnlich Brinkmann (1980, 112): die „Zeichen für religiöse Sachverhalte [...] fassen in Chiffern zusammen, was sonst oft umfänglicher dogmatischer Aussage bedürfte“; (422): „Physiologus, der Verhaltensweisen von Tieren in einem Zeichen vereint, um so eine geraffte Aussage über religiöse Sachverhalte der menschlichen Existenz zu schaffen“.

193 Vgl. Nicklas (2013).

194 Vgl. dazu unten bei Anm. 231. 
verlassenheit (Mk 15,34 par. Mt 27,46), Paradies (Lk 23,43), Übereignung in Gottes Hände (Lk 23,46; vgl. Joh 10,17-18: Hingabe der Seele), ferner der Willenskonflikt in Gethsemane (Mk 14,36 parr.) und schliesslich die Grablegung. Der christologische Diskurs verbindet sich meist mit der Figur der Höllenfahrt Christi, wofür auch wieder ein Herrenwort den Beleg liefert (Mt 12,40).

Unsere Schrift kommt im Blick auf das Sterben Jesu mit einer einfachen Lösung aus: Sein Leib hängt am Kreuz, seine Gottheit ist beim Vater im Himmel. Der Physiologus kennt zwar die Höllenfahrt: So wie der Fischotter dem Krokodil in den Rachen springt, stieg Christus in die Hölle hinab (25). Ein Bezug zur zweiten Löwenallegorie wird indes nicht eigens hergestellt. Vielleicht bietet der biblische Prätext dafür doch eine Assoziationsbrücke, denn das „Sitzen zur Rechten“ geht in Ps 110,1 einher mit der Unterwerfung der Feinde, die in der christlichen Rezeption meist auf die widergöttlichen Mächte gedeutet werden.

Exkurs: Zunächst stellt sich die Frage, ob in der zweiten Löwenallegorese des Physiologus eine eigentümliche sehr frühe Trennungschristologie vorliegt. Eine solche wird in der altkirchlichen Überlieferung Kerinth zugeschrieben. ${ }^{195}$ Es empfiehlt sich aber nicht, auf „gnostische Vorstellungen“ zu rekurrieren, die im Physiologus auch in der Engelgleichwerdung Christi greifbar wären. ${ }^{196}$ Unsere Schrift teilt durchwegs die überkommene mehrheitskirchliche Überzeugung von der Inkarnation des Gottessohns; die „Einwohnung“ des Logos hebt mit Zeugung und Jungfrauengeburt an (Joh 1,14).

Wieder gibt die Terminologie des Physiologus einen besseren Fingerzeig: Die explizite Unterscheidung zwischen der Gottheit

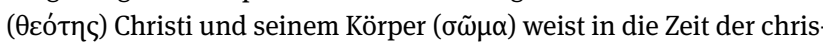
tologischen Debatten des vierten und fünften Jahrhunderts. Das Schema von Gott/Logos-Sarx/Körper ist nicht nur für die „monophysitische“ Christologie der Anhänger des Apollinaris charakteristisch, sondern begegnet, allenfalls mit präzisierender Reformulierung, vielfach bei „diphysitischen“ Theologen, die mit der unvermischten Einheit von göttlicher und menschlicher Natur rechnen. ${ }^{197}$

195 So nach Irenäus, Adversus haereses 1.26.1: der obere Christus sei erst „nach der Taufe auf ihn [sc. Jesus] herabgestiegen“, um sich am Ende wieder von ihm zu trennen; ,Jesus sei gekreuzigt worden und auferstanden, Christus aber sei leidensunfähig geblieben, da er pneumatisch gewesen sei“. Gar nicht in Frage kommen prägnantere doketistische Konzeptionen, die im Ansatz nur von einer einzigen Natur Christi, eben der göttlichen, ausgehen.

196 So Stommel $(1958,128)$ : „Die Himmelfahrt des Logos unmittelbar vom Kreuze aus entspricht gnostischen Vorstellungen [...]; die gleiche gnostische Herkunft verraten die unmittelbar vorhergehenden Ausführungen des Physiologus über den verborgenen Abstieg Christi in der Menschwerdung“.

197 Zur Logos-Sarx-Christologie in Arianismus und Apollinarismus vgl. Grillmeier (1990, 374-382, 494-497). Zur Abwehr der apollinaristischen Konzeption durch Didymos ausgerechnet in der Exegese von Ps 24,7-10, mit dem wir uns oben ausgiebig beschäftigt haben, vgl. Geljon (2011, 70-72). Die Frage, ob die arianische Logos-Sarx-
Einschlägig für unsere Passage im Physiologus ist namentlich der Diskurs über das triduum mortis, der sich im dritten Jahrhundert, zumal bei Origenes, ${ }^{198}$ ankündigt und sich im vierten wie fünften Jahrhundert ausdifferenziert: Was geschieht mit den „Komponenten“ des göttlich-menschlichen Christus zwischen Tod und Auferstehung? ${ }^{199}$ Aus dem dritten Jahrhundert gibt es einige tastende Antworten, die mit einer Trennung des göttlichen vom menschlichen Teil Christi rechnen (Tertullian, Novatian, Hippolyt [?]). Sie kommen als Hintergrund für unseren Physiologus-Text kaum in Frage. Im vierten Jahrhundert dominiert zunächst das am Modell Logos-Sarx orientierte Theorem des Logosabstiegs in die Unterwelt, das mit der Trennung von Christi Gottheit und Leib rechnet (wofür die Gottverlassenheit von Mt 27,46 par. den Schriftbeweis liefert); vertreten wird es nicht nur von Arianern und Apollinaristen, sondern weithin auch von anderen Theologen, darunter den Alexandrinern Alexander und Athanasios. ${ }^{200}$ Selbstverständlich hält man trotz der Höllenfahrt des Logos zugleich fest an dessen simultaner Präsenz sowohl in der ganzen Schöpfung wie besonders im Himmel bei Gott (Joh 1,1). ${ }^{201}$ Ab der Mitte des vierten Jahrhunderts, im Gefolge der apollinaristischen Debatten, setzt sich

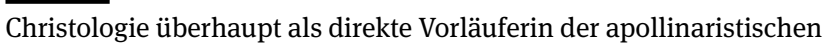
zu erachten ist (so u. a. Grillmeier), braucht uns hier nicht zu beschäftigen; vgl. dazu Brennecke (2015).

198 Das Problem wird diskutiert im Blick auf ein trichotomisches anthropologisches Modell (1 Thess 5,23) von Origenes, Dialogus cum Heraclide 6-8 (SC 67, 68-72; deutsche Übersetzung BGrL 5, 31-32): Nach Christi Tod ist sein Körper im Grab, seine Seele im Hades, sein Geist in Gottvaters Händen, d. h. im Himmel. Erst mit der Himmelfahrt sind die drei wieder vereint $(7,14-8,17)$. Abseits von diesem speziellen Diskussionsgang arbeitet Origenes in derselben Schrift mit

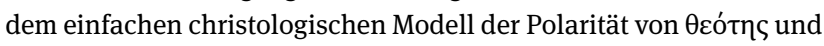
$\sigma \tilde{\omega} \mu \alpha(5,8-6,6)$.

199 Vgl. dazu die kundige - aber leider sehr normativ orientierte und wertende - Darstellung von Grillmeier (1975); ferner Aubineau (1972, 152-154 Anm. 36); Drobner (1982, 114-124). Grillmeier hält „die Vorstellung der Trennung von Logos und Leib“ für eine sehr frühe „populäre Idee“ und weist neben Evangelium Petri 19 auch auf den Physiologus hin (1975, 107 Anm. 19; 172). Die beiden Aussagen sind aber sehr verschieden: Nur der Physiologus handelt von zwei „Akteuren“, die den schon gestorbenen Christus ausmachen. Genau dies weist in eine deutlich spätere Zeit.

200 Vgl. z. B. Athanasios, De incarnatione 21.3-22.5 (SC 199, 342348). Zur Gesamtentwicklung vgl. Grillmeier (1975, 122-126): „Ein zwischen Arianern und ihren Gegnern gemeinsames Theologumenon“ und (127-132): Häresie des Apollinarismus; Grillmeier (1990, 455456): Euseb von Emesa; 469-471: Athanasios: „Der Tod Christi als Logostrennung“. Allerdings dürften die Anschauungen im Einzelnen wesentlich vielfältiger gewesen sein. So deutet etwa ein Katenenfragment (zu Joh 19,33-34: Nr. 146 [Reuss 1966, 59]) darauf hin, dass für Apollinaris Gott mit seinem „Fleisch“ bzw. „Leib“ verbunden bleibt, so dass dieser nicht verwest; vgl. Mühlenberg (2015, 137). Zweifel an der Konstruktion von Grillmeier auch bei Uthemann (2005, 366 Anm. 111).

201 Es ist sogar möglich, die Höllenfahrt als vom Himmel her gewirkte Gotteskraft zu pointieren, Ambrosius, De incarnatione 40 (CSEL 79, 243 [vgl. Grillmeier 1975, 126 Anm. 80]: „Erat ergo caro eius in monumento, sed virtus eius operabatur e caelo“). Vom „Sitzen zur Rechten“, das mit der Unterwerfung der Feinde einhergeht (Ps 110,1), sind wir damit gar nicht weit entfernt! 
auf orthodoxer Seite zunehmend die Überzeugung durch, dass der Gott-Logos mit dem Menschen auch im triduum verbunden bleibt. ${ }^{202}$ Das Schema „Logos-Mensch“ (mit der Wiederentdeckung der Seele Christi) überflügelt das überkommene - und zumal in Alexandria beliebte - Schema „Logos-Sarx“. Die permanente Einheit von Christi Gottheit und Menschheit, auch während der temporären Separation von Körper und Seele in seinem Tod, zählt fortan zu den christologischen Basisüberzeugungen. Eine besonders differenzierte christologische Reflexion über das triduum sacrum findet sich bei Gregor von Nyssa: ${ }^{203}$ Beim Tod Jesu kommt es zur Trennung von Körper und Seele. Diese gelangt in das Paradies (Lk 23,43), identifiziert mit Vaters Händen (Lk 23,46, jener gelangt über das Grab in das „Herz der Erde“ (Mt 12,40), wo er den Tod besiegt. Christi Gottheit ( $\theta \varepsilon$ ćtnৎ) bleibt mit beiden unzertrennlich verbunden.

Unserer Hypothese zufolge ist die Aussage des Physiologus in den umrissenen Diskurskontext einzubetten. Seine schlichte Formulierung kommt mit einem doppelten Ort des gestorbenen Christus aus, mit Erde und Himmel. Dies führt uns eher in die ersten beiden Drittel des vierten Jahrhunderts, wo die Trennung von Gott/Logos und Leib/Fleisch im Tod Jesu zu den gängigen Überzeugungen zählt. ${ }^{204}$ Von einer „häretischen“ Anschauung kann, zumal in dieser Zeit, keine Rede sein. ${ }^{205}$ Überdies ist grösste

202 So etwa Ps.-Athanasios, De incarnatione contra Apollinarium 1.18 (PG 26, 1125B): Christi Sterben war nicht ein Weggang der Gottheit ( Diese bleibt verbunden mit der Gottheit, denn ,in unverhüllter Gott-

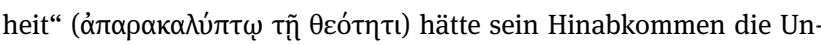

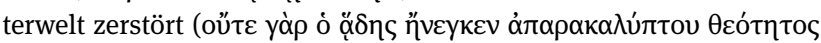

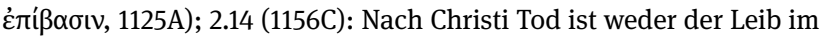
Grab noch die Seele im Hades von der Gottheit getrennt ( $\mu \eta \dot{\tau} \tau \tau \tilde{\eta} \varsigma$

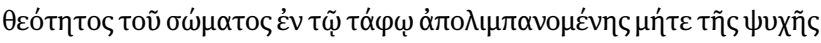

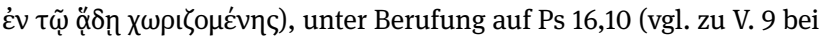
Origenes oben Anm. 100). Zur Gefährdung des Hades durch die „nackte Gottheit" vgl. auch oben bei Anm. 159 und unten bei Anm. 208.

203 Gregor von Nyssa, Epistula 3.22 (GNO 8,2, 25 = SC 363, 140;

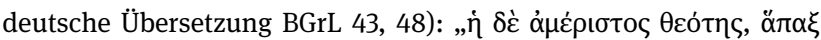

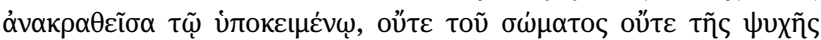

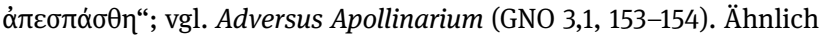
arbeitet es Gregors Osterpredigt heraus (In Christi resurrectionem 1 [GNO 9, 291:12-294:13; vgl. 305:10-12]; vgl. oben Anm. 150 und 166): Christus ist bei seinem Tod zugleich an zwei Orten, somatisch auf der Erde und psychisch im Paradies, in Gottvaters Händen; seine Gottheit bleibt mit seinem ganzen Menschen, mit Körper und Seele, verbunden. Vgl. Drobner (1982, 121-124); Wickham (1981).

204 Anderen zeitgenössischen Formen einer Trennungschristologie wie derjenigen antiochenischer Theologen oder der älteren des Paulus von Samosata steht die Aussage des Physiologus ohnehin recht fern. Ähnliches gilt für die von Grillmeier (1990, 548-553) beschriebene origenistische Trennungschristologie des frühen fünften Jahrhunderts.

205 Anders Stommel (1958, 128): die „zugrundeliegende Vorstellung von menschlichem Leib und göttlichem Logos als den konstitutiven Elementen der Person Jesu Christi ist häretisch“. In diesem Punkt richtig Alpers (1984, 54-55): Die Zweinaturenlehre ist „mehr andeu-
Zurückhaltung davor angebracht, die nur gerade skizzierende Aussage des Physiologus dogmengeschichtlich zu belasten. Sie ist so offen gehalten, dass sie nicht einmal notwendig eine prinzipielle Trennung der Gottnatur Christi vom am Kreuz verstorbenen Leib voraussetzt, sondern auch mit dem Grundsatz der Einheit beider Naturen im triduum vermittelbar ist. ${ }^{206}$

Exkurs: Exemplarisch weise ich auf zwei entlegene, aber aufschlussreiche Texte hin, die die Lokalisierung von Christi Gottheit beim Vater unter festgehaltener Einheit des Gottmenschen dokumentieren.

a. Ein eigenartiges anonymes Katenenfragment bringt Gottheit, Fleisch, Kreuz, Hades und Paradies in ein Verhältnis: ${ }^{207}$ „Indem er alles mit seiner Gottheit erfüllt, war er am Kreuz wegen seinem Fleisch, und im Himmel wegen seiner Gottheit, und herabsteigend vom Kreuz war er im Hades, und den Räuber brachte er ins Paradies [Lk 23,43] kraft der (dortigen) Ankunft seiner Gottheit." Die Aussage ist deshalb interessant, weil sie einerseits der Gottheit Christi Omnipräsenz zuschreibt und sie doch speziell im Himmel und im Paradies lokalisiert, i. U. zum Fleisch, das wie im Physiologus am Kreuz hängt.

b. Ein Hippolyt zugeschriebenes Katenenfragment versucht auf ähnliche Weise, unter Voraussetzung der ununterbrochenen Verbindung mit der Gottheit die Multilokalität der Komponenten des gestorbenen Christus aufzufächern: ${ }^{208}$ „Der Körper lag im Grab, nicht entleert von der Gottheit. Sondern wie er im Hades weilend der Wesenheit nach beim Vater war, so war er sowohl im Körper wie im Hades. Denn wie der Vater ist auch der Sohn unfassbar (d. h. raumtranszendent), und er umfasst alles. Aber willentlich liess er sich in einen beseelten Körper fassen, damit er mit der eigenen Seele in die Unterwelt ginge

tungsweise und natürlich noch nicht in der Art der späteren dogmatischen Verfeinerung vorgetragen“; der Verweis auf Meliton (Anm. 437) ist aber irreführend (vgl. oben bei Anm. 122).

206 In der handschriftlichen Rezeptionsgeschichte wird wieder vereindeutigt, vgl. die lateinische Version b (vgl. Stommel 1958, 128; Alpers 1984, 86 Anm. 439), die die Grablegung nachträgt und v.a. die sessio ad dexteram tilgt: „etenim corporaliter dominus meus obdormiens in cruce et sepultus, deitas eius vigilabat“. Die Version y verstetigt das Sitzen zur Rechten und eliminiert damit den Eindruck eines Trennungsakts im Sterben: ,deitas vero eius semper in dextera patris vigilat“.

207 Catena in Evangelium S. Lucae 23.43 П (Cramer 1844a, 168):

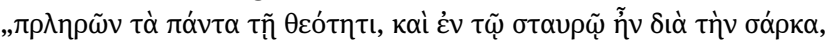

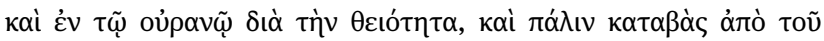

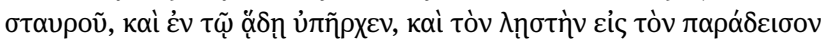

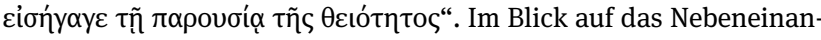
der von $\theta \varepsilon$ cónฺ und $\theta \varepsilon$ เóтnৎ ist daran zu erinnern, dass die Katenenausgabe mangelhaft gefertigt ist.

208 Ps.-Hippolyt, De pascha frag. 3 (GCS 1,2, 268-269); syrisch und

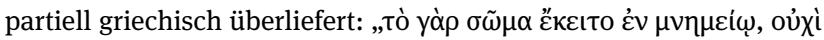

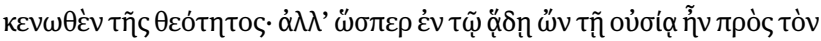

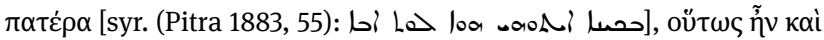

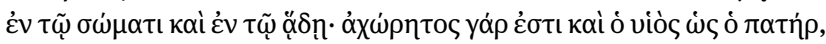

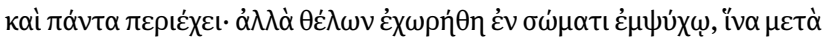

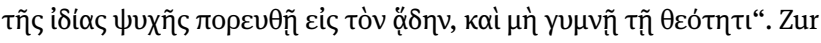
Analyse vgl. Grillmeier (1975, 158-169). 
und nicht mit der nackten Gottheit. “209 Die kleine Passage ist deshalb interessant, weil sie mit der Gottespräsenz in Leichnam und Seele die

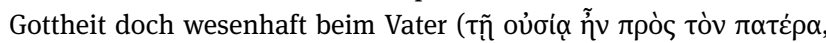
nach Joh 1,1) im Himmel ortet.

Entscheidend ist vor allem, dass der Physiologus durch seine „Bildarbeit“ Christi Einheit zum Zug bringt, nämlich mittels der Relation zwischen „Sachhälfte“ und Gleichnis: Christus wird repräsentiert durch den einen Löwen, der zugleich schläft und wacht. Nämliches gilt für den Schriftbeweis (Hld 5,2): Salomons Ich wacht, und zugleich schläft sein Herz. Die Allegorese schliesslich arbeitet mit sprachlichen Signalen, die das räumlich Getrennte wieder verbinden; sie spricht vom „Leib meines Herrn“, von „seiner Gottheit““. ${ }^{210}$ Wie auch sonst im Physiologus rufen Leerstellen nach der Mitarbeit kompetenter Leser. Ähnlich verhält es sich mit anderen „problematischen“ Formulierungen. Die aus dem Gebärstein des Geiers (19) entwickelte Aussage vom „Leib des Herrn“, der „in seinem Inneren den Klang der Gottheit trug“ (19), braucht man nicht eigens im Licht der - in der Folge häretisierten apollinaristischen Logos-Sarx-Christologie zu lesen. Die Sprachregelung in den einzelnen Texten der Literatur des vierten und auch fünften Jahrhunderts gehorcht weithin nicht der sich anbahnenden dogmatischen Normierung, zumal dann, wenn die Aussagen nicht direkt in den christologischen Auseinandersetzungen Stellung beziehen. ${ }^{211}$ Das Schema „Gott/Logos-Sarx“ basiert auf zentralen biblischen Prätexten (Joh 1,14; 1 Tim 3,16 u. a.). Mit der knappen Aussage des Physiologus ist vor allem der scharfe Kontrast von „Totem“ und „Gott“ zu vergleichen, der die Rhetorik von Osterpredigten mit ihrer Konzentration auf die drei Tage zwischen Kreuz und Auferstehung kennzeichnet. ${ }^{212}$

209 Der Syrer fährt fort (wie oben Ps.-Athanasios, Anm. 202): „damit nicht die untersten Gründe der Erde vor Entsetzen aus den Fugen gerieten“.

210 Wenn unsere oben vorgeschlagene Deutung der Wechselrede von Ps 24,10 richtig ist, wäre sie ein zusätzliches Argument für die bleibende Einheit von Gottheit und Leib Jesu: Eben die Verborgenheit der ersteren in letzterem bei Jesu Auffahrt ist in der christlichen Rezeptionsgeschichte von Ps 24 ja der Grund für die Irritation der Engelmächte.

211 Selbst für die arianischen Auseinandersetzungen gilt: „Bei allen Beteiligten bis in die zweite Hälfte des vierten Jahrhunderts werden Anthropos, Soma und Sarx noch nicht differenziert und völlig selbstverständlich commun benutzt. Von daher erscheint für diese Phase der theologischen Diskussion die Differenzierung in ein LogosSarx- und ein Logos-Anthropos-Schema, das für die späteren Debatten durchaus hilfreich sein mag, wenig geeignet“ (Brennecke 2015, 92).

212 Vgl. z. B. Hesychios, In pascha homilia 2.2, 2.3 (SC 187, 122/124):

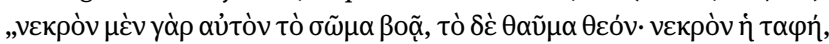

Im Diskurshorizont des triduum mortis artikuliert der Physiologus zwei auffällige Anschauungen: Er konzentriert sich auf den noch am Kreuz hängenden Toten und er lokalisiert die Gottheit Christi in dessen sessio ad dexteram. Das Kreuz bietet sich als Moment des Sterbens Jesu an, zusammen mit dessen beiden einschlägigen letzten Worten (Lk 23,43.46). ${ }^{213}$ Das „Sitzen zur Rechten Gottes" begegnet $\mathrm{m}$. W. nicht eigens im besagten Diskurskontext; üblicherweise bildet es sonst das Finale der Auffahrt. Hier im Physiologus handelt sich bei der sessio um eine Chiffre für das Sein bei Gottvater (vgl. Joh 1,1), die sich im Blick auf das Sterbewort im Lukasevangelium nahelegt - die Übereignung in „Vaters Hände“ (Lk 23,46), die sich leicht verbindet mit der Voraussage des Sitzens zur Rechten (Mt 26,64 parr.). Wieder sollte man die schlichte Aussage des Physiologus nicht mit christologischer Präzision überfordern, etwa mit der Frage, ob Christus erst jetzt, unmittelbar nach dem Sterben, (wieder) seinen Thron einnimmt. Das Zeugnis unserer Schrift steht durchaus im Einklang mit der weithin geteilten altkirchlichen Überzeugung, dass die sessio ad dexteram eine räumlichkörperliche Metapher für den göttlichen Status Christi darstellt. ${ }^{214}$ Der Physiologus hat mit dem Gegenüber des

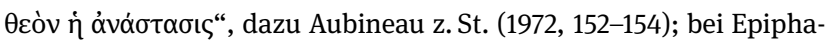

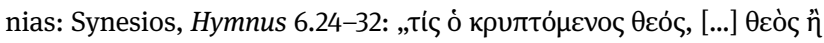
vع́кuৎ;“" von den Magiergeschenken gilt Weihrauch dem Gott, Myrrhe dem Grab.

213 Als Ort sind wir dem Kreuz im Katenenfragment oben bei Anm. 207 begegnet. Vgl. etwa auch das koptische Hippolyt-Fragment bei Grillmeier $(1975,119)$.

214 Auch an diesem Punkt kommt es zu theologischer Differenzierung: Auf der einen Seite ist das Sitzen zur Rechten Gottes als Hoheitsposition Erweis der Gottheit Christi und wird etwa korreliert mit dem „ewigen Thron“ und „ewigen Reich“ (Ps 45,7; 145,13 - so etwa Athanasios, Oratio adversus Arianos 2.13.1 [Metzler und Savvidis 1998, 189-190 = PG 26, 173A/B]; vgl. 1.61.1-62.1 [Metzler und Savvidis 1998, 171-172 = 140A-141A]). Es bezeichnet ein „Verhältnis der Gleichheit“ und das „Erhabene der Würde des Sohns“, Basileios, De Spi-

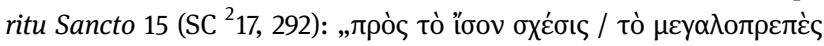

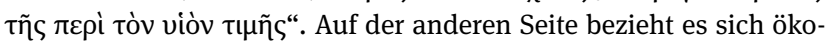
nomisch auf die menschliche Natur Christi, die im Gefolge der Himmelfahrt diese Position erreicht: Die Aufforderung „setze dich zu meiner Rechten“ gilt dem Herrenleib, nicht Gott, denn dieser erfüllt ja alles (Jer 23,24): Athanasios, frag. bei Theodoret, Eranistes Florilegi-

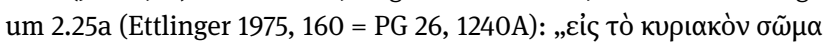

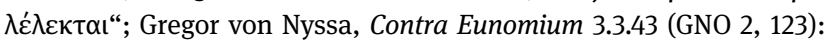
Die Aussage „zur Rechten Gottes erhöht“ von Apg 2,33 bezieht sich

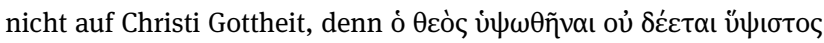

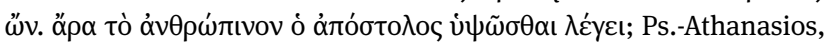
De incarnatione contra Apollinarium 2.15 (PG 26, 1157B), auch in Bezug auf die Verherrlichung, Joh 17,5. Es kann dementsprechend exegetisch differenziert werden (Ps.-Athanasios, In occursum Domini 4 [PG 28, 977C/D]): Der Thron zur Rechten eignet der Gottheit ( $\mu$ oví $\mu$ v 
Schlafenden am Kreuz und des Wachenden ${ }^{215}$ zur Rechten Gottes ein überaus impressives Diptychon erschaffen, das Tiefpunkt und Höhepunkt des Christuswegs im Moment seines Todes simultan zur Darstellung bringt. Die Miniatur hat sowohl in der Literatur ${ }^{216}$ wie vielleicht auch in der bildenden Kunst eine eigene Rezeptionsgeschichte erzeugt. ${ }^{217}$ Jesu Auferweckung selber spart sich unsere Schrift für ihr drittes Löwengleichnis auf.

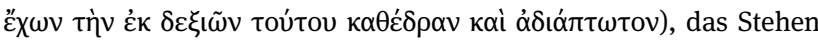
(Apg 7,55-56) und das Sich-setzen eignet der Menschheit Christi. So ergibt sich eine orthodox gewordene Version, die die sessio auf beide Naturen Christi bezieht (Johannes von Damaskus, De fide orthodoxa 75 [PTS 12, 173]): „Mit der Rechten des Vaters bezeichnen wir die

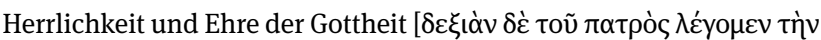

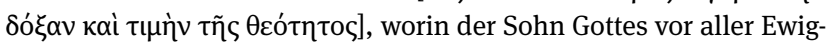
keit als Gott und als gleichwesentlich dem Vater und am Ende fleischgeworden und körperlich sitzt, weil sein Fleisch mit ihm verherrlicht worden ist.“ Zum ganzen Komplex vgl. Markschies (2000).

215 Zum wachenden göttlichen Auge ist neben Ps 121,4 zu beachten ein Aphorismus aus der tragischen Überlieferung: „Nicht schläft das

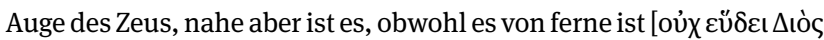

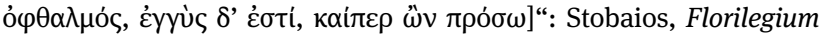
1.3.9 ( $\operatorname{Tr} G F 2,485)$. „Die Vorstellung hat eine schöne Nachgeschichte im Physiologus“, Markschies (2016, 741 Anm. 92; vgl. 393 [hiernach übersetzt]).

216 Das Löwengleichnis scheint eingewirkt zu haben auf die Osterpredigt von Leontios von Konstantinopel (Homilia in sanctum pascha 1.6 [SC 187, 440 = CCSG 17, 267]) mit Verweis auf Gen 49,9 (wie Physiologus 1; vgl. oben Abschnitt 2): „So wie der Löwe in seiner Höhle mit offenen Augen schläft, so schläft der Herr Christus im Tod drei Tage

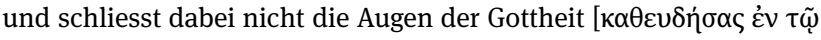

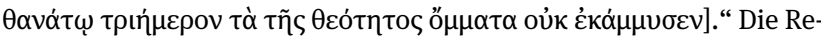
zeptionsspur bestätigt auch unsere Situierung der Löwenallegorie im Diskurs des christologischen triduum. Weitere Texte nennt Aubineau (1972, 467-468 Anm. 62); vgl. auch Uthemann (2005, 333-366: „Christusbild versus Christologie“, 360-361).

217 Am Rand notiere ich die interessante Debatte darüber, ob das Kreuzigungsbild vom Typ des Rabbula-Codex, das den schon toten Jesus (Seitenwunde, Joh 19,34) mit offenen Augen darstellt (vgl. LCI 2, 609-610), vom Physiologus angeregt worden sei. Die These von Grillmeier (1956, 81-94) ist von Stommel (1958) und anderen abgelehnt, von Alpers (1984, 55-56) wieder bekräftigt worden. - Zur Darstellung des Gekreuzigten als „Herr der Herrlichkeit“ vgl. Uthemann (2005, 358-362: „Der Logos am Kreuz: Die offenen Augen eines Toten“): Es geht ,letztlich um eine Darstellung der steten Wachsamkeit [...] Gottesmittels des Symbols der ewig wachen, offenen Augen Gottes“ (361). Uthemann trifft eine Feststellung, die auch für unsere PhysiologusMiniatur richtig ist: Das Bild des Logos am Kreuz „lässt sich nicht als eindeutiger Ausdruck einer bestimmten Christologie interpretieren“ (365).

\section{0 Überlegungen zur Datierung des Physiologus}

Unsere Beschäftigung mit dem Löwenkapitel erlaubt einige Überlegungen zur Datierung der Erstversion(en) des Physiologus. Im vorliegenden Beitrag werden sie nicht eigens abgeglichen mit anderen entgegenstehenden Beobachtungen, die etwa für eine Frühdatierung geltend gemacht werden. Bei allen im Folgenden aufgelisteten Punkten bestätigt und bewährt sich die in der Forschung seit langem vertretene Lokalisierung unserer Schrift in Ägypten, etwa in Alexandria.

1. Mit dem Theologumenon der im Fleisch (bzw. Körper) verborgenen Gottheit Christi befinden wir uns im vierten Jahrhundert, und zwar nach Ausweis der von uns durchmusterten Texte eher in seiner Mitte als an seinem Anfang. In denselben Zeitraum führt uns die Aussage vom doppelten Status des gestorbenen Christus, die wir im damaligen Diskurs über das triduum mortis situiert haben. Für die Datierung des Physiologus, und zwar schon in seiner frühsten noch erkennbaren Textform, liefert der Befund eine feste Grundlage. Dies steht auch im Einklang mit der Fixierung des terminus ante quem im letzten Viertel des vierten Jahrhunderts, wo sich die ersten wirklich sicheren Rezeptionsspuren des Physiologus nachweisen lassen. $^{218}$

2. Demgegenüber scheint die Figur des sich vor den Engeln verbergenden Erlösers auf seinem Abstieg durch die Himmelssphären, die sich am Anfang des Physiologus findet, in eine frühere Zeit zu weisen. Die „gnostische“ Spur ist ja der Hauptgrund für die v. a. mit Friedrich Lauchert

218 Vgl. Perry (1941, 1100-1101): „terminus ante quem für die Entstehung des P. ungefähr das letzte Viertel des 4. Jhdts.“; Scott (1998, 433): „The first hard evidence of the Physiologus' use is in the second half of the fourth century, and here there is a solid phalanx of witnesses“; Greschat (2006, 384): „lässt sich doch mit einiger Sicherheit sagen, dass ein solches Werk seit dem Ende des vierten und zu Beginn des fünften Jahrhunderts sowohl im griechischen als auch im lateinischen Sprachgebiet rezipiert wurde“; Curley (1979, xix-xx): „We can conclude, therefore, that the Greek text was in circulation by the last quarter of the fourth century; it may have been composed as many as two hundred years earlier, although evidence for this opinion is by no means conclusive”; Lazaris (2016, 18-21). Mit der Spätdatierung entfällt die Schwierigkeit, die ,dunklen' Jahrhunderte zwischen dem frühdatierten Physiologus und der sicher nachweisbaren Rezeption zu überbrücken; vgl. etwa die Verrenkungen bei Perry (1941, 11031104); Lazaris (2016, 23-24). - Die lateinischen Übersetzungen führen nicht mit Sicherheit in das vierte Jahrhundert zurück; vgl. gegenüber Carmody (1939, 7-8; sowie 1941, 98) die Bedenken von Henkel (1976, 22-23); vgl. Scott (1998, 434-435); Greschat (2006, 384). Für Mitte oder sogar frühes viertes Jahrhundert plädiert Scully (2018, 435-445). 
einsetzende Frühdatierung unserer Schrift. ${ }^{219}$ Dieser Typ des descensus absconditus begegnet hauptsächlich in ,dissidenten' Schriften. Der Aussage im Physiologus kommen dabei Texte besonders nahe, die sich zwar unterscheiden vom Mainstream kirchlicher Theologie, aber selber nicht als „gnostisch“ zu taxieren sind - Himmelfahrt Jesaias und Epistula apostolorum. Für sich genommen ist die Rezeption dieses Traditionsstücks, über welche Kanäle auch immer, gut im späten zweiten oder im dritten Jahrhundert vorstellbar. ${ }^{220}$ Ebenso möglich ist aber das vierte Jahrhundert, wie die auch dann noch vitale Rezeption gnostischer Texte (zumal derjenigen aus Nag Hammadi) zeigt. ${ }^{221}$ Wir kommen auf diesen Punkt zurück.

3. Bezieht man den Topos der Engelgleichwerdung und die Rezeptionsgeschichte von Ps 24 ein, verändert sich das Bild nochmals. Beide Komplexe verdichten sich im Werk des Origenes, mit erheblicher Fortwirkung in der Theologie der folgenden Jahrhunderte. Es fällt auf, dass der Physiologus das Mythologumenon der in Engelleibern und schliesslich in Menschengestalt verhüllten Gottheit Christi geradezu programmatisch an den Anfang seines Werks stellt. Diese Platzierung ist schwer denkbar ohne die vorangegangene exegetische und systematische Arbeit von Origenes, die ihrerseits viele divergente theologische $\mathrm{Li}$ nien zusammenführt, auch solche gnostischer Herkunft. Im Topos der Gleichwerdung Christi mit den Bewohnern der gestuften Himmelssphären konvergieren für den alexandrinischen Theologen Prinzipientheorie (Logoslehre), Hermeneutik (Akkommodation) und Bibelexegese, die mit den alttestamentlichen Theophanien und Angelophanien befasst ist. Während Origenes das Lehrstück noch mit spürbarer Zurückhaltung vorträgt, hat es sich in der Folge am Rand der grosskirchlichen Theologie etabliert, um schliesslich während der origenistischen Debatten häretisiert zu werden. Der Verfasser des Physiologus greift, vielleicht in Alexandria, ganz selbstverständlich auf dieses Element origenistischer Theologie zurück. Auch die knappe Referenz auf den Schlussteil von Ps 24 setzt feste exegetische und homiletische Auslegungstraditionen voraus, die sich namentlich bei Origenes greifen lassen.

219 Vgl. oben Anm. 3, 36 und 58.

220 Peterson (1959) weist neben der Ascensio Isaiae auch auf andere apokryphe Überlieferungen hin, etwa auf Vita Adae et Evae (247) und Acta Pauli. Er vertritt trotzdem eine Spätdatierung (vgl. unten bei Anm. 226). Zu apokryphen Traditionen im Physiologus vgl. den Beitrag von Spittler in diesem Band.

221 Wichtige koptische Codices stammen aller Wahrscheinlichkeit nach aus dem 4. Jahrhundert: Nag Hammadi, Codex Askewianus, Codex Brucianus. Der Codex Berolinensis gnosticus stammt aus dem 5. Jahrhundert.
Diese Überlegungen führen dahin, den Physiologus nicht vor dem späten dritten Jahrhundert zu verorten. Sie passen gut zu dem Befund, den wir im Blick auf den Leitbegriff der verborgenen $\theta$ cótnऽ Christi erhoben haben. Auch die Figur der Täuschung des Teufels durch den sich inkarnierenden Gottessohn, die der Verfasser des Physiologus offenbar als gut bekannt voraussetzt (26 und 25), baut auf den von Origenes gelegten Grundlagen auf. ${ }^{222}$

Exkurs: Eine Abkehr von der Frühdatierung (diese hat erst seit der Mitte des 20. Jahrhunderts wieder weitreichend an Boden gewonnen) wird in jüngerer Zeit von mehreren Autoren gefordert, durchaus im Rekurs auf die ältere Forschung. ${ }^{223}$ Origenes und sein Euvre als terminus post quem spielen dabei eine gewichtige Rolle. Scott hat 1998 eine Vielzahl bestechender Argumente zusammengestellt. Unter anderem findet sich der Hinweis darauf, dass der Physiologus Origenes' allegorische Methode und dessen zoologisches Material gekannt und benutzt hat. ${ }^{224}$ Diese Beobachtungen werden von Dorfbauer 2013 bestätigt und vertieft. ${ }^{225}$

Schliesslich ist an dieser Stelle darauf hinzuweisen, dass der Physiologus vielfach christliche Asketen und ihre Praktiken mit einer Selbstverständlichkeit voraussetzt, die vor der ersten Hälfte des vierten Jahrhunderts schwer vorstellbar ist. Erik Peterson hat zu Recht auf das enkratitische Profil des Physiologus aufmerksam gemacht. ${ }^{226}$ Unsere

\section{Vgl. oben bei Anm. 168.}

223 Für die ältere Forschung ist neben Peterson (1959) zu verweisen auf Wellmann (1930, 3-4): „Annahme, dass die volle Ausbildung des allegorischen Interpretationssystems in unserm Büchlein die Schule des Origenes zur Voraussetzung hat“; vgl. (10-11): spätes viertes Jahrhundert. Ähnlich hat in ihrer Detailstudie geurteilt Treu $(1959,117)$ : es „wird für die Entstehung des Physiologus die Schule des Origenes vorausgesetzt“; anders dann offenbar Treu (1966; 1993; 1999). Massive Kritik an Wellmann und Treu übt Alpers (1984, 14-16, 59 Anm. 29). $224 \operatorname{Scott}(1998,440-441)$ : Der Physiologus ist ,probably written after Origen and indebted to his theological imagination“. Es ist überaus befremdlich, dass die starken Argumente von Scott in der jüngeren Forschung, die ja die Frühdatierung privilegiert, m. W. bisher kaum zur Kenntnis genommen worden sind; zustimmend jetzt aber Scully (2018, 424-425). Vgl. sodann in diesem Band Spittler, besonders S. 155.

225 Dorfbauer (2013); begründet wird die „Annahme, der Verfasser des Physiologus habe - in der zweiten Hälfte des 3. Jh. - eigenständig mit unterschiedlichen Werken des Origenes gearbeitet und aus diesen teilweise sein Material bezogen“" (241).

226 Vgl. dazu v. a. Peterson (1959, 237-249, 249): „Wie mir scheint, setzt der Physiologos eine in sich geschlossene geistliche Lehre voraus. Diese Doktrin, die die Konkupiszenz in das Zentrum stellt, muss notwendig eine enkratitische Tendenz annehmen“. Zustimmend zur „Grundidee Petersons, der Physiologus sei ursprünglich für mönchisch-asketische Kreise verfasst worden“, Dorfbauer (2013, 226 Anm. 10); Scott (1998, 438). - Andere Argumente hingegen, die Peterson für eine sehr späte Datierung namhaft macht, müssen ausscheiden, wie Treu (1966, 101-103) und Alpers (1984, 14, 59 Anm. 28- 
oben entfalteten theologiegeschichtlichen Überlegungen, die uns in das vierte Jahrhundert führen, stützen die Annahme, dass wir Verfasser und Adressaten des Physiologus nicht im schon älteren urbanen Enkratismus etwa von Alexandria, sondern in einem eigentlich monastischen Milieu zu suchen haben.

Exkurs: Der Physiologus adressiert seine Leser immer wieder als $\pi 0-$

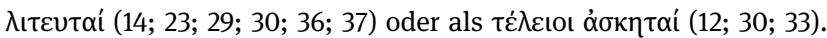
Gerade die erstgenannte Bezeichnung ist sehr auffällig und vor dem vierten Jahrhundert kaum sinnvoll zu deuten: ${ }^{227}$ der Asket als Teilhaber an der christlichen Politeia (Gemeinschaft und Wandel) bzw. am christlichen Politeuma (Bürgergemeinde). ${ }^{228}$ Charakteristisch wird in der Allegorese der beiden Froscharten unterschieden (29): Die

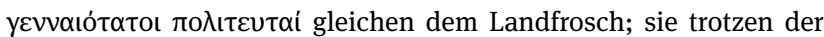

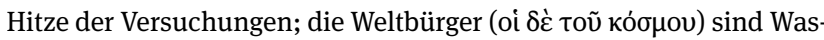
serfrösche, sie können nicht standhalten und tauchen wieder ab. Die

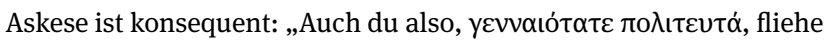
das Weibliche ...“(37). ${ }^{229}$

Zum Schluss dieser theologiegeschichtlichen Überlegungen, die sich auf das Löwenkapitel konzentriert haben, ist ein redaktionsgeschichtlicher Hinweis auf dessen exponierte Stellung angebracht. Man kann die Frage aufwerfen, ob gerade dieses erste Allegorien-Ensemble chronologische Schlussfolgerungen für die gesamte Schrift erlaubt, da ja bei Anfangstexten wie Prologen, Proömien u. a. m. öfter mit einer relativ späten literarischen Schicht $\mathrm{zu}$ rechnen ist - prominentes Beispiel dafür ist vielleicht der Johannesprolog. Die Unsicherheit darüber, ob wir

29) richtigstellen: Das Zitat aus einer Osterpredigt Gregors von Nazianz (Oratio 45,1 [PG 36, 624B]) in Physiologus 16 (Peterson 1959, 252-253) ist textkritisch sekundär; es fehlt z. B. in der ältesten GanzHandschrift G (Offermanns 1966, 68); bei den Referenzen auf Kyrill von Jerusalem (Peterson 1966, 252, 237-238) handelt es sich schlicht um Bibelzitate.

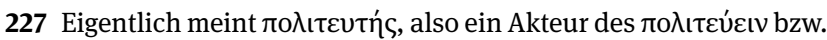

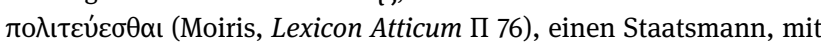
dem „Demagogen“ assoziiert bei Artemidor 1.79, 3.16. So wie zu einem Schiff ein Steuermann gehört, zu einem Heer ein Feldherr, so

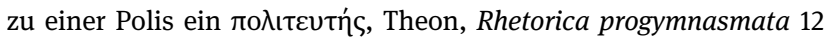
( $R h G$ 2, 127:23). Wichtig für die Assoziation mit einem Lebenswandel nach Massgabe der Christengemeinschaft ist Justin, Apologia 1.65.1: „auch in Werken als tüchtige Mitglieder der Gemeinde und als Beob-

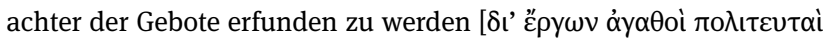

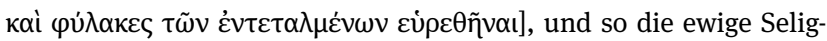
keit zu erlangen“, hier aber noch nicht wie im Physiologus als Kennzeichen eines besonderen Standes, sondern aller Christen.

228 Vgl. PGL 1114a: „follower of Christian life, devotee“ mit Referenz

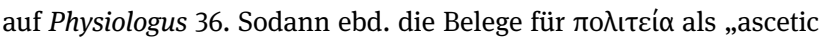

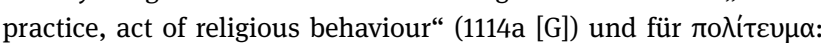

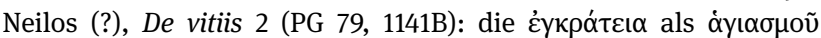

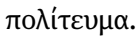

$229 \mathrm{Zu}$ einer besonders markanten asketischen Allegorie, dem Biber (23), vgl. Plümacher (1992, 104-106). überhaupt eine Erstversion des Physiologus postulieren können, verstärkt Bedenken dieser Art. Nun gibt es umgekehrt keinerlei textgeschichtliche oder überlieferungsgeschichtliche Anzeichen für eine Edition des Physiologus, die ohne den Löwen ausgekommen wäre. Der König der Tiere bietet sich ganz selbstverständlich als Einstieg für das Zoopanorama unserer Schrift an. ${ }^{230}$ Ebenso lassen sich nicht die geringsten Indizien namhaft machen, die für eine andere, überschriebene Version statt der uns überkommenen sprächen. Im Gegenteil: Man sieht in den späteren Redaktionen, dass das Löwenkapitel umgeschrieben worden ist, und, seltener, seine Anfangsstellung verloren hat. Wir haben also im überlieferten Löwenkapitel den Anfang des frühsten für uns identifizierbaren Physiologus vor uns. Einige seiner Sprachformen (die „Gottheit“ Christi) und seiner Motive (Christi Verborgenheit vor angelischen bzw. diabolischen Mächten) finden sich auch im übrigen Bestand. Der programmatische Auftakt des Physiologus bildet, wenn man überhaupt von einer Erstversion ausgehen will, mit dem übrigen Corpus ein literarisches Ganzes. Die Interpreten sind deshalb gut beraten, sich wie die impliziten Leser unserer Schrift zu verhalten und Querbezüge zwischen den einzelnen Gleichnissen herzustellen. Der Verfasser des Physiologus setzt dafür ein nicht unerhebliches Wissen um Topoi, Figuren und Schriftbezüge voraus, die in der christlichen Literatur und Theologie schon traditionell geworden sind. Diese Beanspruchung von Leserkompetenzen ist ein Zeichen dafür, dass sich unsere Schrift nicht einfach als unbedarftes „Volksbuch“ charakterisieren lässt, sondern dass sie Bildungsträger adressiert. $^{231}$

Auf dieser Spur führt unsere Analyse in die Zeit nach Origenes, und hier eher in die erste Hälfte bis zur Mitte des vierten Jahrhunderts als in das späte dritte Jahrhundert. Der Verfasser des Physiologus steht wahrscheinlich monastischen Kreisen Ägyptens nahe. Seine Adressaten mögen sich namentlich an der origenistischen Theologie orientiert haben ${ }^{232}$ - ob in Alexandria selber oder im durchaus

230 Vgl. Alpers (1996, 597): „Fast ausnahmslos steht in den griechischen Handschriften und den alten Übersetzungen der Löwe (Kap. 1) als König der Tiere am Anfang“.

231 Dazu passt es gut, dass die ersten Rezeptionsspuren (vgl. oben Anm. 218) zu gebildeten, asketisch orientierten Eliten führen: Im lateinischen Westen „haben also vor allem Christen aus der gebildeten römischen Oberschicht den Physiologus und ähnliche Werke gelesen und fortgeschrieben“, K. Heyden, in diesem Band S. 162 und 171.

232 Vgl. zum schon frühen origenistisch geprägten Mönchtum in Ägypten: Rubenson (1999, bes. 325-329); sodann O’Laughlin (1999); kritisch demgegenüber Gould (1995). Zur Verbindung von Origenismus und ägyptischen Mönchen im späten vierten Jahrhundert vgl. Clark (1992, 9-10, 22, 191-192). Euagrios Pontikos, der den Origenis- 
mit den urbanen Zentren verbundenen Land, lässt sich nicht entscheiden. ${ }^{233}$ Charakteristisch für sie ist ein dezidiert enkratitisches Profil. Über genau diese Kanäle sind wahrscheinlich auch die gnosisnahen Überlieferungen weitergegeben worden, die im Physiologus greifbar sind: Es spricht manches dafür, dass Mönche, darunter solche mit origenistischem Profil, auch Trägergruppen der aus Ägypten stammenden gnostischen Texte, zumal derjenigen aus Nag Hammadi, waren. ${ }^{234}$ Es ist wohl kein Zufall, dass sich eine der frühesten sicheren Rezeptionsspuren des Physiologus, hier der zweiten Löwenallegorie, beim Origenesanhänger und Ägyptenreisenden Rufin von Aquileia an der Wende vom vierten zum fünften Jahrhundert findet. ${ }^{235}$ Auch später scheint unsere Schrift besonders

mus entscheidend fortentwickelt hat, lebte viele Jahre unter ägyptischen Mönchen.

233 Man darf nicht mehr von einem Graben zwischen Stadt (zumal Alexandria) und Land ausgehen, vgl. Rubenson (1999, 326, 336): „The collected evidence of the references to various types of monks in the papyri, and to their economic and social interactions with society, shows that monasticism in Egypt was closely linked to the cities and towns, and that monasticism proper had its roots in urban asceticism" (326). Scott $(1998,430)$ urteilt also richtig: „That the Physiologus was written in Egypt does appear certain, but there is no compelling reason to insist on a connection with Alexandria alexandrinisch“; vgl. 441: „It may have been written in Alexandria, but it may also have been written outside, e. g. in monastic circles“. - Zur Neubewertung der Lese- und Schreibkultur in den „communication networks within early Egyptian monasticism“ vgl. Choat und Giorda (2017, 5-16).

234 Zum (umstrittenen) Stellenwert gnostischer Texte für origenistische Mönche in Ägypten, namentlich im Hinblick auf die Nag Hammadi-Codices, vgl. Lundhaug und Jenott (2015, 238-262: „Origenist Monks?“): „Far from being a marginal trend, Origen’s influence in Egypt appears to have been ubiquitous from the beginning of monasticism, and became controversial only toward the end of the fourth century when archbishop Theophilus abruptly turned against the Origenist monks“ (238). Vgl. Lundhaug (2017); Vecoli (2017, 165167); Fowler (2017 - für unsere Thematik der Engelgleichwerdung in simonianischer Tradition [dazu oben Anm. 38] ist die folgende Beobachtung wichtig: „the representation of Soul in Exegesis on the Soul, is very similar to that of Helen in the myth of Simon Magus and Helen“, 79). Kritisch zur monastischen Verortung Lewis und Blount (2014, 416): „the Nag Hammadi codices belonged to private (i. e., nonmonastic) individuals who commissioned them for their own purposes“. Zu den gnostisch-koptischen Codices s. auch oben Anm. 221. 235 Rufin, De benedictionibus patriarcharum 1.6 (CCSL 20, $193=$ SC 140, 46), mit Bezug auf Gen 49,9 (vgl. oben Anm. 24 zu Physiologus 1 sowie Anm. 216): „nam Physiologus de catulo leonis haec scribit, quod cum natus fuerit, tribus diebus ac tribus noctibus dormiat [...]“. Zur Lektüre des Physiologus bei Rufin und seinem Kreis vgl. K. Heyden, in diesem Band S. 161. gern gelesen worden zu sein in den Klöstern der koptischen Mönche. ${ }^{236}$

\section{Der „Naturforscher“ als Hermeneut: die beiden Bücher Gottes}

Wir schliessen mit einem Ausblick zur Hermeneutik unserer Schrift. Der Фuбıภó́yoৎ rangiert als herausragender Autoritätsträger. Gelegentlich scheint sich der implizite Autor geradezu mit ihm zu identifizieren. ${ }^{237}$ Explizit nimmt der „Physiologos“ kaum je das Wort, ${ }^{238}$ im Unterschied $\mathrm{zu}$ den biblischen Figuren, die häufig selber sprechen. Über seine naturkundliche Kompetenz hinaus wird der „Physiologos“ auch zum Exegeten. ${ }^{239}$ Mehr noch: Er präsentiert sich selber als Weiser. Darin ist er mit Salomon vergleichbar - eine Assoziation, die die Rezeptionsgeschichte der Schrift begleitet hat. ${ }^{240}$ Sein Wissen erhebt einen weisheitlichen Anspruch. Trotzdem ist das Wissen des „Physiologos“ grössernteils kein zuhandenes, alltagsevidentes Wissen. Nicht von ungefähr stammt viel Material aus der Teratologie, den Sammlungen von $p a$ radoxa, mirabilia et stupenda. Zugespitzt formuliert: Das Wissen des „Physiologos“ wird ähnlich wie das Bibelwissen taxiert: Es situiert sich, mindestens teilweise, auf der

236 Dazu sowie zu den fast verlorenen Überresten des koptischen Physiologus vgl. Stroppa (2017, 603-607, besonders 606) sowie Stroppa in diesem Band.

237 Das Verfasser-Ich selber begegnet selten (die 1. Person Nom.

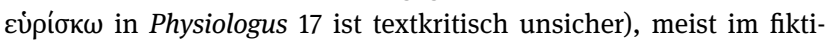

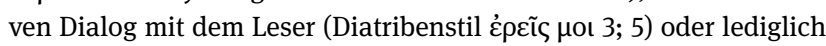

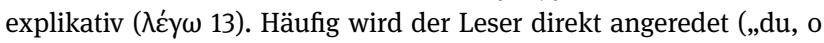

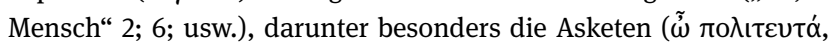
14; 23; 30; usw.; vgl. oben bei Anm. 227).

238 Der Fall ist dies lediglich in 13bis; 35a.

239 So Physiologus 32 (vom Diamantstein): Der „Physiologos“ zitiert

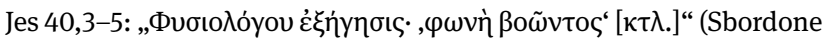
1936a, 106,4-5); er ordnet Schriftaussagen einander zu. In 41 (von der Gazelle) spielt der „Naturforscher“ vielleicht auf Ps 104,18 an. - Beachtenswert ist auch das ein Stück weit technisch gewordene Vokabu-

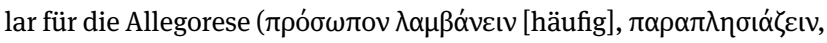

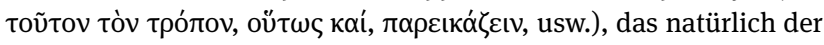
Schriftexegese entstammt. Ich lasse es bei der Frage bewenden, ob

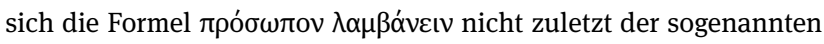
prosopographischen Exegese der Alten Kirche verdankt; zu dieser vgl. Andresen (2009).

240 Vgl. Lauchert (1889, 43-44); Perry (1941, 1076, 1109-1110, 1114). 
Ebene von Offenbarungswissen, da es von einer überragenden Autorität mitgeteilt und verbürgt wird. ${ }^{241}$

Exkurs: Auf dieser Linie ist zu überlegen, ob für die Kategorie des „Physiologos“ neben der Semantik des „Naturforschers“ nicht auch

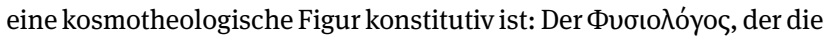

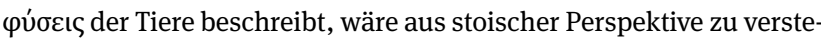
hen als Selbstmitteilung und Explikation des $\varphi v ́ \sigma \varepsilon \omega \varsigma \lambda$ óyoc. Man darf fragen, ob sich hier eine Brücke zum Logos des Johannesprologs abzeichnet, einem der wichtigen Prätexte unserer Schrift $(1 ; 22){ }^{242}$

Der Physiologus stellt eine Wechselwirkung zwischen Schrift und Natur vor Augen. Die allegorisch erschlossene Natur ist dabei eingelassen in die von der Bibel ausgespannte spirituelle Landschaft. Literarisch ist dies fassbar in der Einbettung der Aussagen des „Physiologos“ in Bibelreferenzen. Der Weg führt von der Bibel zur Natur und von hier wieder zur Bibel. ${ }^{243}$ Dabei nimmt der Physiologus offenbar auch markante Anpassungen der zoologischen Überlieferungen selber vor. Prominente Beispiele sind hierfür neben dem dritten Löwengleichnis ${ }^{244}$ der Pelikan (4), der Adler (6), das Einhorn (22) und der Elefant (43): ${ }^{245}$ Es ist kein Überlieferungszufall, dass sich für charakteristische Eigenheiten gerade dieser Tiere, die so sehr

241 Natürlich arbeitet der Physiologus auch und gern mit bekanntem alltäglichem Wissen, vgl. das „du weisst“ (oî́ $\delta \alpha \varsigma$ ) bei Feigen und Schlupfwespen (48). Dass der Physiologus gern an der Grenze dessen operiert, was die Leserschaft noch für glaubwürdig halten kann, arbeitet Nicklas (2013) heraus: Die Naturphänomene „müssen [...] so an der Schwelle dessen liegen, was noch, glaubwürdig', aber schon (an sich) erstaunlich ist, dass sie attraktiv bleiben“ (250; vgl. 247).

242 Zur Bedeutung des Johannesprologs für unsere Schrift und ihr Naturverständnis vgl. Z. Kindschi Garský, in diesem Band S. 90.

243 Vgl. Alpers (1984, 35-47); Nicklas (2013, 244). Leider arbeitet Alpers mit einem längst überholten Gegensatz zwischen (ziemlich negativ gewerteter) Allegorie und (positiv eingeschätzter) Typologie (1984, 42-46; vgl. 1996, 594: „man sollte beim Physiologus nicht von Allegorese sprechen“). Auch Zucker findet im Physiologus statt der negativ beurteilten Allegorie „une leçon de symbologie“ (2005, 41-44). Zum Stellenwert von Allegorie und Typologie vgl. Z. Kindschi Garský in diesem Band.

244 Vgl. dazu oben bei Anm. 25.

245 Vgl. die jeweils zusammenfassenden Hinweise bei Lauchert (1889) und bei Schönberger (2001): zur Pelikanmutter, die sich opfert (4; zu möglichen Vorgaben vgl. Alpers 1984, 28 - die Undankbarkeit der Jungen stammt aus Jes 1,2 - sowie Lewis und Llewellyn-Jones 2018: 532-534); zum seine Flügel verbrennenden und sich selber erneuernden Adler (6; Prätext ist Ps 103,5); zum Einhorn (22; dazu oben Anm. 27) und zur von Mandragora (vgl. Gen 30,14) unterstützten Elefantenliebe und -geburt in Paradiesnähe (!) samt Abwehr der Schlange (43; dazu Peterson 1959, 246-248 mit Hinweis auf die Vita Adae et Evae; zur Mandragora Rahner ${ }^{2} 1957$, 284-351, namentlich 324-326 zum Physiologus). Allerdings muss immer in Rechnung gestellt werden, dass nur ein geringer Teil der antiken naturkundlichen Literatur erhalten geblieben ist. zur christlichen Allegorese einladen, keine entsprechenden Vorgaben bzw. Parallelen in der antiken Zoologie finden. ${ }^{246}$ Der Physiologus greift auf die Bilder und Gleichnisse der Bibel zurück, um sie dann in der Natur wieder zu „entdecken“ - und sie erneut durch Allegorese zu geistiger Wirklichkeit zu machen.

Schrift und Natur konvergieren schliesslich in noch einem entscheidenden Punkt: Sie bekunden beide die Wohlordnung der Schöpfung. Der Physiologus schliesst seine Porträts häufig mit einer stereotypen Aussage: „Wohl also

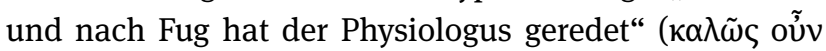

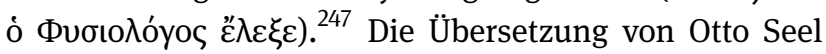
(1960) weist in die richtige Richtung: Die Formel bringt die Schöpfungsordnung zur Sprache, die die Natur gleichnisfähig für die Erlösung macht - in der platonisierenden Perspektive des Physiologus: für die geistigen, intelligiblen Dinge. Es ist bemerkenswert, dass sich eine derartige schöpfungstheologische Sicht ausgerechnet einem dezidiert asketischen Standpunkt verdankt. ${ }^{248}$ Wir dürfen aber darüber hinaus in diesem $\kappa \alpha \lambda \tilde{\omega} \varsigma$ auch einen Reflex des Lobs erkennen, das der biblische Schöpfungsbericht angesichts des Sechstagewerks zur Sprache bringt: „Und

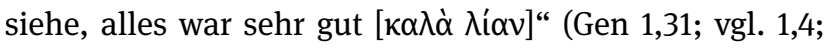
usw.). Die betreffenden Sätze des Physiologus rangieren als Zäsurenmarker, summieren aber zugleich auch sein naturtheologisches Programm. Dazu kommt das nicht gering zu veranschlagende Moment des Unterhaltsamen: Das Reden des „Physiologos“, das der Verfasser eigens immer wieder lobt, animiert die Leser dazu, selber mitzuspielen in den hermeneutischen Brückenschlägen zwischen Natur, geistig-geistlicher Welt und eigener Lebensgestaltung. ${ }^{249}$

Der Physiologus bringt die auch sonst in der christlichen Antike, schon im Neuen Testament, beobachtbare Metapher der beiden Bücher Gottes zum Ausdruck, die sich

246 Unterstrichen von Alpers (1984, 41): „Etwa die Hälfte aller Physiologus-Geschichten hat keine Parallele in der naturkundlichen Nebenüberlieferung des Altertums“ (vgl. 35) - und von der verbleibenden Hälfte ist Wesentliches von der Auslegung her gestaltet oder umgestaltet.

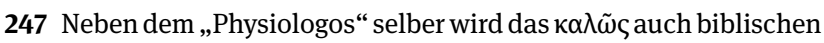
Figuren zugesprochen (1 Jakob; 4 David; 10 der Täufer; 19 Jesus; 27 Jeremias; vgl. 48 Amos).

248 Vgl. zu einem analogen Befund im Neuen Testament Vollenweider (2014).

249 Vgl. dazu Nicklas (2013, 250): „Die Kraft des Textes [...] geht von der [...] erstaunlichen im Text kreierten und gleichzeitig offenen,Welt der Naturphänomene' $\mathrm{au}<\mathrm{s}>$, die auf unterhaltsame Weise den Lesenden in ihren Bann zieht und so anzielt, ihn auf kreative, z. T. überraschende Weise in seiner Lebenshaltung zu bestätigen bzw. im Sinne der vom Text vorausgesetzten Haltung weiterzuführen.“ 
gegenseitig interpretieren. Wir nehmen die seinerzeitige Berner Tagung und den Abdruck des Physiologus Bernensis in diesem Sammelband zum Anlass, den Berner Pfarrer Jeremias Gotthelf zu zitieren: ${ }^{250}$

Und wie Gott dem Menschen zwei Augen gegeben hat, so hat er ihm auch zwei Bücher gegeben, das heilige alte Buch, das nicht blos ein Vikari soll exegisieren können, sonder jeder Christ verstehen; aber auch das wunderbare Buch, das alt ist, und doch jeden Tag neu wird, das wunderbare Buch, das aus göttlichem Quell entsprungen, wie durch unzählige Bäche ein Strom genährt wird, durch Quellen aus jedes Menschen Brust, das Gott mit lebendigem Atem durchhaucht und Blatt um Blatt beschreibt vor der Menschen selbsteigenen Augen. Und wie die beiden $\mathrm{Au}-$ gen einander helfen auf unerklärliche Weise, und eins ohne das andere verwaiset sich fühlt und einsam und nur noch halb so gut als früher, so hat es auch ein Buch mit dem andern Buch, ein Buch wirft Licht auf das andere Buch, beide strömen Leben sich zu und halbdunkel wenigstens bleibt ein Buch ohne das andere Buch. [...] Aber wo der Mensch mit beiden Augen in beide Bücher sieht, da nahen sich Himmel und Erde, ist der Himmel offen, Engel Gottes steigen auf und nieder, strömende Offenbarungen Gottes verklären das Leben, heiligen die Zustände; die Bibel gibt dem Leben seine Weihe, das Leben macht die Bibel lebendig.

\section{Bibliographie}

Alpers, Klaus. 1984. „Untersuchungen zum griechischen Physiologus und den Kyraniden. “In All Geschöpf ist Zung' und Mund: Beiträge aus dem Grenzbereich von Naturkunde und Theologie. Vestigia Bibliae: Jahrbuch des Deutschen Bibel-Archivs 6, hrsg. v. Heimo Reinitzer, 13-87. Hamburg: Friedrich Wittig.

Alpers, Klaus. 1996. „Physiologus.“ TRE 36:596-602.

Alpers, Klaus. 2000. „Physiologus.“ DNP 9:998-1000.

Andresen, Carl. 2009. „Zur Entstehung und Geschichte des trinitarischen Personbegriffes." In Theologie und Kirche im Horizont der Antike: Gesammelte Aufsätze zur Geschichte der Alten Kirche. AKG 112, hrsg. v. Carl Andresen und Peter Gemeinhardt, 55-89. Berlin: De Gruyter.

Aubineau, Michel, Hg. 1972. Homélies pascales: cinq homélies inédites. SC 187. Paris: Éditions du cerf.

Bader, Robert, Hg. 1940. Der ААНӨН $А О Г О \Sigma$ des Kelsos. Stuttgart: W. Kohlhammer.

Banev, Krastu. 2015. Theophilus of Alexandria and the First Origenist Controversy: Rhetoric and Power OECS. Oxford: Oxford University Press.

Barbel, Joseph. ${ }^{2}$ 1964. Christos Angelos: Die Anschauung von Christus als Bote und Engel in der gelehrten und volkstümlichen Literatur des christlichen Altertums. Theophaneia 3. Bonn: Peter Hanstein.

Bardy, Gustave, Hg. 1959. Cuvres de saint Augustin. BAug. Bd. 34: La cité de Dieu. Bd. 2, Paris: Desclée De Brouwer.
Beeley, Christopher A. 2008. Gregory of Nazianzus on the Trinity and the Knowledge of God. OSHT. Oxford: Oxford University Press.

Benin, Stephen D. 1993. The Footprints of God: Divine Accommodation in Jewish and Christian Thought. SUNY Series in Judaica. Albany, NY: State University of New York Press.

Bergjan, Silke-Petra. 2015. „Theodoret von Cyrus, Apollinarius und die Apollinaristen in Antiochien“. In Apollinarius und seine Folgen. STAC 93, hrsg. v. Silke-Petra Bergjan, Benjamin Gleede und Martin Heimgartner, 229-258. Tübingen: Mohr Siebeck.

Bergjan, Silke-Petra, unter Mitwirkung von Dietmar Wyrwa. 2018. „Theodoret von Kyrrhos”. In Riedweg, Horn, und Wyrwa 2018, 1620-1633.

Blaising, Craig A. und Carmen S. Hardin, Hgg. 2008. Psalms 1-50. ACCSOT 7. Downers Grove, IL: InterVarsity.

Bloch, Peter. 1971. „Löwe.“ LCI 3:112-119.

Böttrich, Christfried, und Sabine Fahl, Hgg. 2015. Leiter Jakobs. JSHRZ.NF 1, Apokalypsen und Testamente. Gütersloh: Gütersloher Verlagshaus.

Bousset, Wilhelm. 1907 [1973]. Hauptprobleme der Gnosis. FRLANT 10. Göttingen: Vandenhoeck \& Ruprecht.

Bovon, François. 2003. „Jesus' Missionary Speech as interpreted in the patristic Commentaries. "In Studies in Early Christianity. WUNT 161, hrsg. v. François Bovon, 196-208. Tübingen: Mohr Siebeck.

Brandenburg, Hugo. 1959. „Einhorn.“ RAC 4:840-862.

Bremmer, Jan N. 2000. „Man, Magic, and Martyrdom in the Acts of Andrew'. "In The Apocryphal Acts of Andrew. Studies on the Apocryphal Acts of the Apostles 5, hrsg. v. Jan N. Bremmer, 15-34. Löwen: Peeters.

Bremmer, Jan N. 2001. „The Acts of Thomas: Place, Date and Women." In The Apocryphal Acts of Thomas. Studies on the Apocryphal Acts of the Apostles 6, hrsg. v. Jan N. Bremmer, 74-90. Löwen: Peeters.

Brennecke, Hanns Christof. 2015. „,Apollinaristischer Arianismus“ oder ,arianischer Apollinarismus': ein dogmengeschichtliches Konstrukt?“ In Apollinarius und seine Folgen. STAC 93, hrsg. v. Silke-Petra Bergjan, Benjamin Gleede und Martin Heimgartner, 73-92. Tübingen: Mohr Siebeck.

Brinkmann, Hennig. 1980 [2012]. Mittelalterliche Hermeneutik. Tübingen: Max Niemeyer [Berlin: De Gruyter].

Brodersen, Kai., Hg. 2018. Ailianos: Tierleben. Sammlung Tusculum. Berlin: De Gruyter.

Brucker, Ralph. 2014. „,Wer ist der König der Herrlichkeit?‘ Psalm 23[24] - Text, Wirkung, Rezeption." In Die Septuaginta - Text, Wirkung, Rezeption, hrsg. v. Wolfgang Kraus und Siegfried Kreuzer, 405-429. Tübingen: Mohr Siebeck.

Buchinger, Harald. 2005. Pascha bei Origenes. IThS 64. Innsbruck: Tyrolia.

Bultmann, Rudolf. 1967. „Die Bedeutung der neuerschlossenen mandäischen und manichäischen Quellen für das Verständnis des Johannesevangeliums. "In Exegetica: Aufsätze zur Erforschung des Neuen Testaments, hrsg. v. Rudolf Bultmann, 55-104. Tübingen: Mohr Siebeck.

Carmody, Francis J., Hg. 1939. Physiologus Latinus: Éditions préliminaires versio $B$. Paris: Librairie E. Droz.

Carmody, Francis J., Hg. 1941. „Physiologus Latinus Versio Y.“ University of California Publications in Classical Philology 12,7:95-134.

250 Gotthelf (1843/1844, 300-301). 
Choat, Malcolm, und Maria Chiara Giorda, Hgg. 2017. Writing and Communication in Early Egyptian Monasticism. Texts and Studies in Eastern Christianity 9. Leiden: Brill.

Clark, Elizabeth A. 1992. The Origenist Controversy: The cultural Construction of an early Christian Debate (Princeton, N): Princeton University Press.

Cramer, John Anthony, Hg. 1844a. Catenae Graecorum patrum in Novum Testamentum. Bd. 2, In Evangelia S. Lucae et S. Joannis. Oxford: Typographeum Academicum.

Cramer, John Anthony, Hg. 1844b. Catenae Graecorum patrum in Novum Testamentum. Bd. 6, In Epistolas S. Pauli ad Galatas, Ephesios, Philippenses, Colossenses, Thessalonicenses. 0xford: Typographeum Academicum.

Crouzel, Henri, und Manlio Simonetti, Hgg. 1980. Origène: Traité des principes. Bd. 4, Livres III et IV: Commentaire et fragments. SC 269. Paris: Éditions du Cerf.

Crouzel, Henri. 1999. „Les condemnations subies par Origène et sa doctrine." In Origeniana septima: Origenes in den Auseinandersetzungen des 4. Jahrhunderts. BETL 137, hrsg. v. Wolfgang A. Bienert und Uwe Kühneweg, 311-315. Löwen: Leuven University Press

Curley, Michael J. (1979) ${ }^{2}$ 2009. Physiologus: A Medieval Book of Nature Lore. Chicago: University of Press.

Daley, Brian E. 2006. Gregory of Nazianzus. London: Routledge.

Daniélou, Jean. (1958) ${ }^{2} 1974$. Théologie du judéo-christianisme. Bibliothèque de Théologie 1 , Histoire des doctrines chrétiennes avant Nicée. Tournai: Desclée.

Depietri, Marco, 2010. Der Jüngere Physiologus: Eine sprachwissenschaftliche Untersuchung; Mit einer Datenbank sämtlicher Belegformen und den dazugehörigen Detailanalysen auf einer CD-ROM. PHILOLOGIA: Sprachwissenschaftliche Forschungsergebnisse 153. Hamburg: Kovač.

Diehl, Ernst, Hg. 1906 [1965]. Procli Diadochi in Platonis Timaeum commentaria. Bd. 3. Leipzig: Teubner [Amsterdam: Hakkert].

Diekamp, Franz, Hg. ${ }^{2} 1981$. Doctrina patrum de incarnatione verbi: Ein griechisches Florilegium aus der Wende des 7. und 8. Jahrhunderts. Münster: Aschendorff.

Dorfbauer, Lukas J. 2013. „Fortunatian von Aquileia, Origenes und die Datierung des Physiologus.“ REAugP 59:219-245.

Dorofeeva, Anna. 2017. „Miscellanies, Christian Reform and early medieval Encyclopaedism: A Reconsideration of the prebestiary Latin Physiologus Manuscripts." HiRe 90:665-682.

Drobner, Hubertus R. 1982. Gregor von Nyssa: Die drei Tage zwischen Tod und Auferstehung unseres Herrn Jesus Christus. PP 5. Leiden: Brill.

Drobner, Hubertus R. (2004) ${ }^{3}$ 2011. Lehrbuch der Patrologie. Frankfurt am Main: Peter Lang.

Dünzl, Franz. 1993. Braut und Bräutigam: Die Auslegung des Canticum durch Gregor von Nyssa. BGBE 32. Tübingen: Mohr Siebeck.

Dünzl, Franz, Hg. 1994. Gregor von Nyssa: Homilien zum Hohenlied. FC 16,1. Freiburg: Herder.

Ettlinger, Gerard H., Hg. 1975. Theodoret of Cyrus: Eranistes; Critical Text and Prolegomena. Oxford: Clarendon Press.

Fowler, Kimberley A. 2017. „The Ascent of the Soul and the Pachomians: Interpreting the Exegesis on the Soul $(\mathrm{NHC} \mathrm{II,6)} \mathrm{within} \mathrm{a}$ Fourth-Century Monastic Context.“ Gnosis 2:63-93.

Fürst, Alfons. 2011. „Klassiker und Ketzer: Origenes im Spiegel der Überlieferung seiner Werke.“ In Von Origenes und Hieronymus zu Augustinus: Studien zur antiken Theologiegeschichte, hrsg. v. Alfons Fürst, 209-236. AKG 115. Berlin: De Gruyter.

Fürst, Alfons. 2011. „Hieronymus über die heilsame Täuschung.“ In Von Origenes und Hieronymus zu Augustinus: Studien zur antiken Theologiegeschichte, hrsg. v. Alfons Fürst, 275-292. AKG 115. Berlin: De Gruyter.

García Valdés, Manuela, Luis Alfonso Llera Fueyo und Lucía Rodríguez-Noriega Guillén, Hgg. 2009. Aelianus, Claudius: De natura animalium. BSGRT. Berlin: De Gruyter.

Geljon, Albert-Kees. 2011. „Didymus the Blind: Commentary on Psalm 24 (23 LXX); Introduction, Translation and Commentary.“ Vigiliae Christianae 65:50-733.

Georges, Tobias. 2011. Tertullian: ,Apologeticum‘. KFA 11. Freiburg: Herder.

Gieschen, Charles A. 1998. Angelomorphic Christology: Antecedents and early Evidence. AGJU 42. Leiden: Brill.

Gippert, Jost. 1997. „Physiologus: Die Verarbeitung antiker Naturmythen in einem frühchristlichen Text." Studia Iranica, Mesopotamica et Anatolica 3:161-177.

Gögler, Rolf, Hg. 1959. Origenes: Das Evangelium nach Johannes. MKZU 4. Einsiedeln: Benziger.

Gögler, Rolf. 1963. Zur Theologie des biblischen Wortes bei Origenes. Düsseldorf: Patmos.

Goldstaub, Max. (1899-1901) 1900. „Der Physiologus und seine Weiterbildung, besonders in der lateinischen und in der byzantinischen Literatur." Philologus: Zeitschrift für das klassische Alterthum; Supplementband 8,3:339-404.

Goodspeed, Edgar J., Hg. 1914 [1984]. Die ältesten Apologeten: Texte mit kurzen Einleitungen. Göttingen: Vandenhoeck \& Ruprecht.

Görgemanns, Herwig, und Heinrich Karpp, Hgg. (1976) ${ }^{3} 1992$. Origenes: Vier Bücher von den Prinzipien. TzF 24. Darmstadt: Wissenschaftliche Buchgesellschaft Darmstadt.

Gotthelf, Jeremias. 1843/1844. Wie Anne Bäbi Jowäger haushaltet und wie es ihm mit dem Doktern geht. La Chaux de Fonds: Zahn.

Gould, Graham. 1995. „The Influence of Origen on Fourth-Century Monasticism. Some further Remarks. “In Origeniana Sexta. BETL 118, hrsg. v. Gilles Dorival und Alain Le Boulluec, 591598. Löwen: Peeters.

Grant, Robert, Hg. 1999. Early Christians and Animals. London: Routledge.

Greschat, Katharina. 2006. „Die Verwendung des ,Physiologus“ bei Gregor dem Grossen: Paulus als gezähmtes Einhorn in Moralia in Job XXXI." StPatr 43:381-386.

Grillmeier, Alois. 1956. Der Logos am Kreuz: Zur christologischen Symbolik der älteren Kreuzigungsdarstellung. München: Hueber.

Grillmeier, Alois. 1975. „Der Gottessohn im Totenreich: Soteriologische und christologische Motivierung der Descensuslehre in der älteren christlichen Überlieferung. "In Mit ihm und in ihm: Christologische Forschungen und Perspektiven, hrsg. v. Alois Grillmeier, 76-174. Freiburg: Herder.

Grillmeier, Alois. (1990) 2004a. Jesus der Christus im Glauben der Kirche. Bd. 1, Von der apostolischen Zeit bis zum Konzil von Chalcedon (451) Freiburg: Herder.

Grillmeier, Alois. (1989) 2004b. Jesus der Christus im Glauben der Kirche. Bd. 2,2, Die Kirche von Konstantinopel im 6. Jahrhundert. Freiburg: Herder. 
Guillaumont, Antoine. 1962. Les „Képhalaia gnostica“ d’Évagre le Pontique et l'histoire de l'origénisme chez les Grecs et chez les Syriens. PatSor 5. Paris: Editions du Seuil.

Haar, Stephen. 2003. Simon Magus: The first Gnostic? BZNW 119. Berlin: De Gruyter.

Hagelberg, Leonie. 2007. „Physiologos.“ DNP: Supplemente I Online-Band 2; Geschichte der antiken Texte: Autoren- und Werklexikon. http://dx.doi.org/10.1163/2452-3054_dnpo2_ COM_0170.

Hall, Robert G. 1999. „Astonishment in the Firmament: The Worship of Jesus and Soteriology in Ignatius and the Ascension of Isaiah." In The Jewish Roots of christological Monotheism. JSJ.S 63, hrsg. v. Carey C. Newman, James R. Davila und Gladys S. Lewis, 148-155. Leiden: Brill.

Hall, Stuart George. 1975. „The Christology of Melito: A Misrepresentation exposed." StPatr 13:154-168.

Hall, Stuart George, Hg. 1979. Melito of Sardis: On Pascha and Fragments, texts and translations. OECT. Oxford: Clarendon Press.

Hammond Bammel, Caroline P. 1985. Der Römerbrieftext des Rufin und seine Origenes-Übersetzung. VL.AGLB 10. Freiburg: Herder.

Hanson, Anthony T. 1980. The New Testament Interpretation of Scripture. London: SPCK.

Haeuser, Philipp, Hg. 1917. Des Heiligen Philosophen und Martyrers Justinus Dialog mit dem Juden Tryphon. BKV 1,33. Kempten: J. Kösel'sche Buchhandlung.

Heither, Theresa, Hg. 1990. Origenes: Commentarius in epistulam ad Romanos; Römerbriefkommentar. FC 2,1. Freiburg: Herder.

Henkel, Nikolaus. 1976. Studien zum Physiologus im Mittelalter. Hermaea: Neue Folge 38. Tübingen: Max Niemeyer.

Henkel, Nikolaus. ${ }^{2}$ 2010. „Physiologus.“ LLex 9:213-215.

Hennecke, Edgar, Hg. ${ }^{1}$ 1904. Neutestamentliche Apokryphen in deutscher Übersetzung und mit Einleitungen. Tübingen: J.C.B. Mohr (Paul Siebeck).

Heyden, Wichard von. 2014. Doketismus und Inkarnation: Die Entstehung zweier gegensätzlicher Modelle von Christologie. TANZ 58. Tübingen: Francke.

Hommel, Fritz, Hg. 1877. Die äthiopische Übersetzung des Physiologus nach je einer Londoner, Pariser und Wiener Handschrift. Leipzig: J.C. Hinrichs.

Hommel, Fritz, 1890. „Der äthiopische Physiologus.“ Romanische Forschungen 5:13-36.

Hoppe, Barbara. 2003. „Zoologie.“ DNP 15/3: 1198-1229.

Hornschuh, Manfred. 1965. Studien zur Epistula Apostolorum. PTS 5. Berlin: de Gruyter.

Hübner, Reinhard M. 1999. „Melito von Sardes und Noët von Smyrna." In Der paradox Eine: Antignostischer Monarchianismus im zweiten Jahrhundert; Mit einem Beitrag von Markus Vinzent. SVigChr 50, hrsg. v. Reinhard M. Hübner, 1-37. Leiden: Brill.

Imorde, Joseph. 2003. „Physiologus.“ $R G G^{4}$ 6:1330.

Jacobsen, Anders-Christian. 2009. „Christology in the Homilies of Origen“. In Origeniana Nona: Origen and the religious Practice of his Time. BETL 228, hrsg. v. György Heidl und Róbert Somos, 637-651. Löwen: Peeters.

Kähler, Ernst. 1958. Studien zum Te Deum und zur Geschichte des 24. Psalms in der Alten Kirche. VEGL 10. Göttingen: Vandenhoeck \& Ruprecht.

Kaimakis, Dimitris, Hg. 1974. Der Physiologus nach der ersten Redaktion. Meisenheim am Glan: A. Hain.
Karnejev, Alexander, Hg. 1894. „Der Physiologus der Moskauer Synodalbibliothek: Ein Beitrag zur Lösung der Frage nach der Vorlage des armenischen und eines alten lateinischen Physiologus.“ ByzZ 3:26-63.

Kees, Reinhard J. 1995. Die Lehre von der Oikonomia Gottes in der Oratio catechetica Gregors von Nyssa. SVigChr 30. Leiden: Brill.

Kettler, Franz H. 1966. Der ursprüngliche Sinn der Dogmatik des Origenes. BZNW 31. Berlin: De Gruyter.

Klauck, Hans-Josef. 2005. Apokryphe Apostelakten: Eine Einführung. Stuttgart: Katholisches Bibelwerk.

Klauck, Hans-Josef. 2008. Die apokryphe Bibel: Ein anderer Zugang zum frühen Christentum. Tria Corda 4. Tübingen: Mohr Siebeck.

Knight, Jonathan. 1996. Disciples of the Beloved One: The Christology, Social Setting and Theological Context of the Ascension of Isaiah. JSPSup 18. Sheffield: Sheffield Academic Press.

Kovacs, Judith L. 1989 [2015]. „The Archons, the Spirit, and the Death of Christ: Do we need the Hypothesis of Gnostic Opponents to explain 1 Corinthians 2,6-16?" In Apocalyptic and the New Testament: Essays in Honor ofJ. Louis Martyn. JSNT.S 24, hrsg. v. Joel Marcus und Marion L. Soards, 217-236. Sheffield: Sheffield Academic Press [London: Bloomsbury].

Kroll, Josef. 1932 [1963]. Gott und Hölle: Der Mythos vom Descensuskampf. SBW 20. Leipzig: Teubner [Darmstadt: WBG].

Kuehn, Clement A., und John D. Baggarly, S.J., Hgg. 2007. Anastasius of Sinai: Hexaemeron. OCA 278. Rom: Pontificio Istito Orientale.

Lalleman, Pieter J. 1995. „Polymorphy of Christ.“ In The Apocryphal Acts of John. Studies on the Apocryphal Acts of the Apostles 1, hrsg. v. Jan N. Bremmer, 97-118. Kampen: Pharos.

Land, Jan P. N., Hg. 1875. Anecdota syriaca. Bd. 4. Leiden: Brill. Lauchert, Friedrich, Hg. 1889 [1974]. Geschichte des Physiologus. Strassburg: Karl J. Trübner [Genève: Slatkine].

Lazaris, Stavros. 2016. Le Physiologus grec. Bd. 1, La réécriture de l'histoire naturelle antique. Micrologus Library 77.1. Florenz: SISMEL.

Lechner, Thomas. 1999. Ignatius adversus Valentinianos?: Chronologische und theologiegeschichtliche Studien zu den Briefen des Ignatius von Antiochien. SVigChr 47. Leiden: Brill.

Lechner, Thomas. 2018. „Ignatios von Antiochia und die Zweite Sophistik.“ In Die Briefe des Ignatios von Antiochia: Motive, Strategien, Kontexte. Millennium-Studien 72, hrsg. v. Peter von Möllendorff und Thomas Johann Bauer, 19-68. Berlin: de Gruyter.

Ledegang, Fred. 2018. „Animals.“ Brill Encyclopedia of Early Christianity Online. http://dx.doi.org/10.1163/2589-7993_eeco_ SIM_00000174.

Lewis, Nicola Denzey, und Justine Ariel Blount. 2014. „Rethinking the Origins of the Nag Hammadi Codices." JBL 133: 399-419.

Lewis, Sian, und Lloyd Llewellyn-Jones. 2018. The Culture of Animals in Antiquity: A Sourcebook with Commentaries. London: Routledge.

Lietzmann, Hans. 1949. An die Korinther I/II. HNT ${ }^{4} 9$. Tübingen: Mohr Siebeck.

Lindemann, Andreas. 2000. Der erste Korintherbrief. HNT 9,1. Tübingen: Mohr Siebeck.

Löhr, Winrich A. 1996. Basilides und seine Schule: Eine Studie zur Theologie- und Kirchengeschichte des zweiten Jahrhunderts. WUNT 83. Tübingen: Mohr Siebeck. 
Lona, Horacio E. 2005. Die „Wahre Lehre“ des Kelsos. KFA.ErgBd 1. Freiburg: Herder.

Lundhaug, Hugo, und Lance Jenott. 2015. The Monastic Origins of the Nag Hammadi Codices. STAC 97. Tübingen: Mohr Siebeck.

Lundhaug, Hugo, 2017. „The Nag Hammadi Codices in the complex World of 4th- and 5th-Cent. Egypt." In Beyond Conflicts: Cultural and religious Cohabitations in Alexandria and in Egypt between the 1st and the 6th Cent. CE. STAC 103, hrsg. v. Luca Arcari, 339-358. Tübingen: Mohr Siebeck.

Maas, Paul. 1936. „Drei Rezensionen.“ ByZ 37:376-381.

MacDonald, Dennis Ronald, Hg. 1990. The Acts of Andrew and the Acts of Andrew and Matthias in the City of the Cannibals. SBLTT 33. Atlanta: Scholars' Press.

Margoni-Kögler, Michael. 1994. „Psalm 24 und Christi Himmelfahrt: Ein Beitrag zur patristischen Psalmenauslegung.“ Diplomarbeit, Universität Wien [nicht konsultiert].

Markschies, Christoph. 1992. Valentinus Gnosticus? Untersuchungen zur valentinianischen Gnosis mit einem Kommentar zu den Fragmenten Valentins. WUNT 65. Tübingen: Mohr Siebeck.

Markschies, Christoph. 2000. „,Sessio ad dexteram': Bemerkungen zu einem altkirchlichen Bekenntnismotiv in der Diskusion der altkirchlichen Theologen.“ In Alta Trinità Beata: Gesammelte Studien zur altkirchlichen Trinitätstheologie, hrsg. v. Christoph Markschies, 1-69. Tübingen: Mohr Siebeck.

Markschies, Christoph, und Jens Schröter, Hgg. 2012. Antike christliche Apokryphen in deutscher Übersetzung. Bd. 1, Evangelien und Verwandtes. Tübingen: Mohr Siebeck.

Markschies, Christoph. 2016. Gottes Körper: Jüdische, christliche und pagane Gottesvorstellungen in der Antike. München: Beck.

Maspero, Giulio. 2010. „Trid spat. De tridui ... spatio.“ The Brill Dictionary of Gregory of Nyssa 739-742

Mateo-Seco, Lucas Francisco. 2010. „Liturgy.“ The Brill Dictionary of Gregory of Nyssa 451-453.

Metzler, Karin, und Kyriakos Savvidis, Hgg. 1998. Athanasius Werke. Bd. 1,1,2, Die dogmatischen Schriften: Orationes I et II contra Arianos. Berlin: De Gruyter.

Metzler, Karin, und Kyriakos Savvidis, Hgg. 2000. Athanasius Werke. Bd. 1,1,3, Die dogmatischen Schriften: Oratio III contra Arianos. Berlin: De Gruyter.

Michl, Johann. 1962. „Engel: I-IX.“ RAC 5:53-258.

Mitchell, Margaret M. 2016. „'Problems and Solutions' in Early Christian Biblical Interpretation: A Telling Case from Origen's Newly Discovered Greek Homilies on the Psalms (Codex Monacensis Graecus 314).“ Adamantius 22:40-55.

Mitchell, Margaret M. 2017. „Pauline Accommodation and “Con-

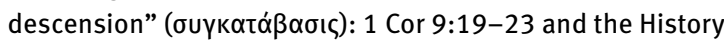
of Influence." In Paul and the Emergence of Christian Textuality. Collected Essays, Vol. I. WUNT 393, hrsg. v. Margaret M. Mitchell, 193-217. Tübingen: Mohr Siebeck.

Möhler, Johann Adam. 1840. Patrologie, oder christliche Literärgeschichte. Regensburg: Manz.

Moreschini, Claudio, und Enrico Norelli. 2007. Handbuch der antiken christlichen Literatur. Gütersloh: Gütersloher.

Moutsoulas, Elias. 2010. „Ascens.“ The Brill Dictionary of Gregory of Nyssa 86-87.

Mühlenberg, Ekkehard. 2015. „Theologie und Frömmigkeit bei den Apollinaristen." In Apollinarius und seine Folgen. STAC 93, hrsg. v. Silke-Petra Bergjan, Benjamin Gleede und Martin Heimgartner, 129-139. Tübingen: Mohr Siebeck.
Müller, C. Detleff G. ${ }^{6} 1997$. „Die Himmelfahrt des Jesaja.“ In Neutestamentliche Apokryphen in deutscher Übersetzung. Bd. 2, Apostolisches, Apokalypsen und Verwandtes, hrsg. v. Wilhelm Schneemelcher, 547-562. Tübingen: Mohr Siebeck.

Müller, C. Detleff G. 2012. „Die Epistula Apostolorum.“ In Antike christliche Apokryphen in deutscher Übersetzung. Bd. 1, Evangelien und Verwandtes, hrsg. v. Christoph Markschies und Jens Schröter, 1062-1092. Tübingen: Mohr Siebeck.

Müller, Reinhard. 2008. Jahwe als Wettergott: Studien zur althebräischen Kultlyrik anhand ausgewählter Psalmen. BZAW 387. Berlin: De Gruyter.

Muradyan, Gohar, Hg. 2005. Physiologus: The Greek and Armenian Versions with a Study of Translation Technique. HUAS 6. Löwen: Peeters.

Nicklas, Tobias. 2013. „Staunen über Natur und christliche Lebenshaltung: Die Welten des Physiologus“. In Credible, Incredible: The Miraculous in the ancient Mediterranean. WUNT 321, hrsg. v. Tobias Nicklas und Janet E. Spittler, 227-250. Tübingen: Mohr Siebeck.

Nicklas, Tobias. 2015. „Der Philipperbrief in der Hand von ,Häretikern': Ascensio Isaiae und Evangelium Veritatis.“ In Der Philipperbrief des Paulus in der hellenistisch-römischen Welt. WUNT 353, hrsg. v. Jörg Frey und Benjamin Schliesser, 327-347. Tübingen: Mohr Siebeck.

Norelli, Enrico, Hg. 1995. Ascensio Isaiae: Commentarius. CCSA 8. Brepols: Turnhout.

Offermanns, Dieter, Hg. 1966. Der Physiologus nach den Handschriften $G$ und M. BKP 22. Meisenheim am Glan: A. Hain.

O’Laughlin, Michael. 1999. „Closing the Gap between Antony and Evagrius.“ In Origeniana septima: Origenes in den Auseinandersetzungen des 4. Jahrhunderts. BETL 137, hrsg. v. Wolfgang A. Bienert und Uwe Kühneweg, 345-354. Löwen: Leuven University Press.

Ostheim, Martin R. von, 2008. Ousia und Substantia: Untersuchungen zum Substanzbegriff bei den vornizänischen Kirchenvätern. Zürcher Arbeiten zur Philosophie 1. Basel: Schwabe.

Otto, Johann K. Th. von, Hg. 1857. Corpus Apologetarum Christianorum saeculi secundi. Bd. 9. Jena: Mauke.

Perry, Ben E. 1941. „Physiologus.“ PRE 20,1:1074-1129.

Peters, Emil, Hg. 1898 [1976]. Der griechische Physiologus und seine orientalischen Übersetzungen. Festschriften der Gesellschaft für deutsche Philologie 15. Berlin: S. Calvary [Hildesheim: Olms].

Peterson, Erik. (1954) 1959. „Die Spiritualität des griechischen Physiologos.“ In Frühkirche, Judentum und Gnosis: Studien und Untersuchungen, hrsg. v. Erik Peterson, 236-253. Rom: Herder (= Byzantinische Zeitschrift 47:60-72).

Pitra, Jean Baptiste, Hg. 1855. „Veterum gnosticorum in Physiologum allegoricae interpretationes." In Spicilegium Solesmense complectens sanctorum patrum scriptorumque ecclesiasticorum anecdota hactenus opera. Bd. 3, In quo praecipui veteres auctores de re symbolica proferuntur et illustrantur, hrsg. v. Jean Baptiste Pitra, 338-373; 391-394. Paris: Firmin Didot.

Plümacher, Eckhard. 1992. „Paignion und Biberfabel: Zum literarischen und popularphilosophischen Hintergrund von Acta Iohannis 60f.48-54.“ Apocrypha 3:69-109.

Ponce de Leon, Luis, Hg. 1587. Sancti Patris nostri Epiphanii episcopi Constantiae Cypri ad Physiologum. Rom: Zanetti \& Ruffinelli.

Prinzivalli, Emanuela. 1999. „The Controversy about Origen before Epiphanius.“ In Origeniana septima: Origenes in den Auseinan- 
dersetzungen des 4. Jahrhunderts. BETL 137, hrsg. v. Wolfgang A. Bienert und Uwe Kühneweg, 195-213. Löwen: Leuven University Press.

Prostmeier, Ferdinand R., Hg. 1999. Der Barnabasbrief. Kommentar zu den Apostolischen Vätern 8. Göttingen: Vandenhoeck \& Ruprecht.

Rahner, Hugo. ${ }^{2} 1957$. Griechische Mythen in christlicher Deutung. Zürich: Rhein.

Reuss, Joseph, Hg. 1966. Johannes-Kommentare aus der griechischen Kirche: Aus Katenenhandschriften gesammelt. TU 89. Berlin: Akademie Verlag.

Richard, Marcel, Hg. 1956. Asterii Sophistae Commentariorum in Psalmos quae Supersunt Accedunt Aliquot Homiliae Anonymae. Oslo: A.W. Brogger.

Riedinger, Rudolf. 1973. „Der Physiologos und Klemens von Alexandreia.“ Byzantinische Zeitschrift 66:273-307.

Riedweg, Christoph, Christoph Horn und Dietmar Wyrwa, Hgg. 2018. Die Philosophie der Antike. Band 5: Philosophie der Kaiserzeit und der Spätantike. Grundriss der Geschichte der Philosophie. Begründet von Friedrich Ueberweg. Basel: Schwabe.

Riedinger, Rudolf. 1977. „D. Kaimakis, Der Physiologos nach der ersten Redaktion. [Meisenheim am Glan 1974]." Byzantinische Zeitschrift 70,1:109-112.

Rouwhorst, Gerard. 2014. „Hymns and Prayers in the Apocryphal Acts of Thomas." In Literature or liturgy? Early Christian Hymns and Prayers in their literary and liturgical Context in Antiquity. WUNT II/363, hrsg. v. Clemens Leonhard und Hermut Löhr, 195-212. Tübingen: Mohr Siebeck.

Rubenson, Samuel. 1999. „Origen in the Egyptian Monastic Tradition of the Fourth Century. "In Origeniana septima: Origenes in den Auseinandersetzungen des 4. Jahrhunderts. BETL 137, hrsg. v. Wolfgang A. Bienert und Uwe Kühneweg, 319-337. Löwen: Leuven University Press.

Runia, David T. 2002. Philo of Alexandria: On the Creation of the Cosmos according to Moses. Philo of Alexandria Commentary Series 1. Brill: Leiden.

Sbordone, Francesco, Hg. 1936a [1976, ${ }^{2}$ 1991]. Physiologus. Rom: Società Anonima Editrice ,Dante Alighieri` [Hildesheim: Olms].

Schenke, Hans-Martin, Hg. 1997. Das Philippus-Evangelium: (NagHammadi-Codex II,3). TU 143. Berlin: Akademie Verlag.

Schenke, Hans-Martin, Hans-Gebhard Bethge und Ursula Ulrike Kaiser, Hgg. ${ }^{3}$ 2013. Nag Hammadi Deutsch: Studienausgabe. Berlin: De Gruyter.

Schmidt, Carl, Hg. 1925. Pistis Sophia: Ein gnostisches Originalwerk des dritten Jahrhunderts aus dem Koptischen übersetzt. Leipzig: J.C. Hinrichs.

Schneemelcher, Wilhelm, Hg. ${ }^{6} 1997$. Neutestamentliche Apokryphen in deutscher Übersetzung. Bd. 2, Apostolisches, Apokalypsen und Verwandtes. Tübingen: Mohr Siebeck.

Schneider, Horst. 2016. „Physiologus.“ RAC 27:722-743.

Schoedel, William R. 1990. Die Briefe des Ignatius von Antiochien: Ein Kommentar. München: Kaiser.

Schönberger, Otto. (2001) 2014. Physiologus: Griechisch/Deutsch. Stuttgart: Reclam.

Schrage, Wolfgang. 1991. Der erste Brief an die Korinther (1 Kor 1,1-6,11). EKK 7,1. Zürich: Benziger; Neukirchen: Neukirchener.

Schwager, Raymund. 2015. Der wunderbare Tausch. Zur Geschichte und Deutung der Erlösungslehre. Gesammelte Schriften 3. Freiburg: Herder.
Scott, Alan. 1998. „The Date of the Physiologus.“ Vigiliae Christianae 52:430-441.

Scully, Jason. 2018. „Redemption for the Serpent: The Reception History of Serpent Material from the Physiologus in the Greek, Latin, and Syriac Traditions.“ ZAC 22:422-455.

Seel, Otto. $(1960)^{3}$ 2005. Der Physiologus: Tiere und ihre Symbolik. (Zürich: Artemis \& Winkler) Düsseldorf: Patmos.

Seibt, Werner. 1993. „Physiologus.“ LMA 6:2117-2118.

Seiler, Ingrid. 1975. Didymos der Blinde: De trinitate; Buch 2, Kapitel 1-7. BKP 52. Meisenheim am Glan: Anton Hain.

Sellin, Gerhard. 2009. „Das ,Geheimnis‘ der Weisheit und das Rätsel der ,Christuspartei“ (zu 1 Kor 1-4).“ In Studien zu Paulus und zum Epheserbrief. FRLANT 229, hrsg. v. Gerhard Sellin, 9-36. Göttingen: Vandenhoeck \& Ruprecht.

Stamatiou, Aristides, und Andreas Weckwerth. 2010. „Löwe.“ $R A C$ 23:257-286.

Stander, Hendrik F. 1989. „The Starhymn in the Epistle of Ignatius to the Ephesians (19:2-3).“ Vigiliae Christianae 43: 209-214.

Steiger, Christoph von, und Otto Homburger, Hgg. 1964/ 2012. Physiologus Bernensis: Voll-Faksimile-Ausgabe des Codex Bongarsianus 318 der Burgerbibliothek Bern, Basel: Alkuin. / Bern, Burgerbibliothek, Cod. 318: Physiologus Bernensis, redigiert und ergänzt von Florian Mittenhuber, Juni 2012, http://www.e-codices.unifr.ch/de/list/one/bbb/0318.

Stommel, Eduard. 1958. „A. Grillmeier: Der Logos am Kreuz; Zur christologischen Symbolik der älteren Kreuzigungsdarstellung (München 1956).“JAC 1:127-129.

Stroppa, Marco. 2017. „The Physiologus in Egypt.“ In Proceedings of the XI International Congress of Egyptologists. Archaeopress Egyptology 19, hrsg. v. Gloria Rosati und Maria Cristina Guidotti, 603-607. Oxford: Archaeopress.

Ter-Mekerttschian, Karapet, und Erwand Ter-Minassiantz, Hgg. 1907. Des heiligen Irenäus Schrift zum Erweise der apostolischen Verkündigung: In armenischer Version, entdeckt, herausgegeben und ins Deutsche übersetzt; Mit einem Nachwort und Anmerkungen von A. Harnack. TU 31,1. Leipzig: J.C. Hinrichs.

Thümmel, Hans Georg, Hg. 2011. Origenes'Johanneskommentar: Buch I-V. STAC 63. Tübingen: Mohr Siebeck.

Tischendorf, L. F. Konstantin von, Hg. 1866. Apocalypses apocryphae Mosis, Esdrae, Pauli, Iohannis, item Mariae dormitio, additis evangeliorum et actuum apocryphorum supplementis. Leipzig: Hermann Mendelssohn.

Treu, Ursula. 1959. „,Otterngezücht‘: Ein patristischer Beitrag zur Quellenkunde des Physiologus.“ZNW 50:113-122.

Treu, Ursula. 1966. „Zur Datierung des Physiologus.“ ZNW 57:101104.

Treu, Ursula. (1981) ${ }^{3}$ 1998. Physiologus: Naturkunde in frühchristlicher Deutung, Hanau: Artia.

Treu, Ursula. 1993. „The Physiologus and the Early Fathers.“ Studia patristica 24:197-200.

Treu, Ursula. (1999) 2009. „Physiologus.“ LThK ${ }^{3}$ 8:276-277.

Uhrig, Christian. 2004. „Und das Wort ist Fleisch geworden“: Zur Rezeption von Joh 1,14a und zur Theologie der Fleischwerdung in der griechischen vornizänischen Patristik. MBT 63. Münster: Aschendorff.

Uthemann, Karl-Heinz, Remco F. Regtuit und Johannes M. Tevel, Hgg. 1994. Homiliae Pseudo-Chrysostomicae: Instrumentum studiorum. Bd. 1. Turnhout: Brepols. 
Uthemann, Karl-Heinz. 2005. Christus, Kosmos, Diatribe: Themen der frühen Kirche als Beiträge zu einer historischen Theologie. AKG 93. Berlin: De Gruyter.

Vecoli, Fabrizio. 2017. „Writing and Monastic Doctrine.“ In Writing and Communication in Early Egyptian Monasticism. Texts and Studies in Eastern Christianity 9, hrsg. v. Malcolm Choat und Maria Chiara Giorda. 165-186. Leiden: Brill.

Vogt, Hermann J. 1983; 1990; 1993. Origenes: Der Kommentar zum Evangelium nach Matthäus. BGrL 18; 30; 38. Stuttgart: Hiersemann.

Vogt, Hermann J. 1999. „Wie Origenes in seinem MatthäusKommentar Fragen offen lässt." In Hermann Josef Vogt: Origenes als Exeget, hrsg. v. Wilheln Geerlings, 105-111. Paderborn: Ferdinand Schöningh.

Vogt, Hermann J. 1999. „Warum wurde Origenes zum Häretiker erklärt? Kirchliche Vergangenheitsbewältigung in der Vergangenheit.“ In Hermann Josef Vogt: Origenes als Exeget, hrsg. v. Wilheln Geerlings, 241-263. Paderborn: Ferdinand Schöningh. Vollenweider, Samuel. 1989. Freiheit als neue Schöpfung: Eine Untersuchung zur Eleutheria bei Paulus und in seiner Umwelt. FRLANT 147. Göttingen: Vandenhoeck \& Ruprecht.

Vollenweider, Samuel. 2002. „Zwischen Monotheismus und Engelchristologie: Überlegungen zur Frühgeschichte des Christusglaubens." In Horizonte neutestamentlicher Christologie: Studien zu Paulus und zur frühchristlichen Theologie. WUNT 144 hrsg. v. Samuel Vollenweider, 3-27. Tübingen: Mohr Siebeck.

Vollenweider, Samuel. 2012. „Luzifer - Herrlichkeit und Sturz des Lichtengels: Eine Gegengeschichte zu Demut und Erhöhung von Jesus Christus.“ In Das Böse. JBTh 26 (2011), hrsg. v. Jörg Frey und Gabrielle Oberhänsli-Widmer, 203-226. NeukirchenVluyn: Neukirchener.
Vollenweider, Samuel. 2014. „Weltdistanz und Weltzuwendung im Urchristentum" In Der Mensch zwischen Weltflucht und Weltverantwortung: Lebensmodelle der paganen und der jüdischchristlichen Antike. STAC 87, hrsg. v. Heinz-Günther Nesselrath und Meike Rühl, 127-145. Tübingen: Mohr Siebeck.

Wellmann, Max. 1930. „Der Physiologos: Eine religionsgeschichtlich-naturwissenschaftliche Untersuchung.“ Philologus: Zeitschrift für das klassische Altertum; Supplementband 22,1:1116.

Wickham, Lionel R. 1981. „Soul and Body: Christ's Omnipresence.“ In The Easter Sermons of Gregory of Nyssa: Translation and Commentary, hrsg. v. Andreas Spira und Christopher Klock, 279-292. Philadelphia: Patristic Foundation.

Williams, Frank, Hg. ${ }^{2}$ 2009. The Panarion of Epiphanius of Salamis: Book I (Sects 1-46). NHMS 63. Leiden: Brill.

Windisch, Hans. 1920. Der Barnabasbrief. HNT 19. Tübingen: Mohr Siebeck.

Winling, Raymond, Hg. 2000. Grégoire de Nysse: Discours catéchétique. SC 453. Paris: Éditions du cerf.

Witte, Bernd, Hg. 1993. Die Schrift des Origenes über das Passa: Textausgabe und Kommentar. Arbeiten zum spätantiken und koptischen Ägypten 4. Altenberge.

Zambon, Marco, unter Mitwirkung von Dietmar Wyrwa. 2018. „Origenes." In Riedweg, Horn, und Wyrwa 2018, 957-997.

Zucker, Arnaud. (2004) 22005. Physiologos: Le bestiaire des bestiaires. Grenoble: Jérôme Millon. 


\section{Rainer Hirsch-Luipold \\ Unicornis captivatur}

\section{Das Deutungsverfahren des Physiologus und die Rezeption und theologische Deutung seiner Tiersymbolik in mittelalterlicher Dichtung und zeitgenössischer Musik}

\begin{abstract}
The Engelberg Codex 314, a medieval manuscript kept in the library of the Benedictine abbey in Engelberg, Switzerland, contains a poetic adaption of the Latin version of the Physiologus. The goal of the presentation of the animals, however, has changed: the Physiologus intends to present a theological interpretation of nature, whereas the medieval hymn, inspired by the Physiologus, arranges the biblical animal symbolism into a narrative of the fall and restoration of humankind as well as the sacrificial death and resurrection of Christ, using the multifaceted animal imagery of the bible. This contribution examines this new perspective, also considering a musical rendition of Unicornis captivatur for a-capella choir by the Norwegian composer Ola Gjeilo (written in 2001). It is hoped that the change of perspective afforded by both the hymn and the modern composition will shed additional light on the hermeneutics of nature in the Physiologus.
\end{abstract}

\section{Zum Deutungsverfahren des Physiologus anhand des „Hirsches“}

„Wie den Hirsch nach Wasserquellen dürstet, so dürstet meine Seele nach Dir, o Gott“. Mit dem Zitat aus Ps 42,2 $\left(41,2^{\mathrm{LXX}}\right)$ beginnt der Physiologus sein Kapitel zum Hirschen, den er - als Feind der Schlange, des Ursymbols des Bösen - durchaus zu loben weiß. Der Hirsch spült die

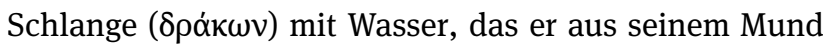
strömen lässt, aus ihrem Versteck, um sie zu töten. So ist er Urbild Christi der durch sein Opfer alles Böse und zuletzt den Tod zertritt. Zugleich ist der Hirsch das Bild der Jesus nachfolgenden Asketen: Wie der Hirsch aus Ps $41,2^{\mathrm{LXX}}$ dürstend zur Quelle eilt, so eilen sie mit ihrem entbehrungsvollen Leben - wie von Durst gequält - zu den Quellen der rettenden Reue.

Gerne hätte ich es wie Jürgen W. Einhorn gemacht der eine große Monographie zum Einhorn geschrieben hat $^{1}$ - und meine Darstellung dem Hirsch gewidmet. Aber leider wird gerade der Hirsch in dem auf dem Physiologus basierenden mittelalterlichen Hymnus über das „Einhorn“ (Unicornis captivatur), dem dieser Beitrag vor allem gelten soll, nicht aufgegriffen. Immerhin einleitend lohnt es sich dennoch, auf den Hirsch einzugehen. Denn an der Deutung des Hirsches lässt sich der Zugriff des Physiologus auf den Text der Bibel ebenso deutlich machen wie das angewendete Deuteverfahren. ${ }^{2}$ Nach diesem ersten Teil werden wir in einem zweiten Schritt vergleichend einen Blick auf den auf dem Physiologus aufbauenden mittelalterlichen Hymnus und dessen Verfahren in der Deutung der Tiere werfen, um so im Spiegel der Rezeption die jeweiligen Besonderheiten besonders deutlich hervortreten zu lassen. Dabei nehmen wir auch Ola Gjeilos moderne musikalische Umsetzung des Hymnus in einer zeitgenössischen Komposition für achtstimmigen Chor a-capella mit in den Blick, wodurch wir gewissermassen ein dreidimensionales Bild im Spiegel der Rezeption erhalten.

Ziel des Physiologus ist eine christologische Gesamtdeutung der Natur. Im Hintergrund steht die Überzeugung, so wäre meine These, dass der göttliche Schöpfungslogos, der nach dem Johannesprolog Joh 1,1-18 in die Welt eingegangen ist und sie so ins Sein gerufen hat, aus dieser Welt erkennbar ist. Dieser Schöpfungslogos aber ist Christus, wie dem Prolog ebenfalls zu entnehmen ist $(1,17)$. Um diesen Logos innerhalb der Welt zu entdecken und aufzudecken, gehen die einzelnen Abschnitte oft von biblischen, vielfach den Psalmen entnommenen Zitaten aus, in denen

1 Die Arbeit trägt den Titel „Spiritalis Unicornis. Das Einhorn als Bedeutungsträger in Literatur und Kunst des Mittelalters“ (Einhorn [1998]).

2 T. Kraus diskutiert am Beispiel des Einhorns den typischen Aufbau eines Physiologus-Abschnitts (im vorliegenden Band S. 68): 1. Septuaginta-Stelle; 2. Formelhafte Überleitung zum Physiologus, 3. Explikation/Charakterisierung durch den Physiologus, 4. Auslegung/Allegorese; 5. Abschlussformel. Auch wenn mich die Unterscheidung von 3 und 4 nicht wirklich überzeugt, weil bereits die Charakterisierung durch den Physiologus verschiedentlich von der Deutungsebene her gearbeitet und nur von dort her verständlich ist, wie es für eine Allegorie kennzeichnend ist, so ist der Ansatz m.E. wichtig und richtig, dass wir mehr über die Deutungstechnik des Physiologus erfahren müssen, die von Tier zu Tier durchaus signifikant variiert, wobei sich bestimmte Deutungsmuster herausarbeiten lassen. 
Tiere erscheinen, ${ }^{3}$ und verbinden diese mit naturkundlichem Handbuchwissen oder Details aus Mirabilia- oder Paradoxa-Sammlungen. ${ }^{4}$ So ist in Blick auf den Hirsch in mehreren naturkundlichen Texten ${ }^{5}$ tatsächlich zu lesen, dass er die Schlange mit seinem Atem (nicht freilich mit Wasser) aus einem Versteck herauszieht. Es ist eine scheinbar kleine Änderung, die der Physiologus vornimmt - Wasser statt Atem. Sie zeigt indes, wie die naturkundlichen Darlegungen des Physiologus bisweilen bereits von der Deutungsebene, also der Christologie, her konstruiert $\operatorname{sind}^{6}$ : nicht mit seinem Atem besiegt nämlich Christus die Schlange, den Tod, sondern mit Blut und Wasser, das aus seinem Leib fließt (Joh 19,34). So gelingt es, die für das Evangelium zentrale Wassermetaphorik (Christus als Geber lebenstiftenden Wassers; Joh 4,10.13-15; vgl. 7,38) in das Bild aufzunehmen. Manches Mal bestimmt die christologische Aussageabsicht die Darstellung wie die Deutung in einer solchen Weise, dass man sich durchaus fragen mag, ob überhaupt ein Interesse an dem vorgegebenen biblischen Text bzw. den tatsächlichen Naturzusammenhängen besteht oder diese lediglich als „Sprungbrett“ für die entsprechenden Deutungen fungieren. ${ }^{7}$

Am Beispiel des Hirschs lässt sich ein Deutungsverfahren im Dreischritt sichtbar machen, das auch eine Reihe anderer Kapitel prägt.

\subsection{Analyse/Dekonstruktion}

Zunächst einmal wird der vorangestellte Bibelvers („Wie den Hirsch nach Wasserquellen dürstet, so dürstet meine Seele nach Dir, o Gott“; Ps 41, $2^{\mathrm{LXX}}$ ) im Physiologus in seine

3 Fast in der Hälfte der Fälle steht ein Bibelvers am Anfang, der allegorisierend gedeutet wird, oftmals - wie hier - aus den Psalmen. 4 Die Grenze zwischen naturwissenschaftlichem Handbuch und Mirabilienliteratur ist hier vielfach fließend - es kann im Folgenden nicht darum gehen, die Deutungen des Physiologus zu bewerten und auf ihre wissenschaftliche Exaktheit im modernen Sinne hin zu befragen, sondern zunächst einmal darum, die Hermeneutik und Auslegungstechnik des Physiologus zu verstehen.

5 Plinius, Naturalis historia 8.118; Aelian, De natura animalium 2.9; Oppian, Kynegetika 2.236-240; vgl. Schönberger (2001, 120).

6 Dass etwa der Löwe mit dem Schwanz seine Spuren verwischt, wird sich wohl kaum durch Naturbeobachtung untermauern lassen, obwohl sich Ähnliches durchaus in antiker naturkundlicher Literatur findet (vgl. dazu den Beitrag von S. Vollenweider im vorliegenden Band). Es versteht sich nur von einer christologischen Gesamtdeutung her.

7 Die Formulierung „Sprungbrettargument“ hat Heinz Gerd Ingen-

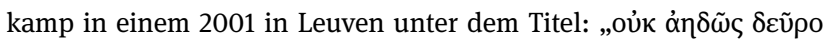

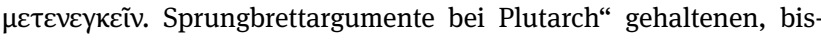
lang aber unveröffentlichten Vortrag zu Plutarch geprägt. einzelnen Bilder aufgelöst und die einzelnen Bildfelder je für sich betrachtet (Hirsch/Schlange/Wasser) und christologisch ausgedeutet.

\subsubsection{Einbeziehen weiterer Bibelstellen zum jeweiligen Motivfeld}

Dieses dekonstruktive Verfahren macht es möglich, das Bildmaterial des jeweiligen Bibelverses mit anderen biblischen Verwendungen der enthaltenen Einzelmotive kurzzuschließen. Bestimmte Schriften treten dabei favorisiert auf, so in den christologischen Deutungen das Johannesevangelium und in den ethischen Deutungen das Matthäusevangelium. In unserem Beispiel können, nachdem Hirsch und Wasser zu zwei Einzelbausteinen auseinandergenommen worden sind, alle Stellen hinzugenommen werden, in denen eines der Motive vorkommt. Die Dekonstruktion des Bibelverses und die christologische Deutung der Einzelmotive erlaubt es, das Verhältnis von Hirsch und Wasser in doppelter Weise neu zu bestimmen. Nicht nur dürstet den Hirsch nach Wasser wie im Psalmvers. Im Physiologus lässt der Hirsch umgekehrt Wasser aus sich heraussprudeln, wird also zur Quelle des lebenspendenden Wassers. Damit wird eine Verbindung von Ps 42 mit der Wassermetaphorik des Johannesevangeliums hergestellt. Der Hirsch wird so zum Bild des johanneischen Christus als des Gebers von lebendigem Wasser (Joh 7,38; 19,34).

\subsection{Synthese}

In einer allegorisierenden Deutung wird das atomisierte Bildmaterial des Bibelverses mit anderen christologischen, anthropologisch-ethischen oder auch auf Tod und Teufel bezogenen Verwendungen desselben Motivs kurzgeschlossen und auf diese Weise schließlich in einer synchron-kanonischen Betrachtung $\mathrm{zu}$ einem christologisch-soteriologischen Mosaik neu zusammengesetzt. ${ }^{8}$ Dass der Hirsch Wasser aus sich strömen lässt, um die Schlange hervorzuholen, dreht zwar das Psalmbild um und ist in dieser Form in antiker Tierliteratur singulär (dort ist eben vom Atem die Rede). Von der zentralen Be-

8 Der Begriff des Bildes scheint gegenüber dem der Allegorie deshalb geeigneter, weil es sich bei der Hermeneutik des Physiologus nicht um ein rein sprachlich-literarisches Verfahren handelt. Vielmehr ist die sprachliche Operation nur durch eine tatsächliche Beziehung in der gegenständlichen Welt gedeckt, die wiederum, wie bereits gesagt wurde, durch das Eingehen des göttlichen Schöpfungslogos in diese Welt zustandegekommen ist. 
deutung des Wassermotivs im Johannesevangelium her ist es indes - vor dem Hintergrund der christologischen Deutung des Hirsches - sofort verständlich: im Johannesevangelium spendet tatsächlich Christus Wasser, und zwar solches Wasser, das den Dürstenden dauerhaft tränkt und ihm so ewiges Leben schenkt (insb. Joh 4,10-15; 7,37-38; $\left.19,34^{9}\right)$. Das lebenspendende Wasser, das von Christus ausgeht, wird als „aus den himmlischen Wassern“ stam-

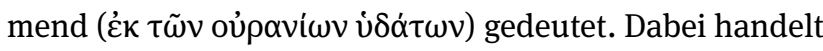
es sich um eine ganz johanneische Formulierung, die aber in dieser Form nicht bei Johannes vorkommt (lediglich als „Brot vom Himmel“ wird Jesus in Joh 6 bezeichnet). Zudem: Wer den Erzählfortschritt in Joh 4 im Blick hat, wo es Jesus zunächst dürstet und er deshalb die Frau am Brunnen um Wasser bittet $(4,7)$, nur um ihr wenig später zu sagen, sie hätte eigentlich ihn um Wasser bitten sollen $(4,10)$, den wird diese Umkehrung des Bildes schwerlich verwundern. Nach dem Physiologus erfolgt die Lebensgabe aber dadurch, dass Christus mit dem Wasser die Schlange (sc. den Teufel) tötet. Diese Deutung verbindet die johanneisch-christologische Vorstellung von Christus als dem Spender des Lebens in typischer Weise mit der matthäisch-ethischen Sicht der Überwindung des Todes durch die Überwindung von Sünden und Lastern.

Das führt auf eine doppelte Deutung: eine im Kern unjohanneisch-ethische, die aber mit der johanneischen Vorstellung von Jesus als dem göttlichen Wort kurzgeschlossen ist und der asketisch-ethischen Auslegungstendenz des Physiologus entspricht: das Wasser sind die göttliche Worte, die zehn Gebote nämlich, die nach Mt 19,18-19 den Weg zum Leben führen. Dieser Deutung entsprechend wird der Hirsch im Verlauf des Textes auf den Asketen gedeutet: mit seinem enthaltsamen Leben macht er sich gleichsam dürstend „zu den Quellen der rettenden Reue“ auf, löscht die „feurigen Geschosse des Bösen“ (Eph $6,16)$ aus und tötet so die Schlange in seinem Herzen. ${ }^{10}$

Ganz johanneisch indes ist die zweite christologischsoteriologische Deutung, die der johanneischen Passionsgeschichte folgt: aus der von einem römischen Soldaten am Kreuz geöffneten Seite Jesu fließt - gemischt mit Blut heilsames Wasser heraus (Joh 19,34), das im Physiologus

9 Vgl. dazu Ng (2001); Jones (1997). Vgl. auch Sir 15,3: Die Weisheit speist den Gottesfürchtigen mit Verständnis und tränkt ihn mit dem

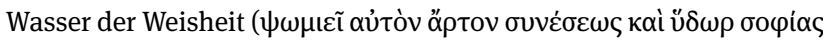

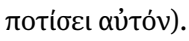

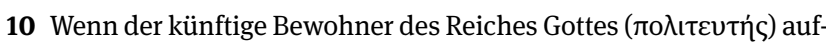
gefordert wird, sein Innerstes ( $\tau \grave{\alpha}$ ỏyycĩa) mit Wasser aufzufüllen $(\varepsilon \dot{\varepsilon} \pi \dot{i} \mu \pi \lambda \eta \mu)$, dann werden dabei wörtlich die am Anfang des Kapitels mit Blick auf den Hirsch verwendeten Formulierungen aufgenommen

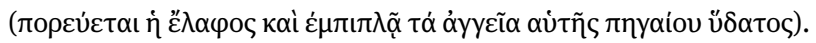

als „Bad der Wiedergeburt“ gedeutet wird. ${ }^{11}$ Durchaus typisch für solchermaßen bildhaft strukturierte Literatur bekommen wir im Anschluss sogleich noch eine Etymo-

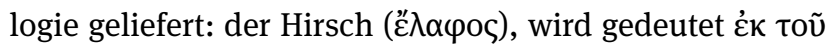

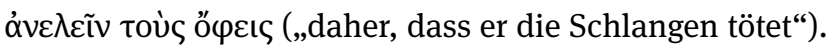
Und die Schlange (ő $\varphi$ ı) wird gedeutet als ò $\varphi$ ń („,Sprecher"), weil sie damals die Eva angesprochen und in Versuchung geführt hat und so zu Urheberin und Inbegriff der Spende geworden ist.

\section{Der mittelalterliche Hymnus unicornis captivatur und seine musikalische Umsetzung durch Ola Gjeilo}

Im Folgenden möchte ich - als ein exemplarisches Beispiel der vielfältigen Rezeption des Physiologus - den mittelalterlichen Hymnus Unicornis captivatur herausgreifen und dessen musikalische Umsetzung in einem zeitgenössischen Chorstück von Ola Gjeilo vergleichend mitbetrachten. Beim Unicornis captivatur handelt es sich um eine mittelalterliche lateinische Nachdichtung des Physiologus, die sich im Engelberger Kodex 314 findet, einer im Benediktiner-Stift Engelberg entstandenen liturgischen Handschrift, die auch bereits eine musikalische Notierung enthält. Es ist davon auszugehen, dass die Nachdichtung eine frühere lateinische Version voraussetzt, vielleicht den (nicht erhaltenen) lateinischen Physiologus, der in einem von Abt Frowin Mitte des 12. Jhs. (1131-1178) ebenfalls in Engelberg angefertigten Bücherverzeichnis genannt wird. $^{12}$

Im nun folgenden Vergleich gilt es insbesondere herauszuarbeiten, wie dieser Hymnus - wiewohl auf der Tradition des Physiologus beruhend - einem anderen Zugriff und Aufbau sowie einer anderen hermeneutischen Grundidee folgt, sodass durch den Blick auf den mittelalterlichen Hymnus im Kontrast ein Schlaglicht auf die ganz anders gelagerte Hermeneutik der Natur im Physiologus fällt.

11 Vgl. die mit der Taufe verbundene abrenuntiatio diaboli. 12 Vgl. Henkel (1976, 56). Den Hinweis verdanke ich Zbyněk Kindschi Garský; gedankt sei auch unserem Berner Handschriften- und Philologieexperten Kurt Keller für vielfachen Rat in diesem Teil. 
A. Unicornis captivatur, Aule regum presentatur Venatorum laqueo.

Palo serpens est levatus,

Medicatur sauciatus

Veneno vipereo.

Alleluia canite agno morienti,

Alleluia pangite,

Alleluia promite leoni vincenti.

B. Pellicano vulnerato

Vita redit pro peccato,

Nece stratis misera.

Phos fenicis est exusta,

Concremanturque vetusta

Macrocosmi scelera.

Alleluia...

C. Idrus intrat crocodillum,

Extis privat, necat illum

Vivus inde rediens.

Tris diebus dormitavit

Leo, quem resuscitavit

Basileus rugiens.

Alleluia...
Das Einhorn wird gefangen,

Dem Königshofe wird es vorgeführt

In der Schlinge der Jäger.

Vom Stamm wurde die Schlange emporgehoben, Verwundet wird sie geheilt

Durch das Schlangengift.

Singt Halleluja dem sterbenden Lamm, Spielt Halleluja,

Ruft Halleluja dem siegreichen Löwen.

Durch den Pelikan - verwundet

Um der Sünde willen - kehrt das Leben zurück,

Durch seinen elenden Tod für die Hingestreckten.

Das Licht des Phoenix ist ausgebrannt,

Und mit verbrennen die uralten

Vergehen der ganzen Welt.

Singt Halleluja ...

Die Hydra tritt in das Krokodil ein,

Beraubt es seiner Eingeweide, tötet es

Und kehrt lebendig von dort zurück.

Drei Tage schlief

Der Löwe, bis ihn wieder aufweckte

Der König mit Gebrüll.

Singt Halleluja ...

Tab. 1: Der mittelalterliche Hymnus Unicornis captivatur - Text und Übersetzung 


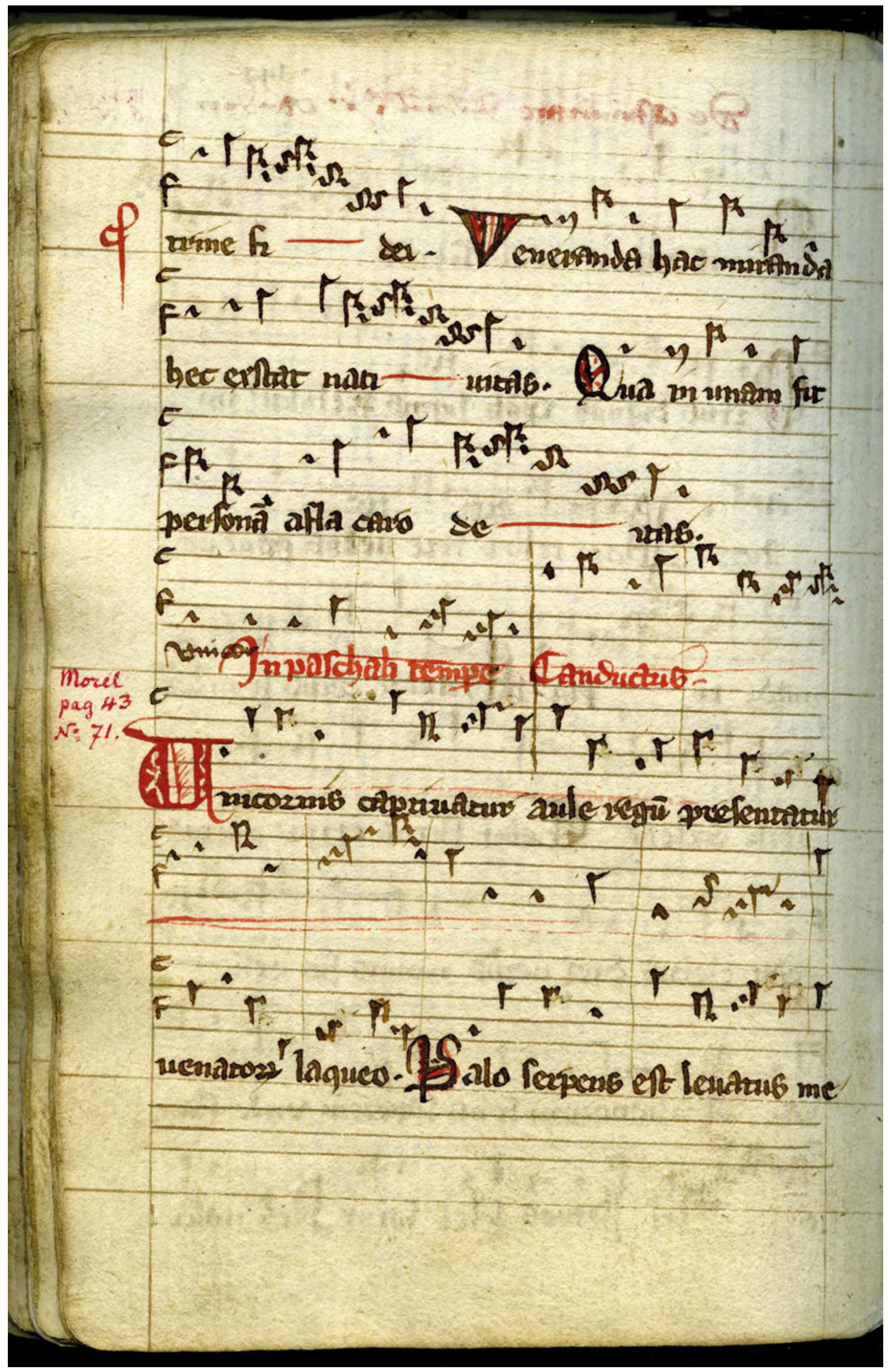

Abb. 1: Anfang des Hymnus Unicornis captivatur mit Überschrift in der Stiftsbibliothek Engelberg, cod. 314, Blatt 150. 
Ein Beispiel vorab: Im Physiologus stellt sich ein pädagogischer Effekt dadurch ein, dass die Bibelstellen vielfach erläuternd beigegeben und die entsprechenden bildhaften Deutungen expliziert werden. Dieser pädagogische Aspekt fehlt im Hymnus, freilich auch aufgrund der Gattung, völlig. Nicht einmal die Identifikation mit Christus wird hier explizit vorgenommen, sie wird vielmehr angesichts der vorausliegenden Geschichte der Hermeneutik des Physiologus bereits vorausgesetzt. Am Beginn der Geschichte aber, im Physiologus, müssen selbst dem mit der biblischen Bildwelt Vertrauten die komplexen christologischen Bilder des Textes irgendwann begleitend erläutert werden.

Anhand der Auslegung des biblischen Textes im Physiologus, dessen Deutung und Fortschreibung im mittelalterlichen Hymnus und schließlich der musikalischen Umsetzung dieser mittelalterlichen Deutung in einem zeitgenössischen Musikstück für Chor a capella lässt sich ein kleines Stück Auslegungsgeschichte vorführen. ${ }^{13}$

\subsection{Gliederung des Hymnus}

Der Hymnus (s. Tab. 1 und Abb. 1) besteht aus drei Strophen (Schweifreimen), die jeweils aus zwei dreizeiligen Teilen nach dem Reimschema aab/ccb zusammengesetzt sind. Jede Dreiergruppe ist jeweils einem Tier gewidmet, in jeder Strophe sind damit jeweils zwei Tiere zusammengruppiert: Einhorn und Schlange, Pelikan und Phönix, Fischotter und Löwe.

Im Refrain kommt das aus der Johannesoffenbarung bestens vertraute Paar Lamm und Löwe hinzu. Auf den ersten Blick auffällig bei diesem Aufbau: der Löwe erscheint zweimal.

Der Hymnus beruht mit seiner Tiersymbolik auf der Tradition des Physiologus, verdichtet aber diese Symbolik aufs Äußerste. Bereits daran lässt sich ein verändertes Interesse ablesen. Hier geht es nicht, wie im Physiologus, um eine umfassende theologische Deutung der Natur. Vielmehr sind die Tiere, von der Bildsprache des Physiologus ausgehend, in ein am zweiten Artikel des Credo orientier-

13 Dass wir dabei auch die Übersetzung korrigieren müssen, die der Komponist seinem Werk zugrundelegt, zeigt, wie überaus komplex und verdichtet die Bildsprache des Hymnus (und entsprechend auch ihre theologische Deutung) ist. Daraus ergibt sich eine interessante hermeneutische Frage, auf die ich allerdings nicht eingehen werde: Wie sind eigentlich theologische Fehldeutungen innerhalb von musikalischen Interpretationen zu behandeln, oder solche Deutungen, die wie in Gjeilos Musik zwar das Unicornis captivatur zu interpretieren suchen, dabei aber auf einer falschen Übersetzung und Interpretation des lateinischen Originals aufbauen? tes christologisches Gesamtkonzept eingeordnet, das die Geschichte Christi als Heilsgeschichte von der Fleischwerdung über Passion, Tod und Höllenfahrt bis hin zur Auferweckung beschreibt. Der Hymnus orientiert sich dabei wesentlich unmittelbarer und systematischer an den christologisch zentrierten Tiersymbolen des Neuen Testaments. Ethische und anthropologische Zuspitzungen finden sich im Unicornis captivatur nicht.

Diesen Hymnus hat der 1978 geborene norwegische Komponist Ola Gjeilo im Jahr 2001 in ein Stück für achtstimmigen a-cappella-Chor umgesetzt. Gjeilo, der bereits eine Reihe geistlicher Chorwerke für unterschiedliche Besetzungen komponiert hat, verbindet hier eine gregorianische Tonsprache mit ostliturgisch-spätromantischen Klängen. ${ }^{14}$ Wir werden seine musikalische Interpretation des Hymnus vergleichend heranziehen.

\section{Von der theologisch-ethischen Naturdeutung zum christologischen Hymnus}

\subsection{Die Anfänge im Vergleich}

Die unterschiedliche Grundkonzeption lässt sich bereits an den Anfängen deutlich machen. Während der Physiologus mit dem Löwen beginnt, stellt der mittelalterliche Hymnus das Einhorn an den Anfang.

\subsubsection{Der Löwe - König der Tiere und messianischer König (Physiologus)}

Der griechische Physiologus widmet - wenig überraschend - gleich das erste Kapitel dem Löwen und folgt damit gewissermaßen der Ordnung der Natur, indem er den König der Tiere an den Anfang stellt. ${ }^{15}$

Der Löwe spielt zugleich in den messianischen Ankündigungen der Schrift eine zentrale Rolle, und zwar ebenfalls im Sinne königlicher Symbolik. ${ }^{16}$ In Gen 49,9-10 repräsentiert der Löwe den messianischen König, was im NT in Offb 5,5 aufgenommen wird:

14 Nicht uninteressant für die Deutung ist die Überschrift: in paschali tempore conductus.

15 Vgl. S. Vollenweider, im vorliegenden Band, S. 94.

16 Vgl. S. Schroer, im vorliegenden Band, S. 56. 


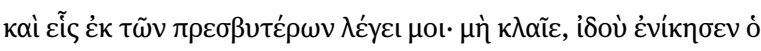

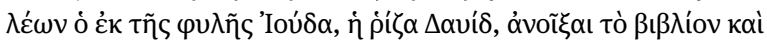

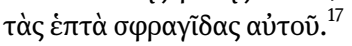

Und einer von den Ältesten spricht zu mir: Weine nicht! Siehe, es hat überwunden der Löwe aus dem Stamm Juda, die Wurzel Davids, aufzutun das Buch und seine sieben Siegel.

Die aus der Naturbetrachtung sich ergebende Ordnung kann der Phyiologus also durchaus mit einer biblischen Logik verbinden. Wie wir bereits gesagt hatten, kann man hinter dieser Verbindung eine von Joh 1,14 inspirierte theologische Hermeneutik der Natur erkennen: weil alles durch den fleischgewordenen göttlichen Logos geschaffen ist, lässt sich die Struktur des göttlichen Logos in allen Teilen der Schöpfung wiedererkennen. ${ }^{18}$

Drei Dinge über den Löwen sind für den Physiologus wichtig, weil sie sich direkt mit einer christologischen Deutung versehen lassen:

a. Der Löwe verwischt seine Spuren mit dem Schwanz, um nicht vom Jäger gefangen zu werden. ${ }^{19}$ So verbarg Christus seine göttlichen Wurzeln, als er Mensch wurde (Joh 1,14). ${ }^{20}$

b. Der Löwe schläft mit offenen Augen. Selbst am Kreuz, so die Deutung, die sich unmittelbar anschließt, bleibt die göttliche Natur Christi wach. ${ }^{21}$

c. Die «dritte Eigenheit» des Löwen ist für den Physiologus wohl die entscheidende: Löwenbabys werden, so sagt er, tot zur Welt gebracht und erst am 3. Tag zum Leben erweckt, indem ihnen der Vater ins Gesicht bläst. «Wenn die Löwin ihr Junges gebiert, bringt sie es tot zur Welt und umsorgt das Junge, bis der Vater am dritten Tag herbeikommt, ihm ins Gesicht bläst und es so zum Leben erweckt. So hat auch unser Gott, der Allherrscher und Vater der Welt, am dritten Tage seinen vor aller Schöpfung erstgeborenen Sohn ${ }^{22}$,

17 Vgl. Jes 11,1.

18 Man könnte hierin einen stoisch-pantheistischen Zug erkennen, dieser tritt aber in der frühen Kaiserzeit ins Gespräch mit der platonischen, von der Schöpfungstheologie inspirierten Logos-Theologie ein.

19 Unter Aufnahme eines Wortes aus Hld 4,8: „Komm mit mir, meine Braut, vom Libanon, komm mit mir vom Libanon, steig herab von der Höhe des Amana, von der Höhe des Senir und Hermon, von den Wohnungen der Löwen, von den Bergen der Leoparden!“

20 Vgl. S. Vollenweider im vorliegenden Band.

21 Auf Hld 5,2 gedeutet und - von Mk 16,19 auf Christus am Kreuz, der während des Todesschlafs seines Körpers bei Gott sitzt; der Beleg aus Ps 121,4 zeigt die Theologie dahinter, die von einer göttlichen Natur in Christus ausgeht. Vgl. S. Vollenweider zur Zweinaturenlehre im vorliegenden Band S. 120.

22 Vgl. Kol 1,15. unseren Herrn Jesus Christus, von den Toten erweckt, auf dass er das verirrte Geschlecht der Menschen erlöse». ${ }^{23}$ Der Physiologus verspricht das Ereignis der Auferweckung Christi als des Erstgeborenen von den Toten mit der uranfänglichen Schöpfung des Menschen, dem Gott in Gen 2,7 den Atem einbläst. Die Auferweckung des Löwen Jesus ist hier also als Akt der Neuschöpfung begriffen, der mit der Erweckung des

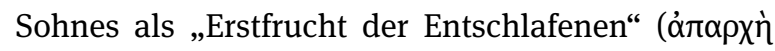

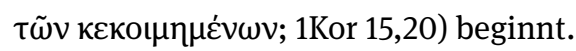

Wen diese Verhaltensweisen von Löwen überrascht, der wird sich noch mehr wundern, dass man manches davon tatsächlich in antiker naturkundlicher Literatur finden kann (nicht freilich die Totgeburt der Jungen) ${ }^{24}$ Aristoteles berichtet, der Löwe lasse seinen Schwanz beim Fliehen hängen (Historia animalium 9.44), und Aelian schreibt explizit: „Der Löwe verwischt durch Hin- und Herlaufen seine Spur“ (De natura animalium 9.30). Der Physiologus gründet seine Aussagen also durchaus nicht allein auf biblische Aussagen und christologische Allegorisierungen, sondern auch auf naturkundliche Überlieferung, die er dann freilich von theologischen Überlegungen her allegorisierend ausgestaltet. ${ }^{25}$

\subsubsection{Das Einhorn: Inkarnation und Passion als Rahmen (Hymnus)}

Im Unicornis captivatur spielt der Löwe zwar eine zentrale Rolle. Am Beginn aber steht, wie schon der Titel verrät, ein anderes Tier, nämlich das Einhorn. ${ }^{26}$ Biologisch gesehen eher ein Randphänomen, ein äußerst merkwürdiges Tier, das in der mittelalterlichen Symbolik eine wesentliche Rolle spielt und von dort aus eine große Karriere macht. Nach seinen biblischen Wurzeln muss man erst suchen, ähnlich

23 Üs. Schönberger.

24 Anders Alpers (1984, 35).

25 Deshalb betont Alpers völlig zu Recht, dass in vielen Fällen die naturkundliche Tradition im Blick auf die Deutungsebene ausgewählt und gestaltet ist. „Ebenfalls hat man längst gesehen, dass in manchen anderen Fällen die Auslegung nicht eine vorgegebene Eigenschaft deutet, sondern gerade umgekehrt die Eigenschaft des jeweiligen Tieres überhaupt erst von der Auslegung her gestaltet oder auch nur umgestaltet ist, diese also nicht das Sekundäre, sondern das Primäre darstellt“ (1984, 35).

26 Zum Einhorn vgl. Bloch (1997) sowie T. Kraus im vorliegenden Band auf S. 68-70. 
wie nach denen des Phönix, des Idrus und des Krokodils, während die anderen Tiere - Schlange, Lamm und Löwe im Zusammenhang von Schöpfung und messianischer Erwartung eine zentrale Rolle spielen.

„Das Einhorn wird gefangen, dem Königshofe wird es vorgeführt in der Schlinge der Jäger“, so beginnt der Hymnus. Drei Fragen stellen sich:

1. Wie kommt das Einhorn in einen auf biblischen Tierbildern basierenden Christushymnus?

2. Was ist ein Einhorn überhaupt?

3. Wieso läuft es dem Löwen am Anfang den Rang ab? Und natürlich, hinter diesen drei Fragen: Was sollen diese Zeilen überhaupt bedeuten?

Ad 1: Für das Einhorn kann sich der Physiologus durchaus auf biblische Grundlagen berufen. Es kommt zwar nicht im hebräischen Alten Testament vor, wohl aber erscheint

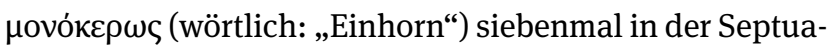
ginta - jeweils als Übersetzung für hebräisch רֵָ (,Büffel" / "Wildstier"). In der Vulgata wird es kongruent mit unicornis wiedergegeben. Das führt bereits auf die zweite Frage:

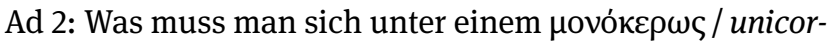
nis am ehesten vorstellen? Im Physiologus wird das Einhorn als ein kleines, wenn auch starkes Tier beschrieben, einem Böcklein oder einem scheuen Reh ähnlich, mit einem Horn auf dem Kopf.

Das Einhorn wird am Beginn von Gjeilos Chorstück wunderbar melodisch - nur von Frauenstimmen und anfangs sogar unisono - als ein zartes, scheues Tier vorgestellt (Takte 1-9 unisono, 10-21 im Frauenchor); in dieser Zartheit wird das Tier sogleich mit dem Löwen kontrastiert, der im vierstimmigen Satz zunächst im Alleluia triumphalisch-majestätisch (Takte 29-30 und nochmals 50-51) und später als Sieger über den Tod im fortissimo geradezu brachial (als brüllender Löwe in den Takten 104-106 und 121-124) erscheint. Wiederholte Taktwechsel am Anfang vermitteln dabei etwas Hüpfendes, das durchaus an ein springendes Böcklein erinnern mag (Takte 5-21, ab 14 noch durch Akzente unterstrichen).
Das $\mu$ ovóke $\rho \omega \varsigma^{27}$ der Septuaginta will nicht recht zu dem scheuen Fabeltier passen ${ }^{28}$ : Dieses Tier zeichnet sich durch Stärke und Macht aus, in Ps $21,22^{\mathrm{LXX}}$ auch durch Bedrohlichkeit, wenn es dort nämlich neben den Löwen gestellt wird: „Rette mich aus dem Rachen des Löwen, und vor den Hörnern der Einhörner meine Niedrigkeit.“29

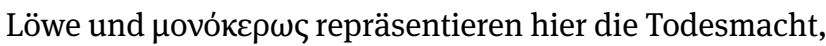
der gegenüber die Hilfe und der Schutz Gottes erfleht wird. Man hat deshalb immer neben dem Wildochsen auch das Nashorn ins Gespräch gebracht. Mir geht es aber weniger um die (umstrittene) genaue Identifizierung des Tieres ${ }^{30}$

27 Bloch (1997); Schrader (1892, 573-581). Nach Aristoteles gibt es

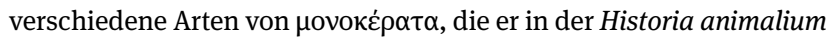
2.1.499b20 den wesentlich häufigeren doppelt gehörnten Tieren ge-

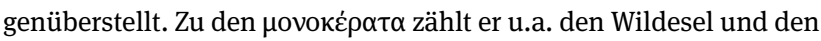
« indischen Esel » (vgl. Aristoteles, De partibus animalium 3.2.663a22:

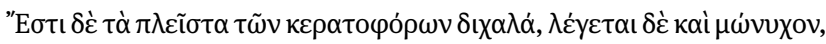

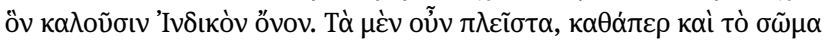

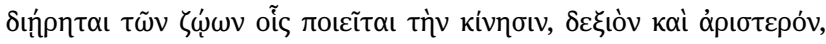

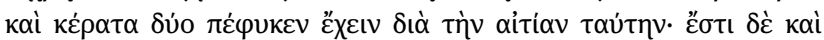

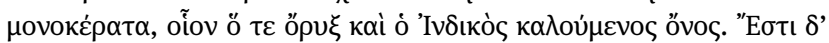

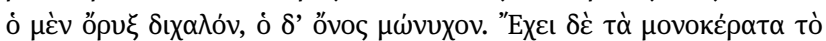

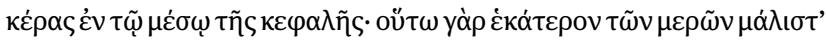

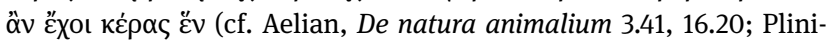
us, Naturalis historia 8.76, 11.255). Schrader sucht nach persischem Einfluss, weil dort Darstellungen von Tieren mit Hörnern erhalten sind (auch Löwen finden sich auf den entsprechenden Darstellungen). Schraders Fazit lautet, es müsse sich um eine "Antilopenart" (580; öpv६) oder um einen Wildochsen/Wisent gehandelt haben. Er notiert als Kuriosität, dass alle Übersetzungen der Septuaginta (äthiopisch, arabisch, assyrisch) mit "Nashorn" wiedergeben, was s.E. sich nur

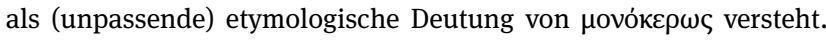
Gleichwohl ist das Nashorn in der römischen Welt durchaus bekannt, wie wir etwa Mosaikdarstellungen entnehmen können (z. B. in der Villa Romana del Casale bei Piazza Armerina, Sizilien, 3. Jh. n. Chr., auf dem Mosaik der „grossen Jagd“. Literarische Nachrichten über Nashörner in der Arena sind reichlich, z. B. Plinius, Naturalis historia 8.71 bei den Spielen des Pompeius; s. Toynbee 1973, 112). Und dem Physiologus ist eben nicht nur an akkurater biologischer Zuordnung gelegen, sondern an (durchaus auch etymologischer) Deutung, die sich christologisch auswerten lässt. Ganz verfehlt scheint mir Schönbergers These (2001, 117): „Das Einhorn war ein weit verbreitetes Fabelwesen, das durch eine unzutreffende Übersetzung von 4. Mose 23,22 ins Christentum Eingang fand“. Schönberger liefert keinen Hinweis, wo wir dieses Fabelwesen vor dem Physiologus belegt haben. Der Physiologus nimmt nicht ein verbreitetes Sagenwesen auf, sondern er schafft selbst den Übergang zu einem Fabelwesen, indem er die Naturbetrachtung in der Tradition des Aristoteles verbindet mit einer christologischen Deutung, wodurch das wilde Einhorn aus Ps $21^{\mathrm{LXX}}$ gleichsam gezähmt wird.

28 Auch wenn im Physiologus durchaus gesagt wird, ein Jäger könne sich dem Tier aufgrund von dessen Stärke nicht nähern.

29 Üs. Septuaginta deutsch (2009). Vgl. aber Ps 28,6 $6^{\text {LXX }}$ : „Er lässt hüpfen wie ein Kalb den Libanon, den Sirjon wie einen jungen Wildstier."

30 Vgl. hierzu die Hinweise bei Kraus, im vorliegenden Band S. 68. 
als vielmehr um die Frage, wie es sich vom gewaltigen Wildstier, der alles zermalmt, zum niedlichen Böcklein oder Pferdchen der mittelalterlichen Mythologie wandeln konnte, das es zuletzt bis nach Hollywood geschafft hat. ${ }^{31}$ Das führt auf die dritte Frage:

Ad 3: Wieso bildet das Einhorn hier anstelle des Löwen den Anfang? Dies gibt Aufschluss über den anderen hermeneutischen Zugriff des mittelalterlichen Hymnus. Der Grund ist, wie ich im Folgenden darzulegen versuche, dass das Unicornis captivatur nicht, wie der Physiologus, eine Deutung der Natur bieten will. Vielmehr will der Hymnus - aufbauend auf der Symbolik des Physiologus - die Geschichte von Inkarnation, Kreuz, Auferstehung und Erlösung erzählen. Dabei folgt sein Aufbau - ähnlich wie der des zweiten, christologischen Artikels des Credo - einer Logik der Heilserzählung in Christus, beginnend eben mit der Inkarnation, dessen Symbol das Einhorn ist. ${ }^{32}$

\subsection{Die Symbolik des Physiologus im Rahmen der christologischen Heilserzählung des Hymnus Unicornis captivatur}

Wenn wir im Folgenden auf die einzelnen Abschnitte des Hymnus eingehen und dabei die gestellten Fragen weiterverfolgen, so wird sich zeigen, wie jeweils die Symbolik des Physiologus aufgenommen und in einer ganz eigenen Weise verarbeitet wird.

\subsubsection{Der göttliche Logos gefangen im Schoß einer Jungfrau - das Einhorn}

Um die Geschichte von der Geburt bis zur Passion zu erzählen, genügen dem Hymnus zwei Worte: Unicornis captivatur. Dass sich hinter dem Wort captivatur indes der Gedanke der Inkarnation verbirgt und das Einhorn mit Christus zu identifizieren ist, kann lediglich derjenige verstehen, der den Physiologus als Interpretationsschlüssel voraussetzt. Das Einhorn wird dort mit dem göttlichen Logos identifiziert. Fangen lässt es sich, wie es dort heißt,

31 Mit einer positiven Deutung des Einhorns liebäugeln aufgrund von Ps $28,6^{\mathrm{LXX}}$ Dorival und Schaper, welcher letztere es durchgehend als messianisch verstehen will. Skeptisch Brucker, Septuaginta deutsch Komm. ad loc.

32 Filium eius unicum, Dominum nostrum: / qui conceptus est de Spiritu Sancto, / natus ex Maria Virgine, / passus sub Pontio Pilato, / crucifixus, mortuus, et sepultus, / descendit ad inferos: / tertia die resurrexit a mortuis. allein im Schoß der Maria, der Jungfrau: «Eine reine, schön gekleidete Jungfrau setzen sie vor ihm nieder, und es springt ihr auf den Schoß, und die Jungfrau nährt das Tier und bringt es dem König in den Palast» (Kap. 22). ${ }^{33}$ Es folgt im Physiologus ein erläuterndes Zitat aus Joh 1,14: er «nahm Wohnung im Leib der wahrhaft reinen Jungfrau Maria, «und das Wort ist Fleisch geworden, und es wohnte unter unsı». Dabei klingt zugleich die Geburtsgeschichte des Lukas an, die Gelegenheit bietet, die alttestamentliche Heils-Metaphorik des Horns (die es durchaus auch gibt: Gott verleiht den Menschen Macht ${ }^{34}$ ) mit der Geburt Jesu zu verbinden (Lk 1,69: „Und Gott richtete uns ein Horn des

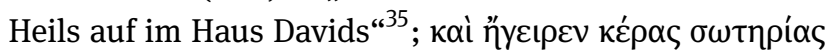

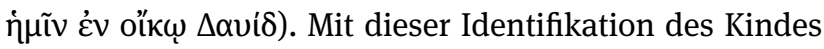
in der Krippe mit dem gewaltigen Horn des Heils wird die Verwandlung des Einhorns verständlicher. Der Gedanke, dass sich der Herrscher der Welt im Schoß einer Jungfrau inkarniert, erklärt m.E. die Verwandlung des Einhorns von dem gefährlichen Koloss in der Septuaginta in ein von einer Jungfrau bezähmbares Tier.

Kehren wir zum Hymnus zurück. Bereits das zweite Wort (captivatur) schlägt hier den Bogen zur Gefangenschaft Jesu im Prätorium vor Pilatus, wie die folgende Zeile zeigt: aule regum presentatur. ${ }^{36}$ Hier ist, ganz im Sinne der johanneischen Christologie, aufs äußerste verdichtet, dass der Eintritt Gottes in die körperliche Welt von Werden und Vergehen ein Eintritt in letzter Konsequenz ist, der von Anfang an den Gedanken von Leiden und Tod mit impliziert. Damit ist der Rahmen abgesteckt - den gesamten Zusammenhang müssen der Leser oder die Hörerin freilich aus der Tradition ergänzen.

Festhalten können wir im Blick auf die Rezeption des Physiologus schon einmal den antitypischen Apell der Bildsprache des Hymnus: Ein ursprünglich todbringendes Tier (wie der Löwe) wird hier zum Bringer des Lebens. ${ }^{37}$

33 Üs. Schönberger.

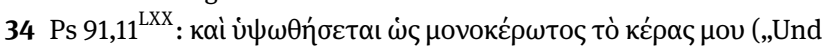
mein Horn wird erhöht werden wie das des Einhorns“), vgl. Num 23,22; 24,8; 33,17 u.ö.

35 Mit dem Zitat aus Ps $91,11^{\mathrm{LXX}}$, der am Anfang des Abschnittes über das Einhorn steht; bei Lukas allerdings fehlt das Einhorn gerade! 36 Eine Pointe besteht in der Formulierung regum, insofern Pilatus freilich kein König ist, Christus aber, wie die Kreuzesinschrift zeigen wird, durchaus.

37 Vgl. insbesondere die Identifikation des Löwen mit einem geschlachteten Löwen in der Johannesoffenbarung (Offb 5,5-13). 


\subsubsection{Tod und Heilmittel vom Tod - Die Schlange}

Die antitypische Bildsprache wird in der zweiten Strophe mit Schlange und Pfahl weitergeführt, ${ }^{38}$ um das Heilsereignis in Christus als Überwindung des Todes durch den Tod zu verdichten.

\author{
Palo serpens est levatus, \\ Medicatur sauciatus \\ Veneno vipereo. \\ Vom Stamm wurde die Schlange emporgehoben, \\ Verwundet wird sie geheilt \\ Durch das Schlangengift.
}

Über Schlange und Stamm/Pfahl mischen sich hier Paradies- und Sündenfalltypologie mit Erlösungstypologie. Die drei Zeilen oder 8 Worte stecken voller Anspielungen und schillernder Intertextualität, denn mit dem Emporheben am palus spielt der Text auf das johanneische Motiv der Kreuzigung als Erhöhung an. Genau dies wird in Joh 3,14-15 in Aufnahme von Num 21,6-8 mit der Schlange in Verbindung gebracht: „Wie Mose in der Wüste die Schlange erhöht hat, so muss der Menschensohn erhöht werden, damit alle, die an ihn glauben, das ewige Leben haben“

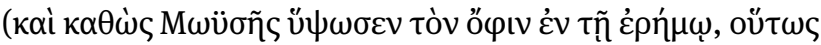

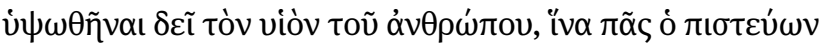

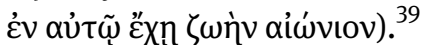

Die dichte Bildsprache macht im Hymnus bereits die Übersetzung zum Abenteuer. Gjeilo gibt seiner Komposition folgende englische Übersetzung bei:

creeping, it (sc. das Einhorn) freed itself from the pole, because it is wounded, it heals itself with the viper's venom.

Da hier serpens („kriechend“) als auf unicornis bezogenes Partizip verstanden wird - wohl aus sachlichen Erwägungen und weil das Substantiv eher als Femininum geläufig ist, gibt es dieser Übersetzung zufolge in diesem Vers keine Schlange, sondern nur Schlangengift, und entsprechend gibt es auch kein antitypisches Bild.

Diese englische Übersetzung erscheint indes aus verschiedenen Gründen problematisch:

38 Vgl. Frey (2013).

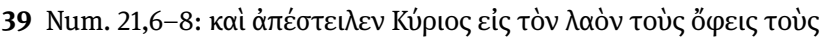

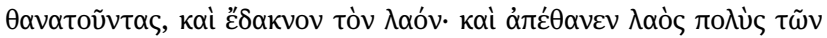

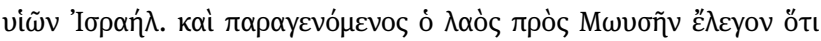

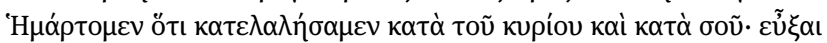

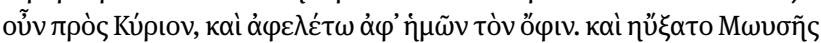

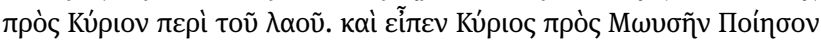

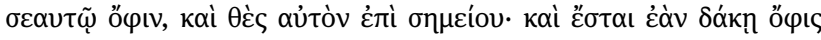

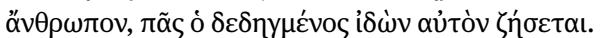

a. Zwar wird sachlich die Erzählung von dem fleischgewordenen Wort durchaus fortgesetzt, auf der Bildebene aber ist ein windend sich vom Pfahl befreiendes Einhorn schwer verständlich.

b. Schaut man zudem auf die Gliederung des Hymnus insgesamt, so zeigt sich, dass jeweils nach einem Dreizeiler ein neues Tier eingeführt wird.

c. Das Problem, das sich den Übersetzern offenbar gestellt hat, dass nämlich die Schlange durchs Schlangengift geheilt wird, weist zugleich den Weg zu seiner Lösung. Sie liegt m.E. in der antitypischen Motivik, die uns bereits im erstem Vers begegnet war.

Die Schlange wird also, so behaupte ich, tatsächlich durch Viperngift geheilt. Was soll das heißen?

Zunächst: Die Schlange ist bereits im Physiologus ambivalent. Dort gibt es aufeinanderfolgend zwei Schlangenkapitel: Kap. 10 ist der schlechten, Kap. 11 der guten Schlange gewidmet (dazu erzählt das oben bereits angesprochene Kapitel 30 vom Hirsch und der - hier wiederum schlechten - Schlange). Insgesamt erscheinen vier verschiedene griechische Begriffe, die sich mit „Schlange“ übersetzen lassen, und es ist nicht immer ganz klar, schon gar nicht biologisch, wie sie jeweils zu unterscheiden und einzuordnen sind:

a. ̋ $\varphi$ ıৎ «Schlange» erscheint am Anfang von Kap. 11. In Gen 3,1 ${ }^{\mathrm{LXX}}$ wird sie als das klügste der Tiere bezeichnet und in diesem Sinne in Mt 10,16 (,Seid klug wie die Schlangen und ohne Falsch wie die Tauben!“) positiv verwendet. Sie steht für die Wiedergeburt - durch Fasten häutet sie sich von ihrer alten Existenz und kann so als Vorbild des asketischen Christen dienen. Zugleich spielt ihre negative Seite in der Paradiesgeschichte in der Folge eine entscheidende Rolle. In Kap. 3 über den Regenpfeifer wird sie am Ende als Beispiel dafür angeführt, dass Tiere unrein und deshalb $\mathrm{zu}$ tadeln und gleichzeitig zu loben sind. In der pseudobasilianischen dritten recensio ist im Kap. 29 von einer

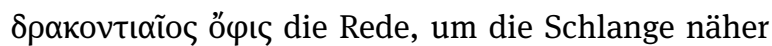
zu qualifizieren.

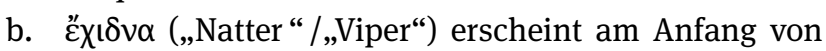
Kapitel 10. Was der Physiologus dort allerdings beschreibt, ist ein Mischwesen aus Mensch und Krokodil. Diese Bezeichnung $\varepsilon$ $\chi ı \delta v \alpha$ schleudert der matthäische Jesus seinen Gegnern entgegen (Mt 3,7; 23,33 ${ }^{40}$ ).

c. $\delta \rho \alpha ́ \kappa \omega v(, W a s s e r s c h l a n g e “ /, W a s s e r d r a c h e “)$ ist grundsätzlich negativ besetzt und erscheint in Kap. 26 als Todfeind des Ichneumon; nach Kap. 16 hat der Pan-

40 Hier gemeinsam mit ő $\varphi$ ıs. 
ther, der als Bild Christi Wohlgeruch aus seinem Mund

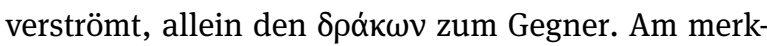
würdigsten ist Kap. 30, wo zunächst ö $\varphi$ ıs in der Überschrift steht, dann aber $\delta \rho \alpha ́ k \omega v$ im Text ${ }^{41}$ (so mehrfach in Offb 12-13; 16; 20; ö $\varphi$ ıs findet sich ebenfalls in Offb 9,19; 12,14-15; 20,2).

d. áoтiৎ (ägyptische Kobra) erscheint ohne besondere Wertung im Kapitel 21 über das Wiesel.

Durch die Schlange (ő $\varphi$ ı), das Symbol des Versuchers, kommt im Paradies der Tod in die Welt (Gen 3). Im Hymnus bringt die Schlange, die nun antitypisch mit Christus und seinem Tod identifiziert wird, selbst tödlich verwundet, die Restitution und Überwindung des Todes - zunächst für sich selbst (verwundet wird sie geheilt), und im zweiten Schritt für alle Menschen, die von der Vernichtung des Todes profitieren. Um zu dieser Deutung zu kommen, spielt der Text mit dem Emporheben am palus (est levatus) auf die Erzählung von der ehernen Schlange in Num 21,6-8 an, die in Joh 3,14-15 aufgenommen und mit dem Motiv der Kreuzigung in Verbindung gebracht wird. ${ }^{42}$ Als die Israeliten aufgrund ihres Ungehorsams von einer Schlangenplage dahingerafft werden, so erzählt Num 21, da reckt Moses auf Geheiss Gottes eine eherne Schlange auf einem Stab in die Höhe. Alle, die auf die Schlange schauen, werden durch sie geheilt. Bei Johannes ist der Gedanke universalisiert: Alle, die von der Schlange gebissen und so dem Tod geweiht sind (und das sind alle sterblichen Menschen), werden aus dem Tod gerettet und erhalten ewiges Leben, wenn sie auf diese erhöhte Schlange (den am Kreuz erhöhten Christus) schauen. Der Kreuzesstamm erscheint als Umkehrung des durch den Baum der Weisheit symbolisierten Sündenfalls.

Dieses neue Schlangenzeichen am Pfahl überwindet nicht nur temporäre Vergänglichkeit, sondern bringt das ewige Leben. Es scheint mir diese Bildsprache zu sein, die im Unicornis captivatur mit der Rede von der durch Schlangengift geheilten Schlange aufgenommen ist.

\subsubsection{Der Refrain: Sterbendes Lamm und siegreicher Löwe}

Nur im Vorbeigehen möchte ich auf das als Refrain eingefügte Halleluja eingehen.

41 Ist ọ̋ı also der Oberbegriff? Oder wird es einfach um der Etymologie willen aufgenommen, die auf die Schlange im Paradies hinführt? 42 S.o. Anm. 39.
In der musikalischen Umsetzung von Ola Gjeilo findet sich an dieser Stelle erstmals der volle 8st. Chor zusammen (Takte 22-30). Gjeilo folgt dem mittelalterlichen Hymnus darin, dass er den Lobpreis des Löwen als Refrain dreimal wiederholt:

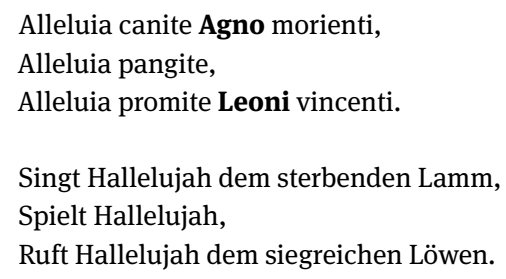

Der siegreiche Löwe wird hier gemeinsam mit dem geschlachteten Lamm gepriesen - ganz entsprechend der Bildsprache der Offenbarung, ${ }^{43}$ aber in signifikantem Unterschied zum Physiologus, der die Tiere in der Regel getrennt behandelt, und - wichtiger noch - in dem das Lamm signifikanterweise nahezu keine Rolle spielt. ${ }^{44}$ Hier korrigiert das Unicornis captivatur den Physiologus mit Blick auf die Bildsprache der Bibel. Das ist aus zwei Gründen ausgesprochen interessant. Zum einen: Der Hymnus greift damit ein weiteres antitypisches Bild auf, das im Neuen Testament in Aufnahme prophetischer Metaphorik bereits vorgegeben ist. Zum anderen: es zeigt sich darin, dass der Hymnus stärker als der Physiologus von einem aus der Bibel entnommenen christologischen Gesamtbild ausgeht, bei dem das Lamm nicht fehlen darf, während der Physiologus von Tiermetaphern insbesondere aus den Psalmen ausgeht und ihnen eine christologische Deutung beilegt.

Bei Gjeilo wird die antitypische Metaphorik sehr sachgemäß umgesetzt: Die Bilder von Leiden und Herrschaft sind gleichsam ineinander geblendet durch die Dynamik, die vom sterbenden Lamm im Piano innerhalb eines Taktes ins Fortissimo des Halleluja mit dem Preis des Löwen führt - mit gewaltigen Oktavtürmen in e (Takt 23 auf 24). Dieses Überblenden führt vor Augen, dass das geschlachtete Lamm und der siegreiche Löwe sachlich identisch sind, sodass man durchaus auch vom siegreichen Lamm sprechen kann. ${ }^{45}$ So ist es in der Offenbarung nicht der Löwe, der schließlich das Buch öffnet, wie in Offb 5,5 angekündigt, sondern das Lamm (Offb 6,1).

$\overline{43 \text { Offb } 5,5-6,1 .}$

44 Außer in Kap. 41 (Gazelle) und Kap. 44 (Achat und Perle). 45 Man vergleiche nur die weitverbreitete Ikonographie des Lammes mit der Siegesfahne. 


\subsubsection{Das Kreuz als Überwindung der Sünden der Welt - Pelikan und Phönix}

Nach Schlange, Löwe und Lamm folgen zwei exotische Tiere. Der Pelikan kommt immerhin in Ps 101,7 ${ }^{\text {LXX }}$ vor, „Phönix" erscheint lediglich in Apg 27,12 als Name eines Hafens auf Kreta. ${ }^{46}$

Mit diesen beiden Bildern sind wir nun beim Kreuzesgeschehen selbst und seiner todüberwindenden Kraft.

\author{
Pellicano vulnerato \\ Vita redit pro peccato, \\ Nece stratis misera. \\ Phos fenicis est exusta, \\ Concremanturque vetusta \\ Macrocosmi scelera.
}

\begin{abstract}
Durch den Pelikan - verwundet
Um der Sünde willen - kehrt das Leben zurück, Durch seinen elenden Tod für die Hingestreckten. Das Licht des Phoenix ist ausgebrannt Und mit verbrennen die uralten Vergehen der ganzen Welt.
\end{abstract}

Durch den verwundeten Pelikan, so verstehe ich den Text, kehrt das Leben zurück.

Wieder ist das im Physiologus zum Pelikan Erzählte vorauszusetzen. Der Physiologus stellt nämlich einen Bezug zur Sintflut her ${ }^{47}$ : Der Pelikan, so heißt es dort, töte zunächst seine Jungen, weil ihn deren Geschrei ärgere. In der Sintfluterzählung in Gen 6 reagiert Gott auf die übergrosse Sünde der Menschen dadurch, dass er sie durch eine Sintflut vernichtet: „Als aber Gott sah, dass der Menschen Bosheit gross war auf Erden und alles Dichten und Trachten ihres Herzens nur böse war immerdar" (Gen 6,5). Noch deutlich näher ist das im Physiologus Erzählte am altbabylonischen Atramchasis-Epos, wo tatsächlich von Geschrei die Rede ist, das die Tötung der Menschen provoziert. Aber Gott bereut die Vernichtung der Menschen. Im Bild: der Pelikan öffnet mit dem Schnabel seine Seite, um die Jungen durch sein eigenes Blut wieder zum Leben zu erwecken ein deutlicher Bezug auf das Erlösungswerk Gottes im Neuen Testament, das durch das Blut des eigenen Sohnes geschieht. Das Öffnen der eigenen Seite erinnert an den Lan-

\footnotetext{
46 Den Reflex, dies sei doch allenfalls eine äquivoke Verwendung und tue hier nichts zur Sache, sollten wir unterdrücken, solange nicht klar ist, dass nicht genau diese Stelle die Verwendung des Phoenix im Physiologus legitimiert.

47 Schönberger nimmt diesen Bezug merkwürdigerweise nicht auf, sondern verweist lediglich auf Jes 1,2: „Höret, ihr Himmel, und Erde, nimm zu Ohren, denn der HERR redet: Ich habe Kinder großgezogen und hochgebracht, und sie sind von mir abgefallen!“
}

zenstich in Joh 19,34, als ein Soldat seine Lanze in die Seite des am Kreuz hängenden Jesus sticht um zu sehen, ob er bereits tot ist.

Diese gesamte Erzählung des in der Sünde der Menschen verlorenen und durch den Tod des Sohnes wiedergewonnenen Heils und Lebens ist im Unicornis captivatur auf nur wenige Worte verdichtet. ${ }^{48}$ Nota bene: es heißt im Hymnus nur „verwundet“ (vulnerato). Anders als im Physiologus ist nicht davon die Rede, dass der Pelikan sich selbst verletzt - mit seiner neutraleren passivischen Formulierung ist der Hymnus erneut näher am Neuen Testament. ${ }^{49}$ Und ein zweiter auffälliger Zug, der uns überraschen mag, aber ganz dem Physiologus entspricht: Wenn der Pelikan sich selbst die Seite öffnet, so fallen in der Perspektive des Unicornis captivatur der erzürnte Vater der Sintfluterzählung und der am Kreuz durchbohrte Sohn, aus dessen Seite Blut und (in Joh 19,34) Wasser fließen, in dem Pelikan in eins, eine Tendenz, die sich an verschiedenen Stellen innerhalb des Hymnus beobachten lässt. ${ }^{50}$

An den Gedanken des stellvertretenden Todes für die Sünden schließt der Phoenix unmittelbar an: seine Selbstverzehrung im Feuer bedeutet zugleich die Vernichtung aller Sünden. Im Tod Jesu verbrennt wie im Feuer des Phönix die alte Welt und ihre Sünde vollkommen. Gleichzeitig ist der freilich ein geradezu sprichwörtliches Bild für die Auferstehung. ${ }^{51}$

48 Vgl. sauciatus von der Schlange und moriens vom Lamm.

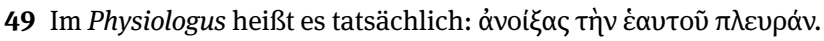
50 Die Deutung von nece stratis misera würde eine ausführlichere Diskussion erfordern, die hier nicht zu leisten ist. Auch in dieser Formulierung kann man wohl eine antitypische Stuktur erkennen: die Hingestreckten werden durch den Tod eines weiteren wiederaufgerichtet und zum Leben erweckt.

51 Lukian lässt den Peregrinus, einen religiösen Scharlatan, in De morte Peregrini 27 ankündigen, er werde nach seiner Selbstverbrennung sich wie Phönix aus der Asche erheben. Da Peregrinus durchaus als Karikatur der Christusfigur gedacht ist, kann man hieraus schließen, dass der Phoenix schon früh auf Christus gedeutet wurde. Im Physiologus handelt es sich nicht um eine übertragene Deutung der Natur. Vielmehr bietet der Phoenix, nach dem griechischen Physiologus (7) ein „Vogel aus Indien“, einen Vergleich oder besser einen Analogieschluss a minore ad maius: Wenn schon ein Tier existiert, das sein Leben dahingeben und danach in neuem Leben erstehen kann, dann muss die Aussage Jesu in Joh 10,17-18 nicht überraschen: „Deshalb liebt mich der Vater, weil ich mein Leben hingebe, um es wieder zu nehmen“. Überraschend ist das Motiv des Wohlgeruchs (Phoenix sammelt ihn auf dem Flug nach Ägypten [!], nach Heliopolis, auf den Bäumen des Libanon), auf das man nicht ohne weiteres kommen würde. Interessant mag man - im Blick auf die Weinmetaphorik in Joh 15 auch finden, dass der Phönix sich ausgerechnet mit Rebenholz verbrennt. 


\subsection{5 descensus ad inferos - Der Fischotter im Krokodil}

\author{
Idrus $^{52}$ intrat crocodillum, \\ Extis privat, necat illum, \\ Vivus inde rediens. \\ Der Fischotter tritt in das Krokodil ein, \\ Beraubt es seiner Eingeweide, tötet es \\ Und kehrt lebendig von dort zurück.
}

Den Gedanken der Auferstehung nimmt die nächste Strophe auf: Vivus inde rediens, „lebendig kehrt er von dort [sc. aus dem Tod] zurück." Der Fischotter ist das Bild des Christus. Er steigt, wie es das Apostolische Glaubensbekenntnis formuliert, „in das Reich des Todes“. Im Hymnus heisst es: „Der Fischotter geht in das Krokodil hinein“. Erneut liefert der Physiologus die Hintergründe. Der Idrus, eine Tran-

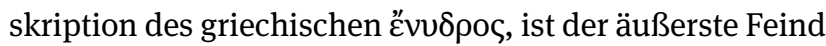
des Krokodils, so heisst es dort. Halten wir uns nicht mit der Frage auf, ob tatsächlich an einen Fischotter gedacht ist, wie Schönberger (jedenfalls nahe an der Etymologie) übersetzt oder eher um den im anschließenden Kapitel 26 behandelten Ichneumon, die Pharaonenratte, die Reptilien frisst und wie der Mungo ein Schlangentöter ist. Entscheidend ist für die Deutung, dass das Tier das Krokodil überwindet, das im Bild den Tod repräsentiert. Der Physiologus erklärt, wie die Tötung des Krokodils vor sich geht: Im Schlaf hält es sein Maul ( $\sigma \tau o ́ \mu \alpha)$ aufgesperrt, was man durchaus nachvollziehen kann (auch wenn das Krokodil freilich in Wirklichkeit nicht schläft, wenn es zu schlafen scheint). Was über den Fischotter gesagt wird, ist indes offenkundig von der Deutungsebene, also der Christologie her konstruiert: Der Fischotter „bestreicht seinen ganzen Leib mit Lehm ( $\chi \rho \dot{\varepsilon} \varepsilon \tau \alpha \mathrm{l} . . . \pi \eta \lambda \tilde{\omega})$, und wenn der Lehm getrocknet ist, springt er dem Krokodil in den Rachen, zerbeißt ihm den ganzen Schlund und frisst seine Eingeweide. “ $\chi \rho i ́ \varepsilon \sigma \theta \alpha ı$ dürfte um seiner christologischen Anklänge willen gewählt sein, die Täuschung geschieht durch Umkleiden mit „Lehm“, also mit Menschlichkeit und Sterblichkeit. Der Christus verkleidet sich also (wie wir das beim Löwen auch schon gehört hatten). Die christologische Deutung folgt denn auch unmittelbar: So nahm Christus ,den Lehm des Fleisches an (1Kor 15,47-48), stieg in die Hölle hinab und löste die Schmerzen des Todes, indem er denen, die in Banden lagen, zurief: „Kommet heraus!“, und denen in der Finsternis: „Kommt ans Licht! (Lk 1,79)“.

Der Unterweltskampf, der damit beschrieben ist, wird im frühchristlichen Nikodemusevangelium ${ }^{53}$ in der sog.

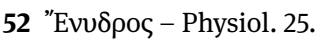

53 Vgl. S. Vollenweider, im vorliegenden Band, S. 107.
Höllenfahrt Christi erzählerisch ausgestaltet: Christus steigt in den Hades hinab, der auch dort als eine allerdings anthropomorphe Gestalt auftritt. Ihm reisst Jesus förmlich - beginnend mit Lazarus - die Toten aus dem Bauch heraus; Hades hatte Christus verschlungen, nicht wissend, mit wem er es zu tun hat und dass ihm das nicht gut bekommen würde: In der Tat wird das Grollen in seinem Bauch zunehmen und er wird kurz später alle Toten hergeben müssen. ${ }^{54}$

In Gjeilos Chorstück wird der Unterweltskampf durch die rhetorische Reihung extis privat, necat illum, die mehrfach hintereinander gefügt und durch eine Rückung rhetorisch unterstrichen ist, schön nachgezeichnet (Takte 52-65). Die Sequenz endet im Schrei necat illum und in der siegreichen Rückkehr des Lebendigen aus dem Tod (vivus inde rediens). Es erinnert an den Triumphschrei aus Jes 25,8, den Paulus in 1Kor 15,55 aufnimmt: «Der Tod ist verschlungen in den Sieg. Tod, wo ist dein Stachel? Hölle, wo ist dein Sieg?».

\subsubsection{Aus dem Grab herausgerufen: der Löwensohn}

Dieses bei Gjeilo ausgesprochen lyrisch ausgestaltete vivus inde rediens (Takte 66-98), das einen großen Teil des übrigen Stückes einnimmt, führt auf das letzte, wohl raffinierteste antitypische Bild des Unicornis captivatur, für das der Löwe noch einmal wiederkehrt.

Tris diebus dormitavit

Leo, quem resuscitavit

Basileus rugiens.

Drei Tage schläft der König der Tiere, bevor er aufgeweckt wird, durch ein königliches Brüllen aus dem Grab hervorgerufen. Gjeilo setzt diese Neuschöpfung, die mit dem vivus inde rediens schon begonnen hatte, eindrücklich um durch eine Linie beginnend im pianissimo nur mit dem $\mathrm{h}$ der Bässe in Takt 99 bis hin zu einem brüllenden Fortissimo des Basileus, des Königs in Takt 106. ${ }^{55}$

54 Die Identifikation des Fischotters mit dem Erlöser und des Krododils mit dem Teufel (nicht mit dem Tod bzw. Hades, wie im Nikodemusevangelium, das die beiden Figuren voneinander abhebt) wird sogleich im Text nachgeliefert. Interessant ist, dass das Krokodil in

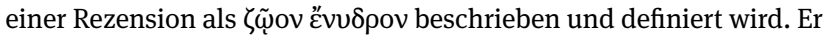
ist eine Mischung aus Löwe und Schlange. Man kann auch dies also als ein antitypisches Bild betrachten.

55 Gegenüber dem siegreichen Löwen des Refrains (= Christus; vgl. Offb 5,5: «Und einer von den Ältesten sagt zu mir: Weine nicht! Siehe, den Sieg errungen hat der Löwe aus dem Stamm Juda, der Spross Davids; er kann das Buch und seine sieben Siegel öffnen»), ist hier offen- 
Wieder spielt diese dritte Strophe, vom Text des Neuen Testaments ausgehend, mit antitypischer Motivik. In 1Petr 5,8 finden wir nämlich eine ganz andere Motivik des Löwen, der dort nicht für den Christus, sondern für den Antichristus steht: „Seid nüchtern und wacht; denn euer Widersacher, der Teufel, geht umher wie ein brüllender Löwe und sucht, wen er verschlingen kann. ${ }^{* 56}$ Hier ist der Löwe aufgrund seiner Gefährlichkeit und Wildheit Bild des Todes bzw. des in ihm wirksamen Teufels, der mit seinem Brüllen das Verderben ankündigt und so der Schrecken aller Menschen ist; das ist die vordringliche Bedeutung des Löwen im Alten Testament, nicht nur in Ps 22,14 (Ps $21,14^{\mathrm{Vg}}$ : quasi leo capiens et rugiens; Ri 14,5; Jes 5,29 u.ö). Mag das Brüllen des Todes hier auch nur noch ein fernes Echo sein, im Partizip präsens rugiens von rugire ist es sogar in der Verbform aufgenommen (die im AT mehrfach ${ }^{57}$, im NT aber nur hier erscheint). Im Unicornis captivatur hat der allverschlingende Löwe ausgebrüllt, wie die Schlange ihre tödliche Kraft verloren hat: Tod, wo ist dein Stachel? Das Brüllen ist übergegangen auf den König, der seinen Sohn und in ihm alle Glaubenden zum Leben ruft (das Auferwecken durch einen lauten Ruf mag zudem an Joh 11,43 erinnern, wo Jesus den toten Lazarus mit lauter Stimme aus dem Grab herausruft). Damit ist die Geschichte zu Ende erzählt. Hier hat der König der Tiere zwar nicht das erste Wort, wohl aber das letzte.

sichtlich Gott selbst der Löwe, der die Neuschöpfung ins Werk setzt. Wieder stehen wir vor mehreren Rätseln, die teils mehr theologischer, teils mehr historischer Natur sind. Wer ist der basileus? Doch offenbar auch der Löwe, genauer der Löwenvater als der König der Tiere. Aber warum heißt er nicht rex, sondern als griech. Lehnwort basileus? Ein ähnliches Lehnwort hatten wir bereits mit phos. Dort könnte es wegen der Alliteration gewählt sein (phos phoenicis), hier vielleicht aus metrischen Gründen? Kurt Keller hat mich auf die ornamentale Verwendung griechischer Begriffe in der lateinischen Literatur des Mittelalters aufmerksam gemacht (vgl. dazu Stotz 2011, der freilich nicht auf unseren Hymnus eingeht, aber auf die besondere Nähe zu ornamentalem Griechisch in der liturgischen Dichtung des hohen Mittelalters hinweist [324]).

56 sobrii estote vigilate quia adversarius vester diabolus tamquam leo rugiens circuit quaerens quem devoret.

57 Vgl. S. Schroer im vorl. Band: „hingegen kann Israels Gott JHWH wie ein Löwe brüllen und zum reißenden Löwen für Israel werden (Am 1,2; Hos 5,14)“. Vgl. weiter Am 3,8.
Gjeilo steigert am Ende des Stücks das Halleluja zum Fortissimo und verbindet es mit dem zweimal wiederholten, ebenfalls im Fortissimo gehaltenen Lob des Basileus rugiens, (Takte 104-106 und 121-124), der den Löwen vom Tod erweckt hat.

\section{Fazit}

1. Zum Verständnis der Aussagen des Unicornis captivatur braucht man den Physiologus bzw. die in ihm enthaltenen Traditionen, als Schlüssel. Das Einhorn, der Fischotter, der Löwe sind sonst nicht verständlich.

2. Dennoch darf man die Aussagen des Unicornis captivatur nicht einfach durch den Physiologus auflösen und damit das Rätsel als gelöst erachten. Vielmehr nimmt die poetische Nachdichtung über den Physiologus hinaus unmittelbar biblische, v.a. neutestamentliche Bildsprache auf, die sich nicht aus der Darstellung des Physiologus erheben lässt.

3. Im Physiologus werden die Tiere auf unterschiedliche theologische Größen gedeutet: Mensch, Teufel, Christus. ${ }^{58}$ Dabei geht der Physiologus von der Vorstellung aus, dass der geschaffenen Welt eine vernünftige Struktur zugrunde liegt, weil sie in der Schöpfung durch den Logos ins Sein gerufen wurde. Im Unicornis captivatur dagegen sind die Deutungen in ein christologisches Gesamtkonzept einbezogen. Der Hymnus bringt die spannungsreichen Tierbilder der Bibel dazu in eine narrative Ordnung und erzählt - vom Physiologus inspiriert, aber in der Struktur eher dem Credo ähnlich - in antithetischer Typologie die Unheils- und Heilsgeschichte als Geschichte vom Menschwerden, Leiden, der stellvertretenden Lebenshingabe und der Auferweckung Christi nach. Aus der Spannung dieser antitypischen Bilder, die der biblischen Tradition entnommen sind, gewinnt das Unicornis captivatur seinen besonderen Reiz.

\section{Bibliographie}

Alpers, Klaus. 1984. „Untersuchungen zum griechischen Physiologus und den Kyraniden. “In All Geschöpf ist Zung' und Mund: Beiträge aus dem Grenzbereich von Naturkunde und Theologie. Vestigia Bibliae: Jahrbuch des Deutschen Bibel-Archivs 6, hrsg. v. Heimo Reinitzer, 13-87. Hamburg: Friedrich Wittig. Bloch, René. 1997. „Einhorn“. DNP 3:916. http://dx.doi.org/10. 1163/1574-9347_dnp_e327420.

58 Der Charakter der Deutungen ist manchmal informativ, meist aber ethisch-appellativ. 
Brucker, Ralph. 2011b. „Psalm 28[29].“ In Septuaginta Deutsch. Bd. 2, Erläuterungen und Kommentare, hrsg. v. Martin Karrer und Wolfgang Kraus, 1574-1580. Stuttgart: Deutsche Bibelgesellschaft.

Einhorn, Jürgen W. (1976) ${ }^{2}$ 1998. Spiritalis Unicornis. Das Einhorn als Bedeutungsträger in Literatur und Kunst des Mittelalters. Münsterische Mittelalter-Schriften 13. München: Wilhelm Fink.

Frey, Jörg. 2013. „,Wie Mose die Schlange in der Wüste erhöht hat... Zur frühjüdischen Deutung der ,ehernen Schlange“ und ihrer christologischen Rezeption in Joh 3,14f." In Die Herrlichkeit des Gekreuzigten: Studien zu den johanneischen Schriften I. WUNT 307, hrsg. v. Jörg Frey, 89-145. Tübingen: Mohr Siebeck. Henkel, Nikolaus. 1976. Studien zum Physiologus im Mittelalter. Tübingen: Max Niemeyer Verlag.

Jones, Larry Paul. 1997. The Symbol of Water in the Gospel of John. JSNTS 145. Sheffield: Academic Press.

Ng, Wai-Yee. 2001. Water Symbolism in John: An Eschatological Interpretation. Studies in Biblical Literature 15. New York: Peter Lang.
Schönberger, Otto. 2001. Physiologus: Griechisch/Deutsch. Stuttgart: Reclam.

Schrader, Eb. 1892. „Die Vorstellungen vom Monokeros und ihr Ursprung. "In Sitzungsberichte der Preußischen Akademie der Wissenschaften, 573-581. Berlin: Verlag der Königlichen Akademie der Wissenschaften.

Stotz, Peter. 2011. „Ornamentales Griechisch im mittelalterlichen Latein." In Influencias léxicas de otras lenguas en le latín medieval / Lexical influences of other languages on medieval Latin, 319-343, hrsg. v. Maurilio Pérez González und Estrella Pérez Rodríguez. León / Valladolid: Universidad de León / Universidad de Valladolid.

Toynbee, Jocelyn. 1973. Tierwelt der Antike, übersetzt von Maria R.-Alföldi und Detlef Misslbeck. Mainz: Zabern. 



\section{The Physiologus and the Apocryphal Acts of the Apostles}

\begin{abstract}
Animals play prominent roles in the apocryphal acts of the apostles, and the authors of these texts seem to have drawn on natural historical information similar to what is found in the Physiologus. Nevertheless, the relationship between the acts and the Physiologus is complicated and often puzzling. There is at least one instance in which the apocryphal acts (the Acts of Thomas) clearly presuppose information about an animal (the wild ass) also presented in the Physiologus, as well as two instances in which the Physiologus refers to a character from the apocryphal acts (Thecla). Otherwise, the most striking result of comparing the acts with the Physiologus is the absence of clearly coinciding material. Relatively few animals occur in both the Physiologus and the acts, and, when they do, there is little, if any, overlap in content. This paper will detail the points of contact between the Physiologus and the apocryphal acts, as well as the absence of contact where such could easily be imagined. Ultimately, I will show that the Physiologus and the apocryphal acts of the apostles exhibit a similar attitude toward the natural world and the use of similar source material, but the exact relationship between these texts remains obscure.
\end{abstract}

\section{Introduction}

I first encountered the Physiologus when writing my dissertation on animals in the apocryphal acts of the apostles. When searching the Thesaurus Linguae Graecae for other accounts of bedbugs, snakes, talking dogs, licentious partridges, friendly lions and the other various animals that populate the apocryphal acts, I continually stumbled upon the Physiologus (along with the works of Aelian, Oppian, Antigonus of Carystus, Phlegon of Tralles, Apollonius the paradoxographer, and other authors that I hadn't ever heard of-but some of which were so interesting that they have now become my research focus). At the time, my interest was in understanding the apocryphal acts, not the Physiologus, and I was not particularly interested in investigating the relationship-if any-between any of the apocryphal acts and the Physiologus. I have since grown more interested in the Physiologus for its own merits. However, reading through much of the modern scholarship on the Physiologus, particularly the arguments concern- ing the date of its composition and its religious milieu, ${ }^{1}$ it occurred to me that a more careful consideration of the text alongside the apocryphal acts, particularly the Acts of John, Acts of Paul, and Acts of Thomas ${ }^{2}$ might have something new to offer. What I have found is fewer direct connections than I might have imagined, but, nevertheless, a shared perspective on the natural world that is, in my opinion, well worth noting.

In what follows, I will first evaluate proposed connections between the Physiologus and the Acts of Paul (more precisely, the Acts of Paul and Thecla), the Acts of John and the Acts of Thomas. The first two are connections that have been noticed and discussed by others, the third is my own proposal. From there I will turn to a consideration of broader similarities in these texts' apparent attitudes towards the natural world and, above all, the animals within it.

\section{The Acts of Paul and Thecla and the Physiologus}

The clearest connection of the Physiologus with the apocryphal acts is the mention of Thecla in chs. 17 and 40. In c. 17, which describes the aspidocelone, a big fish that attracts little fishes with the sweet smell of its mouth and swallows them, whereas the mature fish know better than

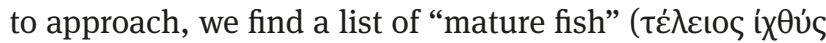
in the G manuscript; including also the phrase toù $\delta \dot{\varepsilon}$

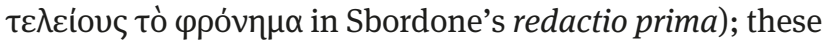
"mature fish" include Moses, Isaiah, Jeremiah and all the prophets, Judith, who escaped Holophernes, Esther, who escaped Artaxerxes, Susannah, who escaped the elders,

\footnotetext{
1 Is it a product of the $4^{\text {th }}$ century CE (as, for example, Wellman and Scott have argued) or of the $2^{\text {nd }}$ century (as, for example, Perry and Treu have maintained)? Is it "gnostic" (as Treu contends) or is it orthodox (as Perry believed)? See Wellmann (1930), Scott (1998), Perry (1941), and Treu (1966).

2 In Animals in the Apocryphal Acts of the Apostles (Spittler 2008) I argue that the Acts of John, Acts of Paul, Acts of Peter, and Acts of Thomas share an interest in the natural characteristics of animals and a positive evaluation of the natural world, whereas the Acts of Andrew and Acts of Philip (the "exceptions that prove the rule") espouse a more negative evaluation of animals and the natural world or a lack of interest, respectively. In what follows, when referring to the "apocryphal acts of the apostles" as a group, I am referring to the Acts of John, Acts of Paul, Acts of Peter, and Acts of Thomas.
} 
and, finally, Thecla, who escaped Thamyris. In c. 40, a rather odd chapter describing the ibis, ${ }^{3}$ we find Thecla again. Here, she is listed among individuals who are saved by making the sign of the cross with their own bodies; these include Moses, Daniel, and Jonah, followed by the same list of women found in c. 17, now in almost reversed order (Thecla, Susannah, Judith, and Esther). Here we find a longer report on Thecla: according to the $\mathrm{G}$ manuscript, Thecla conquered "fire and beasts, and was saved by faith"

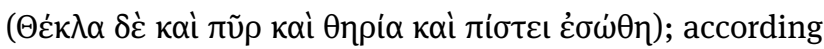
to Sbordone's redactio prima "Thecla was cast into fire and to beasts and seals, and the figure of the cross saved

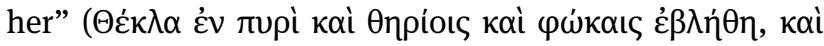

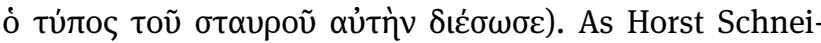
der has noted, both versions are compatible with the text of the Acts of Paul and Thecla, in which Thecla "having

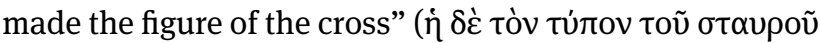

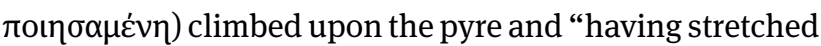

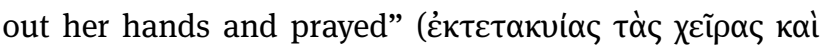

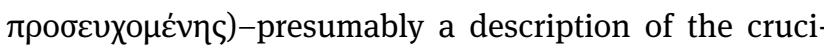
form orans pose-baptized herself in a pool of seals in the course of a beast fight. ${ }^{4}$ Schneider correctly concludes that the author of these passages had the text of the Acts of Paul and Thecla before him, inasmuch as the details correspond so closely. ${ }^{5}$ Moreover, these details cannot have derived from the most popular images of Thecla (e.g. on pilgrim flasks from the cult site of St. Menas) in which, contra the written text of the Acts of Paul and Thecla and the description in the Physiologus 40, Thecla is depicted with arms bound behind her. ${ }^{6}$

As Schneider has suggested, it is quite possible that the reference to Thecla in c. 40 is an interpolation; in Sbordone's redactio prima the syntax pairs her with Jonah, but then leaves Jonah grammatically dangling. When, however, the two phrases involving Thecla are removed, the syntax flows smoothly. ${ }^{7}$ If Thecla is indeed an interpo-

3 On the ibis chapter see Schneider (2002a).

4 Schneider (2002a, 161).

5 Schneider (2002a, 161).

6 See discussion by Castelli (2004, 166-167). Note, however, that in the apparently earliest visual depiction of Thecla, in a mid-fourth century burial chamber in Thessaloniki, she is depicted in the cruciform orans pose (See discussion in Castelli 2004, 159-162). Is it possible that early (largely not extant) images of Thecla depicted her in the orans pose, whereas later images moved away from the text's written image, depicting her instead with arms bound? Could this help us in dating the reference to Thecla in the Physiologus 40?

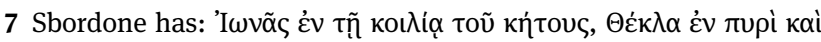

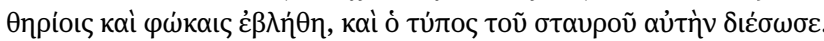

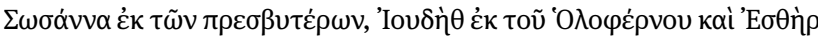

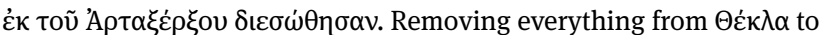

lation in c. 40, however, I think Schneider's suggestion, "daß die Erwähnung des Thekla-Exempels in Kapitel 17 die Interpolation in Kapitel 40 provoziert haben könnte,"8 is very likely correct. I do not see any reason to suspect that the mention of Thecla in c. 17 is not original; that said, because c. 17 mentions only the names Thecla and Thamyris, without any of the details found in c. 40, it could reflect a general familiarity with the Thecla narrative, rather than an author who has the text of the Acts of Thecla before him.

And indeed, as Alan Scott has written, "it is not surprising that the Physiologus refers to Thecla, not only because she was a popular figure but because the author of the Physiologus surely must have been interested in the fantastic stories about animals in these legends." 9 That is an entirely reasonable observation, but I cannot help but ask myself: why aren't there any seals in the Physiologus? ${ }^{10}$ Why not mention Thecla or, for that matter, Paul in the report on the lion in c. 1? In other words, I can imagine and even might expect more connections between the Physiologus and the Acts of Thecla than what we actually have.

\section{The Acts of John and the Physiologus}

Erik Peterson has suggested that the report in Sbordone's Physiologus 31a (concerning the three youths in the furnace) that the apostles moved mountains into the sea

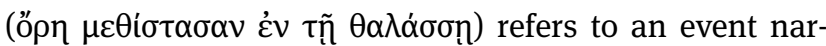
rated in the Acts of John. ${ }^{11}$ No such episode is found in the extant Acts of John, but Theodore the Studite, in an oration on Saint John, includes a list of miracles performed by him, including moving a mountain into the water (opos

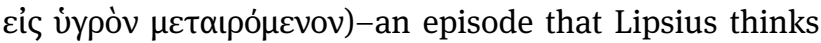

$\overline{\delta \text { เ̇́} \sigma \omega \sigma \varepsilon}$ would clearly improve the syntax; that said, it would also

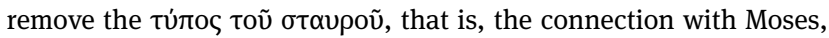
Daniel and the primary content of the chapter. A look at the variants only complicates the situation. As noted above, $\mathrm{G}$ also lacks any reference to the form of the cross; it also lacks mention of Judith and Esther. $\Sigma, \mathrm{O}, \mathrm{s}$ and $\mathrm{W}$ include Thecla and the form of the cross, adding also the three youths in the furnace; A, I and E include only the initial example of Moses (see Kaimakis 1974, 114a-115b).

8 Schneider (2002a, 163).

9 Scott (1998, 437-438).

10 For evidence that there was plenty of material to work with, had the author of the Physiologus wanted to include seals, see Horst Schneider's excellent article "Thekla und die Robben" (2001).

11 Peterson $(1959,236)$. 
was drawn from the original Acts of John. ${ }^{12}$ Given the fragmentary state of the Acts of John, this is entirely possible; in fact, Lipsius takes Theodorus' list of miracles performed by John as evidence of how little of the oldest form of the Acts of John is extant. ${ }^{13}$ Lipsius may well be right in assigning an episode involving the moving of mountains to the Acts of John. After all, John does bring down half of the temple of Artemis in Ephesus in c. 42-a comparable feat. But while plausible, it remains far from certain that the Physiologus refers to the Acts of John in c. 31a.

It is equally difficult to establish a clear connection between the description of the partridge in Acts John 56-57 and the Physiologus 18. In the Acts of John the apostle marvels at a partridge fluttering and rolling in the dust-an activity that somehow scandalizes a certain priest who observes John's delight at the sight. The episode in the Acts of John seems to depend on the partridge's general reputation for bad behavior and lust (reported by Aristotle, Ps. Antigonus, Pliny, Plutarch, Aelian and others). The lustiness of the bird was so well-known, in fact, that Athenaeus can write "the animal is employed symbolically for lust" ( characteristic makes some sense of the priest's otherwise odd reaction: he is appalled to find the apostle delighting at the activities of a notoriously wicked and lascivious creature. In the Physiologus 18, we find a very different report, that is, that the partridge gathers and broods other birds' eggs, which will abandon the false parent once they hatch. This report is quoted from the LXX and is taken up also by Origen, ${ }^{16}$ but I find no hint of it in the partridge episode in

12 Lipsius (1883, 442-443). The text of Theodore the Studite is from Cod. Par. Gr. 1197.

13 Lipsius (1883, 442-443). Lipsius laments (443): "Von all diesen Wundergeschichten, mit Ausnahme der einen schon erwähnten, hat sich sonst keine Spur erhalten: wir ersehn hieraus zu unserm Bedauern deutlich, wie geringe Reste wir noch von den alten Johannesacten besitzen."

14 Acts of John 56-57 = Cod. Par. Gr. 1468v; see Junod and Kaestli (1983, 141-158, 373).

15 See discussion in Spittler (2008, 116-124).

16 The behavior described in LXX Jer 17:11 does not, to my knowledge, correspond to any reports concerning the partridge ( $\pi \varepsilon \dot{\rho} \delta\llcorner\xi)$ in Greek sources. The explanation of the report provided by the Physiologus seems, perhaps, to relate to ancient reports of the cuckoo

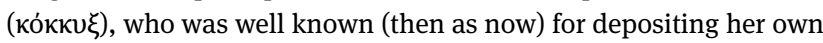
eggs in the nests of other species of birds. As Aelian writes, "when [the cuckoo's young] are fledged and recognize themselves as bastards, they fly away and set out for their [real] parent" (De natura animalium 3.30); perhaps the Physiologus, familiar with the cuckoo, has understood the partridge in Jer 17:11 as the bird on the receiving end of the cuckoo's egg deposit. Notably, Origen does not take this tack, instead satisfying himself with determining whether the partridge is the Acts of John. Likewise, the Physiologus makes no use of the lustiness of the partridge-thus I see no connection at all, at least as far as the partridge goes.

It is then plausible, though not at all certain, that the author of the Physiologus was familiar with either the text of the Acts of John or some of the stories therein. But if Peterson is correct in suggesting that the author of the Physiologus borrows from the Acts of John, then why not include the famous bedbugs from the Acts of John 60-61? Why is the partridge presented so differently? As with the Acts of Thecla, there are fewer connections than we might hope for.

\section{The Acts of Thomas and the Physiologus}

There is one instance in the apocryphal acts in which an author clearly indicates knowledge of a report on animal behavior also present in the Physiologus. In the Acts of Thomas act 8, we find an interesting episode involving wild asses: ${ }^{17}$ Thomas, travelling with a certain captain, on his way to help the man's wife and her daughter, both possessed by demons, has set out in a wagon drawn by typical beasts of burden (ن் exhausted and the wagon comes to a halt; seeing a herd of wild ass colts grazing near the road, he instructs the captain to go into the herd and tell the wild asses that "Judas Thomas the apostle of the Christ, the son of God," has need of their services. The captain is afraid, and well he should be: wild asses are dangerous creatures, according to the ancient natural historians. ${ }^{18}$ But these wild asses respond immediately and positively, competing for the honor of being yoked to Thomas' wagon, and, once yoked, pulling that wagon directly to the captain's house with no direction. When they arrive, Thomas commands one of the wild asses to enter the courtyard and call out the demons that have possessed the two women. The wild ass then enters the courtyard, opens his mouth and speaks-in fact say-

good or bad (and thus whether it should be understood as representing Christ or the devil). Turning to what the natural historical sources report about the partridge, including both it's general reputation for lust, and a specific behavior involving the deception of hunters, Origen concludes it must be interpreted as the devil. In all likelihood, Origen here depends on some version of Aristotle's Historia Animalium, which describes the partridge's deception of hunters and its general bad character at $613 \mathrm{~b}$.

17 See my more extensive discussion in Spittler (2008, 199-221). 18 See Aelian, De natura animalium 4.52; Oppian, Cynegetica 3.183207. 
ing much more than Thomas commanded. Moreover, after the apostle exorcises the demons-a process that leaves the women seemingly dead on the ground-the wild ass speaks up yet again, this time both scolding the apostle for his inaction and delivering something of a sermon, warning the crowds who have gathered about "false apostles and prophets of lawlessness" who "are not satisfied with one wife" but "destroy many women"; they "say one thing with their mouths, but they think another in their hearts," they "command others to keep away from fornication, theft and greed, but all these things-they live their lives in them, while teaching others not to do them."19

This is a strange episode, raising multiple questions, foremost in my mind being: why a wild ass? Why choose this particular animal to play this prominent role in the text, delivering this particular message? As I have argued elsewhere, the report on the wild ass in Physiologus 9 (reported also in Ps.-Aristotle's On Marvelous Things Heard, by Oppian and, of the African wild ass, by Pliny ${ }^{20}$ offers a clear answer:

Concerning the wild ass : It is written in Job, "who has set the wild ass free?" The Physiologus has said concerning the wild ass that he is the leader of a herd, and should any of the roaming females give birth to males, their father cuts all their genitals, so that they not produce seed. For the patriarchs sought to sow bodily seed, but the apostles, [to sow] noetic children, practiced encratism, seeking heavenly seed, as it is written, "be of good cheer, sterile woman who does not give birth; break out and shout, you who do not have birth pangs; for the children of the desert are more than those of the woman who has a husband." The old is the seed of promise; the new is of encratism. The Physiologus spoke well about the wild ass.

The behavior here described coordinates perfectly with the warning issued by the wild ass: male wild asses, according to the Physiologus, are indeed "not satisfied with one wife," and "destroy many women"; moreover, they "say one thing with their mouths"-quite literally with their castrating bite-while practicing just the opposite. Note that in the Acts of Thomas c. 70, the herd of wild asses are referred to explicitly as $\pi \dot{\omega} \lambda$ ot, ${ }^{21}$ "colts" or "young males"; according to the natural historians, these should be, then, a heard of eunuchs, grazing together in the desert. Who better to rail against the hypocrisy of false prophets who

19 Acts of Thomas 79.

20 Ps.-Aristotle, De mirabilibus auscultationibus 10; Oppian, Cynegetica 3.191-207; Pliny, Naturalis historia 8.46; cf. Solinus Collectanea rerum memorabilium 27.27.

21 Note, however, that there are variant readings of this word in manuscripts $\mathrm{U}$ and $\mathrm{V}$. engage in fornication? Who better to represent the encratic message of the Acts of Thomas?

It seems, then, that the author of the Acts of Thomas was well aware of the natural historical information on the wild ass reported in the Physiologus and elsewhere, but also conscious of the specific Christian meaning attached to these animals by the Physiologus. It is plausible that the Acts of Thomas, likely composed in a Greek-Syriac bilingual environment in the mid third century, is in fact literarily dependent on the Physiologus in this section. That said, of the two other animal-related episodes in the Acts of Thomas, one involves an animal not treated in the Physiologus (a domestic ass); the other, involving a love-sick, murderous snake, has no obvious connections to the Physiologus 10 or 11, where snakes are discussed..$^{22}$ Moreover, the well-known "hymn of the pearl" in the Acts of Thomas 108-113 shows no contact with the report on the agate and the pearl in the Physiologus $44 .^{23}$

\section{What do the apocryphal acts and the Physiologus have in common?}

While direct literary connections between the Physiologus and the apocryphal acts are slimmer than we might hopeor, perhaps I should say, slimmer than I had hoped-there are still strong connections in terms of interests and attitude toward the natural world. In what follows, I will discuss three common interests that I think are significant for understanding the overall aims of these texts.

22 Brief mentions of the eagle (in Acts of Thomas 91 and 111), the partridge (in Acts of Thomas 91), and the dove (in Acts of Thomas 91 and 50) have no contacts with the reports on these birds in the Physiologus 12,18, 28 or 35 (in any of its versions). Notably, the reference to the

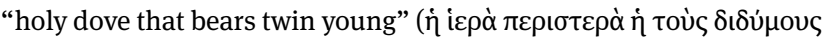

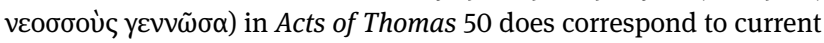
natural historical information, where it is reported that doves generally lay two eggs at a time and raise two chicks (see Aristoteles Historia Animalium 6.4.562b)

23 There is a minor point of contact in the mention of adamant in in Acts of Thomas 108 (at line 8 of the Hymn of the Pearl). The ex-

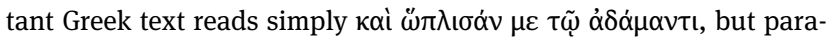

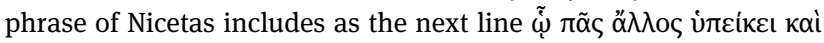

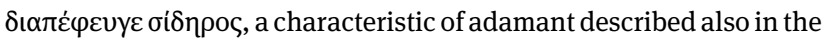
Physiologus 42. This, however, is easily the most well-known characteristic of a well-known stone (see, e. g., Pliny Naturalis historia 37.57), and so there is no reason to suspect that the author of the Hymn of the Pearl was dependent upon the Physiologus. 
1 The Physiologus and the apocryphal acts of the apostles share a strong interest in the particular characteristics of real animals

This point, I think, bears repeating-especially with respect to the animals described in the Physiologus-because the opposite is often at least implied by our own (that is, scholars') habits in describing the text. Take, for example, the first sentence of Wellmann's work on the Physiologus: he refers to the text with its "wunderbaren Geschichten vom Einhorn, Vogel Phönix, Pelikan, Ameisenlöwen," etc. Given that three of the four animals listed are, in the modern world, well-known mythical creatures, this description-though not the substance of Wellmann's work-leaves the impression that the Physiologus has little to do with real animals in the natural world. Ben Edwin Perry notes that the text describes both real and mythical creatures, but calls the characteristics described "fabelhaft." ${ }^{24}$ Ursula Treu writes that the Physiologus reads "more like fabulous stories than like specimens of zoological history." 25 Alan Scott describes the content of the Physiologus as "the exposition of fantastic beasts for moral purposes.” Patricia Cox Miller is more sympathetic to the complexities of the Physiologus, but nevertheless emphasizes the fabulous nature of the reports, writing: "if nature is a text, and if what the text gives to be read are images and likenesses of hidden realities, then of course the reading will yield fantastical creatures." ${ }^{26}$ Similarly, Otto Schönberger dismisses the importance any relationship between the animals described in the Physiologus and real animals in the real world, writing "es geht nicht darum, ob es das Einhorn wirklich gibt, sondern es kommt auf die rechtgläubige Erklärung seiner Bedeutung an."27

But the truth is that, even from a contemporary perspective, the vast majority of animals described in the Physiologus are real, not mythical, animals-the exceptions being the phoenix, sirens and centaurs, the ant-lion and unicorn. From an ancient perspective, not even all of these are clearly mythical: many clearly regarded the phoenix as a real, if exceedingly rare, bird $;^{28}$ the unicorn

24 Perry $(1941,1074)$.

25 Treu $(1993,198)$.

26 Cox Miller $(2001,65)$.

27 Schönberger (2001, 145-146).

28 Herodotus, Histories 2.73; Pliny, Naturalis historia 10.2; Ovid, Metamorphoses 15.392; Mela, De situ orbis 3.8; Aelian, De natura animalium 6.58; Philostratus, Vita Apollonii 3.49; Tacitus, Annales 6.28. To be sure, several of these authors question the validity of the reports concerning the bird's resurrection; nevertheless, it is clear that many in antiquity were convinced of the bird's existence. was known to roam the deserts of India; ${ }^{29}$ and, while he regards the hippocentaur as a clear fabrication, Aelian wonders if the-from his perspective-very real onocentaur, which resembles a very hairy man from the waist up and an ass from the waist down, didn't give rise to the notion. ${ }^{30}$ Phlegon of Tralles claims that a live hippocentaur was found and captured in Saune, a city in Arabia; it was first sent to Egypt, but did not survive the change in climate. There it was embalmed and sent along to the emperor in Rome, where it was exhibited in the palace. Phlegon writes that "anyone who is skeptical can examine it for himself, since as I said above it has been embalmed and is kept in the emperor's storehouse."31

Moreover, while the majority of the animal (and plant and mineral) characteristics described in the Physiologus are, from a contemporary perspective, demonstrably inaccurate, it is not correct to call them "fabulous" or "fantastic." Better are terms like "amazing” or "astonishing," inasmuch as, much like the reports in paradoxographical literature, ${ }^{32}$ there is in the Physiologus an underlying assumption that the reports are true-that they describe real animals in the real world. The contemporary reader might find, just taking one example, the notion that the panther uses its sweet breath to attract prey rather far-fetched, but this characteristic is reported matter-of-factly by Aristotle, Pliny, Plutarch and Aelian. ${ }^{33}$ Early readers of the Physiologus were likely "amazed" in the same way that contemporary audiences are amazed by an evening spent watching the cable network Animal Planet or reading National Geographic. $^{34}$

\section{Aelian, De natura animalium 16.20.}

30 Aelian, De natura animalium 17.9.

31 Phlegon of Tralles, Book of Marvels 34-35. Compare also Jerome's Vita Pauli, in which Antony, on his way to visit Paul in the desert, encounters both a centaur and a satyr. The section concludes with a report strikingly similar to Phlegon's, that is, that, lest anyone doubt that satyrs in fact exist, a live satyr had recently been displayed in Alexandria and, after its death, was preserved in salt and brought to Antioch (Jerome, Vita Pauli 8).

32 The Physiologus is often compared with paradoxography, though not always with a good understanding of the paradoxographical genre. Contrary to being patently fabulous or marvelous, paradoxographies are characterized by the frequent citation of venerable sources (above all Aristotle and Theophrastus); thus, while the goal of paradoxographical texts was clearly to amaze, and to present anecdotes that stretch believability, they present themselves as very much grounded in reality.

33 See Aristotle, Historia Animalium 8(9).6.612a; Pliny, Naturalis historia 8.62; Plutarch, De sollertia animalium 976D; Aelian, De natura animalium 5.40 .

34 Note, moreover, that some of the reports in the Physiologus are, in fact, perfectly plausible: some birds are indeed monogamous (as 
The animals in the apocryphal acts of the apostles are, in some ways, more amazing than the animals of the Physiologus, inasmuch as they sometimes speak with a human voice. But, generally speaking, the situation is much the same: while the apocryphal acts never explicitly describe or discuss the characteristics of animals, animals are typically presented enacting characteristics for which they were well known. As I have argued elsewhere (and as is, I hope, clear in the example of the wild ass), the animal episodes in the apocryphal acts assume a basic naturalhistorical knowledge of each animal's characteristics, and that knowledge is often necessary to make good sense of the animal-related episodes. ${ }^{35}$

\section{The Physiologus and the apocryphal acts of the apos- tles share a positive evaluation of the natural world}

This second common element is very much rooted in the first: it is the particular characteristics of real animals thatproperly understood-reveal the ultimate goodness of creation and its creator. The Physiologus and the apocryphal acts make the argument that nature itself is inscribed with the Christian message; the evidence for this argument is the characteristics of animals, plants and minerals. Thus, far from Schönberger's claim that, for the author of the Physiologus, it doesn't matter whether the unicorn exists or not, the real existence of these animals in nature is necessary for the argument to be persuasive. In the Acts of John, Acts of Peter, Acts of Paul, and Acts of Thomas individual animals are frequently depicted quite positively, often as recognizing and revering the apostles and modeling ideal Christian behavior in a way that surpasses the behavior of human characters in the narratives. Similarly, the Physiologus presents some animals as modeling ideal Christian behavior (e. g. the hoopoe's care of its parents; the ant's industry; the crow's monogamy, etc.).

But, for neither the Physiologus nor the apocryphal acts, is the goodness of creation evident only in the good creatures. Rather, for the careful observer-the one who really studies nature (the "physiologus," as it were)-it is clear that all of nature is inscribed with Christian meaning. While the Physiologus views nature itself, represented above all by the creatures within it and their peculiar characteristics, as a text to be interpreted, the authors of the apocryphal acts take the further step of borrowing from

Physiologus 27 and 28 report of the crow and dove); the owl is indeed active at night (c. 5); it is unclear precisely which stones are referred to in c. 37, but the notion of stones that ignite is hardly far-fetched given the existence of flint; and, of course, magnets, as in c. 38, do indeed attract iron!

35 See Spittler (2008) passim. that text, weaving those creatures and their characteristics into narratives. The underlying attitude toward the natural world-that is, as the creation of God, which holds not-so-hidden meaning for those who attend to it-is the same.

\section{The Physiologus and the apocryphal acts of the apos- tles share a strong interest in asceticism}

That both the Physiologus and the apocryphal acts advocate asceticism, particularly self-control with regard to sex, is well known. The apocryphal acts emphasize abstention from all sex, even within marriage. In the Physiologus we

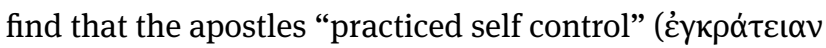

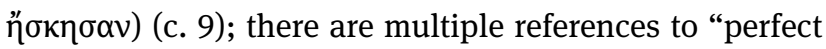

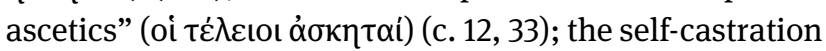
of the beaver is behavior to be imitated (at least metaphorically) (c. 23); the reader is advised to flee from the female ( $\varphi \varepsilon \tilde{y} y \varepsilon$ tò $\theta \hat{n} \lambda v$ ) so as not to be aflame with passion (c. 37); and there are warnings for those "just beginning in the life of asceticism” (

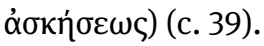

What is interesting here is the combination of the positive evaluation of the natural world-including its animalsalongside the emphasis on asceticism. This combination is a bit unusual, inasmuch as the association of the human being's base passions with animals is a commonplace in Greek literature. ${ }^{36}$ Other early Christian texts that promote asceticism did typically use animals to represent passions and temptations. Taking just one example, in Athanasius' Life of Antony we find demons assuming the forms of animals to attack the desert monk (Vita Antonii 9) as well as real animals sent by the devil to attack him (Vita Antonii 50-52). Antony does not cohabit peacefully with animals in the desert: at best he commands them and they obey, but his command is that they leave his presence. ${ }^{37}$ As Ingvild Saelid Gilhus puts it, "there was no place for animals in the new paradise that Antony had made in the desert.",38

While there are surely "bad" animals in both the apocryphal acts and the Physiologus, it is interesting to note that neither really uses animals to represent incontinent,

36 Perhaps most influential was Plato's description of the human soul as a trichotomous hybrid in the Republic 588b-589c; cf. also (and much closer to our time period) the Tabula of Cebes, where the man who has overcome his vices is described as having conquered the "greatest of beasts" (23.1-2).

37 See discussion by Gilhus (2006, 205-226).

38 Gilhus $(2006,266)$. Compare, however, Jerome's Vita Pauli, where ravens deliver rations to Antony and Paul, and two lions mourn and dig a grave for the deceased Paul. 
lustful behavior. ${ }^{39}$ In fact, in the Physiologus in particular, it is notable that even animals that elsewhere are closely associated with lust are not described in those terms. As we have already seen, the partridge is, in other Greek authors, a veritable symbol of lust, but that characteristic plays no role in c. 18 of the Physiologus. And while the report on the hyena in c. 24 does understand the animal's yearly sex change as representing a human sexual behavior to be avoided (that is, men taking the role of women in homosexual sex), there is no hint of the extreme lustiness that Clement attributes to the hyena in Paedagogus 2.10. ${ }^{40}$ The hare, perhaps the lustiest creature of all for Clement, ${ }^{41}$ does not appear in the redactio prima of the Physiologus; its treatment in the redactio secunda, moreover, makes no mention of lust, instead offering the hare's tendency to run uphill to avoid hunters (cf. Aelian De natura animalium 13.14) as an example for Christians to imitate.

Instead, and rather surprisingly, we find in the Physiologus multiple examples of animals who are, by nature, continent, if not straightforwardly ascetic: thus, the beaver, a "thoroughly gentle and quiet animal" ("ᄁ $\pi$ iov

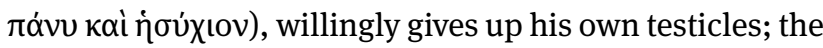
crow and the turtledove are, by nature, monogamous; the elephant has no desire for sex; and, finally, young male wild asses are essentially eunuchs-making them appropriate creatures both to be compared, in the Physiologus, with the apostles who practiced self control and to deliver, in the Acts of Thomas, an ascetic message.

\section{Conclusion}

Alan Scott has argued that, within the context of early Christian literature, the Physiologus fits best "in the wake of Origen's theology,” regarding it probable that a liter-

39 The exception among the apocryphal acts is, as noted above, the Acts of Andrew, which differs substantially from the remaining four major apocryphal acts of the apostles in precisely this regard.

40 For Clement (who like both the Physiologus and Barnabas 10.7 seems to have mistakenly understood a ban on eating hyenas in Deuteronomic law (presumably Deut 14:8) and, like the Physiologus, also cites Jer 12:9, where the hyena is indeed mentioned) the hyena is the supreme example of excessive sexual activity, having been supplied by nature with an extra organ specifically to accommodate nearly constant, non-procreative sex. See Clement's lengthy and detailed discussion in Paedagogus 2.10.

41 The hare, which Clement treats alongside the hyena (and which is in fact declared unclean in Lev 11:6 and Deut 14:7), is the hyena's nat ural counterpart, inasmuch as that animal is characterized by similar lust accompanied by nearly constant, but now procreative, sex. See Clement, Paedagogus 2.10. ary relationship existed between the two, the direction of influence and/or borrowing flowing from Origen to the Physiologus. ${ }^{42}$ While Scott acknowledges the Physiologus' "extensive parallels with paradoxography," he states that "extensive treatment of paradoxographical material in the formative years of Christian theology is unknown." ${ }^{43}$ Further, Scott writes that the Physiologus' "allegorical treatment of largely pagan (pseudo)-scientific material simply does not fit the framework of second century Christian literature." ${ }^{44}$ It is particularly this allegoricalv element that, to Scott's mind, associates the Physiologus with Origen-though he ultimately concludes that the Physiologus differs inasmuch as it "disengages allegory from the text of a canon and applies it to the natural world.” Because I rather disagree with his position, I think it's worth quoting Scott at some length:

In Origen the feeling is present that every nuance and corner of scripture is full of significance. He believed that nothing he found in the Bible had come there by accident; everything had a secret meaning. In the Physiologus, this idea is applied not so much to scripture, but to nature as a whole. The author has the idea that nature itself is filled with theological meaning which can be discerned allegorically. This idea that nature might be in terpreted in the same way as a book was not obvious to early Christian theology, and in fact a theology of the natural world was otherwise slow in developing. ${ }^{45}$

Whether or not Origen, too, viewed nature as a text to be interpreted is itself, I think, debatable. ${ }^{46}$ The key point for the present purposes, however, is that this is exactly what

42 Scott $(1998,440-441)$. Scott argues that "Origen frequently refers to pagan zoological/paradoxographical material, and in doing so he normally relies on pagan sources, not on Christian sources, and certainly not on a primitive work like the Physiologus. That a Christian in Egypt might use Origen is easy to believe; that Origen might use a book like the Physiologus is doubtful” (440).

$43 \operatorname{Scott}(1998,439)$. While it is unclear what exactly what date range is intended in the phrase "formative years," I would note that at the end of the second century Clement of Alexandria was rather deeply engaged with paradoxographical material, being-just as one example-our earliest confirmed reader of one of the earliest paradoxographical texts, Apollonius' Amazing Stories. Clement reproduces, without citation, Amazing Stories 46, a discussion of the Pythagorean prohibition on eating beans. See discussion in my forthcoming edition, translation and commentary on Apollonius' Amazing Stories (in FGrHist).

$44 \operatorname{Scott}(1998,440)$.

45 Scott $(2002,86)$.

46 Compare, for example, Cox Miller, who draws just the opposite conclusion: "This view of the natural world as a potentially explosive cache of theological realities was developed in a Christian context by the Alexandrians Clement and Origen, both of whom considered meditations on phusis to be a way of initiation into the sensuous enig- 
the Physiologus has in common with the apocryphal acts of the apostles.

The Acts of John, Acts of Peter, Acts of Paul, and Acts of Thomas have used contemporary natural historical information on animals, similar-if not identical-to what we find in Aristotle, Philo, Pliny, Aelian, the various paradoxographers and the Physiologus, to construct narrative episodes in which the known characteristics of real animals play central roles. ${ }^{47}$ I have already discussed how I see this happening in act eight of the Acts of Thomasand that is, in fact, one of the clearest examples of the phenomenon-but there are many others: the obedient bedbugs, the snake, and the partridge in the Acts of John; the snake in the Acts of Thomas; the talking dog in the Acts of Peter; and the multiple lions in the Acts of Paul.

Elsewhere, I have concluded that one of the interests evident in the depiction of animals in the Acts of John, Acts of Peter, Acts of Paul, and Acts of Thomas "is to underscore the goodness of creation and its creatures and to emphasize, against those who espouse a wicked biblical demiurge, that it is the product of God." ${ }^{48}$ I still think that is basically right, and I think it makes good sense if our typical dating of these texts (that is, as composed between the mid second and mid third centuries) is correct; this seems like a good time for Christians, perhaps especially ascetic Christians, to make a positive argument for the goodness of creation and its creator. Was that also a good time for the Physiologus to have been composed? Here I offer a resounding maybe. I would not, on the basis of the evidence presented here, argue against a late third or fourth century date for the Physiologus, but I certainly do not think the second century can be excluded on the basis of the religious and intellectual milieu, as Scott does. The evidence provided by comparison with the apocryphal acts suggests, instead, a date of composition allowing for both familiarity with the Thecla narrative and the possible usage of the Physiologus by the author of the Acts of Thomas, that is, a date somewhere between the last quarter of the second century and first half of the third. To reiterate: I do not think the evidence gleaned from the apocryphal acts makes a conclusive case, but I do think it indicates the plausibility of such a date.

One final point: the interest in the natural world present in both the Physiologus and the apocryphal acts is, I would wager, not exclusive to these texts. To the contrary, I suspect that the more we work with the Physiologus-in

mas of the spirit. Nature was a symbolic language, a theological text" (2001, 64-65).

47 See Spittler (2008).

48 Spittler (2008, 231). its straightforward and very obvious interest in the natural world-and the more familiar it becomes to scholars of early Christian literature, the more we will see that a wide variety of early Christian authors were reflecting on the natural world in interesting ways. I look forward to seeing what we will learn, once the Physiologus (along with Aelian, and Pliny the Elder, and paradoxography, etc.) becomes basic reading for scholars of the New Testament and early Christian literature. My intuition is that we will find an early Christianity very much engaged in debates about the natural world and the Christian's place within it.

\section{Bibliography}

Castelli, Elizabeth. 2004. Martyrdom and Memory: Early Christian Culture Making. New York: Columbia University Press. Cox Miller, Patricia. 2001. The Poetry of Thought in Late Antiquity: Essays in Imagination and Religion. Burlington: Ashgate.

Gilhus, Ingvild Saelid. 2006. Animals, Gods and Humans: Changing Attitudes to Animals in Greek, Roman and Early Christian Thought. New York: Routledge.

Junod, Eric, and Jean-Daniel Kaestli, Eds. 1983. Acta Iohannis. CCSA 1. Turnhout: Brepols.

Kaimakis, Dimitris, Ed. 1974. Der Physiologus nach der ersten Redaktion. Meisenheim am Glan: A. Hain.

Lipsius, Richard A. 1883. Die apokryphen Apostelgeschichten und Apostellegenden: Ein Beitrag zur altkirchlichen Literaturgeschichte. Vol. 1. Braunschweig: C. A. Schwetschke und Sohn.

Perry, Ben E. 1941, “Physiologus.” PRE 20,1:1074-1129.

Peterson, Erik. (1954) 1959. “Die Spiritualität des griechischen Physiologos.” In Frühkirche, Judentum und Gnosis: Studien und Untersuchungen, ed. by Erik Peterson, 236-253. Rom: Herder (= Byzantinische Zeitschrift 47:60-72).

Schneider, Horst. 2001. “Thekla und die Robben.” Vigiliae Christianae 55:45-57.

Schneider, Horst. 2002a. “Das Ibis-Kapitel im Physiologus.” Vigiliae Christianae 56:151-164.

Schönberger, Otto. (2001) 2014. Physiologus: Griechisch/Deutsch. Stuttgart: Reclam.

Scott, Alan. 1998. “The Date of the Physiologus.” Vigiliae Christianae 52:430-441.

Scott, Alan. 2002. "Zoological Marvel and Exegetical Method in Origen and the Physiologus." In Reading in Christian Communities: Essays on Interpretation in the Early Church. Christianity and Judaism in Antiquity 14, ed. by Charles A. Bobertz and David Brakke, 80-89. Notre Dame, IN: University of Notre Dame Press).

Spittler, Janet. 2008. Animals in the Apocryphal Acts of the Apostles: The Wild Kingdom of Early Christian Literature. WUNT 2.247. Tübingen: Mohr Siebeck. 
Spittler, Janet. Forthcoming. “Apollonios, Amazing Stories (1672).” In Die Fragmente der Griechischen Historiker. Part IV, ed. by Stefan Schorn (2011-) and Guido Schepens (1998-2010). Leiden: Brill. First published online in April 2016 http://dx.doi. org/10.1163/1873-5363_jciv_a1672.

Treu, Ursula. 1966. "Zur Datierung des Physiologus.” ZNW 57:101104.

Treu, Ursula. 1993. "The Physiologus and the Early Fathers.” In Studia Patristica. Vol. 24, Papers presented at the Eleventh International Conference on Patristic Studies held in Oxford 1991, ed. by Elizabeth A. Livingstone, 197-200. Leuven: Peeters.
Wellmann, Max. 1930. "Der Physiologos: Eine religionsgeschichtlich-naturwissenschaftliche Untersuchung." Philologus: Zeitschrift für das klassische Altertum; Supplementband 22,1:1-116. 



\section{Katharina Heyden \\ Liber creaturae und sacra scriptura}

\section{Zur Bedeutung der Naturkunde für die Bibelexegese der lateinischen Kirchenväter}

\begin{abstract}
This article gives an insight into the theoretical approach to and the practical application of natural knowledge by Latin Christians in Late Antiquity. Based on the only explicit reference of a church father to the Physiologus, by Rufin of Aquileia, and on theoretical considerations in Augustine's De doctrina christiana and De civitate dei, the two basic functions of natural history - exegesis and apologetics - are presented in their respective historical and conceptual contexts. In a second part, concrete applications of natural knowledge in various Latin Christian authors, for whom the Physiologus may have served as a kind of handbook, are examined. These examples illustrate the increasing argumentative significance of nature for Latin Christians, and the simultaneous diversity in concrete implementation. The paper thus forms the bridge from the original Hellenistic context of the Physiologus to its reception in the Latin cultural area - and thus also to the Bernese Physiologus.
\end{abstract}

\section{Einleitung}

Der Physiologus, aber auch Naturkunde im weiteren Sinn, hat in der patristischen Forschung bislang eine marginale Rolle gespielt. ${ }^{1}$ Mindestens drei Gründe lassen sich dafür nennen: Erstens handelt es sich beim Physiologus und vergleichbaren Werken eben um Naturkunde, also um jene Mischung aus exakter Beobachtung und phantasievoller Erzählung, die Wissenschaftlern der Neuzeit lange Zeit suspekt war und jedenfalls nicht geeignet für ernsthafte Forschung erschien. Zweitens haben die christlichen Autoren auf diesem Gebiet nichts wesentlich Neues hervor- gebracht, sondern in christlichem Interesse ausgewählt und interpretiert, was ihnen die griechisch-römische Kultur vorgegeben hatte. ${ }^{2}$ Und drittens haben wir es beim Physiologus mit einer Art der Überlieferung und Rezeption $\mathrm{zu}$ tun, die jedenfalls eine philologisch orientierte Patristik vor erhebliche Probleme stellt, weil sie zum einen jede Vorstellung von einem Urtext - und damit auch von einem Autor -, und zum anderen die Frage nach Vorlage, Redaktion und Benutzung an ihre Grenzen treibt. ${ }^{3}$ Angesichts seiner komplexen und fluiden Überlieferung könnte man den Physiologus fast als eine Art antike Wikipedia bezeichnen - allerdings mit dem erschwerenden Unterschied, dass die Entwicklung des Textes hier weniger präzise archiviert wurde als im Internetlexikon. ${ }^{4}$ Die antiken christlichen Quellen konnten daher zur Erforschung des Physiologus, zu Verfasser- und Datierungsfragen nur wenig beisteuern, und man kann auch nur mit großer Ungewissheit bestimmen, ob ein Kirchenvater wirklich den oder besser gesagt: einen Physiologus vor sich hatte oder ein anderes, ähnliches Werk, etwa die Historia naturalis des Plinius, oder ob er lediglich aus einem allgemeinen naturkundlichen Wissensfundus schöpfte. Wenn Hieronymus beiläufig erwähnt, er habe zur Entschlüsselung der Bedeutung der Taube in Hld 2,14 (,Meine Taube in den Felsklüften, in den Steinritzen, zeige mir deine Gestalt, lass mich hören deine Stimme etc.“) „physiologos“ hinzugezogen, so scheint er jedenfalls nicht auf ein bestimmtes Werk, sondern auf ,Naturkundler' im Allgemeinen zu rekurrieren. ${ }^{5}$ Und Ambrosius führt in einem später noch eingehender zu untersuchenden Beispiel sein naturkund-
1 „Naturkunde“ meint hier - in Übereinstimmung mit der „Begriffs klärung“ von Schneider (2016, 724-725) - die Kenntnis der Tier- und Pflanzenwelt. Dass dieser Bereich in der Patristik zu Unrecht vernachlässigt ist, hat Marek Starowieyski in seinem am 11.08.2015 im Rah men der XII Conference on Patristic Studies in Oxford gehaltenen Vor trag „Les animaux dans l'œuvre des Pères de l'Eglise“ betont. Anders verhält es sich mit der Kosmologie, die im Rahmen der Auslegung des biblischen Schöpfungsberichts im frühen Christentum als sog. Hexaemeron-Literatur eine große Rolle spielte, siehe dazu stellvertretend für einen breiten Forschungszweig Köckert (2009) und Hen ke (2000). Wichtige Hinweise bietet auch die (leider nicht in einem Verlag publizierte, aber in der Burgerbibliothek Bern als Manuskript archivierte) Dissertation von Vermeille (2006, bes. 53-69, 74-78).
2 Zur Gattung und zum Verhältnis des Physiologus zur paganen Naturkunde der Antike siehe Schneider (2016, 725-727) und Vermeille (2006, 53-60).

3 Pollmann stellt sehr treffend fest: „In der Antike, in großem Unterschied zu der Zeit nach der Erfindung des Buchdrucks, herrschte ein stärkeres Bewusstsein von und auch eine viel größere Toleranz gegenüber der Fluidität von Texten.“ (Pollmann 2016, 9).

4 Zur Überlieferung des Physiologos siehe Schneider (2016, 727-731); ausführlicher Vermeille (2006, 11-40).

5 Hieronymus, Adversus Iovianum 1 (PL 49:846): „Legamus physiologos, et reperiemus, turturis hanc esse naturam...“. Inhaltlich erinnert die im Folgenden zitierte Passage über die Taube am ehesten an Plinius, Naturalis historia 10.34. 
liches Wissen auf „allgemeine Rede“ (sermo frequens) zurück. ${ }^{6}$

Man muss also anders ansetzen, um ,den' Physiologus im antiken Christentum angemessen zu verorten und seinen überlieferungsgeschichtlich enorm erfolgreichen Weg ins und im Mittelalter ${ }^{7}$ erklären zu können. Dies will ich versuchen, indem ich nicht nach ganz konkreten Rezeptionsvorgängen frage, sondern skizziere, welche Bedeutung die Naturkunde für christliche Theologen in der Spätantike hatte. Dabei beschränke ich mich hier auf die lateinische Tradition, die das Scharnier zwischen dem griechisch-hellenistischen Entstehungskontext des Physiologus und seiner reichen und komplexen Rezeption im mittelalterlichen Abendland darstellt. ${ }^{8}$

Um trotz der skizzierten, etwas vertrackten - aber dafür umso spannenderen - Quellenlage doch ein wenig sicheren Boden unter die Füße zu bekommen, werde ich zunächst die beiden einzigen expliziten Erwähnungen des Physiologus in der lateinischen christlich-antiken Literatur behandeln und diese nach ihrem Quellenwert befragen (2), in einem zweiten Schritt die konzeptionellen Verhältnisbestimmungen von Naturkunde und Schriftexegese bei Augustinus, dem für das lateinische Mittelalter maßgeblichen antiken Theologen, darstellen (3), und schließlich in einem dritten Teil anhand eines Beispiels untersuchen, welche dieser Verhältnisbestimmungen von Naturkunde und Schriftverständnis tatsächlich Anwendung fanden (4) - welche also den hermeneutischen Nährboden bildeten, auf dem sich der Physiologus im Abendland vermehrt und angereichert hat.

6 Siehe unten 4.1.

7 Hierzu siehe Lauchert (1889).

8 Dass die vorliegende Studie auch für das lateinische Christentum nur exemplarisch sein kann, ergibt sich aus der Komplexität und Unübersichtlichkeit der Quellenlage: Wollte man alle theoretischen Aussagen lateinischer christlicher Schriftsteller zur Bedeutung der Natur für die Schrifthermeneutik und dazu die konkreten Anwendungsbeispiele sammeln, so müsste man sämtliche Kommentare und Predigten systematisch durchgehen. Dies wäre bereits im Rahmen einer Monographie kaum zu leisten, geschweige denn in einem Tagungsbeitrag. Die hier gewählten Beispiele können immerhin eine gewisse Prominenz für sich beanspruchen: Augustinus galt vor allem im Mittelalter als der Kirchenvater schlechthin, und ebenso hat die Schlange in der christlichen Tiersymbolik eine hervorgehobene (wenn auch zweifelhafte) Stellung.

\section{Die beiden lateinischen Testimonia für den Physiologus}

\subsection{Das Decretum Gelasianum}

Das einzige Zeugnis der christlichen Latinität, das sich unzweifelhaft auf den Physiologus als ein konkretes literarisches Werk bezieht, verdankt sich ausgerechnet dem Versuch, das Werk zu diffamieren. Das Decretum Gelasianum vom Ende des 5. oder Anfang des 6. Jahrhunderts, das den Kanon der 27 neutestamentlichen Bücher sowie eine blacklist verbotener Bücher enthält, ${ }^{9}$ nennt unter letzteren auch den liber Physiologus:

Liber Physiologus, qui ab haereticis conscriptus et beati Ambrosii nomine praesignatus: apocryphus.

Das Buch Physiologus, das von Häretikern zusammengeschrieben und mit dem Namen des heiligen Ambrosius bezeichnet wurde: apokryph. ${ }^{10}$

Diese Notiz ist ebenso kurz wie aufschlussreich. Sie offenbart mit dem unbestimmten Plural „ab haereticis“ zunächst ein Wissen um die Problematik der Verfasserschaft, die auch die moderne Forschung umgetrieben hat ${ }^{11}$ und deutet außerdem mit dem Wort „praesignatus“ an, dass das Werk fälschlicherweise Ambrosius, dem Bischof von Mailand, zugeschrieben wurde. Ganz abwegig ist diese Zuschreibung freilich nicht, denn zum einen macht Ambrosius in seiner Auslegung des biblischen Schöpfungsberichts intensiv Gebrauch von naturkundlichem Wissen, ${ }^{12}$ und zum anderen stammt das zweite lateinische Testimonium für den Physiologus aus der Feder Rufins von Aquileia, der zum asketischen Umfeld des Ambrosius gehörte. Unbekannte Verfasserschaft bzw. Pseudepigraphie ist in der Alten Kirche ein Kriterium für die Identifikation apokrypher Bücher, ${ }^{13}$ so dass im Decretum Gelasianum bereits in der Bezeichnung des Werkes die Begründung für seine Ablehnung gegeben wird. Freilich hat das Dekret seine Intention, der Beliebtheit des Physiologus und anderer in der Liste aufgeführter Werke ein Ende zu bereiten, in diesem Fall offensichtlich verfehlt: In der Mitte des 13. Jahrhunderts konnte sich Vinzenz von Beauvais in seinem

\footnotetext{
9 Zum Decretum Gelasianum siehe Schneemelcher ( $\left.{ }^{6} 1990,30-33\right)$ und Grossi (2001, 231-355).

10 Decretum Gelasianum 6.11 (Dobschütz 1912).

11 Siehe dazu Schneider (2016, 6-9) und Vermeille (2006, 49-52).

12 Ambrosius, Hexaemeron (Banterle 1979; CSEL 32,1); vgl. Henke (2000).

13 Siehe dazu Meade (1986) sowie Becker und Scholz (2012).
} 
Speculum naturale explizit auf die Autorität des Physiologus berufen und zugleich, im Prolog desselben Werkes, das Decretum Gelasianum zitieren. ${ }^{14}$

\subsection{Rufin von Aquileia}

Die zweite explizite Referenz auf den Physiologus findet sich bei Rufin von Aquileia, einem stark von der alexandrinischen Tradition und besonders von Origenes geprägten Theologen des späten 4. Jahrhunderts, der eine beeindruckende Übersetzungstätigkeit entfaltet hat. ${ }^{15}$ In seiner in den Jahren 407 oder 408 verfassten Auslegung der Segnungen Jakobs (Gen 49), die als Hauptwerk Rufins gilt, stellt er verschiedene Möglichkeiten vor, den Vergleich Judas mit einem Löwenjungen in Gen 49,9 zu deuten - in Rufins Übersetzung: „Ein Löwenjunges ist Juda: Aus dem Spross bist du als mein Sohn heraufgekommen, liegend hast du geschlafen wie ein Löwe und wie ein Löwenjunges: Wer wird ihn aufschrecken?" ${ }^{16}$. In einem ersten Anlauf wird dieser Vers auf die Kriegstüchtigkeit, Stärke und Kraft gedeutet, die Juda als Löwenjunges von seinem Vater erbt und die ihm die Ruhe und das Selbstvertrauen eines schlafenden Löwen verleihen. Dann folgt der zweite Anlauf zu einer Deutung, die Rufin mit dem Hinweis einleitet:

Sed multo conuenentius aptabitur huic loco mystica expositio,

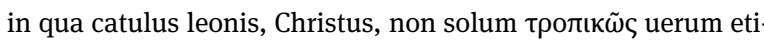
am $\varphi v \sigma ı \kappa \tilde{c} \varsigma$ designatur. Nam Physiologus de catulo leonis haec scribit, quod cum natus fuerit, tribus diebus ac tribus noctibus dormiat; tum deinde patris fremitu uel mugitu tamquam tremefactus cubilis locus suscitet catulum dormientem. Iste ergo catulus ascendit ex germine. ${ }^{17}$

Aber viel angemessener wird eine geheimnisvolle Erklärung auf diese Stelle angewandt, in der das Löwenjunge, Christus, nicht nur auf tropische, sondern auch auf natürliche Weise beschrie-

14 Vinzenz von Beauvais, Speculum naturale Prolog 13 (1624). Der Physiologus wird hier allerdings nicht unter den im „Decretum Gelasii Papae“ genannten apokryphen Schriften genannt - vielleicht ein Hinweis darauf, dass er zu dieser Zeit einen quasi-,kanonischen` Status hatte. Zum Gebrauch des Physiologus im Speculum naturale siehe Lauchert (1889, 21-22).

$15 \mathrm{Zu}$ Rufin, der lange Zeit im Schatten seines früheren Freundes und späteren Rivalen Hieronymus stand, siehe die beiden von der Accademia Cardinale Bessarione und dem Centro di Antichità Altoadriatiche herausgegebenen Sammelbände (1986 und 1992).

16 Rufin von Aquileia, De benedictionibus patriarcharum 1.6 (Simonetti 1961, 192-193): „Catulus leonis Iuda: de germine filius ascendisti, recubans dormisti sicut leo et sicut catulus leonis: quis suscitabit eum?“

17 Rufin von Aquileia, De benedictionibus patriarcharum 1.6 (Simonetti 1961, 193,1-16). Die zitierte Stelle findet sich auch im Physiologus, Kapitel 1. ben wird. Denn Physiologus schreibt über das Löwenjunge folgendes: dass es, wenn es geboren wird, drei Tage und drei Nächte schläft; dann aber setzt der Schlafplatz, durch das Dröhnen und Brüllen des Vaters gleichsam zum Zittern gebracht, das Löwenjunge in Bewegung. Dieses Junge also steigt aus dem Spross hervor.

Rufin lässt keinen Zweifel daran („multo conuenentius“!), dass er diese Deutung auf Christus jener auf die Kriegstüchtigkeit Judas vorzieht. Eine Steigerung beinhaltet der

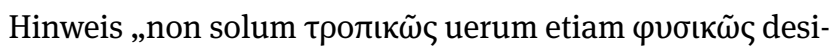
gnatur“, mit dem die „mystica expositio“ genauer erläutert werden soll. Das Geheimnisvolle an der Deutung des Löwenjungen auf Christus wird also offenbar gerade durch die Verbindung von tropischer und naturkundlicher Erklä-

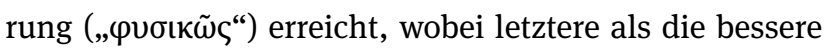
gilt. Dies ist ein wichtiger Hinweis auf die Bedeutung der Naturkunde in der Spätantike - und zwar bei Christen wie bei Nichtchristen gleichermaßen: Naturbetrachtung dient nicht der Aufklärung von Geheimnissen und Wundern, sondern sie dient der Einweihung in diese Wunder.

Eine weitere wichtige Erkenntnis aus diesem kurzen Rufin-Zitat ergibt sich nicht aus der isolierten Lektüre des Textes, sondern erst, wenn man das Milieu betrachtet, in dem er entstanden ist. Das Werk wurde ausweislich des Prologs angeregt durch einen Briefwechsel Rufins mit seinem Freund Paulinus von Nola, der Rufin um Hilfe bei der Auslegung des Segens für Juda gebeten hatte. Beide, Rufin und Paulinus, gehören zu den Kreisen, die stark von Ambrosius geprägt waren. ${ }^{18}$ Dieser hatte in seiner Schrift De patriarchis (390/391 n. Chr.) bereits eine christologische Deutung des Segens über Juda vorgelegt, allerdings ohne auf den Physiologus Bezug zu nehmen. ${ }^{19}$ Ob Rufin die Auslegung des Ambrosius kannte, wissen wir nicht - es ist aber nicht ganz unwahrscheinlich, weil beide demselben kirchlichen, gebildeten, von der Theologie des Origenes geprägten „Milieu“ angehörten. ${ }^{20}$

Beide Testimonia zusammen - Decretum Gelasianum und Rufin - verweisen uns also auf den Rezeptionskontext des Physiologus, der von seinem Entstehungskontext zwar geographisch, nicht aber geistig weit entfernt ist. Tatsächlich sind es genau die Kreise um Ambrosius, die der lateinischen Welt die exegetische Tradition der Alexandriner vermittelten. Daher erklärt sich wohl auch die im Decretum Gelasianum erwähnte Zuschreibung des Physiologus an Ambrosius. Anders als es die in der älteren

18 Zum Mailänder Kreis und der dort praktizierten Schriftauslegung siehe Drecoll (2007).

19 Hierzu und zu den griechischen Vorlagen siehe Tábet (2000).

20 Sordi (1990) weist gegenseitige Abhängigkeiten in der Legende um die Kreuzauffindung nach. 
Literatur zum Physiologus gelegentlich verwendeten Begriffe „Volksbuch“ oder „Gebrauchsliteratur“ insinuieren, haben also vor allem Christen aus der gebildeten römischen Oberschicht den Physiologus und ähnliche Werke gelesen und fortgeschrieben.

In dieses Milieu gehört nun auch Augustinus, der seine Einweisung in das Christentum in den 380er Jahren von Ambrosius in Mailand erhielt und sich auch von diesem taufen ließ, bevor er in seine Heimat Nordafrika zurückkehrte und dort zum einflussreichsten christlichen Theologen des Abendlandes avancierte.

\section{Naturkunde und Schriftauslegung bei Augustinus}

Einem oft zitierten Bonmot von Wilhelm Geerlings zufolge besteht die gesamte abendländische Theologiegeschichte aus Fußnoten zu Augustinus. ${ }^{21}$ Es ist hier nicht der Ort zu diskutieren, ob diese Aussage in ihrer Absolutheit zutreffend ist. Dass Augustinus der für die lateinische Christenheit maßgeblichste Theologe der Spätantike gewesen ist, wird jedoch niemand bestreiten. Umso erstaunlicher mag es daher erscheinen, dass die Fußnote zur Bedeutung der Naturkunde für die Schrifthermeneutik Augustins noch nicht geschrieben wurde. ${ }^{22}$ Dies sei hiermit nachgeholt, indem ich drei unterschiedliche Verhältnisbestimmungen von Natur und Bibel im Werk Augustins in den Blick nehme. ${ }^{23}$

\subsection{Naturkunde als notwendiges Hilfswissen für die Schriftauslegung: De doctrina christiana}

Die erste und konzeptionell am stärksten ausgearbeitete Verhältnisbestimmung von Natur und Bibel findet sich in De doctrina christiana - am besten vielleicht zu übersetzen: ,Über die christliche Lehre und Bildung ‘ -, einer

21 Geerlings (2002, 148).

22 Soweit ich sehen kann, hat sich niemand bisher systematisch mit diesem Aspekt der Augustinischen Theologie befasst. Wolfgang Hübner (2008, 959) erwähnt im Augustinus-Lexikon die Metapher „liber naturae“. Ansonsten wird der Naturbegriff Augustins vorrangig in Bezug auf die - im Denken des Kirchenvaters zweifellos zentrale - Gegenüberstellung von natura und gratia behandelt.

23 Die Abfolge der drei Verhältnisbestimmungen spiegelt keine Chronologie oder Entwicklung im Augustinischen Denken. Vielmehr finden sich alle drei Varianten nebeneinander und zu gleicher Zeit in seinem Werk. für christliche Exegeten und Prediger, aber explizit auch für Laien verfassten enzyklopädischen Schrift, die Augustin nach der Wende in seiner Gnadenlehre um das Jahr 396/397 n. Chr. zu schreiben begonnen und nach 410 n. Chr. vollendet hat. ${ }^{24}$ Im zweiten Buch findet sich folgende Bemerkung zur Naturkunde:

Rerum autem ignorantia facit obscuras figuratas locutiones, cum ignoramus vel animantium vel lapidum vel herbarum naturas aliarumve rerum, quae plerumque in scripturis similitudinis alicuius gratia ponuntur. ${ }^{25}$

Die Unkenntnis der Dinge aber erzeugt dunkle, figürliche Redeweisen, wenn wir Eigenschaften von Lebewesen oder Steinen oder Pflanzen oder anderen Dingen nicht kennen, die meistens wegen irgendeines Vergleichspunktes in den Schriften angeführt werden. ${ }^{26}$

Augustinus knüpft damit an die alexandrinische Kommentartradition an, für die die Sachkenntnis aller in einer Schrift vorkommenden Dinge unabdingbare Voraussetzung jeden, auch des allegorischen, Verständnisses von Texten war. ${ }^{27}$ Er hatte sich mit dieser Tradition der Schriftauslegung während seiner Mailänder Zeit bei Ambrosius vertraut gemacht. In De doctrina christiana fügt er diese philologische Forderung nach Sachkenntnis nun in ein umfassendes semantisches Konzept ein. Deshalb muss man, um die ganze Bedeutung der Naturkunde für das Verstehen und Weitergeben der christlichen Lehre erfassen zu können, etwas weiter ausholen und den zitierten Abschnitt in den Gesamtzusammenhang des in De doctrina christiana entfalteten augustinischen Wirklichkeitsverständnisses stellen.

Die doppelte Wiedergabe des Titelworts „doctrina“ als „Lehre und Bildung“ ist deshalb angemessen, weil Augustinus im ersten Buch die Hauptinhalte der christlichen Lehre entfaltet und im zweiten und dritten Buch darlegt, welche Kenntnisse aus dem antiken Bildungskanon für das Verständnis und die Weitergabe dieser Lehre notwendig sind. Die graphische Darstellung in Abb. 1 auf S. 163 gibt eine Übersicht über den dihäretischen, d. h. aus einer Reihe von kategorialen Unterscheidungen gewonnenen, Aufbau der ersten drei Bücher von De doctrina christiana: Die Grundunterscheidung, die Augustinus allem Erkennen zugrunde legt, ist diejenige zwischen res (Ding, Sache) und signa (Zeichen). Wir haben es also mit einem semiotischen

$24 \mathrm{Zu}$ De doctrina christiana insgesamt siehe Pollmann (1996); und neuerdings Schultheiß (2016).

25 Augustinus, De doctrina christiana 2.16.24 (Daur und Martin 1962, 49).

26 Übersetzung: Pollmann (2002, 66).

27 Diesen Aspekt hebt Neuschäfer (1987) zu Recht hervor. 


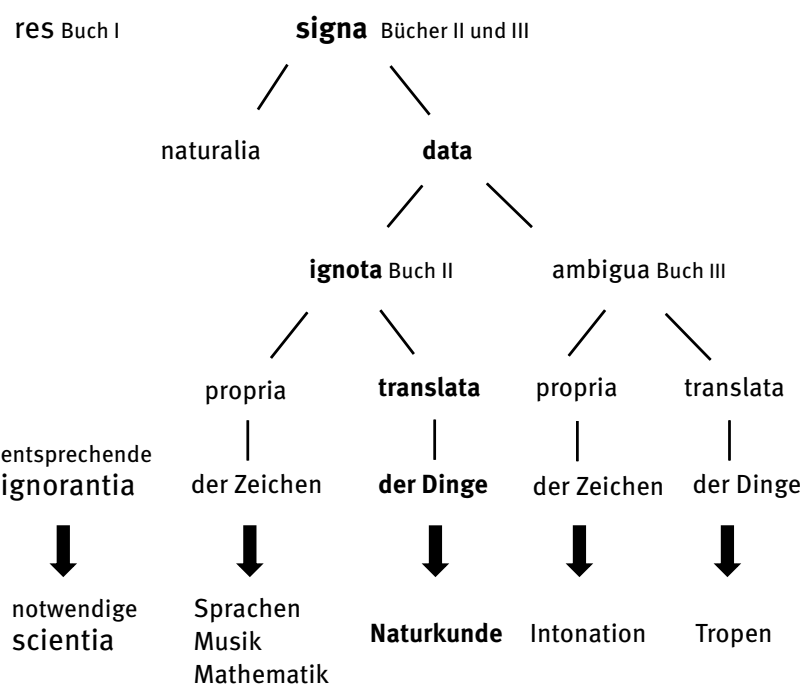

Abb. 1: Die Stellung der Naturkunde im dihäretischen System gemäß Augustinus, De doctrina christiana 1-3.

Wirklichkeitsverständnis $\mathrm{zu}$ tun. Wichtig ist aber für $\mathrm{Au}-$ gustinus, dass es letztlich nur eine res gibt, nämlich den trinitarischen Gott, weil er das Einzige ist, das nicht über sich hinaus auf ein Anderes, sondern allein auf sich selbst verweist. Alle anderen „Sachen“ verdanken sich dem göttlichen Sein und sind daher eigentlich signa auf die (eine und einzige) res Gott hin, selbst wenn sie ein eigenes Sein haben (wie z. B. ein Hund oder ein Haus). Die gesamte Welt ist letztlich ein komplexes Zeichensystem, das auf Gott hinweisen soll - und dementsprechend verstanden werden will.

Diesem Verständnis dient nun eine ganze Reihe von Unterscheidungen innerhalb der signa, die in den Büchern II und III entfaltet werden. Es gibt natürliche Zeichen (naturalia), wie den Rauch als Zeichen des Feuers oder Tierspuren, und solche Zeichen, die auf Konvention der Menschen beruhen (data), wie zum Beispiel Buchstaben. Letztere sind für das Verständnis der Heiligen Schriften relevant. Das Verständnis wird erschwert durch unbekannte (ignota) und mehrdeutige (ambigua) Zeichen, die wiederum jeweils für sich stehen (propria) oder auf anderes übertragen worden sein (translata) können. Im ersten Fall besteht die Gefahr in der Unkenntnis der Zeichen selbst, im zweiten in der Unkenntnis der hinter den Zeichen stehenden Phänomene.

Die in der Bibel erwähnten Naturphänomene ordnet Augustinus den signa data ignota translata zu, weshalb ein Wissen (scientia) um das mit diesen Zeichen Bezeichnete für das Schriftverständnis unabkömmlich ist. Naturkunde gehört also zum Bereich der scientia, die Augustinus auf dem siebenstufigen Weg zur Weisheit an dritte Stelle setzt. ${ }^{28}$ Der (von Gott als dem Urheber aller Dinge und der Schrift intendierte) Sinn der signa ignota und ambigua in den Heiligen Schriften ist es, den menschlichen Geist zur Aufmerksamkeit anzuregen, denn Bekanntes verursacht Gewöhnung und Langeweile. Daher hat der (gebildete) Mensch die Allegorie lieber als den Wortsinn.

Das Schema macht deutlich, dass das Interesse an Naturphänomenen in diesem Konzept ganz von der Bibel her bestimmt ist: Ein Christ muss für Augustinus nur diejenigen Dinge kennen, die in der Heiligen Schrift erwähnt werden, ja er soll eigentlich auch gar nicht mehr wissen. Denn die menschliche Neugierde ist gefährlich, weil sie den Geist zu pervertiertem, selbstbezogenem Wissen verführt, das nicht auf die Erkenntnis Gottes zielt. Es droht eine Verwechslung zwischen res und signa, oder anders gesagt: Das Bewusstsein für die Zeichenhaftigkeit und Verweisfunktion aller Dinge und Geschöpfe auf Gott hin geht verloren.

Naturkunde steht damit ganz im Dienst der Schriftauslegung. Wenn der Mensch sich für die Natur um der Natur willen interessiert, dann ist für Augustinus die kritische Grenze überschritten. Daher adaptiert Augustinus die Faustregel des Terenz auf den christlichen Wissensdurst: „Nichts im Übermass! [ne quid nimis!]“. ${ }^{29}$ Die Bibel bestimmt durch ihre Zeichen, welches Wissen sich ein Christ aneignen soll und darf.

Als Hilfsmittel zu dieser biblisch dosierten Wissensaneignung empfiehlt Augustinus Handbücher, die alle in der Heiligen Schrift genannten Zeichen und das zu ihrem Verständnis notwendige Wissen auflisten. Er verweist etwa auf die chronologischen Werke des Eusebius von Caesarea und bemerkt daraufhin:

Sicut autem quidam de verbis omnibus et nominibus hebraeis et syris et aegyptiis, vel si qua alia lingua in scripturis sanctis inveniri potest, quae in eis sine interpretatione sunt posita, fecerunt ut ea separatim interpretantur, et quod Eusebius fecit de temporum historia propter divinorum librorum quaestiones quae usum eius flagitant, quod ergo hi fecerunt de his rebus, ut non sit necesse christiano in multis propter pauca laborae, sic video posse fieri, si quem eorum qui possunt benignam sane operam fraternae utilitati delectet impendere, ut quoscumque terrarum locos quaeve animalia vel herbas atque arbores sive lapides vel metalla incognita spieciesque quaslibet scriptura commemorat, ea generatim digerens, sola exposita litteris mandet. ${ }^{30}$

28 Augustinus, De doctrina christiana 2.7.10 (Daur und Martin 1962, 37).

29 Terenz, Andria 61, zitiert bei Augustinus, De doctrina christiana 2.39.58 (Daur und Martin 1962, 72).

30 Augustinus, De doctrina christiana 2.39.59 (Daur und Martin 1962, 72-73). 
Genauso aber, wie einige [i. e. Gelehrte] im Blick auf alle hebräischen, syrischen und ägyptischen Wörter und Namen - oder welche anderen Sprachen in den heiligen Schriften noch vorkommen und dort ohne Erklärung verwendet werden - dafür gesorgt haben, dass diese separat erklärt werden; und analog zu dem, was Eusebius geschaffen hat über die Geschichte der Zeiten wegen der Fragen der göttlichen Bücher, die seinen (des Eusebius) Gebrauch erforderlich machen; analog zu dem also, was diese geschaffen haben über diese Dinge, damit es für einen Christen nicht notwendig ist, sich in vielen (Wissensbereichen) wegen weniger (Detailfragen) abzumühen, halte ich es für möglich, dass von denen, die dazu in der Lage sind, jemand - falls er Freude daran hätte, ein gütiges und hilfreiches Werk zum brüderlichen Nutzen aufzuwenden - alle möglichen Orte auf Erden oder Tiere oder Kräuter, unbekannte Bäume, Steine oder Metalle und beliebige weitere Erscheinungen, die die Schrift erwähnt, in Gattungen unterteilt und einzeln erklärt, schriftlich niederlegt. ${ }^{31}$

Augustinus hielt also das Produzieren von Handbüchern zur biblischen Welt für nützlich. Ob ihm hierbei ein Werk in der Art des Physiologus vorschwebte, das selbst bereits christliche Deutungen vorbringt, geht aus seinen Bemerkungen nicht eindeutig hervor - vielleicht dachte er doch eher an eine auf die in der Bibel vorkommenden Naturphänomene reduzierte Adaption der Naturalis historia des Plinius, die nicht die christliche Interpretation, sondern lediglich das zur Abstützung einer christlichen Interpretation notwendige naturkundliche Wissen darlegt.

\subsection{Naturkunde als Verteidigung der Schrift: De civitate dei}

In De civitate dei, jener monumentalen Verteidigung des Christentums gegen den Vorwurf, die Christen trügen Schuld an der Plünderung Roms durch die Westgoten im Jahr 410 n. Chr. und am Niedergang des Römischen Reiches, ${ }^{32}$ führt Augustinus die Naturkunde als Instrument der Apologie ein - freilich nicht so systematisch wie in De doctrina christiana, sondern eher im Vorübergehen. Im vorletzten Buch, verfasst in den 420er-Jahren, stellt Augustinus die christlichen Jenseitsvorstellungen dar. Dabei kontert er auch den gegen die Vorstellung vom Höllenfeuer vorgebrachten Einwand, dass kein Körper lebendig im Feuer brennen könnte ohne zu sterben und zu verbrennen. ${ }^{33}$ Ob dieser Einwand tatsächlich erhoben wurde oder ob Augustinus ihn nur als Gedankenspiel anführt, ist ungewiss.

31 Übersetzung: Pollmann (2002, 95).

$32 \mathrm{Zu}$ Charakter und Beweisziel der Schrift siehe die Beiträge in Horn (1997); O’Daly (1999); Wetzel (2012); Mayer (2014).

33 Augustinus, De civitate dei 21.2-5 (Dombart und Kalb 1955b, 764766).
Um ihn zu widerlegen, führt er jedenfalls einige Phänomene aus der Natur - konkret: den Salamander in Feuerflammen, die Vulkane Siziliens und Edelsteine - an, die beweisen sollen, dass nicht alles, was brennt, vergeht. Er beruft sich dabei explizit auf ,diejenigen, die die natürlichen Eigenschaften der Tiere neugierig erforschen [ut scripserunt qui naturas animalium curiosius indagarunt]." ${ }^{34}$ Lassen wir einmal die Frage nach der Beweiskraft der angeführten Beispiele beiseite und schauen auf die allgemeineren Aussagen über die Funktion der Naturbetrachtung, die Augustinus in seine Argumentation einstreut. Sämtliche angeführten Beispiele sind für ihn mirabilia bzw. miracula, also staunenswerte, wunderbare Phänomene, die nicht etwa die Aufgabe haben, konkrete Aussagen der Schrift zu beweisen, sondern die beschränkte Erkenntnisfähigkeit des Menschen zu demonstrieren. Die Pointe der mit sichtlicher Freude am Unerklärlichen vorgebrachten Beispiele besteht darin zu zeigen, dass nicht alles sinnlich Wahrnehmbare auch rational erklärbar ist. Diese Einsicht wendet Augustinus dann auch explizit gegen den Erfahrungspositivismus und den Rationalismus seiner Gegner an, die ,auf keinen Fall annehmen wollen, dass es etwas geben kann, das sie nicht erfahren haben.“35

quod si fieri ab homine non posse peruiderint, fatendum est eis non ideo aliquid non fuisse uel non futurum esse, quia ratio inde non potest reddi, quando quidem sunt ista, de quibus similiter non potest. ${ }^{36}$

Wenn sie sich bewusst werden, dass dies nicht menschenmöglich ist, müssen sie sofort auch zugeben, dass etwas noch nicht allein deshalb als unmöglich abgelehnt werden darf, weil sich davon keine vernunftgemäße Erklärung geben lässt; denn jene Erscheinungen, die man ebensowenig erklären kann, sind nun einmal wirklich vorhanden.

Das Argument ist also: Da es schon in der Natur so viele Merkwürdigkeiten gibt, die die Menschen zwar wahrnehmen, aber nicht erklären können, haben sie kein Recht, die ebenfalls merkwürdigen und „übernatürlichen“ Vorstellungen in den heiligen Schriften rational zu hinterfragen. Die Natur wird hier zur Verteidigung der Glaubwürdigkeit der Schrift herangezogen, weil sie die Grenzen der Erkenntnisfähigkeit des Menschen aufzeigt. Sie dient also der Verteidigung der Schrift gegen menschlichen Erfahrungspositivismus und Rationalismus. Anders als in De doctrina christiana, beschränkt sich das Interesse an der Natur hier nicht auf solche Phänomene, die in der Bibel

34 Augustinus, De civitate dei 21.5 (Dombart und Kalb 1955b, 766). 35 Augustinus, De civitate dei 21.3 (Dombart und Kalb 1955b, 760): „ut, quod experti non sunt, nequaquam esse posse arbitrentur.“ 36 Augustinus, De civitate dei 21.4 (Dombart und Kalb 1955b, 762). 
genannt sind, sondern bezieht sich auf alles Wundersame, Erstaunliche, Unerklärliche.

\subsection{Natur als Ergänzung und Erfüllung der Schrift}

Dieses gegenüber De doctrina christiana erweiterte Interesse an der Natur liegt auch der Augustinischen Wortschöpfung und Vorstellung von der Natur als Buch (liber naturae/creaturae) zugrunde, die sich an unterschiedlichen Stellen im Augustinischen Werk finden lässt und die ich als dritte und weitestgehende Verhältnisbestimmung anführen möchte. Die Natur wird dabei zu einem Offenbarungsort neben der Schrift, der die Aussagen der Schrift bestätigt, aber durchaus auch ohne Schriftbezug zur Wirkung kommen kann. Exegese und Apologie sind - nach dem bisher Ausgeführten wenig überraschend - die beiden Kontexte, in denen die Metapher von der Natur als Buch zur Anwendung kommt.

In seinem Werk gegen den Manichäer Faustus, in dem Augustinus die ihn lebenslang umtreibende Frage nach dem Ursprung des Bösen traktiert, argumentiert er gleichermaßen mit Heiliger Schrift und Natur: „Wie in jener evangelischen Schrift, so konnte ich auch in dieser Welt nichts Böses finden. “37 Und gegen die manichäische Abwertung alles Kreatürlichen wendet er ein:

uniuersam creaturam ita prius aspiceres, ut auctori deo tribueres, quasi legens magnum quendam librum naturae rerum atque ita si quid ibi te offenderet, causam te tamquam hominem latere posse tutius crederes quam in operibus dei quicquam reprehendere auderes. ${ }^{38}$

Aber wenn du die gesamte Schöpfung eher so ansehen würdest, dass du sie Gott als Autor zuschreiben würdest, gewissermassen jenes große Buch der Naturdinge lesend, dann würdest du, wenn dich dort etwas verstört, eher glauben, dass der Grund in dir, dem Menschen, verborgen ist als dass du wagtest, irgendetwas an den Werken Gottes zu tadeln.

Die Natur hat ihre eigene - freilich mit der Schrift korrespondierende - Evidenz (,in hoc ipso mundo euidenter ostendit“). ${ }^{39}$ Daher kann und soll sie von Leseunkundigen und von Nichtchristen, die die Bibel als Offenbarungsquelle nicht anerkennen, als ein Buch Gottes anstelle der Heiligen Schrift gelesen werden, wie Augustinus in einer Auslegung zu Psalm 45 betont:

37 Augustinus, Contra Faustum 32.20 (Zycha 1891, 781): „sicut in illa scriptura euangelica, ita in hoc mundo nihil mali putare potuisti.“

38 Augustinus, Contra Faustum 32.20 (Zycha 1891, 781-782).

39 Augustinus, Contra Faustum 32.20 (Zycha 1891, 781).
Liber tibi sit pagina diuina, ut haec audias; liber tibi sit orbis terrarum, ut haec uideas. In istis codicibus non ea legunt, nisi qui litteras nouerunt; in tot mundo legat et idiota. ${ }^{40}$

Ein Buch sei dir die göttliche Seite, damit du dies hörst; ein Buch sei dir der Erdkreis, damit du dies siehst. In diesen Kodizes [i. e. der Hl. Schrift ] kann niemand lesen, der die Buchstaben nicht kennt; in der ganzen Welt aber liest auch der Ungebildete.

Die Erde wird hier als Buch göttlicher Offenbarung der Heiligen Schrift an die Seite gestellt. Die ungebildeten Christen profitieren von der „Buchhaftigkeit“ der Natur, die offenbar gleichwertig ist mit der Heiligen Schrift. Wer lesen kann, hat eine doppelte Offenbarungsschrift zur Verfügung.

Schließlich kann neben die Gleichsetzung von Natur und Bibel als Offenbarungsquellen sogar der Gedanke treten, dass sich das in der Schrift Angekündigte in der Natur als erfüllt erweist, wie Augustinus in einem Rundbrief an Prediger darlegt: „Unser grösseres Buch ist der Erdkreis; in ihm lese ich als erfüllt, was ich im Buch Gottes als verheissen lese. “41

Die drei verschiedenen Zuordnungen von Natur und Schriftauslegung zeichnen keine gedankliche Entwicklung Augustins nach. Sie finden sich nebeneinander und zu gleichen Zeiten an verschiedenen Stellen in seinem Werk. Sie schließen für Augustinus einander also offenbar nicht aus, sondern können sich ergänzen. Dies mag erstaunen, denn die Naturkunde kann in jeder der drei Zuordnungen eine andere Selbständigkeit und einen unterschiedlich weiten Wirkungskreis für sich beanspruchen: Ist sie gemäß des Bildungsprogramms in De doctrina christiana vollkommen limitiert durch die Bibel, so können die wundersamen Beispiele in De civitate dei auch dann angeführt werden, wenn sie sich nicht in der Schrift finden. Schließlich sind mit der Rede vom liber creaturae bzw. naturae als Buch neben der Heiligen Schrift keine Grenzen mehr gesetzt: Die ganze Natur kommt in den Blick, im äußersten Fall sogar als Vollendung des in der Schrift Verheißenen.

40 Augustinus, Enarrationes in Psalmos 45.7 (Dekkers und Fraipont 1956, 522).

41 Augustinus, Epistulae 43.25 (Goldbacher 1898, 107): „maior liber noster orbis terrarum est; in eo lego cempletum, quod in libro dei lego promissum.“ 


\section{Ein Anwendungsbeispiel: Schlangengeburt (Physiologus 10)}

Welche dieser Verhältnisbestimmungen aber kamen in der antiken lateinischen Christenheit tatsächlich zur Anwendung? Dieser Frage soll abschließend anhand eines Beispiels nachgegangen werden, das Augustinus selbst in $D e$ doctrina christiana zur Illustration seiner Forderung naturkundlicher Sachkenntnis heranzieht:

Ut ergo notitia naturae serpentis inlustrat multas similitudines quas de hoc animante dare scriptura consuevit, sic ignorantia nonnullorum animalium, quae non minus per similitudines commemorat, impedit plurimum intellectorem. ${ }^{42}$

Wie also die Kenntnis der Natur der Schlange viele Vergleichspunkte veranschaulicht, welche die Heilige Schrift gewöhnlich von diesen Lebewesen bietet, so hindert die Unkenntnis einiger Lebewesen, welche sie nicht weniger durch Vergleichspunkte erwähnt, das Verständnis am meisten.

Als Beispiel dafür, wie die naturkundliche Unkenntnis das Schriftverständnis verdunkeln bzw. erhellen kann, erwähnt Augustinus in De doctrina christiana 2.24.59 die Aufforderung in Mt 10,16: „Seid listig wie die Schlangen!“ Die beiden Eigenschaften der Schlange, die Augustinus zur Erklärung dieser Aufforderung anführt - das Schützen des Kopfes bei Gefahren und die durch Häutung vollzogene Verjüngung in Felsspalten - werden übrigens auch im 10. Kapitel des Physiologus genannt und mit Mt 10,16 in Verbindung gebracht, wobei hier freilich insgesamt vier nachahmenswerte Eigenschaften der Schlange angeführt werden. Doch ist die Frage, ob Augustinus den Physiologus benutzt hat, und wenn ja: welchen Physiologus er benutzt hat, aus bereits genannten Gründen nicht eindeutig $\mathrm{zu}$ beantworten.

Dies gilt auch für alle anderen Autoren - neben den hier zu behandelnden Lateinern Ambrosius, Prudentius und Gregor dem Großen zählen dazu die griechischsprachigen Autoren Klemens von Alexandrien, ${ }^{43}$ Basilius von Caesarea $^{44}$ und Johannes Chrysostomus ${ }^{45}$ : Sie operieren mit Informationen zur Natur der Schlange, die in Physiologus 10 oder 11 enthalten sind, ohne dass eine direkte $\mathrm{Ab}$ -

42 Augustinus, De doctrina christiana 2.16.24 (Daur und Martin 1962, 49).

43 Klemens von Alexandrien, Stromata 4.16 .100 (Stählin ${ }^{2}$ 1939, 292). 44 Basilius von Caesarea, Homiliae in Psalmos 14.1.3 (PG 29:256). 45 Johannes Chrysostomus, Homiliae in Matthaeum 36.11.1-2 (PG 57:413-419). hängigkeit festgestellt oder ausgeschlossen werden könnte. Dabei scheint sich die in Physiologus 10 beschriebene Begattung und Geburt der Nattern wesentlich größerer Beliebtheit unter den christlichen Autoren erfreut zu haben als die Informationen aus dem 11. Kapitel. Als Auslegung von Mt 3,7, wo die Pharisäer von dem Täufer Johannes als

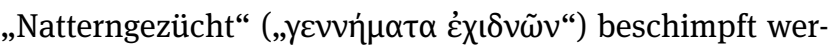
den, heißt es in (der wohl ältesten griechischen Redaktion des) Physiologus 10:

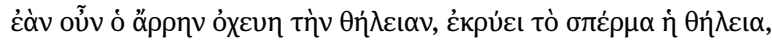

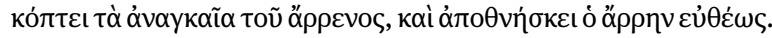

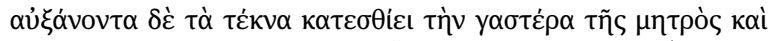

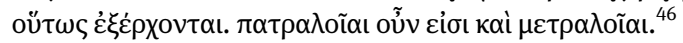

Wenn nun das Männchen das Weibchen begattet, lässt es den Samen in das Maul des Weibchens fallen, und wenn das Weibchen den Samen hinuntergeschluckt hat, beißt es die Geschlechtsteile des Männchens ab, und dieses stirbt davon. Schnell wachsen die Kinder heran, beißen sich durch den Bauch des Weibchens und kommen so heraus. Vater- und Muttermörder sind sie.

Für den Physiologus ist der Vergleich dieser Art der Fortpflanzung mit den Pharisäern „treffend“ und „schön“

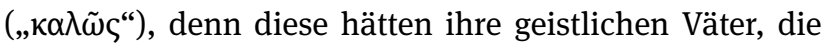
Propheten, ebenso getötet wie die neugeborenen Schlangen ihre Eltern. Die drei lateinischen Autoren, die im folgenden betrachtet werden, müssen nicht notwendig auf ,den' (oder einen) christlichen Physiologus zurückgegriffen haben: Von der Geburt der Schlangen berichten auch Herodot (Historiae 3.109), Aelian (De natura animalium 1.24) und Plinius (Naturalis historia 10.62.169). Allerdings findet sich die Vorstellung einer Befruchtung durch das Maul bei ihnen nicht - möglicherweise handelt es sich um ein Missverständnis des Kompilators des christlichen Physiologus. ${ }^{47}$ Ein Missverständnis freilich, das in der konkreten Anwendung auf Bibeltexte durchaus produktive Kraft entfalten konnte, wie zumindest bei Prudentius deutlich werden wird.

\subsection{Ambrosius: Die Nattern als Metapher für das Zinswesen in De Tobia}

Augustins Lehrer und Taufvater Ambrosius, der ausweislich des Decretum Gelasianum bei einigen Zeitgenossen als Autor des Physiologus galt, geht - soweit die Quellen-

46 Physiologus 10 (Sbordone 1936a, 34,1-5).

47 Dies vermutet Lauchert (1889, 14-15). Allerdings erwähnt auch Aristoteles, Historia animalium 5.34, eine Befruchtung im Maul:

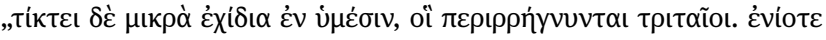

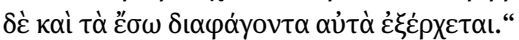


lage diesen Schluss zulässt: als erster lateinischer Autor auf die in Physiologus 10 geschilderten Vorgänge bei der Geburt der Nattern ein. ${ }^{48}$ Er tut dies in einer Auslegung des jüdisch-hellenistischen Buches Tobit, die zwischen 376 und 380 n. Chr. entstanden sein dürfte und eine Art Programmschrift gegen Zinsnahme und Wucher darstellt. In dieser bemerkenswerten Homilie will Ambrosius nach eigener Aussage die Tugenden des Protagonisten Tobias, „welche die Schrift in erzählerischer Weise (,historico more") ausgebreitet hat, straffer zusammenfassen und wie in einem Auszug sammeln. “49 Zwar ist die schriftliche Ausarbeitung der Homilie im Ergebnis keineswegs kürzer ausgefallen als das biblische Buch Tobit selbst, aber der Satz verdeutlicht doch den Anspruch, mit dem Ambrosius ans Werk gegangen ist: Er möchte durch Systematisierung und Straffung die Inhalte des biblischen Buches, die durch den erzählerischen Charakter in den Hintergrund zu geraten drohen, präzise und klar darstellen. Konkret heißt das auch, dass Ambrosius bestimmte Aspekte hervorhebt, die sich vom Buch selbst her nicht unbedingt aufdrängen, aber in der Zeit des Ambrosius von großer Aktualität sind. Dazu gehört die Polemik gegen Zinsnahme und Wucher. In der Novelle wird erzählt, dass Tobit im Land Medien bei einem Mann Geld zur Aufbewahrung hinterlegt. Kurz vor seinem Tod erinnert er sich wieder daran und beauftragt seinen Sohn Tobias, nach Medien zu reisen um das Geld zu holen. Der Engel Raffael, der Tobias incognito auf dieser Reise begleitet, lehnt bei der Rückkehr der beiden seinen Anteil an diesem Geld ab (Tob 12).

Ambrosius nimmt diesen Plot nun zum Anlass für eine grundlegende Kritik des Zinswesens. Um seinem Publikum die Perfidität des Zinsnehmens zu veranschaulichen, bemüht er den Vergleich mit den Nattern:

echinna quaedam est faenerationis pecunia, quae tanta mala parturit. echinna tamen fecunda poenis uiscera trahens partu suo rumpitur et morte materna docet subolem non esse degenerem in matrem. igitur primium incipiunt esse serpentes illam morsibus suis scindunt. illic ubi nascitur uenenum primum probatur. pecunia autem faenerationis omnia mala sua concipit: parit, nutrit, atque ipsa magis in subole sua crescit tristi prole numeriosor, non minus flexuosa quam serpens atque in orbem tota se colligens, ut caput seruet, reliquo flagellat corpore, illud solum producit ad uulnera: spiris ingentibus quos comprehenderit ligat, solo capite interficit: saluo capite, etiamsi reliqua pars ei-

48 Ambrosius erwähnt die Befruchtung der Nattern nicht. Dies könn te ein Hinweis darauf sein, dass er seine Informationen nicht aus dem christlichen Physiologus, sondern aus einer anderen Quelle - Herodot, Aelian oder Plinius - entnommen hat.

49 Ambrosius, De Tobia 1.1 (Schenkl 1897, 519): „... ut ea quae scriptura historico more digessit latius nos strictius conprehendamus uirtutum eius genera uelut quodam breuiario colligentes.“ us delapidata fuerit, reuiuiscit. diuersa quoque serpentibus sunt conueniendi et parturiendi tempora, pecunia faenebris a die initae conventionis cresecentibus erpit usuris, quae parturire non nuvit, quia dolores magis in alios ipsa transfundit. ibi dolores sicut parturientis. unde etiam тóкоvৎ Graeci usuras appelaverunt eo quod dolores partus animae debitoris excitare videantur. veniunt calendae, parit sors centesimam: veniunt menses singuli, generantur usurae, malorum parentum mala proles. haec es generatio uiperarum..$^{50}$

Das Geld der Zinsleihe ist eine Art Natter, die so viele Übel hervorbringt. Die fruchttragende Natter nämlich, die ihre Nachkommen unter Schmerzen trägt, wird bei ihrer Niederkunft zerrissen, und durch den mütterlichen Tod zeigt der Sprössling, dass er nicht von anderer Art ist als die Mutter. Sobald sie beginnen Schlangen zu sein, zerreißen sie jene mit ihren Bissen. An dem Ort, an dem ihr Gift geboren wird, wird es zum ersten Mal erprobt. Das Geld der Zinsleihe trägt alle seine Übel in sich: es gebiert, ernährt, und wächst selbst immer mehr durch seinen Sprössling, zahlreicher durch seine traurige Nachkommenschaft, nicht weniger verkrümmt als eine Schlange, die sich vollkommen auf dem Erdboden zusammenzieht, damit der Kopf geschützt ist, und mit dem übrigen Körper um sich schlägt. Dieser allein ist Verwundungen ausgesetzt: mit starken Windungen bindet sie die zusammen, die sie umschlungen hat, allein mit dem Kopf tötet sie: wenn der Kopf gerettet wird, selbst wenn ihr ganzer übriger Teil zersplittert ist, lebt sie wieder auf. Während die Zeiten der Paarung und der Geburt bei den Schlangen [serpentibus] wirklich unterschiedlich sind, kriecht und wuchert [serpit] das Geld der Zinsleihe vom Tag des Vertragsbeginns an mit wachsenden Zinsen, die es nicht hervorbringen kann, weil es vielmehr selbst Schmerzen auf andere überträgt. Hier sind Schmerzen wie die einer Gebärenden. Daher nannten die Griechen Zinsen auch

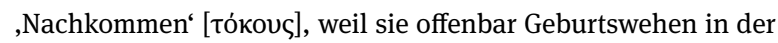
Seele des Schuldners verursachen. Der Monatserste kommt, das Kapital bringt hundert hervor; es kommen die einzelnen Monate, Zinsen werden geboren, üble Nachkommen von üblen Eltern. Das ist die Fortpflanzung der Nattern.

Zwei Informationen über das Verhalten der Nattern, die in Physiologus 10 und 11 unabhängig voneinander dargestellt werden, erscheinen hier miteinander verbunden, indem der Schutz des Kopfes bei Gefahr mit dem Geburtsvorgang verknüpft wird. Weil der Körper des Muttertiers bei der Geburt von den Sprösslingen mit Giftbissen zerfetzt wird, schützt das Weibchen seinen Kopf, indem es den todgeweihten Körper in Windungen um den Kopf herumlegt, um sich nach der Geburt regenerieren zu können. Für Ambrosius ist dies eine Metapher für die beständige, Übel verursachende Selbstreproduktion von Zinsen. Durch die drastische Darstellung aus der Tierwelt unterstreicht er die Schädlichkeit des Zinsnehmens. Der Bibeltext bietet ihm im Wortlaut keinen Anknüpfungspunkt,

50 Ambrosius, De Tobia 12.41-42 (Schenkl 1897, 542-543). Übersetzung von Katharina Heyden. 
vielmehr schafft Ambrosius die Anknüpfung im letzten Absatz selbst, indem er das Ansteigen der Zinsen als ein „Kriechen“ (,serpere“) bezeichnet und es damit etymologisch mit den Schlangen („,serpentes“) verbindet. Wie aus der Einleitung in das Werk hervorgeht, will Ambrosius die Botschaft des Bibeltextes klarer zur Geltung bringen, als es der erzählerische Stil des Buches Tobit vermag. Er lässt sich dabei nicht auf die vom Bibeltext vorgegebenen Inhalte beschränken, wie Augustinus es in De doctrina christiana fordert, sondern ergänzt die Heilige Schrift mit Beobachtungen aus der Natur, wie es eher dem Konzept vom liber creaturae entspricht.

\subsection{Prudentius: Die Schlangengeburt als Metapher für die Entstehung der Sünden}

Noch unabhängiger vom Bibeltext nimmt der christliche Dichter und „Laientheologe“ Prudentius (geb. 348 n. Chr. $)^{51}$ in seinem poetischen Werk Hamartigenia die Geburt der Schlangen auf, um seine Ansicht zu untermauern, wonach der von Gott mit Willensfreiheit ausgestattete Mensch ganz allein selbst für die Existenz der Sünden in seinem Leben verantwortlich ist. ${ }^{52}$

Sed quid ego omne malum mundique hominumque maligni hostis ad invidiam detorqueo, cum mala nostra, ex nostris concreta animis, genus et caput et vim, quid sint, quid valeant, sumant de corde parente? Ille quidem fomes notrorum et causa malorum est...53

Was aber schiebe ich alles Böse der Welt und der Menschen auf den Neid des grimmigen Feindes, da unsre Übel, aus unseren Seelen erwachsen, Art und Ursprung und Stärke, was sie sind und vermögen, vom Herzen selber erhalten? Wir erzeugen all unser Übel aus eigenem Leibe... ${ }^{54}$

Als biblisches Beispiel nennt Prudentius David, der mit seinem Sohn Absalom einen Sünder und Vatermörder zeugte, um dann fortzufahren:

Nostra itidem diro urente propagine natos pectora parturiunt, versis qui protinus in nos morsibus insuescunt gignentum vivere poenis; depopulantur enim nimium fecunda parentum viscera et interitu genitalis stirpis aluntur. ${ }^{55}$

$51 \mathrm{Zu}$ Leben und Werk des Prudentius siehe Fels (2011, IX-XXXII). 52 Zur Theologie des Werkes siehe Dykes (2011) und Malamud (2011, 51-212).

53 Prudentius, Hamartigenia 553-556 (Palla 1981, 82).

54 Übersetzung: Fels $(2011,111)$.

55 Prudentius, Hamartigenia 569-573 (Palla 1981, 82).
Ebenso setzt unser Herz unter Schmerzen schreckliche Kinder in diese Welt, die gleich ihre Bisse gegen uns wenden und die auch lernen, von Qualen ihrer Erzeuger zu leben; denn sie verzehren das allzu fruchtbare Fleisch ihrer Eltern, und sie ernähren sich mit dem Tod ihres Stamms, der sie zeugte. ${ }^{56}$

In diesen Zeilen tönt bereits der Geburtsvorgang der Nattern an, der wenig später explizit und detailreich geschildert wird. Dabei machen die einführenden Zeilen mit „si licet ex ethicis quidquam praesumere uel si de physicis exempli aliquid“ deutlich, dass Prudentius sich der im Vergleich zur Bibel etwas weniger starken Autorität dieser Quellen bewusst ist:

Si licet ex ethicis quidquam praesumere uel si de physicis exempli aliquid, sic uipera, ut aiunt, dentibus emoritur fusae per uiscera prolis, mater morte sua, ... 57

Wenn es erlaubt ist, von Moralisten ${ }^{58}$ etwas zu nehmen oder ein Beispiel aus der Zoologie, so stirbt eine Viper, wie man sagt, durch den Biss des im Körper geborenen Nachwuchses durch ihren Tod wird sie Mutter, ... ${ }^{59}$

Mit viel Freude an biologischen Details und anschaulicher Sprache wird nun der Begattungs- und Geburtsvorgang der Vipern poetisch verdichtet, wie Prudentius ihn von Herodot, Plinius oder auch einem christlichen Physiologus gekannt haben konnte. Die allegorische Deutung auf die Seele, die ihre tödlichen Sünden durch Vermählung mit dem Sohn des Belial - einer Schlange! - selbst hervorbringt, ist jedoch seine eigene theologische Leistung:

Non dispar nostrae conceptus mentis. Ab ore uipero infusum sic conbibit illa uenenum coniuge Beliade [...] Tunc praegnans letale genus concepta maligni fert opera ingenii de semine conplicis hydri [...] Ipsam porro animam crudelia uulnera carpunt mille puerperiis, suboles dum parturit ex se contra naturam genitas, peccamina crebra scilicet et pastos materno funere natos. ${ }^{60}$

Ähnlich wird unsre Seele empfangen: so schlürft aus Vipernrachen jene das ausgegossene Gift, sich vermählend mit dem Sohn des Belial [...] Dann trägt sie schwanger als tödliche Kinder Werke von üblem Geist aus, vom Samen der mit ihr verbündeten Schlange empfangen [...] Fernerhin schwächen die Seele grau-

56 Übersetzung: Fels (2011, 112).

57 Prudentius, Hamartigenia 581-584 (Palla 1981, 84).

58 An dieser Stelle gibt es ein textkritisches Problem in der Überlieferung: Manche Handschriften lesen „ethnicis“ (also „Heiden“) statt „ethicis“. Wenn diese Variante dem ursprünglichen Text entsprechen würde, müsste ein christlicher Physiologus als Quelle des Prudentius ausgeschlossen werden. Die Argumente für ,ethicis“ sind jedoch stärker, siehe dazu Palla (1981, 256-257).

59 Übersetzung: Fels $(2011,112)$.

60 Prudentius, Hamartigenia 608-610, 613-614, 617-620 (Palla 1981, $86)$. 
same Wunden durch viele tausend Geburten, wenn sie aus sich heraus Nachwuchs ans Licht bringt, widernatürlich gezeugt, ich meine die häufigen Sünden, und jene Kinder, welche sich nährten vom Tod ihrer Mutter. ${ }^{61}$

Prudentius mischt sich mit seinem Poem in die zu seiner Zeit innerhalb des Christentums wie auch zwischen den Religionen intensiv und kontrovers diskutierte Frage nach der Herkunft des Bösen ein. ${ }^{62}$ Ob der Vergleich der Sündenvermehrung im Menschen mit dem Geburtsvorgang der Vipern wirklich geeignet ist, um die Eigenverantwortung des Menschen für seine Sünden zu illustrieren, kann man mit guten Gründen fragen. Schließlich handelt es sich bei den Schlangen gerade nicht um einen willentlichen, sondern um einen zur Selbsterhaltung der Art notwendigen Vorgang, der nicht per Willensentschluss unterlassen oder anders gestaltet werden könnte. Aber es geht hier nicht um die Beurteilung der theologischen Plausibilität bei der konkreten Anwendung naturkundlichen Wissens, sondern um eine Beschreibung der unterschiedlichen Rezeptionsweisen und den zugrunde liegenden Hermeneutiken.

Für Prudentius kann festgehalten werden, dass er das Beispiel der Schlangen nicht nutzt, um eine Bibelstelle zu entschlüsseln oder allegorisch auszulegen, sondern um eine theologische These zu illustrieren, wofür er ein biblisches und ein naturkundliches Beispiel anführt. Auch dies entspricht weniger dem Vorgehen, das Augustinus in $D e$ doctrina christiana vorschwebt, als vielmehr dem Konzept der Ergänzung der Heiligen Schrift durch Naturbeobachtung, wie es hinter der Metapher vom liber naturae steht. Auffallend ist, dass Prudentius das biblische Beispiel, Absalom als Nachkomme Davids, kaum ausschmückt, obwohl die Bibel hierfür reichlich Vorlagen geboten hätte (2 Sam 15-18), während er das zoologische Exempel in allen Details ausbreitet. Dies verweist auf einen nicht unwichtigen Aspekt in der Rezeption naturkundlichen Wissens durch Christen: Anders als beim kanonisch festgelegten und geschützten Bibeltext waren der Phantasie in der Anwendung von Naturbeispielen kaum Grenzen gesetzt. Für Prudentius mochte zudem eine Rolle gespielt haben, dass er an diesem Beispiel die Verderbtheit einer ganzen Art (und nicht nur einzelner Personen wie im Fall von Absalom und David) illustrieren konnte. Die Übertragbarkeit auf das ganze Menschengeschlecht war mit einem Beispiel aus der Natur eher gegeben als mit einem biblischen Exempel.

61 Übersetzung: Fels (2011, 113).

62 Siehe zu diesen Diskussionen Arruzza (2011); Schäfer (2002); Rottenwöhrer (1986).
Nur am Rande sei bemerkt, dass die theologische These, die Prudentius mit dem Schlangen-Exempel unterstreichen wollte - dass nämlich der Mensch die Sünden selbst in sich produziert - sich nicht durchgesetzt hat. Vielmehr wurde die Sündenlehre des späten Augustinus im Abendland wirkmächtig, die den freien Willen negiert und folglich den einzelnen Menschen von der Verantwortung für die Sünde unter Verweis auf die Ur- und Erbsünde Adams freisprach - und dies nicht zuletzt mit dem Hinweis auf die Verführung durch eine Schlange!

\subsection{Gregor der Große: Schlangentypologie der Versuchungen}

In der typologischen Anwendbarkeit liegt auch für Gregor den Großen der Reiz des Wissens um die Fortpflanzung der Schlangen. Er macht davon in seinen Moralia in Job Gebrauch, einer kommentarischen Auslegung des biblischen Hiobbuches, die auf in Konstantinopel gehaltenen Predigten beruht. ${ }^{63}$

Laut seinem Widmungsschreiben an Leander von Sevilla $^{64}$ wurde Gregor von einem elitären Kreis gebildeter Mönche und Laien gebeten, nicht nur eine allegorische Auslegung des historischen Gehalts der Erzählung vorzulegen, sondern vielmehr den Sinn der Allegorien moralisch zuzuspitzen. ${ }^{65}$ Begründet ist die Freiheit des Exegeten gegenüber dem Text mit dem Ziel der „Erbauung“ der Zuhörer. ${ }^{66}$ Diese Freiheit betrifft sowohl die Abfolge des Textes (von der der Exeget abweichen darf), als auch die Entscheidung über die Frage, ob ein Text wörtlich, allegorisch oder moralisch zu verstehen sei. Innerhalb eines Kommentars muss man also die exegetische Vorgehensweise wechseln. Obwohl Gregor sich implizit von der Hermeneutik seines nur wenig älteren Zeitgenossen Cassiodor distanziert ${ }^{67}$ - dieser hatte, ähnlich wie Augustinus, das Studium der weltlichen Wissenschaften als Voraussetzung für die Schriftexegese verstanden und empfoh-

63 Zum Charakter der Schrift und dem Adressatenkreis siehe Greschat (2005, 23-30).

64 Einführend siehe Greschat (2016, 111-121); Kessler (2000, 691700); Moorhead (2005, 129-157). Zur exegetischen Methode in Moralia in Job anhand von Passagen des ersten und des dritten Buches: Recchia (1996, 355-404).

65 Gregorius Magnus, Epistula ad Leandrum 1 (Adriaen 1979a, 2): „non solum uerba historiae per allegoriam sensus executerem, sed allegoriarum sensus protius in exercitium moralitatis inclinarem.“ 66 Gregorius Magnus, Epistula ad Leandrum 2 (Adriaen 1979a, 4). 67 So Greschat (2005, 62-63). 
len ${ }^{68}$-, greift er in der Auslegung des Hiobbuches doch auch selbst auf naturkundliches Wissen zurück. So etwa in der Interpretation der zweiten Rede des Zofar in Ijob 20. Das Exempel aus der Natur ist ihm freilich bereits vom Autor des Hiobbuches - hier in der Version der Vulgata, die Gregor höchstwahrscheinlich benutzt hat - vorgegeben. Im Hiobbuch beschreibt Zofar, einer der drei Freunde Hiobs, das Schicksal des Gottlosen mit folgenden Bildern (Ijob 20,12-16 ${ }^{\mathrm{Vg}}$ ):

cum enim dulce fuerit in ore eius malum abscondet illud sub lingua sua parcet illi et non derelinquet illud et celabit in gutture suo panis eius in utero illius vertetur in fel aspidum intrinsecus civitias quas devoravit evomet et de ventre illius extrahet eas Deus caput aspidum suget occidet eum linguae viperae.

Wenn ihm das Böse in seinem Mund süß schmeckt, wird er es unter seiner Zunge bewahren, er hegt es und lässt es nicht los und bewahrt es in seinem Gaumen, und so wird seine Speise sich inwendig im Leib in Natterngalle verwandeln. Die Güter, die er verschlungen hat, wird er wieder ausspeien, und Gott wird sie aus seinem Bauch stoßen. Er wird das Gift der Nattern saugen, und die Zunge der Schlange wird ihn töten.

Während in der biblischen Vorlage lediglich von einer Vergiftung durch das Trinken von Schlangengift die Rede ist, verweist Gregor in seiner Auslegung auch auf den Geburtsvorgang und unterscheidet dabei, die im Bibeltext verwendeten Gattungsbegriffe aufnehmend, zwischen zwei Schlangenarten:

Aspis parvus est serpens, uipera uero prolixioris est corporis; et aspides oua gignunt, atque ex ouis eorum filii procreantur, uiperae autem cum conceperint, filii earum in uentre saeuiunt, qui ruptis lateribus matrum ex earum uentribus procedunt. Unde et uipera, eo quod ui pariat, nominatur. Uipera itaque sic nascitur ut uiolenter exeat et cum matris suae exstinctione producatur. Quid ergo nisi latentes suggestiones immundorum spirituum figurantur, qui cordibus hominum parua prius persuasione subripiunt? Quid uero per linguam uiperae nisi uiolenta diaboli tentatio designatur? Prius enim leniter subripit, postmodum uero etiam uiolenter trahit. Caput itaque aspidum sugit, quia initium suggestionis occultae paruum prius in corde nascitur; sed occidit eum lingua uiperae, quia postmodum capta mens ueneno uiolentae tentationis necatur. ${ }^{69}$

Die Natter ist eine kleine Schlange, die Viper aber hat einen längeren Körper; und die Nattern legen Eier, aus welchen ihre Kinder geboren werden. Wenn aber die Vipern den Samen aufgenommen haben, wüten ihre Kinder im Mutterleib - nachdem sie die Seiten der Mutter zerfetzt haben, kommen sie aus den Mut-

68 So Cassiodor in seinem Werk Institutiones divinarum et saecularium litterarum, siehe dazu Hafner $(2002,79-85)$ und Troncarelli (1989).

69 Gregorius Magnus, Moralia in Job 15.19 (Adriaen 1979b, 759). terleibern heraus. Daher wird sie auch Viper genannt, weil sie mit Gewalt [vis] gebiert. Die Viper wird also auf diese Weise geboren, um mit Gewalt herauszukommen, und sie wird zugleich mit der Vernichtung der Mutter hervorgebracht. Was anders wird also damit bezeichnet als die verborgenen Einflüsterungen der unreinen Geister, die sich zuerst durch kleine Eingebungen in die Herzen der Menschen einschleichen? Was aber wird mit der Zunge der Viper bezeichnet, wenn nicht die gewaltsame Verführung durch den Teufel? Zuerst nämlich schleicht er sich milde ein, dann aber zerreißt er gewaltsam. Er [der Gottlose] saugt also den Kopf der Nattern, weil zunächst ein kleiner Anfang einer verborgenen Einflüsterung im Herzen geboren wird; aber die Zunge der Viper tötet ihn, weil später der Verstand, vom Gift der gewaltsamen Verführung erfasst, vernichtet wird.

Dass im Bibeltext zwei unterschiedliche Schlangenarten genannt werden, kann für Gregor kein Zufall sein, sondern verweist auf eine allegorische Tiefenschicht des Textes. Um diese zu erhellen, greift er auf naturkundliches Wissen zurück, das den Unterschied zwischen ,aspides“ und „uiperae“ zu erfassen hilft. Er handelt hier ganz im Sinn der Empfehlung, die Augustinus in De doctrina christiana ausgesprochen hatte: ,Weltliche' Wissenschaften sollen dann (und nur dann!) zur Anwendung kommen, wenn ohne ihren Gebrauch der Sinn einer Bibelstelle nicht entschlüsselt werden kann. Genau dies scheint aus Gregors Sicht hier der Fall zu sein, sieht er sich doch vor die Herausforderung gestellt, dem Bibeltext einen moralischen Sinn abzugewinnen. Seine durch Naturkenntnis gewonnene moralische Deutung besteht in der Identifikation der verschiedenen Schlangenarten mit unterschiedlichen Arten der Verführung (,suggestiones“) durch den Teufel, verbunden mit einer zeitlichen Abfolge ihrer Wirksamkeit: Die kleineren Nattern repräsentieren harmlose Einflüsterungen, mit denen der Mensch zunächst (,prius“) angelockt und schleichend innerlich verdorben wird. Die größeren, in einem Gewaltakt geborenen Vipern symbolisieren die daraus erwachsenden Verführungen, die ihre zerstörerische Kraft von innen heraus entfalten, nachdem sich die Einflüsterungen fast unbemerkt im Herzen des Menschen einnisten konnten.

Interessant und aufschlussreich ist, dass Gregor daneben noch eine zweite Deutung für den Schlangenvergleich in Ijob 20,16 anbietet. Vielleicht, so fügt er an, müsse man diese Stelle auch durch eine entgegengesetzte Deutung verstehen (,intellegere etiam per contrariam interpretationem“). Die Erwähnung der beiden Schlangenarten und ihre Abfolge könne nämlich auch auf die Tatsache zurückzuführen sein, dass das Gift der Nattern schneller wirke als das der Vipern. Dann würde die Natter die plötzliche und gewaltsame, die Viper hingegen die leichtere, aber andauerndere Versuchung bezeichnen. Die moralische Erkenntnis dieser Interpretation wäre, dass eine plötzlich 
auftauchende Versuchung den Geist unter Schmerzen töte, während eine leichtere und andauernde langsam zum Tod führe. ${ }^{70}$ Diese Deutung kommt ohne die im Physiologus (und anderswo) überlieferten Informationen über die Geburtsvorgänge bei Schlangen aus.

Es ist für Gregor also offenbar nicht wichtig, eine ,richtige‘ allegorisch-moralische Deutung des Textes vorzulegen. Stattdessen tastet er mithilfe naturkundlichen Wissens unterschiedliche Möglichkeiten ab, den Text auszulegen. Entscheidend ist dabei, dass die dem Text innewohnende moralische Bedeutung zum Vorschein kommt. Diese besteht im konkreten Fall in einer für asketische Kreise typischen Beschäftigung mit den Versuchungen des Teufels. Hier wird die Adressatenbezogenheit dieser Auslegung deutlich: Gregor spricht und schreibt für einen Kreis von asketisch interessierten Eliten, die führende kirchliche Ämter innehaben und selbst auch als Schriftausleger wirken. ${ }^{71}$ Seine Aufgabe sieht Gregor darin, für diesen Kreis eine angemessene Verbindung zwischen dem Bibeltext und der darin bezeichneten Sache zu präsentieren. Da in asketischen Kreisen die Überzeugung herrschte, dass die Bibel vor allem das innere Leben der Gläubigen betreffe, knüpft Gregor an diese Vorstellung an. Anders als bei Ambrosius und Prudentius illustrieren die Beispiele aus der Tierwelt hier nicht eigenständige Argumentationen, sondern sie sind vom Bibeltext vorgegeben und müssen entschlüsselt werden, um verborgene Sinnebenen des Textes aufdecken zu können. Darin folgt Gregor den Anweisungen des Augustinus in De doctrina christiana, die er offenbar gekannt, beherzigt und für sein spezifisches Auslegungsinteresse fruchtbar gemacht hat.

Es sind solche allegorisch-moralischen Deutungen, die der Tierwelt im Mittelalter in der Literatur, aber auch in der bildenden Kunst zu größter Beliebtheit verholfen haben. Die Tierfiguren an Friesen und Säulen romanischer Kirchen bis hin zu Wasserspeiern an gotischen Kathedralen sind ohne diese lebenspraktisch-moralischen Deutungen kaum zu verstehen. ${ }^{72}$ Sie repräsentieren in Bild und Stein, was auch auf der Textebene gilt: Das Faszinieren-

70 Gregorius Magnus, Moralia in Job 15.19 (Bocognano 1975, 38; Adriaen 1979b, 760): „Sed fortasse haec ipsa intellegere etiam per contrariam interpretationem ualemus. Nam quia ueneno suo aspis concite, uipera autem tardius occidit, per aspidem uiolenta et subita, per uiperam uero lenis et diuturna tentatio designatur. Unde et illi mors in suctione capitis, uiperae autem in linguae esse perhibetur, quia repentina tentatio saepe inopinatam mentem mox ut surgit interficit; longa uero tentatio quia praua diutius persuadendo suggerit, uelut ex lingua uipera occidit.“

71 Zur Adressatenfrage siehe Greschat (2005, 243-255).

72 Zur Bedeutung der Tierwelt für die Künste: Tori und Steinbrecher (2012); Houwen (1997); Baxter (1998). de an der Tierwelt war die Mischung aus Anschaulichkeit und Deutungsoffenheit. Die Freude am phantasievollen Ausgestalten (von Texten und Steinen) konnte mit dem Bedürfnis nach moralischer Orientierung verbunden werden - und war daher für breite und sehr unterschiedliche Personenkreise rezipierbar.

\section{Ertrag}

Angesichts der faszinierenden Fluidität der Überlieferung ,des' Physiologus in Antike und Mittelalter und im Bewusstsein um die damit verbundenen methodischen Probleme, kann als Ertrag aus dieser exemplarischen Studie Folgendes festgehalten werden:

1. Augustinus, der im Mittelalter als die theologische Autorität galt, kennt mindestens drei Weisen der Verhältnisbestimmung von Naturkunde und Schriftauslegung: (a) die Naturkunde als Hilfswissenschaft der Exegese; (b) die apologetische Verwendung von Naturphänomenen zur Verteidigung der Plausibilität von Wundern in der Bibel; (c) das Verständnis von Natur als einem „Buch“, das heißt als eine die Heilige Schrift ergänzende Offenbarung Gottes. Während er die Reduktion der Naturkunde auf eine exegetische Hilfswissenschaft in einer Programmschrift zur christlichen Bildung fordert, macht er selbst in konkreten Anwendungsfällen deutlich breiteren Gebrauch von naturkundlichem Wissen.

2. Anhand der exemplarischen Fallstudie zu den im Physiologus überlieferten Informationen über die Geburt der Schlangen konnte gezeigt werden, dass die Autoren von allen drei Augustinischen Verhältnisbestimmungen Gebrauch machen: Ambrosius und Prudentius rekurrieren auf naturkundliches Wissen eher im Sinne der Ergänzung der Heiligen Schrift, Gregor der Große nutzt es zur Entschlüsselung und allegorischmoralischen Deutung einer schwierigen Bibelstelle.

3. Dabei liegt nur bei Prudentius die Vermutung nahe, dass er sein Wissen aus ,dem ' christlichen Physiologus schöpfte, denn nur er geht auf die in Physiologus 10 beschriebene Befruchtung der Schlangen durch das Maul ein. Gregor und Ambrosius könnten ihr Wissen um die Geburt der Schlangen aus anderen Quellen (Herodot, Aelian oder Plinius) gezogen haben. Diese Sachlage illustriert einmal mehr, wie schwierig es ist, direkte Rezeptionen ,des' Physiologus zu rekonstruieren.

4. Die drei behandelten Autoren geben auch Hinweise auf das Rezeptionsmilieu für die Anwendung von $\mathrm{Na}$ - 
turkunde bei der Schriftauslegung. Es handelt sich ausnahmslos um hochgebildete Autoren, die asketisch orientiert sind. Derartige Kreise werden wohl auch die Verbreitung, Bearbeitung und Anwendung des Physiologus in der lateinischen Christenheit vorangetrieben haben.

5. Schließlich ist durch die Untersuchung der theoretischen Reflexionen wie auch der konkreten, praktischen Anwendungen naturkundlichen Wissens hoffentlich auch deutlich geworden, warum sich der Physiologus im Mittelalter so großer Beliebtheit erfreute: Christlich gefärbte Naturkunde konnte einerseits die Neugier und Phantasie von Hörerinnen und Lesern anregen, bestach aber auch durch die mit Naturphänomenen assoziierte Evidenz und ,natürliche Beweiskraft" für Bibelstellen und deren moralische Ausdeutung. Es ist wohl die Bandbreite an hermeneutischen Möglichkeiten, Bibel - und Naturdeutung zueinander ins Verhältnis zu setzen, die der Tierwelt und ihrer Symbolik im Mittelalter eine so große Bedeutung verliehen hat.

\section{Bibliographie}

Accademia Cardinale Bessarione und Centro di Antichità Altoadriatiche, Hgg. 1987. Rufino di Concordia e il suo tempo: atti del Convegno Internazionale di Studi Rufino di Concordia e Il Suo Tempo, Concordia-Portogruaro, 18-21 settembre 1986. Antichità altoadriatiche 31. Udine: Arti Grafiche Friulane.

Accademia Cardinale Bessarione, Centro di Antichità Altoadriatiche, Hgg. 1992. Storia ed esegesi in Rufino di Concordia. Antichità altoadriatiche 39. Udine: Arti Grafiche Friulane.

Adriaen, Marc, Hg. 1979a. Gregorius Magnus: Moralia in Job; Libri I-X. CCSL 143. Turnhout: Brepols.

Adriaen, Marc, Hg. 1979b [2000]. Gregorius Magnus: Moralia in Job; Libri XI-XXII. CCSL 143A. Turnhout: Brepols.

Adriaen, Marc, Hg. 1985. Gregorius Magnus: Moralia in Job; Libri XXIII-XXXV. CCSL 143B. Turnhout: Brepols.

Arruzza, Cinzia. 2011. Les mésaventures de la théodicée: Plotin, Origène, Grégoire de Nysse. Nutrix 6. Turnhout: Brepols.

Balme, David M., Hg. 2002. Aristotle: Historia Animalium. Bd. 1, Books I-X: Text. Cambridge Classical Texts and Commentaries 38. Cambridge: Cambridge University Press.

Banterle, Gabriele, Hg. 1979. I sei giorni della creazione (Esamerone). Opera Omnia di Sant'Ambrogio 1, Rom: Città Nuova.

Baxter, Ron. 1998. Bestiaries and their users in the Middle Ages. Stroud: Sutton.

Becker, Eve-Marie, und Stefan Scholz, Hgg. 2012. Kanon in Konstruktion und Dekonstruktion: Kanonisierungsprozesse religiöser Texte von der Antike bis zur Gegenwart. Berlin: De Gruyter.

Bocognano, Aristide, Hg. 1975. Grégoire le Grand: Morales sur Job; Livres XV-XVI. SC 221. Paris: Cerf.

Daur, Klaus-Detlef, und Joseph Martin, Hgg. 1962 [1996]. Augustinus: De doctrina christiana. CCSL 32. Turnhout: Brepols.
Dekkers, Eligius, und Johannes Fraipont, Hgg. 1956 [1990]. Augustinus: Enarrationes in Psalmos I-L. CCSL 38. Turnhout: Brepols.

Dobschütz, Ernst von, Hg. 1912. Das Decretum Gelasianum de libris recipiendis et non recipiendis. Texte und Untersuchungen zur Geschichte der altchristlichen Literatur 38,4. Leipzig: J.C. Hinrichs.

Dombart, Bernard, und Alfons Kalb, Hgg. 1955a. Augustinus: De civitate dei; Libri I-X. CCSL 47. Turnhout: Brepols.

Dombart, Bernard, und Alfons Kalb, Hgg. 1955b. Augustinus: De civitate dei; Libri XI-XXII. CCSL 48. Turnhout: Brepols.

Drecoll, Volker Henning. (2007) 2014. „Ambrosius als Taufvater Augustins und der ,Mailänder Kreis““. In Augustin Handbuch, hrsg. v. Volker Henning Drecoll, 127-143. Tübingen: Mohr Siebeck.

Dykes, Anthony. 2011. Reading Sin in the World: The Hamartigenia of Prudentius and the Vocation of the Responsible Reader. Cambridge: Cambridge University Press.

Fels, Wolfgang, Hg. 2011. Prudentius: Das Gesamtwerk. Bibliothek der Mittellateinischen Literatur 9. Stuttgart: Hiersemann.

Geerlings, Wilhelm. 2002. „Augustinus: Lehrer der Gnade“. In Theologen der christlichen Antike: Eine Einführung, hrsg. v. Wilhelm Geerlings, 148-167. Darmstadt: Wissenschaftliche Buchgesellschaft. [= Geerlings, Wilhelm. 2010. Fussnoten zu Augustinus: Gesammelte Schriften Wilhelm Geerlings, hrsg. v. Georg Röwekamp, 3-28. Turnhout: Brepols.]

Goldbacher, Alois, Hg. 1898. Augustinus: Epistulae. CSEL 34. Prag: F. Tempsky.

Greschat, Katharina. 2005. Die Moralia in Job Gregors des Großen. Studien und Texte zu Antike und Christentum 31. Tübingen: Mohr Siebeck.

Greschat, Katharina. 2016. „Gregor der Große: Die epistula dedicatoria und die praefatio zu den Moralia in Job“. In Handbuch der Bibelhermeneutiken: Von Origenes bis zur Gegenwart, hrsg. v. Oda Wischmeyer, 111-121. Berlin: De Gruyter.

Grossi, Vittorino. 2001. „Il ,Decretum Gelasianum‘: nota in margine all'autorità della Chiesa di Roma alla fine del sec. V.“'Augustinianum 41:231-355.

Hafner, German. 2002. Cassiodor: Ein Leben für kommende Zeiten. Stuttgart: F. Steiner.

Henke, Rainer. 2000. Basilius und Ambrosius über das Sechstagewerk: Eine vergleichende Studie. Chrêsis VII. Basel: Schwabe Verlag.

Horn, Christoph, Hg. 1997. Augustinus: De civitate dei. Klassiker Auslegen 11. Berlin: Akademie Verlag.

Houwen, Luuk A.J.R., Hg. 1997. Animals and the symbolic in mediae val art and literature. Mediaevalia Groningana 20. Groningen: Egbert Forsten.

Hübner, Wolfgang. 2008. „Liber (libellus)“. Augustinus-Lexikon 3,56:954-960.

Kessler, Stephan Ch. 2000. „Gregor der Große und seine Theorie der Exegese: Die Epistula ad Leandrum“. In L'esegesi dei padri latini dalle origini a Gregorio Magno: XXVIII incontro di studiosi dell'antichità cristiana, Roma, 6-8 maggio 1999. Studia Ephemeridis Augustinianum 68, 691-700. Rom: Institutum Patristicum Augustinianum.

Köckert, Charlotte. 2009. Christliche Kosmologie und kaiserzeitliche Philosophie: die Auslegung des Schöpfungsberichtes bei Origenes, Basilius und Gregor von Nyssa vor dem Hintergrund kaiserzeitlicher Timaeus-Interpretationen. STAC 56. Tübingen: Mohr Siebeck. 
Lauchert, Friedrich, Hg. 1889 [1974]. Geschichte des Physiologus. Strassburg: Karl J. Trübner [Genève: Slatkine].

Malamud, Martha A. 2011. „An Interpretative Essay“. In Prudentius: The Origin of Sin; An English Translation of the Hamartigenia. Cornell Studies in Classical Philology 61, hrsg. v. Martha A. Malamud, 51-212. Ithaca: Cornell University Press.

Mayer, Matthias. 2014. „Augustinus’ De Civitate Dei: Philosophie der Geschichte oder Geschichte der Philosophie?" Freiburger Zeitschrift für Philosophie und Theologie 61,2:412-429.

Mayhoff, Karl, Hg. 1892-1909. C. Plinii Secundi naturalis historiae libri XXXVII. 6 Bde. Leipzig: Teubner.

Meade, David G. 1986. Pseudonymity and Canon: An Investigation into the Relationship of Autorship and Authority in Jewish and Earliest Christian Tradition. WUNT 39. Tübingen: J.C.B. Mohr (P. Siebeck).

Moorhead, John. 2005. Gregory the Great: The Early Church Fathers. London: Routledge.

Neuschäfer, Bernhard. 1987. Origenes als Philologe. Basel: Friedrich Reinhardt.

O’Daly, Gerard. 1999. Augustine's City of God: A Reader's Guide. Oxford: Clarendon Press.

Palla, Roberto, Hg. 1981. Prudenzio: Hamartigenia. Biblioteca di studi antichi 26. Pisa: Giardini.

Pollmann, Karla. 1996. Doctrina Christiana: Untersuchungen zu den Anfängen der christlichen Hermeneutik unter besonderer Berücksichtigung von Augustinus „De doctrina christiana“. Paradosis 41. Fribourg: Universitätsverlag.

Pollmann, Karla. 2002. Augustinus: Die christliche Bildung (De doctrina Christiana). Stuttgart: Reclam.

Pollmann, Karla. 2016. „Alte Kirche: Einführung.“ In Handbuch der Bibelhermeneutiken: Von Origenes bis zur Gegenwart, hrsg. v. Oda Wischmeyer, 9-12. Berlin: De Gruyter.

Recchia, Vincenzo. 1996. „Il metodo esegetico di Gregorio Magno nei Moralia in lob (II,1; 2; 4,1-47)“. In Gregorio Magno Papa ed esegeta biblico. Quaderni di Invigilata Ivcernis 4, hrsg. v. Vincenzo Recchia, 355-404. Bari: Istituto di studi classici e cristiani. Università di Bari.

Rottenwöhrer, Gerhard. 1986. Unde malum? Herkunft und Gestalt des Bösen nach heterodoxer Lehre von Markion bis zu den Katharern. Bad Honnef: Bock und Herchen.

Sbordone, Francesco, Hg. 1936a [1976, ${ }^{2}$ 1991]. Physiologus. Rom: Società Anonima Editrice ,Dante Alighieri“ [Hildesheim: Olms].

Schäfer, Christian. 2002. Unde malum? Die Frage nach dem Woher des Bösen bei Plotin, Augustinus und Dionysius. Würzburg: Königshausen \& Neumann.
Schenkl, Karl, Hg. 1897. Ambrosius: De Tobia. CSEL 32,2. Prag: F. Tempsky.

Schneemelcher, Wilhelm, Hg. ${ }^{6} 1990$. Neutestamentliche Apokryphen in deutscher Übersetzung. Bd. 1, Evangelien. Tübingen: Mohr Siebeck.

Schneider, Horst. 2016. „Physiologus.“ RAC 27:722-743.

Schultheiß, Jochen. 2016. „Augustinus: De doctrina christiana.“ In Handbuch der Bibelhermeneutiken: Von Origenes bis zur Gegenwart, hrsg. v. Oda Wischmeyer, 47-61. Berlin: De Gruyter.

Simonetti, Manlio, Hg. 1961. Tyrannius Rufinus: Opera. CCSL 20. Turnhout: Brepols.

Sordi, Marta. 1990. „La tradizione dell'inventio crucis in Ambrogio e in Rufino“. Rivista di storia della Chiesa in Italia 44:1-9.

Stählin, Otto, Hg. (1906) ${ }^{2}$ 1939. Clemens Alexandrinus. Bd. 2, Stromata I-VI. GCS 15. Leipzig: J.C. Hinrichs.

Tábet, Michelangelo. 2000. „L'esegesi greca nei commenti dei primi scrittori di lingua latina alla Benedizione di Giacobbe a Giuda (Gen. 49,8-12)“. In L'esegesi dei padri latini dalle origini a Gregorio Magno: XXVIII incontro di studiosi dell'antichità cristiana, Roma, 6-8 maggio 1999. Studia Ephemeridis Augustinianum 68, 57-75. Rom: Institutum Patristicum Augustinianum.

Thierfelder, Andreas, Hg. 1972. Terenz: Andria. Heidelberg: F. H. Kerle.

Tori, Luca, und Aline Steinbrecher, Hgg. 2012. Animali: Tiere und Fabelwesen von der Antike bis zur Neuzeit. Zürich: Schweizerisches Nationalmuseum / Mailand: Skira.

Troncarelli, Fabio. 1989. „L'ordo generis Cassiodororum e il programma pedagogico delle Institutiones“. Revue des Récherches Augustiniennes 35:129-134.

Vermeille, Alexandre. 2006. Physiologus: De l'Orient à l'Occident; Un patchwork multiculturel au service de l'Écriture Mémoiree Univ. Neuchâtel: Université de Neuchâtel, http://data.rero.ch/ 01-R007269519.

Vinzenz von Beauvais. 1624 [1964]. Speculum quadruplex sive speculum maius: naturale, doctrinale, morale, historiale. Douai: Balthasar Bellerus [Graz: Akademische Druck- und Verlagsanstalt].

Wetzel, James, Hg. 2012. Augustine's City of God: A Critical guide. New York: Cambridge University Press.

Zycha, Joseph, Hg. 1891. Augustinus: Contra Faustum. CSEL 25,1. Prag: F. Tempsky. 

Teil V: Der Berner Physiologus 



\title{
Florian Mittenhuber \\ Die Berner Physiologus-Handschriften
}

\author{
Drei Bücher, drei Geschichten
}

\begin{abstract}
The term Physiologus Bernensis usually refers to the richly illustrated Codex 318 of the Burgerbibliothek Bern. The oldest surviving illuminated manuscript of Physiologus, created in the second third of the $9^{\text {th }}$ century, justifiably ranks among the highlights of the manuscript collection of the French humanist and diplomat Jacques Bongars (1554-1612), who brought it to Bern as part of his library in 1632. Accordingly, it has been the subject of much scholarly commentary. However, the Bongars collection contains two other Carolingian Physiologi (cod. 233 and 611) which also count among the oldest and best representatives of the respective Latin version, but which are much less famous because they lack illustrations. This article, therefore, will widen the focus somewhat: from the much-discussed images in Cod. 318 towards the substantive and compositional aspects of the three Physiologus manuscripts in Bern. The discussion of the contents includes a brief overview of the various versions of the Latin Physiologus, while the composition section deals with the selection and compilation of the respective manuscript texts. It is noticeable that all three Bern Physiologi are anthologies, which raises the interesing question of whether there are certain trends in the selection of texts. Also of interest in reconstructing the textual tradition is the fact that two of the three manuscripts were torn apart once again in early modern times, and that the fragments are now in different libraries. These events, which can possibly be attributed to certain persons (or groups), are examined in the final part.
\end{abstract}

\section{Einleitung}

Wenn man die Begriffe „Bern“ und „Physiologus“ hört, denkt man unweigerlich an den reich bebilderten Codex 318 der Burgerbibliothek Bern. ${ }^{1}$ Die im zweiten Drittel des 9. Jahrhunderts entstandene älteste überlieferte Bilderhandschrift des Physiologus zählt zu Recht zu den Spitzenstücken der Handschriftensammlung und wurde in der kunstgeschichtlichen Forschung entsprechend breit

1 Als Faksimile herausgegeben von Steiger und Homburger (1964); die Handschrift ist online abrufbar unter http://www.e-codices.unifr. ch/de/list/one/bbb/0318; vgl. auch den Abdruck in diesem Band. rezipiert. $^{2}$ Die Abteilung Bongarsiana/Codices beherbergt aber noch zwei weitere karolingische Physiologi: Cod. 233 und $611,{ }^{3}$ die jedoch aufgrund der Tatsache, dass sie keine Bilder enthalten, weitaus weniger bekannt sind. In der Burgerbibliothek Bern findet sich mit Cod. 233 (Versio B), Cod. 318 (Versio C) und Cod. 611 (Versio Y) also je ein Vertreter der drei ältesten lateinischen Textrezensionen. $\mathrm{Zu}$ diesen drei Handschriften, die alle zu den ältesten und wichtigsten Textzeugen der jeweiligen Version zählen, fehlt jedoch bis heute eine vergleichende Studie, welche nebst den inhaltlichen und kompositorischen Aspekten auch die Überlieferungsgeschichte des jeweiligen Codex mit berücksichtigt.

\section{Die verschiedenen Versionen des lateinischen Physiologus}

Entstehung und Überlieferung des Physiologus sind seit den Anfängen der modernen wissenschaftlichen Beschäftigung mit dem Text in zahlreichen Abhandlungen untersucht worden, ohne dass die Forschung zu abschliessenden Erkenntnissen gelangt wäre. ${ }^{4}$ Kurz gesagt ist die Überlieferungslage des Physiologus äusserst kompliziert, da die lateinischen Versionen zu verschiedenen Zeiten von verschiedenen griechischen Vorlagen übersetzt wurden. ${ }^{5}$ Der nachfolgende knappe Überblick beschränkt sich aufgrund des Inhalts der Berner Physiologus-Handschriften auf die drei reinen lateinischen Versionen, ${ }^{6}$ es sind dies in der Reihenfolge ihres Alters die Versionen Y, C und B. ${ }^{7}$

2 Grundlegend hierzu Woodruff (1930) sowie Homburger (1962, 101117).

3 Cod. 611 ist online abrufbar unter http://www.e-codices.unifr.ch/ de/list/one/bbb/0611.

4 Zum Stand der Forschung bis 1940 vgl. Perry (1941), zur Forschungsliteratur nach 1940 vgl. Henkel (1976, 1-11).

5 Grundlegend für die griechische Überlieferung ist die Textausgabe von Sbordone (1936a); ergänzend dazu Offermanns (1966) sowie Kaimakis (1974).

6 Einen guten Überblick über die lateinische Überlieferung geben Sbordone (1949), McCulloch (1960, 21-44), Henkel (1976, 21-58) sowie Orlandi (1985).

7 Als vierte Textrezension sei Versio A erwähnt, die lediglich in der Hs. Brüssel, Bibliothèque Royale, Nr. 10074 überliefert ist. Diese kon- 
Versio $\mathrm{Y}^{8}$ ist mit 49 Kapiteln die umfangreichste und in Inhalt und Reihenfolge der Kapitel eng verwandt mit einer griechischen Handschrift des 11. Jahrhunderts (Codex Mosquensis Graecus 432), die ihrerseits zu den ältesten Textzeugen der griechischen Tradition zählt. ${ }^{9}$ Wie sich aus verschiedenen der Vetus Latina nahestehenden $\mathrm{Bi}$ belzitaten ergibt, dürfte Versio Y bereits Ende des 4. Jahrhunderts vorgelegen haben; überliefert ist sie in sechs Handschriften des 8. bis 10. Jahrhunderts, wobei die drei ältesten jeweils verschiedene Verfasser angeben, nämlich Chrysostomus (Cod. Monacensis latinus 19417), Johannes IV. von Konstantinopel (Cod. Monacensis latinus 14388) sowie einen nicht näher bestimmten orthodoxen Bischof (Burgerbibliothek Bern, Cod. 611). ${ }^{10}$ Abgesehen von einigen Kapiteln, die sich auch in anderen Versionen finden, hat die Versio Y, die nach dem 11. Jahrhundert verschwindet, keinen Einfluss auf die spätere Tradition gehabt.

Bei Versio $\mathrm{C}^{11}$ handelt es sich textgeschichtlich betrachtet um einen leider ziemlich korrupten Auszug aus einer der ältesten griechischen Fassungen, der in Inhalt und Reihenfolge der Kapitel der äthiopischen Textfassung nahesteht. Die Versio C enthält bloss 24 Kapitel und ist in zwei Handschriften des 9. Jahrhunderts überliefert, nämlich in Cod. 318 der Burgerbibliothek Bern sowie dem lange kaum beachteten Cod. Gudianus latinus 148 in Wolfenbüttel. Ersterer verdankt seinen Ruhm der Tatsache, dass es sich um den ältesten illustrierten Textzeugen des Physiologus handelt, der ohne Zweifel nach einer antiken Bildvorlage kopiert worden ist. ${ }^{12}$ Doch abgesehen von der heute in Brüssel befindlichen, ebenfalls illustrierten Handschrift, Bibliothèque Royale, Nr. 10074, aus dem 10. Jahrhundert, ${ }^{13}$ scheint die Bildtradition keinen Einfluss auf die spätere Physiologus-Überlieferung gehabt zu haben - wohl aber auf die verschiedenen Bestiarien des Mittelalters.

taminierte Version enthält 36 Kapitel, wovon 13 Kapitel aus der Versio Y, die restlichen aus der Versio B stammen.

8 Edition des Textes bei Carmody (1941); Edition des Textes von Cod. 611: Sbordone (1943, 89-117).

9 Auf den ersten Blick mag es erstaunen, dass die ältesten erhaltenen griechischen Handschriften um drei Jahrhunderte jünger sind als die ältesten erhaltenen lateinischen, die bis ins 8. Jahrhundert zurückreichen. Überlieferungsgeschichtlich gesehen ist dieser Anachronismus zwar nicht ungewöhnlich, vgl. jedoch den Beitrag von Stroppa zum Papyrusfragment PSI XVI 1577 aus dem 6. Jh., oben S. 39.

10 Cod. 611, f. 116v: ,Incipit tractatus episcopi ortodoxi de natura animalium.“

11 Edition des Textes bei von Steiger und Homburger (1964, 52-115). Bei Sbordone $(1949,249)$ als Versio x bezeichnet.

12 Vgl. dazu den Artikel von Christoph Eggenberger in diesem Band. 13 Einziger Vertreter der Versio A, vgl. oben Anm. 7.
Versio $\mathrm{B}^{14}$ schliesslich enthält 36 Kapitel. Sie charakterisiert sich vor allem dadurch, dass mit den griechischen Vorbildern viel freier umgegangen wird als in den beiden vorher besprochenen Versionen. So sind beispielsweise die Tierbeschreibungen detaillierter, die Allegorien werden durch neue Bibelzitate vermehrt und die Kapitel werden neu zusammengestellt. Ein weiteres Charakteristikum ist die handschriftliche Verbreitung: Zwar gibt es auch von der Versio B nur einige wenige reine Handschriften aus karolingischer Zeit, darunter Cod. 233 der Burgerbibliothek Bern als ihr ältester Vertreter. Im Gegensatz zu den Versionen $\mathrm{Y}$ und $\mathrm{C}$ hat die Versio $\mathrm{B}$ jedoch schon früh eine Weiterentwicklung erfahren, wobei auch Inhalte aufgenommen wurden, die nichts mit dem ursprünglichen Physiologus-Text zu tun haben; daraus haben sich verschiedene Familien entwickelt, wie z. B. die B-Isidor-Version, ${ }^{15}$ die Dicta Chrysostomisostomi ${ }^{16}$ oder der Physiologus Theobal$d i,{ }^{17}$ welche ihrerseits in den mittelalterlichen Bestiarien verarbeitet wurden und so letztlich auch für das Weiterleben des Physiologus im Mittelalter verantwortlich gewesen sind.

\section{Der Physiologus in den Berner Handschriften}

Aufgrund der eben kurz umrissenen Überlieferungsgeschichte sind Auswahl und Reihenfolge der Kapitel in den drei reinen Versionen Y, B und C sehr verschieden; ${ }^{18}$ aber auch innerhalb der jeweiligen Versionen bestehen teils markante Unterschiede zwischen den einzelnen Handschriften. Da die Charakteristika der einzelnen Handschriften in den Texteditionen von Carmody oftmals zu wenig klar herausgearbeitet wurden bzw. der genaue Inhalt nicht immer klar ersichtlich ist, ${ }^{19}$ soll dies im Folgenden für die beiden Berner Physiologi Cod. 611 (Y) und 233 (B) exemplarisch nachgeholt werden. ${ }^{20}$

14 Edition: Carmody (1939, 11-61).

15 Edition: Mann (1888, 37-73).

16 Edition: Wilhelm (1916 [1960], 15-44); die Kapitel 1-5 und 27 sind ebenfalls ediert bei Sbordone (1949, 259-270).

17 Edition: Eden (1972).

18 Vgl. dazu die übersichtliche Zusammenstellung bei McCulloch (1960, 26-27)

19 Vgl. die Ausführungen von Sbordone (1949, 249-252) für die Versio Y, der am Schluss selbstkritisch eine neue Edition unter Einbezug aller sechs verfügbaren Handschriften fordert.

20 Vollständiger Vergleich der Titel in Inhaltsverzeichnis und Text von Cod. 611 (Y) und Cod. 233 (B) in Tabelle 1 auf S. 187. 
Schon bei der ersten Betrachtung fällt auf, dass beide Handschriften am Beginn des Physiologus ein Inhaltsverzeichnis enthalten. In Cod. 611 (Sigle $\mathrm{Y}^{3}$ ) findet sich dieses auf f. 116v bis 117v; es ist geschrieben in ungelenker Unzialis und enthält vierzig Kapitel. Ab f. 117v folgt, in schwer $\mathrm{zu}$ lesender merowingischer Kursive, der leider nicht sehr sorgfältig gegliederte Text. Zwar stimmt die Reihenfolge der Kapitel im Textteil genau mit derjenigen des Inhaltsverzeichnisses überein; es finden sich bei den ersten Kapiteln jedoch öfters nur die Nummer und Textanfang, nicht aber die Titel; erschwerend kommt hinzu, dass die in roter Unzialis geschriebenen Titel verschiedentlich so stark abgerieben sind, dass der genaue Wortlaut nur noch erahnt werden kann. Bei den letzten drei Kapiteln stehen die Titel am Schluss des jeweiligen Textes - ein aus griechischen Handschriften wohl bekanntes Gliederungselement, das auf die Verwendung einer ebensolchen Vorlage hindeutet.

Auch stimmen Reihenfolge und Anzahl der Kapitel nicht mit Carmodys Edition von 1941 überein: Während dieser für die Y-Version 49 Kapitel auflistet, fehlen in Cod. 611 gegenüber der Edition sieben Kapitel ganz (Nr. 28: Psycomora, Nr. 33: Mirmicoleon, Nr. 37: Hyena/Belua, Nr. 40: Cornicola, Nr. 44: Rana, Nr. 45: Salamandra, Nr. 48: Columbae); das Kapitel Nr. 25: Onager et Simia ist in zwei Kapitel aufgeteilt. Bei drei Kapiteln (Nr. 17: Ibis, Nr. 23: Sostoros lapis, ${ }^{21}$ Nr. 49: Saura Eliace) fehlen die Titel in Inhaltverzeichnis und Textteil, der Text ist jedoch vorhanden. Der Physiologus-Text in Cod. 611 weist also insgesamt 43 Kapitel auf. Zu Beginn ist die Reihenfolge der Texte dieselbe wie in Carmodys Edition, dasselbe gilt, abgesehen von den erwähnten Auslassungen, für den Schluss. Im Mittelteil ist die Reihenfolge jedoch verschieden: Auf das Kapitel Vulpis (Nr. 18) folgen zunächst Monoceras (Nr. 35), Castor (Nr. 36), Simia (Nr. 25b) und Panther (Nr. 29); erst dann kommen die Kapitel Arbor Peridexion (Nr. 19), Elephas (Nr. 20) und Dorchon bzw. Capriola (Nr. 21). Danach springt der Text zu den Kapiteln Adamantinus Lapis (Nr. 24), Onager (Nr. 25a), Sendyticus Lapis (Nr. 26), Fulica (Nr. 27); erst dann werden die ausgelassenen Kapitel Achatis Lapis (Nr. 22) und Sostoros Lapis (Nr. 23) nachgeholt. Nebst dieser ungewöhnlichen Reihenfolge ist auch der Inhalt der Kapitel verschieden, denn der Wortlaut zu Vulpis (Nr. 18), Monoceras (Nr. 35), Castor (Nr. 36) sowie Onager (Nr. 25a) und Simia (Nr. 25b) ist der Versio B entnommen. Cod. 611 ist also nicht eine reine Handschrift der Versio Y, sondern enthält auch Texte der Versio B. ${ }^{22}$ Diese Beobach-

21 Das Kapitel wird bei Sbordone (1949, 251) nicht berücksichtigt, weshalb die Liste nur 48 Nummern umfasst.

22 Bei Carmody $(1941,98)$ beiläufig erwähnt. tung ist aufgrund des Alters von Cod. 611 bedeutsam, weil für diese Kapitel somit ein älterer Textzeuge zur Verfügung steht als Cod. 233, der bislang als der älteste Vertreter der Versio B galt.

Das Inhaltsverzeichnis von Cod. 233 (Sigle B) auf der Titelseite (f. 1r) enthält 32 Kapitel und ist in derselben gut leserlichen karolingischen Minuskel geschrieben, wie der darauffolgende Text. Die Nummern 1 bis 30 des Inhaltsverzeichnisses stimmen, abgesehen von der doppelten Zählung von Kapitel 28 und der daraus resultierenden fehlerhaften Nummerierung der beiden folgenden Kapitel, mit Carmodys Edition von 1939 genau überein, da er dieser ja die Handschrift zu Grunde legt. Im Gegensatz zur vorher besprochenen Handschrift unterscheidet sich aber die Kapitelzählung im Text von Cod. 233 von derjenigen des Inhaltsverzeichnisses: So findet sich für die Kapitel Leo (Nr. 1) und Formica (Nr. 11) im Inhaltsverzeichnis jeweils ein Eintrag, im Text hingegen fungiert jede ihrer drei Naturen unter einem eigenen Titel. ${ }^{23}$ Beim Kapitel Sirene et Onocentauris (Nr. 12) steht dem klassischen Titel ein zweiter Eintrag im Text gegenüber, ${ }^{24}$ ebenso ist das Kapitel Mustella [et Aspis] (Nr. 26) im Text in die Abschnitte Mustella und Aspis unterteilt. Weitere Besonderheiten finden sich im Textteil vor Corcon (= Dorcon, Nr. 20: unpassende Kapitelzählung) ${ }^{25}$ sowie vor Cervus (Nr. 29: Zahl XXXIIII übersprungen).

Der Physiologus-Text in Cod. 233 weist also insgesamt 36 Kapitel auf, die den 30 Kapiteln des Inhaltsverzeichnisses entsprechen. Dessen letzte beiden Einträge, „XX. de simia“ und „XXI. de carnium usu vel piscium“, sind offensichtlich Nachträge, was auch daraus ersichtlich wird, dass das Kapitel Simia (Nr. 21b) auf f. 13v, also der letzten Seite der Handschrift nachgetragen ist. ${ }^{26}$ Der letzte Eintrag hat keine Entsprechung im Text und gehört auch gar nicht zum Bestand des Physiologus; es handelt sich um einen Abschnitt aus Isidor (De ecclesiasticis officiis 1.45; PL 83:777A), der offenbar im Dunstkreis der Physiologus-Überlieferung im Inhaltsverzeichnis von Cod. 233 mit tradiert, aber im Text nicht übernommen wurde.

Solche physiologusfremden Kapitel finden sich auch am Schluss von Cod. 318 (Versio C), nämlich die Abschnitte „Galli cantus“ aus dem Sechstagewerk des heiligen Ambro-

\footnotetext{
23 „De natura ..., secunda natura ..., tertia natura ....“

24 „De serene et uno centauris ..., et uno centaurus duabus naturas constare.“

25 Die am linken Rand vermutlich defekte Zahl [?]XIII findet sich auf f. 9r, d. h. dem ersten, mit Faden angenähten Blatt der zweiten Lage; vgl. unten die Beschreibung der Handschrift.

26 Das Kapitel gehört zu Onager (Nr. 21a), wobei diese beiden Kapitel ja auch in Cod. 611 voneinander getrennt erscheinen.
} 
sius (5.24.88-89; PL 14:240C-241B) sowie - nur im illustrierten Berner Physiologus - „Caballus“ aus Isidors Etymologiae (12.1.42-43; PL 82:430A-B). Die Tatsache, dass sich nicht zum Bestand des Physiologus gehörige Zusätze in mehreren Versionen finden, und vor allem, dass diese im Berner Physiologus auch bebildert sind, zeigt, dass bereits in sehr früher Zeit recht frei mit den Inhalten umgegangen wurde. Es ist also nicht so, dass es einen festen Physiologus-Kanon gab, aus dem einzelne Tierbeschreibungen übernommen wurden. Vielmehr hat man die Tierbeschreibungen abgeändert und mit neuen Allegorien versehen und man scheute sich nicht davor, auch neue Inhalte aus anderen Autoren - allen voran Isidor von Sevilla - aufzunehmen.

\section{Die Zusammensetzung der Berner Handschriften}

Ähnlich heterogen wie die Physiologus-Texte gestaltet sich auch die Zusammensetzung der drei Berner PhysiologusHandschriften - allen drei ist nämlich gemeinsam, dass es sich um Sammelbände mit ganz unterschiedlichen Inhalten handelt oder gehandelt hat. Im Folgenden seien Form und Inhalt der einzelnen Handschriften summarisch zusammengestellt.

\section{Cod. 318 (um 830, Kloster Hautvillers bei Reims)}

Pergament, 131 Blatt, $25,5 \times 18 \mathrm{~cm} \cdot{ }^{27}$ Lagen: $(I V-6)^{2}$ [zwischen $\mathrm{f} .1$ und 2 fehlen die inneren drei Doppelblätter der ersten Lage] +15 IV $^{122}+(I V+1)^{131}$ [das letzte, jüngere Einzelblatt ist angeklebt]. Seiteneinrichtung: Einspaltig, Schriftspiegel $18 \times 10,5-11 \mathrm{~cm}, 23$ mit Griffel gezogene Zeilen (f. 123-130: $19 \times 12 \mathrm{~cm}, 24$ Zeilen; f. 131: $21 \times 13-$ $14 \mathrm{~cm}, 26$ Zeilen); seitliche Begrenzung durch vertikale Doppellinien, Punktierung am Rand. Schrift und Hände: Karolingische Minuskel, rote und schwarze Unzialis für Werk- und Kapitelüberschriften; Capitalis rustica für den Nachtrag (f. 41r), das Explicit (f. 121v und f. 123v sowie für das Schreiberkolophon f.130r). Der ganze Band, ausser f. 1-3, ist von der Haupthand geschrieben. Buch-

27 Genaue Beschreibung, mit Literatur zur Handschrift, Incipit und Explicit der Texte sowie Textnachweisen online unter: http://www. e-codices.unifr.ch/de/description/bbb/0318/; vgl. von Steiger und Homburger (1964, 17-22), Homburger (1962, 101-117), Bischoff (1998, 122, Nr. 574), Mostert (1989, 71, Nr. 153). schmuck: f. 1r: zehnzeilige Initiale „S“, in mehrfarbigem Flechtwerk; f. 7r-22v: 35, in der Regel vor der Titelzeile angeordnete Illustrationen zum Physiologus (Ausnahmen f. 7r-v; 12v); der übrige Text ist schmucklos. Moderner Restaurierungseinband von 1946, der Vorgängereinband ist verloren. $^{28}$

Inhalt

1) f. 1r-5r Vita Sancti Symeonis 1.1-3, 5.21-9.41.

2) f. 5r-6v De ortu et obitu patrum.

3) f. 7r-22v Physiologus latinus (Versio C).

4) f. 23r-125r Fredegarii Chronicon 1.1-4.9.

5) f. 41r Dies Aegyptiaci (Einschub).

6) f. 125r Lectio S. Evangelii secundum Matthaeum 17.1-9.

7) f. $125 \mathrm{v}-130 \mathrm{r}$ Sermo S. Effrem monachem in transfigurationem Domini.

8) f. 130v Praecepta medica.

9) f. 131r-v De septem miraculis mundi.

Cod. 318 beginnt also mit der Lebensbeschreibung des heiligen Symeon sowie Kurzbiographien von achtzehn christlichen Patriarchen; danach folgt der illustrierte Physiologus. Den weitaus grössten Teil machen die vier Bücher der so genannten Fredegar-Chronik aus, die irgendwie nicht so recht in den christlichen Kontext der übrigen Stücke passen. Am Schluss des Bandes folgt eine Perikope aus dem Matthäus-Evangelium, mit der lateinischen Übersetzung des Syrers Ephrem. Die restlichen Stücke (Nr. 5, 8-9) sind erst im 10./11. Jahrhundert hinzugefügt worden. Wenn man der Tatsache Rechnung trägt, dass fast der gesamte Text in sauberer karolingischer Minuskel von einer Hand geschrieben wurde, die einzelnen Stücke über die Lagengrenzen hinaus gehen und sich am Schluss sogar ein Schreibervermerk findet, ${ }^{29}$ bildet der Codex aus kodikologischer Sicht ein homogenes Ganzes.

28 Bei der Restaurierung 1946 wurden die Blätter der zweiten bis vierten Lage (f. 3-26) aus dem Codex herausgelöst und je ein Doppelblatt unter Glas gefasst. 2003 und 2008 erfolgte eine Umlagerung in 12 Passepartouts (I-XII), die heute separat in einer Schachtel aufbewahrt werden.

29 Das Schreiberkolophon steht f. 130r unten, am Ende des ursprünglichen Codex: „Haecpertus [= Egbert] me fecit. Qui istum librum legit, orat pro Hecperto scriptore si Deum habeat adiutorem et defensorem.“ 


\section{Cod. 611 (vermutlich Ostfrankreich, 1. Hälfte 8. Jahrhundert)}

Völlig verschieden präsentieren sich dagegen Form und Inhalt von Cod. $611:^{30}$ hier haben wir ein regelrechtes Sammelsurium vor uns, sowohl im kodikologischen wie auch im inhaltlichen Sinn. Die Handschrift ist aus ursprünglich sechs selbständigen Teilen zusammengesetzt, wobei die Lagen, meist Ternionen oder Quaternionen ${ }^{31}$, z.T. schon bei der Anlage mit Einzelblättern durchsetzt waren. Auch finden wir eine grosse Bandbreite an Schriften, meist vorkarolingische Minuskel merowingischen oder französischen Typs, aber auch Unziale, die von verschiedenen, oft nicht sehr geübten Händen in verschiedenen Etappen geschrieben wurden.

Pergament, 153 Blatt, 18-19 × 14-14,5 cm. Ursprünglich sechs selbständige Teile: I: f. 1-19; II: f. 20-41; III: f. 42-93; IV: f. 94-115; V: f. 116-139; VI f. 140-153. Lagen: $2(\mathrm{III}+2)^{16}$ [f. 3 und 6, 11 und 14 sind Einzelblätter] $+(\mathrm{I}+1)^{19}$ [f. 17 ist gefalzt, an f. 18 angehängt, aber separat geheftet] $+(\text { IV-1 })^{26}$ [rechte Hälfte des innersten Doppelblattes fehlt] $+\mathrm{IV}^{34}+(\mathrm{III}+1)^{41}$ [Ansetzfalz von f. 35 abgebrochen, klebt an f. 41] +2 IV $^{57}+(I V+1)^{66}$ [f. 66 ist mit Falz an f. 57 fixiert, gehört aber zur folgenden Lage] $+2 \mathrm{III}^{78}+\mathrm{IV}^{86}+(\mathrm{III}+1)^{93}$ [f. 89 Einzelblatt] + III $^{99}+$ IV $^{107}+$ III $^{113}+\mathrm{I}^{115}+3 \mathrm{IV}^{139}+$ $\mathrm{I}^{141}+\mathrm{II}^{145}+\mathrm{IV}^{153}$. In Teil III Lagenzählung jeweils auf dem letzten verso unten rechts in groben römischen Kustoden: „I“ (f. 49v), „II“ (f. 57v), „III“ (f. 65v), „VIII“ (f. 86v) [das letzte Blatt von Lage IV, die gesamte Lage V, sowie das erste und letzte Blatt von Lage VII fehlen]. ${ }^{32}$ Seiteneinrichtung: ${ }^{33}$ Teil I zweispaltig, die übrigen Teile einspaltig; Schriftspiegel I: $18 \times 12,5(5-6) \mathrm{cm}, 25-27$ Zeilen; II: 14 $\times 12 \mathrm{~cm}, 16-17$ Zeilen; III: $14-17,5 \times 12 \mathrm{~cm}, 14-27$ (f. $91 \mathrm{v}$ : 36) Zeilen; IV: $17-17,5 \times 13 \mathrm{~cm}, 26-27$ Zeilen; V: $15-17 \times$ 10,5-11 cm, 18-19 (f. 139r-v: 27) Zeilen; VI: $16,5 \times 12,5 \mathrm{~cm}$, 25 Zeilen; alle Teile mit Blindlinierung, Teile II-VI mit

30 Ausführliche Beschreibung, mit Literatur zur Handschrift, Incipit und Explicit der Texte sowie Textnachweisen online unter: http:// www.e-codices.unifr.ch/de/description/bbb/0611/; vgl. Homburger (1962, 21-23), Bischoff (1998, 131, Nr. 609a); Mostert (1989, 81-82, Nr. 222-223 sowie 228, Nr. 1167).

31 Hefte zu drei bzw. vier Doppelblättern.

32 Lage VI, die ursprünglich auf f. 72 des Bernensis folgte, ist erhalten in: Paris BN lat. 10756, f. 62-69: http://gallica.bnf.fr/ark:/12148/ btv1b9065920c/f64.image.r=10756. Der ursprüngliche Inhalt von Teil III (f. 42-93) lässt sich aufgrund des auf f. 92v-93r befindlichen Inhaltsverzeichnisses gut rekonstruieren.

33 Die Ausführungen zu Seiteneinrichtung, Schrift und Buchschmuck basieren auf Lowe, Bd. 5: Paris (1950, 25, Nr. 604) und Bd. 7: Switzerland (1956, 9-10, Nr. 604, 604a-e, 866-867) sowie Homburger (1962, 21-23).
Punktierung. Schrift und Hände: I: Flüchtige, nicht kalligraphische kursive Minuskel merowingischen Typs; ab und zu Tironische Noten; II: Eher flüchtige vorkarolingische Minuskel französischen Typs, mit zahlreichen Ligaturen; Anklänge an die merowingische Urkundenschrift; III: Flüchtige vorkarolingische Minuskel merowingischen Typs, von f. 86v an mit zahlreichen Tironischen Noten vermischt; gleichzeitige Unzialis auf f. 81v/82r und 92v/93r und in den Überschriften, Halb-Unzialis auf f. 68v/69r; am unteren Rand von f. 77v/78r griechisches Alphabet mit lateinischen Äquivalenten; IV: Mehr oder weniger kursive vorkarolingische Minuskel französischen Typs, geschrieben von verschiedenen Händen; Anklänge an die Schule von Luxeuil; V: Kursive (Urkunden-)Minuskel, Unzialis für das Inhaltsverzeichnis des Physiologus und den Anfang von Kapitel 1 auf f. 116v/117r; die Hand auf f. 138v-140v ist dieselbe wie f. 40v-41v; VI: Rohe vorkarolingische Minuskel französischen Typs, mit Anklängen an die Schulen von Luxeuil und Corbie. In allen Teilen Tinte in verschiedenen Brauntönen. Buchschmuck: I: Einfache schwarze Initialen, einige kalligraphisch gestaltet; Zierleisten aus Wellenlinien oder Häkchen; II: Einfache grosse schwarze oder braune Initialen, z. T. gespalten; III: Einfache braune Initialen, teilweise mit Rot oder Schwarz überstrichen; auf f. 93v sorgfältige, mit brauner Tinte gezeichnete Windkarte; IV: Titel in roter oder schwarzer Unzialis; grosse „hohle“ Kapitalen mit Tönen von Rot oder Grün gefüllt; V: Titel auf f. 116v in roter Capitalis und Unzialis; Kapitelüberschriften und -anfänge ebenfalls in roter Unzialis; ansonsten einfache schwarze Initialen; VI: Incipits in Rot und Schwarz, teilweise in ungelenker Unzialis. Moderner Restaurierungseinband von 1987, Teile des Vorgängereinbandes aus dem 16. Jahrhundert sind erhalten. ${ }^{34}$

Als Besonderheit der Handschrift sei erwähnt, dass es sich bei den Blättern des Physiologus und der Kanonischen Exzerpte um Palimpseste handelt. Die darunterliegenden Texte sind im 7. Jahrhundert bzw. in der zweiten Hälfte des 5. Jahrhunderts vermutlich in Italien entstanden: Teil I (f. 116-142, 145) enthält das älteste bekannte Fragment der Passio sancti Sebastiani; erhalten sind 14 oder 15 Blätter, ursprüngliches Format ca. $26,3 \times 18,5 \mathrm{~cm}$, meist zu einem Doppelblatt des jetzigen Codex gefaltet; einspaltig,

34 Um 1937 wurde der ursprüngliche Band durch den Berner Buchbinder Johann Lindt auseinander genommen und die sechs ursprünglichen Teile wurden, offenbar lose, in Papierumschläge in den alten Einband eingelegt; diese Aufteilung geschah möglicherweise in Zusammenhang mit den Arbeiten für die Codices Latini Antiquiores (= CLA). Bei der Restaurierung von März-September 1987 wurden die einzelnen Hefte aufgelöst und die Lagen in einem neuen Einband wieder zu einem Codex vereinigt. 
Schriftspiegel 19,3 × 13,7 cm, 19 Zeilen; weite, eher unbeholfene Unzialis späten Typs; viele Seiten beginnen mit einem grossen Buchstaben. Teil II (f. 143-144) enthält ein Fragment des Markus-Evangeliums (Versio antehieronymiana); erhalten ist ein unvollständiges Doppelblatt, 18,5 $\times 21,6 \mathrm{~cm}$ zu einem Doppelblatt des jetzigen Codex gefaltet; zweispaltig, Schriftspiegel quadratisch 15,4 × 15,4 cm, 22 Zeilen; eher eng gestellte Unzialis alten Typs.

Inhalt

1) f. 1ra-18va Glossarium latinum, alphabetisch $\mathrm{D}-\mathrm{Z}$.

2) f. 18va-19rb Glossarium latinum, alphabetisch $\mathrm{A}-\mathrm{H}$.

3) f. 19v-20r Prognosticon.

4) f. 20v-26r Isidorus: Etymologiae 5.39.1-42 (Exzerpt).

5) f. 26r-40v Isidorus: Etymologiae 9.2.2-135 (Exzerpt).

6) f. 40v-41v Palladius: Historia Lausiaca 32.1-13.

7) f. 42r Carmen de ventis.

8-9) f. 42v-72r Asper minor: Ars grammatica.

10) f. 72v Isidorus: Etymologiae 1.22.1-2 (Exzerpt).

11) f. 73r-80v Aenigmata Bernensia.

12) f. 80v-81r Sententiae, alphabetisch A-T.

13) f. 81v Descriptio Arcae Noae.

14) f. 81v-82r Isidorus: Etymologiae 15.16.2-3 (Exzerpt).

15) f. 82r Hieronymus: Commentarius in Danielem 3.10.12 (Exzerpt).

16) f. 82v-85v Galenus: Epistula De febris.

17) f. 86r-92r Theologica varia, mit Texten des Hieronymus, Taio Caesaraugustanus, Gregorius Magnus, etc.

18) f. 92v-93r Inhaltsverzeichnis zu Teil III (f. 42-93).

18a) f. 92v unten Gregorius Magnus: Moralia in Iob 5.22.43 (Exzerpt).

19) f. $93 \mathrm{v}$ Windkarte.

20) f. 94r-96v Computus Paschalis anni 727 [= Dial. Burg. cap. 1-17].

21) f. 97r-v Isidorus: De ecclesiasticis officiis 1.11.4-12.7 (Exzerpt).

22) f. 98r-99r Gregorius Magnus: Epistula 9.213.

23) f. 99r-100v Gregorius Magnus: Dialogi, lib. 4; Moralia in Iob (Exzerpte).

24) f. 101r-113r Pseudo-Methodius: Apocalypsis.

25) f. 114r-115r Hieronymus: Epistula 22 ad Eustochium, cap. 30 (Exzerpt).

26) f. 116v-138v Physiologus latinus (Versio Y).

27) f. $138 \mathrm{v}-145 \mathrm{v}$ Excerpta canonica: Collectio Bernensis; Concilium Autissiodorense.
28) f. 146r-153v Medica varia: Gargilius, Dynamidia, Pseudo-Oribasius: commentaria in aphorismus Hippocrati, Receptarius.

Diese kurze Auflistung vermittelt einen guten Eindruck von der Heterogenität des Inhalts von Cod. 611: bei den knapp dreissig Einzelstücken handelt es sich mehrheitlich um Texte aus grammatikalischen, patristischen und medizinischen Schriften. Die längeren Stücke, namentlich die lateinischen Glossare (Nr. 1-2), Exzerpte aus Isidors Etymologien (Nr. 4-5), Aspers Ars Grammatica (Nr. 8-9), die sogenannten Berner Rätsel (Nr. 11), Galens Epistula De febris (Nr. 16), der Computus paschalis aus dem Jahr 727 (Nr. 20), die Apokalypse des Pseudo-Methodius (Nr. 24), der Physiologus latinus (Nr. 26), die Kanonischen Exzerpte (Nr. 27) und die Medizinischen Texte (Nr. 28) sind unterbrochen von zahlreichen weiteren Exzerpten aus Isidor, Hieronymus und Gregorius Magnus, die teilweise auch in Tironischen Noten verfasst sind. Es sind also Texte aus fast allen, für die Organisation des klösterlichen Lebens wichtigen Bereichen vorhanden; auffällig ist einzig das Fehlen von chronikalischen Texten.

\section{Cod. 233 (möglicherweise Fleury, 1. Drittel 9. Jahrhundert)}

Pergament, 13 Blatt, $28,5-29 \times 17,5-18,5 \mathrm{~cm} .{ }^{35}$ Lagen: IV $^{8}$ $+(\mathrm{II}+1)^{13}$ [f. 9 mit Faden angenäht, unklarer Zusammenhang wegen Verklebung]. f. $8 \mathrm{v}$ unten karolingische Lagensignatur „,Yr XVIIII“ [korrigiert aus „XII“]. Seiteneinrichtung: Einspaltig (Inhaltsverzeichnis auf f. 1r zweispaltig), Schriftspiegel 21,5 $\times 14 \mathrm{~cm}, 29$ Zeilen, Blindlinierung, Punktierung. Schrift: Frühe karolingische Minuskel, offenes „a“. Buchschmuck: f. 1r fünfzeiliger Titel: „Incipit liber Fisioloto exposito de natura animalium vel avium seu bestiarum", in abwechselnd roter und schwarzer, unverhältnismässig grosser Capitalis quadrata (griechische Buchstaben der Vorlage nachgezeichnet, aber unverstanden), die schwarzen Buchstabenzeilen mit durchsichtigem Gelb oder Violett überstrichen; eingestreut sind stark verkleinerte Buchstaben. Überschriften in ungelenker roter Unzialis, römisch gezählt; Initialen drei- bis fünfzeilig, wechselnd in Tinte bzw. Rot mit einfachen Verzierungen in der Gegenfarbe. Einband: Mit hellem Papier überzogene Pappdeckel, Rücken aus hellem Pergament (Bern, um 1700).

35 Ausführliche Beschreibung der Handschrift im Online-Katalog der Burgerbibliothek Bern: http://katalog.burgerbib.ch/detail.aspx? id=129318; vgl. Homburger (1962, 57), Mostert (1989, 66, Nr. 126). 


\section{Inhalt}

Der Codex enthält heute nur noch den Physiologus auf dreizehn Blättern; die karolingische Lagensignatur auf f. $8 \mathrm{v}$, und vor allem die starke Verschmutzung des letzten Blattes (f. 13v), das auch Rostflecken von einem Einbandbeschlag aufweist, lassen jedoch vermuten, dass es sich um den letzten Teil eines ursprünglich umfangreicheren Sammelbandes handelt. Es wurde bereits vermutet, dass die übrigen Teile in Orléans, Bibliothèque municipale, Ms. 313 (266), sowie in Burgerbibliothek Bern, Cod. 225 (C), überliefert sind. ${ }^{36}$ Der ursprüngliche Codex liesse sich demnach folgendermassen rekonstruieren:

$\begin{array}{ll}\text { Lagen I-XIV: } & \text { Orléans, Bibliothèque municipale, } \\ & \text { Ms. 313, S. 1-223; } \\ \text { Lagen XV-XVI: } & \text { Bern, Burgerbibliothek, Cod. } 225 \text { (C), } \\ & \text { f. 88-103; }\end{array}$

Lagen XVII-XVIII: Orléans, Bibliothèque municipale, Ms. 313, S. 224-255;

Lagen XVIIII-XX: Bern, Burgerbibliothek, Cod. 233, f. 1-13.

Tatsächlich also könnte man die Lagen der Bände zu einem Ganzen zusammensetzen, auch die Kustode „qr“ passt recht gut, aber die leicht unterschiedlichen Verzierungen lassen kein sicheres Urteil zu (vgl. Abb. 1 und 2 auf S. 186). Sollte die Zuweisung dennoch stimmen, hätten wir einen ähnlichen Fall wie bei Cod. 611 vor uns, denn die übrigen Teile enthalten ein breites Spektrum an meist patristischen Texten, darunter auch wieder solche von Isidor, Gregorius Magnus und Hieronymus.

\section{Das spätere Schicksal der Berner Handschriften}

Was die Überlieferungsgeschichte der Handschriften anbelangt, ist von Léopold Delisle schon in den 1870er Jahren erkannt worden, ${ }^{37}$ dass die Handschriften aus der bei Orléans gelegenen Benediktinerabtei Fleury/Saint-Benoîtsur-Loire heute über die Bibliotheken von Bern, Paris, Orléans, Leiden und dem Vatikan verstreut sind. ${ }^{38}$ Die Geschichte der Bibliothek von Fleury und ihre Zerstreuung ist danach in zahlreichen Publikationen beleuchtet wor-

36 So Bischoff (2004, 351, Nr. 3741).

37 Delisle (1874, 364-366).

38 Eine übersichtliche Skizze findet sich im Ausstellungskatalog der Bibliothèque municipale d'Orléans $(2004,196)$, welche auf dem Stemma von Vidier $(1965,215)$ basiert. den. ${ }^{39}$ Eingehender mit den sogenannten Membra disiecta, d.h. zusammengehörigen Teilen von Handschriften, die sich heute in verschiedenen Bibliotheken befinden, hat sich in den 1950er bis 1980er Jahren Elisabeth Pellegrin befasst. Sie hat in verschiedenen Studien nachgewiesen, ${ }^{40}$ dass sich diese Vorgänge oft mit Pierre Daniel (1530-1603) in Zusammenhang bringen lassen, der systematisch seltene Texte aus den ursprünglichen Bänden herausriss und sie befreundeten Gelehrten für Editionsvorhaben zur Verfügung stellte. Dieser Pierre Daniel ist kein Unbekannter, denn er war in den 1560er Jahren für die juristische Verwaltung der Abtei Fleury zuständig. Cod. 318 war, wie das Exlibris bezeugt, sicher in Daniels Besitz. ${ }^{41}$ Auch Cod. 611 muss sich in seinem Besitz befunden haben, denn von den Spiegeln des alten Einbandes stammen zwei Fragmente einer französischen Notariatsurkunde von $1571,{ }^{42}$ deren Anfang sich folgendermassen entziffern lässt: „[C]omme maître Pierre Danyel, avocat au parlement, confesse ...“ Und - falls die Zuweisung zu Orléans, Bibliothèque municipale, Ms. 313 (266) und Burgerbibliothek Bern, Cod. 225 (C) korrekt ist - führen die Spuren auch bei Cod. 233 in diese Richtung, denn diese Handschriften stammen definitiv aus Fleury und weisen Eintragungen von Pierre Daniel auf. Als Pierre Daniel 1603 starb, kaufte Jacques Bongars (15541612), der seit seinem Studium in Orléans und Bourges mit den Gebrüdern Daniel eng befreundet war, zusammen mit seinem Cousin Paul Pétau (1568-1614) Daniels Erben einen Grossteil der Bücher für 1500 „livres“ ab.

Jaques Bongars ${ }^{43}$ stieg Ende des 16. Jahrhunderts unter dem französischen König Heinrich IV. (1553-1610) zu einem der einflussreichsten Exponenten der französischen Aussenpolitik auf; er machte sich aber auch einen Namen als hervorragender Gelehrter. Das Material hierfür fand

39 Vgl. z. B. de Meyier (1947, 91-103).

40 Ihre gesammelten Arbeiten sind 1988 vom Centre National de la Recherche Scientifique in einem Sammelband herausgegeben worden; dort nicht abgedruckt ist der Aufsatz: Pellegrin (1960, 7-37).

41 Vgl. den Besitzeintrag f. 1r oben: „Petri Danielis Aurel[ii]“ sowie verschiedene Randbemerkungen, besonders zur Fredegar-Chronik (74r, 75r, 78r, 78v, 95v, 96r, 106r, 118v). Laut Mostert (1989, 71, Nr. 153) stammt der Band jedoch definitiv nicht aus Fleury; vgl. auf f. 131v den Eintrag aus dem frühen 15. Jahrhundert: „Ce livre appartient a Ragonde Bachelier“; laut Homburger $(1962,102)$ handelt es sich vermutlich um ein Mitglied der angesehenen Reimser Familie Bachelier.

42 Die Urkunde wurde um 1937 bei der Aufteilung des ursprünglichen Bandes herausgelöst und zunächst separat aufbewahrt; 1997 wurde sie dann unter der heute gültigen Signatur Cod. 847.9 aufgestellt.

43 Zur Biographie von Jacques Bongars und den Handschriften der Bongarsiana vgl. die anlässlich seines 400sten Todesjahres in der Schriftenreihe der Burgerbibliothek Bern erschienene Publikation: Burgerbibliothek Bern (2012, 9-21). 
er in seiner Bibliothek, in die er sein gesamtes Vermögen steckte und die bei seinem Tod 1612 etwa 650 mittelalterliche Handschriften sowie 3000 Druckbände aus allen Wissensgebieten umfasste. Jacques Bongars starb kinderlos und vermachte seine Bibliothek testamentarisch Jakob Graviseth (1598-1658), dem Sohn des Strassburger Bankiers und Juweliers Reinhard Graviseth (1560-1633), einem seiner wichtigster Kreditgeber und engsten Freunde. Nach Bongars' Tod 1612 wurden die Bücher zunächst in Strassburg, später in Basel aufbewahrt. 1624 heiratete Jakob Graviseth die Schultheissentochter Salome von Erlach (1604-1636) und schenkte Anfang 1632 die Bibliothek der Stadt Bern. ${ }^{44}$ Mit dem Eintreffen von Bongars Bibliothek hat sich der Bestand der alten Berner Bibliothek auf einen Schlag mehr als verdoppelt. Für die Katalogisierung dieser Büchermasse war der Berner Pfarrer Samuel Hortin (15891652) verantwortlich. Der heute noch erhaltene, mit seinen 13 Kilogramm stattliche Bibliothekskatalog trägt den vielversprechenden Titel Clavis bibliothecae Bongarsianae Schlüssel zur Bongarsischen Bibliothek. ${ }^{45}$

Hortins Katalog ist für uns heute deshalb unentbehrlich, weil im Zuge einer Reorganisation der Bibliothek in den 1690er Jahren die ursprünglich separat aufgestellten Handschriften der Bongarsiana mit dem alten Berner Bestand vereinigt wurden. Da bei dieser Gelegenheit die meisten der originalen Einbände - mit allfälligen Besitzvermerken - entfernt und die gesamte Sammlung ohne Rücksicht auf Herkunft und Inhalt der Grösse nach geordnet wurden, ist Hortins Katalog für uns oft die einzige Quelle, welche die Zugehörigkeit einer Handschrift zur Bongarsiana dokumentiert. Nur hat der Katalog so seine Tücken, denn er verzeichnet die Handschriften nicht unter den heute gültigen Signaturen, sondern nach dem damaligen Standort nach Schrank und Tablar. Zudem sind die Einträge teilweise recht kryptisch, so dass die Zuweisung erst über die Autopsie der Handschrift gelingt (manchmal auch gar nicht). Eine Suche nach den Einträgen zu den drei Berner Physiologi ergab folgendes Resultat:

So findet sich zunächst einmal unter der Rubrik „Isidorus“ der Eintrag „De natura animalium“. ${ }^{46}$ Dieser Eintrag steht aber nicht für einen der drei Physiologi, sondern für Cod. 462, der das gleichnamige Werk des Konrad von Mure enthält. Die weitere Suche ergab, dass sich Cod. 611 hinter dem Eintrag „Grammatica alia latina, horribliter quoque scripta“ in der Klasse der Grammatiker-Handschriften verbirgt. ${ }^{47}$ Die Zuweisung erfolgte aufgrund der Tatsache,

$44 \mathrm{Zu}$ den Hintergründen der Schenkung ausführlich Engler (2015). 45 Hortin (1634) [= Burgerbibliothek Bern, Cod. A 5].

46 Burgerbibliothek Bern, Cod. A 5, S. 35.

47 Burgerbibliothek Bern, Cod. A 5, S. 39. dass Cod. 611 mit zwei Bruchstücken von lateinischen Glossaren beginnt; der Physiologus, der sich erst im hinteren Teil der Handschrift befindet, blieb unberücksichtigt. Bei Cod. 318 ist der Fall ähnlich: diesen Codex finden wir unter dem Eintrag „Vita sancti Symeonis, et aliorum“. ${ }^{48}$ Tatsächlich beginnt die Handschrift mit der Vita des heiligen Symeon; auch hier blieben der Physiologus und vor allem die Fredegar-Chronik, die den Hauptteil der Handschrift ausmacht, unberücksichtigt. Es zeigt sich also, dass Hortin bei der Niederschrift seines Katalogs seine Einträge in den meisten Fällen lediglich aufgrund der Titelseite oder der ersten Texte vorgenommen hat und eine genaue Prüfung des Inhaltes ausblieb. Anders wäre die Katalogisierung der gesamten Sammlung - es waren ja nebst den 650 Handschriften auch die 3000 Drucke aufzunehmen - in der kurzen Zeit von nur zwei Jahren gar nicht zu schaffen gewesen.

Vom dritten Physiologus, Cod. 233, findet sich überhaupt keine Spur in Hortins Katalog. Auch dies hat seine Gründe: Es fällt nämlich auf, dass die gegen 200 Fragmente, die aufgrund verschiedener Indizien mit der Bongarsiana nach Bern gekommen sein müssen, im Katalog Hortins keinen Niederschlag gefunden haben. Hierzu findet sich im Vorwort von Hermann Hagens 1875 gedrucktem Katalog zur Bongarsiana ein interessanter Hinweis. Hagen druckt dort eine von Hortin verfasste und von Jakob Graviseth annotierte „Erinnerung die Bongarsische Bibliothec betreffend" ab, in welcher vor allem Absatz III interessant ist: „So sind noch übrig zwo kisten voll allerley tractetlin, Relationen, Zeitung-Schrifften: Item ungebundne Bücher, etliche defectuos. Welches alles erlesen, collationiert und das beste in die Libery gestellt werden sol.“49 Wenn Cod. 233, der tatsächlich nur zwei Lagen umfasst, nicht in Hortins Katalog auftaucht, dann vermutlich deshalb, weil er sich unter den ungebundenen und defekten Büchern in der besagten Kiste befand. Dass die Handschrift im 1697 nach der erwähnten Reorganisation der Bibliothek geschaffenen Katalog des damaligen Oberbibliothekars Marquard Wild (1661-1747) noch die Signatur Cod. 231 trägt, ${ }^{50}$ untermauert diese Annahme, dass auch um 1700 die zahlreichen Bruchstücke von Handschriften ihren endgültigen Platz in der Bibliothek noch nicht gefunden hatten.

48 Burgerbibliothek Bern, Cod. A 5, S. 18.

49 Hagen (1875, XXXIII).

50 Wild (1697) [= Burgerbibliothek Bern, Cod. A 4], hier f. 54r: Liber De natura animalium. Umgekehrt ist unter der Nummer 233 ein Liber gallicus musicus verzeichnet - es handelt sich hierbei um ein heute unter der Signatur Cod. 231 verzeichnetes Chansonnier-Fragment, das ebenfalls nur 8 Blatt umfasst. 


\section{Bibliographie}

Bibliothèque municipale d'Orléans. 2004. Lumières de l'an mil en Orléanais: Autour du millénaire d'Abbon de Fleury [Ausstellungskatalog]. Turnhout: Brepols.

Bischoff, Bernhard. 1998-2004. Katalog der festländischen Handschriften des neunten Jahrhunderts. Teil I: Aachen-Lambach; Teil II: Laon-Paderborn. Wiesbaden: Harrassowitz.

Burgerbibliothek Bern. 2012. Jacques Bongars. Humanist, Diplomat, Büchersammler [= Passepartout, Bd. 6]. Bern: Stämpfli Verlag.

Carmody, Francis J., Hg. 1939. Physiologus Latinus: Éditions préliminaires versio $B$. Paris: Librairie E. Droz.

Carmody, Francis J., Hg. 1941. „Physiologus Latinus Versio Y.“ University of California Publications in Classical Philology 12,7:95-134.

Delisle, Léopold. 1874. Le Cabinet des Manuscrits de la Bibliothèque Nationale. Bd. 2. Paris: Imprimerie impériale.

Eden, Peter. T. 1972. Theobaldi «Physiologus». Mittelalterliche Studien und Texte 6. Leiden: Brill.

Engler, Claudia. 2015. „Arte e marte: Franz Ludwig von Erlach und die Bongarsiana." In Im Auge des Hurrikans: Eidgenössische Machteliten und der Dreissigjährige Krieg, hrsg. v. André Holenstein, Georg von Erlach und Sarah Rindlisbacher [= Berner Zeitschrift für Geschichte 77,3], 34-50. Bern: Hier und Jetzt.

Hagen, Hermann. 1875. Catalogus Codicum Bernensium. Bern: Haller.

Henkel, Nikolaus. 1976. Studien zum Physiologus im Mittelalter. Hermaea: Neue Folge 38. Tübingen: Max Niemeyer.

Homburger, Otto. Hg. 1962. Die illustrierten Handschriften der Burgerbibliothek Bern: Die vorkarolingischen und karolingischen Handschriften. Bern: Burgerbibliothek Bern.

Hortin, Samuel. 1634. Clavis bibliothecae Bongarsianae MDCXXXIIII. Bern: Burgerbibliothek Bern [Sign: Burgerbibliothek Bern, Cod. A 5].

Kaimakis, Dimitris, Hg. 1974. Der Physiologus nach der ersten Redaktion. Meisenheim am Glan: A. Hain.

Lowe, Elias Avery. 1950-1956. Codices Latini Antiquiores: A Palaeographical Guide to Latin Manuscripts Prior to the Ninth Century. Bd. 5: France: Paris; Bd. 7: Switzerland. Oxford: Clarendon Press.

Mann, Max Friedrich. 1888. Der bestiaire divin des Guillaume le Clerc. Heilbronn: Henninger.

McCulloch, Florence. 1960. Mediaeval Latin and French Bestiaries. Chapel Hill: University of North Carolina Press.

Meyier, Karel Adriaan de. 1947. Paul en Alexandre Petau en de geschiedenis van hun handschriften ... Leiden: Brill.
Mostert, Marco. 1989. The Library of Fleury: A Provisional List of Manuscripts. Hilversum: Verloren Publishers.

Offermanns, Dieter, Hg. 1966. Der Physiologus nach den Handschriften $G$ und M. BKP 22. Meisenheim am Glan: A. Hain.

Orlandi, Giovanni. 1985. „La tradizione del Physiologus e i prodromi del bestiario latino." In Settimane di studio del centro italiano di studi sull'alto medioevo 31 (Spoleto 7-13 Aprile 1983), 1057-1106. Spoleto: Sede del Centro.

Pellegrin, Elisabeth. 1988. Bibliothèques retrouvées. Manuscrits, bibliothèques et bibliophiles du Moyen Age et de la renaissance. Recueil d'études publiées de 1938 à 1985 par Elisabeth Pellegrin. Paris: Editions du Centre de la Recherche Scientifique.

Pellegrin, Elisabeth. 1960. „Essai d'identification de fragments dispersés dans les manuscrits des Bibliothèques de Berne et de Paris." Bulletin de l'information de l'Institut de Recherche et d'Histoire des Textes 9:7-37.

Perry, Ben E. 1941, „Physiologus.“ PRE 20,1:1074-1129.

Sbordone, Francesco, Hg. 1936a [1976, ${ }^{2}$ 1991]. Physiologus. Rom: Società Anonima Editrice ,Dante Alighieri‘ [Hildesheim: Olms].

Sbordone, Francesco, Hg. 1943. I bestiari e le rime amorose del secolo XIII. Napoli: Luigi Loffredo Editore.

Sbordone, Francesco. 1949. „La tradizione manoscritta del Physiologo latino." Athenaeum NS 27:246-280.

Steiger, Christoph von, und Otto Homburger, Hgg. 1964/2012. Physiologus Bernensis: Voll-Faksimile-Ausgabe des Codex Bongarsianus 318 der Burgerbibliothek Bern, Basel: Alkuin. / Bern, Burgerbibliothek, Cod. 318: Physiologus Bernensis, redigiert und ergänzt von Florian Mittenhuber, Juni 2012, http://www.e-codices.unifr.ch/de/list/one/bbb/0318.

Vidier, Alexandre. 1965. L'historiographie à Saint-Benoît-sur-Loire et les miracles de Saint Benoît. Paris: A. et J. Picard.

Wild, Marquard. 1697. Catalogus Librorum Bibliothecae Civicae Bernensis MDCIIIC. Bern: Burgerbibliothek Bern [Sign: Burgerbibliothek Bern, Cod. A 4].

Wilhelm, Friedrich. 1914/1916 [1960]. „II. Der ältere Phyiologus. III. Der jüngere Physiologus.“ Denkmäler deutscher Prosa des 11. und 12. Jahrhunderts (Abteilung A: Text). Münchener Texte 8:4-28 / „II. und III. Der ältere und der jüngere Physiologus“. Denkmäler deutscher Prosa des 11. und 12. Jahrhunderts ( $A b$ teilung B: Kommentar). Münchener Texte 8:13-52. München: Callwey [München: Huber].

Woodruff, Helen. 1930. „The Pysiologus of Bern: A Survival of Alexandrian Style in a Ninth Century Manuscript.“ The Art Bulletin 12,3:226-253. 


\section{Abbildungen}

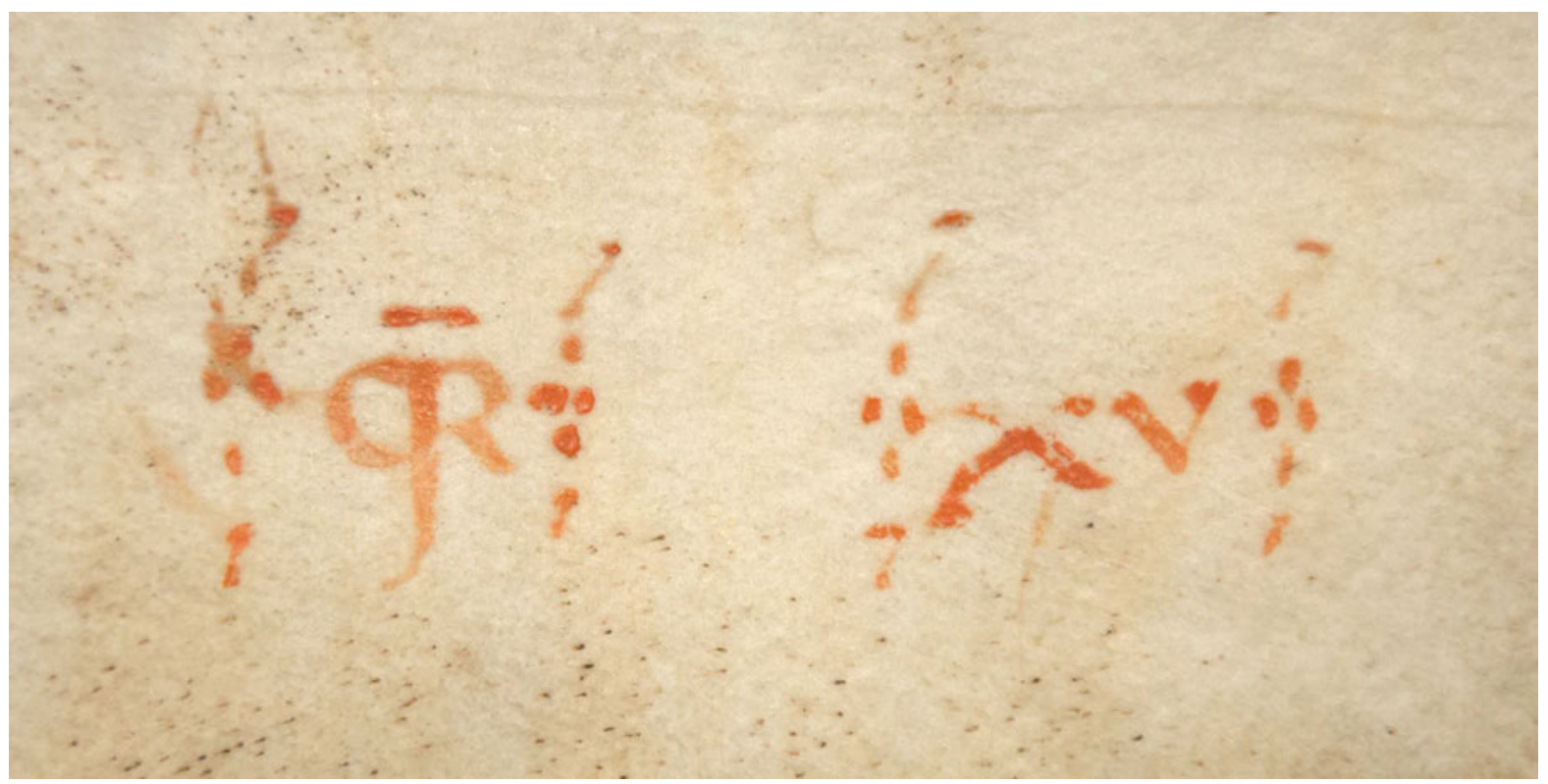

Abb. 1: Burgerbibliothek Bern, Cod. 225 (C), f. 95v.

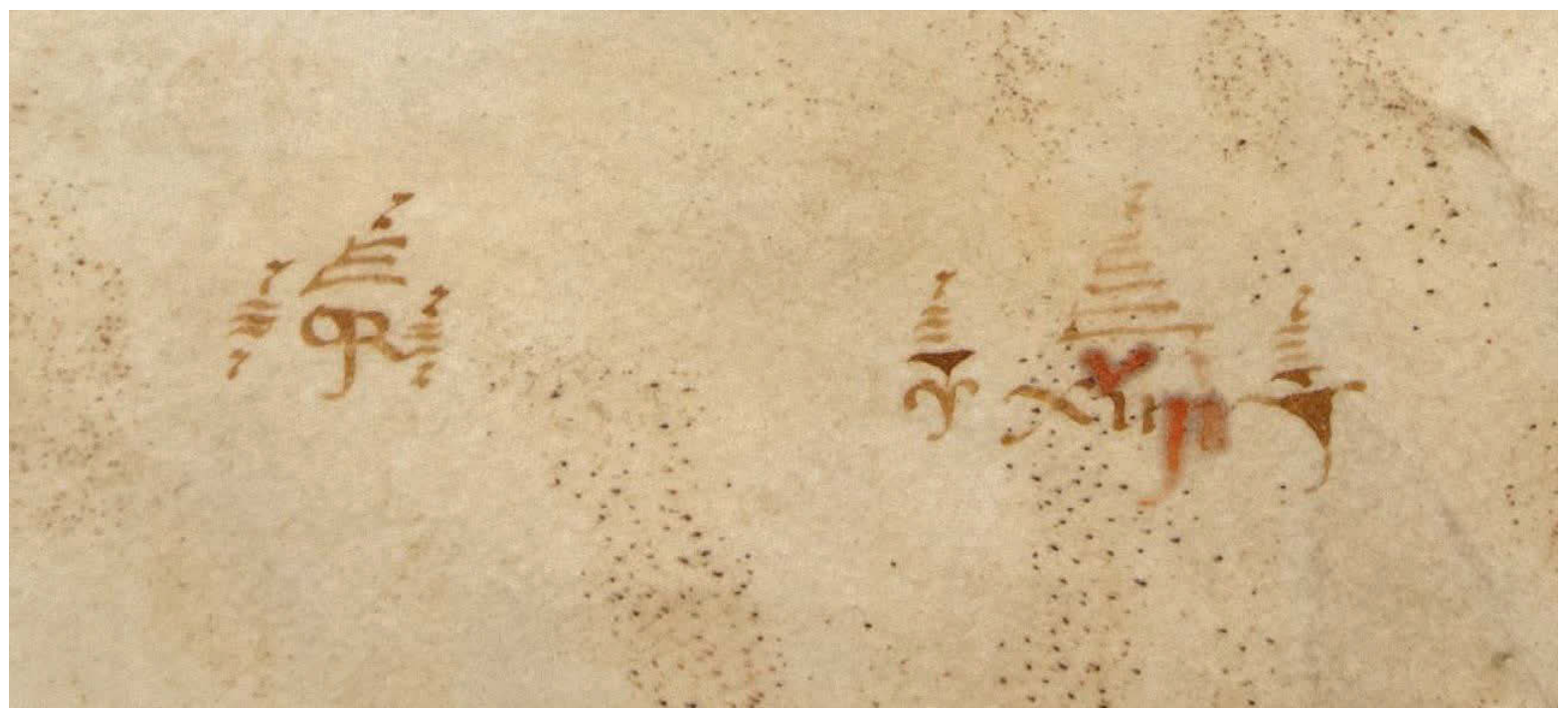

Abb. 2: Burgerbibliothek Bern, Cod. 233, f. 8v. 


\section{Anhang}

Tab. 1: Vergleich der Titel in Inhaltsverzeichnis und Text von Cod. 611 (Y) und Cod. 233 (B).

\begin{tabular}{|c|c|c|c|c|c|}
\hline $\begin{array}{l}\text { Carmody } \\
\text { Ed. } 1941\end{array}$ & Cod. 611: Capitula & Cod. 611: Tituli & $\begin{array}{l}\text { Carmody } \\
\text { Ed. } 1939\end{array}$ & Cod. 233: Capitula & Cod. 233: Tituli \\
\hline 1 & I. de leone & $\begin{array}{l}\text { (Incipit, aber ohne } \\
\text { Titel und Nr.) }\end{array}$ & 1 & $\begin{array}{l}\text { I. de natura leonis tres } \\
\text { dicit }\end{array}$ & $\begin{array}{l}\text { I. de natura leonis; } \\
\text { II. secunda natura leonis; } \\
\text { III. item tertia natura leonis }\end{array}$ \\
\hline 2 & II. de autolaps & II. de atolopos & 2 & II. de auta lops & IV. de auta lobs \\
\hline 3 & III. de lapide pyropoli & III. de lapide pyropoli & 3 & $\begin{array}{l}\text { III. de cerobolim lapides } \\
\text { igniferi }\end{array}$ & $\begin{array}{l}\text { V. de caerobolam lapides } \\
\text { igniferi }\end{array}$ \\
\hline 4 & IV. de serra & IV. (kein Titel) & 4 & IV. de serra in mare & VI. de serra in mare \\
\hline 5 & V. de caradrione & V. (kein Titel) & 5 & V. de caladrius & VII. de caladrius \\
\hline 6 & VI. de pellecano & VI. (kein Titel) & 6 & VI. de pellicano & VIII. de pellicano \\
\hline 7 & VII. de necticora & VII. (kein Titel) & 7 & VII. de nesticorace & VIIII. de neccticorace \\
\hline 8 & VIII. de aquila & VIII. (kein Titel) & 8 & VIII. de aquila & X. de aquila \\
\hline 9 & VIIII. de faenice & VIIII. (kein Titel) & 9 & VIIII. de fenex & XI. de volatilae fenix \\
\hline 10 & X. de oppope & X. de oppope & 10 & X. de uppupa & XII. de uppuba \\
\hline 11 & $\mathrm{XI}$. de onagro & $\mathrm{XI}$. de onagro & 11 & XI. de formice natura & $\begin{array}{l}\text { XIII. de formice natura; } \\
\text { XIIII. secunda eius natura; } \\
\text { XV. item tertia natura }\end{array}$ \\
\hline 12 & XII. de vipera & XII. (kein Titel) & 12 & $\begin{array}{l}\text { XII. de serenis et uno } \\
\text { centauris }\end{array}$ & $\begin{array}{l}\text { XVI. de serene et uno } \\
\text { centauris; } \\
\text { XVII. et uno centaurus } \\
\text { duabus naturas constare }\end{array}$ \\
\hline 13 & XIII. de serpente & XIII. de serpente & 13 & XIII. de herenacis & XVIII. de herenaciis \\
\hline 14 & XIIII. de formica & XIIII. de formica & 14 & XIIII. de hibes & $\begin{array}{l}\text { XVIIII. est volatile quod } \\
\text { dicitur hyciis }\end{array}$ \\
\hline 15 & $\begin{array}{l}X V \text {. de serine et } \\
\text { onocentauri }\end{array}$ & XV. (kein Titel) & 15 & XV. de vulpe & $\begin{array}{l}X X . \text { ergo fisiolocus de } \\
\text { vulpe dicit }\end{array}$ \\
\hline 16 & XVI. de herenatio & XVI. de herenatio & 16 & XVI. de monoceras & XXI. de monoceron \\
\hline 17 & & $\begin{array}{l}\text { (ab f. 126v, Z.6 lbis, } \\
\text { ohne Titel und Nr.) }\end{array}$ & & & \\
\hline 18 & XVII. de vulpe & $\begin{array}{l}\text { XVII. de vulpe } \\
\text { (Text von versio B) }\end{array}$ & 17 & XVII. de castur & XXII. de animal casto \\
\hline 35 & XVIII. de unicorni & $\begin{array}{l}\text { XVIII. de unicorni } \\
\text { (Text von versio B) }\end{array}$ & 18 & XVIII. de hiennaque bellua & XXIII. de hyena que belua \\
\hline 36 & XVIIII. de castur & $\begin{array}{l}\text { XVIIII. de castur (?) } \\
\text { (Text von versio B) }\end{array}$ & 19 & XVIIII. de hildris & XXIIII. de childris \\
\hline $25 b$ & $X X$. de simea & $\begin{array}{l}\text { XX. de simia } \\
\text { (Text von versio } B \text { ) }\end{array}$ & 20 & XX. de corcon & [?]XIII. de corcon \\
\hline 29 & XXI. de panthera & XXI. de panthera & $21 a$ & XXI. de onagro & $X X V$. de onagro \\
\hline 19 & XXII. de arbore perindex & XXII. de arbor perindex & 22 & XXII. de folica & XXVI. de folica \\
\hline 20 & XXIII. de elephante & XXIII. de elephante & 23 & XXIII. de pantera & XXVII. de pa[n]tera \\
\hline 21 & XXIIII. de dorcon sivi & XXIIII. de dorcon sive & 24 & XXIIII. de aspide calone & XXVIII. de aspedo calone \\
\hline
\end{tabular}


Tab. 1: (fortgesetzt)

\begin{tabular}{|c|c|c|c|c|c|}
\hline $\begin{array}{l}\text { Carmody } \\
\text { Ed. } 1941\end{array}$ & Cod. 611: Capitula & Cod. 611: Tituli & $\begin{array}{l}\text { Carmody } \\
\text { Ed. } 1939\end{array}$ & Cod. 233: Capitula & Cod. 233: Tituli \\
\hline 24 & XXV. de adamans & XXV. de adamans & 25 & XXV. de perdice & XXVIIII. de perdicae \\
\hline $25 a$ & XXVI. de honager & $\begin{array}{l}\text { XXVI. de honager } \\
\text { (Text von versio B) }\end{array}$ & 26 & XXVI. de mustella & $\begin{array}{l}\text { XXX. de mustela; } \\
\text { XXXI. de aspide }\end{array}$ \\
\hline 26 & XXVII. de sendytico & XXVII. de sendytico & 27 & XXVII. De asida structio & XXXII. De assida \\
\hline 27 & $\begin{array}{l}\text { XXVIII. de herudio sivi } \\
\text { folicae }\end{array}$ & $\begin{array}{l}\text { XXVIII. de herudio sivi } \\
\text { folicae }\end{array}$ & 28 & XXVIII. de turture & XXXIII. de turtura \\
\hline 22 & XXVIIII. de achatae (?) & XXVIIII. de achatae & 29 & XXVIII[I]. de cervo & $\begin{array}{l}\text { XXXV. [sc. XXXIIII.] de cervo } \\
\text { item in psalmo }\end{array}$ \\
\hline 23 & & $\begin{array}{l}\text { (ab f. } 134 \mathrm{v}, \text { Z.7 Sostros } \\
\text { lapis, ohne Titel und Nr.) }\end{array}$ & & & \\
\hline 30 & XXX. de coeto magno & XXX. de coeto magno & 30 & $\begin{array}{l}\text { XXVIIII. [sc. XXX.] de } \\
\text { salamandra }\end{array}$ & $\begin{array}{l}\text { XXXVI. [sc. XXXV.] de } \\
\text { salamandra }\end{array}$ \\
\hline 31 & XXXI. de perdice & XXXI. de perdice & $21 b$ & $X X$. de simia & XXXVII. [sc. XXXVI.] de simia \\
\hline 32 & $\begin{array}{l}\text { XXXII. de vultor i[d] e[s]t } \\
\text { ambrone }\end{array}$ & $\begin{array}{l}\text { XXXII. de vultor id est } \\
\text { ambrone (?) }\end{array}$ & fehlt & $\begin{array}{l}\text { XXI. de carnium usu vel } \\
\text { piscium }\end{array}$ & (Text nicht vorhanden) \\
\hline 34 & XXXIII. de mustella & XXXIII. de mustella & & & \\
\hline 38 & XXXIIII. de sullo & XXXIIII. de sullo & & & \\
\hline 39 & XXXV. de chineomone & $X X X V$. de chineomone & & & \\
\hline 41 & XXXVI. de turture & XXXVI. de turture & & & \\
\hline 42 & XXXVII. de herundene & XXXVII. de herundene & & & \\
\hline 43 & XXXVIII. de cervo & XXXVIII. de cervo & & & \\
\hline 46 & $\begin{array}{l}\text { XXXXVIIII. de lapide ma- } \\
\text { gnite }\end{array}$ & $\begin{array}{l}\text { XXXXVIIII. de lapide ma- } \\
\text { gnite (Titel am Schluss) }\end{array}$ & & & \\
\hline 47 & $\begin{array}{l}\text { XXXX. de lapide adaman- } \\
\text { tino }\end{array}$ & $\begin{array}{l}\text { XXXX. de lapide adaman- } \\
\text { tino (Titel am Schluss) }\end{array}$ & & & \\
\hline 49 & [Saura Eliace] & (ohne Titel und Nr.) & & & \\
\hline
\end{tabular}




\section{Christoph Eggenberger Der Physiologus Bernensis}

\author{
Bild und Text
}

\begin{abstract}
The illustrated Latin manuscript fragment in Codex 318 of the Burgerbibliothek Bern which contains parts of the Physiologus was written and illustrated around 830 in the monastery Hautvillers near Reims. The true meaning of an illuminated manuscript can be revealed only when the texts are complemented by the parallel stories told by the images. The images are never mere illustrations. In the case of the two outstanding Carolingian manuscripts in Bern, the Physiologus (Codex 318) and the Prudentius (Codex 264), the images allow us to determine which late antique originals were used as models. As for the Prudentius, it may be assumed that the model is the first edition of the Prudentius (Rome, before approx. 405 AD). If the Physiologus genuinely did originate in the $2^{\text {nd }}$ century in Alexandria, there are hardly any possibilities for comparison. The Cotton Genesis of the British Library, probably written and illustrated in Alexandria or Antinoe, is in ruins. Because they were executed in another medium and reflect stylistic changes caused by the passage of time, the mosaics in the vestibule of San Marco in Venice, which were copied from the Cotton Genesis, have only limited relevance as a reference, primarily from an iconographic standpoint. The framed images in the Bern Physiologus are indebted to the $5^{\text {th }}$-century tradition of the studio of Santa Maria Maggiore in Rome, with the Vergilius Vaticanus (Vat. lat. 3225). The unframed images, which are arranged without frames between the lines, reflect the earlier iconographic customs of pictures in book rolls. The book illustrators always followed copies of the original. The illustrations of the Physiologus are undisputedly assigned to the Reims school around Archbishop Ebo (born probably 778; died 20 March 851).
\end{abstract}

\section{Einleitung}

Wir haben das Glück uns beim Codex 318 der Berner Burgerbibliothek auf die feinsinnigen Arbeiten von Otto Homburger (1962 und 1964) und danach 1994 von Florentine Mütherich stützen zu können. ${ }^{1}$ Nach den Vorarbeiten von Helen Woodruff und Dimitri Tselos von 1930 und 1956 sowie 1947 von Kurt Weitzmann präsentiert sich die For-

1 Homburger (1962, 1964); Mütherich (1994). schungsgeschichte des Physiologus Bernensis gleichsam als Paradebeispiel der Erforschung der Anfänge der Buchmalerei in Antike und Mittelalter. ${ }^{2}$ In einer Bilderhandschrift erschliesst sich der ganze Inhalt erst, wenn man die Texte von den Parallelgeschichten begleiten lässt, die die Bilder erzählen. Das Bild ist nie nur blosse Illustration.

Im Fall der beiden herausragenden karolingischen Handschriften in Bern, des Physiologus (Codex 318) und des Prudentius (Codex 264), lassen die Bilder zumindest teilweise eine Bestimmung der benutzten spätantiken Vorlagen zu. ${ }^{3}$ Beim Prudentius darf man annehmen, dass das Vorbild auf die illustrierte Erstausgabe des Prudentius (vor ca. 405 n. Chr.) zurückgeht. ${ }^{4}$ Wenn der Physiologus wirklich im 2. Jahrhundert in Alexandria entstanden ist, können wir versuchen, den Bernensis im Zusammenhang mit der Cotton Genesis zu sehen; doch wir bewegen uns auf dünnem Eis, die Cotton Genesis der British Library, Cotton Otho B 4, ist eine Ruine; die indirekt von ihr inspirierten Mosaiken in der Vorhalle von San Marco in Venedig sind durch das andere Medium und die zeitbedingten, stilistischen Veränderungen nur bedingt, höchstens in ikonographischer Hinsicht beizuziehen. Die gerahmten Bilder des Physiologus Bernensis sind der Tradition des 5. Jahrhunderts der Werkstatt von Santa Maria Maggiore in Rom mit dem Vergilius Vaticanus (Vat. lat. 3225) verpflichtet. ${ }^{5}$ Die ungerahmten Bilder im Physiologus dagegen, die ohne Rahmen zwischen den Zeilen angeordnet sind, lassen die früheren Gewohnheiten der Bilder in den Buchrollen aufscheinen. Kurt Weitzmann wies in seiner Pionierarbeit Illustrations in Roll and Codex von 1947 gar daraufhin, dass das Layout von Folio 12 verso der Berner Handschrift auf Usanzen der ägyptischen Papyri zurückgeht. Die Buchmaler orientierten sich an Kopien, was Rückschlüsse auf das Original nicht ganz ausschliesst, aber erschwert, und hier zumindest den Widerspruch Alexandria-Rom aufzulösen vermag.

2 Woodruff (1930); Tselos (1956); Weitzmann (1947, 71, 99 und passim).

3 Chazelle (1997, 1055-1058). Chazelle fragt neben der Abhängigkeit der karolingischen von den spätantiken Werken nach deren Eigenständigkeit.

4 Beer (1980); Eggenberger (1986, 2013).

5 Wright (1993). 
Die Berner Handschrift und die Bilder des Physiologus werden unbestritten der Reimser Schule rund um Erzbischof Ebo zugeordnet. ${ }^{6}$ Anknüpfend an die künstlerischen Errungenschaften des Aachener Domschatzes und des Wiener Krönungsevangeliars als Spitzenwerke der Hofkunst startete die Malschule unter den Erzbischöfen Ebo (816-845) und Hinkmar (845-882) zu Höhenflügen mit dem Ebo-Evangeliar in der Bibliothèque Municipale von Epernay und dem nach dem Aufbewahungsort genannten Utrecht Psalter. Dazu gehört auch der Berner Physiologus. Er ist vielleicht bloss deshalb nicht als gleichwertig mit den beiden Handschriften empfunden worden, da es sich um ein Fragment handelt, das in der Sammelhandschift Codex Bernensis 318 eingebunden ist. ${ }^{7}$

Die Könnerschaft in der Darstellung der Tiere war im Reimser Atelier gegeben, wie die mit Tieren geschmückten Kanontafeln der Evangeliare in Épernay (Ms. 1), Reims (Ms. 7), Paris (ms. lat. 17968) und in der Pierpont Morgan Library, New York (M. 728), zeigen. Das eine hat sicherlich mit dem anderen zu tun, die auffallenden Tierdarstellungen in den Evangeliaren sind von denjenigen im Physiologus beeinflusst. Ohne dies belegen zu können, es sei denn mit der klaren Evidenz der Bilder, muss man es anders ausdrücken. Die Tierbilder gehen auf die Kopien der spätantiken Originale zurück, die den Malern in Reims vorlagen. ${ }^{8}$

\section{Bild und Text}

Das Bild auf Folio 7r ist im heutigen Zustand der Handschrift das eigentliche Titelbild, es veranschaulicht das Wesen der karolingischen Renaissance; alle Ingredienzen sind schulbeispielhaft auf dieser Seite vereint, begonnen mit dem ausgewogenen, harmonischen Layout, das von grösster Qualität zeugt, und mit dem so typischen Rahmen. Der breite rote Rahmen erhält gegen das Bild hin eine luftig aufgetragene weisse Lasur wie ein Lichtstreifen, der überführt zum schwarzen, schmalen Streifen; er verbindet den Rahmen mit dem Bild, die Konturierung des Horizonts der Hügelkette fliesst nahtlos aus dem Rahmenband heraus. Umso auffallender wirkt der geschwungene Schwanz des Löwen, der sich über den Rahmen schlängelt und dem Bild eine eigene Lebhaftigkeit verleiht, so wie auch der Löwe die Tatze zu Jakob hin hebt als Antwort auf dessen

\footnotetext{
6 Siehe dazu aber Chazelle (1997, 1055-1077). Chazelle tendiert dazu, den Utrecht Psalter in die Zeit Hinkmars zu datieren, was auch den Codex Bernensis 318 betreffen kann.

7 Mütherich (1994, 172-182).

8 Koehler und Mütherich (1994); Mütherich (1976).
}

Segensgestus. Mit vifen Augen erwidert er den stechenden, seherischen Blick Jakobs. Seine aufgerissenen Augen sind stiltypisch für die Reimser Malschule, ebenso wie die inneren Emotionen, die sich auf die quirlige Malweise des Gewandes zu übertragen scheinen.

Das Bild wirkt zum einen harmonisch, ganz im Sinne der pompejanischen Malerei, auf der anderen Seite nervös und von einer Spannung erfüllt. Diese ist nicht römisch, dies ist das neue, das karolingische Element. Ein weiteres Stilelement, das erst die Malerei des 17. Jahrhunderts zu einem Stilmittel erhoben hat, überrascht: die leere Mitte; als ob der Maler dies realisierte und dem horror vacui folgte, liess er zwischen Jakob und Löwe einen Strauch emporwachsen. Die leere Mitte war eine Erfindung des 1600 in Lothringen geborenen und 1682 in Rom verstorbenen Landschaftsmalers Claude Lorrain. Sie wird hier mit Sinn aufgeladen, entsprechend dem Text, der die Tiere biblischexegetisch und auf die Heilsgeschichte bezogen sieht. Die Kraft des Segens, anschaulich gemacht im überproportional ausgestreckten Arm, und des seherischen Blickes von Jakob und die Gestik und das wache Auge des Löwen Juda kulminieren in der dunklen, leeren Mitte. Die leere Mitte bei Claude Lorrain ist meist hell und licht, hier kündet sich das Licht in der Morgenröte über den Bergen und in der hellgrünen Wiese darunter erst an. Die Landschaftsdarstellung verweist auf die intermediäre Kopie des Originals, auf die Zeit- und Stilstufe einer Quedlinburger Itala, der Malereien in Santa Maria Antiqua auf dem Forum in Rom oder die Josua-Rolle bzw. deren Vorbild. ${ }^{9}$

Homburger weist auf die Bemerkung des Berner Privatgelehrten G. Loumyer hin, der 1912 in den Blättern für bernische Geschichte vorschlug, Jakob stehe in diesem Bild stellvertretend für Gottvater, ,der seinen Sohn, den Löwen aus dem Stamme Juda, segnet“. ${ }^{10}$ Den Physiologus als Ausweitung der Heilsgeschichte bis hin zur Schöpfung mit allen Lebewesen zu verstehen, wird in der Literatur erörtert. ${ }^{11}$ Der transparente Nimbus wirft Fragen auf; es ist kein Kreuznimbus, der Träger also nicht Christus-Logos, so wie der Schöpfer in der Cotton Genesis auftritt. ${ }^{12}$ Auf der anderen Seite haftet dem transparenten Nimbus etwas Geheimnisvolles und Überirdisches an; und auf Christus oder Christus-Logos verweist die Schriftrolle in der verhüllten linken Hand; dazu kommt der Zusammenhang mit der Arche Noah in der Genesis.

Der raffinierten Lichtregie entspricht die feine Skalierung der Emotionen; das Aufgeregte, leicht Überdrehte

\footnotetext{
9 Siehe auch den Vergilius Vaticanus, Wright (1993).

10 Homburger (1962, 103, Anm. 1).

11 Alpers (1996).

12 Weitzmann und Kessler (1986).
} 
oben wird unten abgelöst von einer genrehaften Idylle mit den äsenden Tierpaaren auf der grünen Wiese inmitten einzelner Sträucher. Die drei Paare erscheinen so, als würden sie aus der Arche Noah kommen; die Dreiheit ist kaum Zufall. Die bereits erwähnte Cotton Genesis ist im 4. Jahrhundert in Alexandria entstanden; Herbert Kessler denkt heute eher an Antinoë. Sie hat indirekt ausgestrahlt bis zu den Mosaiken des Atriums der Basilica San Marco in Venedig. Im Mosaikfeld, wo Noah die Tiere in die Arche bringt, findet sich eine ziemlich klare Übereinstimmung bei dem einen Löwen mit erhobener Tatze, den beiden Kühen und den Bären; die Hirsche fehlen (ich sage „ziemlich“, immerhin haben wir es ja auch mit einem anderen Medium zu tun). ${ }^{13}$ Kessler korrigierte 2014 seine Meinung, das Original der Cotton Genesis hätte in Venedig als Vorbild gedient, und nimmt an, es habe einen „Doppelgänger“ im Westen gegeben, sicher ab dem 9., wohl aber bereits im 4./5. Jahrhundert - dies mit Blick auf die Wandmalereien in Alt St. Peter und San Paolo fuori le mura in Rom. ${ }^{14}$ Ins 4. Jahrhundert datiert K. Alpers auch die lateinische Übersetzung des Physiologus, da sich Ambrosius bereits darauf bezieht. Janet Spittler hat an der Tagung das 3./4. Jahrhundert für den lateinischen Physiologus nicht ausgeschlossen. ${ }^{15}$ Die Tierpaare und die Parallele zur Arche Noah bedeutet eine Bildaussage, die gegenüber dem in der Diskussion geäusserten Vorschlag stärker zu gewichten ist. Herwig Görgemanns brachte in der Diskussion an der Tagung, auf die der vorliegende Band zurückgeht, die Paulusakten ins Spiel und sieht oben Paulus und den Löwen. ${ }^{16}$

Exkurs: Paulus taufte den Löwen, dieser erkennt ihn in der Gefangenschaft und verschont ihn. Einen Vorteil hat diese interessante Interpretation, sie löst das Problem, in der segnenden Figur Gottvater bzw. Christus Logos zu sehen, zumal der Kreuznimbus fehlt. Auf der anderen Seite, weshalb tritt Paulus in diesem Zusammenhang auf, macht es Sinn, Paulus dem „leo regalis“ gegenüberzustellen? ${ }^{17}$

Die Darstellung der Gruppe als Jakob bzw. Christus Logos mit dem Löwen liegt näher, da dies im ersten Kapitel des Physiologus betont wird: „So auch mein Heiland, von dem gesagt ist: Siehe es hat überwunden der Löwe, der da ist vom Geschlecht Juda, die Wurzel Davids [Offb 5,5]:

13 Büchsel, Kessler und Müller (2014, 191, Tf. 28). Für die Ausführun gen in Herbert Kesslers E-Mail vom 10.7.2016 danke ich herzlich.

14 Kessler (2014a, 11).

15 Siehe den Beitrag von Janet Spittler in diesem Band. Zur Frage der Datierung siehe auch die Beiträge von Horst Schneider und Samuel Vollenweider.

16 Siehe den Beitrag von H. Görgenanns in diesem Band.

17 P. Heid. Inv. Kopt. $300+301$, 4. Jh. Schmidt $(1904 / 21905)$; Plümacher (2003). entsandt vom ewigen Vater, verhüllte er die Fährte seines Weges im Geiste, nämlich seine Gottheit.“18 Diese Beobachtungen müssen sich über den Bildrand hinaus erstrecken; wie als eine Bildlegende stehen unter dem Bild in majestätischer, rubrizierter Capitalis Rustica die ersten Worte des Textes: „EST LEO REGALIS OM / nium animalium \& bestiarium....". Die Capitalis rustica ist die Schrift, die sich auch im Vergilius Romanus, Vat. lat.3867, findet; die intermediäre Kopie zwischen dem alexandrinischen Original und dem Bernensis dürfte in Rom um 500 n. Chr. entstanden sein. Die Textpassage geht auf die Genesis zurück (49,8-12) und kehrt wieder in der Apokalypse (5,5): Der Spross aus der Wurzel Davids, Christus, kann die sieben Siegel des Buches lösen. Es fällt zudem auf, dass die drei Buchstaben „R E G“ genau der Breite der leeren Mitte oben entsprechen, ein frühes Beispiel für das ikonographisch relevante Schriftbild. ${ }^{19}$ Somit haben der Auftraggeber, der concepteur, der Maler und der Rubricator am gleichen Strick gezogen, was eine abweichende Deutung der Bildaussage auschliesst.

Erst im zweiten Bild zur ersten Eigenart des Löwen (7v) sind die weissen Lasurlinien in den Rahmenecken zu sehen; sie geben dem Rahmen Volumen und Tiefe. Sie hätten auf dem Titelbild gestört, dort wird die Räumlichkeit durch den Schwanz des Löwen über dem Rahmen negiert. Wieder hebt der Löwe die Tatze, mit dem Schwanz verwischt er gemäss dem Text seine Spuren, wie Christus in seiner Inkarnation die Gottheit, verbarg: „Und das Wort ward Fleisch und wohnte unter uns" (Joh 1,14). ${ }^{20}$ Es ist ein Nachtbild wie auch dasjenige auf f.10r mit den Nachtraben, den „nocticoraces“. ${ }^{21}$ Nachtbilder in dieser frühen Zeit der Buchmalerei zu sehen, überrascht; erst im 15. Jahrhundert werden sie geläufig. ${ }^{22}$

Die zweite und dritte Eigenart (8r) des Löwen finden auf einer Seite Platz, direkt zum Text gestellt; ein roter Unzialtitel wird nicht wiederholt, die erste Zeile des laufenden Textes unter den Bildern dient als Legende. Der Löwe rechts im unteren Bild nimmt die gleiche Stellung ein wie im Titelbild f. 7r; es symbolisiert die Auferstehung, das totgeborene Junge wird am dritten Tag vom Vater zum Leben erweckt. Das obere Bild des Löwen in der Höhle findet eine enge Parallele im Utrecht Psalter auf f. 8v zu Psalm $16^{\mathrm{Vg}}$ (17) und, Homburger weist darauf hin, im Vergilius Vatica-

$\overline{18 \text { Seel }}\left({ }^{3} 2005,5\right)$.

19 Siehe für das 13. Jahrhundert Wolter-von dem Knesebeck (2007). 20 Seel ( $\left.{ }^{3} 2005,6\right)$.

21 Steiger (1964, 65, Anm. 1): „Luther übersetzt (Psalm 102,7) ,Käuzchen', die Zürcher Bibel ,Eule““.

22 Preiswerk (2014). 
nus (f. 9 r). ${ }^{23}$ Wenn wir Jakob im Titelbild auf f. 7 r Christus gleichsetzen, dann ist hier die Parallele zur Auferstehung Christi klar gegeben. Die Abfolge von vier Bildern zum Löwen unterstreicht bildlich die überragende Position, die der Physiologus ihm als dem König der Tiere zuweist.

Das obere Bild auf 8v zur Sonneneidechse zeigt Unstimmigkeiten bei der Planung des Manuskriptes; die letzte Zeile musste der Schreiber am rechten Rand des oberen Bildes weiter schreiben. Nur am Rande bemerkt, das untere Bild zum Goldregenpfeifer mit der das Augenlicht wieder erlangenden, lagernden Frau erinnert an den trunkenen Noah in der Wiener Genesis; im Titelbild sahen wir Bildparallelen zu den Noah-Mosaiken in Venedig. Bild und Text werden im Bernensis besonders hervorgehoben, indem auf 9r nicht nur der rubrizierte Titel, sondern auch die erste Zeile mit brauner Tinte in Capitalis rustica geschrieben ist. Auf 11v erscheint das erste Bild zwischen den Zeilen und ohne Rahmen, wie es der Tradition der illustrierten Buchrolle entspricht. Wie spielerisch die concepteurs vorgegangen sind, zeigt gleich das nächste Bild auf 12r; es ist wieder ein gerahmtes Bild, das ganz schmal und auch zwischen den Zeilen platziert ist. Unmittelbar schliesst auf der Versoseite die vierte Natur der Schlange an, kombiniert mit der ersten, weiter unten der zweiten Natur der Ameise.

Die grandiose Seite 12v veranschaulicht die kontinuierliche Malerei, wie sie für die antiken Buchrollen charakteristisch ist und an den römischen Triumphsäulen weitergeführt wurde. ${ }^{24}$ Man muss sich fragen, wie dieser Vorgang zu erklären ist. Der Maler wechselt fliessend von der römischen Tradition mit den gerahmten Bildern zur interlinearen Illustration; die Figur, die die Schlange angreift, ragt wie eine Initiale in den Textblock. Dies alles spiegelt nicht Reimser Malpraxis wider, sondern geht zurück auf die alexandrinische Vorlage. In Reims müssen also sowohl die spätantiken Vorlagen vorhanden gewesen sein, die wohl um 500 in Rom entstanden sind, wie auch solche, die auf die antike Tradition der Bilderbuchrollen zurückgehen; vielleicht waren dies einzelne Fragmente. Bewusst betonten Auftraggeber, concepteur und Maler im Sinne der karolingischen Renaissance, den antiken Charakter des Physiologus als altehrwürdiges Standardwerk.

Folia 11r und 13v zu den Vipern sowie den Sirenen und Kentauren präsentieren sich als antike Bilder, und dazu noch als klassische Dialogbilder; der äusserst lebendige Dialog der Mischwesen überrascht, die Vitalität der Figuren und Tiere taucht auch im Reimser Ebo-Evangeliar auf. Die antiken Vorbilder haben die Reimser Malschule stark

23 Homburger (1964, 33).

24 Weitzmann (1947). Siehe auch Schefold (1939). geprägt. Auch das Bild mit dem Einhorn und der verschleierten Frauenfigur auf 16v ist ein Dialogbild; es betont die Mariensymbolik; nur wenn das Einhorn in den Schoss einer Jungfrau Zuflucht findet, kann es gefangen werden. Die Fehlstelle im Bild verunklärt die Gestik der Frau, doch das Einhorn hebt die linke Vorderpfote wie der Löwe im Titelbild; das Einhorn spricht zur Frau, was nahe legt, es sei wie im Physiologus von Smyrna auf die Verkündigung an Maria angespielt. Maria scheint das Einhorn an der Schnauze zu fassen oder etwas von ihm entgegenzunehmen. ${ }^{25}$ In Alexandria weist der Elias-Behang der Abegg Stiftung in Riggisberg in eine andere Richtung; dort wird das Einhorn zum Symbol des Kreuzestodes Christi. ${ }^{26}$

Die Bilder auf f.17v und 18r sind wieder ungerahmt zwischen die Zeilen gemalt, während der Elefant auf 19r und 19v eine besondere Behandlung erfährt, auf 19v gar mit einem quer gestellten Bild, damit dem Maler genügend Breite zur Verfügung stand für die Ausbreitung der mächtigen Tiere. Auf 19r schaut der Elefant mit neugierigem, fast möchte man meinen mit einem humorvollen Blick den Betrachter an; wieder fällt die frische Lebendigkeit auf. Ausserhalb des Physiologus-Textes kehren auf 21r die interlinearen Bilder zurück, unten bezugnehmend auf den Titel „De galli cantu“ (21v) aus dem Hexaemeron des Ambrosius. ${ }^{27}$ Der Hahnenschrei verweist im heilsgeschichtlichen Kontext auf Petri Leugnung; zwei Hähne schauen nach rechts, der dritte zurück nach links gemäss den drei Hahnenrufen in Mt 26,34; erwähnt sei zudem der erste Hahnenschrei auf Seite 4 im Berner Prudentius zur Illustration des Morgenhymnus. ${ }^{28}$ Der Vergleich mit Prudentius, diesmal mit dem antiken Triumphmotiv der reitenden Superbia, hilft das Schlussbild im Physiologus Bernensis, den Pferdereiter auf 22r erklären. Das Bild bezieht sich direkt auf den Text auf 22v nach Isidor, Etymologiae 12.1, auf das Pferd als treuen Begleiter des Menschen; ein rubrizierter Titulus, wie sonst $\mathrm{zu}$ fast allen Bildern, fehlt. Der Bildtypus geht zurück auf die Ikonographie der römischen Triumphbögen und -säulen. ${ }^{29}$

25 Im Physiologus von Smyrna wird die erste Eigenart des Löwen mit der Verkündigung in Parallele gesetzt. Demus (1976, 237, 239); Bernabò (1998, 75-77, 109).

26 Schrenk (1993).

27 Hexaemeron 5.24.88-89; PL 14:255; CSEL 32,1:201-202 (Mittenhuber 2012).

28 Eggenberger (2013).

29 Etymologiae 12,1,42-43 (Lindsay 1911); PL 82:430 (Mittenhuber 2012). 


\section{Fazit}

Die älteste erhaltene Bilderhandschrift des Physiologus, Codex Bernensis 318, enthält einen eindrücklichen Bilderzyklus. Er ist um $830 \mathrm{im}$ Kloster Hautvillers bei Reims entstanden, einem Zentrum der karolingischen Buchkunst. Im Skriptorium des Klosters arbeiteten die besten Schreiber und Maler, die in der Klosterbibliothek über gute spätantike Vorlagen verfügten. Im Sinn der karolingischen Renaissance konnten sie die antike Malerei neu beleben, gleichzeitig waren sie eigenwillige Künstler, die einen eigenen Stil entwickelten. Der quirlige, fast expressionistische Malstil ist ihr Markenzeichen, der auch im Utrecht Psalter zum Tragen kommt. Die Bilder des Physiologus Bernensis sind darüber hinaus geprägt von dem alexandrinischen Original wie von den in Reims zur Verfügung stehenden römischen Kopien des 5. und 6. Jahrhunderts. Das Resultat ist ein Bilderzyklus von einer subtilen Farbgebung und einer packenden Dynamik, was sich vor allem in den Löwen- (f. 7r-8r), den Schlangenbildern (f. 12v-13r) und im Schlussbild (f. 22r) zeigt. Es ist ein Meisterwerk der mittelalterlichen Buchkunst.

\section{Bibliographie}

Alpers, Klaus. 1996. „Physiologus.“ TRE 36:596-602.

Beer, Ellen J. 1980. „Überlegungen zu Stil und Herkunft des Berner Prudentius-Codex 264.“ In Florilegium Sangallense: Festschrift für Johannes Duft zum 65. Geburtstag, hrsg. v. Otto P. Clavadetscher, Helmut Maurer und Stefan Sonderegge, 15-70. St. Gallen: Verlag Ostschweiz; Sigmaringen: J. Thorbecke.

Bernabò, Massimo. 1998. Il Fisiologo di Smirne: Le miniature del perduto codice B. 8 delle Biblioteca della Scuola Evangelica di Smirne; con la collaborazione di Glenn Peers e Rita Tarasconi. Florenz: Sismel.

Büchsel, Martin, Herbert L. Kessler und Rebecca Müller, Hgg. 2014. The Atrium of San Marco in Venice: The Genesis and Medieval Reality of the Genesis Mosaics. Neue Frankfurter Forschungen zur Kunst 15. Berlin: Gebr. Mann Verlag.

Chazelle, Celia. 1997. „Archbishops Ebo and Hincmar of Reims and the Utrecht Psalter.“ Speculum 72,4:1055-1077.

Demus, Otto. 1976. „Bemerkungen zum Physiologus von Smyrna.” Jahrbuch der Österreichischen Byzantinistik 25:235-257.

Eggenberger, Christoph. 1986. „Zur Farbe im Berner Prudentius. Ein Versuch im Gedenken an Heinz Roosen-Runge." In «Nobile claret opus»: Festgabe für Ellen Judith Beer zum 60.Geburtstag, hrsg. v. Liselotte E. Stamm, Rolf Hasler und Ernst Böhlen, 3-8. Zeitschrift für schweizerische Archäologie und Kunstgeschichte 43. Zürich: Karl Schwegler.

Eggenberger, Christoph et al. Hgg. 2013. Bern, Burgerbibliothek, Cod. 264: Prudentius, Carmina. Homburger (1962, 136-158), redigiert und ergänzt von Christoph Eggenberger, Florian Mittenhuber, unter Mitarbeit von Petra Hanschle und Sabine Utz,
Juli 2013, http://www.e-codices.unifr.ch/de/list/one/bbb/ 0264.

Homburger, Otto. Hg. 1962. Die illustrierten Handschriften der Burgerbibliothek Bern: Die vorkarolingischen und karolingischen Handschriften. Bern: Burgerbibliothek Bern.

Homburger, Otto, Hg. 1964. Siehe Steiger und Homburger 1964.

Kessler, Herbert L. 2014a. „Introduction.“ In Büchsel, Kessler und Müller 2014, 9-18.

Kessler, Herbert L. 2014b. „Thirteenth-Century Venetian Revisions of the Cotton Genesis Cycle.“ In Büchsel, Kessler und Müller 2014, 75-94.

Koehler, Wilhelm, und Florentine Mütherich. 1994. Die Karolingischen Miniaturen. Bd. VI,1, Die Schule von Reims: Von den Anfängen bis zur Mitte des 9. Jahrhunderts, 172-182. Berlin: Deutscher Verein für Kunstwissenschaft.

Lauchert, Friedrich, Hg. 1889 [1974]. Geschichte des Physiologus. Strassburg: Karl J. Trübner [Genève: Slatkine].

Lindsay, Wallace Martin. 1911. Isidori Hispalensis episcopi Etymologiarum sive originum libri XX. Oxford: Oxford University Press.

Mittenhuber, Florian, Hg. 2012. Siehe Steiger und Homburger 1964. Mütherich, Florentine, und Joachim E. Gaehde. 1976. Karolingische Buchmalerei. München: Prestel.

Mütherich, Florentine. 1994. Siehe Koehler und Mütherich 1994.

Plümacher, Eckhard. 2003. „Paulusakten.“ RGG4 6:1069-1970.

Preiswerk, Bettina. 2014. Absentia Lucis: Semantisierung der Verhüllung in spätmittelalterlichen Nachtdarstellungen der Buchmalerei. Dissertation 2013. Zürich: Universität Zürich.

Schefold, Karl. 1939. „Altchristliche Bilderzyklen: Bassussarkophag und Santa Maria Maggiore. "Rivista di Archeologia Cristiana 16:289-316.

Schmidt, Carl, Hg. 1904/21905 [1965]. Acta Pauli aus der Heidelberger koptischen Papyrushandschrift Nr. 1: Übersetzung, Untersuchungen und koptischer Text / Acta Pauli: Übersetzung, Untersuchungen und koptischer Text; zweite erweiterte Ausgabe ohne Tafeln. Leipzig: J.C. Hinrichs [Hildesheim: Olms].

Schneider, Horst. 2016. „Physiologus.“ RAC 27:722-743.

Schrenk, Sabine. 1993. „Der Elias-Behang in der Abegg-Stiftung.“ In Begegnung von Heidentum und Christentum im spätantiken Ägypten. Riggisberger Berichte 1, 167-181. Riggisberg: AbeggStiftung.

Seel, Otto. (1960) ${ }^{3}$ 2005. Der Physiologus: Tiere und ihre Symbolik. (Zürich: Artemis \& Winkler) Düsseldorf: Patmos.

Steiger, Christoph von, und Otto Homburger, Hgg. 1964/2012. Physiologus Bernensis: Voll-Faksimile-Ausgabe des Codex Bongarsianus 318 der Burgerbibliothek Bern, Basel: Alkuin. / Bern, Burgerbibliothek, Cod. 318: Physiologus Bernensis, redigiert und ergänzt von Florian Mittenhuber, Juni 2012, http://www.e-codices.unifr.ch/de/list/one/bbb/0318.

Tselos, Dimitri. 1956. „A Greco-Italian School of Illuminators and Fresco Painters: Its Relation to the Principal Reims Manuscripts and to the Greek Frescoes in Rome and Castelseprio." The Art Bulletin 38,1:1-30.

Weitzmann, Kurt. (1947) ${ }^{2}$ 1970. Illustrations in Roll and Codex: $A$ Study of the Origin and Method of Text Illustration. Studies in Manuscript Illumination 2. Princeton, NJ: Princeton University Press.

Weitzmann, Kurt, und Herbert L. Kessler. 1986. The Cotton Genesis: British Library Codex Cotton Otho B. VI. The Illustrations in the Manuscripts of the Septuagint 1. Princeton, NJ: Princeton University Press. 
Wolter-von dem Knesebeck, Harald. 2007. Das Mainzer Evangeliar: Strahlende Bilder - Worte in Gold. Regensburg: Schnell \& Steiner.

Woodruff, Helen. 1930. „The Pysiologus of Bern: A Survival of Alexandrian Style in a Ninth Century Manuscript.“ The Art Bulletin $12,3: 226-253$.
Wright, David H. 1993. Der Vergilius Vaticanus: Ein Meisterwerk spätantiker Kunst. Graz: Adeva. 
Faksimile des Physiologus Bernensis 



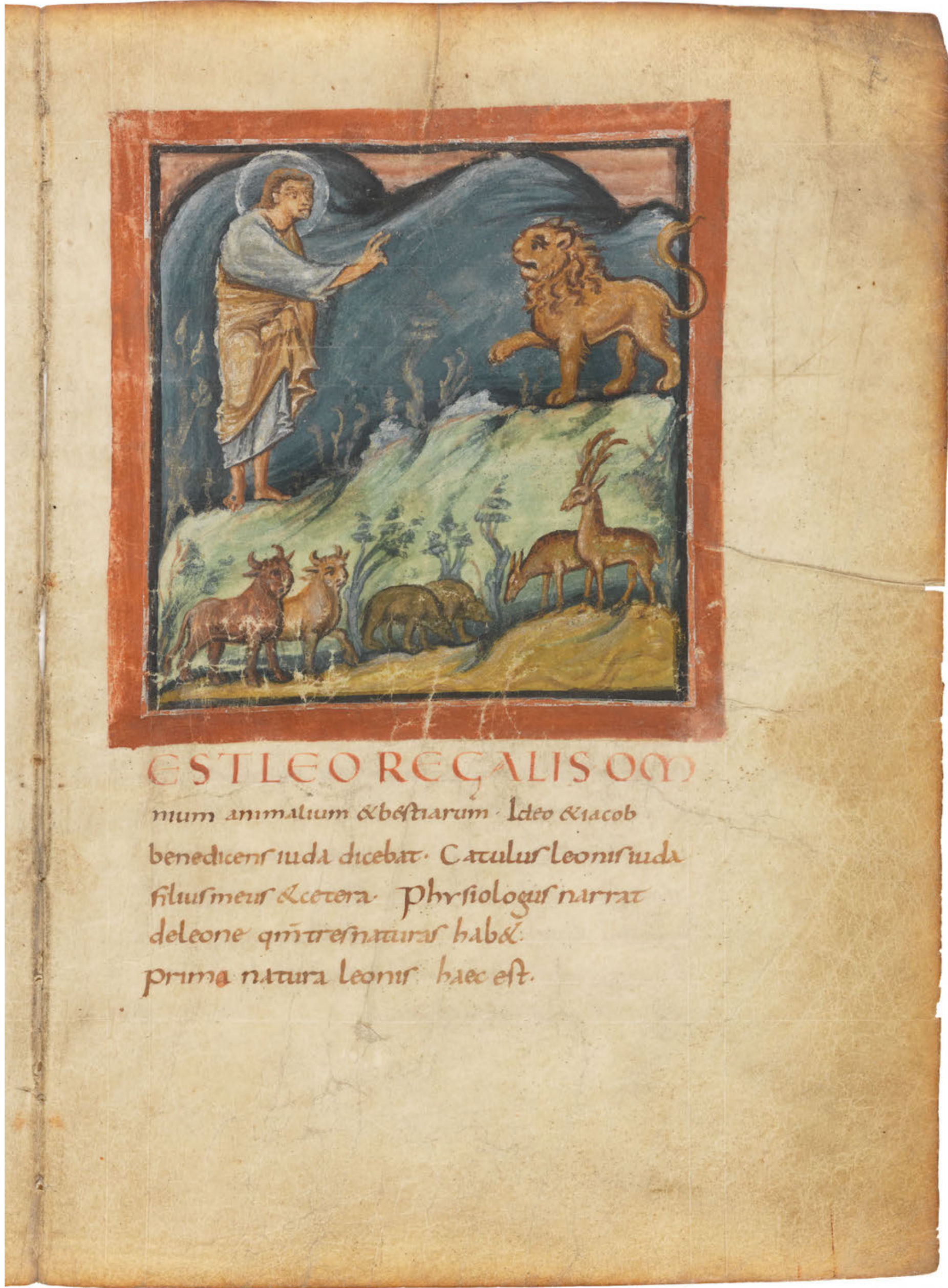




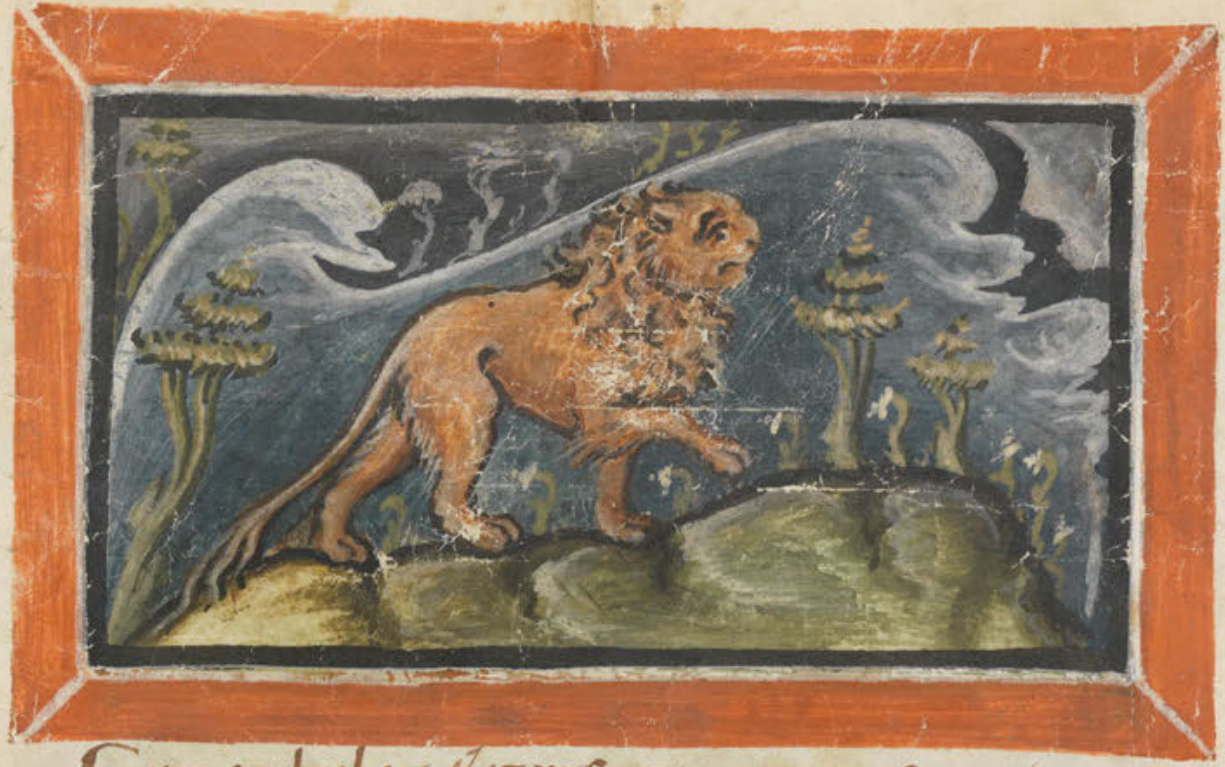

Cum ambulat Literfacit inmonteruente odor uonanqum. Erdecuude cooperrz uefagru fud uznonrequanzur vefagu uentcorer

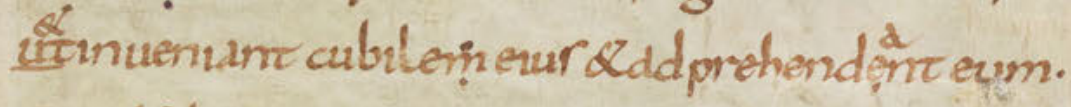
Sic Kriluxtor mear rentrur urleo uncens dermbuudu radixdiued onfur diempreso

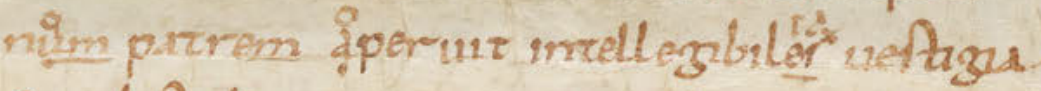
fuxidefi di razem. cum angeler angelor. Cumzhrone it thronor. Cumpotefutubur poter turer. Donecderiendit inuzerum zenerm

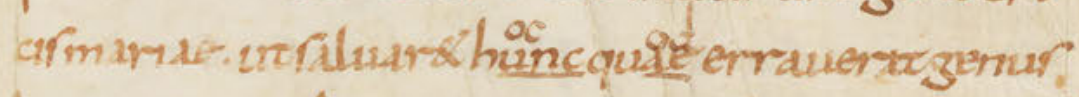

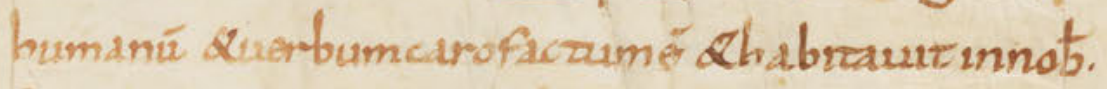

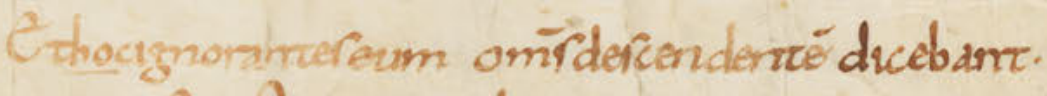
gureft if te rex glomie. 


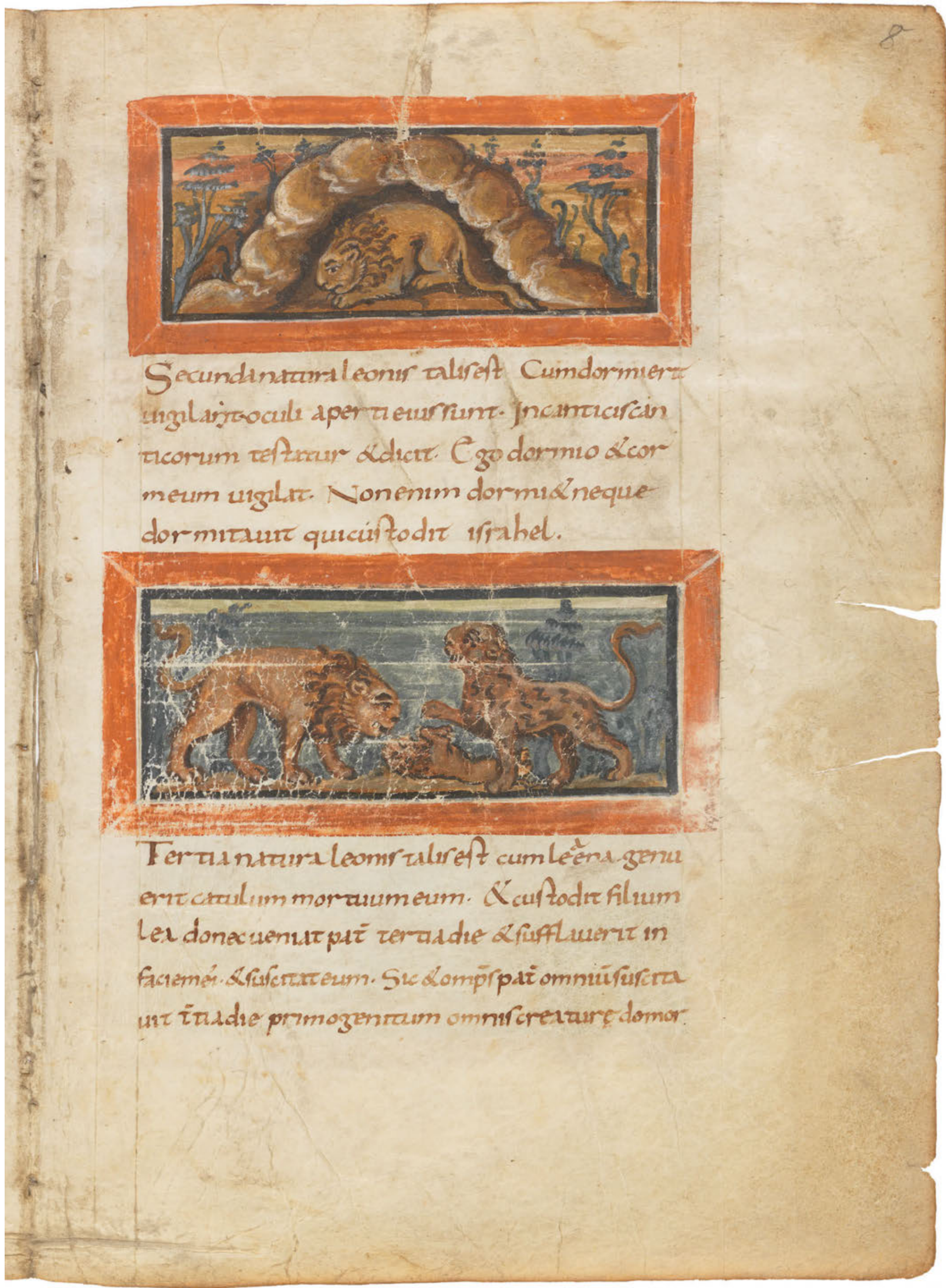


zur dom thm xpm. Bene ucob duct cralurleo nir

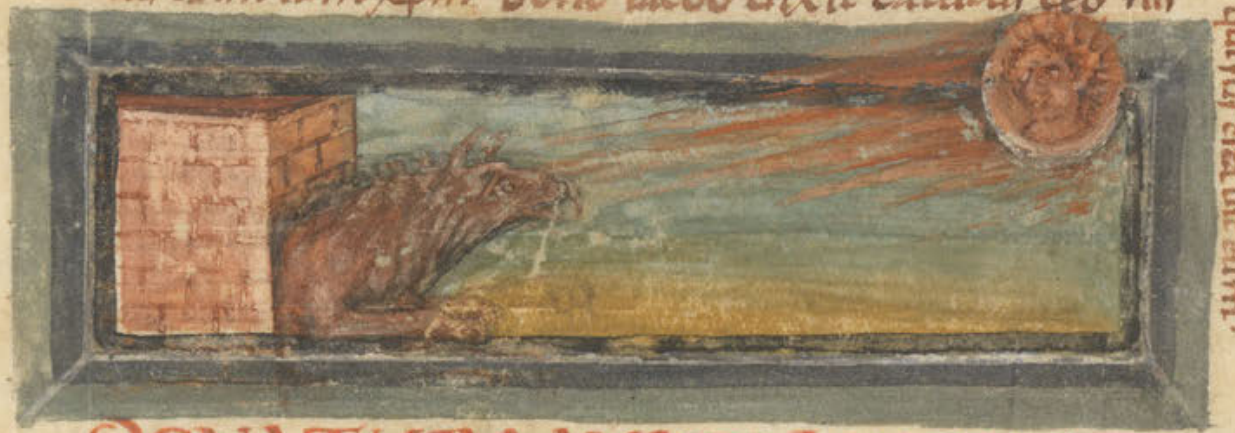

OENATURN NTONLIGONESUI

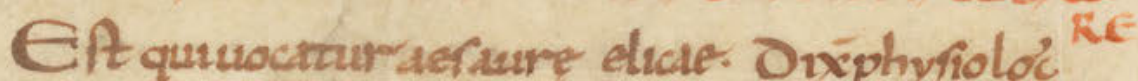
Cumfenuerre impedruy-duoburaculir ckexce ciaur nonudic folir humen euidergofict natu

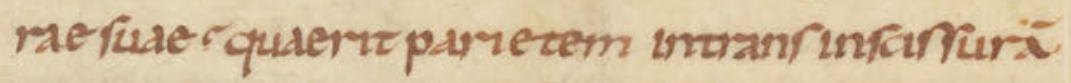

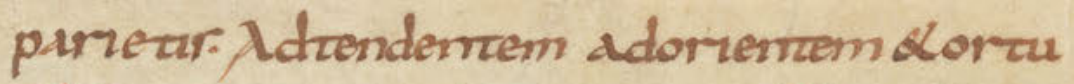
rolif apenennur oculieuri vecordufur alioun do impedisvour Quiere ergo qui orrm fact folemuffirde Onm ahm xxpm eurur nomen

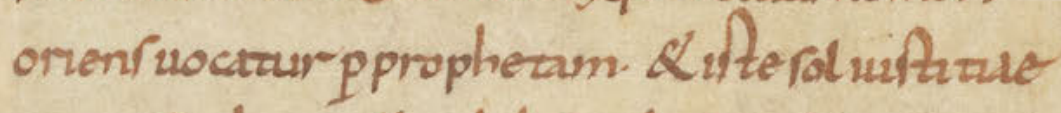

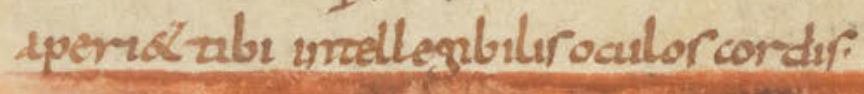

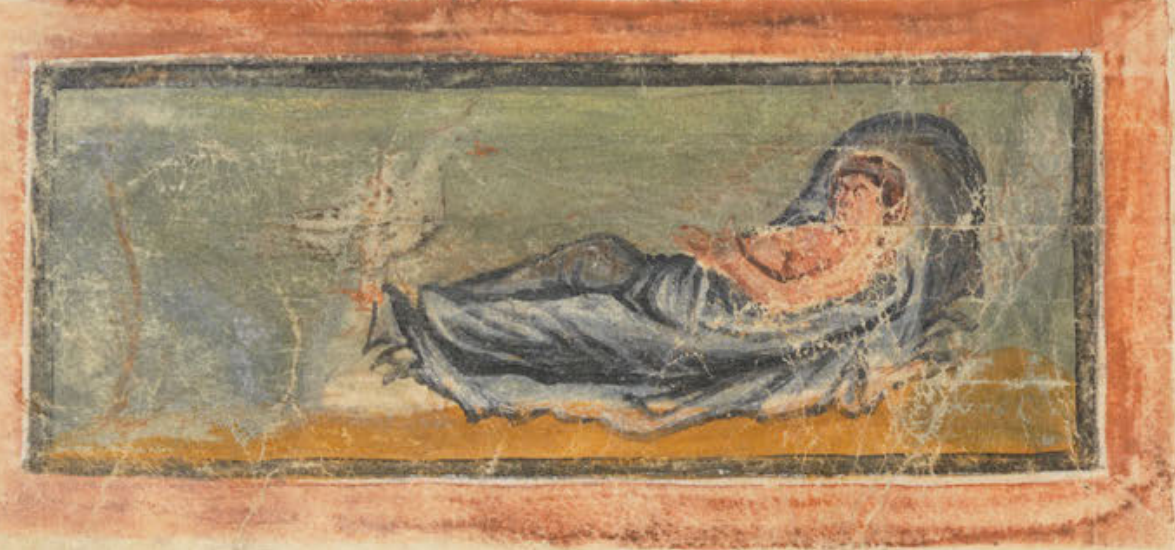


oenviuriciolatiLequae OICITUR CALATRIUS

- Sicut indertrero nomio foripramé phriro locurnarrat deaproamunzocur alburef nullam parcemhabenfinzam.jnernoraenif foermata curam puram ocule quorum caliganantocule \&li trer regum inuentur Cefiquirinfirmuret gxeo calvoriur cognoretrur fiutuse aut moratur Eifieftunfirmizar hamine radmortem luerat Faciemfiam calazrour Lomnercogno rourte quie morzeaur. Szautem infirmizar hominifet ad urtam dipact caldaruur hunceum elenfirmur calatro. Q abrorba infirmizacem hommer a ar

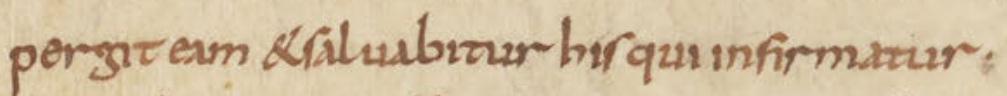
hreccalarrur fimal bon e prona accepit al uato mi: Tour enim albul of drinot ter nonhabent neque unam myzradinem. Ovirentm qü princepr burur mundiuenz. Uenrensenm dercorrum cuelorum a tuder dizatem. Uenrenf sutem idgenter tollens anobir infirmitater Llanguores porcaure Exalazuret ruper Lzmomaruar. Jicenden inaluum capruzam diver cupru uitarem dedre dona homni buf: 
Bene erzo phrfiolocur arrzure decal atmo. Seddiemi quncalsanur huc munduret. Sed adfercierum imp

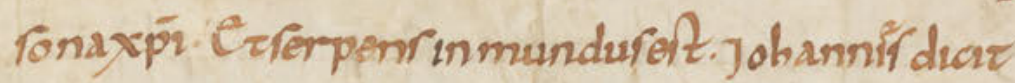
quaficut exalture morfer ferpentemindeferto. raexalrar oporzs filum tominif predeñare

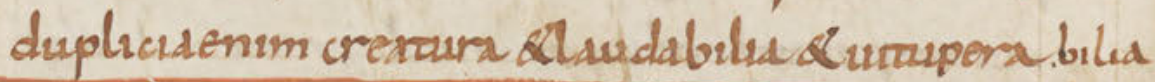

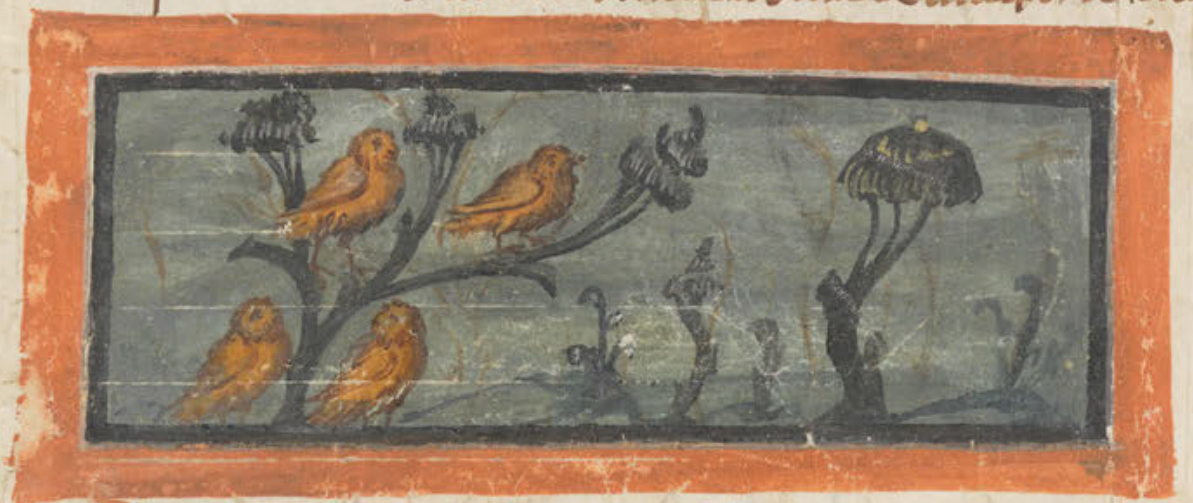

OENATIRA ANIOALIUOOET NOC

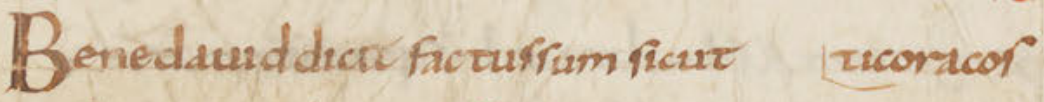
pelicanurinderento L Ricutrocuconacurindomo

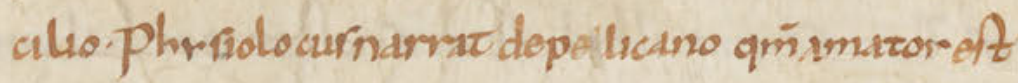

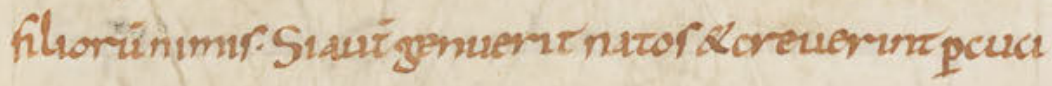
ent inficiemparentam. parenteruzen coloficunt Rocudunzeor. Deindemasericorduan parenter triburdebur luzenaer fileor quorocuder: Teras

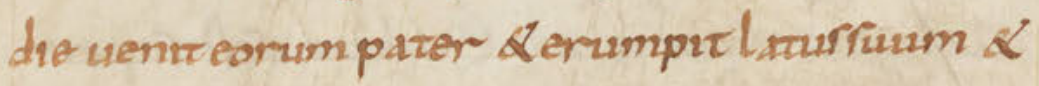
arangur euritill se fiupra morasscorporapullorim

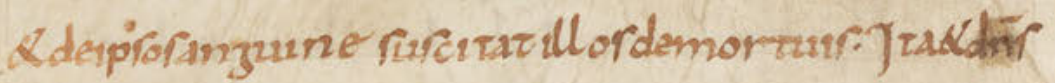




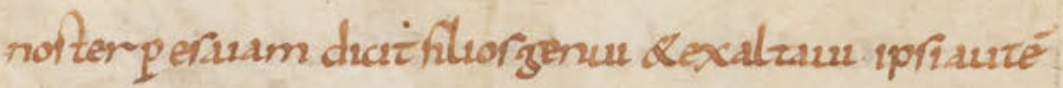
me foreverunt. Fabruckzornof ter gemunenor sper curfimureum. Guamodopartimufeum ferurusmur

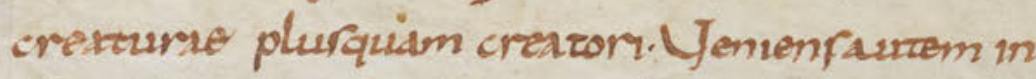
alizudinircruar aluatornof apernent descer renffiumlatur stallaur fangunnem infilutem urzam de żnam. Sinzunempprqquoddar. Jcarp? enfalecem bevediciz. Lquam duemppibapzarmi penizenzas. Benephy fiobocur ar purt depellicans.

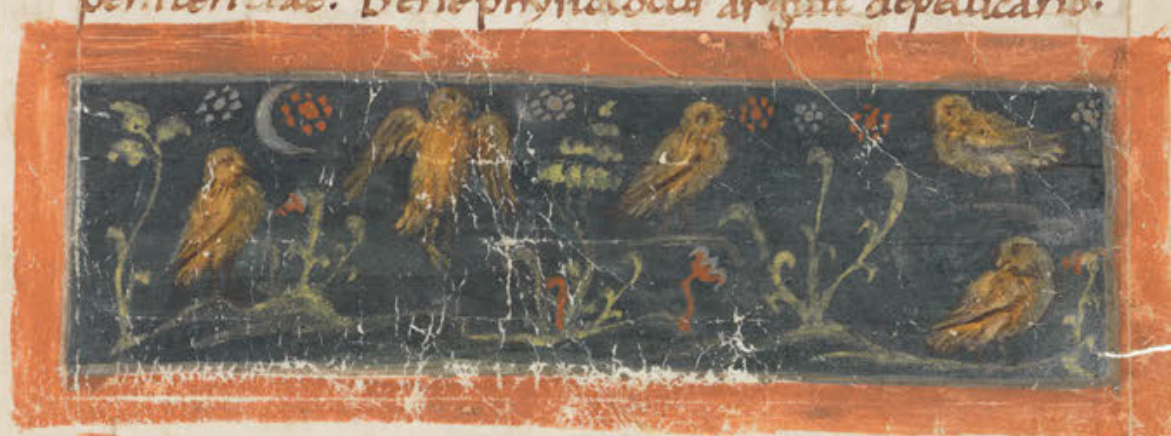

OENOCTI CORNCIS

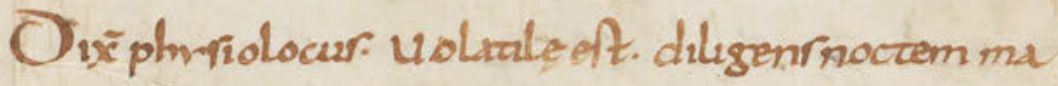

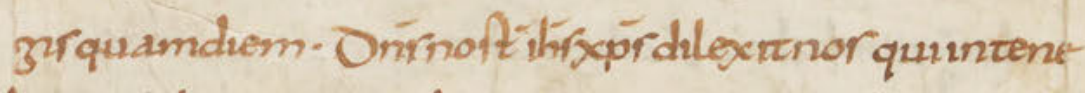
Inirfedebamur. Rumbremonarpopulur gentaum ruprapopulorimiudieomom. Gurazunc adopzronem

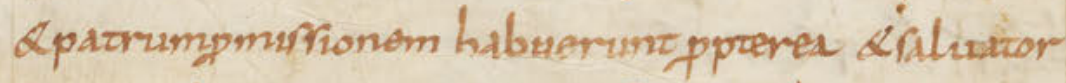
dict. Noliamere purillurgex-hocunim meoconpla curt do. Seddreming quinnocucorax mmunduré fecundum

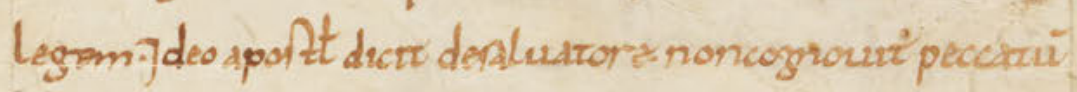

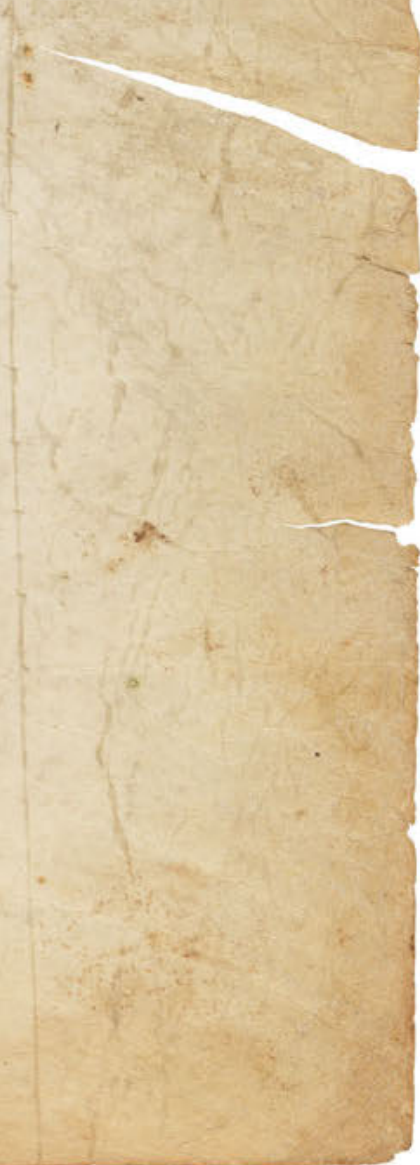


pecatumbonfert. Chumlaurte utnorexulade.

Beneergo phrfiolocur narrat denocncorrar:

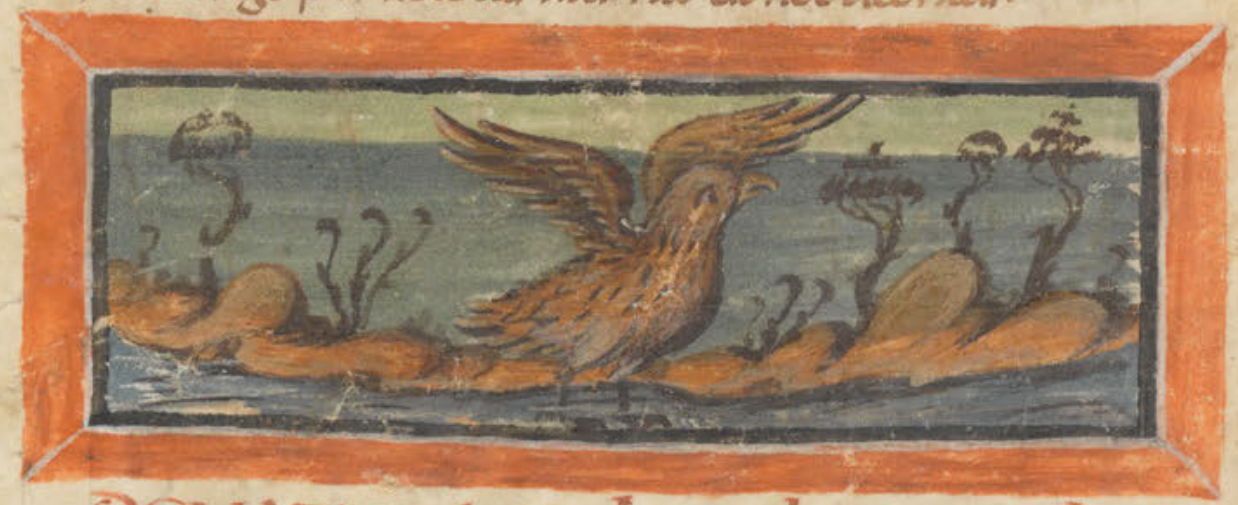

OENATURA GOL A ILE Lquile

Oauddacu renoubaurar ficut aqualo uuenar.

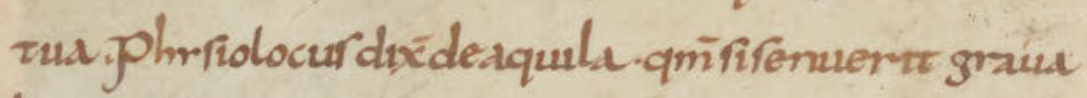

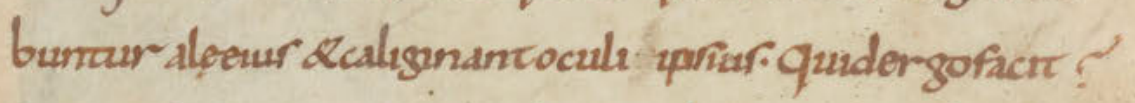
querre forrem aqua munda \&uolat inderafolerex tendrv alas a dercendix infonzem dquido. Bapraz rair per-ver-kifendit reproburicalezanemoculorum \&

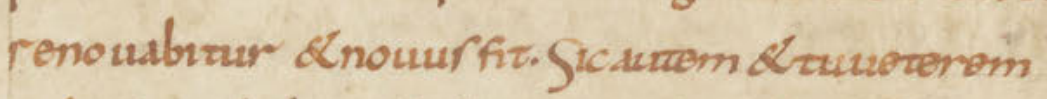

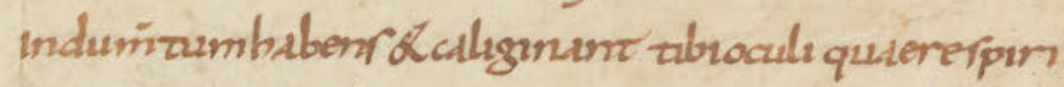
zale forre diuention qudix mederelinquer forrem

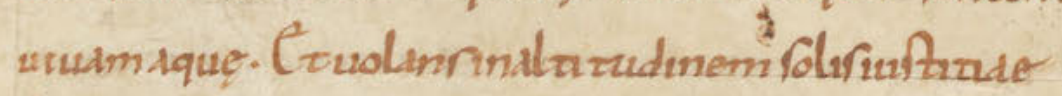

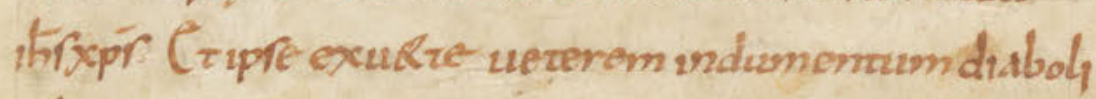
Llaprizure surempiternum forrem. Innominepa

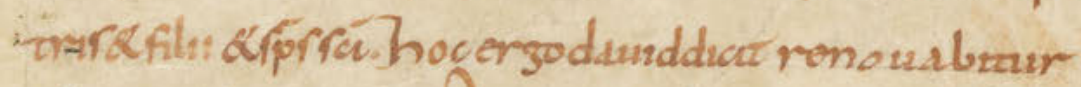
haur dqual a auentustud. 


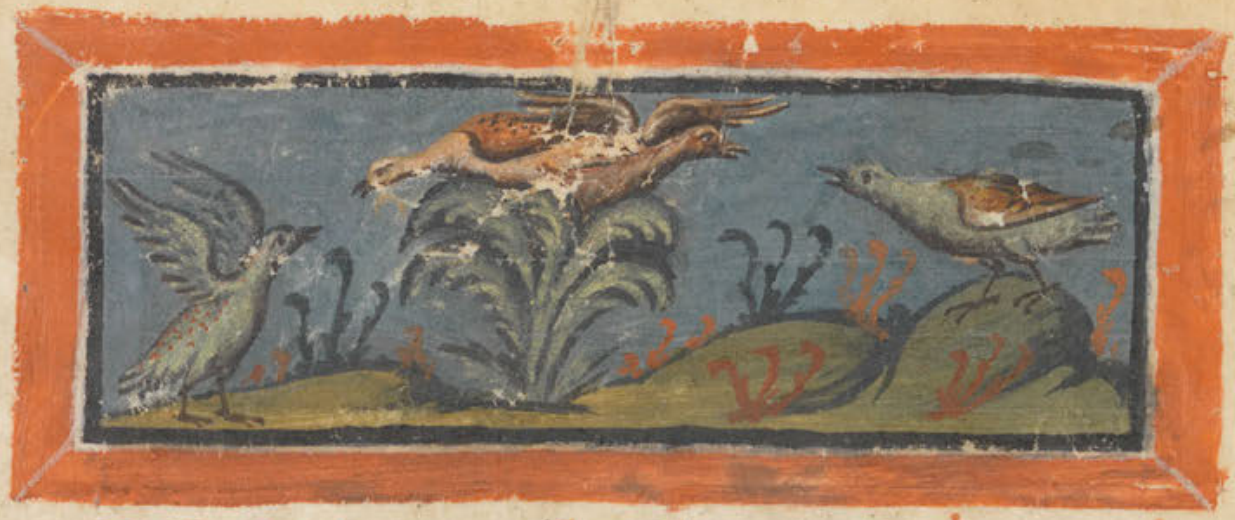

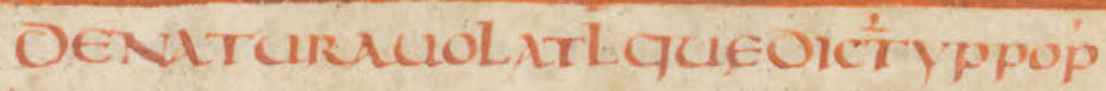
Beneràpumé qumaledivertuptrrendurme

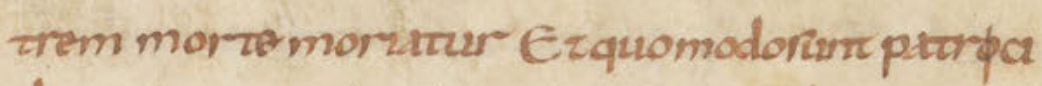
de aur matrpade aliqui quiducrur Lazneyppo pur huuffilu furderem paremenizor fenercenter ezellent pennccruezerer parenraun al tonzuñ oculof eorrm Kcaleficumt parenteffitor \&nousfurt. Quomodoinnusonabiler hominer nonimane parenterfuor Benephirfiolocur arguiz desppopur.

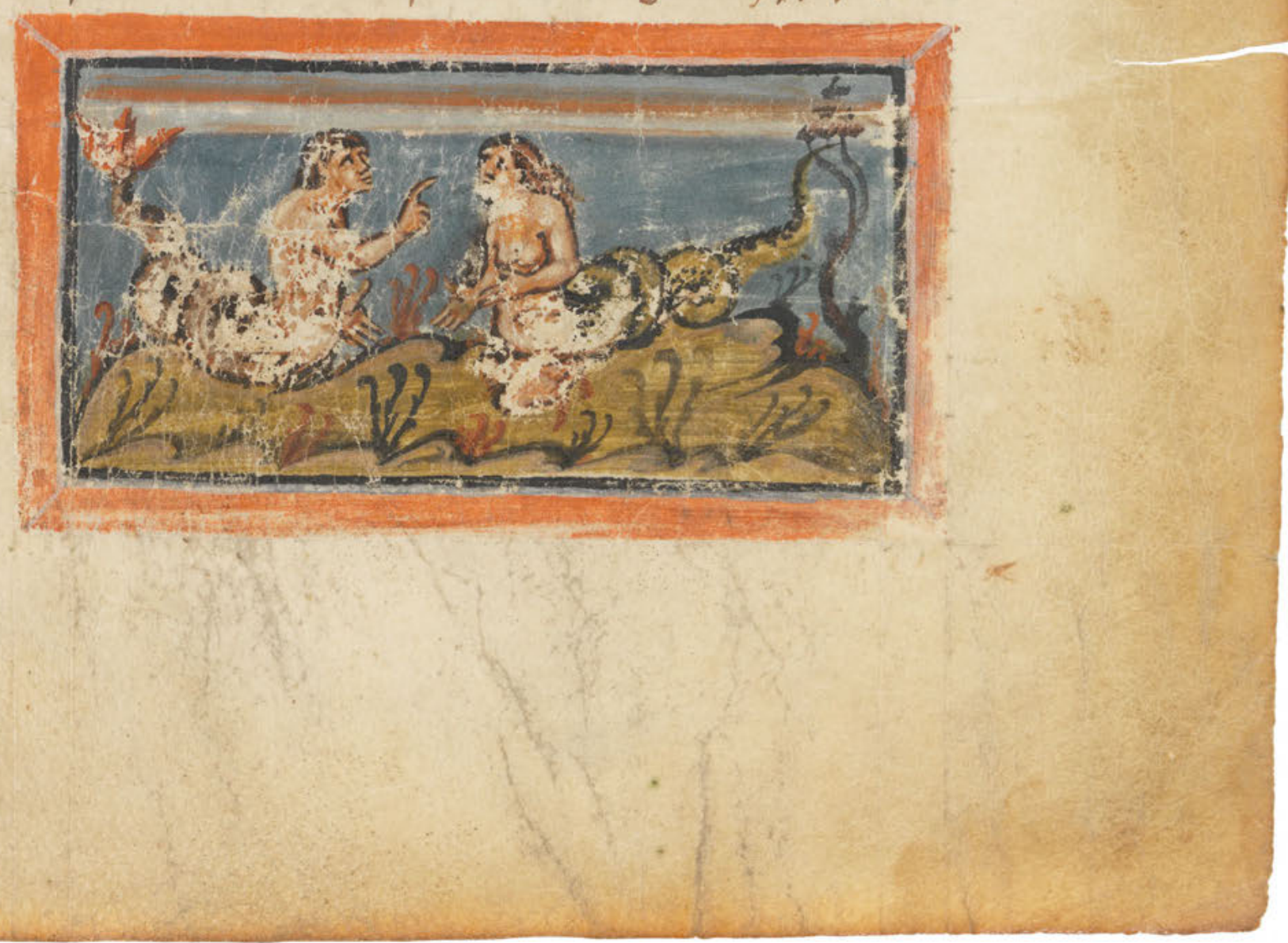


$11 ข$

DENATURA UIPERAE

Benedzerzobanner ddpharifieor generatousupe rarum quaruobirdixafizgere duencumara :-

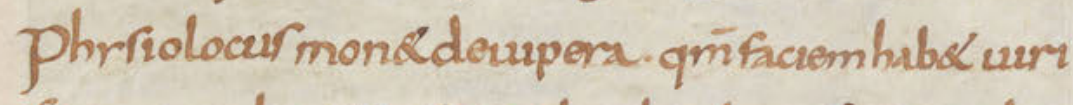
femmi mulioror urque ad umbratum Lurqueadcu dim corcodrillo hab\& figuram. Uadumfeminae nonhabezinfesu fedut formen acur haba. Cefi marculur fiat oumfemma effundrt remen unhor foming. Lribubr remenfeminu pracedirnecera ru marculs omorcur marculur farim. Cum creuerint dutemfiltu comedent uercmemmatrir

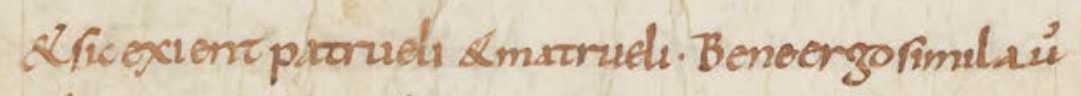

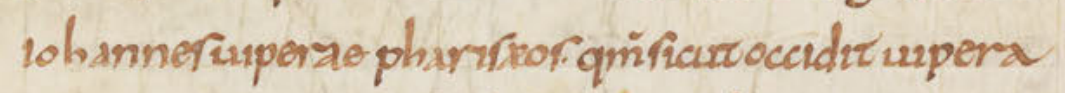
parré uramatrem. Fic pharaffi occiderunt inzellegar

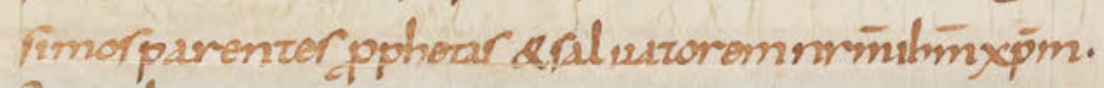

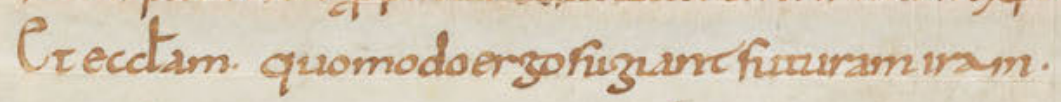

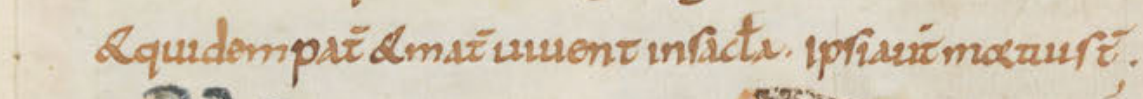

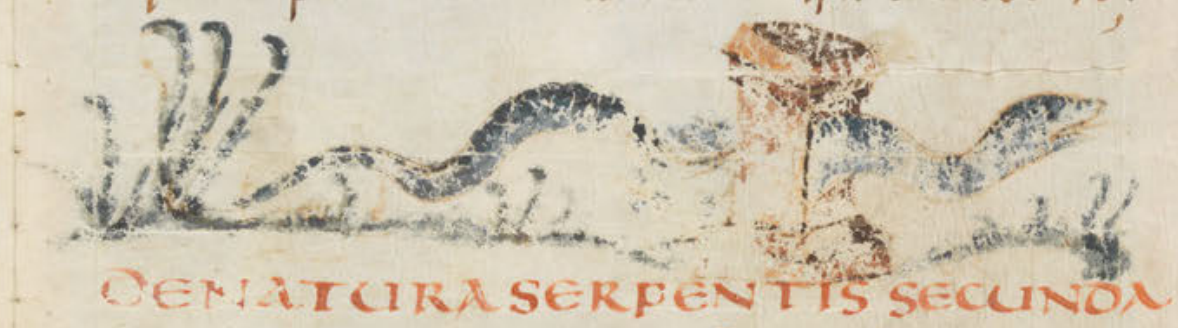
Oñduct meuangedro. Crgo efore prudenterhat

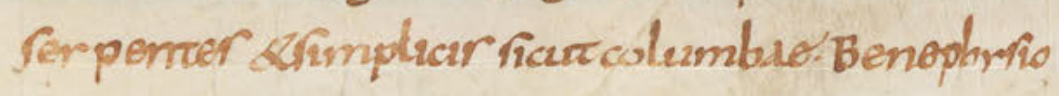




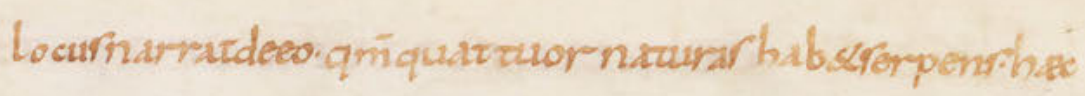

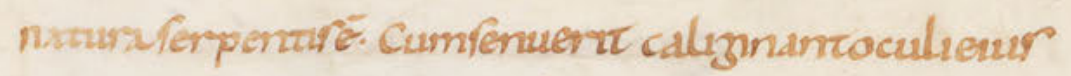

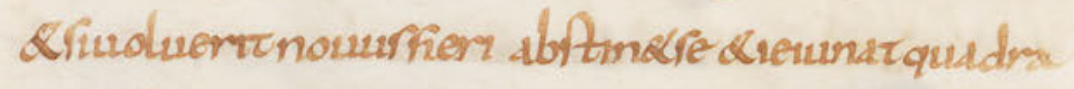

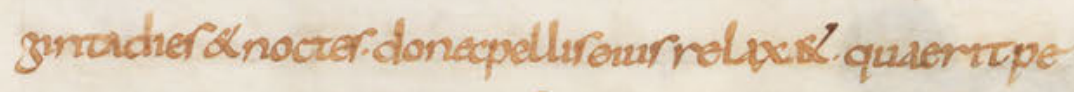

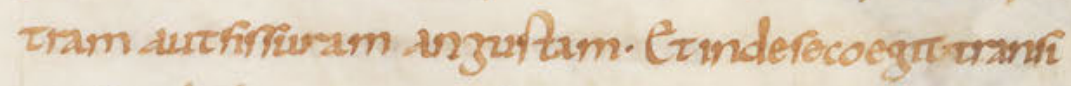
re. Zunbulatcorpraf \&depontifenecturem \&nourer

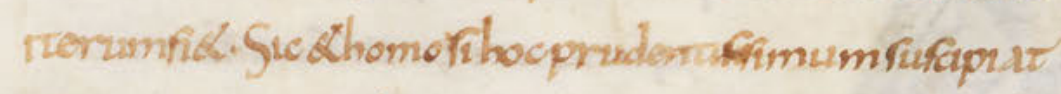

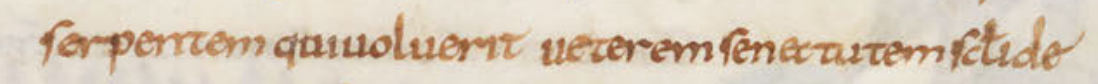

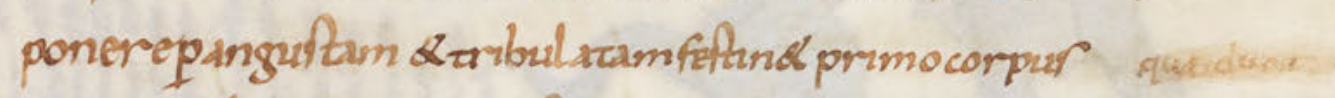

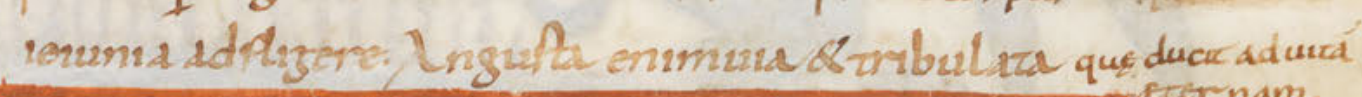

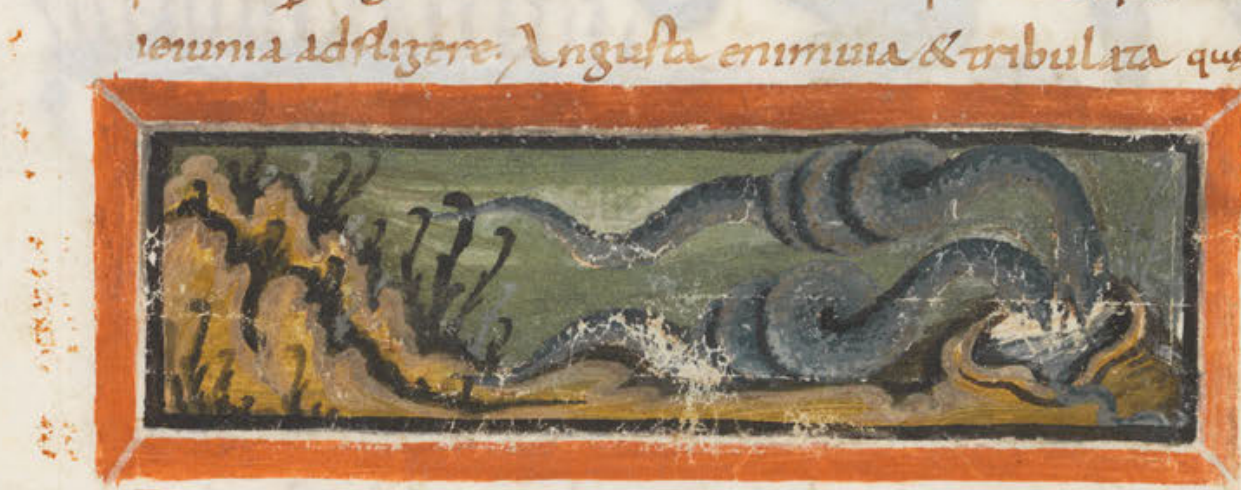

OEIERIILNATUR A SERPENIIS Cumvenerr biberesquam defonce nonad fientuene

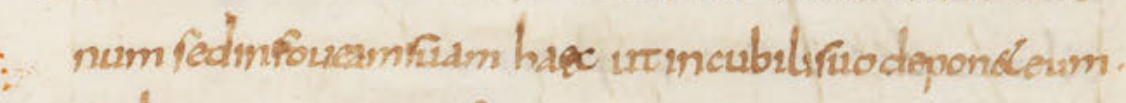

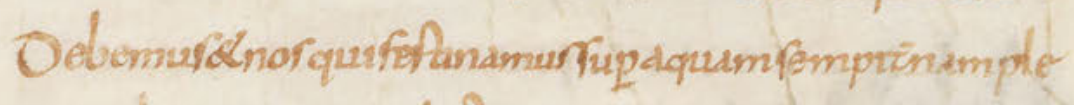

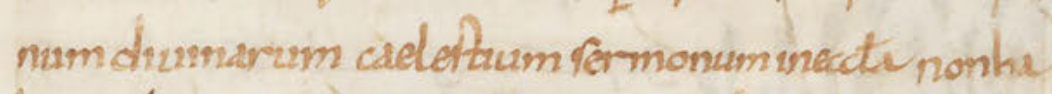
berenobicum malrezo uenenum idestpolluzar concu pircermat fodperfiecurfimi praecedere. 


$$
\text { nen }
$$


Re ritrucumet dut orderm. Surdeumeftdrnutat eum sudir fuper utuaum. EAtergo or deumpeco rum exa Raccept atzicum quu repontaur inor reo. Ordur onim fimlabrour dienu docarne. trucum tequicurem fideripor:

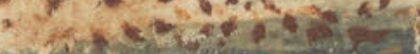

Qftenum formucu quematoribur undurt unrb. Nequereruraum adoperando co zzur fedfponzunuo proporut profiencue firtura dimentorum fubfi

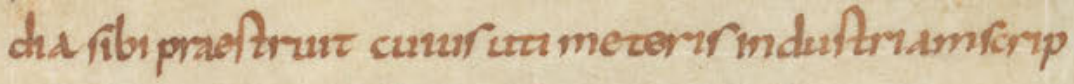
tura tecommondelucent. Conforterdformucum oprzer Rconfiderazureur Letorapremaion jula

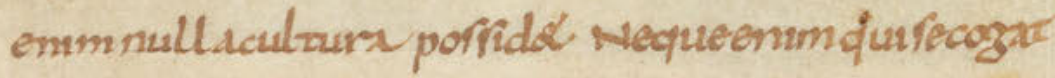
habenr. Neque rubdommo agen quem dolmodum preparat eram abrquedecar tabonburribimer fomrecondu. C cumzuplenum que ezear julx nonindygext. Nilla funzer dauti oprea nulle inpenearibilir eurtodue Nullues inusol abiliricero fpocut cuftur firraque prohblore nonuedebu. Upecr fiudampna porferfor necusndicurngro 
conuctazor azmene priedim pcimpor firenze femr

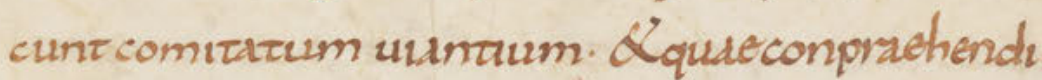
ingurto ore nonporfune humerr gyadud frum zum zundurzar: expecutdníneur rife eruber

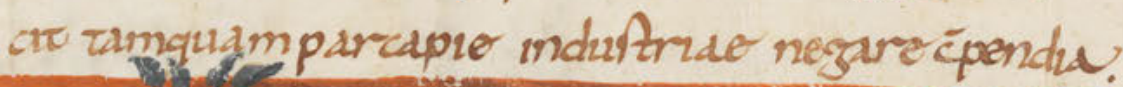

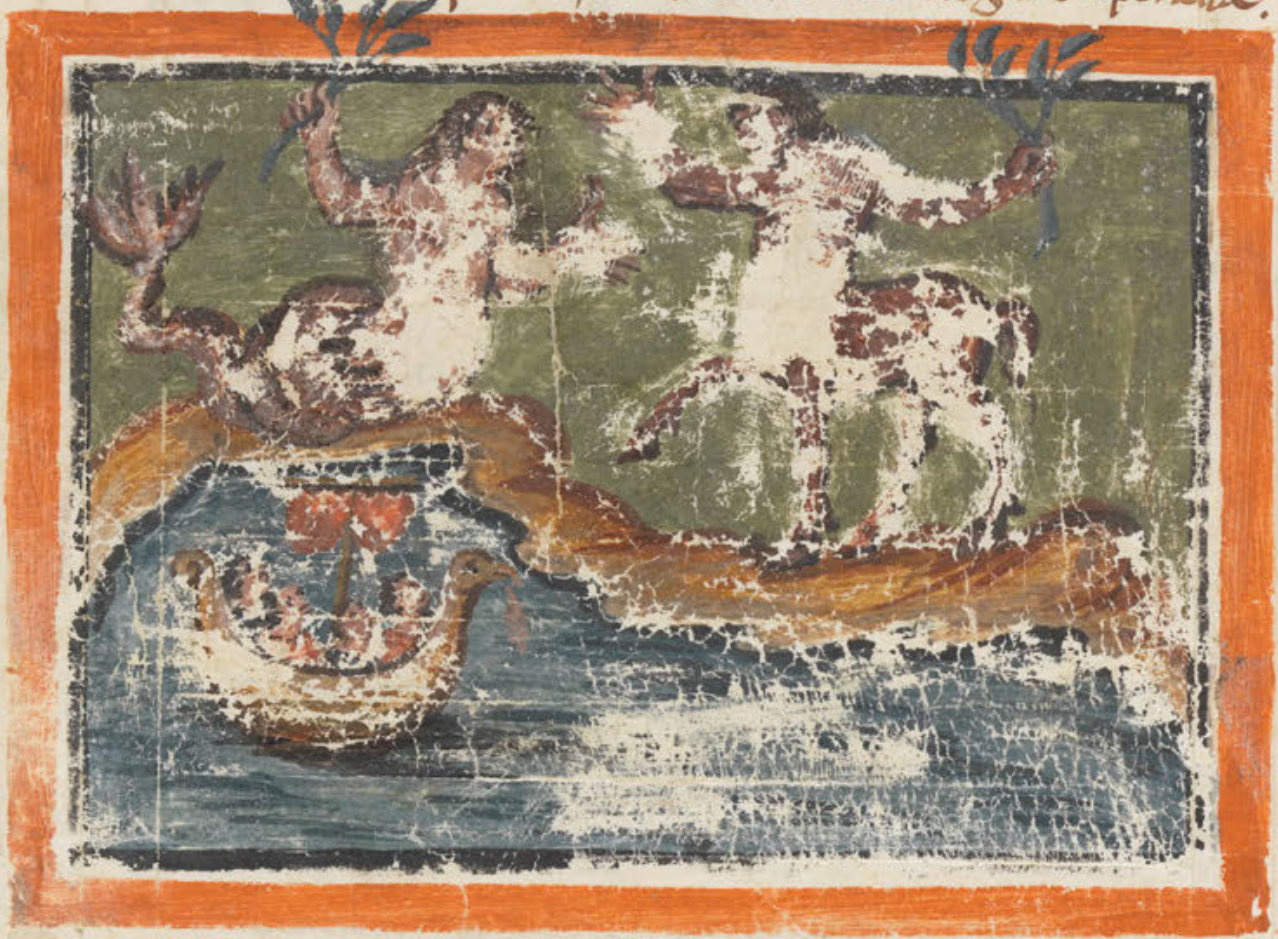

OENATURISERENIEThONOCENTIK

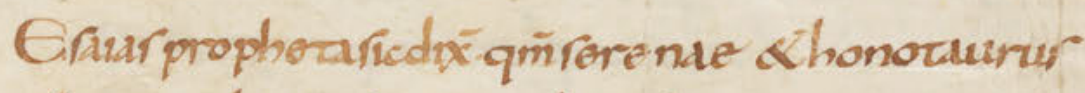

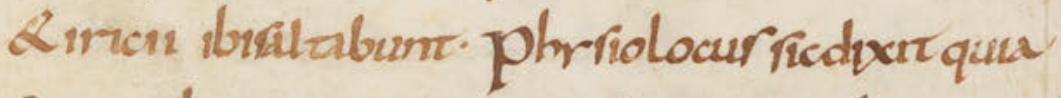
ferenardact en mor aferar zinmure dimutant uobrduverir utnauzganter dum dudierne

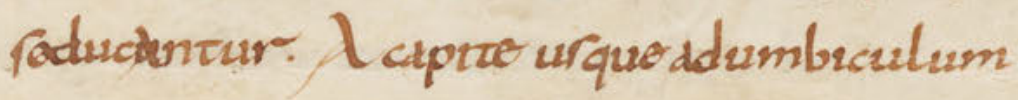




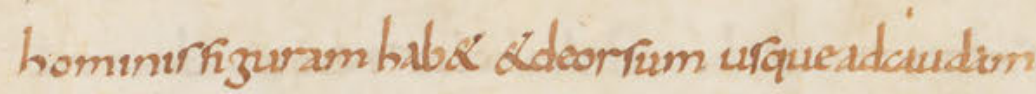

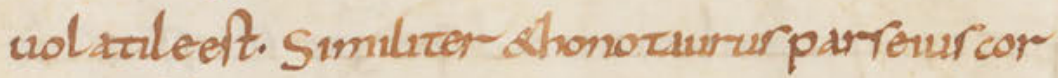
porret hominis: Vters duzemparrain fimle audinom hibe. Torerogoconparancur usm duple acorde quihaber fizuram pieziar plonam sece prenter. Chabent doluerarrorum shereacos. Nampriuazrima eloquarua ficutrerenu redu cunz cordannocenzus:

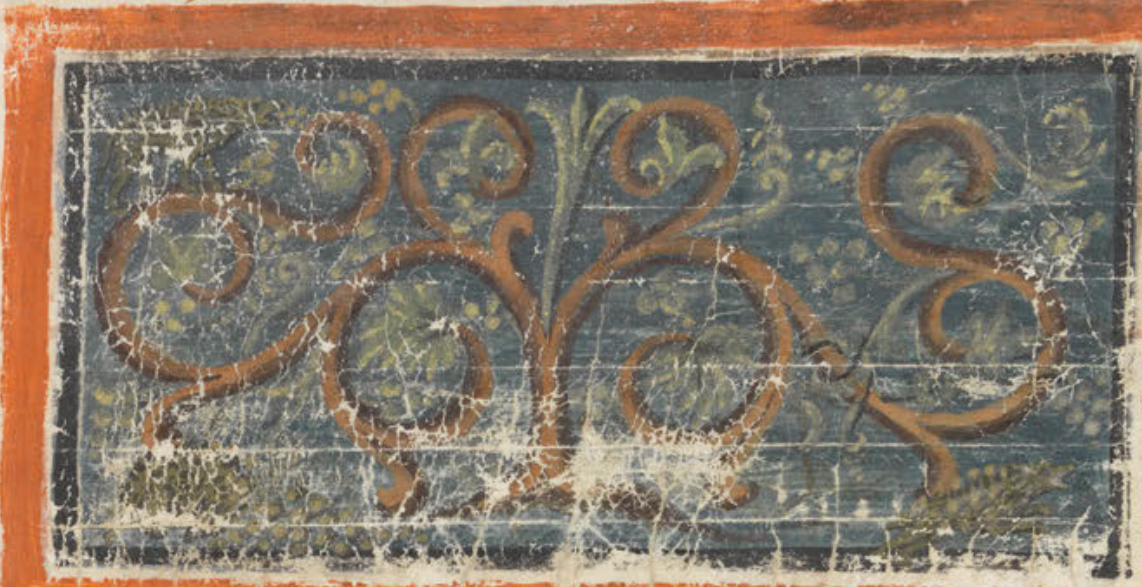

\section{OENATCIRI ARICII}

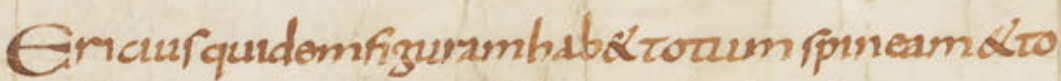

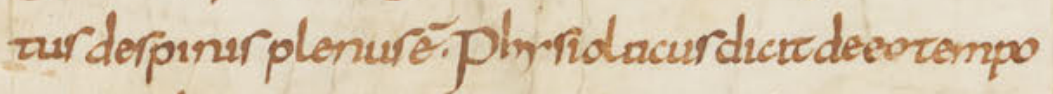
ro undimido drendit murzem fusplorizursm $\alpha$ dercit zyandeunintera Ldercendenruduzaro

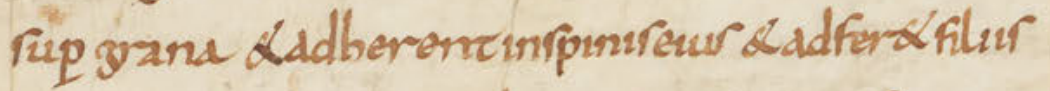

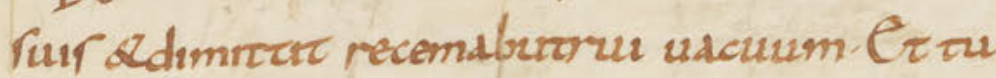
xpianififuerardi urar conferuder zore neacendu 
If adverracur: hoceft dubolur Nequando corru pat unamuambonam adeperzat filupruaride

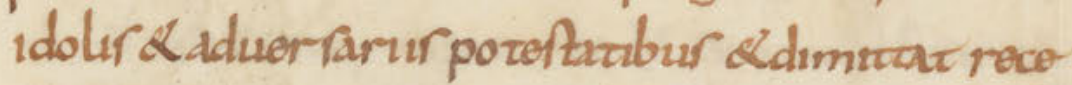
mumzaum uscuum quaribornurzur curto diemf pozerridduci dedipurizalem zorcolarem utreponarir incellario hocet indara reziripu

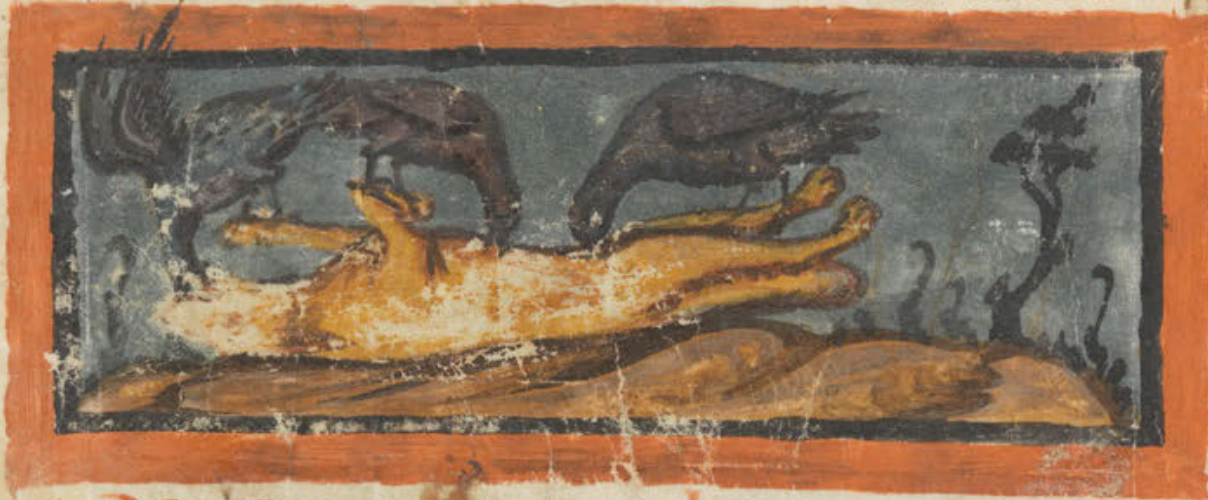

DENATGBA CuLPIS

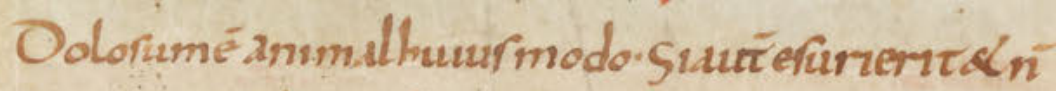
muenut quodmanducé qusern Famivam zerrae $\alpha_{p}$

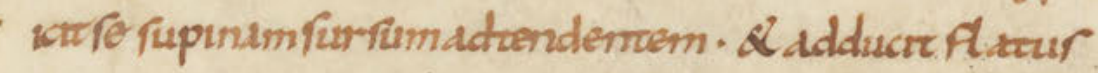
fuum infrafe om nimodo expuran uolatula eameé

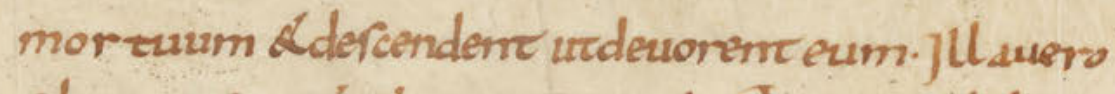

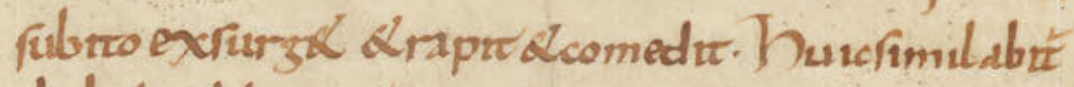
diabolurdoloruse inomnoperafus. guerzouolu erit dccspere decarmbuferur idef deactubureur. ftatm momour Namadaluator-deherodefilio 


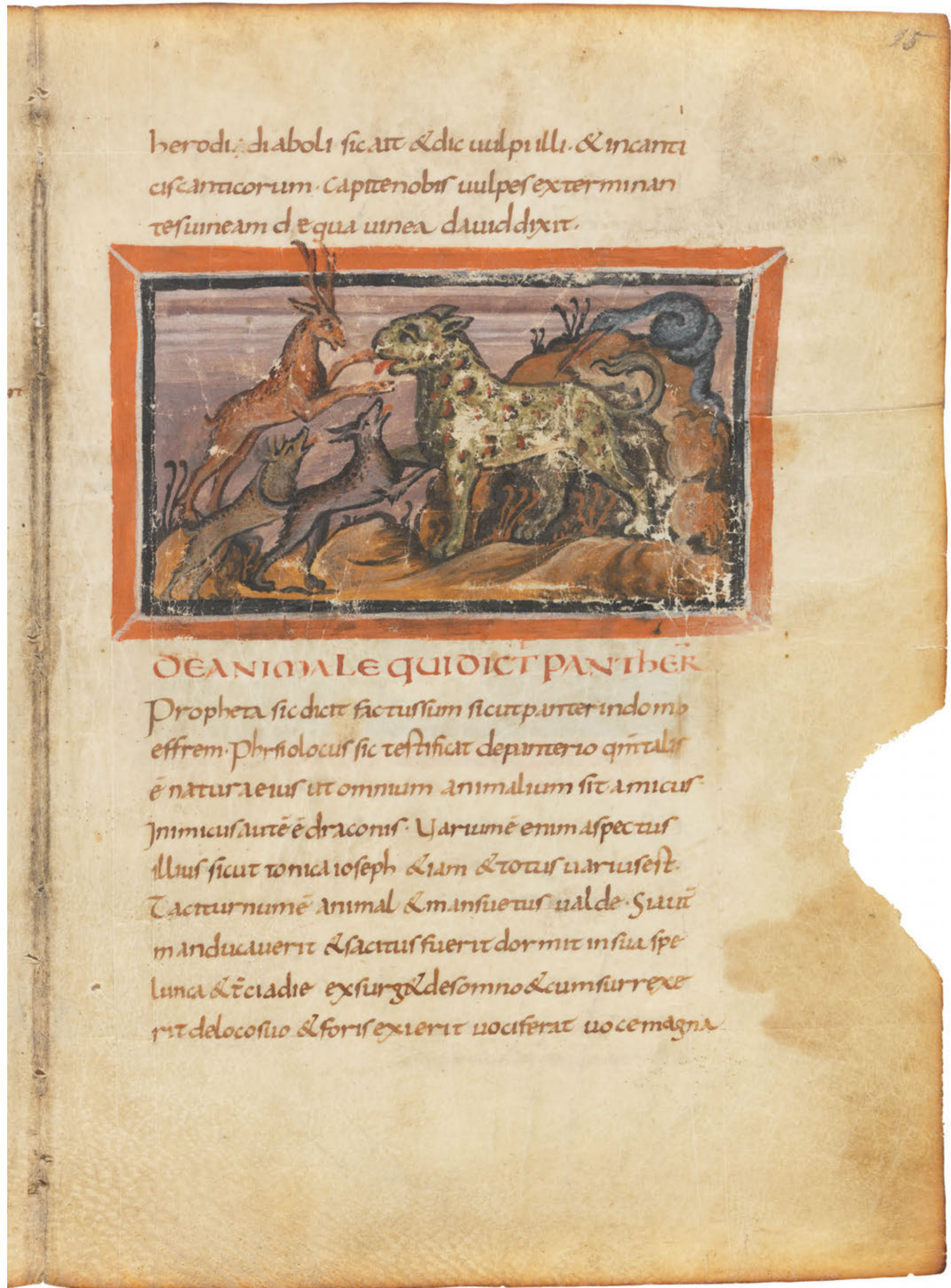


Ldeuoce eur exis finutar uromszum \&qur longe Rppe dberm audionteruocem feannourte

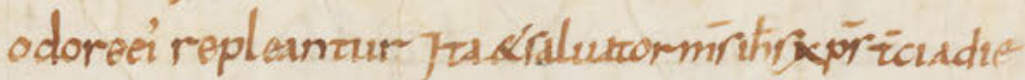
refurrexir amoraur. onf́quilonze Qquzperinz ficuzdax upot repleutzru uuzazem fider. Uarurauz ineo quodmulaplaciz zencer zenre idqueriera spre

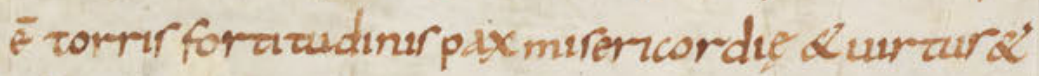
glonde. Oraconem inaquum dubolie ualedrrimú ut dniforequizur ndm nathel cripourate fine Timelizudinenobir

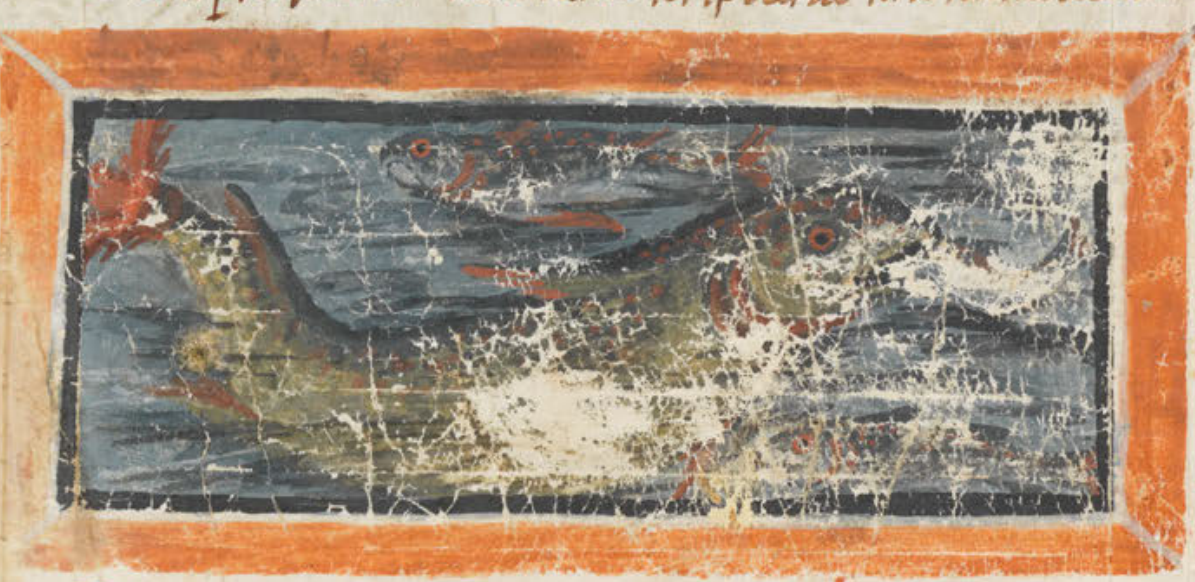
ixser

DECETO ONACNO ASPIOO helunes GAtueur inm are afpudo helune duarnirurar habe

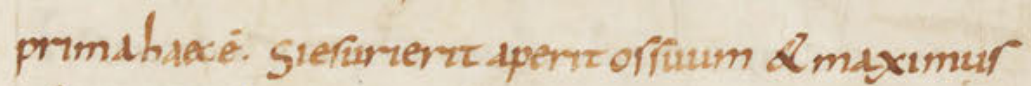
odor exiz deofrizam \& fudurfiza uzinorapisariungan tur Lequanzureurfuauzam Qconzanzuromner

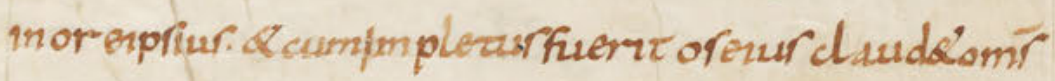

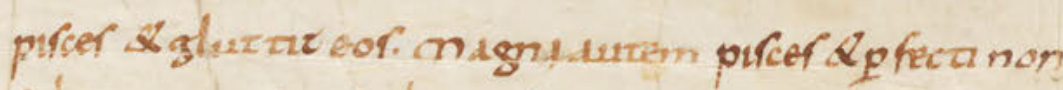
didpropin quare adoreupfiur. 


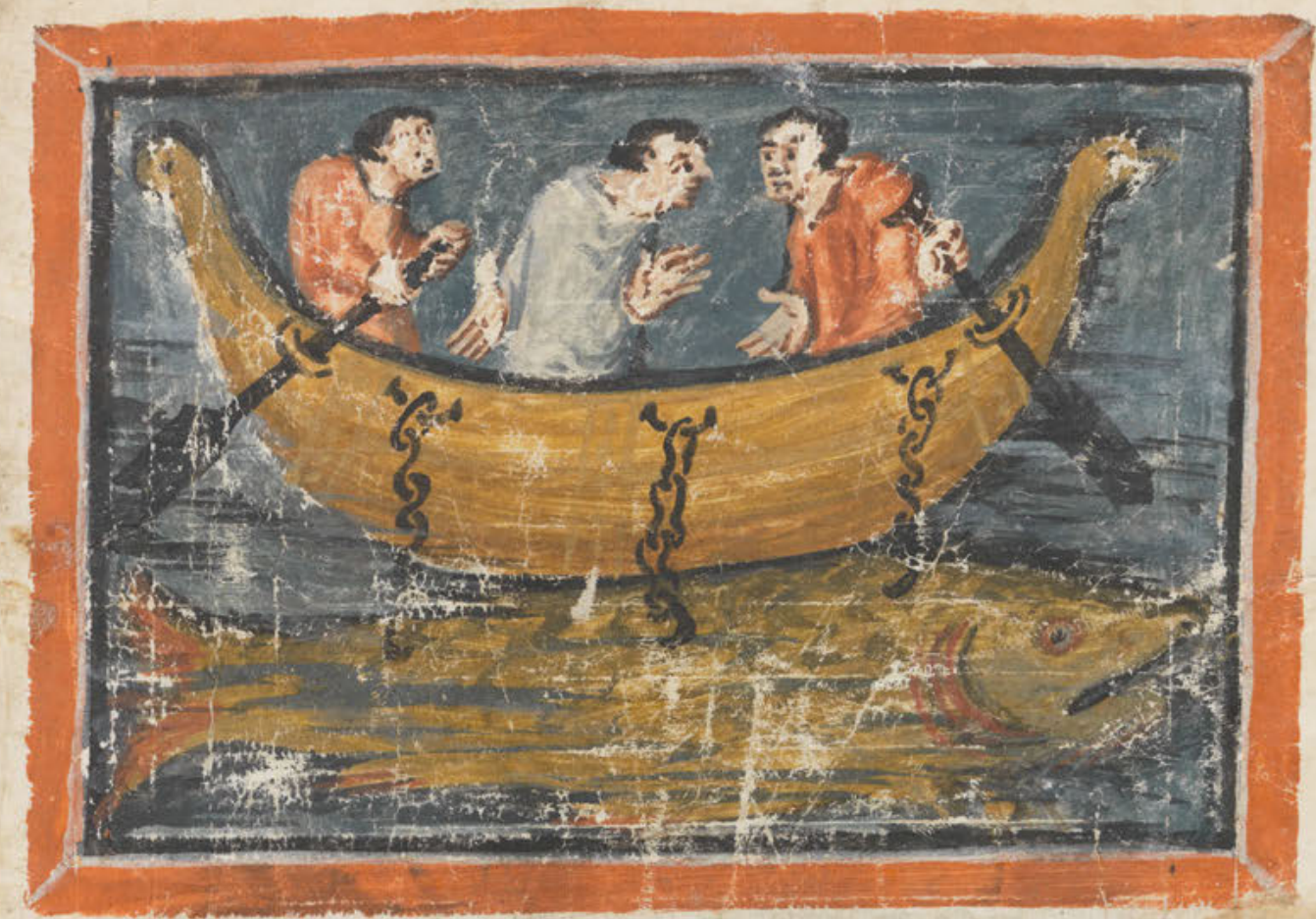

OENATURA SECUNOAPISCIS

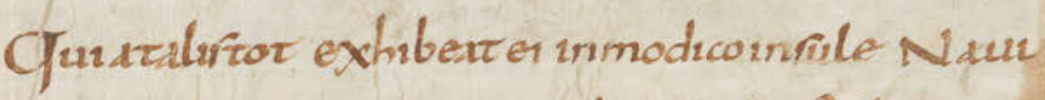

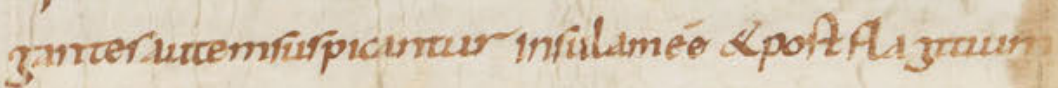
zemperticar ligano nauer ia adeam adum acicende rint uzum fuperm doloquendum dut culeficuendu.

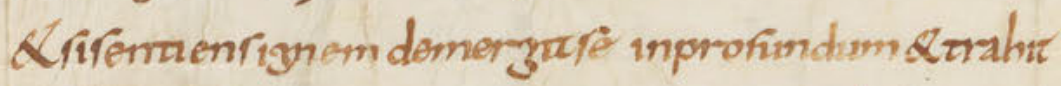
poftre ominduertegater. Tous innmal fimilabuar mulierer form survdo. Oequadictzialomon meleni fill di delabur mere oraci qudeprotarno ungua

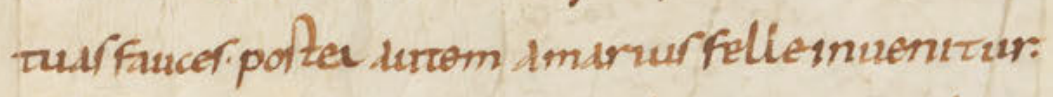
Leduraomaziquam gladur br acurarqude 
morgu urtenebripeccatorem.perfactatizem Lcura nonddpropinquarzes: Qula fera soleph apudmulerem uegrpoum. qualirent helur zezabel arguens: qualarerat furannu inmedio fentorum. Bene ergo fimlazaémuliéthuic pifce.

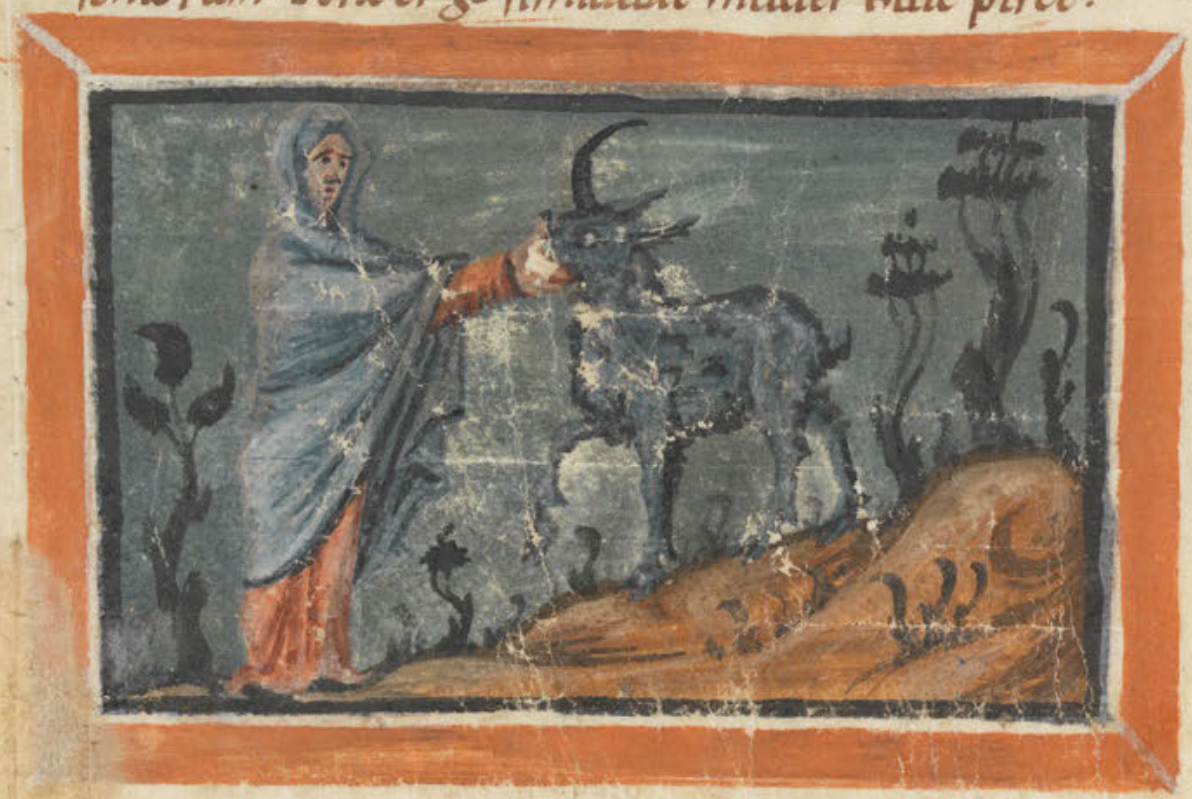

DE INIONLE CINICOR VICIO) Inpralmo ficdrct exulzabraur ficur unicomencornummeum. phrriolocur decodicit quedminor-fix tmal. Ef turem animal fimle edum mantuzoum ualdo unicornu habstupciput - Inomporestuentac adsprnquare expé quodualdo for arrimú habel cornum quardozam arpudisndodufarreficmo do conprehen drour prouctaur- drue ezm unrgo ar 


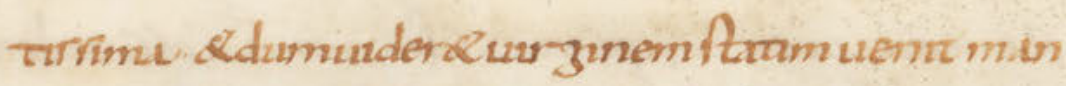

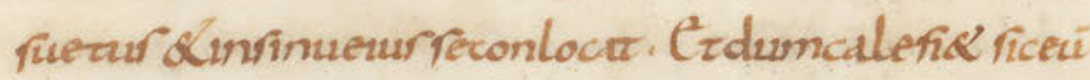
porat fetinanr indomoregr. Namnullureum uentioradphendere uald facalution nof ter:dequoppheadix. Crexiecornutraluarinobrindo moduud Oumenim infotm underecur- null ireger nulliq. poreftuer maligne ualuerume nocereeum. cumuerbum carofizriè sch abizauit innobr.

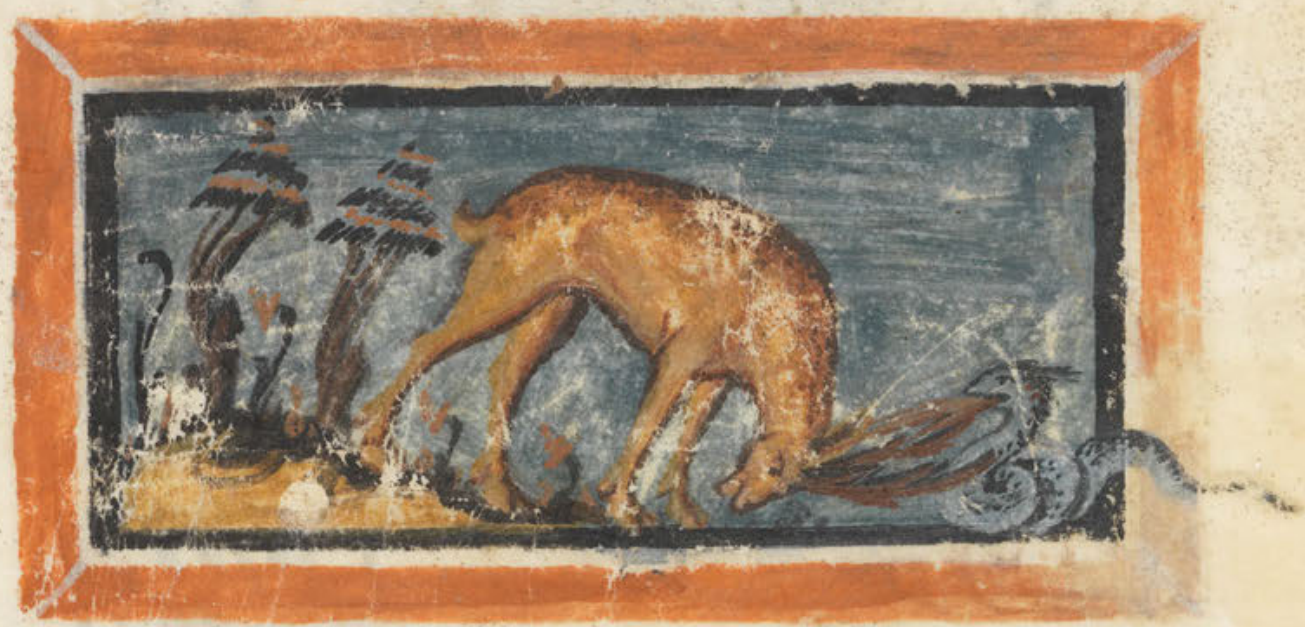

Decercio Phriolocurduci qua inimicufochnconir sprequizur occtdereeri uult.

Oumfigerictraco inteeum Qubronderite in

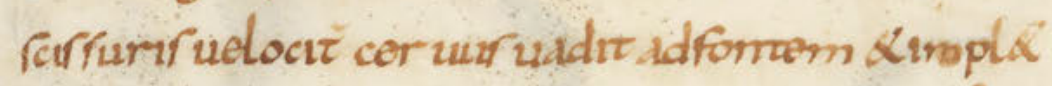
urferarui dquimula duenenr uomenspotteú. Turbaurdraco abaquiexut alborbaleviceruus.

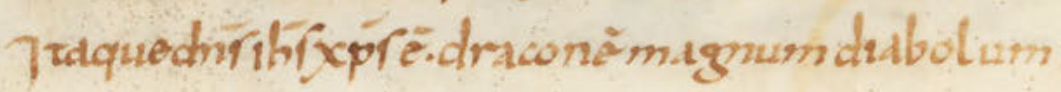




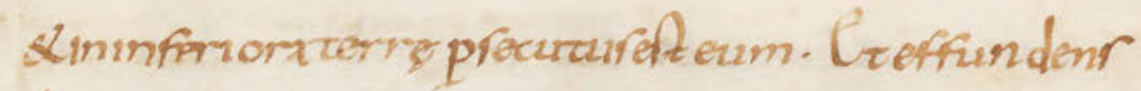
delizerefuo rinzzanem \& Aquam Qeffizaur draconemplauionim regeneracionis sdubole

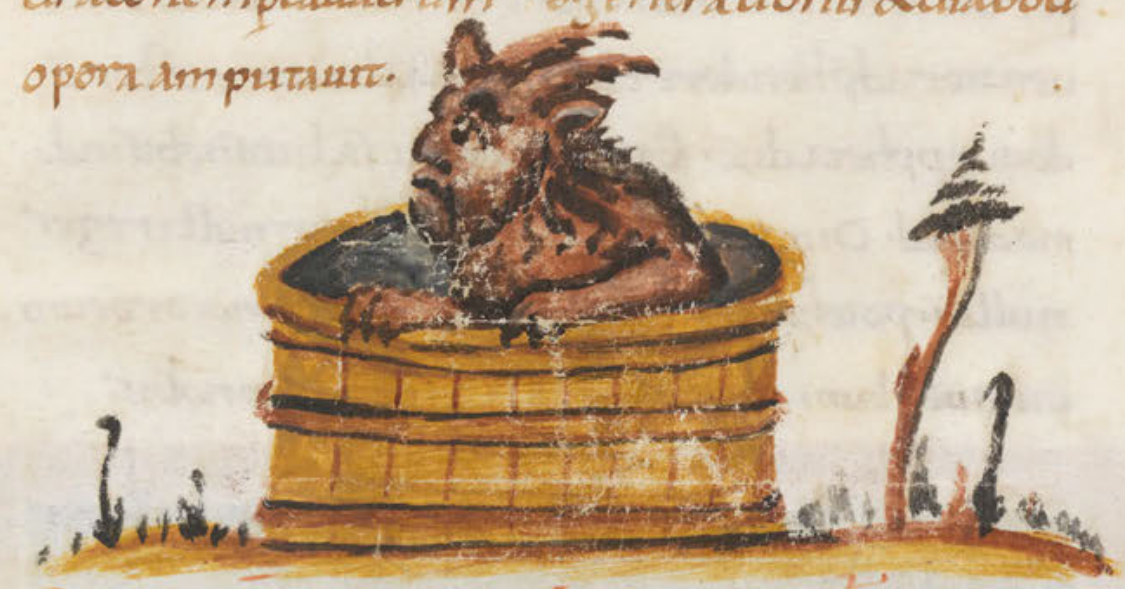

DENITR ANIOAALS GLIOTI SAL XOMIN

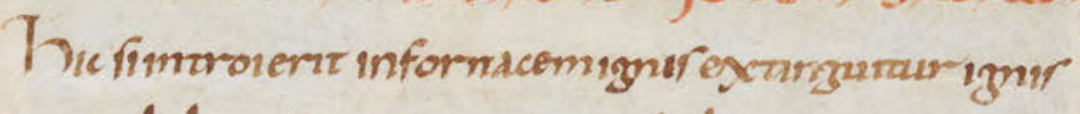

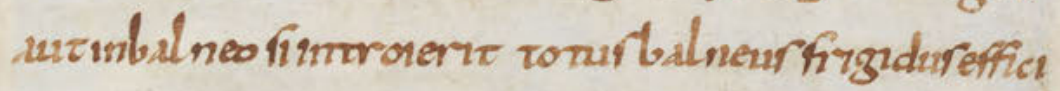

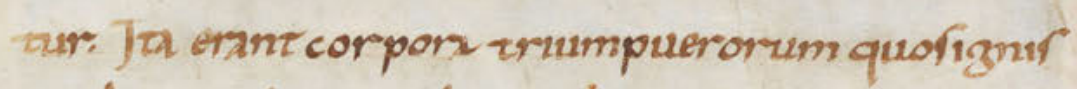

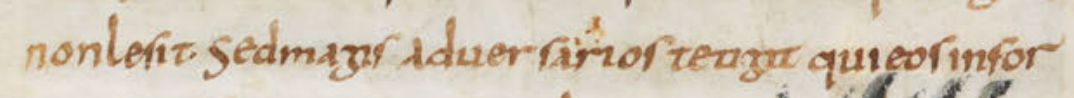

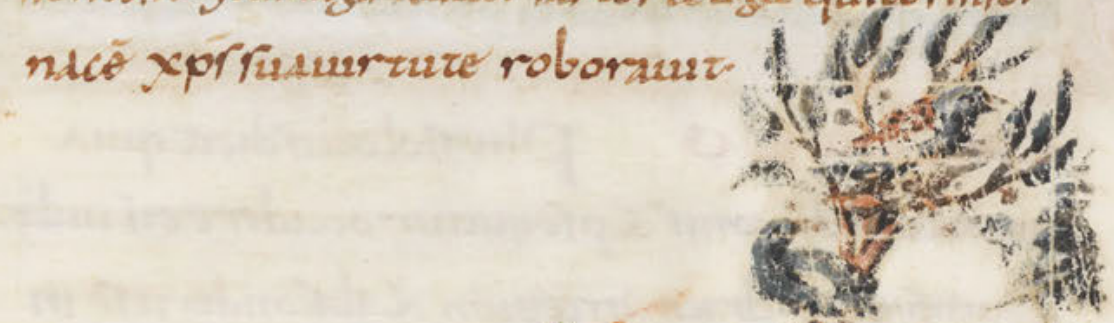
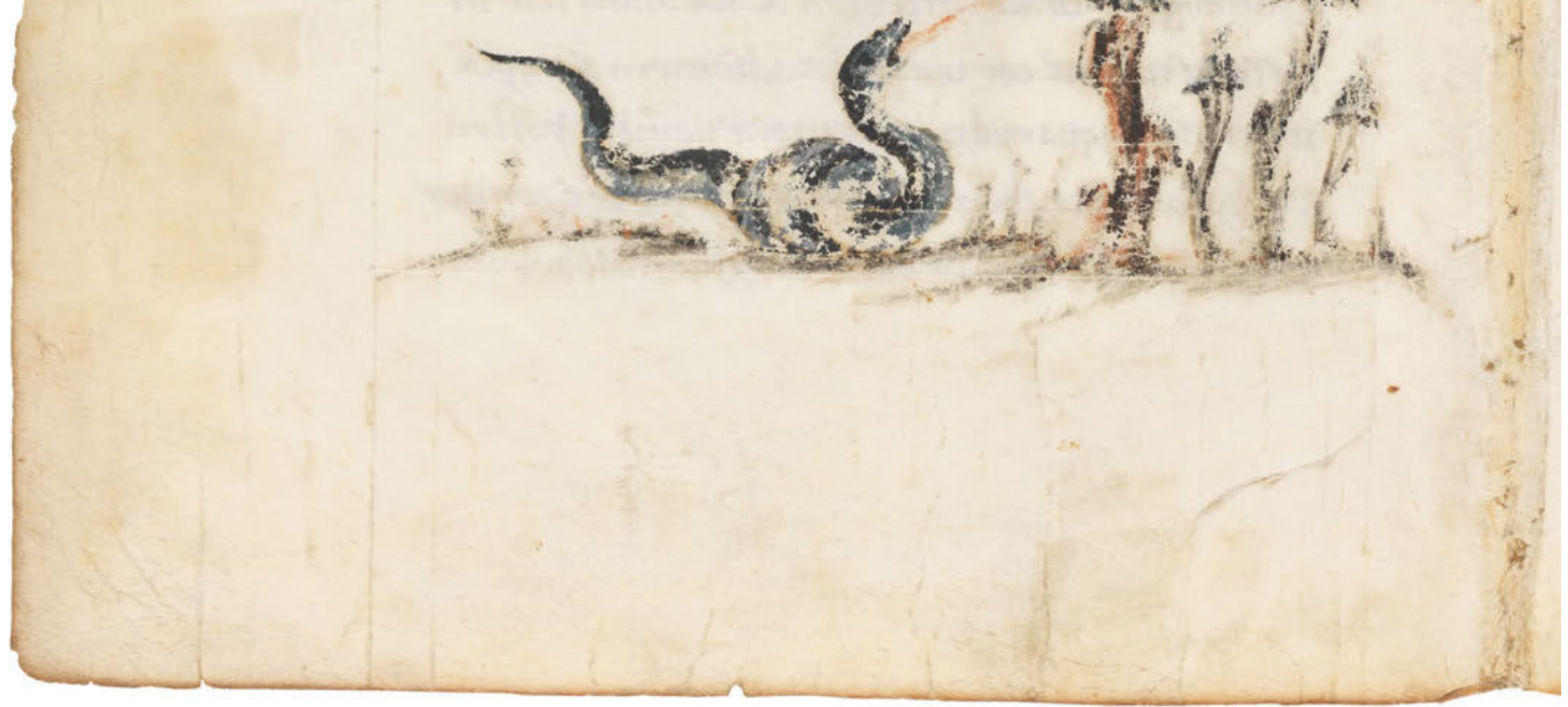
OCNRBOREQUIOICI I PEREOENTON

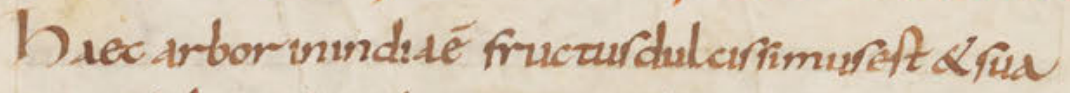
uruilde. Columbar uurem delecarraur nimum

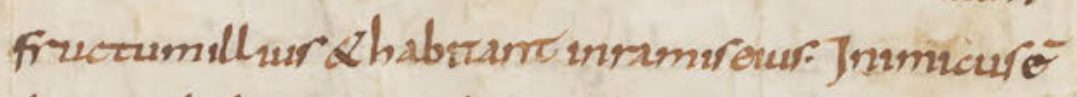
dracocolube \&umsidraco idpropinquare sdarbo

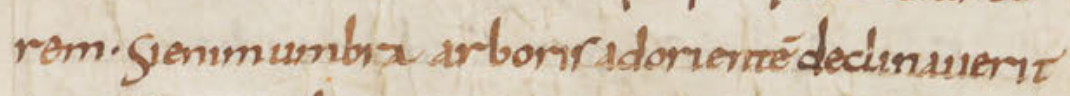

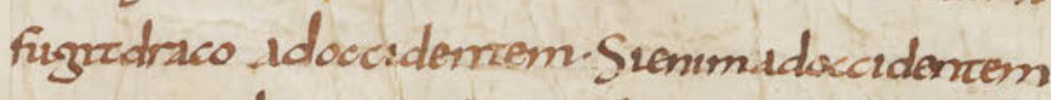

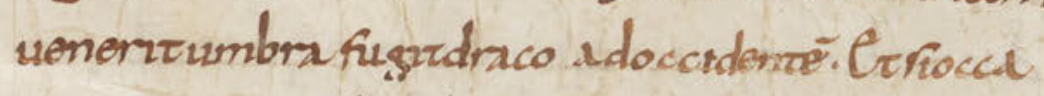
rus operuenz columbe ocadizeedracco. Arboré

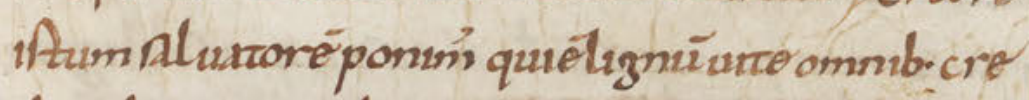
denrab.eri nnumbraturomismerzo. Qdimis aptr

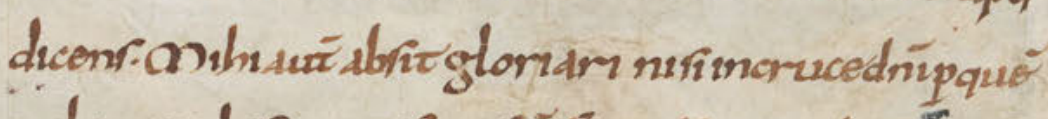
mahmmundufeructixurö Q ogo it mundo.

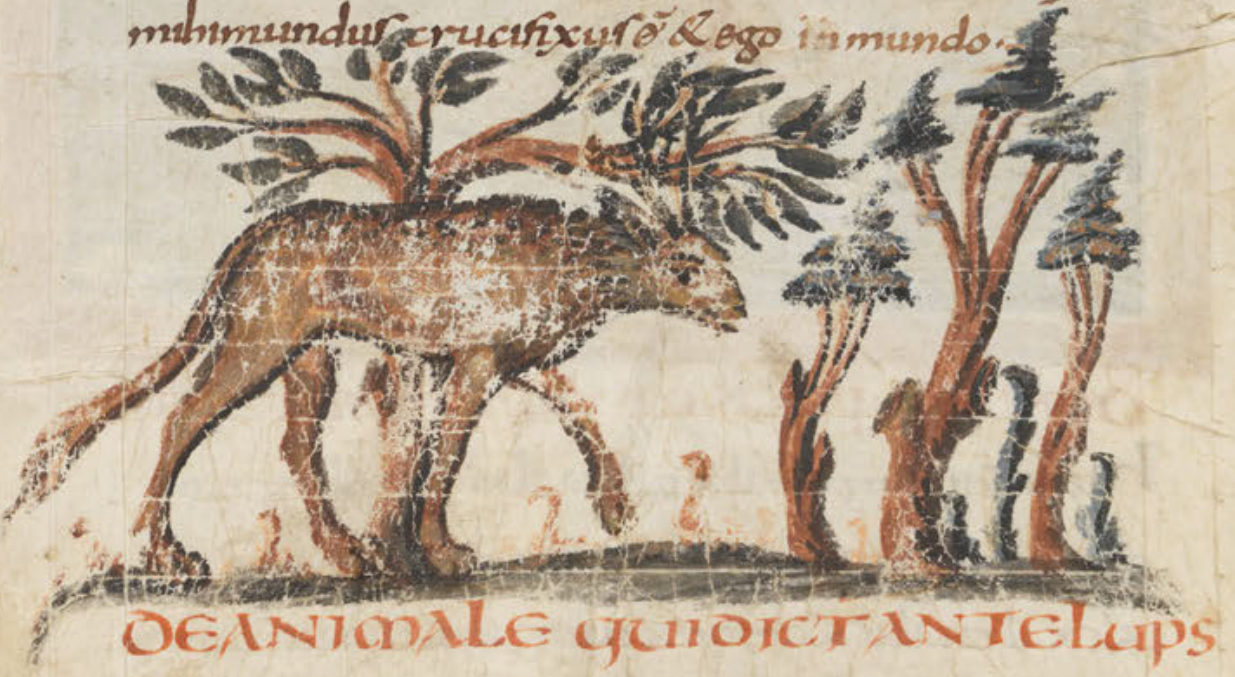
Eft ammal acenrsimar mmis ut necuentzorer meumi pricant. Gabsenam cornulonga forret 
figurahabermer ta utu-borer muzor fecentald terradeponan. Cumenumfaerın uente luunü funvenum zenur huluciramorkcumludendo

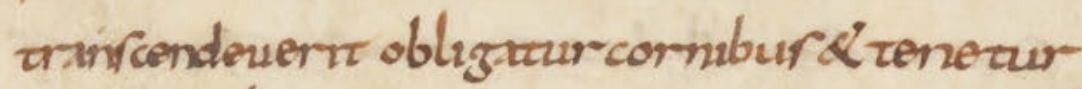
idramof hulicir umquamfinmerzerur \&dama uocteranfuolenf fugere. C Coum dudierze eum uentzor uentz kocudiz oum. Qtuhomorerua duo teitumerra nourun duecere quiterabipro falute dnime diterunt hoc of suartise luxeu iza Comm pomparate Letrincupur obligar.

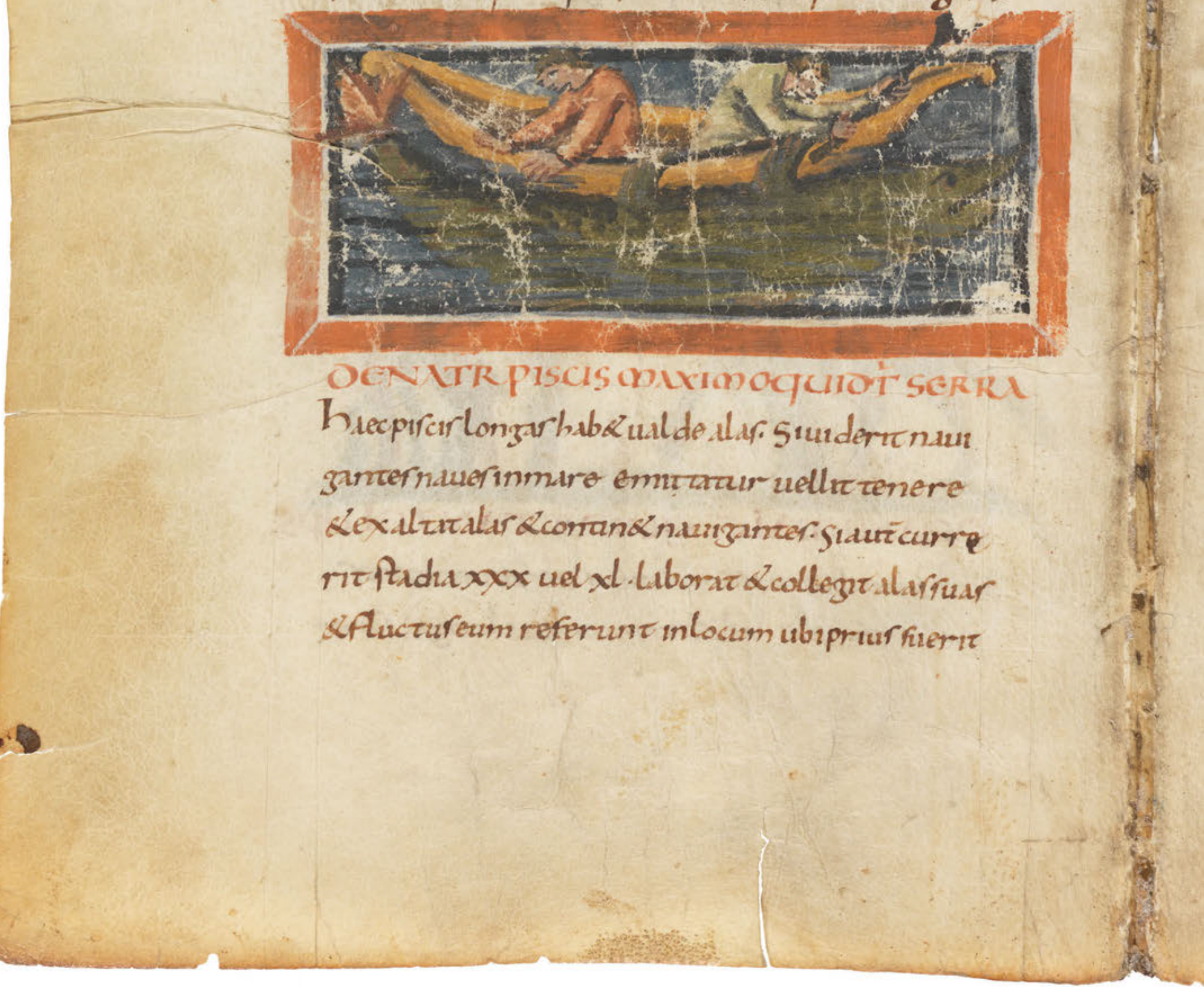


Mire mundureft. vautisi eccts inquibumi populidi. hac urípicer diubolureit quizanifizu racto uelur inangelolucar ur macuzar innmar fraluriporit decipere.

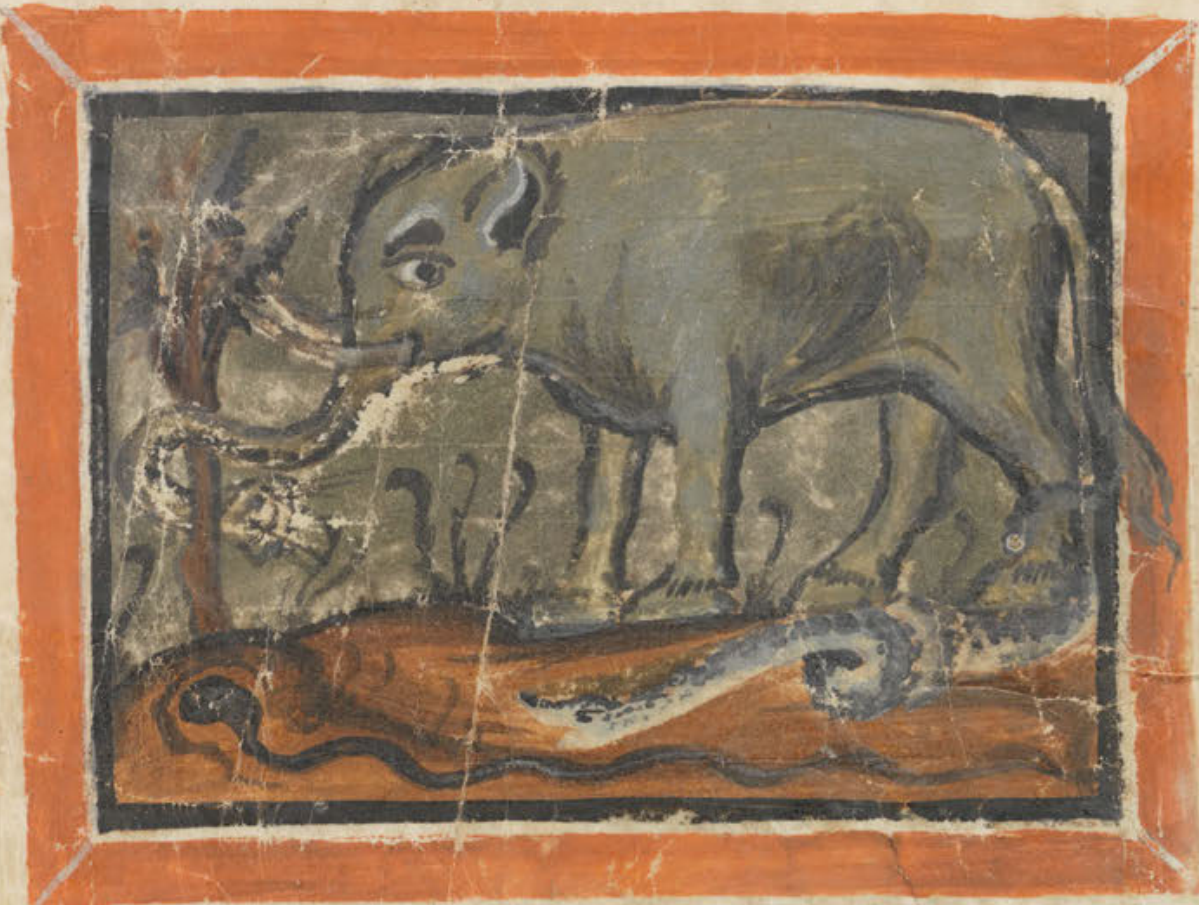

DE CLIFANTOETCONORXCORA

Noneit cortur concupricencuxe quandouluernt ficerequnczonem imbulinfupflumenpari dirfi Einuenume mandracoram quiReüferme difcurret. Lccipiensuerofiminx mandracorx prueftarmaculo cludizcumes donex minduxt e tcummanducauerit marculur conuenut cum. 


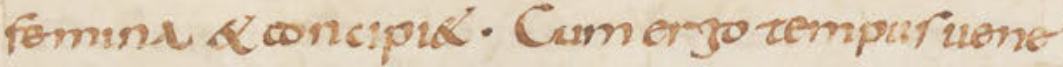

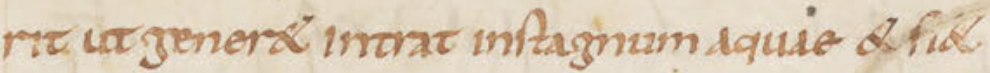
aqua admamillaferur dedmitur natum. urne unzando rup aquar proxsmum habese nizem ma

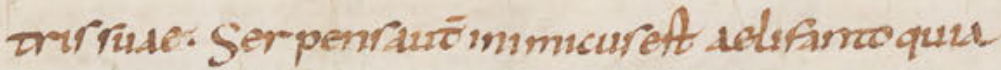
pediburfur anzenficuseum.

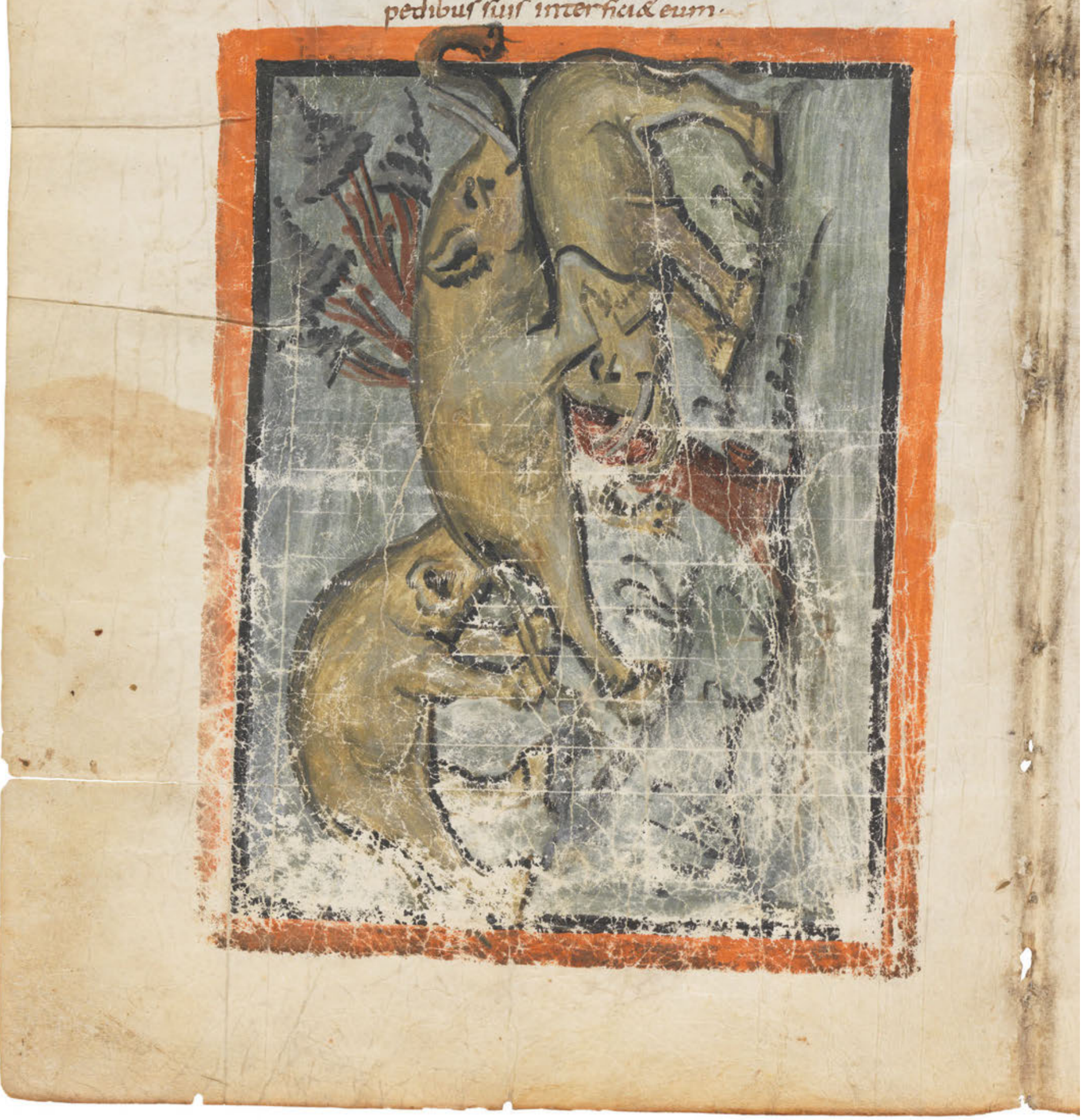


VATCIRA NCITENGLIFANIITALISE Sicecident umpoterzesfiugzere. Nimfiudu errt dormire sdcorborem indinuto dormit.

Tenstoreraurem quando eum idprehendere uolu erme incidunt arborem minur modicum. Ndum uenert indinare clormere fimul cum arbore cadiv. Cum uuz cepera damare forrazer cum

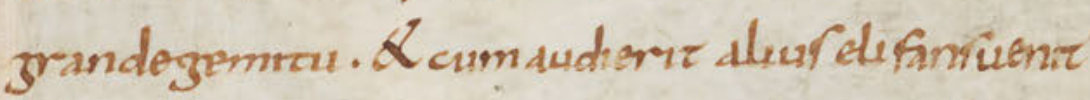
iduuareeum Znonpotert ergereeum socifram ambo. C tuenent alu cononpornint erzzere. Dein

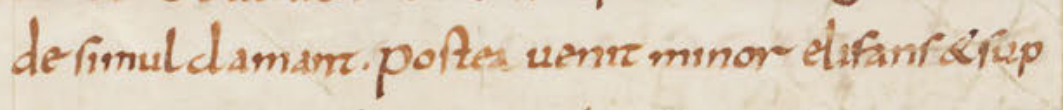
ponte promufadenfium fubtureum Leragreum. Namfizmum deorgiburewer ancerifim porizerat. neque draco neque demon abrereualuit. Clifintr iraq. mafcule stiemne fizuram ddan dere traelle

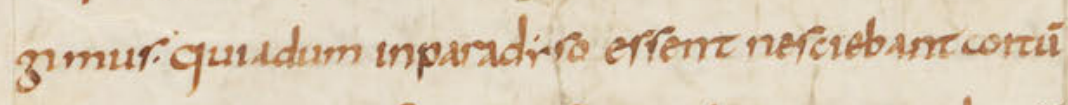

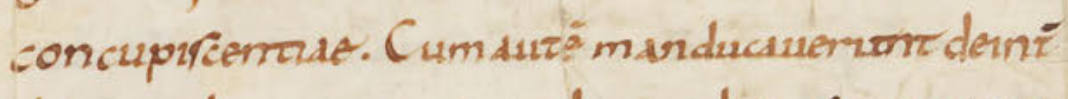

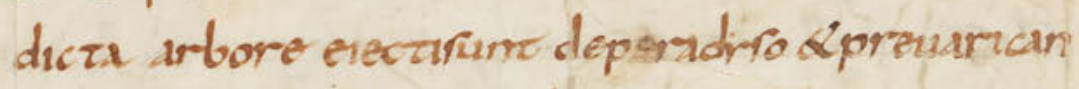
zermorturgint. Lenir lexmorten nonederaur eum oernde dro decim prapher 12 varuenter nec upfi deuduerunteum. Now fifove uente shr hum:

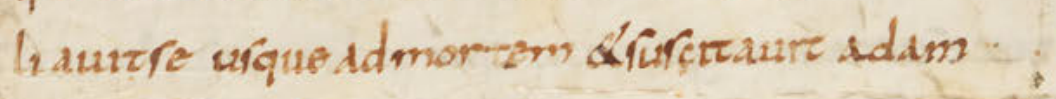
quiceciderit. 


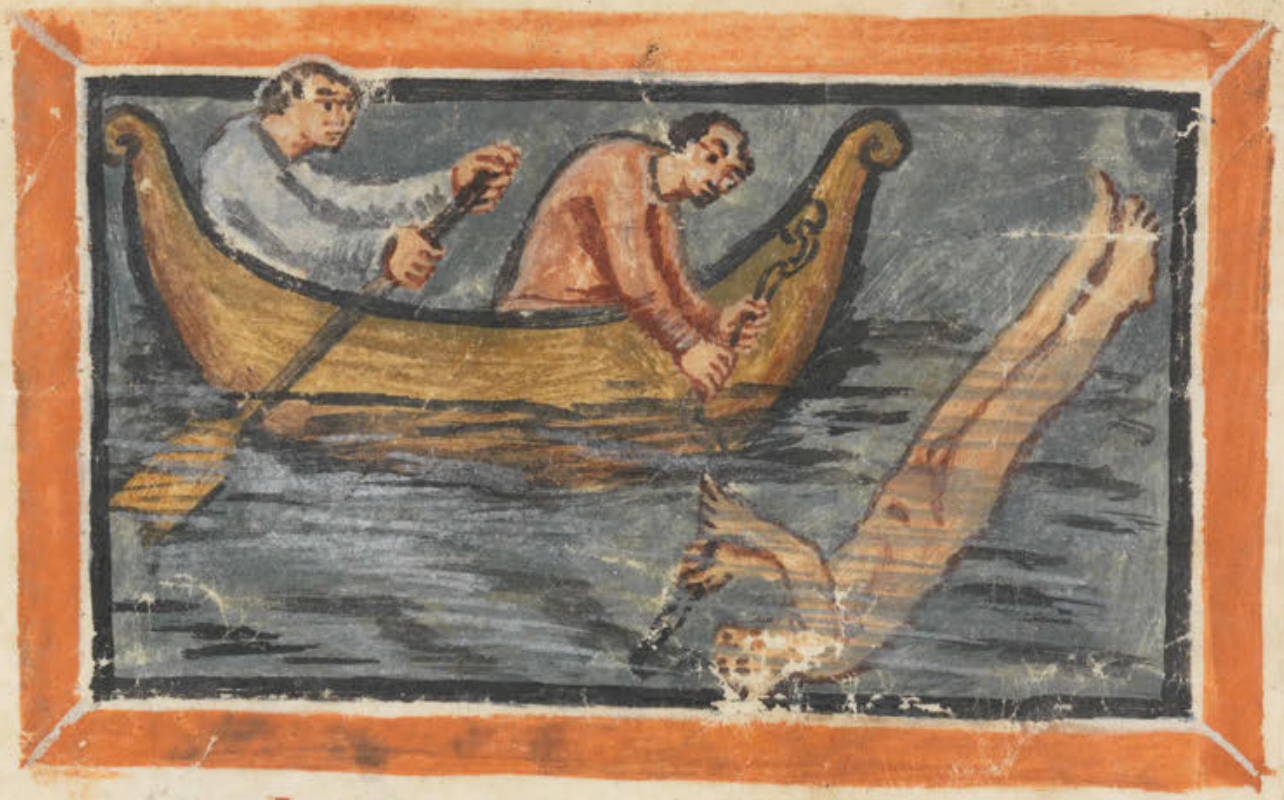

\section{DeLApIOE ACITO}

Qundo arzuficerquerume murgaria pictzu inue

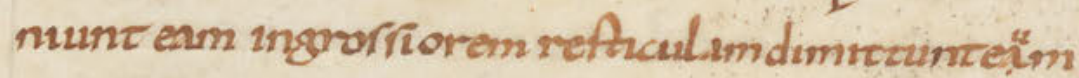

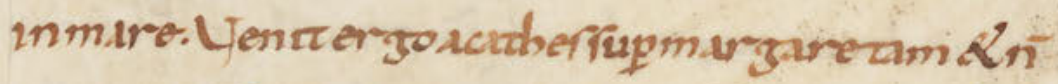

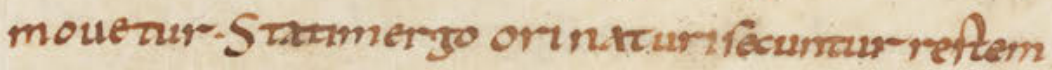
Linuennure murgareai. Conchorizocurur pricerqui

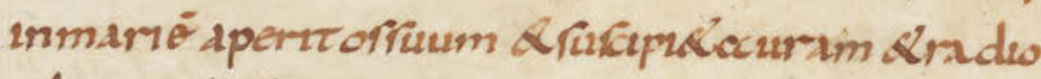

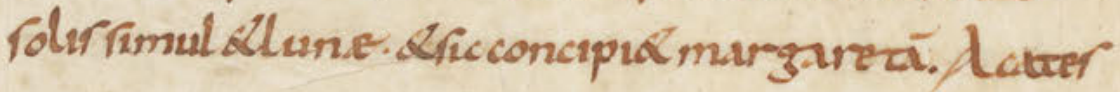
erzo qui zmuente mur zarea. dccipreur-iohanner

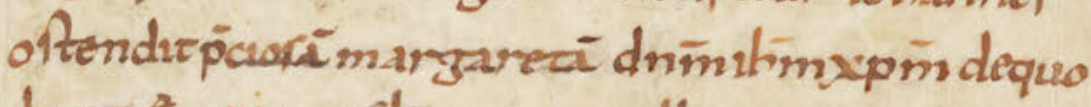

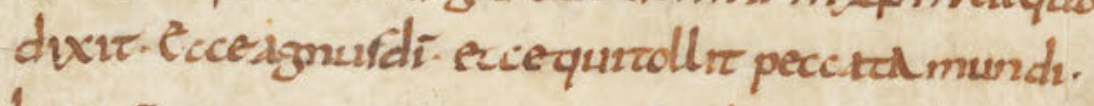

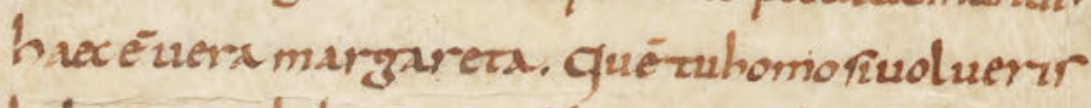
bubereuendebonsus adip uperibur anuerierex. 


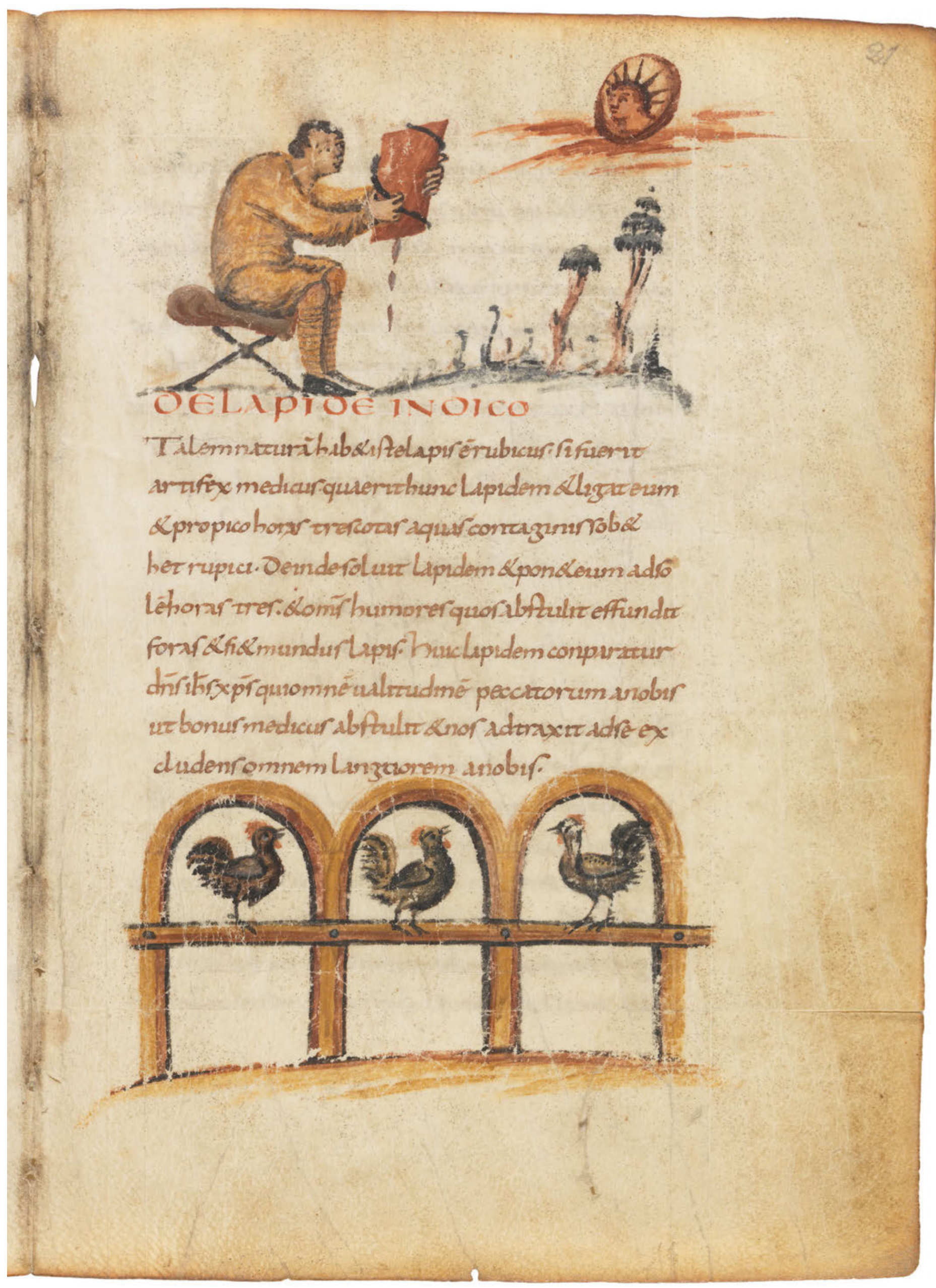




\section{DegALLA CANTLI}

CAtoram gallecuraur fudur innocaburnonfoli

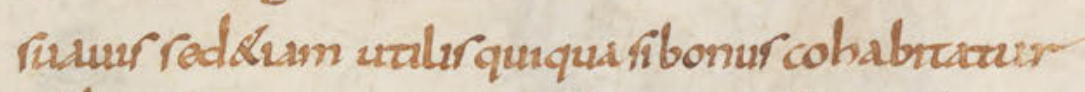

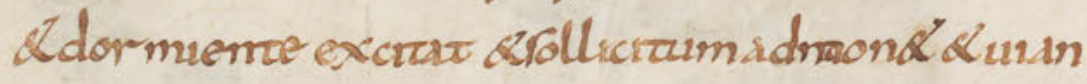

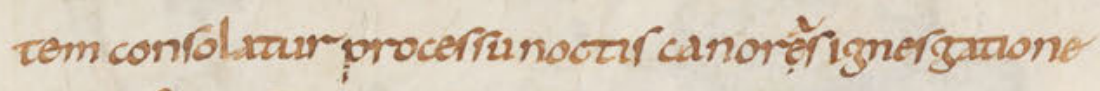
prozefanr hoc canencem lacrofurrelinqualinfidiar: Trocipretuafer excizuro orzurcieluonqueznlu mıvax. hoccinemen mitucu zepucurnuradepont.

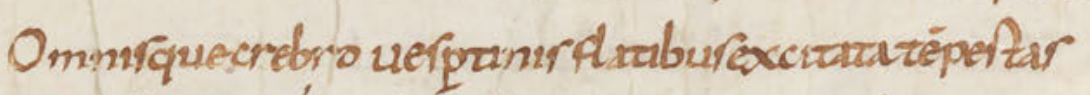

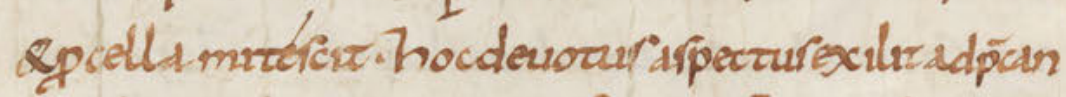
dum legendiquoque norinf tauma hoc pot tremo

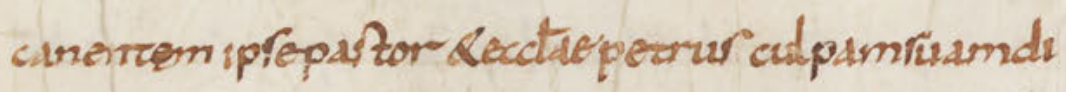
Lut quamprurquam galluranturínezandocon

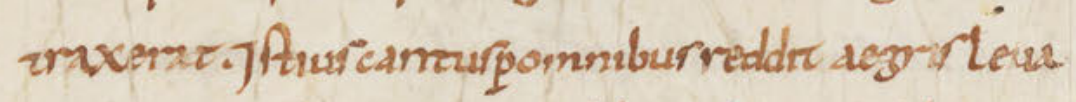
Tura incomodo minuecur-dolorwal nerum febratum

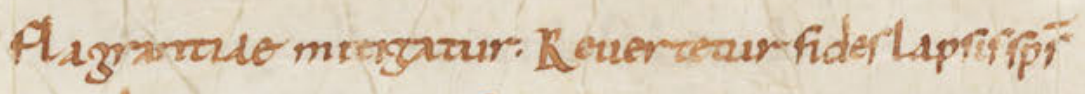

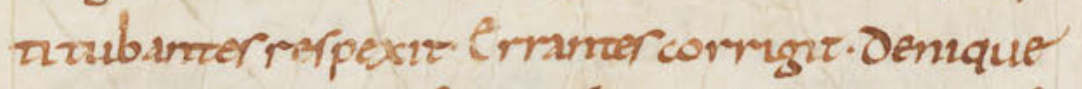

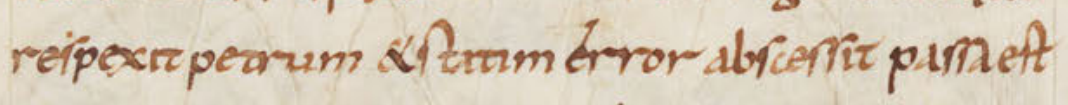
negazo feuza conferiso quodnonforzartus acceder

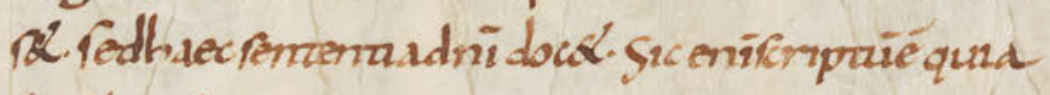

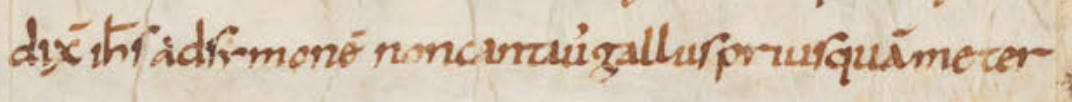

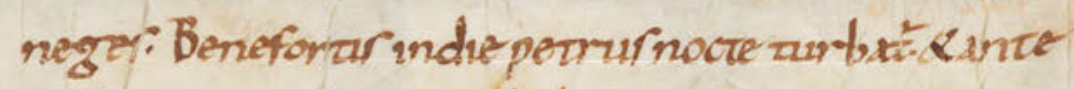

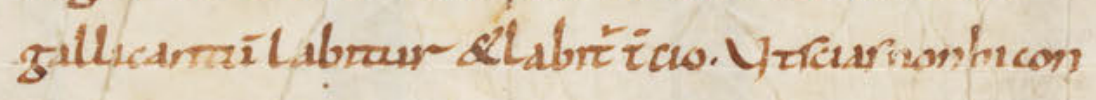


Polat Erriono fermonirelipriam fedmentarquoquo nirazionem tarbitam aurden tamen portgalle

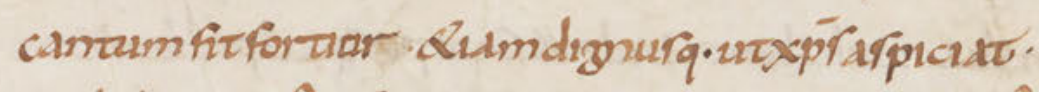

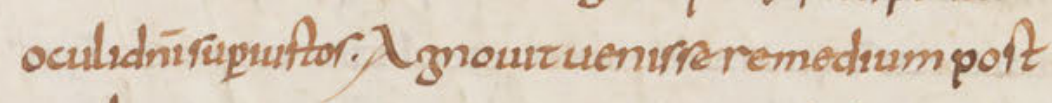
quod uan erraro nonpoffic Linuurcuzé dduer fio

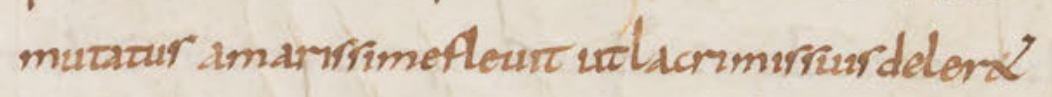
errorem. Rerpucenobrquequednéshuxpöźnor propora cogrotcamus errata.

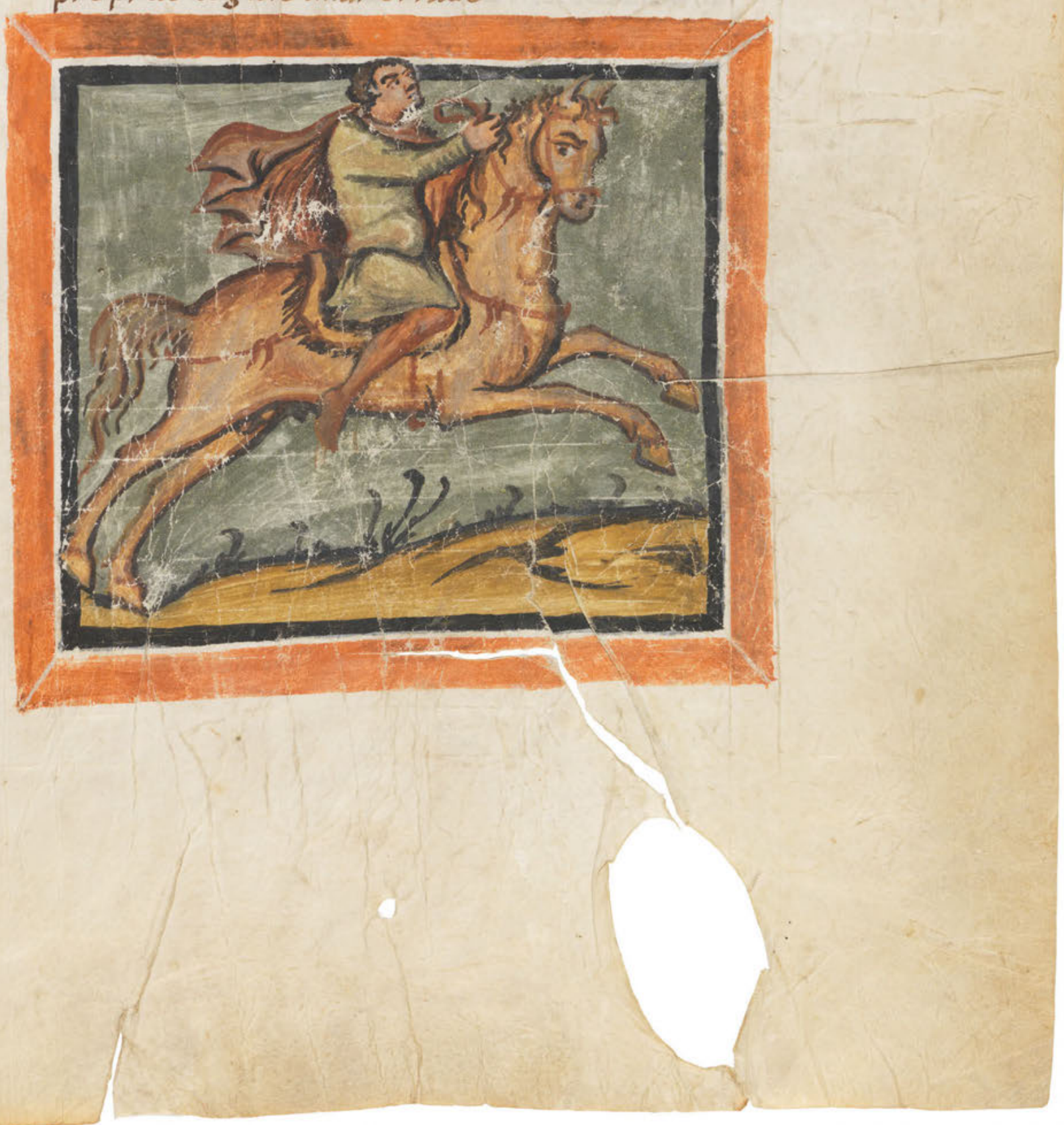


Caballurance caboductur propĩ quodmadienr

- ungula inpraeraterra concuus quodreluyus du mala nonhabont. Inde \& fonu per aquad pechbursonat uruscrar equorum mulav exulani enim incãpr idontruar bellum escramau-fonozube adproe Lutm uoce adcenf adeurfum prouocurzura Dolent cumucofiverint exultant cumuincenmuquidum

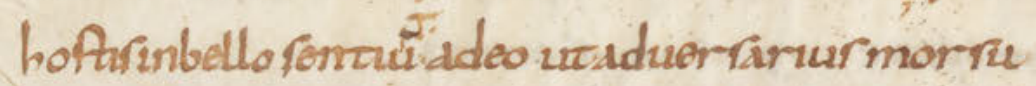
peanre. Nequediam pprordomunor recognoraun. obler manruesudrnirfimuzerrum Ulquipropó dommum dorfonull um recipiunt. inter ficar uel morzenabur dominur mulalicomar fundunt. Solumstam equum propi hommem Lanmare Rdolorir affecum fenture.7ndecenzuurum equorzum shomunum natura permixzieff; 


\section{Verzeichnis der Autorinnen und Autoren}

Prof. Dr. Christoph Eggenberger

Christoph Eggenberger ( $\left.{ }^{*} 1945\right)$ ist Kunsthistoriker; von 2001 bis 2010 leitete er die Handschriftenabteilung der Zentralbibliothek Zürich. 1985 bis 2012 lehrte er als Titularprofessor Kunstgeschichte des Mittelalters an der Universität Zürich.

\section{Prof. Dr. Herwig Görgemanns}

Nach einem Fellowship am Center for Hellenic Studies der Harvard University 1967/1968 trat Herwig Görgemanns (*1931) im Jahr 1972 die Professur für klassische Philologie an der Universität Heidelberg an, wo er bis zu seiner Emeritierung 1997 lehrte.

\section{Prof. Dr. Katharina Heyden}

Katharina Heyden (* 1977) ist Professorin für Ältere Geschichte des Christentums und der interreligiösen Begegnungen am Institut für Historische Theologie der Universität Bern.

\section{Prof. Dr. Rainer Hirsch-Luipold}

Rainer Hirsch-Luipold ( $\left.{ }^{*} 1967\right)$ ist Professor für Neues Testament und Antike Religionsgeschichte an der Universität Bern; seit 2015 zusätzlich Extraordinary Professor at Stellenbosch University (SA), Department of Ancient Studies.

\section{Dr. theol. Zbyněk Kindschi Garský}

Zbyněk Kindschi Garský ( $\left.{ }^{\star} 1970\right)$ ist wissenschaftlicher Mitarbeiter am Institut für Neues Testament der Universität Bern und Pfarrer mit Schwerpunkt Spiritualität an der Kirche Scherzligen in Thun.

\section{Dr. Thomas J. Kraus}

Thomas J. Kraus ( $\left.{ }^{\star} 1965\right)$ ist als Gymnasiallehrer in Deutschland tätig und arbeitet an seinem Habilitationsprojekt zur Rezeptionsgeschichte des Psalm $90^{\mathrm{LXX}}$ am Institut für Neues Testament der Universität Zürich.

\section{Dr. phil. hist. Florian Mittenhuber}

Florian Mittenhuber (*1972), 2009-2013 Leiter der PtolemaiosForschungsstelle am Institut für klassische Philologie der Universität Bern, ist seit 2011 Handschriftenkurator der Burgerbibliothek Bern.

\section{PD Dr. Horst Schneider}

Der klassische Philologe und Byzantinist Horst Schneider (* 1962) ist wissenschaftlicher Mitarbeiter in der Redaktion Fontes Christiani an der Ludwig-Maximilians-Universität München.

\section{Prof. Dr. Silvia Schroer}

Silvia Schroer ( $\left.{ }^{\star} 1958\right)$ ist ordentliche Professorin für Altes Testament mit besonderer Berücksichtigung der biblischen Umwelt an der Universität Bern und seit 2017 Vizerektorin der Universität.

\section{Prof. Dr. Janet Spittler}

Janet Spittler (* 1976) ist Associate Professor of Religious Studies am Department of Religious Studies der University of Virginia und Fellow der DFG-Kolleg-Forschungsgruppe „Beyond Canon“ an der Universität Regensburg.

\section{Dott. Marco Stroppa}

Marco Stroppa (* 1972) ist klassischer Philologe und Papyrologe am Papyrologischen Institut „G. Vitelli“ der Universität Florenz.

\section{Prof. Dr. Samuel Vollenweider}

Samuel Vollenweider ( ${ }^{\star} 1953$ ) bekleidete 1989-2000 die Professur für Neues Testament in Bern und von 2000 bis 2019 in Zürich.

\section{Dr. phil. Beatrice Wyss}

Die klassische Philologin Beatrice Wyss $\left({ }^{\star} 1974\right)$ ist seit 2007 in verschiedenen DFG- und SNF-Projekten tätig, zur Zeit im SNF-Projekt „Image of God and Abyss of Desires. The Theological Implications of Anthropological Conceptualisation in Hellenistic Judaism, Early Christianity and Pagan-Religious Platonism“. 



\section{Bibliographie zum Physiologus (Auswahl)}

\section{Bibel}

BHS. ${ }^{5}$ 1997. Biblia Hebraica Stuttgartensia, hrsg. v. Karl Elliger und Wilhelm Rudolph. Stuttgart: Deutsche Bibelgesellschaft.

LXX. 2006. Septuaginta, hrsg. v. Alfred Rahlfs und neu v. Robert Hanhart. Stuttgart: Deutsche Bibelgesellschaft.

LXX.D. 2009. 2011. Septuaginta Deutsch: Das griechische Alte Testament in deutscher Übersetzung, hrsg. v. Wolfgang Kraus und Martin Karrer. Stuttgart: Deutsche Bibelgesellschaft. Septuaginta Deutsch: Erläuterungen und Kommentare. 2 Bde., hrsg. v. Wolfgang Kraus und Martin Karrer, Stuttgart: Deutsche Bibelgesellschaft.

NA. ${ }^{28} 2012$. Novum Testamentum Graece, hrsg. v. Barbara and Kurt Aland, Johannes Karavidopoulos, Carlo M. Martini und Bruce M. Metzger. Stuttgart: Deutsche Bibelgesellschaft.

VULG. ${ }^{5}$ 2007. Biblia Sacra Vulgata, hrsg. v. Robert Weber und Roger Gryson. Stuttgart: Deutsche Bibelgesellschaft.

\section{Physiologus}

\section{Physiologus Graecus}

Kaimakis, Dimitris, Hg. 1974. Der Physiologus nach der ersten Redaktion. Beiträge zur klassischen Philologie 63. Meisenheim am Glan: A. Hain.

Karnejev, Alexander, Hg. 1894. „Der Physiologus der Moskauer Synodalbibliothek: Ein Beitrag zur Lösung der Frage nach der Vorlage des armenischen und eines alten lateinischen Physiologus.“ ByzZ 3:26-63.

Lauchert, Friedrich, Hg. 1889 [1974]. Geschichte des Physiologus. Strassburg: Karl J. Trübner [Genève: Slatkine].

Offermanns, Dieter, Hg. 1966. Der Physiologus nach den Handschriften $G$ und M. BKP 22. Meisenheim am Glan: A. Hain.

Pitra, Jean Baptiste, Hg. 1855. „Veterum gnosticorum in Physiologum allegoricae interpretationes." In Spicilegium Solesmense complectens sanctorum patrum scriptorumque ecclesiasticorum anecdota hactenus opera. Bd. 3, In quo praecipui veteres auctores de re symbolica proferuntur et illustrantur, hrsg. v. Jean Baptiste Pitra, 338-373; 391-394. Paris: Firmin Didot.

Ponce de Leon, Luis, Hg. 1587. Sancti Patris nostri Epiphanii episcopi Constantiae Cypri ad Physiologum. Rom: Zanetti \& Ruffinelli.

Sbordone, Francesco, Hg. 1936a [1976, ${ }^{2}$ 1991]. Physiologus. Rom: Società Anonima Editrice ,Dante Alighieri‘ [Hildesheim: Olms].

Stroppa, Marco. 2011. „Un papiro inedito del Fisiologo (PSI inv. 295)“. In I Papiri letterari cristiani. Studi e Testi di Papirologia N.S. 13, hrsg. v. Guido Bastianini and Angelo Casanova, 173192. Florenz: Istituto Papirologico „G. Vitelli“.

\section{Physiologus Latinus}

Carmody, Francis J., Hg. 1939. Physiologus Latinus: Éditions préliminaires versio $B$. Paris: Librairie E. Droz.
Carmody, Francis J., Hg. 1941. „Physiologus Latinus Versio Y.“ University of California Publications in Classical Philology 12,7:95-134.

Eden, Peter. T. 1972. Theobaldi «Physiologus». Mittelalterliche Studien und Texte 6. Leiden: Brill.

Mann, Max Friedrich. 1888. Der bestiaire divin des Guillaume le Clerc. Heilbronn: Henninger.

Mittenhuber, Florian, Hg. 2012. Siehe Steiger und Homburger 1964.

Sbordone, Francesco, Hg. 1943. I bestiari e le rime amorose del secolo XIII. Napoli: Luigi Loffredo Editore.

Steiger, Christoph von, und Otto Homburger, Hgg. 1964/2012. Physiologus Bernensis: Voll-Faksimile-Ausgabe des Codex Bongarsianus 318 der Burgerbibliothek Bern, Basel: Alkuin. / Bern, Burgerbibliothek, Cod. 318: Physiologus Bernensis, redigiert und ergänzt von Florian Mittenhuber, Juni 2012, http://www.e-codices.unifr.ch/de/list/one/bbb/0318.

Wilhelm, Friedrich. 1916 [1960]. „Dicta Chrysostomi.“ In Denkmäler deutscher Prosa des 11. und 12. Jahrhunderts (Abteilung B: Kommentar). Münchener Texte 8, hrsg. v. Friedrich Wilhelm, 15-44. München: Callwey [München: Huber].

\section{Physiologus in weiteren Sprachen}

Armistead, Mary Allyson, Hg. 2001. The Middle English Physiologus: A Critical Translation and Commentary. Blacksburg, VA: Virginia Polytechnic Institute and University.

Depietri, Marco, 2010. Der Jüngere Physiologus: Eine sprachwissenschaftliche Untersuchung; Mit einer Datenbank sämtlicher Belegformen und den dazugehörigen Detailanalysen auf einer CD-ROM. PHILOLOGIA: Sprachwissenschaftliche Forschungsergebnisse 153. Hamburg: Kovač.

Erman, Adolf. 1895. „Bruchstücke des koptischen Physiologus“. Zeitschrift für ägyptische Sprache und Altertumskunde 33:5157.

Hommel, Fritz, Hg. 1877. Die äthiopische Übersetzung des Physiologus nach je einer Londoner, Pariser und Wiener Handschrift. Leipzig: J.C. Hinrichs.

Muradyan, Gohar, Hg. 2005. Physiologus: The Greek and Armenian Versions with a Study of Translation Technique. HUAS 6. Löwen: Peeters.

Peters, Emil, Hg. 1898 [1976]. Der griechische Physiologus und seine orientalischen Übersetzungen. Festschriften der Gesellschaft für deutsche Philologie 15. Berlin: S. Calvary [Hildesheim: Olms].

Pitra, Jean Baptiste, Hg. 1855. „Allegoriarum in Physiologum interpretatio vetus armenia." In Spicilegium Solesmense complectens sanctorum patrum scriptorumque ecclesiasticorum anecdota hactenus opera. Bd. 3 , In quo praecipui veteres auctores de re symbolica proferuntur et illustrantur, hrsg. v. Jean Baptiste Pitra, 374-390. Paris: Firmin Didot.

Schröder, Christian, Hg. 2005. Der Millstätter Physiologus: Text, Übersetzung, Kommentar. Würzburger Beiträge zur deutschen Philologie 24, Würzburg: Königshausen \& Neumann.

Stoykova, Ana, Hg. 1994, 2009-2012. Comparative Study of the Medieval South Slavic Physiologus: Byzantine Recension. http://physiologus.proab.info. 
Stroppa, Marco. 2017. „The Physiologus in Egypt.“ In Proceedings of the XI International Congress of Egyptologists. Archaeopress Egyptology 19, hrsg. v. Gloria Rosati und Maria Cristina Guidotti, 603-607. Oxford: Archaeopress.

Wentker, Sibylle, Hg. 2004. Der arabische Physiologus: Edition, Übersetzung, Kommentar. Wien: Universitätsbibliothek der Universität Wien.

Wilhelm, Friedrich. 1914/1916 [1960]. „II. Der ältere Phyiologus. III. Der jüngere Physiologus“. Denkmäler deutscher Prosa des 11. und 12. Jahrhunderts (Abteilung A: Text). Münchener Texte 8:4-28 / „II. und III. Der ältere und der jüngere Physiologus“. Denkmäler deutscher Prosa des 11. und 12. Jahrhunderts ( $A b$ teilung B: Kommentar). Münchener Texte 8:13-52. München: Callwey [München: Huber].

\section{Moderne Übersetzungen des Physiologus}

\section{Deutsch}

Hommel, Fritz, 1890. „Der äthiopische Physiologus“. Romanische Forschungen 5:13-36.

Schönberger, Otto. (2001) 2014. Physiologus: Griechisch/Deutsch. Stuttgart: Reclam.

Seel, Otto. (1960) ${ }^{3}$ 2005. Der Physiologus: Tiere und ihre Symbolik. (Zürich: Artemis \& Winkler) Düsseldorf: Patmos.

Treu, Ursula. (1981) ${ }^{3}$ 1998. Physiologus: Naturkunde in frühchristlicher Deutung. (Berlin: Union) Hanau: Artia.

\section{Englisch}

Curley, Michael J. (1979) ${ }^{2}$ 2009. Physiologus: A Medieval Book of Nature Lore. Chicago: University of Chicago Press.

Grant, Robert. 1999. Early Christians and Animals, 52-72. London: Routledge.

\section{Französisch}

Zucker, Arnaud. (2004) ${ }^{2} 2005$. Physiologos: Le bestiaire des bestiaires. Grenoble: Jérôme Millon.

\section{Italienisch}

Zambon, Francesco. 1975. Il Fisiologo. Milano: Adelphi.

\section{Antike und mittelalterliche Autoren und Texte}

Aelian

Brodersen, Kai., Hg. 2018. Ailianos: Tierleben. Sammlung Tusculum. Berlin: De Gruyter.

García Valdés, Manuela, Luis Alfonso Llera Fueyo und Lucía Rodríguez-Noriega Guillén, Hgg. 2009. Aelianus, Claudius: De natura animalium. BSGRT. Berlin: De Gruyter.

Treu, Ursula, und Kurt Treu, Hgg. 1978. Älian: Die tanzenden Pferde von Sybaris; Tiergeschichten. Leipzig: Reclam.

\section{Ambrosius}

Banterle, Gabriele, Hg. 1979. I sei giorni della creazione (Esamerone). Opera Omnia di Sant'Ambrogio 1, Rom: Città Nuova.

\section{Aristoteles}

Aubert, Hermann, und Friedrich Wimmer, Hgg. 1868. Aristoteles: Thierkunde. Bd. 1. Leipzig: Wilhelm Engelmann.

Balme, David M., Hg. 2002. Aristotle: Historia Animalium. Bd. 1, Books I-X: Text. Cambridge Classical Texts and Commentaries 38. Cambridge: Cambridge University Press.

Balss, Heinrich, Hg. 1943 [2014]. Aristoteles: Biologische Schriften; griechisch und deutsch. München: Heimeran [Berlin: De Gruyter].

Dittmeyer, Leonard, Hg. 1907. Aristotelis De animalibus historia. Leipzig: Teubner.

Flashar, Hellmut, und Ulrich Klein, Hgg. 1972 [2009]. Aristoteles: Opuscula II und III; Mirabilia und De audibilibus. Aristoteles Werke in deutscher Übersetzung 18.2-3. Berlin: AkademieVerlag [De Gruyter].

Kullmann, Wolfgang, Hg. 2007 [2009]. Aristoteles: Über die Teile der Lebewesen. Aristoteles Werke in deutscher Übersetzung 17,1, Zoologische Schriften II. Berlin: Akademie Verlag [De Gruyter].

\section{Decretum Gelasianum}

Dobschütz, Ernst von, Hg. 1912. Das Decretum Gelasianum de libris recipiendis et non recipiendis. Texte und Untersuchungen zur Geschichte der altchristlichen Literatur 38,4. Leipzig: J.C. Hinrichs.

\section{Isidor von Sevilla}

Lindsay, Wallace Martin. 1911. Isidori Hispalensis episcopi Etymologiarum sive originum libri XX. Oxford: Oxford University Press.

Phaedrus

Perry, Ben E., Hg. 1965. Babrius and Phaedrus: Fables. Loeb Classical Library 436. Cambridge, MA: Harvard University Press.

Plinius

König, Roderich, und Gerhard Winkler, Hgg. $(1976)^{2} 2007$. C. Plinius Secundus d. Ältere: Naturkunde / Naturalis historia libri XXXVII; Lateinisch-deutsch; Buch VIII; Zoologie: Landtiere. (München: Heimeran-Verlag) Düsseldorf: Artemis \& Winkler.

König, Roderich, und Gerhard Winkler, Hgg. (1986) ${ }^{2}$ 2007. C. Plinius Secundus d. Ältere: Naturkunde / Naturalis historia libri XXXVII; Lateinisch-deutsch; Buch X; Zoologie: Vögel; Weitere Einzelheiten aus dem Tierreich. (München: Artemis) Düsseldorf: Artemis $\&$ Winkler.

Mayhoff, Karl, Hg. 1892-1909. C. Plinii Secundi naturalis historiae libri XXXVII. 6. Bde. Leipzig: Teubner.

Plutarch

Bouffartigue, Jean, Hg. 2012. Plutarque: Oeuvres morales; Traité 63: L'intelligence des animaux. Paris: Les belles lettres.

Görgemanns, Herwig, et al. Hg. (2003) ${ }^{2} 2009$ [2014]. Plutarch. Drei religionsphilosophische Schriften. Düsseldorf: Artemis \& Winkler [Berlin: De Gruyter]. 


\section{Moderne Autoren}

Ahrens, Karl. 1885. Zur Geschichte des sogenannten Physiologus. Ploen: S. W. Hirt's Buchdruckerei.

Alexandridis, Annetta, Markus Wild und Lorenz Winkler-Horacek, Hgg. 2008. Mensch und Tier in der Antike: Grenzziehung und Grenzüberschreitung. Wiesbaden: Reichert Verlag.

Alpers, Klaus. 1984. „Untersuchungen zum griechischen Physiologus und den Kyraniden. “ In All Geschöpf ist Zung' und Mund: Beiträge aus dem Grenzbereich von Naturkunde und Theologie. Vestigia Bibliae: Jahrbuch des Deutschen Bibel-Archivs 6, hrsg. v. Heimo Reinitzer, 13-87. Hamburg: Friedrich Wittig.

Alpers, Klaus. 1996. „Physiologus.“ TRE 36:596-602.

Alpers, Klaus. 2006 „Physiologus.“ DNP. http://dx.doi.org/10. 1163/1574-9347_dnp_e924920.

Baxter, Ron. 1998. Bestiaries and their users in the Middle Ages. Stroud: Sutton.

Brehm, Alfred Edmund. ${ }^{2}$ 1879. Brehms Thierleben: Allgemeine Kunde des Thierreichs; Große Ausgabe. Bd. 5, Die Vögel. Leipzig: Verlag des Bibliographischen Instituts.

Ciccarese, Maria Pia. 2009. „Bibbia, bestie e Bestiari: l'interpretazione cristiana degli animali dalle origini al Medioevo." In Animali tra mito e simbolo. Biblioteca di testi e studi 503, hrsg. v. Sergio Botta, Alessandro Cerri, Maria Pia Ciccarese, Gilberto Mazzoleni und Adriano Santiemma, 75-124. Rom: Carocci.

Cox, Patricia. 1983. „The Physiologus: A Poiēsis of Nature.“ Church History 52,4:433-443.

Cox Miller, Patricia. 2001. The Poetry of Thought in Late Antiquity: Essays in Imagination and Religion. Burlington: Ashgate.

Dahlerup, Verner. 1889. „Physiologus i to islandske Bearbejdelser.“ In Aarbøger for nordisk Oldkyndighed og Historie. 2. Reihe, Band 4, 199-290. Kopenhagen: Thiele.

Dierauer, Urs. 1977. Tier und Mensch im Denken der Antike: Studien zur Tierpsychologie, Anthropologie und Ethik. Studien zur Antiken Philosophie 6. Amsterdam: Grüner.

Fitzenreiter, Martin. 2013. Tierkulte im pharaonischen Ägypten. Ägyptologie und Kulturwissenschaft 5. München: Wilhelm Fink.

Gallazzi, Claudio, Bärbel Kramer und Salvatore Settis, Hgg. 2008. Il papiro di Artemidoro (P.Artemid.). Mailand: LED.

Gerhardt, Mia I. 1965. „The Ant Lion: Nature Study and the Interpretation of a Biblical Text, from the Physiologus to Albert the Great." Vivarium: Journal for the Philosophy and Intellectual Life of the Middle Ages and Renaissance 3:1-23.

Gilhus, Ingvild Saelid. 2006. Animals, Gods and Humans: Changing Attitudes to Animals in Greek, Roman and Early Christian Thought. New York: Routledge.

Goldstaub, Max. (1899-1901) 1900. „Der Physiologus und seine Weiterbildung, besonders in der lateinischen und in der byzantinischen Literatur." Philologus: Zeitschrift für das klassische Alterthum; Supplementband 8,3:339-404.

Gottheil, Richard. 2003. „The Greek Physiologus and Its Oriental Translations." The American Journal of Semitic Languages and Literatures 15:120-124.

Graf, Georg. 1906. „Der georgische Physiologus.“ Caucasica 2:93114.

Grant, Robert, Hg. 1999. Early Christians and Animals. London: Routledge.

Gregory, Caspar R. 1909. Textkritik des Neuen Testaments. Leipzig: J.C. Hinrichs.
Grubmüller, Klaus. 1978 [2010]. „Überlegungen zum Wahrheitsanspruch des Physiologus im Mittelalter.“ Frühmittelalterliche Studien 12,1:160-177.

Grzimek, Bernhard. 1970. Grzimeks Tierleben. Bd. 8, Vögel II. Zürich: Kindler.

Günter, Wolfgang. 2007. Taube, Löwe, Kreuz und Anker. Christliche Symbole und ihre Bedeutung. Wuppertal: R. Brockhaus.

Hagelberg, Leonie. 2007. „Physiologos.“ DNP: Supplemente I Online - Band 2; Geschichte der antiken Texte: Autoren- und Werklexikon. http://dx.doi.org/10.1163/2452-3054_dnpo2_ COM_0170.

Hassig, Debra. 1995. Medieval Bestiaries: Text, Image, Ideology. Cambridge: Cambridge University Press.

Henkel, Nikolaus. 1976. Studien zum Physiologus im Mittelalter. Hermaea: Neue Folge 38. Tübingen: Max Niemeyer.

Henkel, Nikolaus. ${ }^{2}$ 2010. „Physiologus.“ LLex 9:213-215.

Homburger, Otto. Hg. 1962. Die illustrierten Handschriften der Burgerbibliothek Bern: Die vorkarolingischen und karolingischen Handschriften. Bern: Burgerbibliothek Bern.

Imorde, Joseph. 2003. „Physiologus.“ $R G G^{4}$ 6:1330.

Kaimakis, Dimitris. 1976. Die Kyraniden. Beiträge zur klassischen Philologie 76. Meisenheim am Glan: A. Hain.

Kinzelbach, Ragnar. 2009. Tierbilder aus dem ersten Jahrhundert: Ein zoologischer Kommentar zum Artemidor-Papyrus. Berlin: De Gruyter.

Klauck, Hans-Josef. 2008. Die apokryphe Bibel: Ein anderer Zugang zum frühen Christentum. Tria Corda 4. Tübingen: Mohr Siebeck.

Kühner, Ruth. 1985. "Physiologus". In Acts of the Second International Congress of Coptic Studies, ed. by Tito Orlandi and Frederik Wisse, 135-147. Rom: CIM.

van Lantschoot, Arnold. 1950. „A propos du Physiologus“. In Coptic Studies in Honor of Walter Ewing Crum, 339-363. Boston: The Byzantine Institute.

Lauchert, Friedrich, 1890. „Zum Physiologus“. Romanische Forschungen 5:3-12.

Lazaris, Stavros. 2016. Le Physiologus grec. Bd. 1, La réécriture de l'histoire naturelle antique. Micrologus Library 77.1. Florenz: SISMEL.

Maas, Paul. 1937. „B. E. Perry, Studies in the Text History of the Life and Fables of Aesop. Haverford, PA 1936. Physiologus ed. F. Sbordone. 1936. A. B. Drachmann, Die Überlieferung des Cyrillglossars. Kopenhagen 1936.“ Byzantinische Zeitschrift 37,2:376-381.

McCulloch, Florence. 1960. Mediaeval Latin and French Bestiaries. Chapel Hill: University of North Carolina Press.

Mielsch, Harald. 2005. Griechische Tiergeschichten in der antiken Kunst. Mainz: Philipp von Zabern.

Moretti, Paola Francesca. 2012. „,Ut leo, sic formica vocor sermone Pelasgo': Some remarks about the ant-lion and its metamorphosis in the tradition of the Latin ,Physiologus “". In Meminisse iuvat: Studi in memoria di Violetta de Angelis, hrsg. v. Filippo Bognini, 581-596. Pisa: ETS.

Newmyer, Stephen T. 2008. „The Human Soul and the Animal Soul: Stoic Theory and Its Survival in Contractualist Ethics." In Mensch und Tier in der Antike: Grenzziehung und Grenzüberschreitung, hrsg. v. Annetta Alexandridis, Markus Wild und Lorenz Winkler-Horacek, 71-80. Wiesbaden: Reichert Verlag.

Newmyer, Stephen T. 2014. „Animals in Plutarch“. In A Companion to Plutarch, hrsg. v. Mark Beck, 223-234. Malden, MA: WileyBlackwell. 
Nicklas, Tobias, und Spittler, Janet. 2016. „Christ and the Pelican: Function, Background and Impact of an Image.“ ETL 92:323337.

Nicklas, Tobias. 2013. „Staunen über Natur und christliche Lebenshaltung: Die Welten des Physiologus“. In Credible, Incredible: The Miraculous in the ancient Mediterranean. WUNT 321, hrsg. v. Tobias Nicklas und Janet E. Spittler, 227-250. Tübingen: Mohr Siebeck.

Orlandi, Giovanni. 1985. „La tradizione del Physiologus e i prodromi del bestiario latino." In Settimane di studio del centro italiano di studi sull'alto medioevo 31 (Spoleto 7-13 Aprile 1983), 1057-1106. Spoleto: Sede del Centro.

Perry, Ben E. 1937. „Physiologus, ed. F. Sbordone. Milan 1936.“ AJP 58,4:488-496.

Perry, Ben E. 1941. „Physiologus.“ PRE 20,1:1074-1129.

Perry, Ben E. 1968. „Der Physiologus nach den Handschriften G und M by Dieter Offermanns.“ Gnomon 40,4:416-418.

Peterson, Erik. (1954) 1959. „Die Spiritualität des griechischen Physiologos.“ In Frühkirche, Judentum und Gnosis: Studien und Untersuchungen, hrsg. v. Erik Peterson, 236-253. Rom: Herder (= Byzantinische Zeitschrift 47:60-72).

Prostmeier, Ferdinand R., Hg. 1999. Der Barnabasbrief. Kommentar zu den Apostolischen Vätern 8. Göttingen: Vandenhoeck \& Ruprecht.

Rahner, Hugo. 1964. Symbole der Kirche: Die Ekklesiologie der Väter. Salzburg: Otto Müller.

Riedinger, Rudolf. 1973. „Der Physiologos und Klemens von Alexandreia." Byzantinische Zeitschrift 66:273-307.

Riedinger, Rudolf. 1977. „D. Kaimakis, Der Physiologos nach der ersten Redaktion. [Meisenheim am Glan 1974]. “ Byzantinische Zeitschrift 70,1:109-112.

Sbordone, Francesco, 1936b. Ricerche sulle fonti e sulla composizione del Physiologus Greco, Neapel: Torella.

Sbordone, Francesco. 1949. „La tradizione manoscritta del Physiologo latino." Athenaeum NS 27:246-280.

Schneemelcher, Wilhelm, Hg. ${ }^{6} 1990$. Neutestamentliche Apokryphen in deutscher Übersetzung. Bd. 1, Evangelien. Tübingen: Mohr Siebeck.

Schneemelcher, Wilhelm, Hg. ${ }^{6} 1997$. Neutestamentliche Apokryphen in deutscher Übersetzung. Bd. 2, Apostolisches, Apokalypsen und Verwandtes. Tübingen: Mohr Siebeck.

Schneider, Horst. 2001. „Thekla und die Robben.“Vigiliae Christianae 55:45-57.

Schneider, Horst. 2002a. „Das Ibis-Kapitel im Physiologus.“ Vigiliae Christianae 56:151-164.

Schneider, Horst. 2002b. Rezension von „Physiologus, Griechisch/ Deutsch, übersetzt und herausgegeben von Otto Schönberger, Stuttgart 2001.“ Göttinger Forum für Altertumswissenschaft 5:1019-1034.

Schneider, Horst. 2016. „Physiologus.“ RAC 27:722-743.

Scott, Alan. 1998. „The Date of the Physiologus.“ Vigiliae Christianae 52:430-441.

Scott, Alan. 2002. „Zoological Marvel and Exegetical Method in Origen and the Physiologus. "In Reading in Christian Communities: Essays on Interpretation in the Early Church. Christianity and Judaism in Antiquity 14, ed. by Charles A. Bobertz and David Brakke, 80-89. Notre Dame, IN: University of Notre Dame Press).
Scrivener, Frederick H. A. 1893. Adversaria Critica Sacra: With a Short Explanatory Introduction. Cambridge: Cambridge University Press.

Seibt, Werner. 1993. „Physiologus.“ LMA 6:2117-2118.

Sorabji, Richard. (1993) 1995. Animal Minds and Human Morals: The Origins of the Western Debate. Ithaca, NY: Cornell University Press.

Spittler, Janet. 2008. Animals in the Apocryphal Acts of the Apostles: The Wild Kingdom of Early Christian Literature. WUNT 2.247. Tübingen: Mohr Siebeck.

Steiner, Gary. 2008. „Das Tier bei Aristoteles und den Stoikern: Evolution eines kosmischen Prinzips." In Mensch und Tier in der Antike: Grenzziehung und Grenzüberschreitung, hrsg. v. Annetta Alexandridis, Markus Wild und Lorenz Winkler-Horacek, 27-46. Wiesbaden: Reichert Verlag.

Stroppa, Marco. 2012. „La gazzella e la pietra adamantina in un papiro del Fisiologo greco (PSI inv. 295)“. In Actes du 26e Congrès international de papyrologie. Recherches et Rencontres 30, hrsg. v. Paul Schubert, 721-727. Genf: Droz.

Stroppa, Marco. 2013. „L'uso di rotuli per testi cristiani di carattere letterario." Archiv für Papyrusforschung 59:347-358.

Stroppa, Marco. 2016. „The Physiologus and the Greek Papyri. Animals in comparison." Reinardus 28:169-185.

Suciu, Alin. 2014. „Quotations from the Physiologus in a Homily of the Coptic Holy Week Lectionary. “In $\Sigma Y N A \equiv I \Sigma$ KAOONIKH: Beiträge zu Gottesdienst und Geschichte der fünf altkirchlichen Patriarchate für Heinzgerd Brakmann zum 70. Geburtstag, hrsg. v. Diliana Atanassova and Tinaitin Chronz, 677-689, Wien: Lit Verlag.

Thompson, D’Arcy Wentworth. (1895) ${ }^{2}$ 1936. A Glossarry of Greek Birds. (Oxford: Clarendon Press) Oxford: Oxford University Press.

Tori, Luca, und Aline Steinbrecher, Hgg. 2012. Animali: Tiere und Fabelwesen von der Antike bis zur Neuzeit. Zürich: Schweizerisches Nationalmuseum / Mailand: Skira.

Treu, Ursula. 1959. „,Otterngezücht': Ein patristischer Beitrag zur Quellenkunde des Physiologus.“ ZNW 50:113-122.

Treu, Ursula. 1966. „Zur Datierung des Physiologus.“ ZNW 57:101104.

Treu, Ursula. 1982. „Vom Löwen bis zum Wildesel. Die dritte, sogenannte pseudobasilianische Redaktion des Physiologus.“ In Festschrift für Fairy von Lilienfeld. Zum 65. Geburtstag, hrsg. v. Adelheid Rexheuser und Karl-Heinz Ruffmann, 446-478, Erlangen: Institut für Gesellschaft und Wissenschaft an der Universität Erlangen-Nürnberg.

Treu, Ursula. 1993. „The Physiologus and the Early Fathers.“ In Studia Patristica. Bd. 24, Papers presented at the Eleventh International Conference on Patristic Studies held in Oxford 1991, hrsg. v. Elizabeth A. Livingstone, 197-200. Leuven: Peeters.

Treu, Ursula. (1999) 2009. „Physiologus.“ LThK ${ }^{3}$ 8:276-277. Vermeille, Alexandre. 2006. Physiologus: De l'Orient à l'Occident; Un patchwork multiculturel au service de l'Écriture Mémoiree Univ. Neuchâtel: Université de Neuchâtel, http://data.rero.ch/ 01-R007269519.

Wellmann, Max. 1896. „Aegyptisches.“ Hermes: Zeitschrift für classische Philologie 31,2:221-233.

Wellmann, Max. 1930. „Der Physiologos: Eine religionsgeschichtlich-naturwissenschaftliche Untersuchung.“ Philologus: Zeitschrift für das klassische Altertum; Supplementband 22,1:1116. 
Wildberger, Jula. 2008. „Beast or God? - The Intermediate Status of Humans and the Physical Basis of the Stoic scala naturae." In Mensch und Tier in der Antike: Grenzziehung und Grenzüberschreitung, hrsg. v. Annetta Alexandridis, Markus Wild und Lorenz Winkler-Horacek, 47-70. Wiesbaden: Reichert Verlag. Wöhrle, Georg, Hg. 1999. Geschichte der Mathematik und der Naturwissenschaften in der Antike. Bd. 1, Biologie, Stuttgart: Franz Steiner.
Woodruff, Helen. 1930. „The Pysiologus of Bern: A Survival of Alexandrian Style in a Ninth Century Manuscript. “ The Art Bulletin 12,3:226-253. 



\section{Stellenregister (Auswahl)}

\section{Bibel}

\section{Altes Testament}

\section{Genesis}

1,20-2,19 65

1,31126

$2,796,139$

2,25-4,1 89

3143

3,1 142

3,1589

3,2463

6144

6,5144

$8,8-12 \quad 57$

$22,3 \quad 57$

2895

28,12 116

30,14126

30,14-16 89

37,336

39,14-15 7

49,8-12 191

$49,956,94,96,122,125$

49,9-10 138

49,11 112

49,14-15 57

Exodus

13,3058

19,458

$20,17 \quad 57$

34,2058

Levitikus

1165

11,1-38 66, 67, 76, 77

11,6155

11,1358

11,17-18 67, 74, 75, 87

11,1967

$12,8 \quad 57$

14,14-17 57

14,2257

22,2271

Numeri

12,1573

12,2273

21,6-8 142, 143

22,22-33 57

22,2363

$23,2268,69,140$

$24,868,141$

33,17141

Deuteronomium

5,1357

5,2157

1465
14,3-21 66, 67, 76, 77

14,7-8 155

14,16-17 18

14,17-18 67, 74, 75

32,1158

$33,1768,69$

33,20-22 56

Josua

5,13-15 63

Richter

14,5-6 56, 146

1. Buch Samuel

17,3656

25,42 57

2. Buch Samuel

1,2356

1. Buch der Könige

10,18-20 56

17,2196

2. Buch der Könige

4,24 57

1. Chronikbuch

24,15 58

Nehemia

10,2158

Tobit

12167

ljob

4,11a 70, 71

10,9109

12,7-9 86

$20,12-16^{\mathrm{Vg}} 170$

24,4 57

$39,5-9 \quad 57,59$

39,968

39,19-25 57

40,25-32 112, 114

Psalmen

2,2 114

7,356

$9,30^{\mathrm{LXX}} 95$

$16,9-10\left(15,9-10^{\mathrm{LXX}}\right) 107$

$17\left(16^{\mathrm{Vg}}\right) 191$

$17,34^{\text {LXX }} 73$

18,10-11 112

19,286

$22,14\left(21,14^{\mathrm{Vg}}\right) 146$

$22,22\left(21,22^{\mathrm{LXX}}\right) 68-69,140$

$23\left(22^{\mathrm{LXX}}\right) 108$

$24\left(23^{\mathrm{LXX}}\right) 96,101-102,105-108$

24,7-10 95, 96, 102, 105-109, 112, 114-119

$24,7-10\left(23,7-10^{\mathrm{LXX}}\right) 107$

$28,6^{\text {LXX }} 68,69$

$29,6\left(28,6^{\mathrm{LXX}}\right) 140,141$

$42,2\left(41,2^{\mathrm{LXX}}\right) 63,72,73,77,133,134$

45,1036

47,6 106 


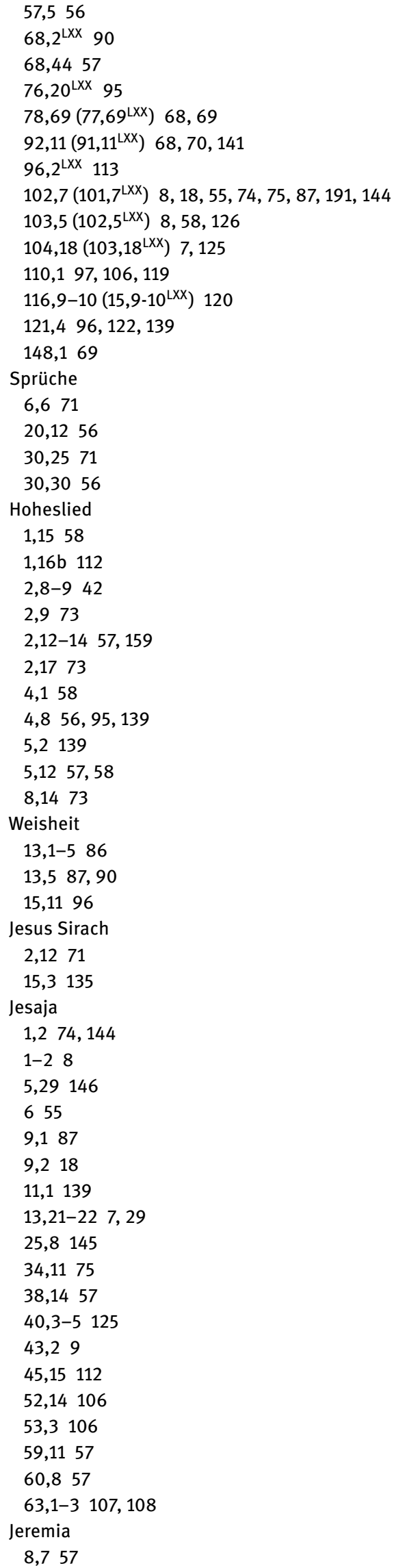

12,9155

17,11 151

23,24 121

48,28 57

Ezechiel

1,1095

23,2057

29,397

37,996

Daniel

39

5,2157

Hosea

$5,1456,146$

6,276

7,11 57

Amos

$1,256,146$

$3,856,146$

Jona

2,1 76

Micha

1,1658

Nahum

2,857

Zefanja

2,17 75

Sacharia

$6,129,11$

9,9-10 57

Maleachi

3,20 11

\section{Neues Testament}

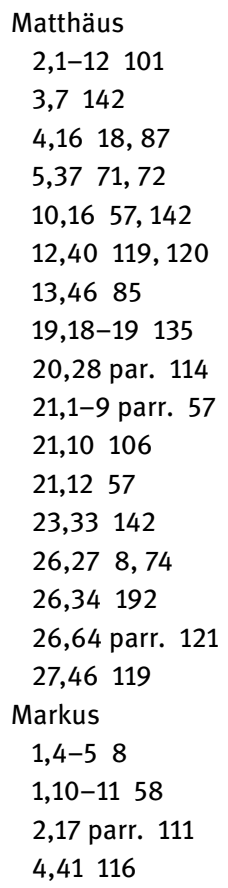


10,44118

11,15 parr. 57

14,36119

15,34119

16,19139

Lukas

$1,6968,70,97,141$

1,7811

$1,7918,145$

2,2457

3,38

11,37113

12,3018

$12,3218,87$

23,43.46 119-121

24,45 par. 91

Johannes

1,1 109, 119, 121

1,1-3 91

$1,1-18102,126,133$

1,597

1,8109

$1,1468,91,95,97,110,112,115-117,119,121,139,141,191$

1,2942

2,2185

3,13 117

3,14-15 142, 143

3,31 117

4135

4,10-15 134, 135

6135

7,37-38 134, 135

8,23117

8,469

8,59 96, 97, 101

10,17-18 119, 144

11,43146

12,2685

12,35-36 97, 101

15,1-8 29

16,1385

17,5121

19,33-34 119

19,34 122, 134, 135, 144

20,2296

20,28109

21,2583

Apostelgeschichte

2,33 121

7,55-56 122

13,248

19,98

27,12 144

27,4325

Römerbrief

1,20 12, 86, 110

$1,20^{\mathrm{Vg}} 111$

1,258

7,1485

8,3112
9,487

1. Korintherbrief

2,6-8 101, 106, 114

2,6-16 100, 101

2,8 96, 100, 101, 105, 114

2,9 98, 113

2,159

9,9-10 24

$9,2298,100,103,104,108,117,118$

13,29

$15,3-576$

15,2497

$15,4590,118$

15,47-48 145

15,55145

2. Korintherbrief

1,17-18 71, 72

3,685

$5,2118,87$

8,998

Galaterbrief

4,21-5,1 84

5,2236

Epheserbrief

1,21-22 95, 97

1,23102

$3,10108,113,114$

4,10117

4,22-24 11

6,12108

6,16135

19,1-3 101

Philipperbrief

2,6-8 90, 96, 98, 102, 103, 110, 112, 118

Kolosserbrief

1,15-20 95, 97, 102, 103, 139

2,15 114

2,9 110

$2,9^{\mathrm{Vg}} 111$

3,9 11

1. Thessalonicherbrief

5,23119

1. Timotheusbrief

2,4 90, 118

$3,16103,110,112,121$

2. Timotheusbrief

2,1942

Titusbrief

2,13 109

Hebräerbrief

1,8-9 109

2,14104

4,15 113

10,20113

Jakobusbrief

1,7-8 71

1. Petrusbrief

3,19 107

$3,2268,95,97$

4,6107 


\author{
5,8146 \\ 2. Petrusbrief \\ 1,1 109 \\ Offenbarung \\ 4,795 \\ $5,586,95,96,138,143,145,191$ \\ $5,5-6,1141,143$ \\ 5,696 \\ $5,12^{\mathrm{Vg}} 111$ \\ 9,19143 \\ $12,7-963$ \\ 12,14-15 143 \\ 12-13 143 \\ 14,6103 \\ 16143 \\ 20143 \\ 20,2143
}

\section{Physiologus}

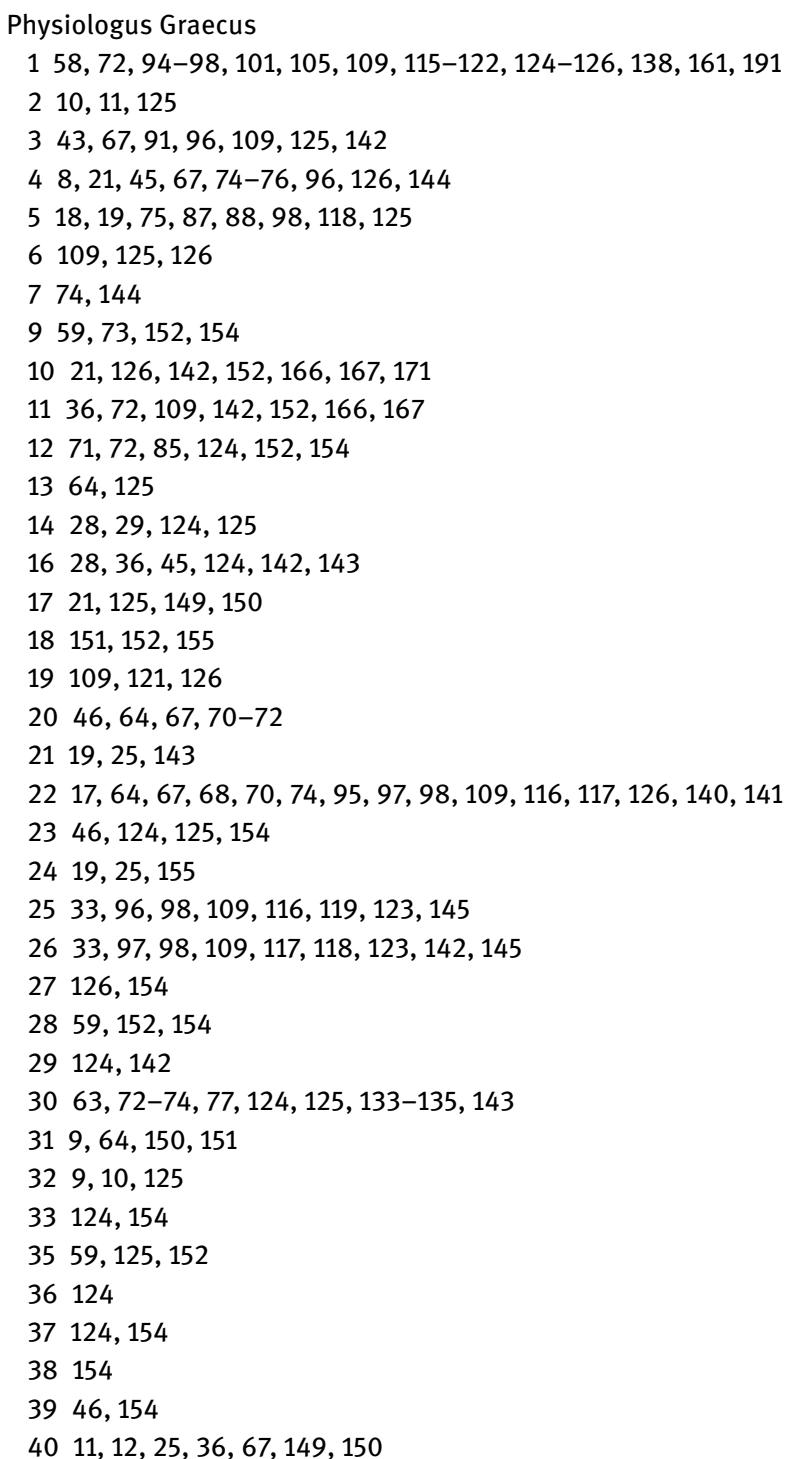

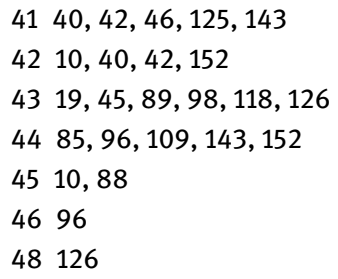

Physiologus Bernensis siehe Namen- und Sachregister

\section{Weitere Autoren und Schriften}

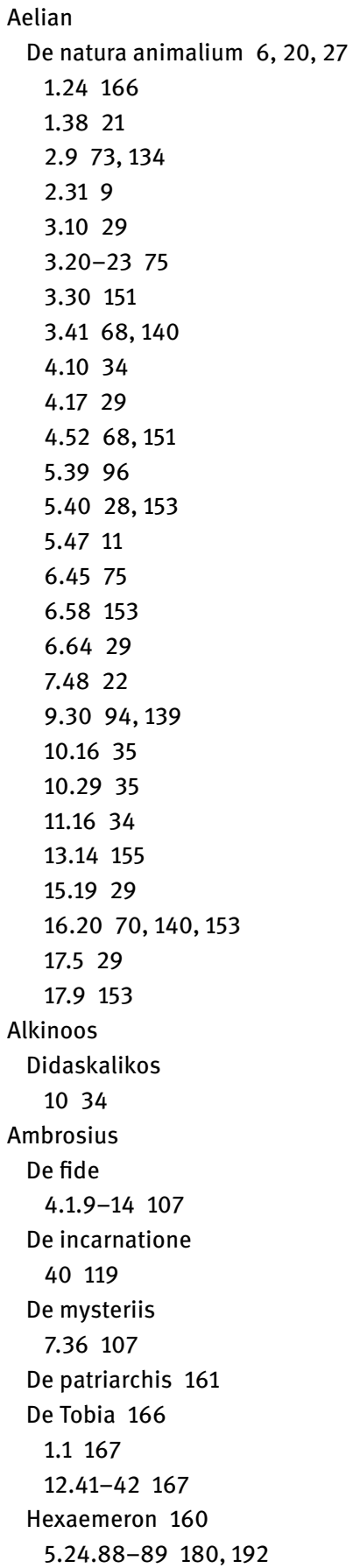


Anastasios Sinaites

Hexaemeron

4.5.5 113

12.5 .1113

Ps.-Anastasios

Adversus ludaeos dialogus alius 113

Adversus ludaeos disputationes

2113

Anaxandrides

frag. 4022

Andreas-Akten 149, 155

(A) Martyrium Andreae prius 16110 Anthologia Palatina
6.16929
6.4529

Apion

Aiүuптıкко́ 23

Apollonios von Tyana

Mirabilia

46155

Aristeasbrief 24

142-169 23

Aristophanes

Vögel 21

Aristoteles

De anima 30

2.2.413a26-414a3 30

2.4.415a26-b7 19

3.2.426a20 84

3.4.429a10-429b10 30

De arte poetica

$1.1447 \mathrm{~b} 196,84$

De generatione animalium 19, 29

2.1.731b24-35 19

3.6.756b13-757a13 19

5.6928

De incessu animalium 19, 29

9.709a9-10 19

De motu animalium 19, 29

De partibus animalium 6,19, 29

1.1.641a7 84

1.519

3.2.663a22 140

Historia animalium 6, 19, 29, 151

2.1.498a9 19

2.1.499b20 140

5.19.552b15 9

5.34166

6.4.562b 152

6.32.579b16-30 19

8(9).6.612a 153

8-9 21

9.6.612a12-15 28

9.34.619b18-23 18

9.44.629b35-36 95, 139

Metaphysica

1.5.986b14 84

1.8.990a3 84

Ps.-Aristoteles

De audibilibus 29
De mirabilibus auscultationibus 29

10152

De mundo

392a31-33 33

Artemidor

1.79124

3.16124

Ascensio Isaiae 101, 102, 106, 123

6-11 96, 100, 101

Asterios

Homilia in Psalmum

15.16109

Athanasios

De incarnatione

21.3-22.5 119

frag. bei Theodoret, Eranistes Florilegium

1.39112

2.25a 121

Oratio contra Arianos

1.61.1-62.1 121

2.8 .1112

2.13 .1121

3.50 .2112

3.67 .6112

Vita Antonii

9154

50-52 154

Ps.-Athanasios

De incarnatione contra Apollinarium

1.18120

2.3112

2.14120

2.15121

In occursum Domini

4121

Quaestiones aliae

20114

Athenaios

Deipnosophistae

3.101a 84

Atramchasis-Epos (altbabylonisch) 144

Augustin de Dacia

Rotulus pugillaris

1.256.19 91

Augustinus

Contra Faustum

32.20165

De civitate dei 164,165

7.1111

21.2-5 164

De doctrina christiana $162,164-166,168-171$

1-3 163

2.7.10 163

2.166

$2.16 .24162,166$

2.24.59 166

2.39.58-59 163

De genesi ad litteram

5.16 
Enarrationes in psalmos

$45.76,165$

Epistulae

43.25165

Sermo

337.1108

Barnabasbrief 24-26, 85

5.6109

5.10-11 109

10.1-3 86

10.5-11 25

10.7155

Basileios von Caesarea

De Spiritu Sancto

15121

Homiliae in Psalmos

14.1.3 166

Basileios von Seleukia

Orationes

23.1113

28.1113

Caesar

De bello Gallico

6.2789

Cassiodor

Institutiones divinarum et saecularium litterarum 170

Catena siehe Katenen

Celsus siehe Kelsos

Chaldäische Orakel

frag. 3795

Cicero

De natura deorum

2.123-7 30

Clemens siehe Klemens von Alexandrien

1. Clemensbrief 85

2. Clemensbrief

1,1 109

Collectio Sabbaitica (=Akakios, Epistulae)

8113

Decretum Gelasianum 160, 161, 166

6.11160

Didymos (?)

De trinitate 2.7.8.9 104

Diodor

Bibliotheca historica

1.821

Diogenes Laertios

Vitae philosophorum

1.1023

7.18784

Dion von Prusa

Orationes

12.3534

Ps.-Dionysios Areopagites

De caelesti hierarchia

15.895
Epikur

Sententiae (Gnomologium Vaticanum Epicureum)

2984

Epiphanios

Adversus haereses

21.2.499

Epistula apostolorum 102

11-14 100

Euseb

Commentarius in Isaiam

2.28112

Commentarius in Psalmos

23 106, 108

Demonstratio evangelica

5.4.4-9 112

Fredegar-Chronik 180, 183, 184

Gelasius

Historia ecclesiastica

2.19.26 113

Gellius

Noctes Atticae

5.1422

Ginza

Rechter Teil, 5.138-14699

Gregor der Große

Epistula ad Leandrum

1169

2169

Moralia in Job

$15.19170,171$

Gregor von Nazianz

Epistula

101.1697

Orationes

24.9113

32.18112

39.13113

40.10113

45.22113

45.25108

Gregor von Nyssa

Adversus Apollinarium 120

Contra Eunomium

3.3.43 121

Epistula

3.22120

Homilia 4 in Canticum canticorum GNO 6, 108112

Homilia 5 in Canticum canticorum 2.15108

Homilia 11 in Canticum canticorum

24109

In ascensionem Christi 108

324.11-12 108

326.2-6 108

In Christi resurrectionem

1 112, 114, 120 


$$
\begin{aligned}
& \text { Oratio catechetica } \\
& \begin{array}{l}
23.3-26.1112 \\
25.1108 \\
32.6108
\end{array}
\end{aligned}
$$

Hermas, Hirt des

$$
\text { 40.4-6 } 110
$$

Herodot

Historiae

$$
2.73153
$$$$
3.109166
$$

Hesych

In pascha homilia

$$
1.5107
$$$$
\text { 2.2-3 } 121
$$

Hieronymus

Adversus lovianum

1159

Commentariorum in Amos Prophetam

$$
\text { 7.7-9 } 10
$$

De viris illustribus

$$
722
$$

Epistula

124.12103

Sermo paschale

2109

Vita Pauli 154

8153

Hippolyt

frag. 20 in Ps 23,7 (= Theodoret, Eranistes Florilegium 2.16) 107

Refutatio omnium haeresium

$$
\text { 6.19.698 }
$$

Ps.-Hippolyt

Contra Beronem et Heliconem haereticos 111

De pascha

frag. 3120

De teophania

$$
4113
$$

Horapollon

Hieroglyphica

$$
1.1996
$$

Hugo von St. Victor

Eruditio didascalica

6.585

Ignatius

Epistula ad Ephesos

19114

19.2107

Ps.-Ignatius

Epistula ad Antiochenos (recensio longa)

5.1110

Irenaeus

Adversus haereses

1.23.3 98

1.26.1 119

1.30.4-699

2.30 .3106

3.8.3 106

3.16 .8106
4.33.13 106

Demonstratio apostolicae praedicationis

84-85 106, 107

Isidor

De ecclesiasticis officiis

1.45179

Etymologiae

12.1192

12.1.42-43 180

Joasaph von Ephesos

Epistula Joasaphi ad Nilum

501-548 113

Johannes Chrysostomos

De incomprehensibili dei natura

3.53-193 108

4.133-158 108

Homiliae in Matthaeum

36.11.1-2 166

Ps.-Johannes Chrysostomos

De ascensionem Domini

4108

De Pharisaeo 113

Homilia 5 in Psalmum 96113

In annuntiationem et contra Arianos 113

In assumptionem Domini 113

In centurionem 113

In sanctum pascha

6.61107

Oratio de nativitate

1113

Johannes von Damaskus

De fide orthodoxa

75122

Johannes-Akten 149-151, 154, 156

56-57 151

60-61 151

Johannesapokalypse

1111

13111

Justin der Märtyrer

Apologia

1.51.6-7 105

1.65 .1124

Dialogus cum Tryphone 85, 95

36.3-6 105

85.1-4 105

9197

Justinian

Anathemata synodis Constantinopolitani, Anathema 7 103, 104

Epistula ad Menam, Anathema 4 103, 104

Katenen

Catena in Epistolam ad Philippenses

г 113

Catena in Evangelium S. Lucae

$23.43 \sqcap 120$

Fragmenta in Joannem (in catenis)

146119 


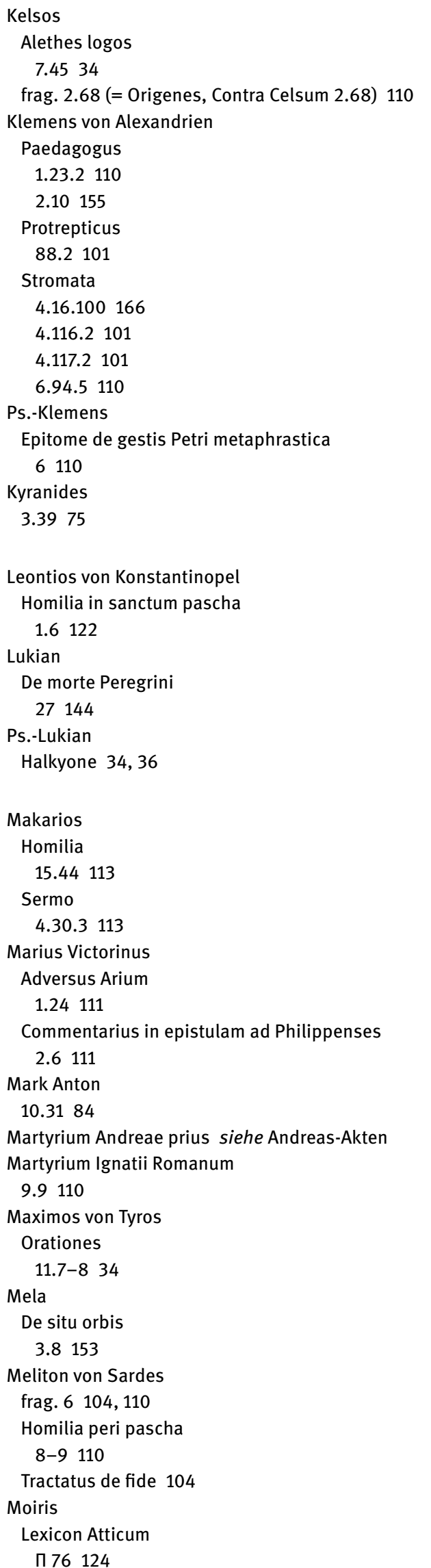

Mure, Konrad von

De natura animalium 184

Nag Hammadi Codices (NHC)

Der zweite Logos des großen Seth (NHC 7,2)

56.21-29 99

Die dreigestaltige Protennoia (NHC 13,1)

47-49 99

Eugnostosbrief (NHC 3,3/5,1)

$3 / 299$

Noēma (NHC 6,4)

41-42 99

Philippus-Evangelium (NHC 2,3)

57.28-58.3 99

67.9-12 100

Sophia Jesu Christi (NHC 3,4)

9499

Zostrianos (NHC 8,1)

13099

Neilos (?)

De vitiis

2124

Nikarchos

Epigrammata

AGr 11.16619

Nikodemusevangelium 145

21107

2563

Novatian

De trinitate

11.1111

11.4111

12.5111

Oden Salomos

42.3-4 101

Oppian

Kynegetika

2.236-240 73, 134

3.183-207 151, 152

Oracula Sibyllina

8.291-292 101

12.32101

Origenes

Commentariorum series in Matthaeum

27112

76114

92114

125114

Commentarius in epistulam ad Romanos (Rufin)

1.6.2 103

5.7.5 103

Commentarius in lohannem

1.107110

1.216-219 103

2.168-170 97

6.288107

19.38103

frag. 18112 
Commentarius in Matthaeum

12.18114

12.30114

16.8114

16.19 106, 107

28103

40114

De pascha

2.28-30 107

De principiis 103

3.3.2 114

Dialogus cum Heraclide

5-8 119

Excerpta in Psalmos 107

17112

Fragmenta in Lamentationes 107114

Homilia 2 in Psalmum 15107 105.19-21 107

Homiliae in Genesim

$\begin{array}{ll}8.8 & 103 \\ 9.3 & 114 \\ 14.1 & 103\end{array}$

14.1103

Homiliae in Isaiam

3.2107

Homiliae in Leviticum

1.1112

1.3103

Homiliae in librum ludicum

7.2107

Homiliae in Lucam

$$
\text { 6.4-6 } 114
$$

Selecta in Psalmos 114

Ovid

Metamorphoses

2.531-532 34

$11.410-748 \quad 35$

14.53834

15.392153

Pamphilos

Apologia (Rufin)

143107

Paulus-Akten 123, 149, 154, 156

Petrus-Akten 149, 154, 156

Petrusapokalypse

17105

Petrusevangelium

19119

Phaedrus

Fabulae

56322

Philippus-Akten 149

Philodemos von Gadara

De musica

108 Kempke 84

Philon von Alexandrien

De animalibus 21, 35

De Josepho

14533

\author{
De migratione Abrahami \\ 173-174 105 \\ De opificio mundi \\ 23105 \\ De somniis \\ 1.238105 \\ De specialibus legibus \\ 4.100-118 24
}

Quis rerum divinarum heres sit

$$
\text { 127-128 } 58
$$

Philon von Byblos

FGH 790F4 22

Philostrat

Vita Apollonii

3.49153

Phlegon von Tralleis

De rebus mirabilibus 34-35 153

Pistis Sophia

1.11-13 99

799

10-1499

Platon

Kratylos

414c 23

435c 23

Politeia

430b8 21

$488 \mathrm{c} 23$

$588 \mathrm{~b}-589 \mathrm{c} 154$

Protagoras 21

Plinius

Naturalis historia 6, 27, 159, 164

8.1321

8.2489

8.46152

8.5622

$8.6228,153$

8.71140

8.76140

8.88-89 97

$8.11873,134$

8.13328

8-11 20

10.2153

10.34159

10.62.169 166

10.67.188 9

10.89-91 35

10.11829

11.255140

29.4.76 9

29.129-131 11

37.15.55-61 10

37.57152

37.1907

Plutarch

De esu carnium 31

De Iside et Osiride

362B 23 
380F 23

381A 25

$382 \mathrm{AB} \quad 23,34$

74-76 22

De recta ratione audiendi

43A 23

De sollertia animalium 21

960A 31

966D-973A 29, 32-34

974C 28

975AB 34, 36

976BC 34

976D 28, 153

981F-983F 33, 35

$985 \mathrm{C} 31$

1821

Gryllus

986C-992C 31, 33

992E 34

Quaestiones convivales 670BC 96

Porphyrios

De abstinentia 21

$$
\text { 2.22-24 } 21
$$

Proklos

In Timaeum 3.158.6-7 95

Prokop

Commentarius in Isaiam 113

Prudentius

Hamartigenia

553-556, 569-573, 581-584 168

608-610, 613-614, 617-620 168

Quaestiones Bartholomaei

11-15 107

Rufin von Aquileia

De benedictionibus patriarcharum 161

$1.6125,161$

Sedrachapokalypse

12-16 111

Seneca

De beneficiis

2.19 .122

Dialogi

3.3.6 30

4.3.130

Epistulae

41.134

71.3230

Naturales quaestiones 27

Sextus Empiricus

Adversus mathematicos

732

Pyrrhonische Hypotyposen

1.835

1.2935

$1.62-7831,32$
Solinus

Collectanea rerum memorabilium 27.27152

Stobaios

Florilegium

1.3.9 122

Strabon

Geographica

17.2418

Synesios

Hymnus 6

24-32 121

Tabula Cebetis

23.1-2 154

Tatitus

Anales

6.28153

Terenz

Andria

61163

Tertullian

Adversus Praxean

30.5111

Apologeticum

5.2111

21.30-31 111

De anima

34.498

De carne Christi

14104

Scorpiace

9.1111

Thekla-Akten 12, 149-151, 156

40150

Theodoret

Commentarius in Psalmum

23.7-10 108

Curatio graecarum affectionum

6.77113

De incarnatione Domini

14113

18112

Eranistes

Dialog 1113

Oratio de providentia

10113

Theokrit

Eidyllion

7.21-22 11

Theon

Rhetorica progymnasmata

12124

Theophilos von Alexandria

Epistula paschalis

= Hieronymus, Epistula 96.10104

Epistula synodica

= Hieronymus, Epistula 92.4104

Theophrast

De historia et causis plantarum 6 


\section{De igne}

609

Thomas-Akten 149, 151, 152, 154-156

8151,156

50152

70152

79152

80111

91152

108-113 152

\section{Valentin}

frag. 3 (= Klemens von Alexandrien, Stromata 3.59.3) 110 Vinzenz von Beauvais

Speculum naturale

Prolog 13161

Vita Adae et Evae 123, 126

Vita sancti Symeonis 180,184

\section{Xenophon}

Kyropädie

2.321 



\section{Namen- und Sachregister (Auswahl)}

\author{
Absalom 168, 169 \\ Achat siehe Steine \\ Adam 11, 113 \\ - neuer $90,113,118$ \\ - und Eva 89 \\ Adler siehe Tiere
}

Adressaten 118, 124, 169, 171

Affe siehe Tiere

Ägypten $11,17,23,25,35-37,39,43,45,46,57,59,75,86,93,122$, $124,125,144,153,155$

- Ägypter 22, 23, 34

- ägyptisch 22, 23, 29, 39, 56, 84, 97

Akademie 21

Alexander von Myndos 6

Alexandria, alexandrinisch 5, 20, 24, 35, 43, 45, 104, 105, 110, 112, $120,122-125,153,161,162,189,191-193$

Allegorese $68,71,72,74,84,85,87,88,94-98,114,115,117,125$, 126,133

Allegorie, allegorisch 6, 8, 11, 24, 55, 58, 64, 73, 74, 84-91, 94, 95, $97,105,118,123,124,126,133,134,155,162,163,168-171$, 178,180

Allegorisierung 139

Ambrosius 159-162, 166-168, 171

Ameise siehe Tiere

Ameisenlöwe siehe Tiere

Analogie 144

Anthropozentrismus 21, 31

Antichristus 146, siehe auch Teufel

Antilope siehe Tiere

Antiochenische Theologie 112, 113, 120

Antonius 154

Aphrodite 57

Apollinaris, Apollinarismus 111-113, 119, 121

Arche Noah 190, 191

Aristophanes von Byzanz 20

Aristoteles, aristotelisch 17-20, 22, 23, 30, 33, 39, 166

- Peripatetiker 30, 36

Askese, Asketen 55, 85, 123-125, 133, 135, 142, 154, 156, 160, 171, 172

Astarte 57,58

Atem 73, 127, 134, 139

Auferweckung siehe Christus, Auferstehung

Augustinus, augustinisch 85, 160, 162-166, 168-171

Autorität

- einer Person 6-8, 10, 11, 17, 19, 25, 26, 125, 126

- eines Textes 77, 161, 168

Biber siehe Tiere

Bilderbuchrollen 192

Bilderhandschrift 177

Bildung 20, 22, 36, 37, 63, 162, 171

- Bildungskanon, -programm 12, 162, 165

Blindheit 11

Blut 8, 10, 20, 21, 72-75, 103, 104, 134, 135, 144

- Bocksblut 5, 10

Bolos von Mendes 17, 21
Bongars, Jacques 183, 184

- Bongarsiana 177, 183, 184

Böse 10, 24, 42, 72, 73, 112, 133, 135, 144, 165, 168-170

- böser Geist 10, 29, 89, 170

Buße 8,74, 111

Castleton, Grafschaft Derbyshire 63

Celsus siehe Kelsos

Chorwerk 133, 135, 138, 140, 143

Christologie

- Engelchristologie 100, 102

- johanneische Christologie 141

- kosmische Christologie 104

- Logos-Sarx-Christologie 119, 121

- monophoysitische Christologie 119

- Pneuma-Sarx-Christologie 110

- Trennungschristologie 119,120

Christologie, christologisch $28,69,84,85,87,88,94,95,102,103$, $110,111,113,118-122,133-135,138,146,161$

Christus

- am Kreuz 8, 73-75, 94, 96, 100-104, 106-108, 115, 117-121, 135, 138, 139, 141-144, 192

- Auferstehung 11, 26, 28, 74, 85, 94, 96, 97, 100, 105, 107, 108, 110, $114,117-119,121,122,138,139,141,143-146,191,192$

- der Gesalbte 95, 114

- Engelgleichwerdung 96, 98, 100, 102-105, 108, 115, 116, 119, 123, 125

- Erlöser 18, 19, 42, 67, 68, 70, 73-75, 87, 93-103, 106, 108, 111, $114-118,122,141,142,145$

- Fleischwerdung 19, 68, 91, 94-109, 111-117, 119, 120, 122, 138 , $139,141,142,145,191$

- Geburt 17, 101, 114, 115, 119, 141

- Gottessohn 96, 97, 103, 109, 114, 115, 122, 123

- Gottheit, Gottsein ( $\theta$ cótns) 95-98, 108-122, 124, 191

- Göttlichkeit 96

- Himmelfahrt 97, 99, 100, 102, 105-109, 111, 112, 114-119, 121

- Höllenfahrt 28, 98, 100-102, 107-109, 115-117, 119, 123, 138, 145

- König 10, 57, 105, 106, 109, 115-117, 141

- Logos 91, 100-102, 104-106, 112, 113, 119, 133, 134, 139, 146, 190 , 191

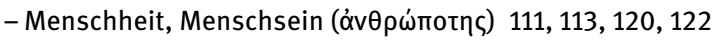

- Messiasgeheimnis 114

- Opfertod 74, 76, 103, 114, 133

- Taufe 58, 59, 110, 119

- Verhüllung 95, 96, 98, 109, 112-114, 116, 117, 191

- zur Rechten Gottes 96, 97, 105, 118-122

- Zweinaturenlehre 120

Chrysippos 21

Dämon 103, 104, 114, 151

Daniel, Pierre 183

David 42, 56, 72-76, 106, 126, 168, 169

- Haus Davids 68,141

- Prophet 108

descensus absconditus siehe Höllenfahrt

Diamant siehe Steine

Dionysios 6 
Doketismus, doketistisch 99-102, 115, 119

Drache siehe Tiere

Drei Jünglinge im Feuerofen 9, 150

\author{
Eidechse siehe Tiere \\ Einhorn siehe Tiere \\ Elefant siehe Tiere \\ Elias-Behang, Abegg Stiftung 192 \\ Emotion 27, 30, 190 \\ Engel 63, 68, 95-97, 99-103, 105-109, 111, 114-118, 122, 127 \\ Enthaltsamkeit 12, 59, 89 \\ Erlösung 70, 74, 126, 142, 144 \\ Esel siehe Tiere \\ Eule siehe Tiere \\ Eusebius von Caesarea 163, 164 \\ Evangelium 10, 73, 103 \\ ewiges Leben $8,74,135,143$
}

Fabeltiere, Fabelwesen 7, 55, 68, 71, 83, 140, 153, siehe Mischwesen

Falke siehe Tiere

Fasten 12, 28, 36, 142

Fisch siehe Tiere

Fischotter siehe Tiere

Fleury 182, 183

Fortpflanzung 19, 55, 89, 90, 166, 167, 169

Frosch siehe Tiere

Frowin, Abt 135

Fuchs siehe Tiere

Gazelle siehe Tiere

Geier siehe Tiere

Gerechtigkeit 11, 24, 31, 33, 87

Gjeilo, Ola 133, 135, 138, 140, 142, 143, 145, 146

Glaube 11, 12, 25, 85, 91, 142, 165

Gnosis, Gnostiker, gnostisch, gnostizierend 93, 95, 98-102, 104, $105,115,119,122,123,125,149$

Gotteserkenntnis 25, 86

Gotthelf, Jeremias 127

Gottvater 95, 97, 100, 113, 118-122, 139, 190, 191

Graviseth, Jakob 184

Graviseth, Reinhard 184

Gregor der Große 166, 169-171, 182, 183

Hades 119, 120, 145

Hagen, Hermann 184

Handschriften

- Artemidorus Papyrus (Fondazione per l'Arte della Compagnia di San Paolo, Turin) 45, 46

- Charta Allaciana (Biblioteca Vallicelliana, Rom)

- 216 (CXLI) 10

- Climax lacobi (slawisch-orthodox)

$-4.4695$

- Codex 10074 (Bibliothèque Royale, Brüssel) 177, 178

- Codex 225 (Burgerbibliothek Bern) 183, 186

- Codex 231 (Burgerbibliothek Bern) 184

- Codex 233 (Burgerbibliothek Bern) 177-179, 182-184, 186, 187

- Codex 318 (Burgerbibliothek Bern) siehe Physiologus Bernensis

- Codex 397 (Pierpont Morgan Library, New York) 5

- Codex 462 (Burgerbibliothek Bern) 184

- Codex 611 (Burgerbibliothek Bern) 177-179, 181-184, 187
- Codex 847.9 (Burgerbibliothek Bern) 183

- Codex Gudianus latinus 148 (Herzog August Bibliothek, Wolfenbüttel) 178

- Codex Lipsiensis Universitatis 35 (Universität, Leipzig) 73

- Codex Manichaicus Coloniensis (Papyrussammlung, Universität Köln)

$-2.10101$

$-38.2-3101$

$-41.11101$

- Codex Monacensis latinus 14388 (Bayrische Staatsbibliothek, München) 178

- Codex Monacensis latinus 19417 (Bayrische Staatsbibliothek, München) 178

- Codex Mosquensis Graecus 432 (Synodalbibliothek, Moskau) 178

- Codex Ms. 313 (Bibliothèque municipale, Orléans) 183

- Codex Oxoniensis Baroccainus graecus (Bodleian Library, Oxford) 73

- Codex Par. lat. 10756 (Bibliothèque Nationale, Paris) 181

- Codex Vaticanus graecus 695 (Biblioteca Apostolica Vaticana Rom) 73

- Codex Par. Gr. 1197, Theodoros Studites (Bibliothèque nationale de France, Paris) 151

- Codex Par. Gr. 1468v (Bibliothèque nationale de France, Paris) 151

- Cotton Otho B4 (Cotton Genesis, British Library London) 189-191

- Ebo-Evangeliar (Ms. 1, Bibliothèque Municipale Ebernay) 190, 192

- Evangeliar (Codex Par. lat. 17968, Bibliothèque Nationale, Paris) 190

- Evangeliar (M. 728, Pierpont Morgan Library, New York) 190

- Evangeliar (Ms. 7, Reims) 190

- Josua-Rolle (Cod. Vat. Palat. gr. 431, Biblioteca Apostolica Vaticana Rom) 190

- Minuskel GA 537 (University of Michigan) 83

- Papyrus Berol. (inv. 7999, Ägyptisches Museum und Papyrussammlung, Staatliche Museen zu Berlin) 43, 44

- Papyrus PSI XVI 1577 (inv. 295, Istituto Papirologico Girolamo Vitelli, Florenz) 39-43

- Physiologus Bernensis (Codex 318, Burgerbibliothek Bern) 64, 177-180, 183, 184, 189-192

- Physiologus von Smyrna (zerstört, nur Fotos erhalten) 192

- Prudentius (Codex 264, Burgerbibliothek Bern) 189, 192

- Quedlinburger Itala (Cod. theol. lat. 285, Staatsbibliothek Berlin (4 Blätter) und Stiftskirche St. Servatius in Quedlinburg (1Blatt)) 190

- Rabbula-Codex (cod. Plut. 1.56, Biblioteca Medicea Laurenziana, Florenz)

- fol. 13v 122

- Utrecht Psalter (Ms. 32, Universitätsbibliothek Utrecht) 190, 191

- Vergilius Romanus (Vat. lat. 3867, Biblioteca Apostolica Vaticana Rom) 191

- Vergilius Vaticanus (Vat. lat. 3225, Biblioteca Apostolica Vaticana Rom) 189,190

-f.9r 192

- Wiener Genesis (cod. theol. gr. 31, Österreichische Nationalbibliothek, Wien) 192

Hathor 61

Heilige Schrift siehe Bibel

Heiliger Geist 85, 105, 106, 108

Heilsgeschichte $23,77,89,101,138,146,190,192$

Hellenismus, hellenistisch, hellenistisches Judentum 6, 20, 22, 23 , 58,59 
Heraklit 20

Hermeneutik 55, 112, 123, 125, 134, 135, 138, 139, 160, 162, 169

Hieronymus $159,161,182,183$

Himmel 95, 97, 99-109, 112-114, 117-121

- Tore 63, 96, 99, 102, 105-109, 116-118

Hinkmar, Erzbischof 190

Hirsch siehe Tiere

Hirt 55, 56, 113

Homer 6, 8

Hortin, Samuel

- Clavis bibliothecae Bongarsianae (Cod. A 5, Burgerbibliothek Bern) 184

Hund siehe Tiere

Hymnus 20, 121, 133, 135, 138, 140-144, 146, 192

Hyäne siehe Tiere

Ibis siehe Tiere

Ichneumon siehe Tiere

Igel siehe Tiere

Instinkt 21, 31

Intertextualität 85, 86, 88-91, 142

Ischtar 56, 57, 60, 62

Isidor 180, 182, 183

Israel 55-58, 69, 96, 143, 146

Jäger $19,22,46,70,89,94,97,115-117,136,139,140,151$

Jakob 126, 190-192

Jeremia 126

Jesus siehe Christus

Johannes der Täufer 42, 113, 126, 166

Juba II. von Mauretanien 6

Juden, Judentum 18, 24, 25, 63, 87, 88, 95, 96, 109

Justin der Märtyrer 106

Karfunkelstein siehe Steine

karolingische Renaissance 192, 193

Käuzchen siehe Tiere

Kelsos 12

Krähe siehe Tiere

Krokodil siehe Tiere

Kuckuck siehe Tiere

Kunst

- Buchmalerei 68, 189, 191-193

- Katachombenmalerei 9

-Wandmalerei 191

Lamm siehe Tiere

Lazarus 145, 146

liber creaturae, liber naturae $6,83,162,165,168,169$

Licht 11, 18, 87, 97, 144, 145, 169, 190

Liebe

- Christi $18,19,87,88$

- Elternliebe 21, 27, 33, 45, 74, 75

- Gattenliebe 33, 35, 57, 58

Logos 91, 97, 141, 191

Lorrain, Claude 190

Lösegeld 112-114

Löwe siehe Tiere

Lust 151, 155
Maat 60

Mächte $68,70,95-109,112-117,119,121,124$

Magnetstein siehe Steine

Malerei siehe Kunst

Maria 68, 70, 95-98, 101, 141, 192

Mensch 9, 21, 31-36, 85, 86, 89-91, 95, 120, 139, 144, 192

Metamorphose 7, 35, 36, 100, 102

Metapher 55, 58, 59, 113, 121, 126, 143, 162, 165-169

Mirabilienliteratur 20, 21, 29, 134, 153

Mischwesen 6-8, 12, 142, 192

Mosaik 140, 189, 191

Mose 23-25, 103, 142, 143, 150

Muschel siehe Tiere

Musik siehe Chorwerk, siehe Gjeilo, siehe Hymnus

Nachtrabe siehe Tiere

Natur

- deutung 84, 87, 88, 90, 91, 138, 172

- kunde 12, 17, 19, 59, 97, 159-165, 171, 172

- theologie 83

Neugierde 12, 163, 164, 172, 192

Neuschöpfung 71, 139, 145, 146

Offenbarung 12, 105, 126, 127

Ontologie 19, 95

Oppian 6

Orakel 94

Origenes 100,102-111, 114, 117, 119, 151, 155

- antiorigenistisch 104

Palimpsest 181

Panther siehe Tiere

Paradies 89, 119, 120, 126, 142, 143

Paradoxographie siehe Mirabilienliteratur

Paulinus von Nola 161

Paulus 22, 42, 150

Pelikan siehe Tiere

Perle siehe Steine

Pétau, Paul 183

Pferd siehe Tiere

Philon von Alexandrien 6, 24, 25, 27, 105

Physiologus siehe Stellenregister

Physiologus Bernensis siehe Handschriften

Phönix siehe Tiere

Platon, Platoniker, platonisch 23, 24, 31, 34, 36

Plinius der Ältere 27, 29

Plutarch 22-25, 27-29, 31-37

poetisch $73,85,86,88,89,146,168$

Poseidonios 21

Prudentius 166, 168, 169, 171

Pyrrhon, Pyrrhoneer 31, 35, 36

Pythagoras, Pythagoreer, pythagoreisch 21-23, 31, 155

Qedeschet 56,61

Regenpfeifer siehe Tiere

Reihervogel siehe Tiere

Reims 180, 183, 190, 192, 193

Reinheit $65,67,75,77$

res - signa 162,163 
Rhinoceros siehe Tiere

Rom 153, 164, 192

Rufin von Aquileia 103, 160, 161

Sachmet 56, 61

Salamander siehe Tiere

San Marco, Venedig 189, 191

Santa Maria Antiqua, Rom 190

Santa Maria Maggiore, Rom 189

Satan siehe Teufel

Schlange siehe Tiere

Schwalbe siehe Tiere

Schönheit 86, 87

- der Geschöpfe 87, 90

- der Natur 86

- der Sterne 87

- der Tiere 20

- des Göttlichen 23, 105

- des Menschen 20

Schöpfung $8,12,30,65,75,84,96,101,119,126,133,134,139$, $140,146,159,160,165,172,190$

- Schöpfer 8, 75, 87, 90, 190

- Schöpfungstheologie 126,139

Seehund siehe Tiere

Seele

- Christi 119-121

- der Pflanzen 30, 34

- der Tiere 30, 33, 36

- des Menschen 30, 63, 71, 72, 101, 133, 134, 167, 168

- körperlose Wesen 33

- Seelenwanderung 7

Sextus Empiricus 27, 31, 32, 36

Simon Magus 93, 98, 125

Sintflut 57

Skarabäus siehe Tiere

Speisegesetze 23-26, 67, 75

Steine 7,11, 33, 64

- Achat 7, 21, 85, 143

- Diamant 5-7, 9, 10, 21, 40, 42, 125

- Karfunkelstein 6

- Magnetstein 7, 21, 154

- Perle 7, 85, 109, 143, 152

Stern $19,30,85$

- Gestirne 33, 86

- Morgenstern 34

- Wunderstern 101

Stoa, Stoiker, stoisch 21, 22, 24, 30-34, 36, 126

Sünde $18,19,87,88,135,136,144,168,169$

- Erbsünde 169

- Sündenfall 7, 89, 114, 142, 143

- Sünder 111, 168

- Todsünde 168

Taube siehe Tiere

Teufel $10,29,63,72,73,88,90,97,98,101,109,112-114,117,123$, $134,135,145,146,151,170,171$

Thekla 150

Theophilos von Alexandria 104

Theophrast 6
Tiere

- Adler 7, 8, 18, 58, 66, 67, 76, 86, 90, 126, 152

- Affe 7, 65, 66, 76, 88, 90

- Ameise 7, 31, 65-67, 70, 71, 76, 85, 90, 192

- Ameisenlöwe 7, 64-67, 70, 71, 76, 77, 153

- Antilope 7, 65, 66, 76

- Biber 7, 22, 46, 65, 66, 76, 124

- Drache 45, 97, 142

- Eidechse 10, 11, 18, 66, 76, 192

- Einhorn 5, 7, 17, 64-72, 74, 76, 77, 90, 97, 126, 133, 136, 138-142, $146,153,192$

- Eisvogel 7, 33-36

-Elefant 7, 19, 20, 33, 34, 45, 46, 65, 66, 76, 89, 90, 118, 126, 155, 192

- Esel 57, 58

- Eule 154

- Falke 23

- Fisch 6, 7, 25, 31, 34, 46, 65, 76, 86, 112, 149

- Fischotter 7, 65, 66, 76, 98, 119, 138, 145, 146

- Frosch 7, 65, 66, 76, 124

- Fuchs 7, 21, 65-67, 76, 90

- Gazelle 40, 42, 46, 65, 66, 76, 125, 143

- Geier 7, 58, 66, 67, 76, 109, 121

- Hirsch 63, 65-67, 70, 72, 73, 76, 77, 133-135, 142, 191

- Hund 31, 33, 55, 95

- Hyäne 7, 19, 20, 25, 65-67, 76, 155

- Ibis $11,12,22,25,36,66,67,76,179$

- Ichneumon 7, 33, 65-67, 76, 90, 97, 98, 109, 114, 117, 118, 142

- Igel 7, 28, 29, 55, 65, 66, 76

- Käuzchen 7, 8, 18, 66, 67, 75, 76, 87, 88, 90, 118, 191

- Krähe 7, 33, 66, 67, 76, 155

- Krokodil 7, 22, 33, 34, 66, 98, 119, 136, 140, 145

- Kuckuck 7,151

- Lamm 66, 76, 96, 136, 138, 140, 143, 144

- Löwe 7, 22, 56, 58, 60-62, 65-67, 71, 72, 76, 86, 90, 94-97, 109, $115-119,121,122,124,125,134,136,138-141,143-146,161$, 190-192

- Muschel 21, 85

- Nachtrabe 7,18-20, 25, 66, 75, 76, 87, 191

- Panther 7, 28, 31, 36, 45, 46, 56, 65-67, 76, 143, 153, 179

- Pelikan 7, 8, 21, 45, 46, 55, 66, 67, 74-77, 87, 90, 126, 136, 138, 144,153

- Pelikan (4) 66

- Pferd 55, 57, 58, 192

-Phönix 5, 7, 55, 66, 67, 74, 76, 90, 138, 140, 144, 153

- Rebhuhn 7, 66, 67, 76, 151, 152, 155, 156

- Regenpfeifer 66, 67, 76, 91, 109, 142, 192

- Reihervogel 66,67

- Rhinoceros 69

- Salamander 5, 7, 9, 66, 76, 164

-Schlange 7, 11, 22, 23, 34, 36, 45, 46, 55, 61, 66, 67, 72, 73, 77, 89, $126,133-136,138,140,142-146,152,160,166-171,192,193$

- Natter 21, 63, 66, 76, 109, 142, 166-168, 170

- Otter 63

- Schlangengift 72, 136, 142, 167, 168, 170

- Viper 63, 142, 168-170, 192

- Schwalbe 66

- Seehund 150

- Skarabäus 22, 23

- Taube 7, 22, 55, 57-59, 66, 67, 76, 142, 152, 159 
- Tiger 28

- Ungetüm „Säge“ 65, 66, 76

-Walfisch 21, 65, 66, 76

- Wiedehopf 7, 22, 66, 76, 90, 154

-Wiesel 5, 7, 19, 22-25, 65-67, 76, 90

- Wildesel 10, 57-59, 65-68, 76, 88, 90, 140, 149, 151, 152, 154

Tierkult 10, 22, 23, 35-37

Tiersymbolik 17, 20, 22-24, 26, 55, 58, 86, 94, 133, 138, 160

Tiger siehe Tiere

Tod, tot $8,18,34,35,58,74,75,87,108,134,136,139,140$, 142-146, 167-169, 171

Triumphsäulen, Rom 192

Tugend 21, 30, 31, 33, 167

Typologie 26, 84, 85, 126, 169

Ungetüm „Säge“ siehe Tiere

Unreinheit, unrein $24,25,58,65,67,75,77,87$

Vegetarismus 21, 31

Venus 57
Vergänglichkeit 33,143

Vernunft 21, 22, 27, 31-34, 104, 164

- vernunftlos 31-33

Versuchung 12, 113, 124, 135, 169-171

Vetus Latina 111, 178

Wahrheit 32, 73, 83, 85, 91, 100, 111

Walfisch siehe Tiere

Wasser 8, 33, 58, 62, 72-75, 89, 90, 133-135, 144

Weisheit 27, 36, 55, 58, 100, 101, 125, 135, 143, 163

Wellmann, Max 17, 23, 153

Wiedehopf siehe Tiere

Wiesel siehe Tiere

Wild, Marquard 184

- Katalog (Cod. A 4, Burgerbibliothek Bern) 184

Wildesel siehe Tiere

Wunder 9, 12, 107, 110, 111, 151, 161, 164, 165, 171

Wüste $8,22,29,74-76,142,154$

Xenokrates von Ephesos 6,10 
